\title{
URAL TEXT-BOOK SERIES
}

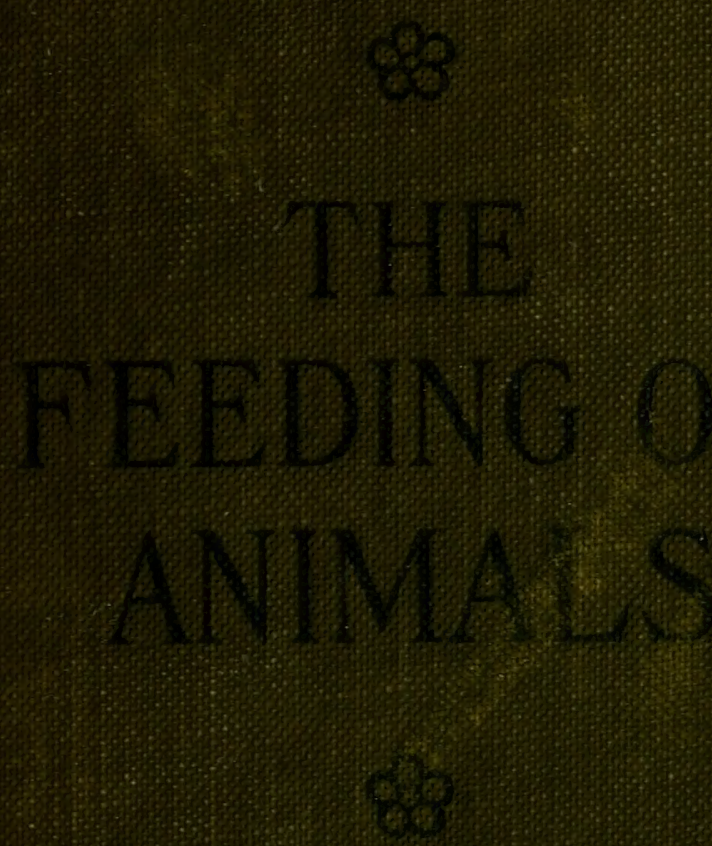

9.6.9.

och
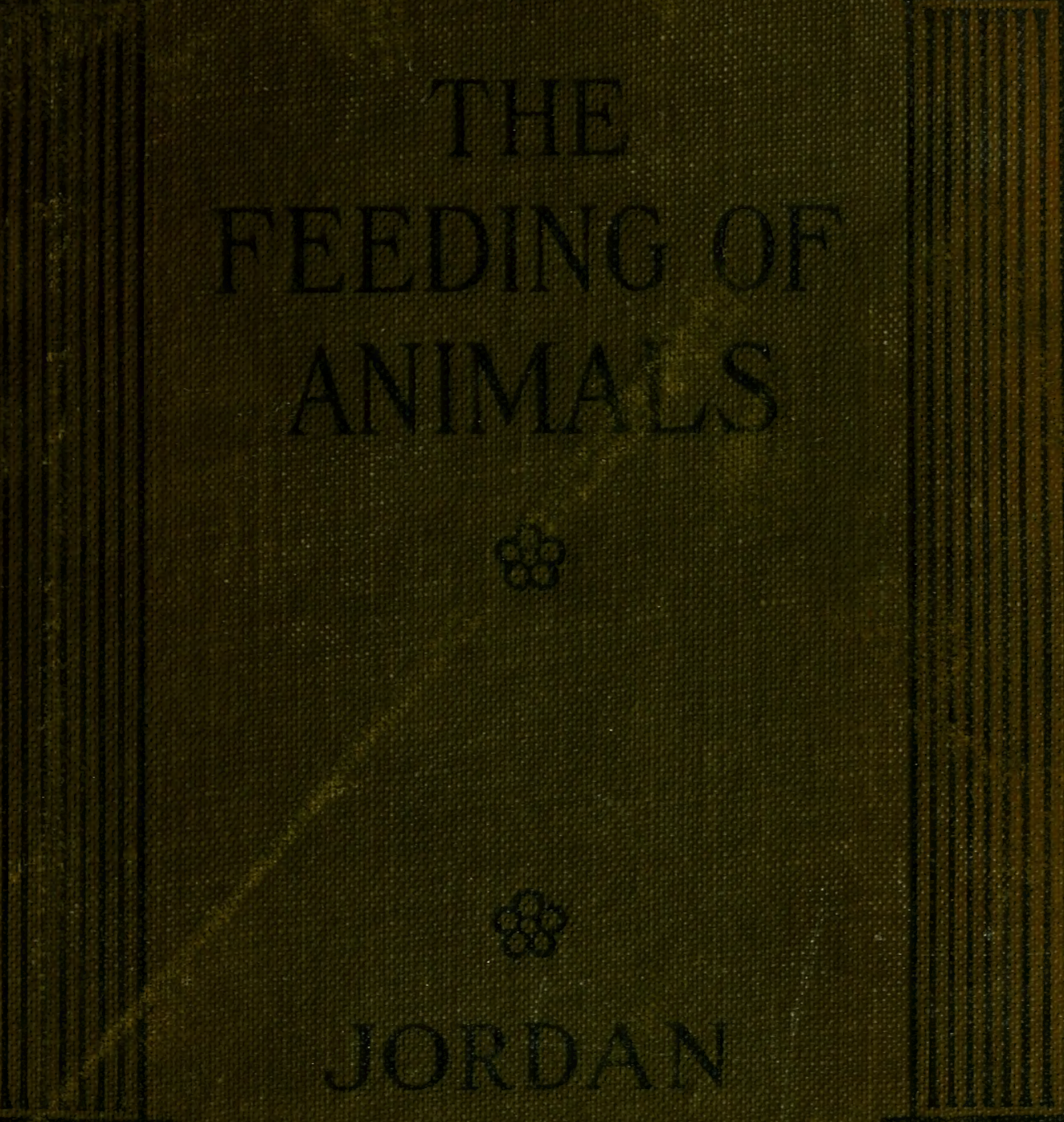

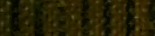

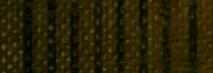

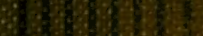

19. 912

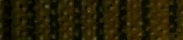

$3 \sqrt{3}$

(4)
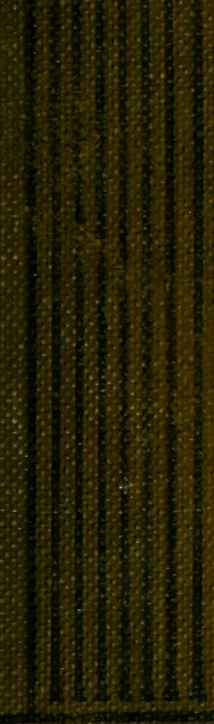

8. 
ช 






\title{
The tRural $\tau$ ext $=\$ B$ ook Iertes
}

\author{
Edited By L. H. BAILEY
}

\section{THE FEEDING OF ANIMALS}




\title{
Tbe tRural Cext $=$ JBook Ðeries
}

\author{
Edited By L. H. BAILEY
}

Carleton, The Small Grains.

B. M. Duggar, Plant Physiology, with special reference to Plant Production.

J. F. Duggar, Southern Field Crops.

Gay, The Breeds of Live-Stock.

Gay, The Principles and Practice of JUDGING LIVE-STOCK.

Goff, The Principles of Plant Culture, Revised.

Harper, Animal Husbandry for Schools.

Harris and Stewart, The Principles of Agronomy.

Hitchcock, A Text-Book of Grasses.

Jeffery, Text-Book of Land Drainage.

Jordan, The Feeding of. Animals. Revised.

Livingston, Field Crop Production.

Lyon, Fippin and Buckman, SorLs-Therr

Properties and Management.

Mann, Beginnings in Agriculture.

Montgomery, The CoRN Crops.

Piper, Forage Plants and Their Culture.

Warren, Elements of Agriculture.

Warren, FARM MANAGEMENT.

Wheeler, Mandres and Fertilizers.

White, Principles of Floriculture.

Widtsoe, Principles of Irrigation Practice. 



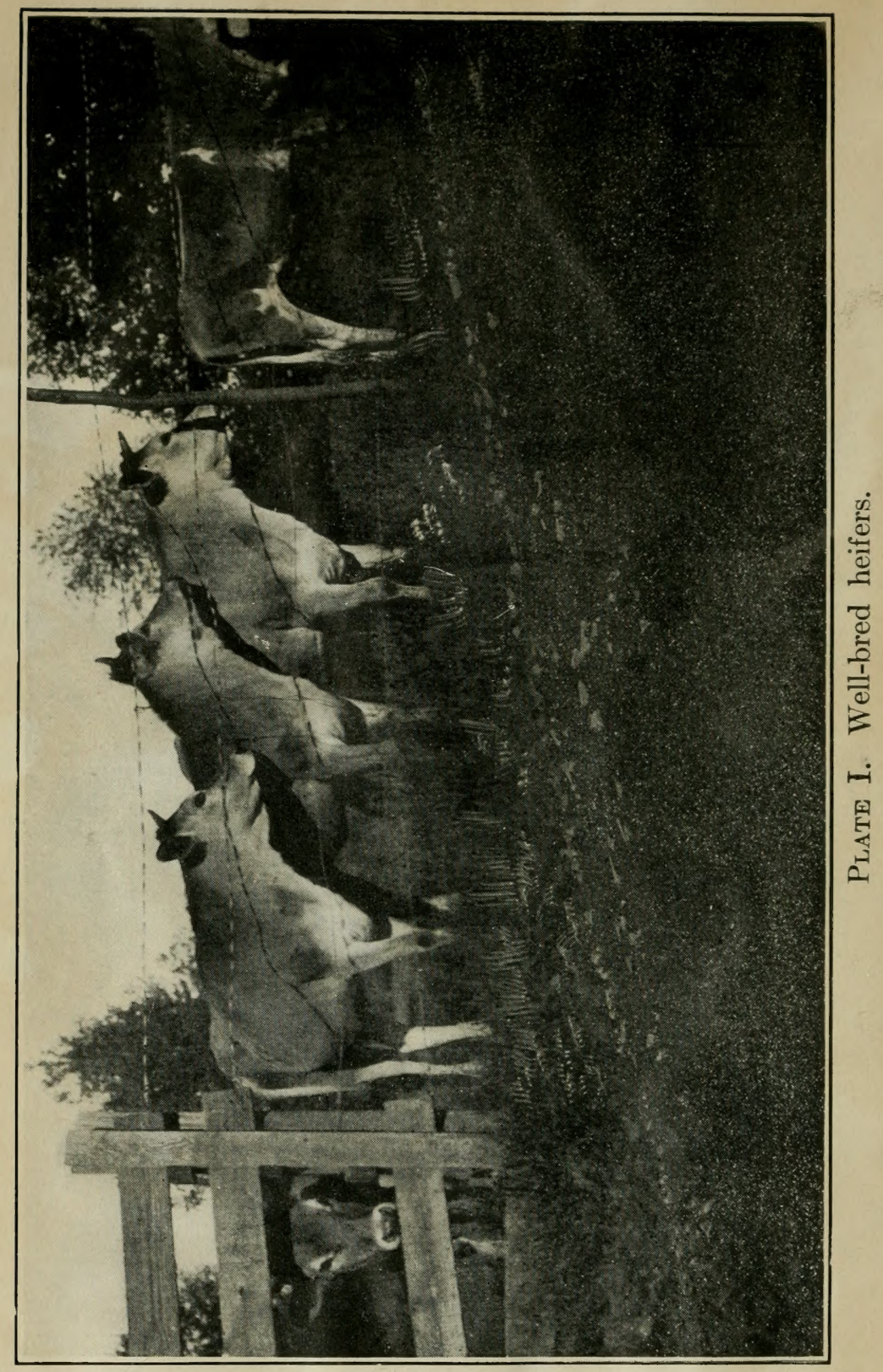




\title{
THE \\ FEEDING OF ANIMALS
}

\author{
BY \\ WHITMAN HOWARD JORDAN
}

DIRECTOR OF THE NEW YORK AGRICULTURAL

EXPERIMENT STATION, GENEVA

REVISED EDITION

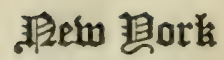

THE MACMILLAN COMPANY

1917

Alte rights reserveá 


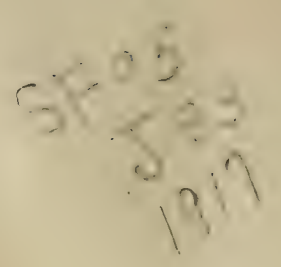

\section{COPYRIGHT, 1901 AND 1917 BY THE - MACMILLAN COMPANY}

Set up and electrotyped June, 1901

Reprinted September, 1903; February, 1905; October, 1906

February, 1908; January and July, 1909; October, 1910

February, 1912; January, 1914

New and Revised Edition, January, 1917

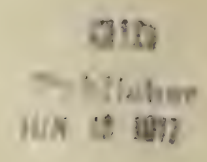

mount

J. Horace McFarland Cumpany

Harrisburg, $\mathrm{Pa}$. 


\title{
TABLE OF CONTENTS
}

\section{PART I. THE PRINCIPLES OF FEEDING}

\author{
CHAPTER I \\ Introduction: Man's Relation to Antmal Life . \\ PAGES \\ $3-8$ \\ The conditions and problems involved in feeding animals.
}

\section{CHAPTER II}

The Relations of Plant and Anmmal Life

Origin of animal foods, 1; The plant stores energy, 2; Plant substance a source of animal substance, 3 ; The plant a source of animal heat, 4 ; Food a source of motive power, 5 .

\section{CHAPTER III}

The Chemical Elements Involved in Animal NutriTION

Chemical elements involved in animal growth, 6. The Elements and Their Sources: Carbon, 7; Carbon in the air, 8; Oxygen, 9; Uses of oxygen, 10; Hydrogen, 11; Nitrogen, 12; Supply of nitrogen, 13; Uses of nitrogen, 14; Argon, 15; Sulfur, 16; Phosphorus, 17; Chlorine, 18; Iodine, 19; Potassium, 20; Sodium, 21; Calcium, 22; Iron, 23. Proportions of the Elements in Plants and Animals: Elements in plants, 24; Elements in plant ash, 25; Elements in animals, 26; Ash elements in animals, 27; Classes of matter, 28; Combustion does not destroy matter, 29; Relation of combustible to incombustible substance, 30; Organic and inorganic classes, 31 . 


\section{CHAPTER IV}

The Compounds of Animal Nutrition

The classes of compounds, 32; Distribution of elements, 33. Water: Measurement of water-content, 34; Hygroscopic water, 35; Physiological water, 36; Water in living plants, 37; Sap or plant juice, 38; Proportion of water in plants, 39; Effect of stage of growth on water-content, 40; Influence of soil moisture, 41; Supply of water to plants, 42 ; Water in feeding-stuffs, 43 ; Conditions affecting water-content of feeds, 44; Relation of water to preservation of cattle foods, 45; Water in the animal, 46; Variations of water-content of animal bodies, 47. Ash: Mineral compounds in the ash of plants and animals, 48; Rearrangement of ash elements during ignition, 49; The ash compounds of plants, 50; Variations of plant ash, 51; Variations of ash due to species, 52 ; The distribution of mineral compounds in the different parts of the plant, 53; Influence of manufacturing processes on the ash constitutents, 54; The mineral compounds of animal bodies, 55; The distribution of inorganic compounds in the animal body, 56; Ash elements in the soft tissues, 57; Ash elements in the blood, 58 .

\section{CHAPTER V}

The Compounds of Animal Nutrition, ContinuedThe Nitrogen Compounds

The importance of protein, 59. Protein: How protein is determined, 60; So-called proteins greatly unlike, 61; Classification of proteins, 62; The true proteins, 63; Ultimate composition of proteins, 64; Familiar examples of proteins, 65. Simple Proteins: The albumins, 66; The globuiins, 67; Plant globulins, 68; Animal globulins, 69; Glutenins, 70; Alcohol-soluble proteins, 71; Albuminoids, 72; Histones, protamines, 73. Conjugated Proteins: Nucleo-proteins, , 74; Glyco-proteins, 75; Phospho-proteins, 76; Hæmoglobin, 77; Lecitho-proteins, 78. Derived Proteins: 1. Primary Protein Derivatives: Proteins and metaproteins, 79; Coagulated pro- 
teins, 80. 2. Secondary Protein Derivatives: Proteoses, PAGES peptones, 81; Important properties of the proteins, 82; The unlike constitution of the various proteins, 83; Cleavage products of the proteins, 84. Nitrogen Compounds That Are Non-Proteins: Amino-acids and amides, 85; Extractives, 86.

\section{CHAPTER VI}

The Compounds of Animal Nutrition, ConcludedCarbohydrates, Acids, Fats, and Oils

Elementary composition of the non-nitrogenous compounds, 87; Classification of non-nitrogenous compounds, 88; The carbohydrates, 89; Classification of carbohydrates according to structure, 90; The monosaccharides or simple sugars, 91; Dextrose, 92; Levulose, 93; Galactose, 94; The pentoses, 95; Di-saccharides, 96; Saccharose, 97; Maltose, 98; Lactose, 99; The sugars as a class, 100; Other more complex poly-saccharides, 101; The starches, 102; Glycogen, 103; The pentosans, 104; Galactans, mannans, levulans, dextrans, 105; The pectin bodies, 106; Dextrin, 107; Cellulose, 108; The acids, 109; Fats and oils, 110; Fats or oils in grains and seeds, 111; Nature and kinds of fats, 112; Physical properties of the fats and oils, 113; Milk-fat, 114; Fatty acids, 115; Ether-extracts, 116; Lecithins, 117; Enzyms, anti-bodies, hormones, vitamines (accessories), 118.

\section{CHAPTER VII}

The Digestion of : Food

Digestion vs. assimilation, 119; General changes in food through digestion, 120. Ferments: Definition of ferments, 121; Organized ferments, 122; Structure and distribution of organized ferments, 123; Conditions of growth of organized ferments, 124; Results of fermentation, 125; Manner of action of ferments, 126; Bacteria in the digestive tract, 127; Unorganized ferments, 128; Enzyms and their action, 129. The Alimentary Canal: 
Parts of the alimentary canal, 130. The Mouth: MastiPAGES cation, 131; The teeth, 132; The saliva, 133; Origin of saliva, 134; Properties and office of saliva, 135; Quantity of saliva excreted, 136. The Stomach: The ruminant stomach, 137; Esophageal groove, 138; The rumen, 139; The reticulum, 140; Rumination, 141; The omasum, 142; The abomasum, 143; The gastric juice, 144; Artificial digestion, 145; Changes in stomach digestion, 146; Hydrochloric acid essential in stomach digestion, 147; The stomachs of the horse and pig, 148. The Intestines: Form and length of intestines, 149; Food in the small intestine, 150; The bile, 151; Functions of bile, 152; The pancreatic juice, 153; The enzyms of the pancreatic juice, 154; Steapsin, 155; Amylopsin, 156; Intestinal juices, 157; Intestinal bacteria, 158; Effects of intestinal fermentations, 159; Stimuli to digestion, 160 ; Secretins, 161; The psychic factor, 162; Digestion of food as a whole, 163; Stomach digestion, 164; Digestion in intestines, 165; Digestive fluids act together, 166; Action of intestinal juices, 167; Summary of changes in digestion, 168. Absorption of Food: Function of lacteals and blood vessels in absorption, 169; Manner of food absorption, 170; Changes in the walls of the intestinal tract, 171; Place of maximum absorption of food, 172. The Feces: Constituents of feces, 173; The feces not wholly undigested food, 174. The Relation of the Different Food Compounds to the Digestive Processes: Digestibility of the proteins, 175; Digestibility of the carbohydrates, 176; Starches unlike in rate of digestibility, 177; Digestibility of cellulose and gums, 178; Digestibility of the fats, 179. Factors Which May Influence Digestion: Meaning of "digestibility," 180.

\section{CHAPTER VIII}

Conditions Influencing Digestion • . • . . 123-137

Palatableness, 181; Influence of quantity of ration, 182; Effect of drying fodders, 183; Influence of the conditions and methods of preserving fodders, 184; Influ- 
ence of the stage of growth of the plant, 185; Influence PAGES of methods of preparation of food, 186; Wetting food, 187; Cooking foods, 188; Influence of grinding foods, 189 ; Effect of common salt, 190; Influence of frequency of feeding and watering animals, 191; Influence of season and storage, 192; Influence of the combination of food nutrients, 193; Influence of work, 194; Influence of species, breed, age, and individuality, 195; Lower digestibility with horses for coarse foods, 196; Determination of digestibility, 197; The inaccuracies of digestion coefficients, 198.

\section{CHAPTER IX}

The Distribution and Use of the Digested Food

The blood, 199; The blood corpuscles, 200; The blood plasma, 201; The heart, 202; Circulation of blood, 203; The lungs, 204; Object of respiration, 205; The use of food, 206; Nutrients are oxidized, 207; Oxidases, 208; Proteins not wholly oxided, 209; Rate of oxidation of nutrients, 210. Elimination of Wastes: Elimination of urea, 211; Elimination of carbon dioxid, 212; Elimination of water, 213. The Liver: Regulation of carbohydrate use, 214.

\section{CHAPTER X}

The Functions of the Nutrients . . . . . . 151-196

General uses of food, 215; Uses of energy, 216; Functions of water, 217. Functions of the Mineral Elements: Relation of mineral elements to vital processes, 218; Relation of mineral elements to animal structure, 219; Distribution of mineral elements in animal body, 220; Relation of mineral elements to elimination of waste products, 221; Relation of mineral elements to a proper equilibrium between the acids and bases of the animal body, 222; Relation of mineral elements to osmosis, 223; Relation of mineral elements to muscular control, 224; Relation of mineral elements to tissue development, 225; General considerations, 226; Supply of mineral ele- 
ments, 227; Relative efficiency of different phosphorus compounds, 228. Functions of Protein: Proteins as tissue-formers, 229; Protein as a source of fats, 230; Protein as a source of energy, 231. Functions of Carbohydrates: Carbohydrates the chief source of energy, 232; Proportion of ration used as fuel, 233; Fats from carbohydrates, 234. Functions of the Fats and Oils: Fats and carbohydrates similar in function, 235. Food as a Source of Energy: Work performed by the animal organism, 236; Work requires the expenditure of energy, 237; The animal organism does not originate energy, 238; The nature of energy, 239; Transformations of energy though the use of machinery, 240; The horse a machine, 241; Measurement of energy, 242; Determination of energy units in feeding-stuffs, 243; Metabolizable energy, 244; Loss of food energy in feces, 245; Loss of food energy in urine, 246; Loss of food energy in gases, 247; Recent determinations of metabolizable energy, 248; Distribution of losses of food energy, 249; Influence of size of ration on losses of methane, 250; Influence of size of ration on losses in the undigested residue, 251; Influence of individuality on energy losses, 252; Estimates of metabolizable energy on the basis of digestible organic matter, 253; Comparison of metabolizable energy in coarse fodders and grains, 254; Net energy, 255; Work of mastication, 256; Difference in total energy use with different rations, 257; The work of digestion, 258; Total energy expended in feed consumption, 259; Calculation of net energy value, 260; Net energy of various feeds, 261; Computing net energy values of feeding-stuffs, 262; Estimation of produotion values proposed by Armsby, 263. Energy Relations.-Heat Regulation: Relation of protein to muscular activity, 264; Energy chiefly from carbohydrates and fats, 265; Heat regulation, 266; Animal heat a secondary or waste product, 267; The critical temperature, 268. The Nutritive Inter-Relation of the Food Compounds and the Need of Combining These in the Ration: Protein physiologically necessary, 269; Carbohydrates 
physiologically economical, 270; Protein-sparers, 271; Nutritive value of the gums, 272; Relative importance of the nitrogen compounds of feeding-stuffs, 273; Relative nutritive efficiency of the true proteins, 274; A single amino acid a limiting factor, 275; Nutritive value of the gelatinoids, 276; Synthesis in the animal of phosphorus-bearing proteins, 277; The function of certain unidentified bodies, 278; Relation of production values to profit from feeding animals, 279 .

\section{CHAPTER XI}

LAWW OF NUTRITION .

\section{CHAPTER XII}

Sources of KNowledge .

Conclusions from feeding practice, 289; Practical feeding experiments, 290; Inconclusiveness of ordinary feeding experiments, 291; Chemical and physiological studies, 292; More accurate methods of investigation than practical feeding tests, 293; Studies of food sources of animal fats, 294; The respiration apparatus, 295; Determination of energy values, 296; Calculation of the energy value of a ration, 297; Energy value of digested nutrients, 298; Measurement of food combustion, 299; Respiration calorimeter, 300; Study of the efficiency of individual proteins, 301.

\section{PART II. THE PRACTICE OF FEEDING}

\section{CHAPTER XIII}

Cattle Foods-Natural Products $.219-241$

Classification of cattle foods, 302. Forage Foods: Classes of forage crops, 303; Green vs. dried fodders; conditions of drying, 304; Effect of drying fodders, 
305; Losses through curing fodders, 306; The harvestPAGES ing of forage crops, 307; Maximum yield of forage crops at maturity, 308; Value of crops not proportional to yield, 309; Age decreases digestibility, 310; Maize unlike other grasses, 311; Alfalfa, 312. Silage: Nature of the changes in the silo, 313; losses in silo, 314; Corn an important silo crop, 315; Extent of loss in the silo, 316; Necessary loss in silo, 317; Financial importance of silo losses, 318; Ensiling vs. field-curing, 319; Crops for silage, 320; Construction of silo, 321; Filling the silo, 322; Mature corn desirable for silage, 323; Cutting and shredding ensilage material, 324; Rate of filling silo, 325. The Straws: 326. Roots and Tubers: 327, Grains and Seeds: 328 . Storage of grain, 329.

\section{CHAPTER XIV}

Cattle Foods-Commercial Feeding-Stuffs .

Classes of commercial by-product feeding-stuffs, 330; Wheat offals, 331; Structure of the wheat grain, 332; The milling of wheat, 333; Composition of milling products of wheat, 334; Milling processes compared, 335; Screenings, 336; Residues from breakfast foods, 337; The oat grain, oat hulls, 338; Oat clippings, 339; Barley feed, 340; Hominy feed, 341; Brewers' grains; maltsprouts, 342; Residues from starch and glucose manufacture, 343; Structure of the maize kernel, 344; Manufacture of starch, 345; Residues from the manufacture of beet-sugar, 346; The oil meals in general, 347; Methods of extracting oils, 348; Cottonseed meal, 349; Cottonseed hulls, 350; Extraction of oil from the cottonseed kernels, 351; Composition of cottonseed oil by-products, 352; Linseed oil (oil meal), 353; Extraction of linseed oil, 354; Old process vs. new process linseed meal, 355. Chemical Distinctions in Cattle Foods: Coarse foods vs. grains and grain products, 356; Classification of feeds according to the proportion of nutrients, 357; Misleading terms for feeding-stuffs, 358; Classification of feeding-stuffs, 359. Foods of Animal Origin: 
360. Milk, 361; Milk of several breeds, 362; Dairy PAGES by-products, 363; Slaughter-house and other animal refuses, 364 .

\section{CHAPTER XV}

\section{The Production of Cattle Foods}

Adaptability of crops to environment, 365; New vs. old species of plants, 366; Adaptability of crops to kind of animal production, 367; Productive capacity of crops, 368; Crops of high productivity, 369; Home supply of protein, 370; Legumes and fertility, 371. Soilingcrops: Soiling-crops a necessity, 372; Conditions favorable to soiling, 373; The economy of soiling-crops, 374; Selection of soiling-crops, 375; Soiling-crop area and rotations, 376 .

\section{CHAPTER XVI}

The Valuation of Feeding-Stuffes

Basis of assigning values to feeding-stuffs, 377; Commercial values of feeding-stuffs, 378. Valuation of feeds by method of least squares, 379; Physiological values, 380 ; Energy values as a basis of valuation, 381 ; Conditions involved in the selection of feeding-stuffs, 382; Digestibility as a basis for selecting feeding-stuffs, 383; Values based on digestibility, 384; Digestibility of various feeds, 385; Valuations based on protein content, 386; Feed values based on feeding experiments, 387 ; The verdict of the cow, 388 .

\section{CHAPTER XVII}

The Selection and Compounding of Rations

Palatableness as a factor in feeding animals, 389; Adaptation of rations; 390; Physiological requirements, 391; Feeding standards, 392; Nutritive ratio, 393; Calculating a ration, 394; Calculation of digestible nutrients, 395; Digestible nutrients in a given ration, 396; Correcting an insufficient ration; 397; . Relation 
of ration to size of animal, 398; The protein supply, PAGES 399; Earlier protein standards revised, 400; Presence of growth-promoting bodies, 401; Influence of ration on quality of product, 402; Home supply of feeding-stuffs to be considered, 403; Selection of a ration largely a business matter, 404 .

\section{CHAPTER XVIII}

Maintenance Rations $307-318$

Definition of maintenance ration, 405; Character of maintenance ration, 406; Uses of production ration, 407; Maintenance ration easily provided, 408. Maintenance Ration for Bovines: Various investigations concerning maintenance needs, 409; Fasting katabolism as a measure of maintenance needs, 410; Distribution of maintenance energy, 411; Use of nutrients in fasting metabolism, 412; Computation of maintenance needs, 413; Maintenance rations for bovines, 414. Maintenance Food for Horses: Studies of the maintenance needs of the horse, 415; Maintenance rations for horses, 416; Maintenance food for sheep, 417.

\section{CHAPTER XIX}

\section{Milk Production .}

Composition of cow's milk, 418; Milk secretion, 419; Food sources of milk proteins, 420; Food sources of milk-fats, 421; The rate of formation of milk solids, 422; Uses of nutrients in milk production, 423; Protein requirements for milk production, 424; Relative importance of protein overstated, 425. Feeding Standards for Dairy Cows: Thaer's hay values, 426; Grouven's milk-feeding standards, 427; Wolff's feeding standard, 428; Kühn's feeding standard, 429; The Wolff-Lehmann feeding standards, 430; American feeding standards, 431; Woll's standard, 432; Standards for milk production based on elaborate American feeding experiments, 433; Requirements of certain feeding standards for dairy cows, 434; Calculation of rations 
for dairy cows, 435; Suggested practical rations for PAGES dairy cows, 436; The sources of commercial protein for milk production; the home supply, 437; Commercial proteins, 438; No single protein food essential, 439. The Relation of Food to the Composition and Quality of Milk: Effect of food on the proportion of milk solids, 440 ; Effect of food on the constitution of milk solids, 441 ; Influence of food on the milk-fats, 442 ; Effect of food on the flavors of milk and its products, 443 .

\section{CHAPTER XX}

Feeding Growing Animals.

The requirements for growth, 444; Food freely appropriated by growing animal, 445; Influence of kind of food on kind of growth, 446; Estimated energy requirements for one pound of gain in weight by growing cattle and sheep, 447; Milk for young animals, 448. The Feeding of Calves: Skimmed milk as a substitute for whole milk in feeding calves, 449; Calf rations without milk products, 450. The Feeding of Lambs: Feeding ewes with lamb, 451; Grain foods accessible to lambs, 452; Standards for growing sheep, 453. Feeding Colts: Food as related to quality of the horse, 454; Feeding the colt through the dam, 455; Rations for the colt before weaning, 456; Oats as horse feed, 457; Rations for growing colts, 458 .

\section{CHAPTER XXI}

Feeding Animals for the Production of Meat

Beef Production: Nature of the growth with beef production, 459; Rate of increase of fattening animals, 460; The food needs of the fattening steer, 461; Scientific experiments with fattening animals, 462; Practical feeding experiments in fattening animals, 463; German fattening for bovine's rations excessive, 464; The selection of a fattening-ration, 465; Suggested rations for fattening steers, 466. Mutton Production: Place of sheep on the farm, 467; The nature and extent of the 
growth in fattening sheep, 468; Food needs of fattenPAGES ing sheep, 469; Quantity of nutrients for fattening sheep, 470; The selection of a ration for sheep, 471 . Pork Production: Changes in pork production, 472; Character of the growth in pork production, 473; Food requirements for pork production, 474; Pigs unwisely fed, 475; Point of view in feeding pigs, 476; Influence of ration on the development of swine, 477; Dairy wastes as food for pigs, 478; Protein foods other than milk products for swine, 479; Forage crops for swine, 480.

\section{CHAPTER XXII}

Feeding Working Animals

The horse a machine, 481; The work performed by a horse, 482 ; Influence of conditions on the food expenditure for a unit of work, 483; The food requirements of a working horse, 484; Estimate of work ration for the horse based on energy relations, 485; Source of the ration for working horses, 486; Nutritive ratio for working horses, 487; Oats for working horses, 488; Suggested rations for working horses, 489 .

\section{CHAPTER XXIII}

The Feeding of Poultry. By William P. Wheeler .

Food needs of birds intensive, 490; Kinds of foods for poultry, 491; Incidental effects of the food with laying hens, 492; Digestive apparatus of birds, 493; Constituents of the body of the hen, 494; Composition of eggs, 495; Necessity for considering the water-supply, 496; Efficiency of protein from animal sources for fowl, 497; Ash constituents important for egg production, 498; Common salt a necessity for fowls, 499; Supply of grit for fowls, 500; Feeding standards for fowls, 501; Maintenance rations for fowls, 502; Rations for laying hens, 503 ; Rations for young birds, 504; Adaptability of various foods for fowls, 505; Knowledge of the nutrition of fowls limited, 506 . 


\section{CHAPTER XXIV}

The Relation of Food to Production

Food unit defined, 507; The unit of production, 508; Factors involved in food economics, 509; Relation of food to production with various species, 510 .

\section{CHAPTER XXV}

General Management

Factors in general management of animals, 511; The selection of cows, 512; The general-purpose cow, 513; The selection of animals for meat production, 514; Relation of age to meat production, 515; Manipulation of the ration, 516; Quantity of the ration, 517; Environment and treatment of animals, 518; Cruelty to animals, 519 .

\section{APPENDIX}

1. Average composition of American feeding-stuffs . 435

2. Average coefficients of digestion . . . . . 441

3. Computation of energy-production values . . 448

4. Food standards for milk production as developed by Haecker, Savage, and Eckles . . . . . 455

5. Feeding standards . . . . . 457

6. Fertilizing Constituents of American Feeding-Stuffs. 460 



\section{PART I}

\section{THE PRINCIPLES OF FEEDING}





\section{THE FEEDING OF ANIMALS}

\section{CHAPTER I}

\section{INTRODUCTION: MAN'S RELATION TO ANIMAL LIFE}

There was a time somewhere in the dim past when the beast of the field knew no master. The only obedience which he rendered to a superior power was an unconscious submission to Nature's stern forces. He wandered forth at will to find in the untilled pastures such food as the wild herbage afforded, and, unrestrained, he sought a place of rest in the tangled thicket. He knew no refuge from the winter's cold and storm but some sheltered nook or forest recess to which his brute intelligence guided him, and he was his own defense against the dangers which beset him.

Man had not come to be a controlling factor in the development of the various forms of animal life. If the brute knew him at all, it was as the huntsman, as an enemy, but not as a superior to whom must be paid a tribute of service or of food and clotiling. The wild ox and horse possessed those characteristics which best fitted them to cope with the untoward conditions of their environment; but there had not yet appeared those specialized capacities of growth, draft, speed, or production which now render these animals so very valuable for the service and sustenance of the human family.

The qualities developed were those demanded by the 
necessities of existence without reference to utility as measured by the needs of a higher form of life. The fiber of the body must possess endurance, and it mattered little whether or not the muscle could furnish a juicy steak. The brute mother must defend her young and supply it with milk, and this being accomplished, her maternal functions ceased. She was neither so endowed that she could open the fountains of her life to feed generously a not too grateful master, nor so submissive that she would. The wild horse must be fleet and enduring that he might escape the enemy, but not that he might bear heavy burdens or win a contest in the prescribed form of the race-track.

In the lapse of centuries there have been many changes in the relation of man to the animal creation. Bird and beast in various forms have come to minister to man's wants, and in their present domesticated condition are, in their turn, utterly dependent upon him for the food and shelter which are necessary to their physical welfare, or even existence. It is not too much to assert that the domestic animal, in the artificial environment imposed upon it, is entirely at man's mercy, even in the development of those attributes and characteristics which otherwise would be determined by the demands of an unaided warfare with nature. The juicy sirloin of the shorthorn, the almost abnormal milk glands of the champion butter cow, the delicate fiber of merino wool, and the marvelous speed of the modern race-horse are evidences of man's skill in recasting natural types into forms of greater usefulness to him. From the animal of nature, under the direction of a higher intelligence, has proceeded the animal of civilization, an organism obedient to the environment which has been created for it. 
This interdependence of man and the lower orders of life has a vast economic significance. A large part of human activity is devoted to the production and transportation of food for animals and to the traffic in the products of the dairy, slaughter-house, and sheepfold, and to their utilization in various ways. The prosperity of every farm is maintained to a greater or less extent by feeding domestic animals, and our railroads, our markets, in fact, nearly all our important business enterprises, are more or less dependent upon the extent and prosperity of animal husbandry.

\section{THE CONDITIONS AND PROBLEMS INVOLVED IN}

FEEDING ANIMALS

The first and simplest form of animal husbandry is that which was practised by the nomad. His flocks and herds subsisted wholly by grazing and were moved from place to place according to the supply of forage afforded by different localities. No shelter was provided for the animals and no food was stored for their use. The only intelligence or special knowledge that was brought to bear upon the business of the herdsman was a familiarity with the traditions and superstitions touching the care of cattle and the acquaintance which a roving life would give with the pastures furnishing the most abundant and sweetest wild grasses during the various seasons of the year. There was not then even a dim promise of the modern traffic in meats or of the fine art of dairying as we now know it. As man began to give up this wandering life, erect permanent dwellings, and confine his ownership of land to definite limits, he acquired the art of tillage, not only that he might have 
food for his family but also for his cattle. He then began to store fodder in stacks, and later in barns, to meet the demands of the inclement portions of the year.

For centuries, however, grazing was the chief dependence for securing the production of meat and milk because the foods supplied during the cold season were not in such abundance or so nutritious as to sustain continuous growth or milk secretion. Even within the remembrance of men now living, live-stock was not expected to produce an increase during the winter months but was simply maintained from autumn until spring in order that profits might be realized from summer pasturage. Formerly the demands of the market were much simpler than they are now. Butter and cheese were produced almost wholly from summer dairying, and no such variety of fresh meats was offered to consumers during the entire year as is now the case. But great changes have occurred during the last fifty years, more especially during the past twenty-five. First of all, we have a modern type of animal, greatly unlike that of previous times. The ideal dairy cow of today is a high-pressure milk-machine extremely sensitive to her environment and demanding a degree of care in management and feeding, if she is to do her safe maximum work, which was not necessary with coarser and less delicate organisms. Every successful dairyman must now provide proper winter quarters for his herd and throughout the entire year must supply rations that will support continuous, generous production. $\mathrm{He}$ must do this, too, by the use of a greater variety of foods than was formerly available. Not only has the number of useful forage crops greatly increased, but the average farmer no longer produces all the food which his animals consume. He now buys numerous kinds of com- 
mercial feeding-stuffs. These purchased materials are not wholly the cereal grains whose value through long experience has come to be measured by certain practical standards, but they consist in part of comparatively new by-products from the manufacture of oils, starch, and human food preparations-feeding-stuffs which differ greatly in their nutritive properties. Besides all these changes, animal husbandry is now called upon as never before to feed the prosperous part of humanity with high-class products having special qualities of texture and flavor that depend to some extent upon feeding. Certainly the conditions and problems to be met in this branch of human industry have grown more and more complex.

We must add to this the fact that, as is true with every department of man's activity, science has laid her hands upon the business of the farmer and has forced him into a new range of thought and practice. This influx of knowledge has greatly influenced the requirements for meeting a sharpened competition and has rendered it imperative for the practitioner to bring to bear upon a great variety of agricultural problems a clear understanding of fundamental facts and principles.

The feeding of animals involves many difficult questions. These begin with the production of forage and grain crops where it is necessary to discover what ones will yield the largest food-values to a unit of expenditure. Economy demands that the several feeding-stuffs which are at command shall be so combined that there shall be no waste of material or energy. With several considerations in view, a decision must be reached as to the most profitable commercial foods to purchase when the number is large and the range of prices is wide. The 
influence of the various foods upon the quality of the product, especially dairy products, has in recent years become an important matter. These and related problems confront the stockman and dairyman, and they demand for their wise solution more than what is ordinarily designated as practical experience. The investigator who shall successfully inquire into these matters must possess scientific qualifications of a high order; and the practical man, who, in a business way, conforms his methods to the highest standard which scientific research has already made possible must be familiar with the knowledge fundamental to the feeder's art. 


\section{CHAPTER II}

THE RELATIONS OF PLANT AND ANIMAL LIFE

Animal nutrition has an intimate relation to plant growth. The farmer producing meat and milk should understand the relation which animal life sustains to plant life in order that he may so direct plant production as to best serve his purposes in feeding whatever class of animals he utilizes. The efficiency of the various plant products in sustaining animal life is to him a matter of great importance.

1. Origin of animal foods.-The compounds which together constitute animal foods have their origin in plant life. For this reason, a study of the fundamental facts of animal nutrition begins with the plant. It is in the plant that the simple compounds derived from the soil and air are utilized for the production of the more highly complex compounds which are used for the growth of the animal body and for the maintenance of its activities.

As soon as the young rootlets from a germinating seed come in contact with the soil and the first leaves reach the air, assimilative growth begins and continues, as for instance, in the wheat plant until the stalk of grain has reached its full height and has attained the ultimate object of its existence in the production of seed. Certain agricultural plants have the capacity of producing not less than 10,000 pounds an acre in a single year of plant substance which may serve as food for animals. 
2. The plant stores energy.-Plant life both synthesizes simpler compounds into complex organic substance and stores energy. We get evidence of this fact when wood is utilized as fuel for the production of heat, heat being one form of energy. Scientific investigation has traced the source of this heat to the chemical energy of the sun's rays, which becomes stored in the plant. Combustion of the plant tissue liberates this energy in another form. Not only does this energy become available as heat, but it is also available for a variety of uses in the animal body. (See Pars. 206, 207.)

3. Plant substance a source of animal substance.The animal body, outside of the water which it contains, has its immediate origin in the food which the animal consumes. The mass of bone and flesh which make up the body of the immense bullock is derived from the plant substance which, in other combinations, was collected from the soil and air. The animal eats his daily ration and makes his daily gain of tissue. If food is withdrawn, his body wastes and dies. If his food varies in amount, his growth is somewhat proportional to the quantity eaten. It is self-evident that the bones, blood, and flesh of an animal are derived from what he eats.

4. The plant a source of animal heat.-The plant not only supplies building-material for the animal body, but is the source of the heat with which the animal organism is kept warm. No matter how cold the surrounding atmosphere, we find that when in health the temperature of the ox remains at about $101^{\circ} \mathrm{F}$., with but small variation. Just as we warm a room through the combustion of vegetable matter, such as wood, so the temperature of the animal is kept at the necessary heat by the combustion of his food. The combustion, in the latter case, 
is not so rapid as in the former, but the changes are the same though more slowly carried on.

5. Food a source of motive power.-Food not only furnishes the constructive material for the ox's body and maintains animal heat, but it also supplies the animal machine with motive power. The energy which the plant acquires during its time of growth, through the vital processes of the animal, is transformed in part into motion. An animal is a living mechanism, a combination of muscles and levers which are moved not by means of a spontaneous internal generation of energy, but through a supply of energy from without, the energy stored by the plant. (See Pars. 236-241.) 


\section{CHAPTER III}

\section{THE CHEMICAL ELEMENTS INVOLVED IN ANIMAL NUTRITION}

IT Is fundamentally necessary, to an intelligent understanding of the principles and economy of cattle-feeding, to know the kinds and sources of the materials out of which vegetable and animal tissues are constructed. We are primarily concerned with chemical elements.

6. Chemical elements involved in animal growth.Approximately eighty substances are now believed to be chemical elements, i. e., substances that have not been resolved into two or more simpler ones, and of which, so far as is now known, all forms of matter are composed. About one-fifth of these fundamental substances are involved in plant growth, those that occupy a prominent place in animal nutrition being even less in number. These fifteen elements are the following, some of which are of minor importance: carbon, oxygen, hydrogen, nitrogen, sulfur, phosphorus, chlorine, iodine, silicon, fluorine, potassium, sodium, calcium, magnesium, iron, and manganese.

At ordinary temperatures, four of these, oxygen, hydrogen, nitrogen, and chlorine are gases and the remaining ones are solids. Carbon, oxygen, hydrogen, and nitrogen are constant and important ingredients of the atmosphere and they exist in the soil in gases as well as in the various combinations. The other eleven, though sometimes present in the air in minute quantities, are 
found to no appreciable extent outside of plants and animals except as fixed compounds in water and in the crust of the earth. These fifteen elementary substances are nearly all absolutely essential to the existence of animal life as now constituted. From the standpoint of necessity, they are, therefore, nearly all of equal value; but, if we take into consideration the relative ease and abundance of the supply, certain ones are greatly more important than the others.

\section{THE ELEMENTS AND THEIR SOURCES}

7. Carbon.-This is a familiar substance in common life. Coal and charcoal consist chiefly of carbon, while graphite, much used in lead-pencils and diamonds, is pure carbon. Carbon makes up a large proportion of vegetable and animal tissue. This is made evident when vegetable and animal tissues become black through heating to a temperature which causes them to decompose, leaving the carbon as a residue while the elements with which it was associated are driven out. The dark humus bodies of the soil have undergone somewhat the same change.

8. Carbon in the air.-An immense quantity of carbon exists in the air, combined with oxygen as carbon dioxid. The average proportion of this compound in the atmosphere by weight is approximately .06 per cent. As the weight of a column of air over 1 inch square of the earth's surface is fifteen pounds, it follows that over every acre of land there is an average of 28.2 tons of carbon dioxid, or 7.7 tons of carbon. As we know that plants draw their supply of carbon from the atmosphere and as vegetable tissue is the primary source of this element to the animal, 
we safely reach the conclusion that the carbon in the tissues of animal life was once floating in space.

Boussingault determined the average yearly amount of carbon withdrawn from the air by the crops grown on a particular field during a period of five years to be 4,615 pounds. A large crop of maize or alfalfa would acquire even more than this. Such large drafts upon the atmospheric supply of carbon raise the question whether this supply remains constant. Investigation has shown that it does. The processes of decay through oxidation of vegetable and animal substance on the earth's surface, the combustion of wood and coal as fuel and of food compounds by animal life are all returning carbon to the air as carbon dioxid and it would appear that a balance is being maintained. The round traveled in the circulation of carbon is from the air to the plant, from the plant to the animal, and from the animal back to the air-a cycle of movement that has always existed and which will continue so long as life exists.

9. Oxygen.- This element, next to carbon, is the most abundant component of the vegetable and animal tissues. It is second to none in the importance of its relations to the vital processes of nearly all forms of life. We are not familiar with this substance by sight because it is a transparent, colorless gas. The air is over one-fifth oxygen by volume. More than $21,000,000$ pounds of this element are contained in the air above a single acre of land, a quantity which remains remarkably constant and is practically uniform over the entire surface of the globe. Like carbon, it is being continuously withdrawn from the air for purposes of combustion and is, like carbon, as continuously returned. Water contains nearly 89 per cent of oxygen, and it is estimated that the crust of the earth is one-half 
oxygen. That which enters directly into the uses of animal life is derived chiefly from the atmosphere and water.

10. Uses of oxygen.-All life, whether vegetable or animal, is dependent on the use of oxygen, during which use this element passes into fixed combinations and back again into the free form. The free oxygen of the air is used by an animal in breathing and this it returns to the air in part combined with carbon as carbon dioxid. On the other hand, the plant appropriates the carbon dioxid and, through synthetical processes, the carbon is built into the plant tissues and the oxygen, which is set free, is returned to the atmosphere and may be used to sustain the demands of animal life. Oxygen is a factor in all processes of decay and in many other chemical changes. Fire is due to its union with the elements of the fuel. It is the agent which maintains combustion in the furnaces of our industries. The energy derived from the sun's rays, which is stored in vegetable tissue, when the oxygen is torn from its union with carbon is set free when through combustion the oxygen is returned to its former combination. This circulation of oxygen is effected through the opportunities offered by the vital processes of the plant and animal. (See Par. 207.)

11. Hydrogen.-In a free state, this element is the lightest known gas and is found abundantly in nature only in combination with other elements. A minute proportion exists in the air which is derived from volcanic action and possibly from decay under certain conditions. When hydrogen and oxygen are combined in the formation of water, intense heat is produced. Hydrogen constitutes about one-ninth of water by weight and it is found also in a large number of soil compounds. It is an essential constituent of vegetable and animal tissues, but 
exists in these in a much smaller proportion than carbon or oxygen. Its source to the plant is largely water and it is furnished to the animal in water and other compounds.

12. Nitrogen and its compounds have been the subject of much scientific investigation in their relations to agricultural practice. Like oxygen, nitrogen is an invisible, tasteless, and odorless gas, which, according to previous determinations, forms about 77 per cent of atmospheric air by weight. The existence in the air of newly discovered elements, such as argon, has modified previous determinations. The only place in nature where nitrogen or its compounds exist in large quantities, outside of the air and in the tissues of living organisms, is the sodium nitrate beds which are found in Chile and other localities. Soil spaces contain nitrogen and it is taken into solution in small proportions in all natural waters. It is found in mineral and organic compounds in the soil, but in quantities very insignificant as compared with such elements as oxygen and silicon. Few agricultural soils contain over $1 / 2$ per cent of combined nitrogen. Minute quantities of its compounds, such as ammonium carbonate and ammonium nitrate, exist in the atmosphere, which are being constantly carried to the soil in rain-water and as constantly replaced by ammonia from decomposing animal and vegetable matter and by the products of oxidation of nitrogen through combustion and electrical action. Although the compounds of nitrogen exist in a comparatively small proportion, they play a very prominent part in agriculture, both commercially and physiologically. The nitrogen balance of the farm is important both to the crop-producer and the cattle-feeder.

13. Supply of nitrogen.-The available supply of nitrogen compounds is often dangerously near the demand, 
and sometimes below it. The large quantity found in the air is inert for animal uses, and is ignored by a large majority of plants. Much of that in the soil is also unavailable. Its immediately useful compounds on the farm are constantly subject to loss through fermentations which the farmer can not wholly prevent and through soil losses which are to some extent beyond control. The sale of crops removes from the farm much nitrogen. The sources of supply to balance this outgo are the nitric acid and ammonia of the rainfall, the free nitrogen captured by a class of plants known as legumes, that which is secured through purchase of fertilizers and the residues of animal foods. These facts relate primarily to plant production, but they also sustain an essential relation to the maintenance of animal life.

14. Uses of nitrogen.-Physiologically, the nitrogen compounds of foods stand in the front rank. These compounds are necessary building-material for the fundamental tissues of the animal, and are intimately related to prominent chemical changes which are involved in growth and in the maintenance of life.

Nitrogen compounds have come to have an important place in commerce. It is the most costly ingredient of fertilizers and the value of commercial cattle foods is in part dependent upon their content of these compounds. For all these reasons, the partial control which the farmer might now assume over the income and outgo of nitrogen compounds has become an important feature of farm economics. (See Par. 59.)

15. Argon.-Argon exists in the atmosphere to the extent of about nine-tenths of 1 per cent. So far as known, argon does not function in vegetable and animal life.

16. Sulfur.-This common and familiar substance is B 
found in all soils and natural waters and in all the higher forms of animal and vegetable life. We know it as "brimstone" when fused in sticks and as "flowers of sulfur" when in a finely divided form. Its most common commercial compounds are sulfuric acid and the sulfates of potassium, sodium, calcium, and magnesium. Sulfur is an element essential to the building up of some of the most important tissues of the animal body and is supplied in food in the form of the sulfates and in protein combinations. (See Par. 64.).

17. Phosphorus.-This element occupies a very important place in animal nutrition. It does not exist in nature in an uncombined form and that found in laboratories is produced only by chemical means, but its compounds are widely distributed, those in the soil being chiefly the phosphates of calcium, magnesium, and iron. Large deposits of calcium phosphate are known, from which is obtained the crude phosphatic rock that serves as a basis for the manufacture of commercial fertilizers. All feedingstuffs in their natural forms contain phosphorus compounds: such as phosphates, certain fats, and organic nitrogen compounds. Phosphorus is a constituent of the fiesh of animals, and, combined with lime, constitutes a large part of bone. (See Par. 55.)

18. Chlorine.-The chief source of chlorine to animal life is common salt. In some form or combination it is essential to the nutrition of the animal. In a free state, at ordinary temperatures, it is a greenish colored, disagreeable gas. When combined with hydrogen, it forms hydrochloric acid-a compound that occupies a prominent place in the digestion of food. Any ordinary mixed ration contains this element in a quantity sufficient for the animal's needs. (See Par. 144.) 
19. Iodine.-Iodine is distributed in nature only in minute quantities. It is apparently absent in some plants, but is found in minute quantities in others. Nevertheless it appears to exercise important functions in animal life.

20. Potassium.-Familiar compounds of this element are the potassium carbonate leached from wood-ashes, saleratus, and the caustic potash of the market. This element is found in the flesh of all animals, mostly as the phosphate, and is abundantly supplied for the purposes of nutrition in the ordinary combinations of natural feeding-stuffs.

21. Sodium.-This is the basal element of common salt, a compound which is furnished to domestic animals in a liberal supply. This is the only sodium compound which it is necessary to consider. Sodium plays an important part in the digestion of food as it is the basis of certain bile salts and is concerned in other ways in the digestive processes. (See Par. 151.)

22. Calcium.-The most commonly known compound of this element is lime, which is calcium united with oxygen. Large masses of lime-rock, or calcium carbonate, exist in many parts of the earth's surface. All soils contain lime compounds. Its universal presence in plant tissues and in the milk of all animals in most instances assures a sufficient supply to meet the demands of animal life. The growing animal makes a generous use of lime because, in union with the phosphoric acid, it is the chief building-material of the bony framework. A deficiency of food lime causes an abnormal development of the bony structure. Lime is especially important for poultry, for egg-shells are mostly a lime compound. (See Par. 55.)

23. Iron.-The common properties of iron are familiar to everyone. Iron rust and iron ore are oxides of this 
element. Iron is taken up by plants and animals in small quantities only, but is absolutely essential to their growth and welfare because of its important relation to certain metabolic processes. (See Par. 200.)

\section{PROPORTIONS OF THE ELEMENTS IN PLANTS AND ANIMALS}

In order to reach an intelligent understanding of the relation of supply and demand which exists between the vegetable and animal kingdoms and the raw materials of the inorganic world, it is necessary to know the proportions in which the elements are found in living organisms.

24. Elements in plants. - It has been estimated by a German scientist, Knop, that if all the species of the vegetable kingdom, exclusive of the fungi, were fused into one mass, the ultimate composition of the dry matter of this mixture would be the following:

Carbon

Per cent

Oxygen 45

Hydrogen 42

Nitrogen

Mineral compounds (ash)

The composition of various single species or parts of a plant, such as the fruit or straw, shows considerable variation from these average figures:

TABLE I

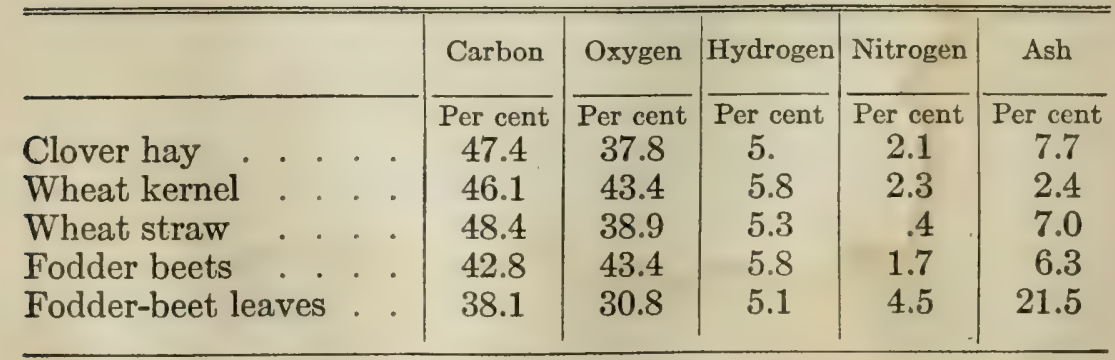


Carbon constitutes a larger proportion than any other element of the dry substance of plants of all species. Oxygen stands next in order, followed by hydrogen and then nitrogen. It is an important fact in the economy of nature that those elements which, on the average, make up 93.5 per cent of the dry matter of plants have as their main source either the atmosphere or water. Only a small percentage of the dry matter is drawn from the soil, and it is this small part that sustains the most important economic relations to the farmer's business.

25. Elements in plant ash.-The elements of the ash vary materially in relative quantity in different plants. The following table gives the proportion of the ash elements in a number of agricultural products:

TABLE II

Ash Elements in Cereal Grains and Vegetables*

\begin{tabular}{|c|c|c|c|c|c|c|c|c|c|c|c|c|c|}
\hline & & & & & $\frac{\vec{E}}{\frac{E}{J}}$ & 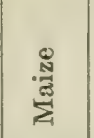 & $\frac{\pi}{\vec{J}}$ & 萢 & 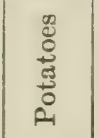 & 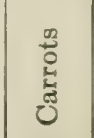 & 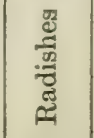 & 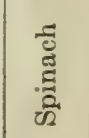 & 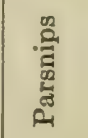 \\
\hline Potassium & & & & & \begin{tabular}{|} 
Per \\
cent \\
.51
\end{tabular} & \begin{tabular}{|l|} 
Per \\
cent \\
.36
\end{tabular} & $\begin{array}{l}\text { Per } \\
\text { cent } \\
.46\end{array}$ & $\left|\begin{array}{c}\text { Per } \\
\text { cent } \\
1.25\end{array}\right|$ & $\begin{array}{c}\text { Per } \\
\text { cent } \\
1.89\end{array}$ & $\left|\begin{array}{c}\text { Per } \\
\text { cent } \\
1.68\end{array}\right|$ & $\left|\begin{array}{c}\text { Per } \\
\text { cent } \\
1.93\end{array}\right|$ & $\mid \begin{array}{c}\text { Per } \\
\text { cent } \\
2.27\end{array}$ & $\mid \begin{array}{c}\text { Per } \\
\text { cent } \\
2.18\end{array}$ \\
\hline Sodium. & & & - & & .029 & .012 & .039 & .029 & .08 & .86 & 1.14 & 4.32 & .053 \\
\hline Calcium & & & 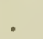 & & .043 & .023 & .08 & .129 & .07 & .44 & .77 & 1.40 & .39 \\
\hline Magnesium & & & & & .14 & .135 & .134 & .16 & .112 & .14 & .13 & .63 & .163 \\
\hline Iron . . & & & . & & .017 & .008 & .026 & .012 & .029 & .038 & .144 & .38 & .038 \\
\hline Phosphorus & & & . & - & .41 & .29 & .35 & .62 & .28 & .31 & .343 & .74 & .412 \\
\hline Sulfur & & & 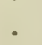 & & .0032 & .0044 & .022 & .049 & .099 & .14 & .19 & .45 & .101 \\
\hline Silicon & & & - & & .018 & .014 & .57 & .011 & .036 & .06 & .031 & .35 & .036 \\
\hline Chlorine. & & & $\theta^{\circ}$ & & .006 & .013 & .029 & .065 & .131 & .25 & .66 & 1.02 & .183 \\
\hline
\end{tabular}

* Calculated from Wolff's "Aschen Analysen." It is realized that more modern methods of analysis might modify the above figures to a small extent, but they are sufficiently accurate for illustration of the variable composition of the ash of different species.

26. Elements in animals.-The proportions of the chemical elements of our larger animals have been deter- 
mined through analyses made of the entire bodies of steers and other domestic animals by Lawes and Gilbert, of England, and the Maine Experiment Station, in this country. These results, combined with our knowledge of the constitution of the compounds of the animal tissues, enable us to calculate very closely the proportion of carbon and other elements in the entire body of an ox:

TABle III

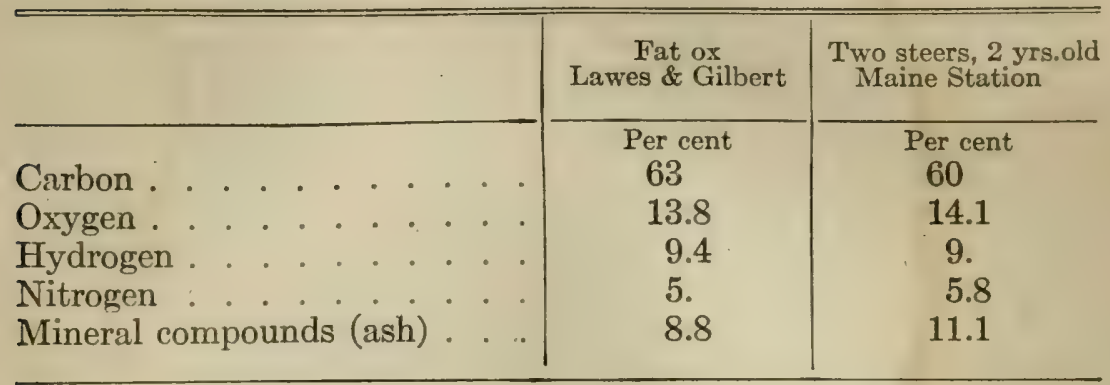

A fat ox contains a much larger proportion of carbon than a lean one, because the fats are richer in carbon than any of the other compounds of the animal body. It is seen that plants and animals are alike in containing much more of carbon than of any other element, and that the quantities of the remaining elements stand in the same order of proportion in the plant and in the animal, oxygen being in greater proportion in the plant, and carbon and nitrogen in the animal. The plant and animal are alike, therefore, in consisting chiefly of elements derived from air and water. Carbon, oxygen, and hydrogen constitute from 83 to 86 per cent of the bodies of fat oxen. It follows that less than one-sixth of the animal is built from elements that have, in part, a commercial value for crop production. Nitrogen and certain elements in the ash of the plant and animal bear a market value. 
27. Ash elements in animal.-The proportions of the ash elements are shown from analyses made of the fat ox by Lawes and Gilbert. For comparison, the proportions of ash elements in the human body are given:

TABLE IV

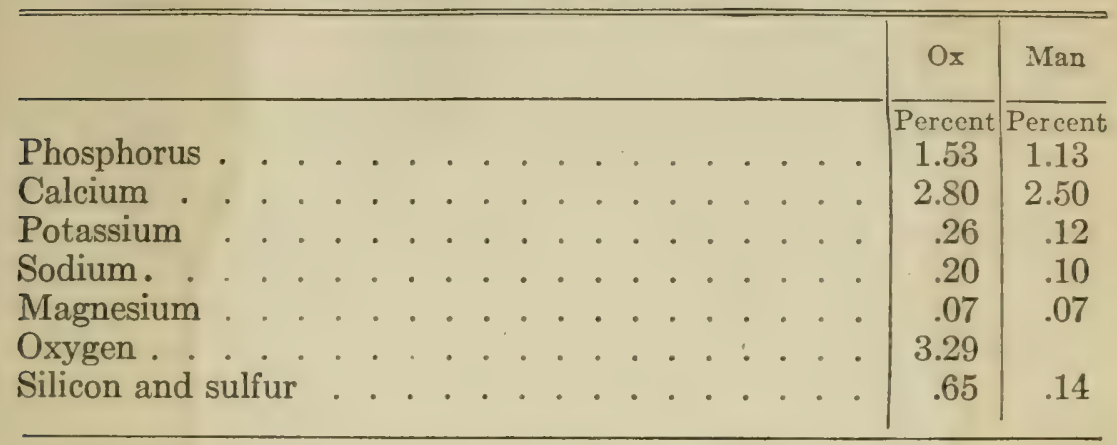

It appears that in the ash, other than oxygen, phosphorus and calcium take a leading place as to quantity, although other elements, such as sulfur, potassium, and sodium are essential to animal growth, even if present in relatively small amounts.

28. Classes of matter.-A common and familiar phenomenon is the destruction of vegetable or animal matter by combustion, with the result that only a small portion of the original material is left behind in visible and solid forms. Fuel, such as wood or coal, is largely consumed when ignited, and we have as a residue the ash. If we incinerate hay, corn, or wheat we get a similar result. The gradual decomposition of exposed dead vegetable matter that occurs in warm weather is a process essentially similar to the combustion of fuel, only more prolonged. In view of these facts, it is customary to classify all the tissues of plants and animals into the combustible and incombustible portions, the former being 
that part of the ignited or decayed substance which disappears in the air as gases, and the latter the residue or ash.

29. Combustion does not destroy matter.-It should be well understood that combustion does not involve a loss of matter; only a change into other forms. If we were to collect the gases which pass off from a stick of wood that is burned, consisting mostly of carbon dioxid, vapor of water, and certain compounds of nitrogen, we would find that their total weight, plus that of the ash residue, is even greater than that of the dry wood, because the carbon and the hydrogen of the wood have united during the combustion with an increased amount of oxygen. The carbon, oxygen, hydrogen, and nitrogen of the plant or animal tissue belong to the combustible portion, although small amounts of two of these elements are found in the ash, as it is usually estimated. The remainder of the fifteen elements previously named is supposed to appear wholly in the ash, although in different combinations from what they exist in the plant.

30. Relation of combustible to incombustible portions.-The relation in quantity of the combustible and incombustible parts of vegetable and animal dry matter is illustrated below:

TABLE V

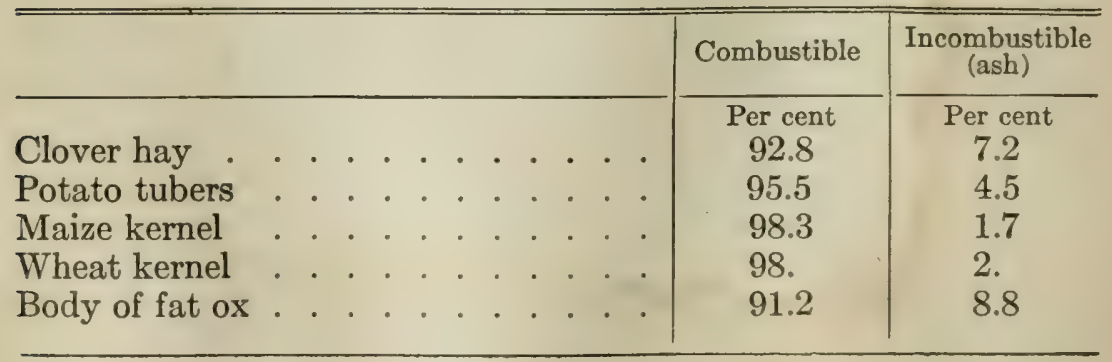


The significance of these facts in their relation to cattle-feeding is that the chemical change which we call combustion is one of the phenomena of animal nutrition. Substances which may suffer either slow or rapid oxidation outside the animal body may undergo complete or partial combustion in the animal; or, stated in another way, the part of the plant which "burns up" in the fireplace or crucible is the part which in general undergoes the same change within the animal organism in so far as the food is digested.

31. Organic and inorganic classes.-The terms combustible and incombustible are less used, perhaps, than two others which represent practically the same divisions of plant or animal substance, viz., organic and inorganic. In chemical literature, the portion of a plant or animal which suffers combustion is called the organic, and the ash is known as the inorganic part. These terms were evidently based on the erroneous assumption that the compounds which burn and break up into simpler ones are peculiarly those which sustain necessary and vital relations to life, and are formed only through the functions of living organisms. To be sure, the dry substance of the plant is organized chiefly by building up compounds of carbon, oxygen, hydrogen, and nitrogen, which suffer combustion; but compounds of sulfur, phosphorus, chlorine, potassium, sodium, and calcium are also constant and essential constituents of the juices and tissues of the plant and animal. They sustain important relations to nutrition and growth. It is true, however, that the portion of a food material which is commonly spoken of as organic embraces those compounds that furnish practically all the energy which is utilized by animal life and much the larger part of the building-material. 


\section{CHAPTER IV}

\section{THE COMPOUNDS OF ANIMAL NUTRITION}

THE animal body consists primarily of elements, but we ordinarily regard it as made up of compounds. These are groups of elements united in such fixed and constant proportions that they have as uniform properties, under given conditions, as the elements themselves. In discussing the composition and uses of cattle foods and the structure, composition, and functions of the animal as an organism, we refer chiefly to the compounds of carbon rather than to carbon itself. In the language of practice, we speak of proteins, carbohydrates, and fats. Commerce recognizes these compounds also. These compounds are the source of the energy that is manifested by animal life, and, with the ash, of nearly all the materials out of which animal tissues are built.

32. The classes of compounds.-The known compounds that belong to life in all its forms are almost innumerable. These sustain a variety of relations to human needs, some serving as food, some as medicine, and some in the arts. Comparatively few of these must be considered in discussing the science and art of cattlefeeding. Moreover, the compounds which play a leading part in animal nutrition are designated, especially for practical purposes, in classes rather than singly, which tends to more or less looseness of expression and definition. For instance, the popular understanding of the term protein doubtless is that it is a single compound. 
The same classification is used for the compounds of both the vegetable and animal kingdoms, which are divided into the following groups:

Water,

Ash (mineral compounds),

Protein (nitrogenous compounds),

Carbohydrates (and related bodies),

Fats (or oils).

Variously named compounds partially theoretical and unclassified: Enzyms, antigens hormones, vitamines accessories, activators. (These terms are in part synonyms.)

Accuracy is here sacrificed to convenience. These class names have come to be regarded, more or less, as representing entities having fixed properties and functions, whereas each class contains numerous compounds differing widely in their characteristics and in their nutritive value and office. Moreover, these terms have a variable significance as used under different conditions. No one of them, except water, uniformly represents just the same mixture of compounds when applied to unlike substances.

33. Distribution of elements.-It is well to gain a clear understanding of the relation which the fifteen elements previously mentioned sustain to these classes of substances. This relation can be shown for the five main classes of nutrients, but not for the unclassified or theoretical bodies. Just what elements enter into these is not known. So far as known they do not have a constructive function. The distribution of the elements can be seen most readily by a tabular display: 


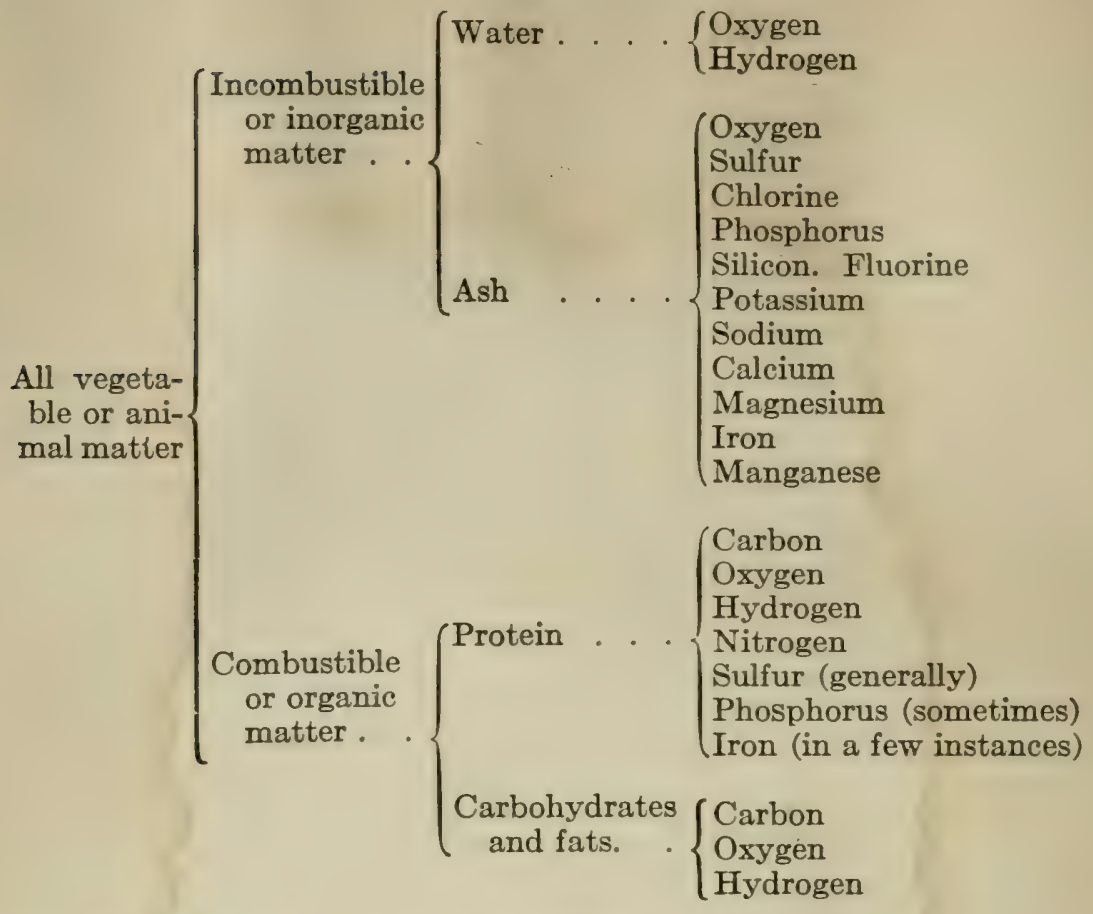

The ash which, on the average, constitutes about onetwentieth of the plant, and never more than one-tenth of the animal, may contain thirteen of the fifteen elements, while the larger proportion of living matter consists mostly of the compounds of three or four elements, in no case of more than six or seven. It is strikingly evident that the dominant elements of life, quantity alone considered, are those derived from the air and water.

\section{WATER}

Water fills a very important place in agriculture. All plant substance, all animal tissue, foods, and nearly all the material things with which man comes in contact in his daily life are made up of more or less water, or are 
associated with it. Sometimes this is rery evident, as with green plants or juicy fruits. It is not so evident with straw and corn meal. If, however, we submit almost any substance, no matter how dry it may appear, except, perhaps. glass and metals, to the heat of an oven at $212^{\circ} \mathrm{F}$., we find that a material loss of weight occurs; and if we so arrange that whatever is driven off is first drawn through some substance that entirely absorbs the water which has been vaporized, we learn that the decrease in weight is nearly all accounted for by the water thus collected.

34. Measurement of water-content.-This suggests to us the chemist's way of determining the proportion of water which any particular material contains. He weighs out a certain amount of the substance and then keeps it in an oven at $212^{\circ} \mathrm{F}$. for five hours perhaps, after which it is re-weighed. The difference in the two weights, or the loss, is assumed to be all water, and the percentage in the original substance is easily calculated. That portion of the material which is left behind after the water is evaporated is called the dry substance.

35. Hygroscopic water.-Water is associated with plant and animal substances and tissues in two ways, hygroscopically and physiologically. It is easy to illustrate the former way. If an ounce of corn meal were to be dried in an oven as described, it would, as stated, lose in weight. If it were subsequently allowed to remain exposed in the open air in a barn or out-of-doors, it would regain part or all of its original weight. The loss would be due to water driven away by heat, and the gain to water absorbed from the atmosphere, which we call hygroscopic moisture.

All solids attract moisture up to a certain proportion 
which varies with the substance and with the conditions that prevail. The surfaces of the particles of matter are ordinarily covered with a thin film of water, which is thicker on a cold, wet day than on a warm, dry day, and so the same quantity of hay or grain weighs less at one time than at another, because the percentage of hygroscopic water varies. An equilibrium will always be established between the attraction of a substance for moisture and the tension of the vapor of water in the surrounding air, which accounts for the effect of temperature and of the degree to which the air is saturated with water-vapor. As all substances do not have the same attraction for moisture, therefore, under similar atmospheric conditions, one feeding-stuff may retain more water than another.

36. Physiological water.-Water that is held physiologically is that which is a constant and essential part of living organisms, in which relation it is necessary to life and performs certain important functions. These functions are of three kinds: (1) The presence of water in the tissues of plants and animals gives them more or less firmness or rigidity combined with elasticity; (2) water acts as a food-solvent; (3) water is the great carrier of food materials and of waste products from one part to another of the vegetable or animal organism.

37. Water in living plants.-Water constitutes a large proportion of the weight of all living plants, especially during the period of active growth. The cured hay weighs much less than did the green grass when it was cut, and this loss in weight is due almost wholly to evaporation of water from the tissues of the plant under the influence of the sun and wind. This water, which is contained in the cells, tubes, and intercellular spaces of the stalk or leaf, is pure water and has no more physiological value for the 
animal than water from any other source excepting that it is pure and is not subject to the contamination which sometimes occurs in streams and wells. There is no such thing as the so-called natural water of plants, which has a peculiar nutritive value or function.

38. Sap or plant juice.-Vegetation water should be distinguished from sap or plant juice. Sap is more than water; it is water holding in solution certain substances such as sugars and mineral salts. When the plant is dried, these soluble compounds do not pass off, but remain behind as part of the dry matter.

39. Proportion of water in plants.-The proportion of water in plants varies greatly in different species, and in the same species according to the stage of growth or the surrounding conditions. These facts have more importance than is generally recognized, because the food value of vegetable substances is largely determined by the proportion of dry matter. It is always necessary to know the percentage of water in a green plant before we can estimate its worth for feeding purposes.

The variations in water-content of the living tissues of different species of plants or parts of plants are well illustrated by the following average figures: (See Pars. 304306.)

\section{Table VI. Water in Green Plants}

Pasture grass (mixed)

Per cent

Timothy grass

80.

Oats (fodder)

61.6

Rye (fodder)

62.2

Sorghum (fodder)

76.6

Fodder corn, dent, kernels glazed

79.4

Red clover .

73.4

Alfalfa

70.8

Horse-bean

71.8

Potatoes (tubers)

84.2

Turnips 
40. Effect of stage of growth on water-content.Immature plants contain more water than older or mature ones. Young pasture grass is more largely water than the same plants would be after the seed is formed. This fact is consistent with the very rapid transference of buildingmaterial during the active stages of growth. Analyses of samples of timothy grass cut at the Maine State College, in 1879, and at the Pennsylvania State College, in 1881, show the marked influence of the stage of growth on the water-content of the living plant:

TABLE VII. TMmothy

Maine State College

Percentage of water

Nearly headed out 78.7

In full blossom

71.9

Out of blossom

65.2

Nearly ripe

63.3

Pennsylvania State College

Cut June 6, heads just appearing

Cut June 23, just beginning to bloom

Cut July 5, somewhat past full bloom

$\begin{array}{cc}\begin{array}{c}\text { Percentage of water } \\ \text { Highly } \\ \text { manured }\end{array} & \begin{array}{c}\text { No } \\ \text { manure }\end{array} \\ 79.7 & 76.5 \\ 69.7 & 69.1 \\ 61.4 & 60 .\end{array}$

What is true of timothy is probably true of all forage crops in the perfectly fresh state. We have here an explanation of the difficulty of curing early cut grass. When the farmer begins haying, at least two drying days are needed in order to secure a product that will not ferment in the mow, while later in the season, grass cut in the morning may be safely stored in the mow before night. At the Maine State College, in 1880, immature timothy grass lost 56.7 per cent weight in curing and the ripe grass only 12.9 per cent. The extreme succulence of immature corn and other crops previous to the formation of seed is a fact which the dairyman who feeds soiling- 
crops must consider if he would uniformly maintain a ration up to the desired standard.

41. Influence of soil moisture.-The proportion of water in plants is influenced also by the lack or excess of soil moisture. The soil and not the atmosphere is the source of supply of vegetation water, which, taken up by the roots, traverses the plant and passes into the atmosphere through the leaves. If the supply is abundant, the tissues are constantly fully charged, but if, by reason of drought, the soil becomes very dry, the outgo of water by evaporation may exceed the income. During a drought vegetation water often falls below the normal, or below what is necessary to maintain the tissues in their usual condition of rigidity or to perform fully their physiological functions.

42. Supply of water to plants.-This leads to the observation that the water in a growing plant is that which is in transit from the soil to the air. This liquid stream enters the plant with its load of building-materials, takes into solution the compounds elaborated in the leaves and aids in transporting them to the points of rapid growth, finally passing into the air from the surface of the foliage. Throughout the entire growing season the plant acts as a pump, drawing from below through the roots the water which it needs for various purposes, and discharging it into the air. It was found that in Wisconsin 309.8 tons of water were evaporated by the plant for each ton of dry matter in the crop. Four tons of dry matter to the acre is not an unusual product with maize, requiring $1,239.2$ tons or 10.4 inches of water for its growth, the equivalent of about five-eighteenths of an average annual rainfall. This is a fact of great significance to the stock-feeder. His success begins with proper hus- 
banding of the plant-food resources of the farm, of which water is an important factor.

43. Water in feeding-stuffs.-Cattle foods, whether in the green or air-dry condition, always contain more or less water. The proportion is greatly variable, depending upon several factors. With the green foods, the range of percentages is similar to that of the living plants previously noted. As, however, forage plants are used at varying lengths of time after cutting, and as a loss of moisture begins immediately after the plant is severed from its source of water-supply, the amount of dry matter in a green forage crop is somewhat uncertain, unless a water-determination is made in the material exactly as it is fed. In all experimental work this precaution is necessary to accuracy. Roots and potatoes contain a large proportion of water, which, owing to their structure, is slowly evaporated. In a cool, moist cellar, their water-content will remain practically unchanged for a long time; in a warm, dry room, evaporation occurs and they shrivel and lose weight.

44. Conditions affecting water-content of feeds.The water-content of air-dry foods varies with the condition in which they were stored, the length of time after storage, and the percentage of moisture in the air. Early cut hay often goes to the barn less perfectly cured than the late cut, and all hay dries out more than is generally realized during the first few months of storage. Concerning these points, the writer has obtained data through experiments at the Maine State and Pennsylvania State colleges. Fourteen lots of hay, some early cut and some late cut, were weighed when stored and again after remaining in the barn for several months. The results follow: 
TABLE VIII

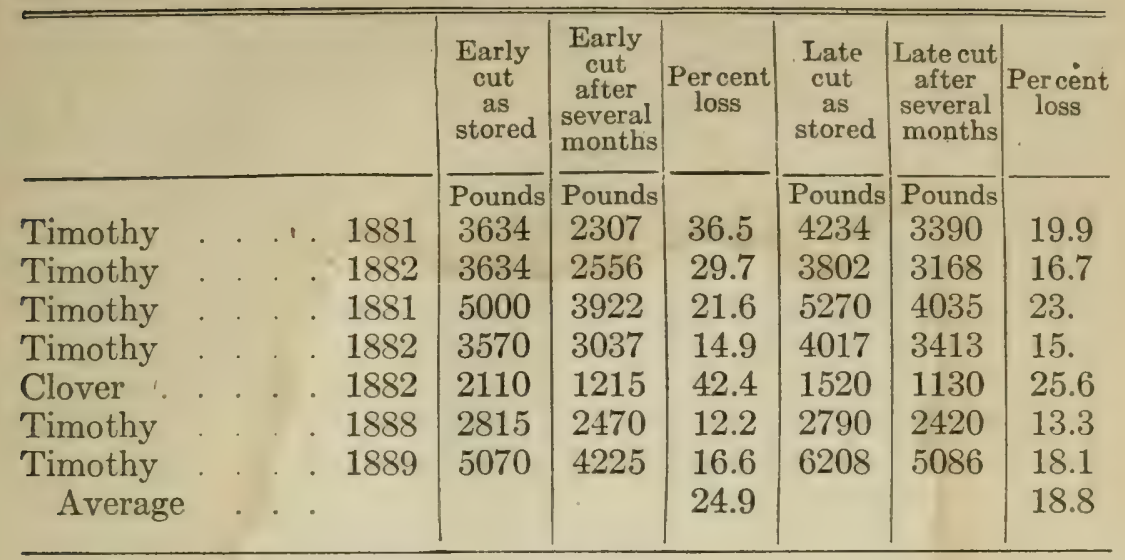

General average loss, 22.2 per cent.

It is probable that hay seldom loses less than oneeighth of its weight during storage, and often much more.

As illustrating the variations in the proportions of water in hay due to changes in air moisture, reference is made to observations by Atwater. He found that dry hay hung in bags in a barn varied in water-content between 7.5 per cent and 13.6 per cent during the months of May, June, and July. Hay in large masses would change less, but would be affected, doubtless, by long periods of very dry weather or very wet.

45. Relation of water to preservation of cattle foods.The proportion of moisture in coarse foods and grains has much to do with their preservation in a sound condition. New hay and grains when packed in large masses are subject to fermentations which injure their quality and diminish their food value. This is due to the fact that sufficient moisture is present to allow the growth of low forms of life with certain attendant chemical changes. Feeding-stuffs containing 20 per cent or more of waterand this is likely to be the case with clover, rowen, ficld- 
cured corn fodder and stover, new oats and new cornwhen stored in large quantities are almost certain to heat and become musty or moldy, always involving a loss of nutritive value. (See Par. 306.)

46. Water in the animal.-Water is an important and abundant constituent of animal organisms, from the lowest to the highest forms. The blood, which is from one-thirtieth to one-twentieth the weight of the bodies of farm animals, is at least four-fifths water, while the soft tissues have been found to contain from 44 to 75 per cent, according to the species, age, and condition of the animal. The most extensive and complete analyses so far made of the entire bodies of animals were performed by Lawes and Gilbert at Rothamsted, England. In this country, four steers were analyzed at the Maine Experiment Station, and in the study of human-nutrition problems many determinations of water have been made:

Table IX. Water in Entire Body

Per cent

Ox, well fed, Lawes \& Gilbert

66.2

Ox, half fat, Lawes \& Gilbert

59.

Ox, fat, Lawes \& Gilbert

49.5

Steer, 17 months old, medium fat, Me. E. S.

Steer, 17 months old, medium fat, Me. E. S.

59.

Steer, 27 months old, fat, Me. E. S.

56.3

Steer, 27 months old, fat, Me. E. S.

51.9

Calf, fat, Lawes \& Gilbert

52.2

64.6

Sheep, lean, Lawes \& Gilbert

67.5

Sheep, well fed, Lawes \& Gilbert

63.2

Sheep, half fat, Lawes \& Gilbert

58.9

Sheep, fat, Lawes \& Gilbert .

50.9

Sheep, very fat, Lawes \& Gilbert

43.3

Swine, well fed, Lawes \& Gilbert

57.9

Swine, fat, Lawes \& Gilbert

Chicken, flesh

74.2 .

Fowl, flesh

65.2

Goose, flesh

42.3

Turkey, flesh

$-55.5$ 
It is very evident that, in general, considerably more than half of the weight of the bodies of our domestic animals consists of water, the limits observed in all species and conditions here mentioned being 42.3 and 74.2 per cent.

47. Variations of water-content of animal bodies.The percentage of water varies with the species, age, and condition. Swine carry a notably small proportion. The calf's body, even though fat, is comparatively watery. It is very noticeable that with oxen, sheep, and swine the lean animals contain a much larger proportion of water than the fat. This does not necessarily mean that in the process of fattening the fat is substituted for water, and so expels it from the organism, but that the increase has a much smaller percentage of water than the body in its original lean condition. This is well illustrated by the data from two independent investigations at Rothamsted and at the Maine Experiment Station. The former investigation showed that when swine, sheep, and oxen were fattened the increase contained from 20 to 24 per cent of water, this being half the proportion found in the entire bodies of the lean animals. The Maine Station results established the fact that in the increase of two steers from the age of seventeen to twenty-seven months, during which time a fattening ration was fed, there was 42 per cent of water, the bodies of the younger steers having 58.2 per cent. It is a common remark among unscientific people that beef from mature animals "spends" better than that from young, the same observation being made in comparing lean and fat beef. Modern investigation shows clearly that the reason for this lies partly in the difference in water-content. Dry matter, and not water, is the measure of food value. 


\section{ASH}

The ash or mineral part of plants and animals has occupied a minor place in the discussions which pertain to the principles and problems of animal nutrition. In the past chief attention has been given to the carbon compounds of living organisms, while the compounds of the mineral world, in their relation to foods and to nutritive processes, have generally been passed by with too brief discussion. It is desirable to gain a clear understanding of the combinations, distribution, and functions of the constituents of the ash, for their importance in animal nutrition is no less than pertains to the carbon compounds.

48. Mineral compounds in the ash of plants and animals.-As previously stated, the mineral portion of a plant or animal is measured by the ash or residue after combustion, the principal ingredients of which are the following:

\section{TABLE X}

Acids

Bases

Hydrochloric acid . . HCl. Potash . . . . $\mathrm{K}_{2} \mathrm{O}$

Sulfuric acid ........ $\mathrm{H}_{2} \mathrm{SO}_{4}$ Soda . . . $\mathrm{Na}_{2} \mathrm{O}$

Phosphoric acid ... $\mathrm{H}_{6} \mathrm{P}_{2} \mathrm{O}_{8}$ Lime ....... $\mathrm{CaO}$

Silicic acid ......... $\mathrm{SiO}_{2}$ MgO

Carbonic acid .......... $\mathrm{CO}_{2}$ Iron oxid $\ldots \mathrm{O}_{3}$

Other mineral compounds are found in the various forms of vegetable life, but those mentioned are all that we need to discuss at length.

The acids and bases do not exist in the ash as shown, but they are united to form salts, and so we have the chlorides, sulfates, phosphates, and carbonates of potassium, sodium, calcium, magnesium, and iron. These are nearly all familiar objects in common life, as, for instance, sodium chloride (common salt), potassium 
chloride (the muriate of potash of the market), potassium sulfate (the sulfate of potash of the market), calcium sulfate (of which gypsum or land-plaster is composed), calcium phosphate (burned bone is chiefly this compound), potassium phosphate (a compound of phosphoric acid and potash found chiefly at the druggist's), and calcium carbonate (limestone).

49. Rearrangement of ash elements during ignition.It should be remembered that the compounds in the ash are not necessarily those of the plant or animal. During the ignition of plant or animal substance, organic compounds are broken up, certain acid and basic elements of which enter into other combinations in the salts of the ash. Much of the lime in the ash is in union with carbonic acid, which in the plant may have been associated with vegetable acids, such as oxalic and tartaric, and part of the sulfur and phosphorus of the ash comes from certain carbon compounds.

The salts of the ash differ greatly in their properties. Some are soluble in water, others are not. To the former class belong all the chlorides, and the potassium and sodium sulfates and phosphates. The normal phosphates of calcium and magnesium are insoluble in water, but soluble in various acids. These facts are important in showing what salts may be found in the plant and animal juices, and what effect leaching with water or other solvents might have on the inorganic portion of cattle foods.

50. The ash compounds of plants.-Upon incineration, all plants and feeding-stuffs yield an ash residue which has been termed the mineral part of the plant. The ash elements are important in this connection because they are the main source of the same elements of the animal body. These may be held in plant tissue in three 
ways: in organic combinations and as the inorganic salts of plant solutions, crystals and incrustations. Outside of phosphorus and sulfur, little is known of the relations to plant structure of the important ash elements, such as potassium, calcium, and magnesium. Their place as bases in organic structures is not fully understood.

51. Variations of plant ash.-The ash from different plants and feeding-stuffs is by no means uniform in composition and quantity, even in the same species or class of materials, although with the grains there is some degree of uniformity in this respect. Certain factors cause variations, such as species, stage of growth, fertility, the part of the plant, and changes due to manufacturing processes.

52. Variations of ash due to species.-Different species of plants, and consequently different feeding-stuffs, are greatly unlike in their content of mineral matter. The figures of Table XI illustrate this fact:

\section{TABLE XI}

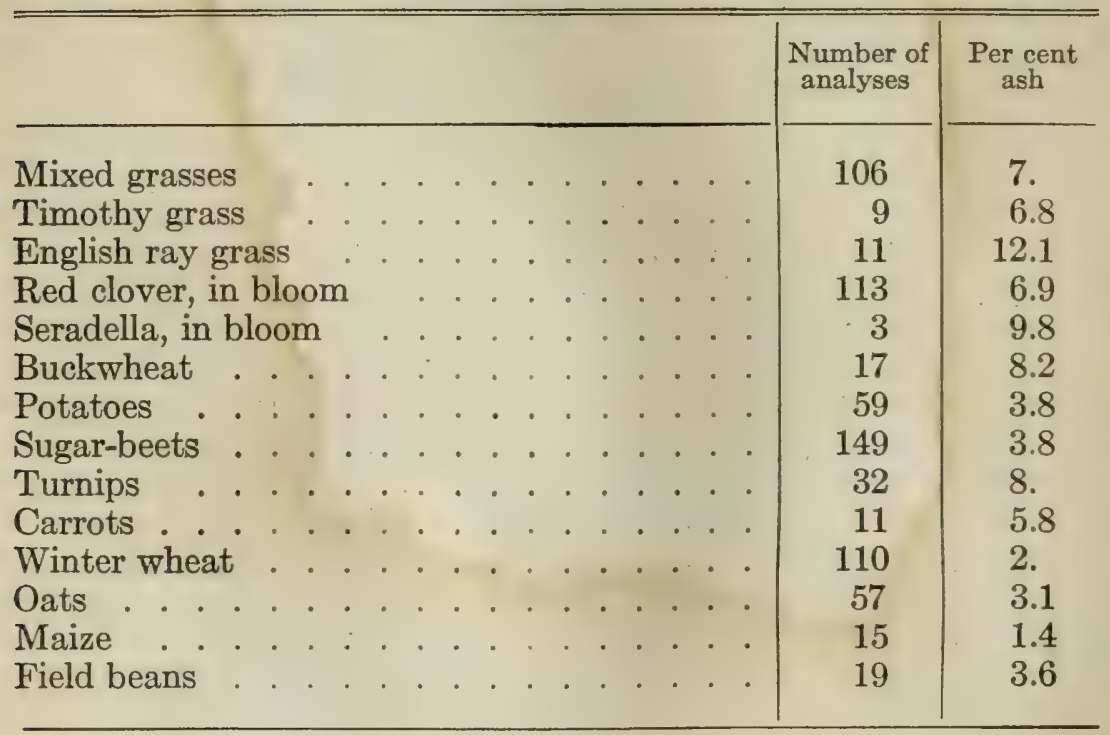




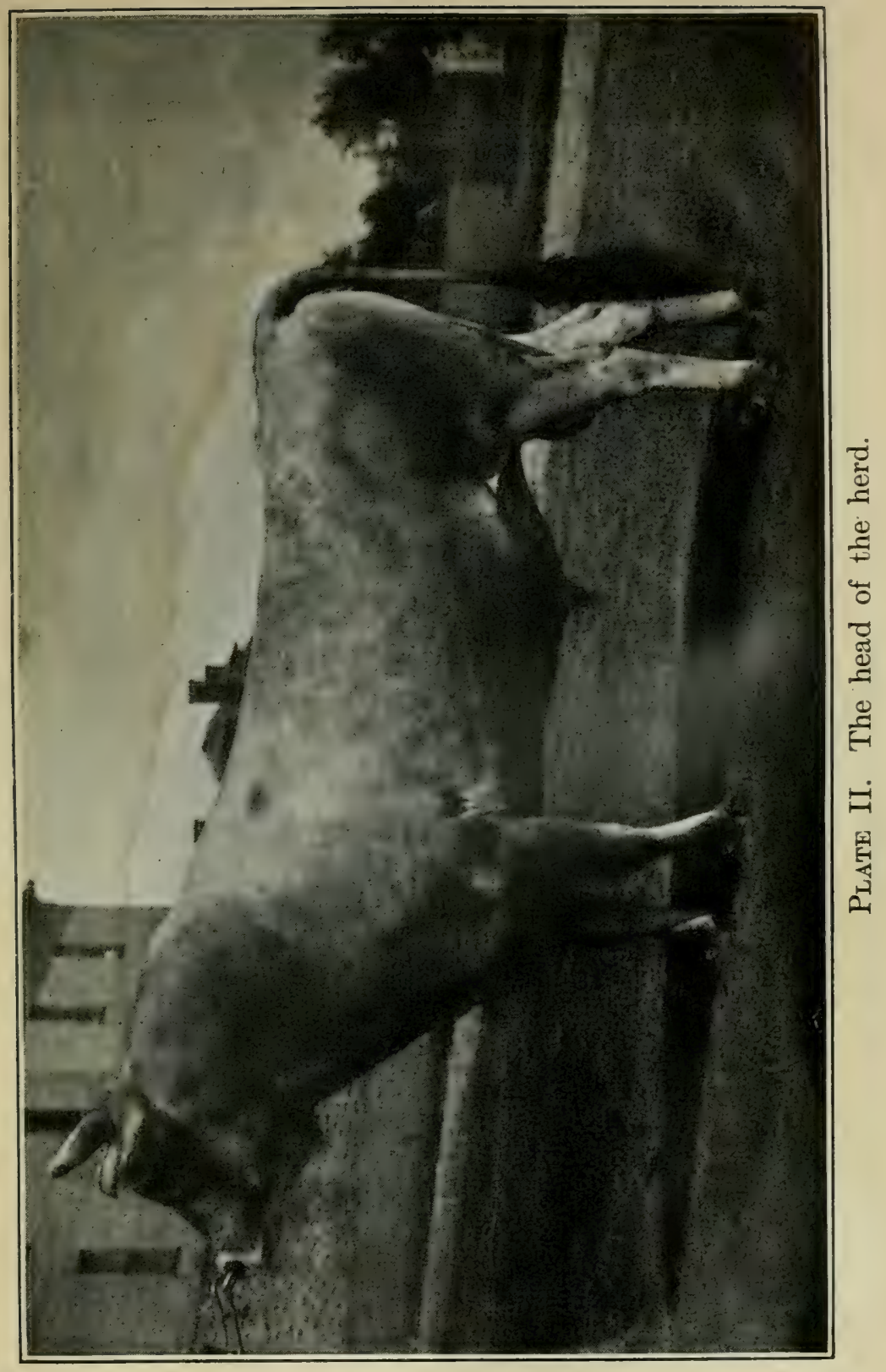



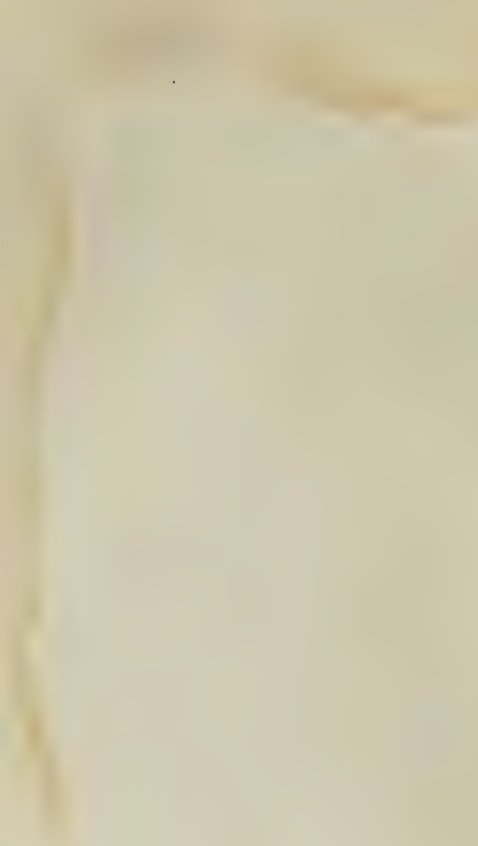
As a rule forage crops contain a higher percentage oî ash than do the grains. These variations pertain not alone to the quantity of ash but to the proportions of compounds which it contains:

Table XiI. The Mineral Compounds of Plants and FeedingStuffes (Per Cent in the Dry Matter)

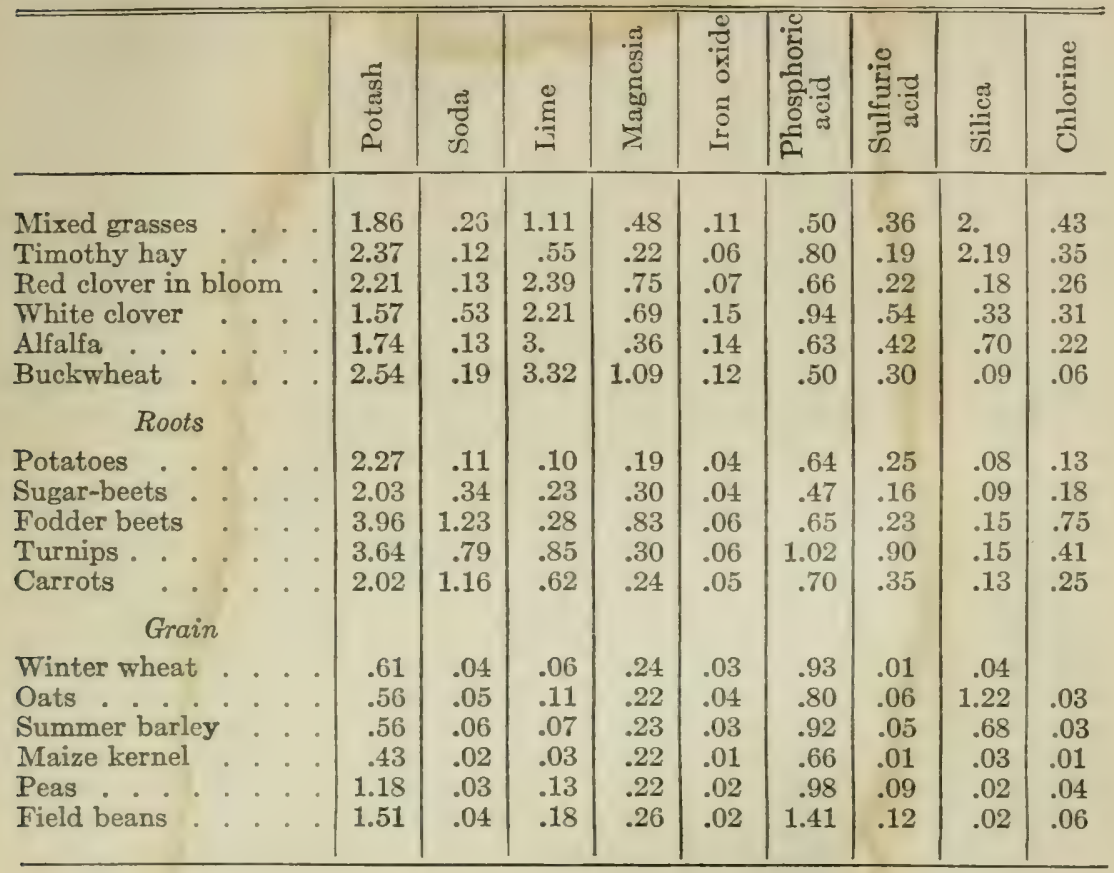

These figures show that potash, lime, magnesia, and phosphoric acid are the prominent mineral compounds of the plant ash, and it is with them that we find the important variations. The true grasses differ from the clovers and related plants in containing much less lime and greatly more silica, the phosphoric acid and potash not being greatly unlike in the two cases. As a source of lime, then, the clover hay is superior. Potatoes and roots have an ash richer in potash and poorer in lime than are 
the coarse fodders. The grains with hulls contain much silica, and those like wheat and corn but little. The seeds of the legumes are richer in potash and lime than those of the grasses. The maize kernel is especially poor in lime.

53. The distribution of mineral compounds in the different parts of the plant.-Because the farmer separates his crops into grain and straw, and the manufacturer goes farther and divides the grain into parts, thus modifying the character of feeding-stuffs, especially by-products, it is necessary to consider just how the mineral compounds are distributed in the stalk, leaves, and fruit, especially of the cereal-grain plants. A comparison of the straws and grains shows striking dissimilarities:

Table XiII. Per Cent in the Dry Matter

\begin{tabular}{|c|c|c|c|c|c|c|c|c|c|c|c|c|}
\hline & & & 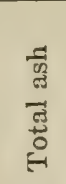 & $\begin{array}{l}\text { भี } \\
\text { जే } \\
0 \\
0\end{array}$ & कृ & 苞 & 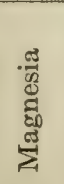 & 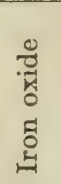 & 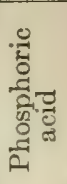 & 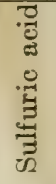 & 导 & 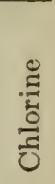 \\
\hline \multicolumn{13}{|l|}{ Wheat- } \\
\hline Straw & 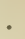 & . & 5.4 & .73 & .07 & .31 & .13 & .03 & .26 & .13 & 3.62 & .09 \\
\hline Kernel & & . & 2. & .61 & .04 & .06 & .24 & .03 & .93 & .01 & .04 & \\
\hline \multicolumn{13}{|l|}{ Oats- } \\
\hline Straw & 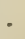 & . . & 7.2 & 2.07 & .24 & .50 & .26 & .08 & .33 & .23 & 3.34 & .31 \\
\hline Kernel & & . & 3.1 & .56 & .05 & .11 & .22 & .04 & .80 & .06 & 1.22 & .03 \\
\hline \multicolumn{13}{|l|}{ Maize- } \\
\hline Straw & & . & 5.3 & 1.93 & .06 & .58 & .30 & .12 & .44 & .28 & 1.53 & .07 \\
\hline Kernel & 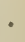 & . & 1.4 & .43 & .02 & .03 & .22 & .01 & .66 & .01 & .03 & .01 \\
\hline \multicolumn{13}{|l|}{ Peas- } \\
\hline Straw & & . & 5.1 & 1.17 & .21 & 1.89 & .41 & .09 & .41 & .32 & .35 & .29 \\
\hline Kernel & $\cdot$ & . & 2.7 & 1.18 & .03 & .13 & .22 & .02 & .98 & .09 & .02 & .04 \\
\hline
\end{tabular}

The straws contain more mineral matter than the grains. In the straws there is much more potash, lime, and silica than in the grains, while phosphoric acid exists in larger proportions in the latter. 
The roots and leares of beets and turnips present a striking difference in mineral-content:

Table XIV. Per Cent in the Dry Matter

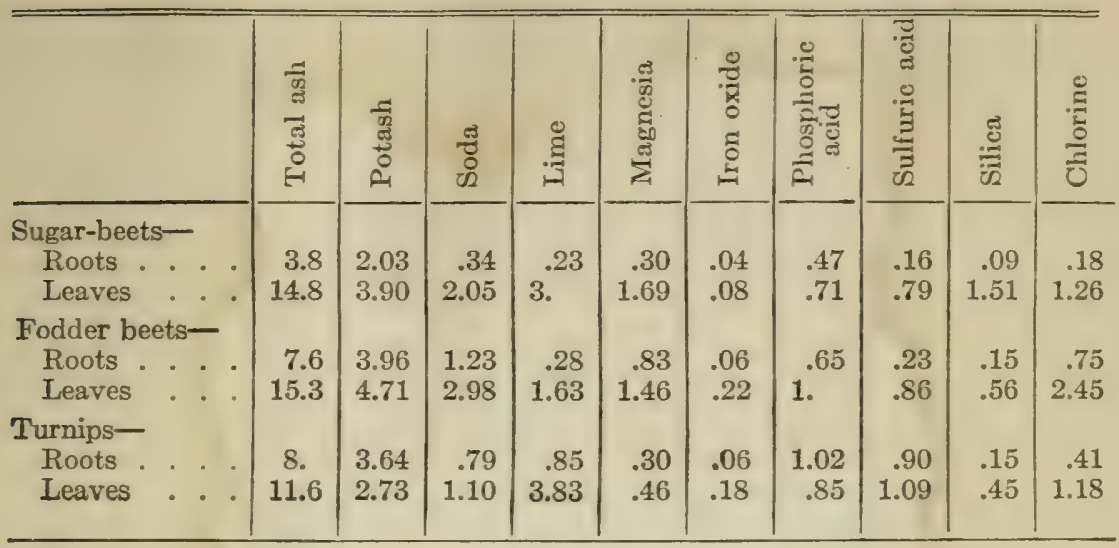

There appears to be a tendency for mineral compounds to accumulate in the leaves of plants, and leafy plants are, as a rule, those which appropriate these most freely.

The ash of the outside of the stem and of the husks of seeds is in relatively large proportions, due sometimes to an excess of silica. Husked rice kernels contain not over .5 per cent of ash, while the husks contain 39 per cent or over.

54. Influence of manufacturing processes on the ash constituents.-The cattle-food market is abundantly supplied with by-products from certain manufacturing industries, such as milling, brewing, and starch production. One prominent by-product is wheat bran. As this is the outside of the kernel, we would naturally expect, in view of the previous statements, that it would be rich in mineral compounds, and we find such to be the case. The wheat kernel contains about 2 per cent of ash, wheat bran about 6 per cent, and wheat flour about .5 per cent. Bran is rich in needed mineral compounds. 
In brewing, the kernels of barley are subjected to a leaching process which results in taking out the soluble mineral salts, chiefly the salts of potassium, calcium, and sodium, leaving behind, in part, the compounds of lime and magnesium. This fact is made clear by comparing the analysis of the ash of barley with that of brewers' grains:

Table XV. Partial Composition of Ash (Per Cent)

\begin{tabular}{|c|c|c|c|c|c|}
\hline & Potash & Soda & Lime & $\begin{array}{l}\text { Mag- } \\
\text { nesia }\end{array}$ & $\begin{array}{l}\text { Phos- } \\
\text { phoric } \\
\text { acid }\end{array}$ \\
\hline Summer barley & .56 & .06 & .07 & .23 & .92 \\
\hline Brewers' grains & .15 & & .64 & .45 & 1.69 \\
\hline
\end{tabular}

As a source of phosphoric acid and lime the brewers' grains are more efficient, pound for pound, than the original barley grains.

55. The mineral compounds of animal bodies.-The mineral compounds of animals are nearly similar in kind to those of plants, but are very different in relative proportions. This is made plain by a comparison of the figures given below:

Table XVI. Ash in Plants and Animal.s

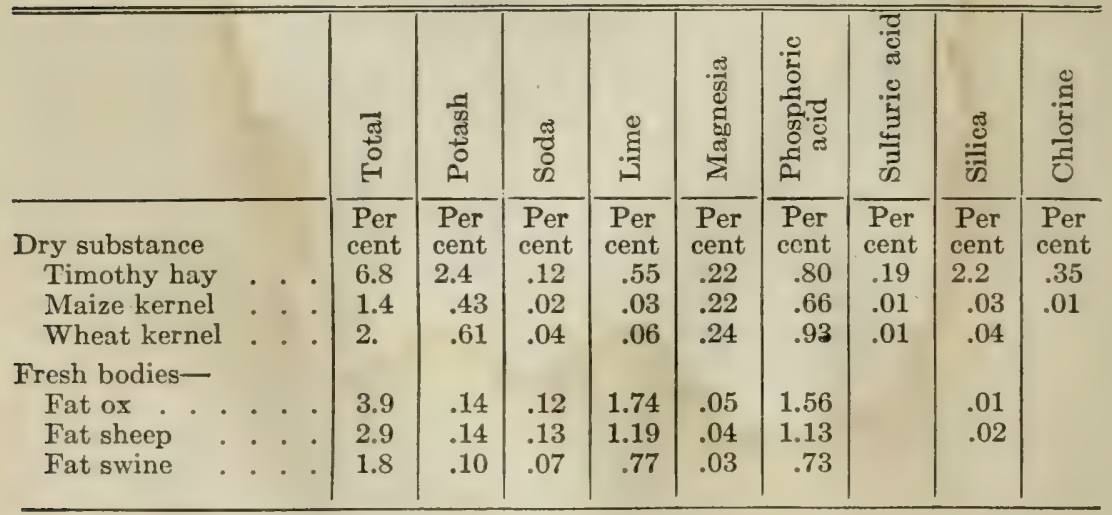


Potash is much less prominent in the composition of the animal than is the case with plants, and phosphoric acid and lime are much more so. In general, more than 80 per cent of the ash of the animal body consists of phosphoric acid and lime in combination as calcium phosphate, whereas these two compounds constitute less than onefifth of the ash of hay and less than one-half of the ash of maize and wheat kernels.

56. The distribution of inorganic compounds in the animal body. - The bones contain a very large proportion of the ash constituents found in the animal body, the soft parts being poor in mineral salts. Between 60 and 70 per cent of the ash comes from bone, and the bony framework is from 6 to 9 per cent of the entire bodies of domestic animals. Williams and Emmett found that the total ash in the bodies of pigs forty to forty-three weeks old was distributed among the parts as follows: about fourfifths in skeleton, one-ninth in the boneless meat and about one-sixteenth in the offal, blood, and the jowl and intestinal fats. Of the water-soluble ash, only about onetwelfth was found in the skeleton, with about three-fifths in the boneless meat. This distribution of the ash was not the same in pigs forty to forty-three weeks of age as for pigs eighteen weeks of age. The offal and carcasses of the younger animals contained practically twice as much as those of the older pigs, while the skeletons contained only about three-fourths as much. More than 80 per cent of the ash of bone is calcium phosphate, which is associated with calcium carbonate, calcium fluoride, calcium chloride, and magnesium phosphate.

The bones of all species of animals show a remarkable similarity of composition, the average of which would not be far from the following: 
Table XVII. In 100 Parts of the Ash of Bone (Average)

Calcium phosphate 83.9

Calcium carbonate 13.

Calcium in other combinations

Fluorine

Chlorine .

57. Ash elements in the soft tissues.-The muscular tissue and other soft parts of the animal body contain less than 1 per cent of incombustible materials. The ash of flesh is mostly phosphoric acid and potash, accompanied by comparatively small amounts of soda, lime, and magnesia and minute quantities of chlorine and iron. Unquestionably, potassium phosphate is the predominating salt in flesh, as calcium phosphate is in bone.

58. Ash elements in the blood.-The blood contains a variety of mineral substances, the chief of which is sodium chloride, or common salt, although a minute amount of iron is present, having a most important function. In the bile, soda is abundant, combined mostly with the peculiar organic acids of this secretion. Chlorine is a constant constituent of the gastric juice, its presence as chlorhydric acid being essential to digestion. The preceding are some of the prominent facts concerning the inorganic compounds of the animal body, but they are only a brief suggestion of the knowledge which pertains to this part of animal chemistry. 


\section{CHAPTER V}

\section{THE COMPOUNDS OF ANIMAL NUTRITION, CONTINUED-THE NITROGEN COMPOUNDS}

THE nitrogen compounds of the vegetable and animal kingdoms have received much attention from scientific investigators and writers during the past fifty years. It has been generally taught that certain members of this class of substances are the ones most important in the domain of animal nutrition, and many writers have given to these a prominent place in discussing the relative value of feeding-stuffs and have almost ignored the other nutrients. It is now conceded that relatively the function and value of protein have been unduly magnified. The present tendency is toward a fuller discussion of the office and value of the non-nitrogenous bodies.

59. The importance of protein.-There can scarcely be any disagreement, however, concerning the general proposition that the proteins play a leading part in the processes and economy of animal nutrition. This is true for several reasons:

(1) The nitrogen compounds are those fundamental to the energies of the living cells which make up the tissues of plants and animals. The basic substance of the active cell is protoplasm, a complex nitrogenous body, which Huxley called "the physical basis of life." Around this primal substance seem to center all vital activities, especially the transformation of the raw materials of the inorganic world into the organized structures of life. 
(2) These compounds are structurally essential to the growth of animal tissues and to the formation of milk. The significance of this fact is intensified by their paucity in many of the feeding-stuffs that are ordinarily produced on the farm.

\section{PROTEIN}

For the sake of brevity and convenience, the nitrogen compounds of cattle foods, both vegetable and animal, have been designated as a class by the single term protein. When, therefore, it is stated that a feedingstuff contains a certain percentage of protein, reference is made to the total mass of nitrogen compounds present, which may be many in number and of greatly differing properties.

60. How protein is determined.-The proportion of protein (total nitrogen compounds) in a feeding-stuff as given in tables of feeding-stuff analyses is ascertained by determining the percentage of total nitrogen and then multiplying this by the factor 6.25 . This method is based on the assumption that the average percentage of nitrogen in protein compounds is 16 , which is not true to so close a degree of approximation as was formerly believed to be the case. It may happen in some instances that a determination made in this way is sufficiently accurate, while in other cases the margin of error is large. Recent investigations with perfected methods show percentages of nitrogen in the numerous single protein substances found in the grains ranging from 15.25 to 18.78. These are largest in certain oil seeds and lupines and smallest in some of the winter grains. Ritthausen, a prominent German authority, conceded that the factor 6.25 should be discarded, and suggests the use of 5.7 for the larger 
number of cereal grains and leguminous seeds, 5.5 for the oil and lupine seeds, and 6 for barley, maize, buckwheat, soja-bean, and white bean (Phaseolus), rape and other brassicas. Nothing short of inability to secure greater accuracy justifies the longer continuance of a method of calculation which is apparently so greatly erroneous.

61. So-called proteins greatly unlike.-As previously stated, protein is the accepted name for a class of compounds. Just how there came about such a grouping of a large number of substances under a single head it is not necessary to consider in this connection, but it should be made clear that the individual compounds which are included under this term are greatly unlike in their chemical and physical properties; and it is known that they differ materially in their nutritive functions.

62. Classification of proteins.-It is very evident that it is not only convenient, but necessary, to classify such a heterogeneous group of bodies into subdivisions more nearly alike in their characteristics.

The most recent classification is one recommended by committees representing certain scientific bodies.* Doubtless this classification is only temporary and will be modified as our knowledge of the compounds of nutrition is enlarged. The grouping now agreed upon is based on chemical constitution; at the same time the lines of cleavage appear to have reference to nutritive function. As will be noticed later, other bodies are related to metabolism and growth which it is not now possible to classify as they have not yet been isolated and their chemical constitution is undetermined. The terms used in this classification are explained in the text which follows:

*Am. Jour. Phys., Vol. XXI. 


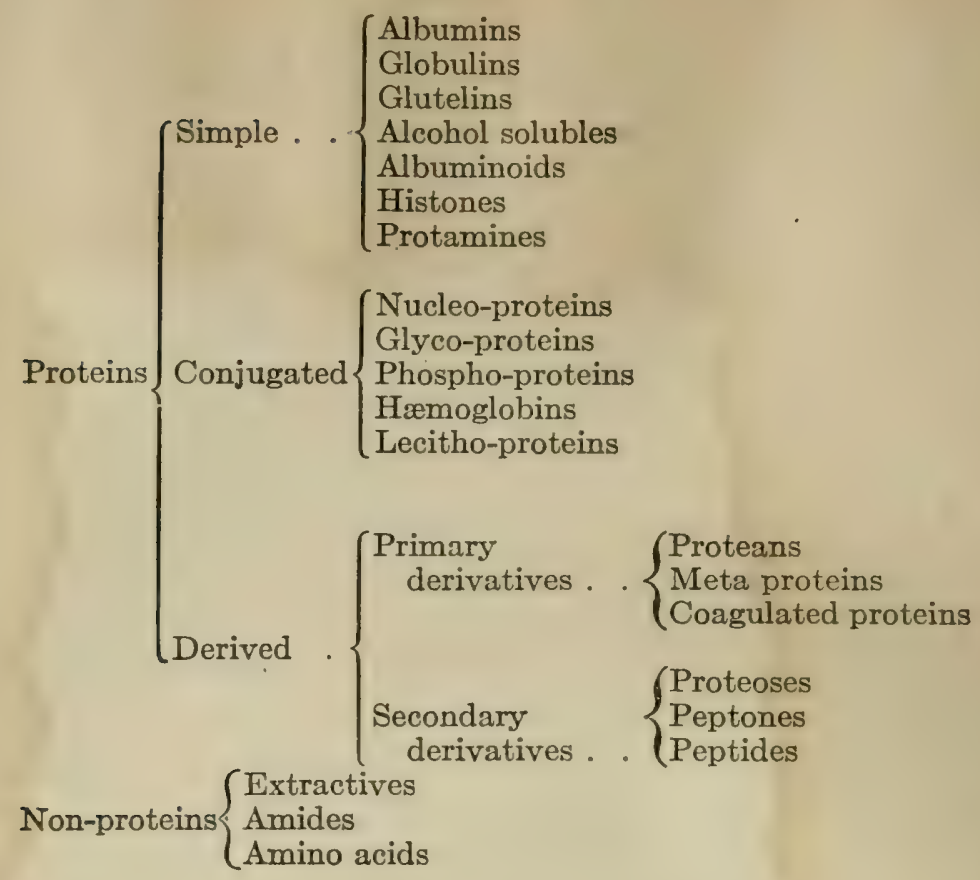

Certain changes in terms and classifications should be noted. The term proteid is abandoned, and the term albuminoid is made to refer to the bodies formerly classed as collagens or gelatinoids. The newer classification groups the proteins on the basis of constitution and characteristic properties.

Other nitrogen compounds are included with the proteins by the present methods of chemical analysis, such as alkaloids and nitrates, but these are so uncommon in foods, or are present in such small quantities, that they may be safely ignored.

63. The true proteins.-The proteins are the main and important nitrogen compounds either in the plant or in the animal. The nitrogenous bodies of seeds are little else than such proteins, while young plants, and especially 
roots, such as beets and turnips, contain more nitrogen in the non-protein form. Proteins are the chief constituents of muscular tissue. Their chemical constitution is not definitely known, but it is generally considered to be very complex, even to the extent of several thousand atoms. These bodies are constructed from the simpler ones of the inorganic world through the vital energies of plants, and in order to serve the purposes of nutrition they must come to the animal fully organized.

64. Ultimate composition of proteins.-The ultimate composition of proteins, that is, the proportions of the elements which they contain, has been carefully studied, and while there are material differences among them in this respect, the limits of variation are not especially wide, as can be seen from the following figures according to Osborne:*

Table XVIII. Composition of Some Typical Proteins

\begin{tabular}{|c|c|c|c|c|c|c|c|}
\hline & arbon & $\begin{array}{c}\text { Hydro- } \\
\text { gen }\end{array}$ & $\begin{array}{c}\text { Nitro- } \\
\text { gen }\end{array}$ & Oxygen & Sulfur & Iron & $\begin{array}{l}\text { Phos- } \\
\text { phorus }\end{array}$ \\
\hline $\begin{array}{l}\text { Egg-albumin } \\
\text { Lact-albumin } \\
\text { Leucosin } \\
\text { Serum-globulin } \\
\text { Myosin . } \\
\text { Edestin } \\
\text { Legumin } \\
\text { Casein } \\
\text { Ovovitellin } \\
\text { Gliadin . } \\
\text { Zein . } \\
\text { Oxyhemoglobin }\end{array}$ & $\begin{array}{l}\text { Per cent } \\
52.75 \\
52.19 \\
53.02 \\
52.71 \\
52.82 \\
51.50 \\
51.72 \\
53.13 \\
51.56 \\
52.72 \\
55.23 \\
54.64\end{array}$ & $\begin{array}{l}\text { Per cent } \\
7.10 \\
7.18 \\
6.84 \\
7.01 \\
7.11 \\
7.02 \\
6.95 \\
7.06 \\
7.12 \\
6.86 \\
7.26 \\
7.09\end{array}$ & $\begin{array}{l}\text { Per cent } \\
15.51 \\
15.77 \\
16.80 \\
15.85 \\
16.67 \\
18.69 \\
18.04 \\
15.78 \\
16.23 \\
17.66 \\
16.13 \\
17.38\end{array}$ & $\begin{array}{l}\text { Per cent } \\
23.02 \\
23.13 \\
22.06 \\
23.32 \\
22.03 \\
21.91 \\
22.90 \\
22.37 \\
23.24 \\
21.73 \\
20.78 \\
20.16\end{array}$ & \begin{tabular}{|l|} 
Per cent \\
1.616 \\
1.73 \\
1.28 \\
1.11 \\
1.27 \\
.88 \\
.385 \\
.80 \\
1.028 \\
1.027 \\
.60 \\
.39
\end{tabular} & Per cer & $\begin{array}{l}.86 \\
.82\end{array}$ \\
\hline
\end{tabular}

*"Chemistry of Food and Nutrition," Sherman, page 35. 
We see that the number of elements ordinarily found in the proteins is five, nitrogen and sulfur being those that chiefly distinguish these bodies from all others which make up the mass of combustible matter. Two other elements are found in certain of these bodies, as, for instance, phosphorus in casein and ovovitellin and iron in a constituent of blood.

65. Familiar examples of proteins.-Proteins are familiar objects, and their properties are matters of common observation. The tenacious cud of gum from wheat gluten, the strings of coagulated albumin which separate from the cold-water extract of fresh lean beef that is brought to the boiling-point, the hardening of the white of an egg into a tough mass as it is dropped into boiling water, the stiffening of the muscular tissue of the slaughtered animal or the rapid formation of strings of fibrin in the cooling blood-in all these instances there are manifested certain chemical or physical properties which pertain to these most important and widely utilized compounds.

\section{SIMPLE PROTEINS}

66. The albumins. - The albumins have several sources. They are found in the juice of plants, in certain liquids of the animal body such as the serous fluids, in the cell substance of muscular tissue, in blood and milk, and abundantly in eggs. Unlike other proteins, these compounds are freely soluble in pure cold water, and when such a solution is heated to the boilingpoint, they separate from solution by coagulation and become insoluble unless acted upon by some strong reagent. 
When macerated beef is treated with cold water the albumin in it goes into solution, and if this extract is boiled the albumin separates in clotted masses.

The clear serous fluid that is left after removing the clot from blood contains albumin. After the casein is removed from milk by acid or rennet, the albumin of the milk remains in the whey. It is this which in part causes milk to clot if brought to the boiling-point. As stated, one example of this class of proteins is the white of an egg, which, when cooking in boiling water, becomes a hard, coagulated mass. Albumin in the serous fluids and in blood is called serum-albumin; in milk, lact-albumin, and in eggs, ova-albumin.

A small proportion of the proteins of plants is found to be albumin; for instance, Osborne found .3 to .4 per cent in wheat, .43 per cent in rye, .3 per cent in barley, .5 per cent in soja-beans, and some in most seeds. This possesses essentially the same characters as the animal albumin described previously. Whenever a vegetable substance is leached with water, it is probably this protein which would be the first to suffer removal or destructive fermentation.

67. The globulins.-These proteins are usually associated with albumins. When animal tissues are treated with water, but a small part of the proteins dissolve. If, however, we add to the water a mineral salt, especially common salt (sodium chloride), sufficient to secure a 10 per cent solution, an additional and considerable amount of protein may be extracted. Certain compounds so extracted are called globulins, and differ from the albumins in being practically insoluble in pure water and in a saturated solution of certain mineral salts, such as sodium chloride. The so-called globulins form an impor- 
tant part of the protein-content of plants and of animal tissues, both in quantity and in having a maximum nutritive usefulness.

68. Plant globulins.--In plants these proteins seem to be especially abundant and widespread. Our most recent and most reliable knowledge of plant proteins comes from investigations by Osborne. In these researches the seeds of many species of agricultural plants were studied, all of which were found to contain globulins. In some the proteins consisted largely of these compounds. The percentage content in certain seeds was determined approximately:

\section{Table XIX. Globulins in Certain Seeds}

\begin{tabular}{|c|c|c|c|}
\hline Kidney bean & $\begin{array}{l}\text { Per cent } \\
20 .\end{array}$ & Lentil & $\begin{array}{l}\text { Per cen } \\
13 .\end{array}$ \\
\hline Cottonseed meal & & Horse bean & \\
\hline Peas & 10. & Maize & .4 \\
\hline Lupin & 26.2 & Soybean & chiefly globulin \\
\hline Wheat & .6 & & \\
\hline
\end{tabular}

The seeds of the legumes, as a rule, contain the largest proportion of these proteins, the cereal grains having only a very small part of their protein in this form.

From present knowledge, many seeds appear to have characteristic globulins which differ among themselves in their chemical properties. These have been given names derived from the general names of the species in which they are found. Thus we have amandin in almonds, avenalin in oats, corylin in walnuts, excelsin from the Brazil-nut, phaseolin in several species of beans, glycin in the soybean, maysin in maize, vicilin in horse beans, lentils, and peas, vignin in the cowpea, and tuberin in the potato. One globulin called edestin appears to be 
quite generally distributed in the seeds of agricultural plants, having been found in a larger number than any other protein yet discovered, including all the cereals, castor bean, cottonseed, flaxseed, hemp, squash, and sunflower, although it is not abundant in any of these.

69. Animal globulins.-The animal globulins exist abundantly in muscle and blood. If finely divided, wellwashed muscle (lean meat) is treated with a 10 per cent salt solution, first by rubbing it in a mortar with fine salt, and then adding enough water to secure the proper strength of solution, a globulin is dissolved which is derived from a muscle protein designated by some authors as myosin. It is believed that myosin coagulates in the muscle upon the death of an animal forming a clot sometimes called myosin-fibrin. The theory has been proposed that myosin acts as a "mother" substance in the muscle from which myosin-fibrin is formed in much the same way as fibrin is developed in clotting blood from a preexisting body, but no single view as to exactly what occurs is fully accepted. Other terminology has been proposed, viz., that the mother substance shall be named myosinogen to correspond to fibrinogen, myosin being the coagulation product. Much confusion and indefiniteness exist with reference to the chemistry of muscle proteins. There is, nevertheless, a general agreement that rigor mortis is due to a clotting of the muscle, accompanied by marked chemical transformations. It is held that ferments are present in the muscle, to the influence of which these changes are due, and without which they do not occur.

Another prominent globulin is the fibrinogen found in the blood. When blood is drawn from the veins and cools, 
it clots, which is nothing more than the formation of strings of fibrin, perhaps through the influence of a ferment, which has been named thrombin. Fibrin as such is not found in living blood. A remarkable fact is that so long as the blood is retained in the arteries and veins, even if the animal dies and grows cold, this clotting does not appear.

Serum-globulin is a collective name for several globulins, which exist in blood-serum and in the other fluids of the animal body, such as lymph and its allies, including those exudations which pertain to diseased conditions, especially dropsical.

One more protein has been generally classified as a globulin, although differing in some respects from the other members of this class, and more recently is classed as a phospho-protein. Reference is made to vitellin, which is the principal protein in the yolk of eggs. It is there intimately mixed with certain peculiar phosphorized bodies, which we shall notice later.

70. Glutenins. - These form a large part of nitrogen compounds of the cereal grains and possibly of other seeds. They are insoluble in water, alcohol, and neutral salt solutions, but readily dissolve in very dilute acids and alkalies. The glutenin of wheat, found in the tenacious substance that is left after washing the starch out of wheat flour, is the best-known protein of this class and is an important constituent of wheat flour, existing there on the average to over 40 per cent of the total protein.

71. Alcohol-soluble proteins. ${ }^{*}$-Alcohol-soluble proteins have been found in all the cereal grains so far exam-

* Osborne and others propose the name prolamins. Science, Vol. XXVI, pages $417-427$. 
ined. The principal ones to be mentioned are gliadin from wheat, zein from corn, and hordein from barley. Gliadin is more abundant in the wheat kernel than is the glutenin with which it is associated, the two together constituting over 80 per cent of the total proteins of that cereal. The proportion of gliadin in wheat flour has much to do with its quality for bread-making purposes. It appears that the best bread flour contains about twice as much gliadin as glutenin.

72. Albuminoids.-This term, according to the classification still in more or less use in the United States, has been understood as including various proteins such as the albumins, and globulins. The classification now recommended confines the term to proteins found chiefly in the animal body in such parts as the cartilages, bones, feathers, hair, hoofs, horns, and nails. These proteins are also obtained from the threads of silkworms and from sponges. The albuminoids have group names, such as collagen in cartilage and bone, keratins in feathers, hair, hoofs, horns, nails, and similar exterior tissues, fibroin in the threads of silkworms, and spongin in the framework of sponges.

Gelatine, so well known to the housewife, is derived from collagen. When meat containing tendons (cartilage) is submitted to the action of boiling water, there is obtained in the extract a gelatinous substance which becomes evident when the extract is cooled. This gelatine is insoluble in cold water, but dissolves in hot. As a dry commercial article, it is a tenacious substance which, when prepared in thin layers, is transparent. When collagen and gelatine are acted upon by tannic acid, as, for instance, when the skin of an animal is treated with an extract from hemlock or oak bark, the result is a sub- 
stance which does not putrefy and which gives to the tanned hide the properties of leather. Gelatine is much used in various food preparations.

It is characteristic of the keratins such as hair and horn that they contain a relatively large proportion of sulfur, the analysis of horn and hair showing as high as 5 per cent, the average amount in horn being 3.3 per cent. The keratin bodies serve to give rigidity and wearing qualities to certain exterior animal tissues.

73. Histones, protamines.--The proteins in these two groups do not occur as such in nature, and are obtained only by separating them from some combination. The two groups are alike in being basic in character and in being found in the spermatozoa of fishes. Histones have also been obtained from the blood corpuscles of a goose and from the white blood corpuscles of thymus glands.

\section{CONJUGATED PROTEINS}

74. Nucleo-proteins.-These are complex, phosphorusbearing proteins that sustain an important nutritive function. They are regarded as a combination of nuclein with an albumin, the nucleins being compounds of nucleic acid and albumin, and nucleic acid yielding on cleavage phosphoric acid, certain nitrogenous bases known as purins, and a carbohydrate.

The nucleo-proteins are associated with the nuclei of the cells that make up both plant and animal tissues. They are relatively abundant in glandular tissues such as the spleen, pancreas, thymus gland, and liver. The spermatozoa masses of fishes are especially rich in these compounds. Because certain bases known as purins 
which arise from the cleavage of nucleo-proteins are regarded as the progenitors of uric acid, persons with uric-acid tendency have been advised to avoid eating certain animal foods such as beef and liver, or any others known to contain these compounds abundantly. Experiments show that the feeding of certain tissues rich in nucleo-proteins increases the output of uric acid, while adding to the diet a large amount of purin-free proteins such as albumin does not have this effect.

75. Glyco-proteins.-These are bodies that upon cleavage are decomposed into a protein and a carbohydrate. The best-known glyco-proteins are the mucins that are secreted by the mucous membranes of the air passages and of the alimentary canal and by certain glands such as the salivary. Certain of these compounds contain phosphorus and others do not.

76. Phospho-proteins.-Like the nucleo-proteins, these compounds contain phosphorus, but on cleavage do not yield the purin bases. The best-known phosphoprotein is the casein of milk, a compound exceedingly important in human nutrition, especially with the young.

This compound is a secretion of the mammary gland of many species of animals, and doubtless originates in the gland cells. The casein from different species of mammals differs somewhat in chemical and physical properties. Casein is insoluble in water, but exists in milk in suspension. It is not coagulated by heat but curdles when a weak acid is added to milk, as, for instance, vinegar. The same result is produced by a generous quantity of common salt. When milk is received into the human stomach, the casein coagulates (the milk curdles) through the action of a ferment in the gastric juice and 
this coagulation is mechanically unlike, at least, with milk from different species. The action of this ferment on casein is utilized in cheese-making in the development of a curd which, with its inclosed fat, is separated from the whey and pressed into compact masses and later allowed to undergo certain changes due to other ferments.

Other phospho-proteins exist, one being the vitellin in the yolk of eggs which, as prepared, contains lecithin.

77. Hæmoglobin.-Blood contains a peculiar compound known as hæmoglobin. When decomposed, it separates into a protein, globin, and a coloring matter hæmochromogen, which, when charged with oxygen, is called hæmatin. This oxidation changes the hæmoglobin to oxy-hæmoglobin. This hæmoglobin in the blood of mammals contains, besides carbon, nitrogen, oxygen, and hydrogen, sulfur and iron. The latter varies in per cent from .34 to .48 , and sustains an essential relation to the functions of the blood. The blood pigment has the property of taking up and releasing oxygen with great readiness, carrying its load of oxygen out of the lungs, giving it up to oxidation processes in various parts of the body, and bringing to the lungs in its place the resulting carbon dioxid to be discharged into the air. The blood changes color with the acquisition and loss of the oxygen.

78. Lecitho-proteins.-From the yolk of eggs, the mucous membranes, and the kidneys, and doubtless from other sources, are obtained a conjugated protein containing lecithin. The constitution and special function of this body are not well understood. 


\section{DERIVED PROTEINS}

These are divided into primary and secondary protein derivatives. Primary protein derivatives are those that have been slightly modified by the action of water, very dilute acids, or enzyms, or are the result of the action of acids and alkalies whereby products soluble in weak acids and alkalies are formed. Coagulated proteins resulting from the action of heat and alcohol are classed in this division.

Secondary protein derivatives are those in which the modifying changes (hydrolytic, or the taking up of water) through the action of acids or enzyms, have proceeded beyond the incipient stage with the formation of bodies that are soluble in water. In this division, the most important compounds are the proteoses and the peptones, the latter having suffered a greater change by hydrolysis than the former.

\section{PRIMARY PROTEIN DERIVATIVES}

79. Proteans and metaproteins.-When proteins are acted on by acids or alkalies, they are modified in proportion to the strength of the reacting acid or alkali and the length of time that the action continues. With acid or alkalies of sufficient strength, there are formed products soluble in weak acids and alkalies (meta-proteins).

80. Coagulated proteins.-There are several agents which convert albumins and other proteins into a coagulated mass, such as a boiling heat, alcohol, and certain neutral salts and the action of an enzym. For instance, 
with albumin from flesh or the white of an egg, boiling water converts it into a coagulum that is insoluble in water and is rendered soluble only by such agents as acids and alkalies upon heating.

Dropping a soluble protein into alcohol has the same effect. Globulins are, as a rule, affected in the same way. The nature of this modification is not known.

\section{SECONDARY PROTEIN DERIVATIVES}

81. Proteoses, peptones.-When various proteins such as albumin or globulin are subjected to the action of a weak acid or of certain enzyms, they undergo what is known as hydrolysis. This change involves a cleavage (splitting) of the protein body accompanied by the taking up of the elements of water. In this way are formed proteoses and peptones, the latter being proteins that are soluble in water. A proteose is an intermediate stage between the original protein and a peptone, and it receives a name according to its source, as albumose, globulose, and caseose, according as an albumin, a globulin, or casein is its source.

Peptone was formerly regarded as the final product of enzym action in digestion, but we now know that the digestion of the proteins proceeds much farther. These hydrolyzed bodies are found abundantly in the digestive tract during digestion, the proteoses as stated being an intermediate stage of digestion between the original proteins and the peptones. This means that the formation of the final products of protein digestion is a progressive step. Proteoses and peptones may also be obtained by laboratory methods. It should be noted that commercial peptones are largely proteoses. 
82. Important properties of the proteins.-The previous description of the various groups of proteins cannot be understood to its fullest extent except by those who have a good knowledge of the fundamentals of organic chemistry. Nevertheless, the facts given serve to impress the important chemical and physical properties which these bodies possess, and point to the necessity of studying them individually in their relation to foods and nutrition. It is not rational to speak of protein as if the term represents an individual entity, but the members of this general class of compounds must be considered by sub-classes at least, in discussing their place in nutrition.

A fact of importance is the varying constitution of the protein molecule, and consequently the possible variation in the nutritive function of the individual proteins.

83. The unlike constitution of the various proteins.We have already seen that certain proteins are particularized in part by containing phosphorus, others sulfur, and others iron. A phosphorus-bearing protein may have, and undoubtedly does have, a nutritive function that cannot be exercised by an albumin not carrying phosphorus.

84. Cleavage products of the proteins.-It is well known that when proteins are submitted to the action of acids, alkalies, and certain ferments (enzyms) they break up into simpler compounds which we speak of as cleavage products, chiefly amino-acids which are sometimes designated as the building-stones of the proteins. It is very significant that the kinds, and especially the proportions, of these products differ greatly with different proteins. For instance, the purin bases, which certainly 
sustain important physiological relations, are present in beef and certain glands used as food, but absent in milk and eggs. The variations in the decomposition products of certain vegetable proteins are striking, as also are the differences in this respect between vegetable and animal proteins, and these differences have an important bearing on the value of the inividual proteins for the purposes of growth. The following table taken from Hammarsten's "Text-book of Physiological Chemistry," seventh edition, is worthy of attention:

Table XX. Cleavage Products of the Proteins

Plant Proteins

\begin{tabular}{|c|c|c|c|c|c|c|c|}
\hline & & & Edestin & Legumin & Hordein & Gliadin & Zein \\
\hline Glycocoll . & . . & . & 3.8 & .38 & & .68 & \\
\hline Alanine & . . & .. & 3.6 & 2.08 & .43 & 2. & 9.79 \\
\hline Valine . & . . & . & 5.6 & 1. & .13 & 3.34 & 1.88 \\
\hline Leucine . & & . . & 20.9 & 8. & 5.67 & 6.62 & 19.55 \\
\hline Serine. & & . & .33 & .53 & & .13 & 1.02 \\
\hline Aspartic acid & & .. & 4.5 & 5.3 & & .58 & 1.71 \\
\hline Glutamic acid & & . & 18.74 & 13.8 & 43.19 & 43.66 & 26.17 \\
\hline Cystine & & 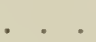 & .25 & & & .45 & \\
\hline Phenylalanine & & . & 2.4 & 3.75 & 5.03 & 2.35 & 6.55 \\
\hline Tyrosine & . . & 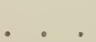 & 2.1 & 1.55 & 1.67 & 1.2 & $3.55-10.1$ \\
\hline Proline & & 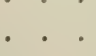 & 1.7 & 3.22 & 13.73 & 13.22 & 9.04 \\
\hline Oxyproline & & . & 2. & • & & & . . \\
\hline Tryptophane & & . . & .38 & & & 1. & \\
\hline Histidine . & & & 1.1 & 2.42 & 1.28 & .61 & .82 \\
\hline Arginine & & & 11.7 & 10.12 & 2.16 & 3.16 & 1.55 \\
\hline Lysine. & & & 1. & 4.29 & & & \\
\hline Ammonia & & . . & . . & 1.49 & 4.87 & 5.22 & 3.61 \\
\hline
\end{tabular}


Animal Proteins

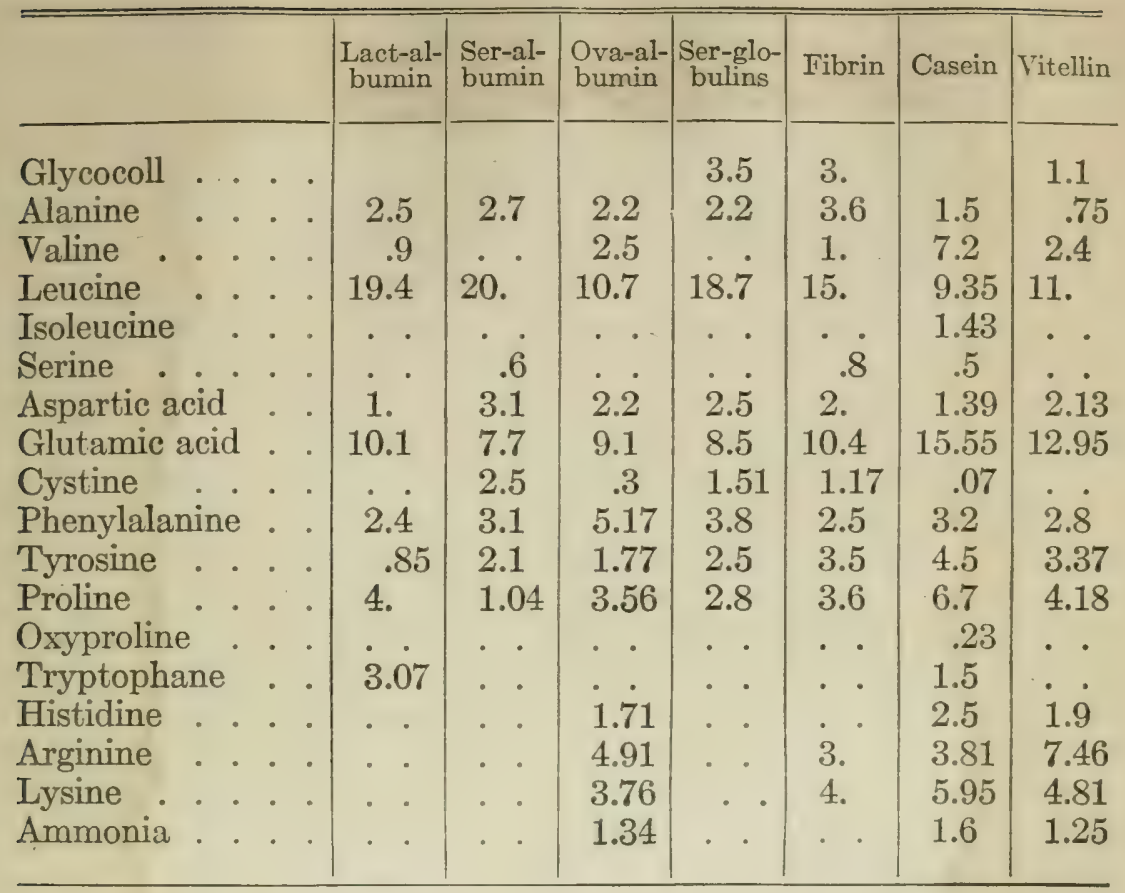

In view of later discussions it is well to note in this connection certain marked differences in the kind and proportions of the cleavage products (building-stones) of the individual proteins.

For example, glutamic acid is found in the plant proteins in much larger proportion than in animal proteins; lysine is absent from the alcohol-soluble proteins hordein, gliadin, and zein, and proline is found in much larger proportion in these than in any others. It is safe to conclude that certain plant proteins cannot be rebuilt into an equal quantity of animal proteins.

It should be noted, however, that a comparison of vegetable and animal proteins shows in general a close resemblance in the kind of building-stones out of which 
they are constructed, although the proportions are unlike.

\section{NITROGEN COMPOUNDS THAT ARE NON-PROTEINS}

In the usual method for determining the proteins of a food by multiplying the total nitrogen present by a factor, there is included in the calculation nitrogen that does not come from true proteins, but from compounds that possess physical and chemical properties greatly removed from those which characterize albumin and other true proteins. Their office as nutrients is probably less comprehensive than that of the proteins.

85. Amino-acids and amides.-These compounds result from the union of organic acids and the group $\mathrm{NH}_{2}$. Whether the resulting compound is an amino-acid or an amide depends upon the manner of combination. Certain of the amino-acids may be produced in the laboratory by synthesis, but in the main they are obtained from the cleavage of protein through the action of acids or alkalies or ferments (enzyms). They are found abundantly in the alimentary canal during the digestion of food as a result of the action of the digestive enzyms on proteins. Amides occur in plants. Asparagine is an amide of amino-succinic acid, first found in young asparagus shoots, and glutamine is an amide of amino-glutaric acid, found in germinating pumpkin seeds. They are soluble in water, and consequently are diffusible throughout the plant tissues. It is believed that such amides are forms in which the nitrogen compounds of the plant are transferred from one part to another, as, for instance, from the stem to the seed. It has generally been held that these bodies are more abundant in young plants than in mature. A larger part of the nitrogen of roots and tubers is found in these compounds 
than in other foods, the proportion in grains being the least, and is very small indeed. Such investigations as have been conducted point to the conclusion that amides do not function wholly as do the proteins. This is one reason for regarding the protein of certain vegetable foods as of less value than that of the grains and grain products.

86. Extractives.-These are bodies found in the extract obtained from beef with cold water. After the albumin has been removed from such an extract by boiling, these compounds known as creatin and creatinin chiefly constitute the nitrogenous solids that remain. Their food value is small, for they appear to be largely eliminated from the body in the urine without change. 


\section{CHAPTER VI}

\section{THE COMPOUNDS OF ANIMAL NUTRITION, CONCLUDED-CARBOHYDRATES, ACIDS, FATS, AND OILS}

Much the larger proportion of the dry matter of cattle foods consists of non-nitrogenous material. While these nitrogen-free compounds have not been regarded as fundamentally so important as are the proteins, in quantity they unquestionably occupy the first rank. The activities of plant life are largely devoted to their production, and their use by animal life is correspondingly extensive. They may properly be called the main fuelsupply of the animal world. Other nutrients aid in maintaining muscular activity, to be sure, but these compounds are the principal storehouse of that sun-derived energy which furnishes the motive power exhibited in all animal life. They also fill a necessary office in the formation of milk and in the fattening of animals. This class of compounds greatly predominates in the usual farm crops, even in those of the legume family.

87. Elementary composition of the non-nitrogenous compounds. - The non-nitrogenous compounds contain only three elements-carbon, hydrogen, and oxygen. They may be derived, therefore, wholly from air and water, and they constitute that portion of foods which is drawn from never-failing and costless sources of supply. The elementary composition of typical nitrogen-free bodies is given in this connection: 
TABLE XXI

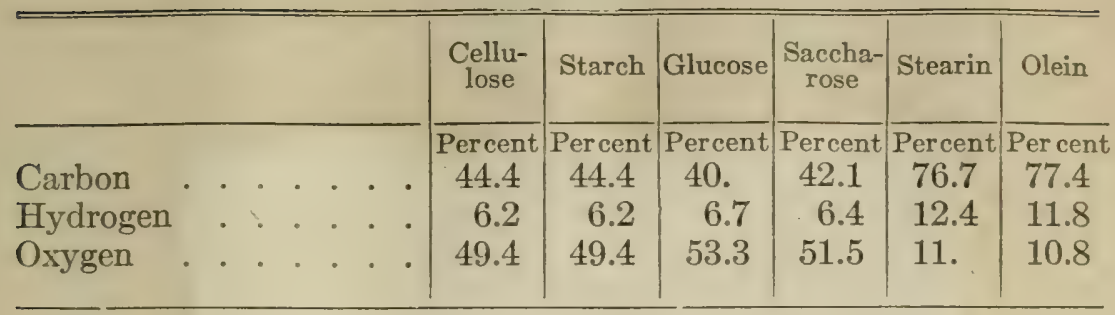

88. Classification of non-nitrogenous compounds.The non-nitrogenous compounds of foods are usually divided into two main classes, viz., carbohydrates and similar bodies and fats and oils. The first class often bears the name nitrogen-free extract, but the carbohydrates are its principal members. Crude fiber belongs in this class. The second is known by the chemist as etherextract, because ether is used to extract the fats or oils from the vegetable substances in which they are contained. The actual fat obtained from vegetable foods is always less, however, than the ether-extract, because the ether takes into solution other compounds than the fats. It should be noted that the last two compounds of the above table, which are fats, are relatively richer in carbon and hydrogen and poorer in oxygen than the other compounds mentioned, which are carbohydrates. This fact has an important relation to nutritive value.

89. The carbohydrates.-In order to understand the carbohydrates as individual compounds and in their relations to each other and to the processes of nutrition, it is necessary to consider them, in general outlines at least, from the standpoint of the chemist.

The term carbohydrates, as it is used, like the term protein, is collective and includes a great variety of compounds. By their common names we know them as sugars, 
starches, celluloses, gums, and so on. Chemically we distinguish them by their structure and by their relation to one another.

90. Classification of carbohydrates according to structure.-The structure of certain sugars is such that their molecules cannot be divided into simpler compounds that retain the carbohydrate character, and these are known as mono-saccharides. To this class belong glucose (grapesugar) and fructose (fruit-sugar). On the other hand, there are a large number of carbohydrates, one molecule of which by treatment in certain ways may be converted into two or more molecules of a mono- (simple) sugar. For instance, one molecule of starch, when submitted to the action of an acid or of certain ferments, breaks up into several molecules of glucose, and so starch is known as a poly-saccharide. Other poly-saccharides are sucrose (cane-sugar), maltose (malt-sugar), lactose (milk-sugar), cellulose, and the gums, all of which may be split up into mono- or simple sugars. The poly-saccharides are subdivided into di, tri, and so on, according as they break up into two, three, or more molecules of a simple sugar.

There are subdivisions of the mono-sugars also, on the basis of carbon atoms in their molecules and thus we have the names diose, triose, tetrose, pentose, hexose, heptose for sugars having two, three, four, five, six, or seven carbon atoms in the molecule. It may be remarked here that it is among the hexose (six-carbon) sugars or their multiples that we find the carbohydrates most important to human nutrition.

91. The mono-saccharides or simple sugars.-The simple sugars that are most important in animal nutrition are dextrose (grape-sugar), levulose (fruit-sugar), and galactose (from milk-sugar). These are hexose (six- 
carbon) sugars. The pentoses are also simple sugars, but, as we shall see, they scarcely occur in nature, being obtained chiefly by splitting up certain gums.

92. Dextrose.-An important simple sugar is dextrose or grape-sugar, or what is known in the market as glucose. Except in the hands of the chemist it is seldom seen as crystals, although these appear in the "candying" of honey and raisins. It is a constituent of molasses and the sirups. Dextrose is found in practically the same plants that contain saccharose, such as sorghum, maize, and the fruits. So far as known, it is always associated with some other sugar. On account of its difficult crystallization and a lower degree of sweetness, it is less valuable for commercial purposes than cane-sugar. That which appears in the market is largely made from starch by the use of an acid, and it is often utilized for adulterating the more costly saccharose. Many seem to regard glucose as a substance deleterious to health, but in consideration of the fact that, in digestion, starch and most other sugars are reduced to this compound before entering the circulation of the animal, this view does not seem to be sustained. There is a lack of evidence to show the ill effect of glucose either upon man or animals.

93. Levulose.-Another simple sugar is levulose or fruit-sugar, the composition of which is identical with dextrose, but which has a different chemical constitution. It accompanies dextrose and is found in some fruits in considerable quantities, and especially in honey. It is as sweet as cane-sugar, but does not form crystals with the same readiness.

94. Galactose.-This is obtained by a cleavage of milk-sugar (see later) into this sugar and dextrose. It may also be obtained from certain gums. 
95. The pentoses.-There are several pentoses, none of which occurs in nature, but which are prepared by chemical methods from the gums. Thus, from gum arabic, containing araban, arabinose may be obtained, and from zylan (wood-gum), zylose may be prepared. Certain of these sugars have been isolated from animal compounds. They also have been found to appear in human urine. They are important in the nutrition of herbivorous animals.

96. Di-saccharides.-These carbohydrates are all sugars which may be decomposed into two molecules of a simple sugar, or one molecule of each of two simple sugars. They are only three in number-saccharose or sucrose (cane-sugar), maltose (malt-sugar), and lactose (milk-sugar). When acted on by weak acids or certain ferments, they break by cleavage (hydrolysis) as follows:

Saccharose+water $=$ dextrose+levulose.
Maltose +water $=$ dextrose+dextrose.
Lactose +water $=$ dextrose+galactose.

These are the changes that occur during the digestion of food.

97. Saccharose.-The most important of these, commercially considered, is saccharose, which is the ordinary crystallized sugar of the markets. As a human food it is widely used, is especially valuable, and its manufacture and sale constitute a prominent industry. This sugar is obtained mostly from two plants, sugar-cane and the sugar-beet. It also exists abundantly in sorghum, pineapples, carrots, and in considerable proportions in the stalk of ordinary field corn. The first spring flow of sap in one species of maple tree is richly charged with it. 
The fruits generally contain saccharose, mixed with other sugars and organic acids, and upon the relative proportions of these compounds depends the character of the fruit as to acidity or sweetness.

98. Maltose.-This sugar is intimately related to the first growth which occurs in the germination of seeds. It stands as an intermediate product between the store of starch in the seed and the new tissues of the sprout. The solution that the brewer extracts from the malted grains contains this compound as the principal ingredient, and through succeeding fermentations in the beer vats it is broken up into alcohol and other compounds. It sustains an important relation, therefore, to the production of beers and other alcoholic liquors. Glucose sirups sometimes contain small quantities of this sugar. It is also found as an intermediary product in the intestinal canal during the digestion of food, being derived from starch and other carbohydrates through the action of ferments. Maltose is similar to cane-sugar in ultimate composition, but not in constitution, although as a nutrient it evidently has an equivalent value.

99. Lactose.-The only sugar of animal origin which is abundant in farm life is the lactose that is found in milk, which is known in commerce as milk-sugar. The milk of all mammals contains sugar, which appears to be the same compound with every species so far investigated. When they are fed wholly from the mother, this is the only carbohydrate which young mammals receive in their food. The average proportion of sugar in the milk of domestic animals varies from three to six parts in a hundred, cow's milk containing about five parts. When the cream is removed, much the larger part of sugar remains in the skimmed milk, and in cheese-making it is nearly all 
found in the whey, from which the milk-sugar of commerce is obtained. Very soon after milk is drawn, unless it is heated to the point of sterilization, or is treated with some antiseptic, the lactose begins to diminish in quantity, being converted into lactic acid through the action of lactic-acid organisms (bacteria). Sour milk, therefore, is different from sweet in containing less sugar or none at all.

100. The sugars as a class.-When considered from the standpoint of efficiency, the sugars are among the most valuable of all the carbohydrates, although in quantity they are less important than the starches, at least in raw food materials.

Unlike starch, they are found in solution in the sap of growing plants. It is probable that these are the forms in which carbohydrate material is transferred from one part of the plant to another. It is easy to see that some such medium of exchange is necessary. The actual production of new vegetable substance takes place in the leaves. When, therefore, cell-walls and starch grains are to be constructed in the stem and fruit, the building-material must be carried from the leaves to these parts in forms which will readily pass through intervening membranes. Excepting certain soluble compounds, closely related to starch, the sugars appear to be the only available bodies fitted for this office.

It is very seldom that a plant contains only a single sugar. Generally two or more sugars are found together. This is especially the case in the corn plant, sorghum, and the fruits, and the proportions of each depend somewhat on the stage of growth of the plant.

101. Other more complex poly-saccharides.-This group includes a large number of carbohydrates that may 
be considered as complexes of the simple sugars already described. Indeed, they make up the principal bulk of the carbohydrate-content of cattle foods. These polysaccharides may be divided into three subgroups: the starch group, the gum and vegetable mucilage group, and the cellulose group.

102. The starches.-Starch is a widely distributed and abundant constitutent of vegetable tissue. Food plants, especially those most used by the human family, contain it in generous proportions, in some seeds as much as 60 or 70 per cent being present. Probably only water and cellulose are more abundant in the vegetable world.

Starch does not exist in solution in the sap, but is found in the interior of plant cells in the form of minute grains which have a shape, size, and structure characteristic of the seed in which they are found. Potato starch grains are large, about $\frac{1}{300}$ inch in diameter, and are kidney-shaped, while those of the wheat are smaller, about $\frac{1}{1000}$ inch in diameter, and resemble in outline a thick burning-glass.' Corn starch grains are angular, being somewhat six-sided, and those of other seeds show marked and specific characteristics. These differences in size and shape furnish the most important means of detecting adulterations of one ground grain with another, a method much used in the inspection of human and cattle foods.

Unless modified by some chemical change, starch is not dissolved by water. The starch grains are not affected at all by cold water, and, in hot water, at first only swell and burst. Prolonged treatment with hot water causes a chemical change to more soluble substances. For this reason the simple leaching of a food material removes no starch by solution. At the same time, the cooking of a ground grain so breaks up and liberates the starch grains 
that they are probably acted on more promptly by ferments in the digestive fluids.

The proportion of starch in plant substances varies greatly. The dry matter of many seeds, such as rice and the cereal grains, wheat, maize, barley, or oats, is largely made up of starch. The same is true of potatoes and other tubers. Johnson quotes the following figures from Dragendorff:*

Table XXII. Amount of Starch in Dry Matter

\begin{tabular}{|c|c|c|}
\hline & Per cent & \\
\hline then & 68. & Peas \\
\hline & 67. & Beans ; \\
\hline & 52.9 & Flaxseed . . \\
\hline le & 65. & Potato tubers \\
\hline
\end{tabular}

It appears that in grain plants starch forms most abundantly during the later development of the seed. At the Maine Station none could be found in very immature field corn cut August 15, while on September 21 the dry matter of the whole plant on which the kernels had matured to the hardening stage contained 15.4 per cent. In general, the stem and leaves of forage plants are poor in starch.

The distribution of starch in seeds is worthy of note. The grain of wheat has been carefully studied in this particular, and it is found that this body does not normally exist in the seed coatings, this tissue consisting largely of mineral matters, proteins, cellulose, and gums. On the contrary, the germ and interior material deposited around it are rich in starch. To be sure, wheat bran, which is now very largely the outer seed coats of the grain, has more or less, but this is due to imperfect milling.

Starch is an important commercial article, and is *"How Crops Grow," page 52. 
mainly obtained from corn and potatoes. Special forms of starch used in cookery are sago, tapioca, and arrowroot. It is used as human food, as a source of dextrin, and in other ways. By treatment with an acid, corn starch is converted into the glucose of our markets, dextrin and maltose being intermediate products.

103. Glycogen.-This is the only uncombined carbohydrate found in the animal body in appreciable quan. tity outside the forms that are in the blood circulation. It is sometimes called animal starch. It is a white powder, soluble in water, and may be extracted in small amounts from the muscles and liver. It is formed out of the sugars that are taken into the circulation from the digestive tract, and, as we shall see, is held a reserve store of fuel for the maintenance of muscular energy, and in this way it performs a very important office in nourishing the animal body. (See Par. 214.) It was formerly believed that another carbohydrate exists in muscle called inosite, but it is now known that this substance belongs to a different class of compounds.

104. The pentosans.-These bodies are very widely distributed in nature, being found in the leaves, stem, roots, and seeds of a great variety of plants, in algæ and in beets and turnips. Certain pentosans are known as gums, such as gum arabic, gum tragacanth, and cherry gum. Pentosans, on hydrolysis, yield pentose sugars, among which are arabinose and zylose. These gum-like substances exist in beets and turnips and probably in all herbaceous plants that serve as cattle foods.

105. Galactans, mannans, levulans, dextrans.-These are compounds of some importance that are more or less associated in the framework of a great variety of plants or parts of plants, including seeds, beets and turnips, 
tubers and bulbs, algæ, lichens, molds, and the wood and bark of many species of trees. On hydrolysis they yield galactose, mannose, levulose, and dextrose respectively. The compounds are designated as hemi-celluloses.

They make up the least valuable part of certain vegetable foods.

106. The pectin bodies.-Another class of compounds much like the gums and perhaps related to them chemically, is the pectin bodies. Some of these substances are gelatinous in appearance. The jellying of fruits, such as apples and currants, is made possible by their presence. They exist in greater abundance in unripe fruit than in the ripe, consequently the former is selected for jellymaking. When such fruits are cooked, the pectin which they contain takes up water chemically and is transformed into a gelatinous substance known as pectose. Mucilages not greatly unlike the gums and pectins exist in certain seeds and roots, the most notable instance being flaxseed.

107. Dextrin, which is sometimes spoken of as a gum, is made by heating starch to about $200^{\circ} \mathrm{C}$. It may also be produced by treating starch with a dilute acid. Dextrin is formed on the outer part of the loaf when wheat bread is baked. It is soluble in water.

108. Cellulose.-This is found in the tough or woody portion of plant tissue. In tables of food analyses we find the term crude fiber, which consists largely of cellulose, a familiar example of which in a nearly pure form is the cotton fiber used in making cloth. Crude fiber is separated from associated compounds by the successive treatment of vegetable substance with weak acids and alkalies, and as so determined is sometimes improperly taken to represent the amount of cellulose in a plant. While crude fiber is mainly cellulose, it contains a small 
proportion of other compounds, and besides, more or less cellulose is dissolved by the acid and alkali treatment, so that the percentages of crude fiber given in food tables only approximately measure the cellulose present.

All plant tissue is made up of cells, the walls of which are chiefly or wholly cellulose. It is this substance out of which is built the framework of the plant, and which gives toughness and rigidity to certain of its parts. The more of this plant tissue contains, the more tenacious it is, other things being equal, and the more difficult of mastication.

The proportions of cellulose in the different parts of a plant are greatly unlike. It is usually most abundant in the stem, with less in the foliage and least in the fruit. With vegetables like potatoes and turnips, the leaves are much richer in fiber than the tubers or roots, which contain a comparatively small proportion. Of the grains or seeds, considerable is present in the outer coatings, while but little is found in the interior. Vegetables such as celery, lettuce, beets, and turnips are relatively rich in crude fiber, while tubers, flours, and meals contain only small amounts. In certain by-products from the grains, like bran, which is made up mostly of the seed coatings, fiber is present in fairly large proportions, while in flour derived from the inner parts of the grain, the percentage is almost negligible.

The stage of growth at which a plant is used for food purposes has a marked influence upon the proportion of crude fiber. In young, actively growing vegetable tissue, the cell-walls are thin, but, as the plant increases in age, these thicken chiefly through the deposition of cellulose. In general, the toughness and hardness of mature plants, as compared with young are due to the increased pro- 
portion of woody fiber, although the decrease in the relative amount of water in the tissues and the deposition of other substances have more or less effect.

109. The acids.-Other substances besides those of a carbohydrate character are included in the nitrogenfree extract. Chief among these are the organic acids, compounds which are found mostly in the fruits, although they appear in certain fermented products, such as silage and sour milk. The most important and well known of these are acetic acid, found in vinegar, citric acid in lemons, lactic acid in sour milk, malic acid in many fruits, such as currants and apples, and oxalic acid in rhubarb. Sometimes these acids are free, that is, not combined with any other compound. In the main they are united with lime or some other base, forming an acid salt. Excepting the fruits, only fermented foods contain acids to an appreciable extent. When milk sours, the sugar in it is changed to lactic acid under the influence of a ferment. The acids of silage are formed at the expense of the carbohydrates that are in the material which is subjected to fermentation.

110. Fats and oils.-When any finely ground foodstuff, either vegetable or animal, is submitted to the leaching action of ether, chloroform, or certain other solvents, several compounds are taken into solution, the main and important ones being fats or oils. These bodies make up the chief portion of such an extract from seeds, while the extract from other vegetable materials also contains a considerable amount of wax, chlorophyl, and other substances. Tables that show the composition of foods have a column which is sometimes designated "ether-extract," and sometimes "fats or oils." The former is the more accurate term, because the compounds which 
it is the intention to describe are often no more than half fats or oils. The real value of the ether-extract from different foods is partly determined, therefore, by its source. When it is all oil, or nearly so, it is worth much more for use by the animals than when it is made up to quite an extent of other compounds.

111. Fats or oils in grains and seeds.-The proportions of fat or oil in cattle foods vary within wide limits. In general, seeds and their by-products contain more than the stem and leaves, the differences in the percentages of actual oil being greater than is indicated by the etherextract. But little is found in the dry matter of roots and tubers. Among the cereal grains and other more common farm seeds, corn and oats show the largest amounts, the proportion in dry matter being from 5 to 6 per cent, while wheat, barley, rye, peas, and rice contain much smaller percentages, wheat having about 2 per cent, and rice sometimes not over one-fifth of 1 per cent. Agricultural seeds that are especially oleaginous are cottonseed, flaxseed, sunflower seeds, and the seeds of many species belonging to the mustard family, such as rape. Peanuts, coconuts, and palm nuts are also very rich in oil. The average percentages in these seeds and nuts are approximately as given below:

Table XXIII. Oil in Certain Seeds

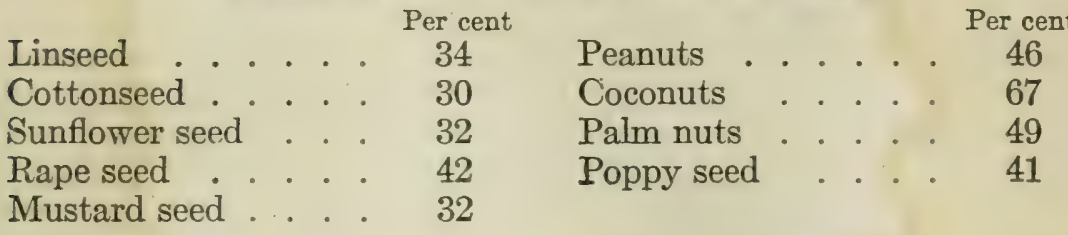

The oils from all the above are important commercial products, being used in a great variety of ways in human 
foods and in the arts. In many cases, the refuse from this extraction goes back to the farm as food for cattle. This is especially true of linseed and cottonseed.

112. Nature and kinds of fats.-The vegetable and animal fats and oils may, for convenience' sake, be discussed in two divisions, the neutral fats, or glycerides, and the fatty acids. The neutral fats are combinations of the fatty acids with glycerin. When, for instance, lard is treated at a high temperature with the alkalies, potash and soda, glycerin is set free, and an alkali takes its place in a union with the fatty acids. This is the chemical change which occurs in soap-making. There are several of these neutral fats, the ones most prominent and important in agriculture being those abundant in butter and in the body fats of animals, viz., butyrin, caproin, caprylin, caprin, laurin, myristin, olein, palmatin, and stearin, the last three being the most abundant and important in human foods. Butyrin is a combination of butyric acid and glycerin, stearin of stearic acid and glycerin, and so on. Because these are combinations of three molecules of a fatty acid radical with one of glycerin, they are sometimes named tri-stearin, tri-palmatin, and tri-olein, and so on. Some single fats (glycerides) are compounds of two or three fatty acid radicals united with glycerin in the same molecule. As glycerin is an alcohol, and as combinations of an alcohol and acids are ethers, the neutral fats are really ethers (esters), although they differ greatly from the common conception of an ether which is gained from ethyl ether or the ether of drug-stores.

113. Physical properties of the fats and oils.-These individual fats possess greatly unlike physical properties. They are all soluble in benzine, chloroform, and ether, and insoluble in water. At the ordinary temperature of 
a room, some are liquid and some are solid, olein belonging to the former class, and palmatin and stearin to the latter. Butter, lard, and tallow differ in hardness at a given temperature, and it may easily be discovered that their melting-points are not the same. As the animal body fats are in all cases chiefly mixtures of olein, palmatin, and stearin, stearin and palmatin being a solid at ordinary temperatures, and olein a liquid at anything above the freezing-point, it is evident that the relative proportions of these compounds will affect the ease of melting and the hardness of the mixtures of which they are a part. Stearin melts at $71.7^{\circ}$ C. and palmatin a.t $62^{\circ} \mathrm{C}$. Tallow, having much more stearin than lard and less olein, is consequently much more solid on a hot day.

The composition and physical properties of the fat from a beef animal seem to vary according to the age of the animal and the locality of the body from which the fat is taken. Fat from an old animal melts at a lower temperature than that from a young animal, and the same is true of fat taken from the outside of the body as compared with that taken from the inside. Fat from the herbivora is in general harder than that from the carnivora.

114. Milk-fat.-This contains not only the three principal fats, but also the others mentioned, butyrin, caprion, caprylin, caprin, laurin, and myristin, in small proportions, and these latter tend to give butter certain properties that distinguish it from the other animal fats, which are almost wholly palmatin, olein, and stearin. These special butter-fats are liquid at ordinary temperatures. Doubtless the flavor, texture, and resistance of butter to the effects of heat, are much influenced by the proportions of the numerous fats it contains. 
115. Fatty acids.-Free, fatty acids exist in nature. They are not found in butter, lard, and tallow unless these substances have undergone fermentations and become rancid. The characteristic flavor of strong butter is due to free butyric acid, which, because of fermentations, has parted from the glycerin with which it was originally combined in the milk. In plant oils, on the other hand, are found considerable proportions of the free fatty acids, some of which have not been discovered so far in animal fats, either free or uncombined.

116. Ether-extracts.-Stellwaag investigated the ingredients of the ether- and benzine-extracts from plants. His results show that not only do these extracts include substances which are not fats, but that a considerable proportion of free, fatty acids is always present, sometimes in quantities exceeding the neutral fats:

Table XXIV. Composition of Ether-Extracts

\begin{tabular}{|c|c|c|c|c|c|c|c|c|c|c|c|c|c|}
\hline & & & & & & & & & & & $\begin{array}{l}\text { Neutral } \\
\text { fats }\end{array}$ & $\begin{array}{l}\text { Free fatty } \\
\text { acids }\end{array}$ & $\begin{array}{l}\text { Material not } \\
\text { saponifiable }\end{array}$ \\
\hline $\begin{array}{l}\text { Potatoe } \\
\text { Beets } \\
\text { Maize, } \\
\text { Barley } \\
\text { Oats }\end{array}$ & $\begin{array}{l}\text { es } \\
\text { kerne } \\
\text { - } \cdot \\
\cdot\end{array}$ & ei & $\begin{array}{l}\cdot \\
\cdot \\
\cdot \\
\cdot \\
.\end{array}$ & ${ }^{\circ}$ & . & $\cdot$ & $\cdot$ & . & . & • & $\begin{array}{l}\text { Per cent } \\
16.3 \\
23 . \\
88.7 \\
73 . \\
61.6\end{array}$ & $\begin{array}{c}\text { Per cent } \\
56.9 \\
35.3 \\
6.7 \\
14 . \\
27.6\end{array}$ & $\begin{array}{c}\text { Per cent } \\
10.9 \\
10.7 \\
3.7 \\
6.1 \\
2.4\end{array}$ \\
\hline
\end{tabular}

It appears, as before stated, that ether-extract, especially that from vegetables, may consist, to some extent, of materials which should not be classed among the fats. The extracts from the grains proved to be nearly all oil. Moreover, the grain oils were made up principally of glycerides, and those from potatoes and beets consisted largely of free, fatty acids. 
117. Lecithins.-These are often called the phosphorized fats. It has previously been stated that neutral fats are combinations of fatty acids and glycerin (glycerol). Lecithins are compounds in which one of the radicals of a fatty acid is replaced by a compound of phosphorus. They are widely distributed in nature. They appear to be an active component of every cell, both of vegetable and animal tissue, and they are especially abundant in seeds, in the nerve system, in fish, eggs, and in the yolk of eggs. These compounds evidently fill an important place in plant and animal nutrition. There are good theoretical reasons for suggesting that lecithins serve as a stepping-stone to the synthesis of the nucleo-proteins. In digestion they behave like the true fats.

118. Enzyms, anti-bodies, hormones, vitamines (accessories).-The science of nutrition must now deal with a class of bodies which have not been isolated, some of which have merely a theoretical standing, and all of which are known chiefly by their reactions.

Certain of these bodies are formed within the animal organism and others are associated with foods.

The subject of enzyms is treated in Par. 128.

Anti-bodies are bodies which in some manner neutralize or hinder the specific action of some other body, as for instance the anti-enzyms. It is held that an antipepsin exists in the mucous membranes of the stomach and an anti-trypsin in the mucous membrane of the intestine which render these linings immune to the action of the digestive juices.

Hormones, or "chemical messengers" are represented by secretin (see Par. 161) which reacts upon certain secretory glands, as for instance the pancreas, causing a flow of the digestive fluid. The formation of secretin is 
believed to be due to the reaction of certain food substances on the inner membranes of the stomach.

Vitamines, or food accessories, are regarded as being attached to foods, and may properly be styled growthpromoting substances. These bodies of an unknown nature seem to fall into two classes (Hart and McCollum), the fat-soluble accessory attached to butter fat, egg yolk fat, pig kidney fat, and certain vegetable fats, and a water-soluble accessory attached to the wheat embryo, egg yolk, milk-powder, and other foods. These accessories are not destroyed by heat, even when subjected to the action of steam for two and one-half hours. The fat soluble accessory may be concentrated in butter oil by fractional crystallization of the harder fats. 


\section{CHAPTER VII \\ THE DIGESTION OF FOOD}

WE have accepted so far without discussion the almost self-evident fact that the food is the immediate source of the substance and energy of the animal body. It now remains for us to consider the way in which nutrition is accomplished. The first step in this direction is the digestion of food. It is necessary for food ingredients to be placed in such relations to the animal organism that they are available for use. This involves both condition and location. The various nutrients in the exercise of their several functions must be generally distributed, and so their compounds, in part at least, must be brought into soluble and diffusible condition, in order that they may pass through the membranous lining which separates the blood vessels and other vascular bodies from the cavity of the alimentary canal.

119. Digestion vs. assimilation.--In discussing physiological relations of food, two terms are employed, viz., digestion and assimilation. Digestion refers to the preparation of food compounds for use, by rendering them soluble and diffusible-changes which are accomplished in what we call the alimentary canal, a passage that begins with the mouth, includes the stomach and intestines, and ends with the anus. Assimilation signifies the appropriation of nutrients, after digestion, to the maintenance of the vital processes and to the building of flesh and bone-processes taking place in the tissues, 
to which the nutritive substances are conveyed by the blood. The two terms are entirely distinct in meaning, although they are confused in popular speech.

120. General changes in food through digestion.In digestion, food undergoes both mechanical and chemical changes. It is masticated, that is, ground into finer particles, after which, in its passage along the alimentary canal, it comes in contact with several juices which profoundly modify it chemically. That portion of it which is rendered diffusible is absorbed by certain vessels that are embedded in the walls of the stomach and intestines, and is conveyed into the blood. The insoluble part passes on and is rejected by the animal as worthless material, and constitutes part of the solid excrement or feces. The forms in which the nutrients are conveyed into the circulation are believed to be the following: The proteins, previous to absorption into the blood, are converted into soluble bodies, at first proteoses and peptones, and finally into simpler nitrogen compounds (amino acids) resulting from a more extensive cleavage; the carbohydrates enter the blood as sugars, chiefly as dextrose. The fats are changed into a finely divided form, either as such or as fatty acids and soaps. A study of digestion includes, then, a knowledge of mastication, of the sources, nature, and functions of the several digestive juices, and a consideration of the various conditions affecting the extent and rapidity of digestive action.

\section{FERMENTS}

The changes involved in rendering food compounds soluble are intimately connected with a class of bodies 


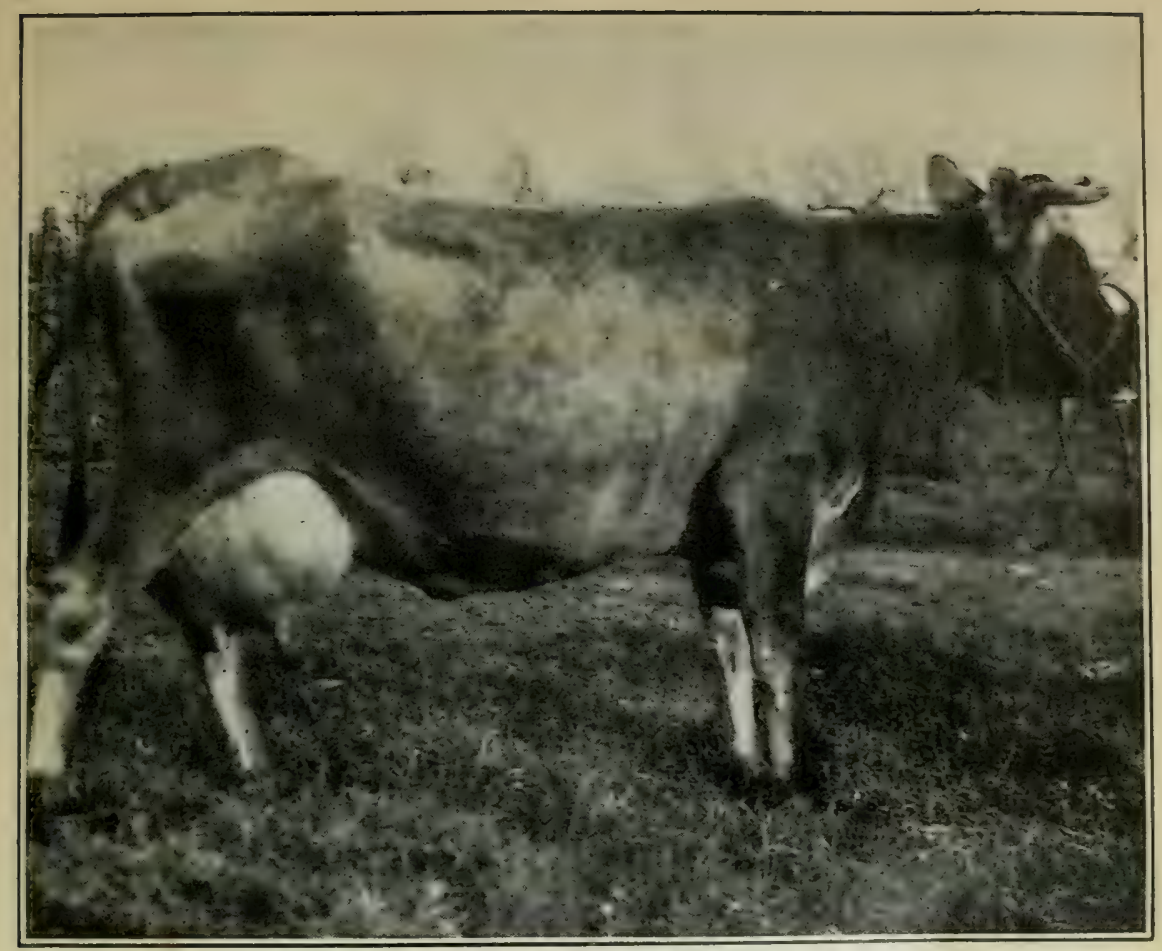

A dairy mother-Guernsey.

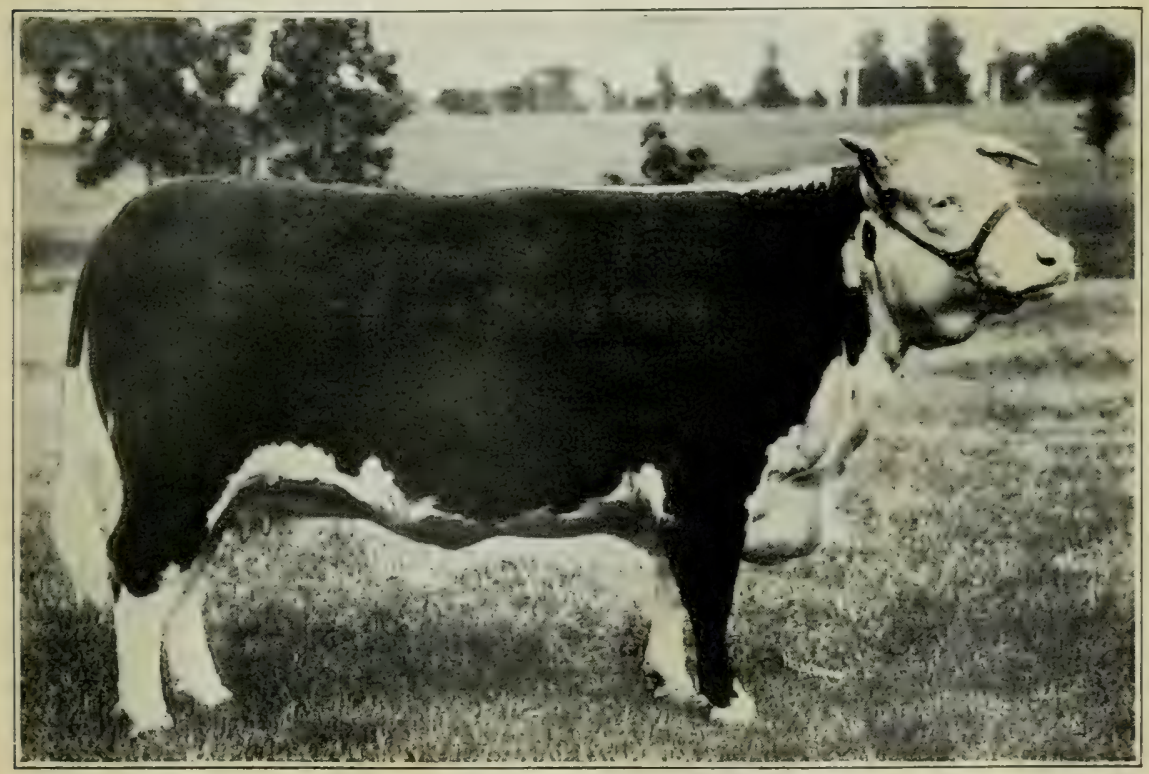

Well-fed Hereford heifer.

Plate III. Two good bovine types. 

known as ferments, and it seems necessary before proceeding to a consideration of digestion as a process to learn something of the nature and function of these agents, which are actively and essentially present in the digestive tract.

121. Definition of ferments.-A ferment may be defined in a general way as an agent which causes the decomposition of certain vegetable or animal compounds with which it comes in contact under favorable conditions. In the past, ferments have been classified into two kinds, organized and unorganized. The so-called organized ferments are low, microscopic forms of vegetable life, generally single-celled plants. The unorganized ferments are not living organisms, but are simply chemical compounds.

122. Organized ferments.-When milk is allowed to remain in a warm room for several hours, it becomes sour. An examination of it chemically shows that its sugar has in part disappeared and has been replaced by an acid. A study of the milk with the microscope, before and after souring, reveals the fact that there has been a marvelous increase in it of single-celled organisms or plants. The presence of this form of life is regarded as the cause of the change of the sugar into lactic acid. We have here a so-called lactic-acid ferment, which may typify the organized ferments known as bacteria. Numerous other fermentations of the same general kind are common to everyday experience, such as the changes in the cider barrel and the wine cask, the spoiling of canned fruits and vegetables, and the heating of hay and grain, which are all illustrations of what is accomplished by these minute organisms.

123. Structure and distribution of organized ferments. - The organized ferments are classed in the vegetable 
kingdom. As a rule, each individual plant is a single cell and so minute as to be invisible to the unaided sight. It corresponds in its general structure to the cells which make up the tissues of the higher vegetable species, i. e., it consists of a cell wall inside of which are protoplasm and other forms of matter. These organisms are distributed everywhere-in the air, in the soil, on surfaces of plants, and in the bodies of animals. Whenever the right opportunity offers itself, they multiply and bring about all the results attendant upon their growth.

124. Conditions of growth of organized ferments.The conditions essential to their development are the proper degree of moisture and temperature and the necessary food materials. Animal and vegetable substances supply the necessary nutrients, but when thoroughly dry do not ferment. Flour and meal that have been dried to a water-content of 10 per cent will keep a long time without loss from fermentative changes. The heat in a mow of hay or in a bin of new grain, with their subsequent musty condition, is due to the fermentations that are made possible through the presence of considerable moisture. Thorough drying is a preventive of these destructive fermentations.

There is a temperature at which each vegetable ferment thrives best, and there are limits of temperature outside of which the growth of these forms of life does not occur, or is very slight. Numerous species thrive between $75^{\circ}$ and $100^{\circ} \mathrm{F}$. Fermentable materials like fruit and meat at the freezing-point or below are not subject to fermentations. The boiling-point of water kills most bacteria, and temperatures above $150^{\circ} \mathrm{F}$. retard or entirely prevent their growth. 
125. Results of fermentation.-Like all life, these organisms must have food. Many species find this in acceptable forms in vegetable and animal products. Because these products contain the sugar, proteins, and mineral compounds which nourish bacteria, many of them are the prey of ferments under proper conditions of moisture and temperature. The prevention of fermentation in cattle foods is desirable because it occasions a loss of nutritive value and often produces undesirable flavors. The loss becomes evident when we consider the nature of the chemical changes that occur. For instance, when the sugars in cider are broken up through the influence of a bacterium, carbon dioxid and alcohol are formed through the appropriation of free oxygen. This means that combustion occurs, causing the liberation of energy which otherwise would have been available if the sugar had been taken as food. Nany other fermentations involve oxidation, all of which are destructive of food value.

126. Manner of action of ferments.-These little plants use sugar and other compounds as food, deriving energy and growth therefrom, the carbonic acid, alcohol, and other new bodies being the by-products of this use. It now appears probable that these organisms develop an unorganized ferment which brings about these fermentative changes. Indeed, it is definitely proved that it is possible to separate from the cells of the yeast plant a substance that, in the absence of the yeast plant itself, converts sugar into carbon dioxid and alcohol. This shows that the effective agent in bacterial fermentations is, after all, a chemical substance, or an unorganized ferment. These later discoveries tend to remove the distinction that has been made between the so-called organized and unorganized ferments. Certain ferments are 
among the most useful agencies with which we deal and some are harmful. The yeast plant is useful in breadmaking, but the putrefaction of meats under the influence of another ferment causes loss.

127. Bacteria in the digestive tract.-The digestive tract of animals is inhabited by countless numbers of bacteria. These inhabit both the stomach and the intestines, especially the colon. They also form a part of the feces. The two main types in which we are interested in their relation to digestion are (1) the fermentative or those that attack the carbohydrates, especially the sugars, and (2) the putrefactive, or those that cause decomposition of the proteins. Under certain conditions such as a sudden change of food to large amounts of young and succulent herbage, especially the legumes, bacterial fermentations may endanger the life of the animal through the excessive formation of acids and gases.

128. Unorganized ferments.- There is another class of ferments which is termed unorganized, and to which the general term "enzym" is given. These are the ferments especially important in digestion. They are merely chemical compounds, formed within the living cells of the plant or animal, which produce a peculiar effect upon certain bodies with which they come in contact. If a thin piece of lean beef be suspended in an extract from the mucous lining of a pig's stomach, to which has been added a small proportion of hydrochloric acid, the liquid being kept at about $98^{\circ} \mathrm{F}$., the beef will soon begin to soften, afterwards swell to a more or less jelly-like condition, and finally dissolve. The same general result would occur with fish, blood fibrin, or the coagulated white of an egg. When starch is placed in a warm-water solution of crushed malt, it soon dissolves, leaving a com- 
paratively clear liquid. A chemical examination of these preparations will reveal the fact that the compounds of the meat are present in solution in somerrhat modified forms, and that the starch has been changed to a sugar or other soluble bodies. In both cases substances insoluble in water have become soluble and diffusible.

129. Enzyms and their action.-The cause of these changes is the presence, one in the pig's stomach and one in the malt, of ferments of the enzym class, the former of which renders proteins soluble, the latter producing a similar result with the insoluble carbohydrates. This action is not entirely like that caused by the presence of the organized ferments, where oxidation occurs in many cases. The enzyms simply induce the proteins and starch to take up the elements of water, a change which is termed hydrolysis. How this is done cannot be explained in simple terms, if at all. Our knowledge of the manner of the change rests to some extent upon theoretical grounds. Enzyms are regarded as catalyzers, that is, compounds which by their presence cause chemical changes while they themselves do not enter into the combinations formed. A small quantity of an enzym may cause changes in a large amount of material, the enzym itself undergoing no appreciable change. The digestion of food is largely accomplished through the specific effect of enzyms, of which every digestive fluid contains one or more. Examples of these are the pepsin and pancreatin of the drugstore that contain enzyms mixed with more or less of impurities. The various enyzms are often given names according to their function: invertase, which inverts or splits sucrose; glucase, that changes any carbohydrate into glucose (also called maltase); lactase, that splits lactose into simpler sugars. In general, the ferments acting 
on starch are called diastases. Enzyms that split fats are designated as lipases and those acting on proteins to produce proteoses are designated as proteases.

THE ALIMENTARY CANAL

The digestion of food is accomplished in the alimentary canal, a duct that extends from the mouth to the anus.

130. Parts of the alimentary canal.-The succession of the various parts of this canal is as follows: the esophagus, stomach, small intestine (duodenum) and the large intestine (colon).

The length of the intestines in the several species of farm animals is very great as compared with the length of the body of the animal, as the following figures show:

Sheep, ratio length of intestine to length of body . 26 times $\mathrm{Ox}$, ratio length of intestine to length of body . . 20 times

Horse, ratio length of intestine to length of body . 12 times

Dog, ratio length of intestine to length of body . 3 times

The food is pushed along the intestinal canal by a muscular movement of the walls of the intestines known as peristalsis, which passes from stomach to rectum, being slower in the large intestine than in the small. During this passage there occurs both the digestion of food and the absorption through the walls of the canal of the digested materials.

THE MOUTH

131. Mastication.-The first step in the digestion of fodders and whole grains is to reduce them to a much finer condition. This is done in the mouth, the teeth being the grinding-tools.* Sometimes the cutting or grinding is

*This is not true of hens, turkeys, and other fowls. 
partially or wholly performed for the animal in haycutters and grain mills. This mastication is essential for two reasons: (1) It puts the food in condition to be swallowed, and (2) fits it for the prompt and efficient action of the several digestive fluids. Dry whole hay or kernels of grain could hardly be forced down the tube leading to the animal's stomach. It is necessary for these materials to be broken down and moistened in order that they may be swallowed. Even if they could be conveyed to the stomach in their natural condition the process of rendering their constituents soluble would proceed very slowly. The more finely any solid is ground, the larger is the surface exposed to the attack of the dissolving liquid and the more rapid the action.

132. The teeth.--Prompt and rapid solution of food is essential, because, if it is too long delayed, uncomfortable and injurious fermentations are likely to set in, and, because of imperfect digestion, the final nutritive effect of the ration may be diminished. For these reasons, animals with diseased teeth, or those that have lost teeth, make poor use of their food, and require an unnecessary amount to keep them in condition. These conditions may often be a cause, especially with horses, of disappointing results from an ordinarily sufficient ration. The teeth of our domestic animals differ somewhat in number and arrangement. Authorities state the following to be the usual number:

\section{TABLE XXV}

\begin{tabular}{|c|c|c|c|c|}
\hline & Total & Incisors & Canines & Molar: \\
\hline & $36-40$ & & & \\
\hline ind goat & $\begin{array}{l}32 \\
32\end{array}$ & 8 & & $\begin{array}{l}24 \\
24\end{array}$ \\
\hline & 44 & 12 & 4 & \\
\hline
\end{tabular}


The incisors or front teeth are those which are used for prehension, and by grazing animals for cutting off the grass and other herbages. With the ox, sheep, and goat, incisors are found only in the lower jaw. These move in their sockets and shut against a tough pad on the upper jaw. They are constantly being pushed out of their sockets and wearing off, and with old animals may be so worn away as to leave only the roots. Such animals do

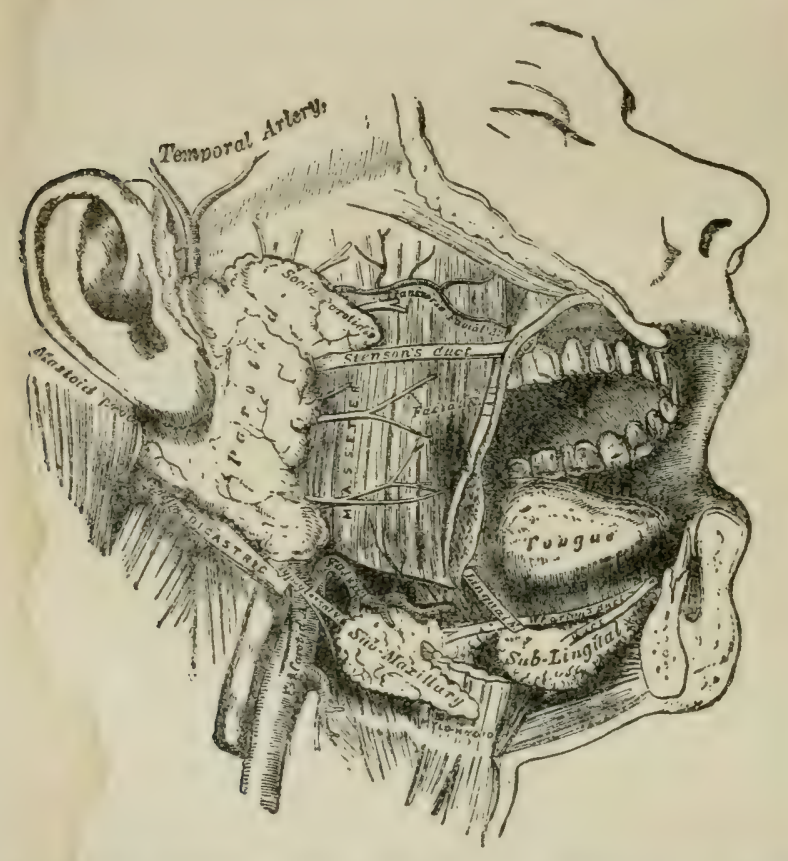

Frg. 1. Glands secreting saliva in man,--parotid, sublingual, submaxillary.

not graze successfully. With the horse and pig, incisors are found in equal numbers in both jaws.

The molars are the grinding teeth. Those of the horse sometimes need filing on the edges in order to prevent irritation and soreness of the adjacent tissues. A diseased 
molar may also occasion an animal much discomfort and cause imperfect mastication.

133. The saliva.-During mastication there is poured into the mouth a liquid called the saliva, which has two important functions: (1) It moistens the food, and (2) with several species of animals it causes a chemical change in certain of the constituents of the food.

134. Origin of saliva.-The saliva has its origin in several secretory-glands that are adjacent to the mouth cavity, and from these this liquid is poured into the mouth through ducts that open in the cheek and under the tongue (Fig. 1). The chief of these glands are located in the side of the face, below and somewhat back of the jaws and beneath the tongue, and are called respectively the parotid, the submaxillary, and the sublingual. Other glands of this character are scattered in the cheeks and at the base of the tongue. The proportions of these glands in the several species of farm animals are as follows:

\begin{tabular}{|c|c|c|c|c|c|}
\hline & \multicolumn{3}{|c|}{ TABLE XXVI } & & \\
\hline Parotid & Horse & $\begin{array}{c}\mathrm{Ox} \\
45\end{array}$ & $\begin{array}{c}\text { Sheep } \\
52\end{array}$ & $\begin{array}{l}\text { Pig } \\
81\end{array}$ & $\begin{array}{l}\text { Dog } \\
48\end{array}$ \\
\hline Submaxillary & 17 & 48 & 43 & 16 & 52 \\
\hline Sublingual & 5 & 7 & 5 & 3 & \\
\hline
\end{tabular}

135. Properties and office of saliva.-The saliva is a transparent and somewhat slimy liquid, and contains generally not less than ninety-nine parts in one hundred of water, and one part or less of solid matter. It is alkaline in reaction, because of the presence of compounds of the alkalies. One important organic compound present is mucin. The specific chemical effect exerted by this liquid on the food constituents may be illustrated by subjecting starch to its action. When this is done, the starch gradually disappears as such and is replaced by dextrin 
and maltose, chiefly the latter. The agent which is active in causing this change is an enzym (see Par. 128), to which the name ptyalin has been given, and which is always present in the saliva of man and of some animals. It is classed among the diastatic ferments, and has an office similar to that of diastase in the germination of seeds, viz., the transformation of starch into a sugar. With man this change begins in the mouth and continues in the stomach until the food becomes so acid that the ferment ceases to act, for ptyalin is inactive except in an alkaline medium. There is yet no reason for concluding that with herbivora the saliva is as important in carbohydrate digestion as with man. Different observers differ in opinion as to the diastatic value of saliva with farm animals.

The saliva also moistens the food, which is a most important office, for it is a necessary preparation to the act of swallowing. The saliva is not the same from the different glands, that from the parotid being watery with no mucin and that from the other glands being rich in mucin and therefore very viscid. The former serves chiefly to moisten the food while the latter aids in swallowing.

136. Quantity of saliva excreted.-With large ruminants, the quantity of saliva required is large, as is evident when we remember that an ox or cow may consume in one day twenty-four pounds of very dry hay and grain, and that rumination goes on much of the time while the animal is not eating. It is estimated that oxen and horses secrete from eighty-eight to one hundred and thirtytwo pounds daily, an apparently enormous quantity of liquid for organs no larger than the salivary glands to supply. The extent and character of the secretion of 
saliva seems to be modified by the nature of the food offered, dry materials stimulating the parotid gland and moist foods only the submaxillary and sublingual. The organic constituents of the saliva are the peculiar products of the secretory activity of the cells of the salivary glands, and the water and inorganic salts are regarded as the result of cell secretion.

\section{THE STOMACH}

When the food leaves the mouth, it passes down the gullet (esophagus) into the stomach. The only modifications it has suffered up to this point are its reduction to a finer condition and a possible action of the mouth ferment upon the starch. After the food is swallowed, changes of another kind begin sooner or later.

Before considering gastric digestion from a chemical point of view, we should become acquainted with the widely differing structure of the stomachs of the various farm animals. Those of the ox and horse are greatly unlike. The stomach of the ox, and of all other ruminants, consists of four divisions or sacs, whereas with the horse and pig it is made up of a single sac.

137. The ruminant stomach.-The ruminant stomach is really quite a complicated affair, and the way in which it disposes of the food is understood only after a careful study of details. It has four divisions or sacs: the paunch, honeycomb, many-plies, and rennet, or what the physiologist has named the rumen, reticulum, omasum, and abomasum. With the ox these cavities contain on the average not far from twenty-five gallons, about ninetenths of this space belonging to the rumen (Fig. 2).

138. Esophageal groove.-A gutter or canal with 
an incomplete wall runs to the reticulum and omasum from the entrance of the esophagus into the rumen. It communicates both with the rumen and reticulum. The interior of this canal is not visible in its passage along the inner wall of the reticulum unless the lips with which it is provided are separated.

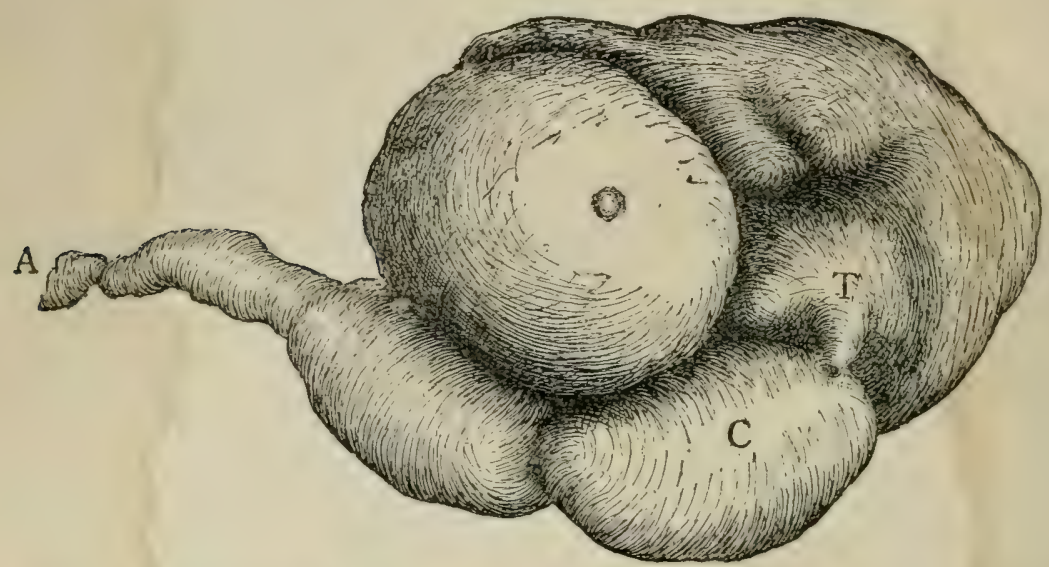

Fig. 2. Stomach of ox. T, rumen or paunch, showing attachment of esophagus; $C$, reticulum or honeycomb; 0 , omasum or many-plies; $A$, abomasum or rennet, showing attachment of small intestine.

139. The rumen.-The food, especially in its first descent from the mouth, passes at first mostly into the paunch through a slit in the gullet. This cavity, as stated, is very large, and it may properly be considered as an immense reservoir for the storage of the bulky materials which the ruminants take as food. It is divided into four sacs by constriction in its walls caused by strong muscular bands. As is the case with the entire digestive canal, the walls of the paunch are composed of three layers of tissue, the middle one being a very thick muscular coat, which seems necessary to produce the churning movement of the large mass of food. The inner or mucous 
layer is covered with numerous leaf-like projections, in which the blood vessels are freely distributed. During its stay in this reservoir, where it is held for remastication, the moist food becomes thoroughy softened and besides undergoes a variety of changes, chiefly those due to bacterial ferments which probably bring about the extensive digestion of the cellulose, estimated at from 60 to 70 per cent. These fermentations are attended by an evolution of gases, which under ordinary conditions are absorbed into the blood current. It may be suggested that hoven and the puffing up of the paunch of a freshly-killed bovine are due to the partial or total failure of the blood to take up these gases. Sometimes unnatural and dangerous fermentations set in, induced often by the consumption in the spring of a large quantity of easily fermentable food such as green clover. This causes hoven, and unless the gas pressure is at once relieved by an opening the animal often dies, due sometimes to the bursting of the rumen. Some authorities claim that proteolytic and amylolytic changes occur in the rumen brought about not by enzyms secreted by the rumen but by those contained in the food.

140. The reticulum.-A portion of the food reaches the reticulum either through the esophageal slit when first swallowed, or through a large opening between the rumen and the reticulum. That which goes directly to the reticulum when swallowed is mostly fluid. The reticulum also communicates with the third stomach by an opening. This is the smallest division of the stomach, and derives its common name from the fact that its interior surface is divided by ridges of the mucous membrane into cells which bear a close resemblance to a honeycomb. These cells, which are several-sided and quite deep, appear to 
be a "catch-all" for the foreign bodies which animals are liable to swallow, such as small stones, pins, and nails. The contents of this compartment of the stomach are very watery, and by being forced into the esophagus and rumen appears to aid the return of the food to the mouth, portion by portion, for remastication.

141. Rumination.-Rumination, which is the re-chewing of food previously swallowed, is peculiar to bovines, sheep, and goats. In the case of these species, the mastication of coarse fodder is not completed before it is swallowed the first time, and they have the power of returning to the mouth the material which has become stored in the rumen and reticulum in order that it may be more finely ground. This is what is termed "chewing the cud." It is an operation which greatly aids digestion by rendering the food mass finer and more susceptible to the action of the digestive fluids. Animals fed on grain alone do not ruminate. They "Iose their cud," a condition popularly and erroneously supposed to be fatal to the animal's life. The bolus or "cud" of the bovine weighs approximately four ounces and requires for its mastication not far from one minute, including preparation, transference to the mouth, and return. It is essential to rumination that the supply of liquid to the rumen be abundant, to which the salivary glands contribute a large share.

142. The omasum.-After remastication, the food does not return wholly to the first and second stomachs, but is mostly carried along the esophageal groove to the third stomach, the omasum. The finer portions may even do this when first swallowed. The omasum is a cavity somewhat larger than the reticulum, which has a most curious interior structure. It is filled with extensions of the mucous membrane in the form of leaves, between which 
the food passes in thin sheets, an arrangement which seems to have for its purpose the further grinding of the food so that when it finally reaches the fourth and last compartment it is in a very finely divided condition and is thoroughly prepared for the action of the juices that are subsequently poured upon it.

143. The abomasum.-It is at the last stage of the journey of the food through this complicated stomach that it is submitted to the true gastric digestion. As a matter of fact, the abomasum, or rennet, is regarded as the true stomach, the other three sacs being considered as enlargements of the esophagus. In the calf, the rennet is only partly developed, the other divisions not coming into use until the animal takes coarse foods in considerable quantity. The fourth stomach is larger than either the second or third. It receives directly from the omasum the finely divided food, upon which it pours the gastric juice, a liquid that is secreted in large quantity by glands located in its inner or mucous membrane.

144. The gastric juice.-This juice, like all the digestive fluids, is mostly water, the proportion being between ninety-eight and ninety-nine parts to less than two parts of various compounds. The latter consist of ferments, a certain amount of free hydrochloric acid and a variety of mineral compounds, prominent among which are calcium and magnesium phosphates and the chlorides of the alkalies, sodium chloride being especially abundant.

145. Artificial digestion.-Especial interest pertains to the ferments of the gastric juice, one of which, in connection with free hydrochloric acid, causes a most important change in the proteins of the food by reducing them through hydrolytic and other cleavages to soluble forms. We know quite definitely about this action, because it can 
be very successfully produced in an artificially prepared liquid. If the mucous lining of a pig's stomach, after carefully cleaning without washing with water, is warmed for some hours in a very dilute solution of hydrochloric acid, an extract is obtained which has the power of dissolving lean meat, wheat gluten, and other proteins. The active agent in causing this solution is pepsin, an unorganized ferment or enzym (see Par. 128) which is present in the gastric fluid of all animals.

146. Changes in stomach digestion.-This juice changes proteins to peptones, bodies soluble and diffusible. The change to peptones is not a single step, for the protein passes through successive stages as acid proteins and proteoses before it reaches the peptone form. This is largely what may be styled progressive hydrolysis. Another ferment present in the gastric juice is the one which gives to rennet its value as a means of coagulating the casein of milk in cheese-making, and is called rennin. The action of this latter body is especially prominent in the stomach of the calf when fed exclusively on milk, and it is the calf's active stomach, the fourth in the mature animal, which is the source of commercial rennet. Lipase, an enzym that acts in the fats, is also possibly present in the gastric juice of herbivoræ. (See Par. 129.)

147. Hydrochloric acid essential in stomach digestion.-The free hydrochloric acid in the gastric juice is also actively concerned in protein digestion. It is found that a solution of pepsin has a limited effect in the absence of free acid, for when, during artificial digestion, the supply of this acid is used up, it must be renewed or digestion is checked.

148. The stomachs of the horse and pig.-These consist of a single sac, so that digestion with these animals is 
a much simpler matter mechanically than with ruminants. Chemically, the results are essentially similar, i. e., the protein is in part changed to peptones. The food, after being swallowed, is not returned to the mouth, but is very soon brought under the action of the gastric juice without so long-continued preliminary preparation by remastication and trituration. For this reason the horse fails to digest coarse fodders so completely as the ox does. Besides, the stomachs of the horse and pig are too small to admit of so large an ingestion of hay or similar material, as is the case with ruminants of similar size. In all species, however, the chemical result of stomach digestion is

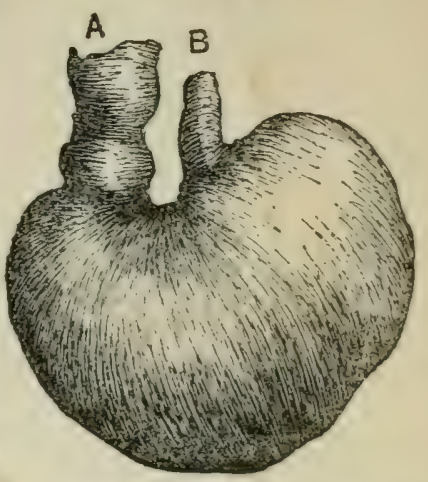

FIG. 3. Stomach of horse. $B$, esophageal attachment; $A$, pyloric end of stomach, with beginning of small intestine. essentially the same, i. e., the protein is in part changed to peptones. (Fig. 3.)

\section{THE INTESTINES}

The most extended portion of the alimentary canal, though not the most capacious in all cases, is the intestines. They consist of a tube differing in size in its various portions, which begins with the stomach and ends with the anus.

149. Form and length of intestines.-This tube is not a straight passage between the points named, but presents curves and folds, so that when straightened out it appears surprisingly long. Its average length with the ox is given as 187 feet, sheep 107 feet, horse 98 feet, and 
hog 77 feet, lengths which are from twelve to twenty-six times that of the body of the animal. The intestines are divided into large and small, the latter being from three to four times as long as the former.

150. Food in the small intestine.-When the food leaves the stomach, it enters the small intestine. At this point it is only partially digested. The fats are probably so far mostly unchanged and, without doubt, the larger proportion of the proteins and carbohydrates that are susceptible of digestion is still in the original condition. Hardly has this partially dissolved material passed into the small intestines before it comes in contact with two new liquids which are poured on it simultaneously or nearly so, viz., the bile and the pancreatic juice, and the changes which began in the mouth and stomach, with others which set in for the first time, proceed vigorously.

151. The bile.-The bile has its source in the liver. It is a secretion of this organ, and after elaboration a reserve is stored, until required, in a small sac attached to the liver which is called the "gall bladder." Gall is conveyed to the intestines through a duct opening very near the orifice leading out of the stomach. The rate of secretion of bile, according to experiments by Colin, is as follows: Horse, eight to ten ounces an hour; ox, three to four ounces an hour; sheep, one-fourth to five ounces an hour; pig, two to five ounces an hour. The secretion and flow of bile are continuous but the flow is not uniform. Bile is a liquid varying when fresh from a golden red color in man to a grass-green or olive-green in certain herbivorous animals. It is alkaline, bitter to the taste and without odor. The specific and characteristic constituents of the bile are two acids, glycocholic and taurocholic, that are combined with sodium and are associated 
with two coloring matters, bilirubin and biliverdin. Numerous other compounds are present in very small proportions, such as fats, soaps, and mineral compounds, but they appear to have no important relation to digestion. If any ferment is present at all, it is only as a trace, and therefore the bile is incapable of effecting decompositions of the proteins and carbohydrates, such as occur in the mouth and stomach.

152. Function of bile.-Nevertheless, this liquid must be regarded as having an important function, which it exerts in two ways, (1) by preparing the chyme (partially digested food from the stomach) for the action of the pancreatic juice and (2) it acts in conjunction with the pancreatic juice in preparing the fats for absorption.

Pepsin, the stomach ferment, acts upon proteins only in an acid medium. The opposite is true of the ferments which the food meets in the intestines, for these require an alizaline medium. The bile neutralizes the acidity of the chyme, and so prepares the way for the pancreatic juice to do its work. It is shown that when the entrance of the bile into the intestines is prevented the fat of the food largely passes off in the feces.

Bile has very little, if any, direct digestive action, but it may be said to coöperate with the pancreatic juice in accomplishing the digestion of fats. It emulsifies fats, especially in the presence of the pancreatic juice. When the fats are split by a ferment in the pancreatic juice we get as a result fatty acids which combine with the alkalies present to form soaps. Both the fatty acids and the soaps are dissolved by the bile. In this way the fats are prepared for absorption. In experiments by Vail on dogs, cutting off the supply of bile reduced the absorption of fat from 99 to 40 per cent. 
It has been asserted that the bile has more or less antiseptic influence and so prevents the intestinal contents from undergoing putrefactive fermentation. A more rational explanation is that because the bile acts as a natural purgative the food residues pass promptly out of the intestinal tract before the putrefactive fermentations set in which would occur in the absence of bile.

153. The pancreatic juice.-This secretion has the most comprehensive action on the food nutrients of any one of the intestinal liquids. It originates in the pancreas (sweetbread). Its flow is intermittent, being induced by the reaction especially of the acids in the partially digested foods from the stomach. The amount secreted and its composition appear to change with the kind of food. It contains with the horse about 98.2 per cent of water and 1.8 per cent of solid matter. With the dog the percentage of water is about 90 . This secretion acts upon all classes of nutrients, as it contains a variety of ferments greatly unlike in function.

154. The enzyms of the pancreatic juice.-The three enzyms present in the pancreas secretion are: a proteinsplitting enzym, trypsin (or its progenitor), a starchsplitting enzym, amylopsin, and a fat-splitting enzym, steapsin. Trypsin, like pepsin, hydrolizes the protein by progressive stages to proteoses, then peptones, after which, in conjuction with erepsin (see later), breaks the peptones into simpler bodies known as the amino acids. (See Par. 84.) Trypsin acts in neutral or in alkaline solutions, a free mineral acid like hydrochloric completely stopping its operation. Organic acids, like lactic, do not seem to have this effect.

155. Steapsin.-The pancreatic secretion acts vigorously on fats, not only splitting them into fatty acids and 
glycerin, but, in conjunction with the bile, also effects their emulsification, this latter result being aided, doubtless, by the soaps which are formed from a union of the fatty acids and the alkaline bases (mostly sodium) in the bile. The clearage of the fats is due to an enzym to which the name of steapsin is given, also called "lipase." (See Par. 128.)

156. Amylopsin.-We have seen that starch is acted upon to a small extent by the saliva, and that this action is not prolonged in the stomach beyond the time when the stomach contents become fully acidified. Starch digestion is therefore carried on mainly in the intestines, chiefly, if not wholly, by a diastatic ferment in the pancreatic juice which has the power of hydrolyzing the starch mostly into maltose. This pancreatic diastase, called amylopsin by some authors, is not found in the digestive tract of young animals as abundantly during the period of milk-feeding as after vegetable foods are taken, for milk does not require the action of a diastatic ferment. The presence of bile is very favorable to the action of amylopsin. (See Par. 128.)

157. Intestinal juices.-Mention has been made of juices that are secreted by small glands distributed in the walls of the small intestine. These are quite important factors in digestion, as they supplement the action of the ferments of the pancreatic juice. It appears to be shown that an enzym, erepsin, is found in these juices that is unable to act upon any of the native proteins except casein, but has the power of decomposing proteoses and peptones into simpler compounds, particularly the amino-acids. These secretions contain, also, the ferments that hydrolize sucrose, maltose, and lactose into dextrose. It is held also that trypsin does not exist as such in the 
pancreatic juice when poured into the small intestine, but that this enzym is formed from a mother substance in the pancreatic juice (trypsinogen) after it comes in contact with the intestinal juice, this result being accomplished through the action of a body probably secreted from the intestinal walls and called by Pawlow "enterokinase." (See Par. 154.)

158. Intestinal bacteria.-So far, in presenting the relation of ferments to digestion, only the unorganized ferments or enzyms have been considered. While these are chiefly concerned in normal digestion, organized ferments are present throughout the entire intestinal canal and play a part in food changes. They are very abundant and active in the rumen and large intestine. They act upon the proteins, causing putrefaction, dissolve cellulose, and cause a decomposition of the carbohydrates. The products of these fermentations include, among other compounds, indol and skatol, which have the characteristic fecal odor, volatile fatty acids, and gases, some of which are carbon dioxid, hydrogen, marsh gas and hydrogen sulfide. The evolution of these gases appears to occur constantly and normally with farm animals, particularly the bovines, the quantity depending somewhat upon the kind of food. (See Par. 127.)

159. Effects of intestinal fermentations.-Under certain conditions, fermentations of this character, which are in part normal and may be beneficial, proceed so far as to be deleterious. Gorging with a very succulent food, such as immature clover, after a period of dry foods, or anything which retards digestion, such as imperfect mastication, excessive eating, and failure of the organs secreting the digestive fluids to supply these fluids in sufficient abundance, give these bacteria a better oppor- 
tunity to act on the food residues, and increase their effect. Recent results appear to indicate that the synthetic activities of intestinal bacteria may be a matter of some importance in the utilization of amides (Par. 273).

160. Stimuli to digestion.-The gastric juice is not constantly poured into the stomach to accumulate there, but is secreted as it is needed under the influence of certain stimuli. These stimuli may be classed as psychic and chemical. Appetizing odors when there is a strong desire to eat, and the agreeable taste of food in the mouth of a hungry person are important psychic or "nervous" influences that promote gastric digestion through stimulating the secretion of an adequate supply of the digesting fluid. Other stimuli that may be called chemical result from the indirect reaction of certain substances upon the secretory glands. With man, meat extracts, proteoses, acids, sugars, alcohol, and condiments seem to be effective in this way. This stimulus comes later than the psychic, but is more prolonged.

161. Secretins.-The more recent researches indicate that the first products of digestion, reacting on the inner membranes of the stomach and duodenum, cause the formation of substances called secretins that belong to the general class of excitants known as hormones, which, carried by the blood stream to the cells of secretory glands, excite the secretion of the digestive juices. It now seems possible that sometime we shall have a definite dietetic method of influencing human digestion, at least, other than a medicinal, for it appears that certain food compounds may stimulate and others retard the activity of digestion.

162. The psychic factor.-The psychic factor is no less important. This being so, it is seen how necessary it is that eating shall be pleasurable. Satisfaction with the 
diet, even with an animal, undoubtedly is a determinative element in good digestion. Moreover, condimental stimulation is a poor makeshift for the effect of a healthy liking for food. There are good reasons for believing that psychic stimulation is an important factor in digestion with farm animals. Whether the theory of chemical stimuli applies to this class of animals is less certain.

163. Digestion of food as a whole.--From what has preceded we learn that several liquids and certain organisms participate in producing the complex changes that food undergoes during digestion. Some of these liquids have certain common functions, as, for instance, proteins are acted upon both by the gastric and pancreatic juices. Moreover, the various digesting fluids appear to act coöperatively. This is made plain by following the course of the food changes.

164. Stomach digestion.-After the food has remained in the stomach for a certain period of time, it is gradually discharged into the small intestine, the rate of discharge varying with the kind of food, that is, with the promptness and rapidity of digestion, which differs with different foods. The progress made up to this point in food transference, so far as we have definite knowledge, is chiefly the cleavage of the proteins into various stages of hydrolysis, the resulting bodies being proteoses and peptones. All proteins appear to be acted on in the stomach, but to different degrees and probably at different rates. Starch, already somewhat dissolved by the saliva, is not further acted upon by the stomach enzyms, neither are the solid and liquid fats affected to any material extent. Simple sugars are not acted upon by the gastric juice, but it seems possible that the di-sugars may be split into simple cnes by the hydrochloric acid. 
165. Digestion in intestines. - It appears, then, that in the intestines protein digestion must be completed with the cleavage of peptones into the simpler amino acids, the larger part of the starch transformed to sugar and the digestion of the fats wholly accomplished or mainly so. As a matter of fact, the partial solution in the stomach of the proteins and the swelling of the undissolved part to a gelatinous mass may be considered as a preparation of the food for intestinal digestion, for through these changes the proteins present a larger surface to the attack of trypsin and other intestinal enzyms and digestion proceeds more promptly than would be the case with the freshly ingested food. Moreover, the compounds in the chyme, especially the acid, indirectly react on the liver and pancreas, and cause an abundant flow of digestive fluids from these glands.

166. Digestive fluids act together.-As soon as the chyme mixes with the bile and pancreatic juice, the mass is changed from an acid to an alkaline condition. This seems to be essential to the effective operation of the pancreatic ferments. While the pancreatic juice will carry on digestion by itself, this is not satisfactory in the absence of bile, one reason for this being that when the latter is not permitted to enter the small intestine, the digestion of fats is very imperfect. It seems essential that these two liquids act together. The bile aids in rendering the digesting mass alkaline, contributes to the formation and solution of the fatty acids and soaps, and in these ways promotes the activity of the pancreas enzyms.

167. Action of intestinal juices.-The juices that flow from the small glands in the intestinal walls appear essentially to supplement the work of the bile and pancreatic juice. In the first place, they probably contain a 
substance that activates the mother substance of trypsin; in the second place, they aid in splitting the peptones into simpler bodies, and, lastly, they convert certain sugars into the final form (dextrose) in which they are absorbed into the blood circulation.

168. Summary of changes in digestion.-If we consider the digestion of the food compounds by classes, the following is a summary of the ways in which they are acted upon: pepsin, trypsin, and erepsin secreted by the stomach, pancreas, and intestinal glands act on the proteins; ptyalin in the saliva, amylopsin from the pancreas, and lactase, maltase, and sucrase in intestinal secretions act on the carbohydrates, and the fats are acted on mainly by the lipase of the pancreatic juice.

The bacteria are not surely known to have necessary specific digestive functions, unless it be their solvent action on the cellulose.

It should be observed that the above is a presentation of the general scheme of digestion, and takes no account of differences between the various species of farm animals of which our knowledge is incomplete.

\section{ABSORPTION OF FOOD}

From the time the food enters the stomach, during nearly its entire course along the alimentary canal, there is a constant production of soluble compounds, which progressively disappear into other channels, so that when the anus is reached only a portion of the original dry matter is found in the residue. In some way, not wholly explainable in all its details, the digested food has been absorbed and received into vessels through which it is distributed to the various parts of the body. 
169. Function of lacteals and blood vessels in absorption (Figs. 4, 5).-A merely casual observation shows us that the inner surface of the walls of the small intestine is covered by numerous projections, called villi. In these are imbedded the minute branches of two systems of vessels,

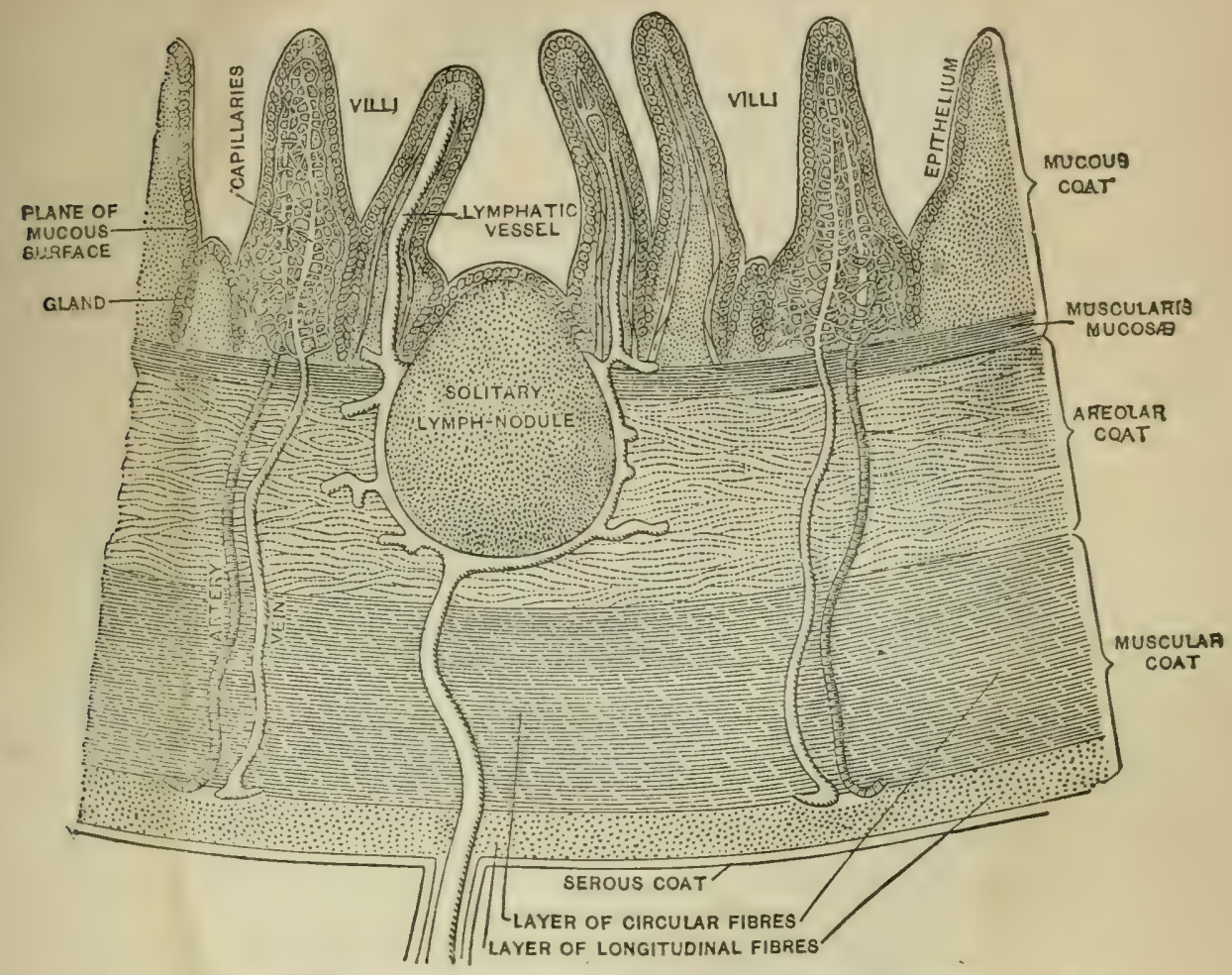

Frg. 4. Cross-section of mucous membrane of small intestine of man, showing capillaries and lacteals. (Gerrish.)

the lacteals, belonging to the so-called lymphatic system, and the capillaries, which are minute branches of the blood system. The lacteal is in the center of each villus and this is surrounded by a network of capillaries. The lymphatic vessels lead to a main tube or reservoir, the thoracic duct, which extends along the spinal column 
and finally enters one of the main blood vessels. Any material, therefore taken up by the lacteals ultimately reaches the blood. The capillaries all converge to a larger blood vessel, known as the portal vein, which enters the liver, transferring to that organ whatever material the capillaries have absorbed.

170. Manner of food absorption.-The manner in which the soluble food is absorbed has been explained in

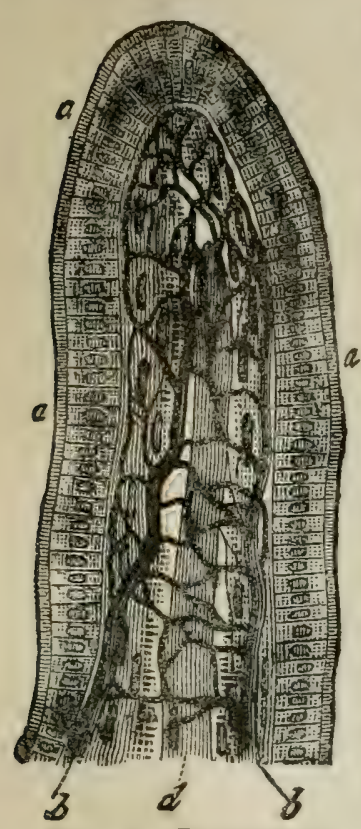

FIG. 5. Intestinal villus, showing: $a$, epithelium; $b$, capillaries; c, lacteal vessels.

part on common physical grounds. When two solutions of different densities, containing diffusible compounds, are separated by a permeable membrane, diffusion through this membrane from the denser to the lighter liquid will always occur. Such a condition as this prevails in the intestines, we may believe. The intestinal solution, the denser one, is separated from a less concentrated liquid, the blood, which is constantly flowing on the other side of a thin dividing membrane. Under these conditions there occurs the passage into the blood of certain parts of the digested food. It is held that in this way water, soluble mineral salts, and sugar pass directly into the blood vessels, chiefly from the small intestine.

171. Changes in the walls of the intestinal tract.In the absorption of peptones and fats, at least, forces are encountered other than the osmotic transference of substances in solution, the operation of which is still more or less unexplained. 
The ingested proteins are changed in the stomach and intestines to peptones, and in part, perhaps mainly, to amino acids resulting from the cleavage of peptones. The fats are split partly, or entirely, into fatty acids and glycerin, with the subsequent formation of soaps by the union of the free acids with alkaline bases. It has been held that in the passage of these new compounds through the walls of the intestine changes occur of a synthetical character, with a partial or total reconstruction of the proteins and fats into forms similar to those in the ingested food. This view as to the proteins has been modified somewhat by the demonstration of the existence of amino acids in the blood showing that, if a synthesis of proteins occurs in the intestinal walls, it is at least not complete. Amino acids may exist in the blood even if synthesis occurs in the intestinal walls. The rebuilding of fats and their transference into the lacteals is regarded as being accomplished through the activity of cells lying in the mucous lining of the intestine. This seems to be proven. It seems, then, that the vital forces residing in these cells probably play a part in the transfer of the nutrients into the blood circulation, and that this absorption can not be explained wholly on the basis of osmotic pressure.

172. Place of maximum absorption of food.-Absorption of digested food takes place to a limited extent from the stomach of man and the dog, but not from the stomach of the herbivora. The main transference of the products of digestion irto the blood is from the intestines, particularly the small intestine. Much of the water that passes into the large intestine is absorbed there, together with the products of digestion not already absorbed and those products that result from bacterial action. 


\section{THE FECES}

The soluble and insoluble portions of the intestinal contents become separated gradually, and the undissolved part arrives finally at the last stage of its journey along the alimentary canal, and is expelled as the solid excrement, or feces.

173. Constituents of feces.-The feces is made up of the undigested food, residues from the bile and other digestive juices, mucus, and more or less of the epithelial cells which have become detached from the walls of the stomach and intestines. Dead and living bacteria also appear to constitute a material portion of the fecal matter. These organisms are not taken in with the food to any great extent, but are the result of their continuous growth in the digestive tract. Small quantities of fermentation products, particularly indol and skatol, are present, which give to the feces its offensive odor. The incidental or waste products may properly be considered as belonging to the wear and tear of digestion.

174. The feces not wholly undigested food.-The ordinary conception of the fecal residue is that it is only the part of the food that has resisted the action of the digestive fluids, but in fact it is much more than that. Not only does it include the various waste products previously referred to, but also compounds that have been absorbed into the blood circulation and returned to the alimentary canal for excretion. It has been shown, for instance, that when a phosphorus compound was injected subcutaneously into a sheep, the phosphorus was excreted in the feces in another combination. It is also proven that mineral compounds absorbed from the intestinal tract may afterward appear in the feces. 
The physical condition of the feces is characteristic with each species of animals, the differences in consistency being due largely to variations in the amount of water present. The amount of water in feces depends more upon the character of the food eaten than upon the amount of water drunk.

THE RELATION OF THE DIFFERENT FOOD COMPOUNDS TO THE DIGESTIVE PROCESSES

Numerous digestion experiments with a large variety of foods have abundantly established the fact that these materials differ greatly in their solubility in the digestive juices. This is an important matter, and one which should be well understood, for we must consider both the weight of the dry matter eaten and its availability in determining its nutritive value. Variations in digestibility are caused primarily by variations in composition; therefore, we must deal fundamentally with the susceptibility of the various single constituents of food to the action of the several digestive ferments.

In this connection, we need to pay little attention to the mineral compounds that exist in the inorganic form in the food. They do not undergo fermentative changes in the way that the carbon compounds do, but are brought into simple solution either in the water accompanying the food, or in the juices with which they come in contact.

175. Digestibility of the proteins.-As has been noted, protein is a mixture of nitrogenous compounds. The gluten of wheat contains at least five of these bodies, and other seeds as many. What is the relative susceptibility of these single proteins to the digestive enzyms either as to rapidity or completeness of change does not appear to be known. 
Some proteins are pratically all digested by artificial methods, and probably are in natural digestion. It is known definitely that protein is much more completely dissolved from some foods than from others. That of milk and meat is practically all digestible, that of some grains very largely so, while with the coarse foods quite a large proportion escapes solution. Whether this is due to differences in the characteristic protein compounds of the various foods is not quite determined. The fact that highly fibrous materials show the lowest proportion of digestible protein suggests as an explanation that the nitrogen compounds of plant tissue are so protected by the cell-walls that they escape the full action of the digestive juices. It is certain, however, that the protein in plant tissue is less fully digested than that from milk and meat products.

176. Digestibility of the carbohydrates. - In the case of the carbohydrates, our knowledge of the relative susceptibility of the individual compounds to enzym action is more definite. First of all, the necessary modification of the sugars, which are already soluble, is slight, and they are wholly digested. In the second place, we have learned in two ways that the starches are wholly hydrolized, first by submitting them in an artificial way to the action of various diastatic ferments, and, second, by discovering a complete absence of starch or its products in the normal feces. Under normal conditions the unprotected starches, like the sugars, are completely digestible.

177. Starches unlike in rate of digestibility.-Digestibility must be considered, however, from the standpoints both of rapidity and of completeness. As to the former factor, starches from unlike sources exhibit some remarkable differences. Investigations by Stone, who sub- 
mitted a number of these bodies to the action of several diastatic ferments, show that "this variation reaches such a degree that, under precisely the same conditions, certain of the starches require eighty times as long as others for complete solution." The potato starches appear to be acted upon much more rapidly than those from the cereal grains.

178. Digestibility of cellulose and gums.-Other carbohydrates, cellulose and hemicelluloses, such as pentosans, galactan mannan, and related bodies, show great variations in digestibility according to their source, these variations ranging in observations by Swartz from 0 to 100 per cent. The extent to which these latter substances disappear from the alimentary canal appears to be dependent on their susceptibility to attack by bacteria.

179. Digestibility of the fats.-The actual extent of the digestion and absorption of the fats or oils is also not definitely known. If we were to accept the figures given for ether-extract in tables of digestion coefficients as applying to the real fats, we would believe that their digestibility varies from less than one-third to the total amount. It is unfortunately true that these coefficients mean but very little. The ether-extract from some foods is only partially fat or oil, as we have seen, and the inaccuracy of a digestion trial is still further aggravated by the presence in the feces of bile residues and other bodies which are soluble in ether, so that the difference between the ether-extract in the ingested food and that in the feces does not give accurate information as to what has happened to the actual fats. It seems very probable that pure vegetable fats and oils and all mixed animal fats are quite completely absorbed. 
The foregoing statements make it plain that when the general composition of a food is known, it is possible to predict with a good degree of certainty whether its percentage of digestibility is high or low. Feeding-stuffs with a high percentage of starch and sugar and a small percentage of fiber have a relatively high digestibility, as, for instance, corn meal, while the coarse foods like timothy hay and straw, with a high proportion of gums and fiber, have a relatively low digestibility.

\section{FACTORS WHICH MAY INFLUENCE DIGESTION}

Digestion has an important relation to the nutritive efficiency of food because only that portion of the food that is digested and absorbed can serve the purposes of growth and the maintenance of the vital functions.

180. Meaning of "digestibility."-In discussing the factors that may influence the digestion of food, it is essential to understand clearly what is involved in the term digestion as it is used in science and in common speech. This term includes at least two elements, completeness of solution of the food nutrients and rate of digestion. The figures that are given for the digestibility of various cattle foods refer to the completeness or extent to which the food is dissolved and transferred to the circulation. But different foods from which come the same proportion of undigested dry matter may differ materially in the rate at which they undergo digestive changes, and in this sense their digestibility is unlike. The ultimate completeness of solution in the digestive fluids may not be influenced by the rate at which the process goes on. 


\section{CHAPTER VIII}

\section{CONDITIONS INFLUENCING DIGESTION}

THE chemical changes and other phenomena constituting digestion, which have been described as occurring in the alimentary canal, are practically outside the control of the one who feeds the animals. They proceed in accordance with fixed chemical and physiological laws. It is, however, within the power of the feeder to so manipulate the food or vary the conditions under which it is fed that the extent or completeness of digestion is modified, and this must be regarded as an important matter when we remember that only the digested food is useful.

181. Palatableness. - It is entirely reasonable to believe that a thorough relish for food is conducive to good digestion. The secretion of the digestive juices is not a mechanical process, but is partly under the control of the nervous system. With man, at least, the enjoyment of eating, even its anticipation, stimulates the secretory power of the salivary glands and those in the mucous lining of the stomach, and it is evident that this holds true with animals. Palatableness is, therefore, an important factor in successful feeding, for it tends to promote a state of vigorous activity on the part of the digestive organs. The experienced feeder knows well the value of stimulating the appetite of his animals by means of attractive mixtures. An agreeable flavor or taste adds nothing to the energy or building-capacity of a food, but 
it does tend to secure a thorough appropriation of the nutrients which enter the alimentary canal. Without doubt, the success of one feeder as compared with the failure of another may sometimes be due, in part, to a superior manner of presenting a ration to the animal's attention and to manipulations that add to the agreeableness of its flavors. (See Par. 162.)

182. Influence of quantity of ration.-Early experiments by Wolff, in which he fed larger and smaller rations of the same fodder to the same animals, have been made the authority for the statement that a full ration is as completely digested as a scanty one, provided the former does not pass the normal capacity of the animal. It must be said, however, that the testimony concerning this point is not unanimous. Since Wolff's experiments, Weiske, in feeding oats to rabbits, found the digestibility to be inversely as the quantity of food taken. In experiments with oxen, by G. Kuhn, at Möckern, when the grain ration was doubled the digestibility of the malt sprouts used was decreased about 9 per cent. Results at the New York Experiment Station from feeding full and half rations to four sheep showed uniformly higher digestion coefficients with the smaller ration, the differences being too large and too constant to be considered accidental. Other experiments give varying and conflicting figures. If we assume that the constituents of feeding-stuffs have a certain fixed solubility in the digestive fluids, then within reasonable limits the amount of food should have no effect upon the proportions of nutrients digested, but such an assumption cannot safely be made.

Doubtless no single statement concerning this point will be found applicable to all animals and all rations. 
Certainly, over-feeding may lessen the extent of solution and is never wise, while under-feeding for the sake of securing a maximum digestibility would not be good practice. It is reasonable to suppose, however, that the relation in quantity between the enzyms and the food compounds has an influence, at least, upon the rapidity of digestion; and indeed investigations by Stone very strongly point to such a conclusion, for he found that the rate of ferment action was proportional to the concentration of the ferment solution.

183. Effect of drying fodders.-At one time the belief became very firmly fixed in the public mind that curing a fodder causes a material decrease in its digestibility. Because this drying is often carried on under conditions that admit of destructive fermentations or of a loss of the finer parts of the plant, this riew is probably correct for particular cases; but, if it is accomplished promptly and in a way that precludes fermentation or loss of leaves, it is doubtful if curing has any material effect upon digestibility.

The point has been the object of six American digestion experiments, Hungarian grass, timothy, pasture grass, corn fodder, crimson clover, and winter vetch being the experimental foods. With four of these, slight but unimportant differences were observed in favor of the dried material, while the reverse was decidedly true of the crimson clover and the corn fodder. German experiments show in a majority of cases greater digestibility for the green fodders. It seems probable that in general practice, because of greater or less unavoidable fermentations and a loss of the finer parts of the plant, dried fodders have a somewhat lower rate of digestibility than the original green material, a fact not due directly to drying, but to 
a decrease, either of the more soluble compounds or of the tender tissues. (See Par. 306.)

184. Influence of the conditions and methods of preserving fodders.-In comparing the conditions and methods of preserving fodders in their relation to digestibility, we may safely rest upon the general statement that when, for any cause, leaching occurs or fermentations set in, digestibility is depressed. The explanation of this statement is that those compounds of the plant which are entirely soluble in the digestive fluids, notably the sugars, are the ones wholly or partially removed or destroyed by leaching or fermentations, while the more insoluble bodies remain unaffected. When, therefore, hay is cured under adverse conditions, such as long-continued rain, digestibility is decreased, and the same effect is inevitable from the changes which occur in a fermenting mass, such as a mow of wet hay, a pile of corn stalks or the contents of a silo. Experimental evidence of the truth of these statements is not wanting. German digestion trials with alfalfa and esparsette, green, carefully dried, cured in the ordinary way, fermented after partial drying and as silage, show a gradually decreasing digestibility from the first condition to the last. A single American experiment, comparing the same fodder both green and as silage, gives testimony in the same direction. On the other hand, field-cured corn fodder, according to nine out of eleven American experiments, is considerably less digestible than silage coming from the same source, although the results of field curing vary greatly according to the conditions of exposure. Here it is largely a question of the relative loss by fermentation in the two cases, and it is to be expected that the outcome would not be wholly one way. 
185. Influence of the stage of growth of the plant.Another generalization, which certainly must hold good with reference to the digestibility of fodder plants, is that any conditions of development which favor a relatively large proportion of the more soluble carbohydrates, viz., starches and sugars, and accompanied by a minimum of gums and fiber, promote a high rate of digestibility, and reverse conditions produce the opposite result. It is well known that, in general, as the meadow grasses mature the relative proportion of fiber increases and the tissue becomes harder and more resisting. Numerous American and European digestion trials unite in testifying almost unanimously to a gradually diminished digestibility as the meadow grasses increase in age. The maturing of maize seems to produce quite the contrary effect. The testimony of experiments conducted at the Connecticut, Maine, and Pennsylvania experiment stations justifies the statement that the corn plant, cut when the ears are full-grown, furnishes not only a larger amount of digestible material, but a larger relative proportion than when cut before the ears have formed; and this is strictly in harmony with our general principle, for the mature plant, on account of the storage of starch in the kernels, has by far a larger proportion of the more digestible carbohydrates. (See Par. 102.)

186. Influence of methods of preparation of food.Much labor and expense have been expended by farmers in giving to feeding-stuffs special treatment, such as wetting, steaming, cooking and fermenting, in order to secure a supposed increase in nutritive value, an increase which must come chiefly, if at all, from a more complete digestion. It is plainly noticeable that these methods of feeding have lost in prevalence rather than gained. 
Practice does not seem to have permanently ratified them, and, so far as digestibility is concerned, this outcome is in accordance with the results of scientific demonstration. The conclusions of German experimenters have been that these special treatments have no favorable influence, their effect being either imperceptible or unfavorable.

187. Wetting food.-It should occasion no surprise that the mere wetting of a food is without influence upon its solubility in the digestive juices, because it becomes thoroughly moistened during the mastication and in the stomach. It is not rational to expect that previous wetting would have the slightest effect unless it induced more complete mastication, which certainly would not be the case with ground grains. The extensive trials by Kühn and others with a hay and bran ration, the bran being fed in several conditions, such as dry, wet, moistened some hours before feeding, treated with boiling water, and fermented, gave results adverse to all of the special methods of preparation as either useless or harmful, and no testimony so thorough and convincing has been furnished on the other side.

188. Cooking foods.-German and American experiments unite in condemning the cooking of foods already palatable, because this causes a marked depression of the digestibility of the protein, with no compensating advantages. Digestion trials with cooked or steamed hays, silage, lupine seed, corn meal and wheat bran, and roasted cotton seed, uniformly show their protein to be notably less digestible than that in the original materials, a fact which may explain the lessened productive value of cooked grains which has been observed in certain experiments. It must be conceded, of course, that when 
cooking feeding-stuffs by steaming or otherwise renders them more palatable, and thereby makes possible the consumption of material otherwise wasted, the influence upon digestibility is a minor consideration.

189. Influence of grinding foods.-Few points are more frequently questioned than the profitableness of grinding grain. There seem to be only two ways in which such preparation can enhance the nutritive value of a feeding-stuff, viz., by diminishing the energy needed for the digestive processes and by increasing the digestibility. While not many experiments bearing upon the digestion side of this question are on record, their evidence is quite emphatic. In three trials with horses, with corn and oats, grinding caused an increase of digestibility varying from 3.3 to 14 per cent. A single experiment with maize kernels gave a greater digestibility of about 7 per cent from grinding, and with wheat, in one trial, the increase was 10 per cent. In one test with sheep, the unground kernels were as completely utilized as the ground. It is reasonable to expect that with ruminants the danger of imperfect mastication is less than with horses and swine, although whole kernels of grain are often seen in the feces of bovines. The profitableness of grinding grain turns, in part at least, upon the relation of the cost of grinding to the loss of nutritive material from not grinding. If the miller's toll amounts to one-tenth the value of the grain the economy of grinding it may be doubtful, especially with ruminants. The utilization of the undigested kernels of grain by pigs is a business point to be considered.

190. Effect of common salt.-It is the custom of many feeders to allow their animals an unlimited supply of salt, and others furnish it in definite and regular quan- 
tities. The belief prevails more or less widely that an abundant consumption of salt is beneficial. If this is true, the advantage arises for other reasons than an increased digestibility. The verdict from earlier experiments by Grouven, Hofmeister, and Weiske that the addition of salt to the ration does not increase the digestibility was confirmed through later tests by Wolff. Indeed, if we give to the data collected a literal and perfectly justifiable interpretation, salt diminished rather than raised the proportion of digestible nutrients.

191. Influence of frequency of feeding and watering animals.-Experiments relative to this point are not numerous. One by Weiske and others, relative to frequency of feeding, and another by Gabriel and Weiske, in which the effects of the time of watering and of the amount of water were tested, gave no indication that the completeness of digestion is materially affected by variations in these details of practice. According to Smith, horses should be watered before being fed. He argues that water does not stop in the stomach but passes directly through it and freshly ingested food would be washed into the intestine before any stomach digestion occurs, an opinion which tallies with the popular view. On the other hand, Tangl asserts, on the basis of extended investigations, that horses may be watered either before or after eating without depressing digestion, except that a horse long deprived of water should be watered before eating. The thing chiefly important is that the plan of feeding and watering should not be varied. It seems probable that the nutritive importance of these minor points in managing animals has been much overestimated by some, especially as affecting the utilization of the food. 
192. Influence of season and storage.-It is well known that the composition of fodder crops grown on the same soil may vary somewhat from year to year according as the season is wet or dry, cold or warm. Such variations may influence digestibility, though no actual demonstration of this fact appears to be on record. The question is often asked whether the storage of hay for a long period affects its nutritive value. The data from four series of experiments touching on this point indicate that there is a perceptible, though not marked, decrease in digestibility of hay during long-continued storage.

193. Influence of the combination of food nutrients.Among the apparently important and freely exploited conclusions drawn from investigations in animal nutrition is the statement that the digestibility of food is influenced to a marked degree by the relative proportions of the several classes of nutrients. It is taught that if more than a certain percentage of starch and sugar, or of feeding-stuffs rich in carbohydrates, like potatoes or roots, is added to a basal ration, the digestibility of the latter is decreased, the protein and fiber being especially affected. The conclusions, as stated by Dietrich and König, on the basis of a critical study of the data involved are that if pure carbohydrates are used to the extent of more than 10 per cent of the dry substance of a basal ration, or if potatoes and roots are fed equivalent in dry matter to more than 15 per cent, a depression of digestibility occurs, which increases with the amount of carbohydrate material added. Kellner taught that if the crude protein in a ration falls below one part to eight of digestible non-nitrogenous nutrients (carbohydrates + fat $\times 2.25$ ) a depression digestibility occurs. It is suggested that when much easily digested carbohydrate material is 
fed the activity of the cellulose digesting bacteria is diverted from the crude fiber to the more readily available starches or sugars. A modifying conclusion is, that if the addition of the carbohydrate material is accompanied by correspondingly more protein, the depression of the digestion coefficients is much lessened or does not occur. Many data are cited in support of these generalizations which are worthy of careful consideration.

It is not unreasonable to suppose that the relative quantity in a ration of the several classes of nutrients may have an influence upon the digestive processes, and we should accept the verdict of previous observations in so far as they will bear critical discussion and further investigation. But it should be said, by way of comment, that the carbohydrate material in the experiments cited has usually been fed in addition to a basal ration, thus increasing the amount of food consumed, and, as we have seen, this may have an influence upon the proportion of total dry matter digested. In this particular, the experiments have not been logical. Again, in these experiments, no allowance has been made for the metabolic wastes in the feces, i. e., that material not belonging to the true undigested residue. As this appears to be independent of the amount of protein fed and stands more nearly in relation to the total digested nutrients, it follows that the smaller the proportion of protein in the digested food, the larger the error caused in the coefficient for protein by the waste nitrogen products. A careful study of this point in the light of more recent knowledge might modify the conclusion reached as to the depression of protein digestion through feeding starch or starchy foods. In all or nearly all the experiments where this effect is apparently shown, the digestible dry 
matter of the ration was largely increased and the protein remained constant or was diminished. However, the depression of the digestibility of the crude fiber is not easily explained on any other ground than that of the influence of the greater proportion of starch.

What is claimed as the effect of a disproportionate addition to the supply of carbohydrates does not appear to be true of a similar increase in the ration of fat and easily digested protein. Several experiments in which oils and albuminoids have been added freely to a basal ration did not indicate that such addition had any material effect upon digestibility.

194. Influence of work.-Such evidence as has been secured with both man and farm animal indicates that even severe labor has no material influence upon digestion one way or the other. Scheunert's work with horses leads him to conclude, however, that exercise improves digestion.

195. Influence of species, breed, age, and individuality.--The conclusion reached by the early experimenters in the field of animal nutrition that the digestive efficiency of the several species of ruminants was practically uniform has not been set aside by more recent observations. The number of experiments upon which this conclusion was based was large, and their verdict is not likely to be reversed by observations less extensive or less complete.

The following coefficients were obtained from German trials with meadow hay:

Dry Stbstance Digested from Meadow Hay (Per Cent)

\begin{tabular}{|c|c|c|c|}
\hline & Samples & Best & Medium \\
\hline & 42 & 67 & 61 \\
\hline Oxes & 10 & 67 & 64 \\
\hline Hors & 18 & 5 & 50 \\
\hline
\end{tabular}


In nine American experiments the digestive efficiency of large and small ruminants has been studied, steers being compared with sheep and cows with goats. In five cases, the large animal digested from 5 to 14 per cent the more, in three cases the excess for the small animal varied between 7 and 17 per cent, and in one case there was little difference. The general effect of such conflicting results is to confirm the older and more numerous observations.

196. Lower digestibility with horses for coarse foods. - The horse and ruminants differ in digestive capacity to a marked extent. The comparisons which have been made show a uniformly lower digestive efficiency for coarse fodders on the part of the former. It appears that because of less perfect mastication, or for some other reason, the horse dissolves much less of the crude fiber than the steer or sheep, and the effect of this is prominent with hays and other fibrous materials. With the grains, ruminant and equine digestion is not greatly unlike, eight samples of oats with sheep and twenty-four with the horse showing almost identical digestion of the dry matter. With maize the case is the same. In experiments with beans, the advantage was slightly with the ruminant. The difference between bovine and equine digestion is certainly least with highly digestible rations containing a minimum of fiber. So far as we are able to judge, swine digest concentrated food about as do ruminants. How this is in the case of fodders we do not know fully, but it is shown that the swine digest crude fiber quite freely.

Past experiments have not revealed any influence of breed upon digestive capacity. There is no reason for supposing that Shorthorn cattle, Southdown sheep, and 
Chester White pigs would digest rations differently from Jerseys, Merinoes, and Yorkshires.

Young animals seem to digest high-quality coarse foods and grains as efficiently as older ones of the same species, which is probably contrary to the popular belief. There is doubtless a variation in the digestive power of individual animals, but the data so far collected do not show this with any degree of definiteness. In those instances where the same four or more steers or sheep have been used in determining the digestibility of several feeding-stuffs, the highest coefficients were obtained sometimes with one animal and sometimes with another.

197. Determination of digestibility.-If we accept as the undigested food the dry matter of the solid excrement, which is practically in accordance with the fact, we have only to subtract the dry fecal residue from the dry matter of the ingested food in order to ascertain the amount and proportion digested. All digestion experiments have proceeded on this basis. Animals have been fed at regular intervals a uniform quantity of carefully analyzed food and the feces have been collected, weighed, and analyzed. From the data thus obtained, the digestion coefficients have been calculated. The method and the mathematics of such experiments are so simple that correct results seem very easy to obtain and they do possess an accuracy sufficiently approximate to truth to render them useful in practice. As digestion trials are usually conducted, the coefficients of digestibility obtained for the dry matter and total organic matter represent, we have reason to believe, very nearly the actual digestible matter in the particular material studied. The proportions secured for particular classes of nutrients may be less accurate, for reasons that will appear. We cannot 
be sure, either, that the digestibility of one hay applies to another produced and cured under totally different conditions. The truth of this latter statement is clearly seen in the effect of the various factors upon digestibility.

198. The inaccuracies of digestion coefficients.-The inaccuracies of digestion coefficients are in part those for protein and fats. The errors in the figures for protein are caused by the presence in the feces of nitrogen compounds which are not a part of the undigested food protein. (See Pars. 173, 174.) These are waste compounds which are residues from the bile and other digestive juices, epithelial cells and mucus which are carried along from the walls of the intestines during the passage of the food. Their quantity seems not to be proportional to the protein fed, but appears to be influenced more or less by the amount of food digested. Their source is in part the "wear and tear" of the digestive apparatus. It follows then that the less protein there is in a ration, the larger the percentage error caused by these metabolic products. In certain experiments with oat straw, the fecal nitrogen has been more than that of the food, although without question much of the straw protein was digested. It has been found, using the best methods known for extracting these waste products, that they cause a much larger error for the protein of the straws than for that of the legume hays. Under some conditions, at least, ten should be added to the coefficients of digestibility of the protein of coarse fodders as usually given in the tables that have been compiled.

Errors are caused in determination of the digestibility of fat in much the same way. Certain of the bile residues in the solid excrement are soluble in the ether which is 
used to extract the fats and consequently the undigested fat appears to be much larger than it really is.

Reference has been made to the return to the intestinal tract of material that was absorbed into the circulation and is in part returned to the intestines for excretion, as, for instance, the phosphorus of phytin and other compounds. Such material is not a part of the undigested food residue. 


\section{CHAPTER IX}

\section{THE DISTRIBUTION AND USE OF THE DIGESTED FOOD}

THE digested food, after absorption, all passes into the blood, either directly or indirectly, and mixes with it. The materials which are to serve the purposes of nutrition are now taken up by a stream of liquid that is in constant motion through the minutest divisions of every part of the animal. Flowing in regular channels the blood reaches not only the bones and muscular tissues, but it passes through several special organs and glands where the nutrients it is carrying and certain of its own constituents meet with profound changes. It is here that we discover the manner in which food is applied to use and what are some of the transformations which the proteins, carbohydrates, and fats undergo in performing their functions.

In order to follow intelligently this most interesting phase of nutrition, we must know something of the blood and of the organs-the lungs, liver, and kidneys-through which it passes.

199. The blood.-The blood, which makes up from 3 to 4 per cent of the total weight of the live animal, when in a fresh state, is apparently colored and opaque, but if a minute portion is examined with a microscope, it is seen to be a comparatively clear liquid in which float numerous reddish disk-like bodies. These bodies, which are known as corpuscles, give to the blood its bright red 
color. The liquid in which they are suspended is called the plasma.

200. The blood corpuscles (Fig. 6).-The corpuscles are not mere masses of unformed matter, but they are minute bodies having a definite form and structure. They make up from 35 to 40 per cent of the blood, and contain over 30 per cent of dry matter. This dry matter consists mostly of hemoglobin, a compound that is peculiar to the blood and equips it for one of its most important offices. Hemoglobin, when broken up in the absence of oxygen, is found to be made up of a protein (globinhistone) and a coloring matter

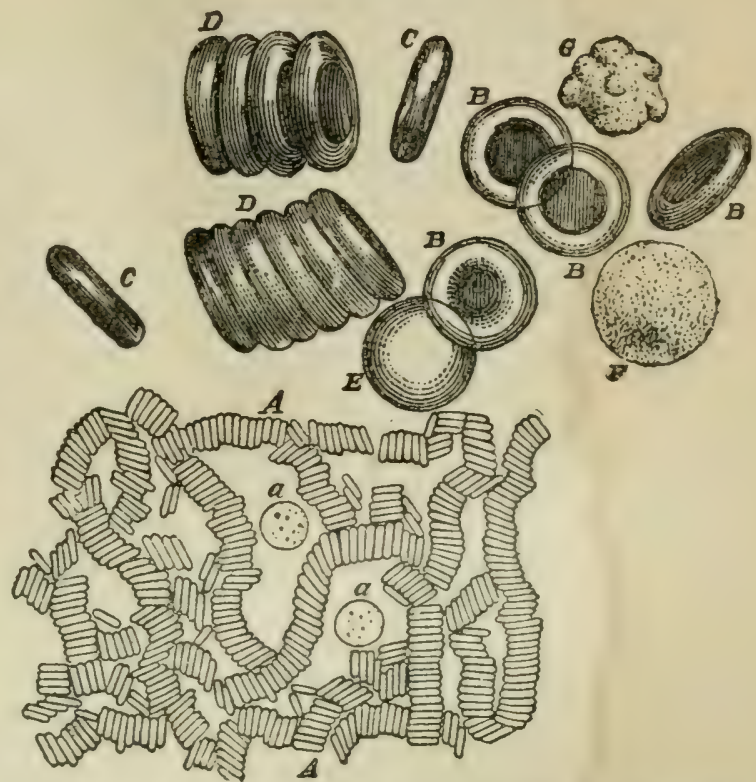

FIG. 6. Red and white corpuscles of blood (magnified). $A$, red corpuscles; $a, a$, white corpuscles; $B, C, D$, red corpuscles, more highly magnified; $F, G$, white corpuscles, more magnified.

(hemochromogen) in the latter of which is combined a definite proportion of iron. When broken up in the presence of oxygen we get globin and hematin, as hemochromogen when oxydized becomes hematin. The peculiar property of hemoglobin which renders it so useful a constituent of the blood is its power of taking up oxygen and holding it in a loose combination until it is needed 
for use. When thus charged, it is known as oxyhemoglobin. Because of this function of their most prominent constituent, blood corpuscles become the carriers of oxygen to all parts of the body. The blood corpuscles are also concerned in gathering up one of the waste products of metabolism, viz., carbon dioxid, and conveying it to the point where it may be thrown off from the body. (See Par. 77.)

201. The blood plasma.-The plasma is a liquid having a very complex composition. It is about ninetenths water, so that it easily holds in solution whatever soluble nutrients are discharged into it from the alimentary canal. Among its constituents are found members of all the classes of compounds that are important in this connection-ash, protein, carbohydrates, and fats. The proportion of ash is about 1 per cent, three-fourths of it being common salt, and the remainder consisting of phosphoric acid, lime, and other important mineral compounds. The solid matter of the plasma is rich in proteins, including the fibrinogen which is the mother substance of fibrin and several albumins and globulins. These proteins make up about 80 per cent of the total dry substance of plasma. Sugar and fats are also present, their proportions undoubtedly varying somewhat with the extent to which they are being absorbed from the digestion of food. It is evident that the blood is charged with those materials which we recognize as necessary to the construction and maintenance of the animal body.

202. The heart.-The blood is contained in the heart and in two sets of vessels, one set called the arteries leading from the heart by various ramifications to all parts of the body, and the other set called the veins, leading from all parts of the body back to the heart. Through 


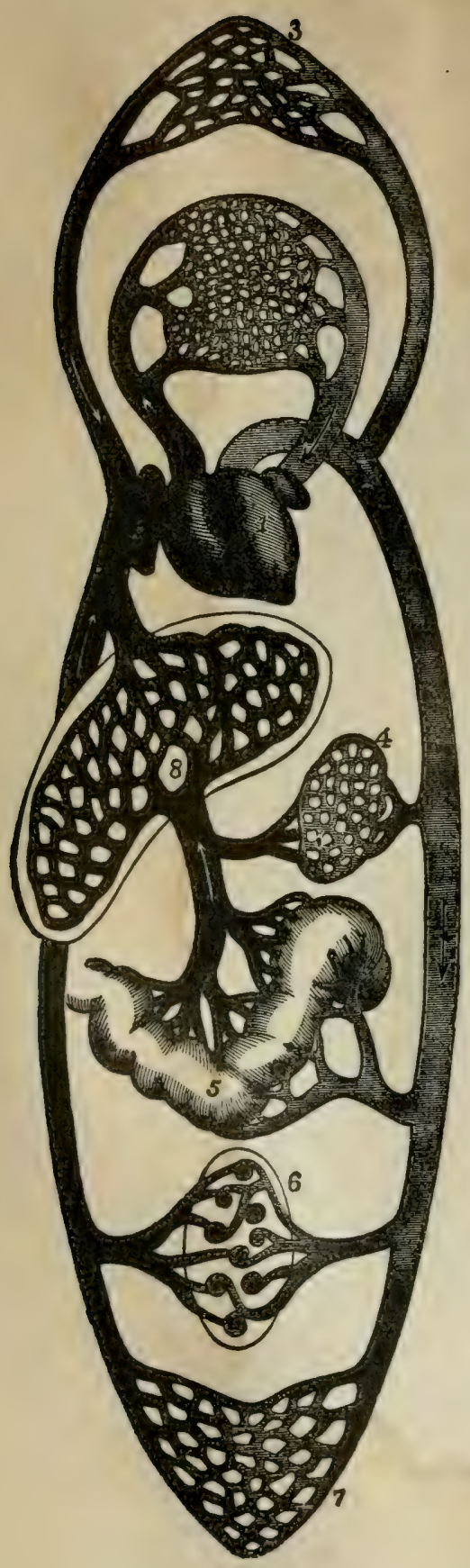

these vessels the blood is moving in a constant stream, which we call the circulation. It does not move of itself, but is forced along by a very powerful pump, the heart. This is a highly muscular organ divided into four chambers, which are separated by valves and partitions, the two upper chambers being called the right and left auricles, and the two lower the right and left ventricles. The right auricle is above the right ventricle and is separated from it by a valve, and the same is true of the left auricle and ventricle. (Fig. 7.)

203. Circulation of blood.Out of the left ventricle the blood is pumped into the arteries and, after reaching the arterial capillaries throughout the entire body, it passes from these into the smallest divisions of the veins and comes back to the heart along the venous system, entering the right auricle. It is then carried to the lungs by

FIg. 8. Diagram of circulation. 1, heart; 2 , lungs; 3 , head and upper extremities; 4 , spleen; 5 , intestine; 6 , kidney; 7 , lower extremities; 8 , liver. (Collins.) 
way of the right ventricle and is returned from the lungs to the left auricle to be sent to the left ventricle, and from there to again start on its journey through the body. (Fig. 8.)

The nutrients, as prepared for use by digestion, enter the blood on its return flow to the heart, coming into the venous cavity by way of the hepatic (liver) vein and the thoracic duct as previously described. When, therefore, the right side of the heart is reached, a new accession of food material is on its way to sustain the various functions of nutrition.

We are more interested in the object of blood circulation than we are in its mechanism. Somehow the digested food disappears into these constantly moving blood currents, and the only evidence of its effect which comes to us from ordinary observation is the warmth, motion, and perhaps growth of the animal that is nourished.

204. The lungs.-The first point where important changes occur is the lungs. Here the blood loses the purplish hue which it always has after being used in the body tissues and takes on a bright scarlet, a phenomenon that is more easily explained when we understand the lung structure. (Fig. 9.)

Breathing is a matter of common experience. We all know how air is drawn into the lungs at regular intervals, an equivalent quantity being as regularly forced out. The mechanism of respiration (breathing) we will not discuss at length. It will aid us, however, if we know that the passage which the air follows to and from the lungs, the trachea (windpipe), divides into two branches, one to each lung, and these divide and sub-divide until they branch into numerous fine tubes. Each of these tubes 
ends in an elongated dilation which is made up of air cells opening into a common cavity. These cells are so numerous in the lung tissues that only a very thin wall separates adjoining ones, and in this wall are carried the

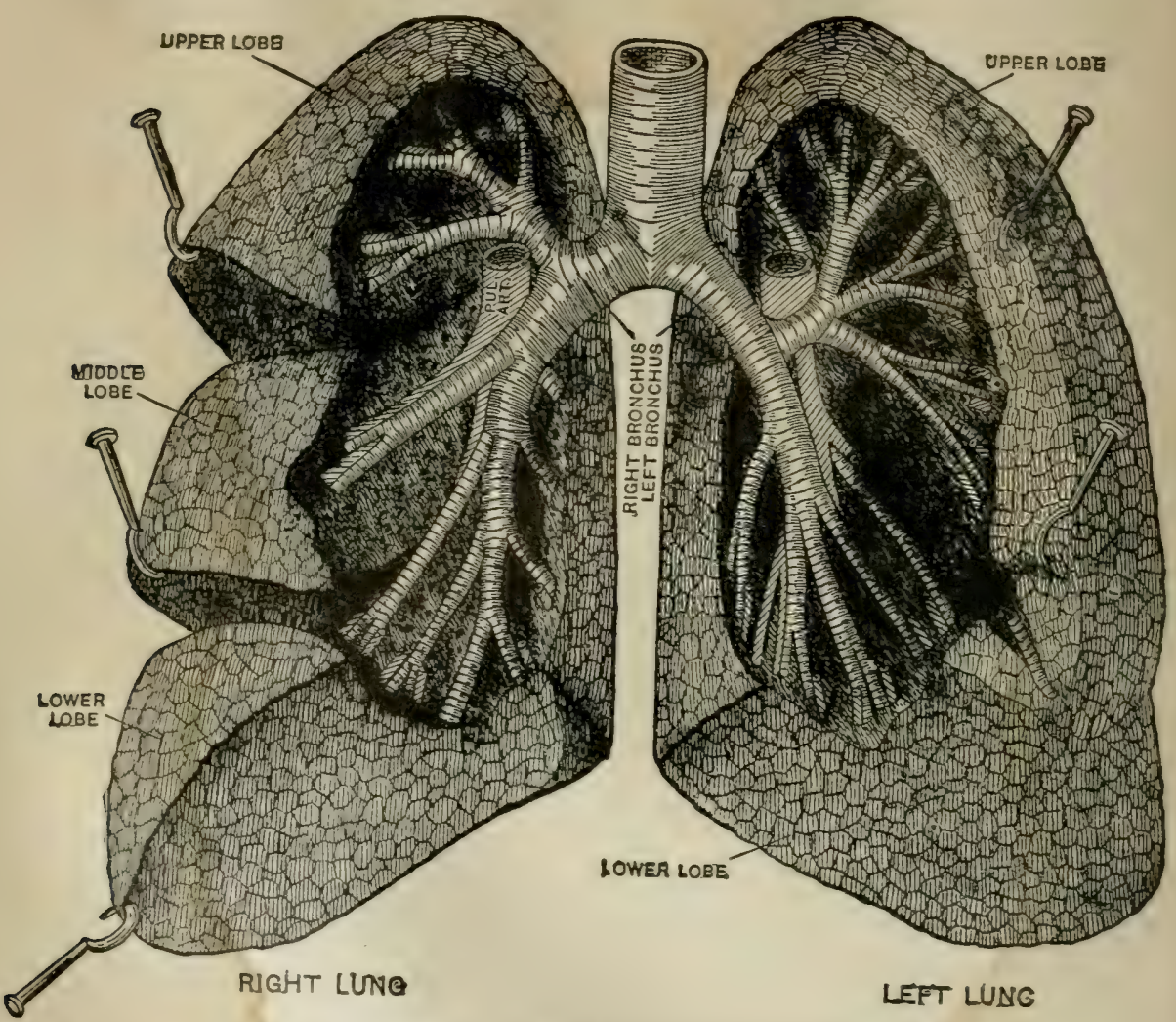

FIG. 9. Air-tubes of the human lung. (Gerrish.)

capillaries or fine divisions of the blood vessels leading from the heart.

205. Object of respiration.-The lung structure permits the blood to take up oxygen as it flows along and transfer certain wastes into the lung cavities, and thus be made ready to go back to the body carrying a joint load of digested food and oxygen. The air that passes out of 
the lungs is less rich in oxygen than when it was taken in, and there have been added to it certain materials which are noticed later.

206. The use of food.-The revivified blood now passes to all parts of the body and is brought into the most intimate relation with the minutest portion of every tissue. Several things happen in the course of time.

In the first place, the new supply of nutritive substances is used by the living cells in a way we do not wholly understand to rebuild worn-out tissue and to form new growth. With the young animal, much material is appropriated in the latter way. In the case of the milch cow, there is furnished to the udder the nutrients out of which certain constituents of milk are formed through the special activities of that gland.

207. Nutrients are oxidized.-Moreover, it is in the tissues that the oxygen which was taken up in the lungs is used to burn slowly a portion of the food. This combustion does not take place by the mere contact of the oxygen and food in the large blood ressels, but it occurs by progressive steps throughout the minute divisions of the muscles and other parts of the whole body. Notwithstanding this oxidation may be very gradual and occupy much time, its ultimate products are, for the most part, similar to those which result from the rapid combustion of fuel. In the fireplace, starch, sugar, cellulose, fats, and similar bodies would be burned to carbonic acid and water, and this is what takes place in the animal to the extent that these nutrients are not used for the formation of body substance. When the protein is not stored as such but is broken up, the result differs somewhat in the furnace and in the animal because in the latter the oxidation is not complete. 
208. Oxidases. - The manner of this oxidation is one of the difficult physiological problems. The present view, and one based on very significant data, is that these oxidations of the nutrients is the result of enzym action and the oxidizing ferments are designated as oxidases. The proteins, carbohydrates, and fats are first acted on during digestion by the hydrolizing enzyms, and the cleavage products are then further broken down, or oxidized, by the oxidases.

209. Proteins not wholly oxided.-The proteins may be partially burned to carbonic acid and water, but unless used for tissue formation a portion of their substance passes from the body principally in the form of urea and uric acid, which are the prominent constituents of urine. These compounds carry with them a certain proportion of carbon and hydrogen which in ordinary fuel combustion would more fully unite with oxygen. The heat production from protein is therefore less in the animal than in the furnace.

210. Rate of oxidation of nutrients. - This oxidation in the animal is constant but not uniform. It varies with the exercise the animal is taking and with the amount of food that must be disposed of. The quantity of oxygen needed is therefore variable, and when the demand for it is largely increased the heart pumps faster, more blood passes through the lungs, the breathing is more rapid and the supply of oxygen is in this way augmented.

\section{ELIMINATION OF WASTES}

The various waste products from this combustion and from the breaking up of the proteins within the animal evidently must be disposed of in some manner. When 
not eliminated from the body, they cause results of a most serious character, as, for instance, when an accumulation of urea in the body produces uræmic poisoning. The blood therefore not only carries to the tissues the necessary nutrients and oxygen, but it has laid upon it the burden of taking into its currents the waste products of combustion and growth and carrying them to the points where they are thrown off. (See Par. 77.)

211. Elimination of urea.--One of the branches of the arterial system of blood vessels runs to the kidneys, and, by repeatedly rebranching, traverses all their substance. The main function of the kidneys is to eliminate certain products through the urine. It is in this way that all the waste nitrogen from the digested protein finds its way out of the body in the form of urea and similar bodies. The blood that enters them carries with it the urea and uric acid which have resulted from a breaking down of protein, and in a most wonderful manner these compounds are filtered out so that they are not present in the outgoing blood. An excess of soluble mineral matters, especially the alkaline salts is also removed by the kidneys, as well as the bile compounds which are absorbed from the alimentary canal.

212. Elimination of carbon dioxid.-The carbon dioxid must in some way also be eliminated from the body. This is not accomplished to any extent until the blood containing it reaches the lungs, where it is exchanged for a new supply of oxygen and passes off in the expired air. In the case of man, the air "breathed out" is nearly a hundred times richer in carbonic acid than the air "breathed in."

213. Elimination of water.-Water may be regarded from one point of view as a waste, for it is produced in 


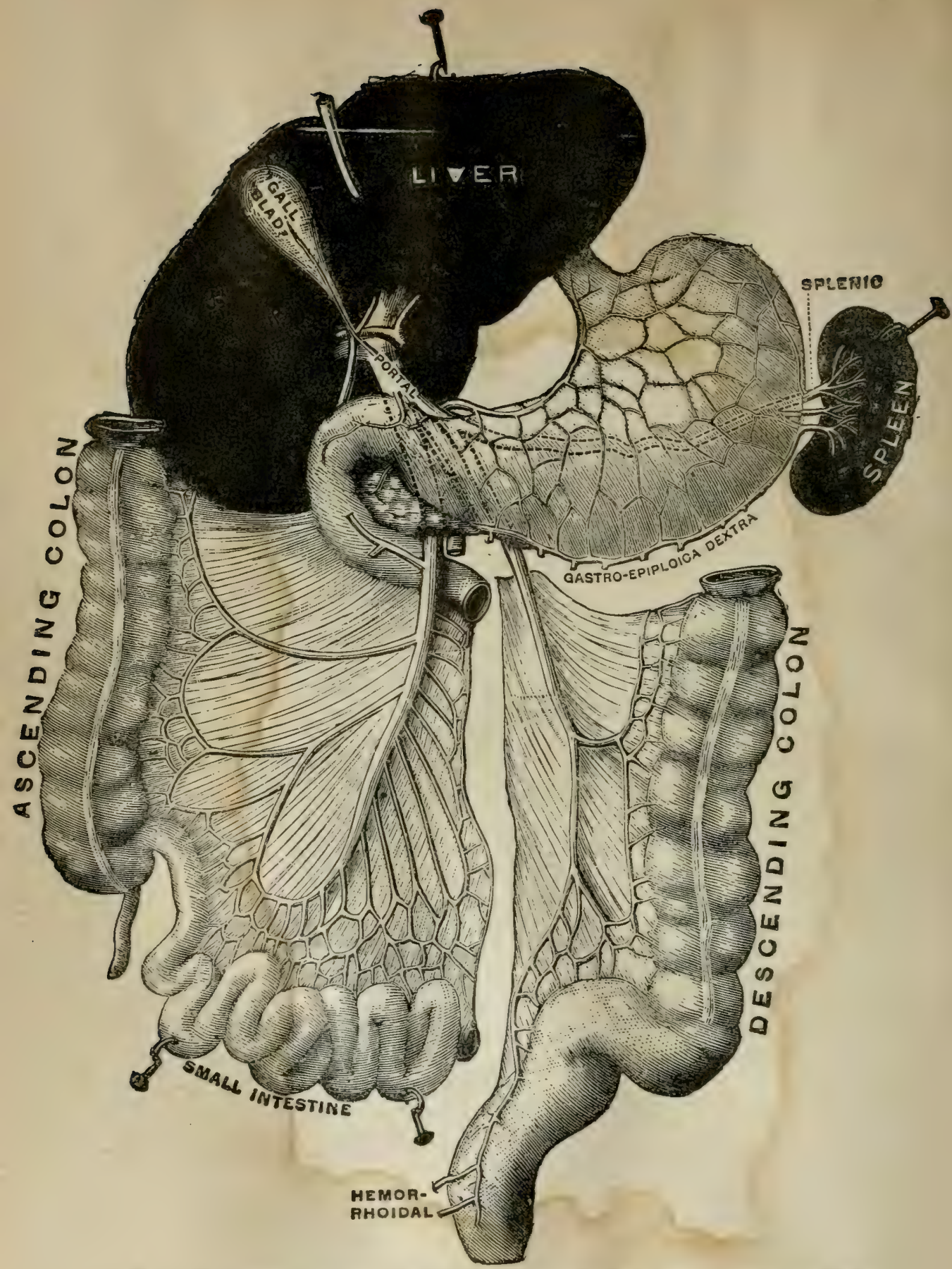

FIG. 10. Portal system of veins in the human subject, showing how absorbed nutrients are collected from intestinal tract and carried to liver by portal vein. 
the oxidation of the food, and this passes off from the lungs as vapor, through the skin as sensible or insensible perspiration, and in considerable quantities through the kidneys.

To summarize, it may be said that the blood is constantly undergoing gain and loss. The gain comes from the food (including water and oxygen), and the loss consists of the compounds in the urine, carbonic acid, and water given off through various channels.

\section{THE LIVER}

214. Regulation of carbohydrate use.-One part of the arterial system of blood vessels runs to the stomach and intestines and is distributed over their walls in fine divisions. These connect with the capillaries of the portal vein which leads to the liver (Fig. 10). During this passage of the blood from one system to the other, part of the digested food is taken up. The quantity of material thus absorbed must vary greatly at different times according to the nature and amount of food supply and the activity of the digestive processes. If, therefore, the blood from the alimentary canal were allowed to pass directly into the general circulation, the supply to the tissues of the sugar resulting from digestion would be very uneven. Just here comes in a liver function. In that organ there is found a starch-like body known as glycogen, which appears in increased quantity following the abundant absorption of sugar from the intestines. It is believed, because of this and other facts, that the liver acts as a regulator of the carbohydrate supply to the general tissues of the body, storing a temporary excess of the sugar in the form of glycogen and then gradually giving it up to the gen- 
eral circulation as it is needed. Glycogen is also stored in the muscles in an amount equal to or greater than in the liver. (See Par. 103.) No better illustration can be cited of the nicety of adjustment of the animal organism to the maintenance of its activities than this regulation of its fuel supply to the areas of oxidation. 


\section{CHAPTER X}

\section{THE FUNCTIONS OF THE NUTRIENTS}

The digestion, absorption, and distribution of food are not its use-they are the preliminaries necessary to use. Not until the nutrients have been converted to available forms and have passed into the blood do they in the slightest degree furnish energy or building-material to the animal organism. We have followed to a certain extent the chemical changes which the digested food suffers, but no detailed statements have been made as to the part taken by each class of nutrients in constructing the animal body and in maintaining its complex activities.

215. General uses of food.-Animals use food in two general ways, viz., for constructive purposes, which involve the building or repair of tissue and the formation of milk, and as fuel for supplying different forms of energy. The tissues which are to be formed are of several kinds, principally the mineral portion of the bone, the nitrogenous tissue of the muscles, tendons, skin, hair, horn, and various organs and membranes, and the deposits of fat which are quite generally distributed throughout the body substance.

216. Uses of energy.-Energy in the forms in which it is used by the animal organism may appear as muscular activity, both internal and external, such as working, walking, breathing, the beating of the heart, the movements of the stomach and intestines, as heat, and as chemical energy necessary for carrying on digestion and 
other metabolic changes. The animal body is certainly the seat of greatly varied and complex constructive and destructive activities, which are sustained by the matter and potential energy of the food. How this is done we do not fully understand, but we know many facts which are of great scientific and practical importance and which the feeder must consciously or unconsciously recognize if he would not come into conflict with immutable laws. (See Pars. 236-241.)

217. Functions of water.-Water fills an important place in the nutrition of all forms of life. In both plants and animals it acts as a solvent of the buildingmaterials which it carries from one part of the organism to another. It also serves as a carrier of wastes, particularly those excreted through the kidneys, and the free use of water is recommended as promoting thorough cleansing of the tissues. It is proper to speak of water as building-material for the animal body, for it is an abundant constituent of animal tissue and takes part in chemical changes such as hydrolysis. It fills an essential office in regulating the heat processes of the body through varying rates of evaporation from the surface of the body.

\section{FUNCTIONS OF THE MINERAL ELEMENTS}

218. Relation of mineral elements to vital processes.The life of an animal is maintained through chemical reactions between substances in solution. These reactions are brought about by means of electrical currents, and the importance of the mineral salts in these relations is seen in the fact that very dilute solutions of the mineral salts in water increase greatly the electrical conductivity. The organic compounds in the body have a low electrical 


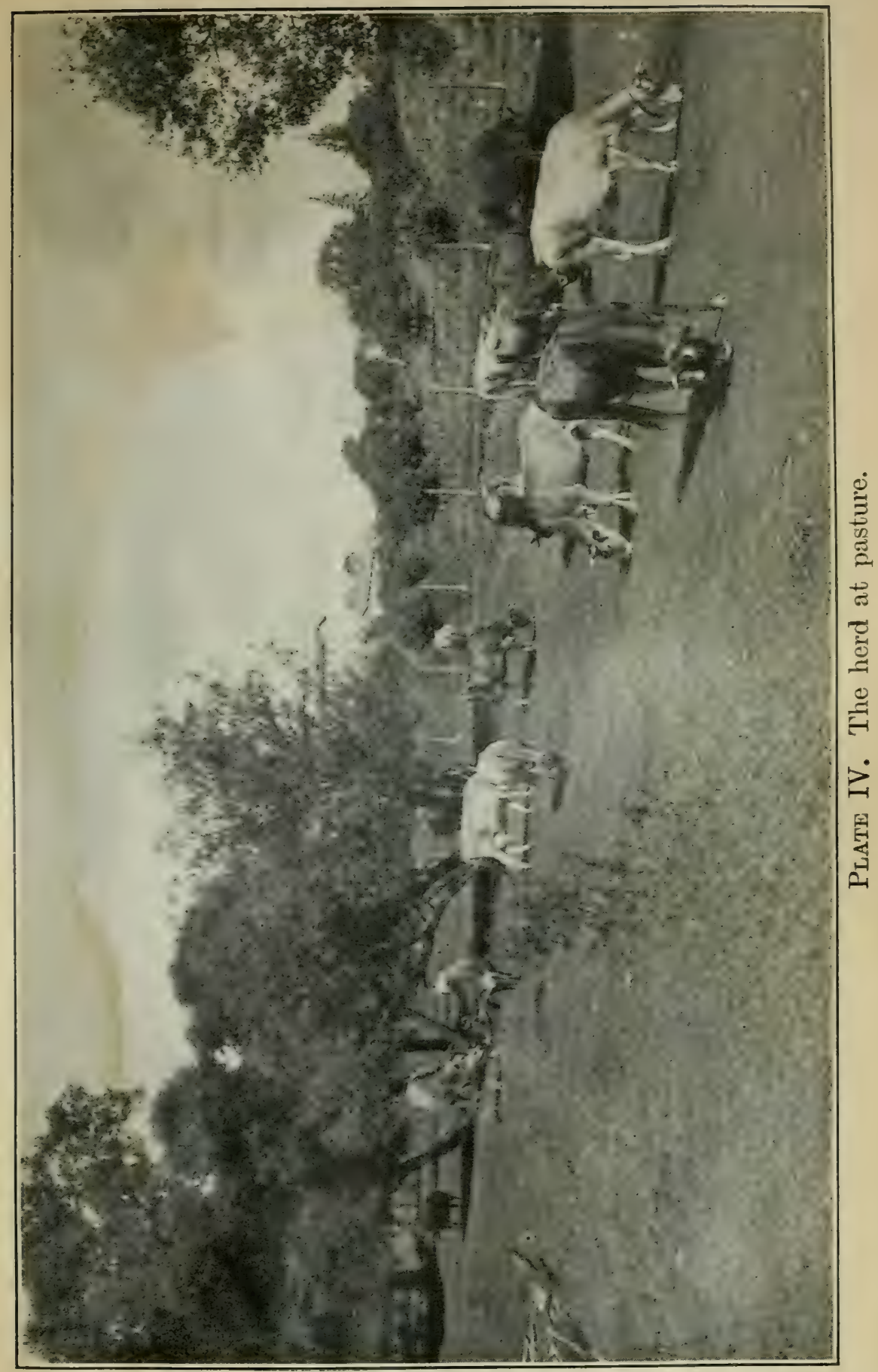



conductivity or are inert, and it is the presence of the mineral elements in solution carrying electrical charges which makes possible the reactions involved in metabolism. Without the mineral elements protoplasm would be dead.

219. Relation of mineral elements to animal structure.-The mineral elements are largely involved in the structure of the animal body. They constitute the entire amount of the ash in which the elements calcium and phosphorus exist in the largest proportions. The following table illustrates the kinds and distribution of mineral elements in the bodies of five species of farm animals.

TABLE XXVII

\begin{tabular}{|c|c|c|c|c|c|c|c|c|c|c|}
\hline & \multicolumn{2}{|c|}{$\mathrm{Ox}$} & \multirow{2}{*}{$\frac{\text { Calf }}{\text { Fat }}$} & \multicolumn{4}{|c|}{ Sheep " } & \multicolumn{2}{|c|}{ Lamb } & \multirow{2}{*}{$\frac{\text { Pig }}{\text { Fat }}$} \\
\hline & $\begin{array}{l}\text { Half } \\
\text { fat }\end{array}$ & Fat & & Thin & $\begin{array}{l}\text { Half } \\
\text { fat }\end{array}$ & Fat & $\begin{array}{l}\text { Very } \\
\text { fat }\end{array}$ & Fat & Thin & \\
\hline & $\begin{array}{l}\overline{\text { Per }} \\
\text { cent }\end{array}$ & $\begin{array}{l}\text { Per } \\
\text { cent }\end{array}$ & $\begin{array}{l}\text { Per } \\
\text { cent }\end{array}$ & $\begin{array}{l}\text { Per } \\
\text { cent }\end{array}$ & $\begin{array}{l}\text { Per } \\
\text { cent }\end{array}$ & $\begin{array}{l}\text { Per } \\
\text { cent }\end{array}$ & $\begin{array}{l}\text { Per } \\
\text { cent }\end{array}$ & $\begin{array}{l}\text { Per } \\
\text { cent }\end{array}$ & $\begin{array}{l}\text { Per } \\
\text { cent }\end{array}$ & $\begin{array}{l}\text { Per } \\
\text { cent }\end{array}$ \\
\hline $\begin{array}{l}\text { Fat . . } \\
\text { Nitrogenous }\end{array}$ & 19.1 & 30.1 & 14.8 & 18.7 & 23.5 & 35.6 & 45.8 & 28.5 & 23.3 & 42.2 \\
\hline matter . . & 16.6 & 14.5 & 15.2 & 14.8 & 14. & 12.2 & 10.9 & 12.3 & 13.7 & 10.9 \\
\hline Minerals . . & 4.66 & 3.92 & 3.8 & 3.16 & 3.17 & 2.81 & 2.9 & 2.94 & 2.67 & 1.65 \\
\hline $\begin{array}{l}\text { Water } \\
\text { Contents of }\end{array}$ & 51.5 & 45.5 & 63. & 57.3 & 50.2 & 43.4 & 35.2 & 47.8 & 55.1 & 41.3 \\
\hline stomach, etc. & 8.2 & 6. & 3.2 & 6. & 9.1 & 6. & 5.2 & 8.5 & 5.2 & 4. \\
\hline Total ... . & 100. & 100. & 100. & 100. & 100. & 100. & 100. & 100. & 100. & 100. \\
\hline Minerals & $\begin{array}{l}\text { Per } \\
\text { cent }\end{array}$ & $\begin{array}{l}\text { Per } \\
\text { cent }\end{array}$ & $\begin{array}{l}\text { Per } \\
\text { cent }\end{array}$ & $\begin{array}{l}\text { Per } \\
\text { cent }\end{array}$ & $\begin{array}{l}\text { Per } \\
\text { cent }\end{array}$ & $\begin{array}{l}\text { Per } \\
\text { cent }\end{array}$ & $\begin{array}{l}\text { Per } \\
\text { cent }\end{array}$ & $\begin{array}{l}\text { Per } \\
\text { cent }\end{array}$ & $\begin{array}{l}\text { Per } \\
\text { cent }\end{array}$ & $\begin{array}{l}\text { Per } \\
\text { cent }\end{array}$ \\
\hline Phosphorus . & .803 & .677 & .67 & .488 & .524 & .454 & .484 & .492 & .465 & .286 \\
\hline Calcium . . & 1.508 & 1.281 & 1.177 & .944 & .965 & .846 & .886 & .915 & .771 & .455 \\
\hline Magnesium . & .051 & .037 & .048 & .034 & .031 & .029 & .033 & .031 & .032 & .019 \\
\hline Potassium . & .17 & .146 & .171 & .144 & .14 & .123 & .131 & .138 & .163 & .115 \\
\hline $\begin{array}{l}\text { Sodium . } \\
\text { Iron }\end{array}$ & .108 & .094 & .109 & .0 & .077 & .072 & .096 & .076 & .082 & .054 \\
\hline $\begin{array}{l}\text { Iron } \\
\text { Sulfur }\end{array}$ & $\begin{array}{l}.028 \\
.015\end{array}$ & $\begin{array}{l}.017 \\
.013\end{array}$ & $\begin{array}{l}.015 \\
.016\end{array}$ & $\begin{array}{l}.026 \\
.021\end{array}$ & $\begin{array}{l}.029 \\
.014\end{array}$ & $\begin{array}{l}.024 \\
.012\end{array}$ & $\begin{array}{l}.021 \\
.011\end{array}$ & $\begin{array}{l}.018 \\
.016\end{array}$ & .015 & $\begin{array}{l}.009 \\
.012\end{array}$ \\
\hline Live weight, lbs. & 1,232 & 1,419 & 258.8 & 97.6 & 105.1 & 127.2 & 239.4 & 84.4 & 93.9 & 185. \\
\hline Age .... & 4 yrs. & 4 yrs. & $\begin{array}{c}9.5 \\
\text { wks. }\end{array}$ & $1 \mathrm{yr}$. & $\begin{array}{l}31 / 4 \\
\text { yrs. }\end{array}$ & $\begin{array}{l}11 / 4 \\
\text { yrs. }\end{array}$ & $\begin{array}{l}13 / 4 \\
\text { yrs. }\end{array}$ & $1 / 2 \mathrm{yr}$. & & \\
\hline
\end{tabular}


220. Distribution of mineral elements in animal body. -The bones carry the greater part of the ash elements. Fresh bones are approximately one-quarter ash. The muscles have between 1 and 2 per cent of ash, and the blood from eight to nine parts in a thousand. The distribution of the mineral elements in the animal body is somewhat as follows: phosphorus and calcium predominate in the bones; sodium salts are found largely in the blood, the serums, and lymph; potassium salts exist most abundantly in the blood, muscles, brain, and liver. Iron compounds are found most largely in the blood, lungs, liver, and spleen; and magnesium in the lungs, muscles, and nervous tissue. Sulfur, as has been seen, is associated with many of the proteins and is found in especially large proportions in hair and horn.

221. Relation of mineral elements to elimination of waste products.-In this respect, iron exercises a particularly important function. As has been seen, it is contained in the hemoglobin of the red corpuscles. In the lungs, oxygen becomes lightly attached to this hemoglobin and is carried to the various parts of the body where it is used for the oxidation of the organic compounds in the food. The red corpuscles seize upon the carbon dioxid which is one of the products of this oxidation and carry this to the lungs where it is eliminated. As these oxidation processes furnish the energy for sustaining the activities of the animal body, it appears that iron is a most important factor in animal metabolism.

222. Relation of mineral elements to a proper equilibrium between the acids and bases of the animal body.The cleavage processes which take place in the use of food compounds give rise to sulphuric and phosphoric acids, and these together with certain organic acids must 
be neutralized through the presence of certain basic elements. Sodium, potassium, and calcium function in this relation. If this neutralization did not occur, the animal would be seriously affected and in time die. As a matter of fact acidosis (acid condition) has not been demonstrated with farm animals. The acidity or the alkalinity determines the function of the action of certain enzyms in the digestion of food, as, for instance, while the pepsin of the stomach acts most effectively in an acid solution, the trypsin and other enzyms of the duodenum act only in an alkaline medium.

223. Relation of mineral elements to osmosis. The transference of substances in solution from one part of the body to another involves the passage of solutions through various membranes and tissues, as, for instance, from the alimentary canal into the blood and from the blood into various tissues which are nourished through such distribution. The penetrability of these membranes seems to be dependent upon the presence of mineral salts.

224. Relation of mineral elements to muscular control.-The contraction of both the voluntary and involuntary muscles seems to be dependent upon a certain balanced chemical environment involving salts of calcium, magnesium, sodium, and potassium.

225. Relation of mineral elements to tissue development.-It has been shown that the eggs of certain marine fishes segment normally only in water containing a mixture of certain salts of a certain concentration, these being the salts of the alkalies and alkaline earths.

226. General considerations. - It is easily seen that the mineral salts sustain very complex relations to the growth of animal tissue and to the maintenance of animal life. It is a matter of common observation that when an 
animal is given food free from the compounds of the mineral elements, the animal suffers physical deterioration and finally dies. In considering the matter of a sufficient supply of mineral element, the feeder should consult tables showing the ash composition of the various feeding-stuffs.

227. Supply of mineral elements (see Pars. 48-54).The supply of the mineral elements in the food of the various classes of animals has not until a comparatively recent time received extensive consideration. It has been practically held that nature has made a generous provision for supplying the animal's needs for mineral substances in our home-raised feeding-stuffs and that mixed rations as usually fed contain in variety and quantity all that is needful of these nutrients for the various kinds of production. It was clearly proved sometime since that an extra supply of mineral compounds is needed for laying hens, especially calcium compounds for the formation of egg shell, and it was also shown that the proper development of the bony structure of swine is not secured through feeding cereal products alone, particularly exclusive corn-feeding, but the mixed rations for bovine production have not been questioned in this direction.

It has remained for Forbes in a recent extensive and exceedingly important investigation as to the mineral supply of liberally producing cows to show that during full milk production, even when the animals were fed on rations that are regarded in practice as highly satisfactory, there were important losses of calcium, magnesium, and phosphorus from the cow's skeleton. It is suggested that the decreasing milk-supply during a given period of lactation and the sometimes observed failure of a highly producing cow to carry her high pro- 
duction successfully through two periods of lactation are due to the removal from the body of these mineral elements not supplied in sufficient abundance in food. It would seem, however, that ordinarily there are periods during which a milch cow recovers her loss of mineral elements.

Forbes calls attention to the importance of iodine in animal metabolism. It has long been known that in the cases of abnormal physical development accompanied by inferior intellectual quality, such subjects being known as cretins, the physical and mental conditions have been improved by an extract of the thyroid gland which carries iodine. An extensive investigation of many feedingstuffs shows an absence of iodine in some and only traces or very small percentages in others. It would appear, however, that under the ordinary system of feeding mixed rations the iodine supplied to our domestic animals is sufficient.

228. Relative efficiency of different phosphorus compounds. - The mineral elements of foods may be supplied to the animal in various forms. This is particularly true of phosphorus which is used so freely by growing animals and milch cows. Because of the importance of this element the problem of the relative nutritive efficiency of organic as compared with inorganic phosphorus compounds has been much studied. The organic forms found in foods are in part nucleo-proteins, phospho-proteins, phytin, and similar compounds found in grains, and lecithin and glycero-phosphates. In an admirable résumé of the whole subject, Forbes shows that the data secured on this question give conflicting testimony but that the majority of evidence seems to favor the conclusion that the organic phosphorus compounds are more efficient, for some species at least, than the inorganic, such as cal- 
cium phosphate. It seems clear, however, that growth can be secured where only inorganic phosphorus is fed, and in many experiments this form has seemed as efficient as the organic. The synthesis in the animal of such compounds as the nucleo-proteins can hardly be doubted. The fact of such synthesis does not show that organic phosphorus compounds may not be in general more efficient than inorganic. This question has some economic importance because it is well to know whether so cheap a material as phosphatic rock may be a useful source for fortifying the phosphorus supply of a ration.

\section{FUNCTIONS OF PROTEIN}

229. Proteins as tissue-formers.-While there are at present many unsolved problems relative to the nutritive offices of protein, there is no reasonable doubt that the vegetable proteins are the primary and main source of all similar substances in the animal body. From these proteins are formed the muscles, the connective tissues, the skin, hair, horn, and hoofs, and the major part of the tissues of the secretive and excretive organs; in short, that they are the source of a large proportion of the working parts of the animal body. So far, scientific research has not succeeded in demonstrating that a protein is ever synthesized (built up from simple compounds) outside of the plant. It appears that bodies of this class must in the main come to animal life fully elaborated. This is a truth of great significance even in its relation to the nutrition of farm animals. The nitrogenous tissues are those that largely. determine the vigor and quality of any animal, and as these are formed rapidly in the early stages of growth, a normal and unrestricted develop- 
ment demands an abundant supply of protein food. It is also true of mature animals that sufficient protein is not only necessary to health and vigor, but it is essential to production that is satisfactory in quantity and quality.

230. Protein as a source of fats.-The functions of protein are not restricted, however, to the use already described, for it is utilized in more ways than any other class of nutrients. It was held at one time that outside the vegetable fats it is the sole source of animal fats, and this view was, not so very long ago, to some extent accepted. Indisputable proof to the contrary is now in our possession. Certainly we must be convinced that nitrogen compounds of the food are, with some species, not the most important source of animal fat, for various investigators, such as Lawes and Gilbert, Soxhlet, and others, have shown upon the basis of searching experiments that sometimes over four-fifths of the fat stored by pigs must have had its origin outside the food protein and fat. Jordan showed that milk-fat may be largely synthesized from carbohydrates. Besides all this, the common experience of feeders that foods highly nonnitrogenous are often the most efficient for fattening purposes is good evidence that fat formation is not greatly dependent upon the protein supply. Nevertheless, the possibility of producing animal fat from protein now appears to be demonstrated.

231. Protein as a source of energy.-Protein can unquestionably serve as fuel, or, in other words, as a source of energy. The amount so used depends much upon the animal fed and the character of the ration. In the case of a dog eating an exclusive meat diet or of a mature fattening animal which receives a ration liberally 
nitrogenous, the greater part of the protein eaten is not stored but, excepting the nitrogen compounds of the urine, is used as fuel. With milch cows or young animals growing vigorously a much larger proportion escapes oxidation. The fuel value of protein will be discussed later under another head.

\section{FUNCTIONS OF CARBOHYDRATES}

232. Carbohydrates the chief source of energy.Carbohydrates are usually characterized as the fuel portion of the food, or that part which is oxidized to produce the various forms of energy. This conception of the function of these bodies is correct in the sense that in the case of farm animals they constitute the larger part of the fuel, although not the whole of it.

233. Proportion of ration used as fuel.-For instance, in the case of a cow eating daily sixteen pounds of digestible organic matter, giving thirty pounds of milk containing 15 per cent of solids, and neither gaining nor losing flesh, not far from five pounds of this organic matter would be found in the milk and urine, leaving about eleven pounds to be used as fuel, about a pound and a half of which might be derived from the protein and fat, the remainder, or nine and one-half pounds, consisting of carbohydrates. If a fattening steer were eating the same amount of the same kind of food and gaining two pounds of live weight daily, the body increase and urine would contain not over two and one-half pounds of dry matter, leaving not less than thirteen and one-half pounds to be oxidized, of which twelve pounds might consist of carbohydrates and fat, mostly the former. It is clear, then, that while other bodies serve as fuel, the 
carbohydrates furnish much the larger part of that which is needed for this purpose.

234. Fats from carbohydrates.-Contrary to views that held for a time, it is now well established that the animal fats may have their source in the carbohydrates; in other words, starch and sugar and related bodies may serve the main purpose in feeding animals for fattening. In many experiments, notably those with swine, the protein and fat of the food have fallen far short of accounting for the fat in the body increase, sometimes much the greater part of the latter having no possible source other than the carbohydrates. A practical expression of this general conclusion concerning the fat-forming function of carbohydrates is seen in the well-recognized value of corn meal as a fattening food, a feeding-stuff nearly seventenths of which consists of starch and its allies. Experiments with milch cows leave no doubt that milk-fat may also be derived from carbohydrates. These more recent views tend to magnify the importance of the carbohydrates as nutrients.

FUNCTIONS OF THE FATS AND OILS

235. Fats and carbohydrates similar in function.So far as is at present known, the possible uses of the food fats and oils and of the carbohydrates are similar. In other words, both may serve as fuel and both may be a source of animal fat. The differences are that the supply of carbohydrates is much the larger, and the fuel value of a unit weight of fats is over twice as great as that of starch and sugar. Moreover, it seems possible for a food fat to become deposited as such in the animal or in milk without essential change, whereas fat formation 
from carbohydrates involves complex chemical transformations not fully understood.

\section{FOOD AS A SOURCE OF ENERGY}

236. Work performed by the animal organism.The living animal, either as a whole or in some of its parts, is constantly in motion. This means that the animal mechanism is ceaselessly performing work. Even if the body is apparently quiet, the heart beats, pumping blood to all parts of the body, the lungs are expanded and contracted, and the stomach and intestines keep up the movements which are essential to digestion. Besides, a living body is the seat of continuous, invisible and complex chemical and physical changes that, if not work in the common meaning of the term, are its equivalent. Walking, trotting, pulling, lifting, pumping blood, breathing, masticating, digesting and assimilating food represent, then, a great variety of operations of those living machines which we have named horse, ox, cow, and sheep.

237. Work requires the expenditure of energy.Now work requires the expenditure of energy. The projection of a rifle ball through space at the rate of 2,000 feet a second is work. The ball does not move of itself, but is propelled by the application of the energy stored in a powerful explosive. Back of every one of our great mechanical operations, such as pumping, grinding, and moving railroad trains, will always be found some sort of energy, and what is true of machinery made of wood and iron is equally true of that made of bone and muscle. The fact that the mechanism is alive does not abrogate a single physical law, so that the fundamental principles 
of energy as applied to machines are as fully applicable to the activities of animal life.

238. The animal organism does not originate energy.It is safe to go farther and say that the animal organism does not originate energy. Among the fundamental conceptions upon which all our knowledge of chemical and physical laws rests is this, that energy and matter are indestructible, and, moreover, that the sum total of these in the universe is unchangeable. If, then, the horse expends the muscular energy necessary to draw a load of one ton over 10 miles of road, the equivalent of this must have been supplied to his body from some outside source. He could not create it. We know that this is so, and we also know it is conveyed to the animal in the food.

239. The nature of energy.-A definition of energy is difficult. It can be illustrated by pointing out some of its manifestations. It is a common observation to see a blacksmith hammer an iron rod until it is red hot. The motion of the hammer-head descending with great velocity was suddenly arrested when it came in contact with the rod. The hammer-head was driven by energy supplied from two sources, gravity or the energy of position, and energy exerted through the blacksmith's arm, that is, energy supplied through oxidation in the blacksmith's body. When the hammer met the iron rod on the anvil, the mass motion ceased. The operating energy was not annihilated, but it appeared in another form. The motion of the hammer-head (kinetic energy), a mass of matter, was communicated to the molecules of the iron rod, and as the vibrations of the molecules increased in rapidity, the rod grew hotter and hotter. Here we have another manifestation of energy, viz., the motion of the molecule. 
The iron rod might have been heated in another wayby plunging it into burning charcoal. Somehow, when it is deposited in the plant, there becomes stored in this carbon, in a way about which we can only theorize, what we may call chemical energy, which, when combustion occurs, is changed into heat or molecular motion. From these phenomena we learn that not only are there several manifestations of energy, but that one manifestation is transferable into another.

240. Transformations of energy through the use of machinery.-Perhaps another illustration may still further serve our purpose. A small dynamo is being run by a pair of horses working in a tread-power such as is used for threshing grain. The horses are constantly climbing up a moving treadway and thereby communicating motion to machinery. The energy thus applied is the result of combustion in the body of the horse. This motion, is, by the dynamo, converted into electricity, which, by passing through the carbon film of an incandescent lamp and there meeting resistance, is in part, at least, manifested as heat. We have, then, in a chain, muscular effort, motion of the mass (pulleys and wheels), electricity, and heat, all manifestations of energy and all transferable one into the other.

241. The horse a machine.-This is a fairly good picture of what goes on with the horse himself, externally and internally, in sustaining life and performing labor for his owner. It is now known that through the combustion of the carbon compounds of vegetable and animal origin, which serve as nutrients, chemical energy may be transformed into those other forms that are manifested in the activities of living beings, and it is a notable triumph of science to be able to declare with certainty that the 
ceaseless and multiple activities of life on this planet are sustained by an energy which comes to the plant in the sun's rays and is stored there through the synthesis of carbon compounds.

242. Measurement of energy.-It is obvious that if the internal and external work performed by the animal is sustained by the food, it is desirable to measure the energy available in different feeding-stuffs, provided, of course, that they differ in this respect. In order to measure anything, we must have a standard or unit of measurement. In this case it cannot be a unit of space or of mass, that is, we cannot declare that corn meal contains so many cubic feet or pounds of available energy. Energy has neither dimensions nor weight. If we measure it at all, it must be by units of temperature or of work performed. Units of this latter kind are the ones applied to the measurement of food energy. The one that has been most commonly used is the Calorie, this being the energy which in terms of heat is sufficient to raise the temperature of one pound of water $4^{\circ} \mathrm{F}$. Expressed in terms of work, the Calorie (large) is very nearly 1.53 foot-tons, or in other words, it is equivalent to the work involved in lifting one ton 1.53 feet. Heat units are expressed in both the large Calorie and the small calorie. When the former is indicated, the word begins with a capital letter. The Calorie represents 1,000 calories. Armsby proposes the use of the term therm, which represents 1,000 Calories, which renders less cumbersome the figures given for the energy of a ration.

243. Determination of energy units in feeding-stuffs.The total energy or heat units developed in the combustion of feeding-stuffs is determined in an apparatus called a calorimeter. The latest form of this device is one 
in which the ground hay is burned under pressure in the presence of pure oxygen, and the heat evolved is all used in warming a known weight of water. Data are thus obtained from which it is possible to calculate the Calories in the particular material burned. The energy value of single compounds, such as albumin, starch, and sugar, may also be found in the same way, as has been done in a large number of instances. These data show that the heat resulting from the combustion of the compounds of a given class is not the same in all cases. The value in large Calories of one gram of several pure nutrients is shown in the following table:

\section{TABLE XXVIII}

\section{Proterns}

\begin{tabular}{|c|c|c|c|}
\hline gluten & $\begin{array}{c}\text { Calories } \\
5.99\end{array}$ & Egg albumin & $\begin{array}{l}\text { Calories } \\
573\end{array}$ \\
\hline Gliasin & 5.92 & Muscle (pure) & \\
\hline Glutenin & 5.88 & Blood fibrin & 5.64 \\
\hline Plant fibrin & 5.94 & Peptone & \\
\hline Serum albumin & 5.92 & Wool. & 5.51 \\
\hline Milk casein & 5.86 & Gelatin & 5.27 \\
\hline Yolk of egg & 5.84 & Asparagin (amide) & 3.45 \\
\hline
\end{tabular}

\section{CARBOHYDRATES}

Starch

Calories

Cellulose

Glucose

Cane-sugar

Milk-sugar

Maltose

Zylose

\subsection{8}

4.18

3.74

3.95

3.95

3.95

3.74

\section{FAtS}

$\begin{array}{ll} & \text { Calories } \\ \text { Of swine } \ldots .38 & 9.38 \\ \text { Of oxen } & 9.41 \\ \text { Of sheep } & 9.28 \\ \text { Maize oil } & 9.47 \\ \text { Olive oil } \quad . \quad 9 & 9.93 \\ \text { Ether-extract of oats } & 8.93 \\ \text { Ether-extract of barley } & 9.07\end{array}$

The heat values of a gram of the dry substance of various cattle foods, which is a mixture of the several nutrients, were found by recent determinations to be the following, expressed in calories: 
Table XXIX

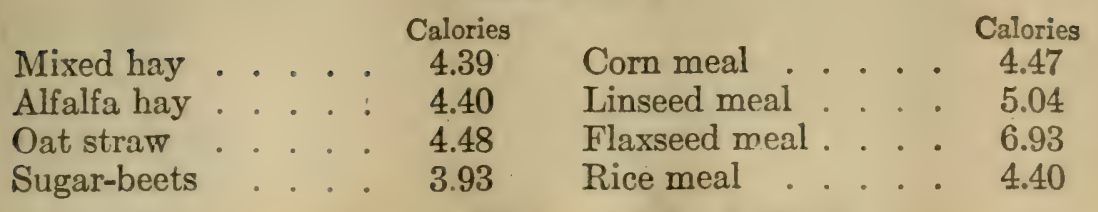

These figures mean that when a gram of each of these materials is wholly burned the heat produced is as stated.

244. Metabolizable energy.-We must distinguish, however, between the heat produced when any food substance is wholly oxidized in a calorimeter and the heat or energy which is available (metabolizable) when the same material is applied to physiological uses. It never happens that the combustible portion of a ration is entirely oxidized in the animal.

245. Loss of food energy in feces.-In the first place, the food of domestic animals is practically never all digested and, as only the digested portion furnishes energy, the available fuel value of a ration must be based primarily, not on the total quantity of dry matter it represents, but on the amount which is dissolved and passes into the blood. If all feeding-stuffs or rations were digested in the same proportion and with the same ease, their total fuel values might show their relative energy worth, but as digestion coefficients for dry matter vary from less than 50 per cent with the straws to nearly 90 per cent with some of the cereal products, it is evident that the fuel waste in the feces is not uniform.

246. Loss of food energy in urine.-In the second place, the digested proteins are never fully burned. A portion of these compounds always passes off in the urine unoxidized, the fuel value of which is lost to the animal. 
For this reason the available energy of the digested proteins is about one-fourth less than the total.

247. Loss of food energy in gases.-In the third place, there is, with ruminants and horses at least, an escape from the alimentary canal of unconsumed gases, due to the fermentations which take place during digestion. These gases, mostly methane (marsh gas) with some carbon dioxid and from green leguminous plants some hydrogen sulfide and nitrogen, have their source in the carbohydrates and crude fiber, and Kellner found them to represent from 10 to 20 per cent of the total energy value of the dry substance digested from various materials. From twenty experiments, upon five different animals, Kühn found the loss in methane to be over one-seventh the energy of the digested crude fiber and nitrogen-free extract.

248. Recent determinations of metabolizable energy. - The most accurate and extensive determinations of metabolizable energy that have been made in this country, or perhaps anywhere, are the result of recent investigations by Armsby and Fries with the aid of a respiration calorimeter. These involved analysis of the feeds used and determinations of the total energy of the feeds and of the losses through the various avenues indicated above. In carrying on this work, nine steers were used, involving 3,401 experiments. Without giving any attention to the technics of the work, which required a costly and extensive equipment of men and apparatus and involved thousands of accurate chemical analyses of foods and the different forms of excreta, the following may be cited as an example of the necessary computation of losses of chemical eneigy from a ration through the excreta and the methane: 


\section{TABLE XXX}

Total energy of feed-

Period 2 Period 3

Calories Calories

Timothy hay . . . . . . . . . 12,477 12,618

Grain mixture, No. 1 . . . . . . 12,549

Total ............... . 25,026 12,618

Energy of 'excreta-

Feces

. $7,371 \quad 5,247$

Urine

627

Methane

- 1,536

1,057

Total

11,005

6,931

Metabolizable energy

14,021

5,687

The above computation is for a mixed ration containing both coarse fodder and grain. In order to ascertain the losses from the grain itself, those for the hay having been determined by other experiments, the following computation was necessary:

TABLE XXXI

\begin{tabular}{|c|c|c|c|c|c|}
\hline & \multirow{2}{*}{$\begin{array}{l}\text { Chemical } \\
\text { energy } \\
\text { of feed }\end{array}$} & \multicolumn{3}{|c|}{ Chemical energy of excreta } & \multirow{2}{*}{$\begin{array}{l}\text { Metabo- } \\
\text { lizable } \\
\text { energy }\end{array}$} \\
\hline & & Feces & Urine & Methane & \\
\hline Tota & $\begin{array}{l}\text { Calories } \\
25,026\end{array}$ & $\begin{array}{c}\text { Calories } \\
7,371\end{array}$ & $\begin{array}{c}\text { Calories } \\
1,536\end{array}$ & $\begin{array}{c}\text { Calories } \\
2,098\end{array}$ & $\begin{array}{l}\text { Calories } \\
14,021\end{array}$ \\
\hline Computed for hay & 12,477 & 5,254 & 591 & 1,003 & 5,629 \\
\hline $\begin{array}{l}\text { Grain mixture by dif- } \\
\text { ference } .\end{array}$ & 12,549 & 2,117 & 945 & 1,095 & 8,392 \\
\hline
\end{tabular}

249. Distribution of losses of food energy.-In the next table there are given for eight individual feedingstuffs and several mixed rations and grain mixtures the percentage of losses through the different avenues and 
the percentage of metabolizable energy, or in other words, that which may be applied to use by the animal, from the several materials involved in the experiments:

TABLE XXXII.

\begin{tabular}{|c|c|c|c|c|}
\hline \multirow{2}{*}{ Feeding-stuff } & \multicolumn{3}{|c|}{ Percentage losses } & \multirow{2}{*}{$\begin{array}{c}\text { Percentage } \\
\text { metabol- } \\
\text { izable } \\
\text { energy }\end{array}$} \\
\hline & $\begin{array}{c}\text { In } \\
\text { feces }\end{array}$ & $\begin{array}{c}\text { In } \\
\text { urine }\end{array}$ & $\underset{\mathrm{CH}_{4}}{\mathrm{In}}$ & \\
\hline Timothy hay & 48.13 & 3.57 & 6.94 & 41.36 \\
\hline Red clover hay & 40.95 & 6.82 & 5.95 & 46.28 \\
\hline Mixed hay . & 43.92 & 5.17 & 7.35 & 43.56 \\
\hline Alfalfa hay & 47.54 & 5.58 & 5.94 & 40.94 \\
\hline Alfalfa meal & 42.01 & 5.89 & 6.11 & 45.99 \\
\hline Maize stover & 42.82 & 4.24 & 7.88 & 45.06 \\
\hline Maize meal. & 14.74 & 3.32 & 9.75 & 72.19 \\
\hline Wheat bran & 31.77 & 5.38 & 7.44 & 55.41 \\
\hline Grain mixture, No. 1 & 17.91 & 7.20 & 7.84 & 67.05 \\
\hline Grain mixture, No. 2 . & 22.03 & 4.54 & 9.06 & 64.37 \\
\hline Hominy chop . ... & 12.15 & 3.84 & 9.20 & 74.81 \\
\hline Alfalfa hay and grain mixture, No. 2 . & 30.27 & 4.83 & 7.98 & 56.92 \\
\hline Mixed hay and maize meal . & 24.22 & 3.87 & 8.89 & 63.02 \\
\hline Mixed hay and hominy chop & 28.02 & 4.44 & 8.15 & 59.39 \\
\hline
\end{tabular}

It will be noted that the main loss is by way of the undigested food residue. The energy loss in the urine ranged from 3.3 to 7.2 per cent. The loss from methane ranged from 5.9 to 9.7 per cent of the total dry matter, or from 4.2 to 5.1 grams to 100 grams of digestible carbohydrates, the average being 4.8 grams. Kellner found 4.2 grams, and these figures may be taken as a basis for the estimate of the probable loss of chemical energy through fermentations. The undigested residue varies greatly according to the nature of the food. These authors have investigated the influence of the quantity of the ration upon the losses of chemical energy. 
250. Influence of size of ration on losses of methane.The losses through gas evolution were found to be greater in twenty-nine cases out of thirty-one with the lighter ration and tended to be somewhat greater on the mixed ration with a very much larger proportion of readily soluble carbohydrates. This simply means that the "bacterial fermentation of the carbohydrates in the digestive tract of cattle proceeds to a distinctly greater extent on light than on heavy rations."

251. Influence of size of ration on losses in the undigested residue.-As is well known, this loss will be by no means uniform as this residue is proportionately much larger with coarse foods than with grain foods. In these comparisons there seemed to be practically no difference in the proportion of loss as between heavy and light rations, these results not agreeing with former observations.

252. Influence of individuality on energy losses. Comparison was made between a pure-bred Shorthorn steer and a so-called scrub. Practically no difference in the loss of chemical energy was discovered as between these two animals.

253. Estimates of metabolizable energy on the basis of digestible organic matter.- It is discovered that the metabolizable energy in a unit of digestible organic matter is fairly uniform as between the different coarse fodders on the one hand and the various concentrates on the other. Various investigators have studied this question and their results show a satisfactory agreement. It appears that the metabolizable energy which may be derived from the several feeding-stuffs will vary quite directly with the proportion of digestible dry matter. The following table shows the figures reached by several investigators: 


\section{TAELE XXXIII.}

Armsby and Fries:

\section{Coarse Feeds}

Timothy hay

Therms

per kilo

Red clover hay

3.49

Mixed hay

3.49

Alfalfa hay and meal .

Maize stover

Average

Kellner and Köhler:

Meadow hay . . . . . . . . . . . 3.50

Oat straw . . . . . . . . . . . . 3.74

Wheat straw . . . . . . . . . . 3.31

Extracted straw _. . . . . . . . . . . 3.64

Average . . . . . . . . . . . 3.55

Armsby and Frics:

\section{Concentrates}

Maize meal . . . . . . . . . . . . . 3.80

Wheat bran . . . . . . . . . . . . . . . 3.99

Grain mixture, No. 2 . . . . . . . . . 3.88

Avcrage . . . . . . . . . . . . . . 3.89

Crain mixture, No. 1 . . . . . . . . . . . . . . . . 3.91

IIominy chop . . . . . . . . . . . . 4.08

Average . . . . . . . . . . . 4.00

Kellner and Köhler:

Beet molasses . . . . . . . . . . . . 3.47

Starch . . . . . . . . . . 3.60

Wheat gluten . . . . . . . . . . . . . 4.79

It is self-evident, of course, that the metabolizable energy will be greatly influenced by the percentage of fat or oil in a ration, as the fats have more than double the energy value of the carbohydrates. 
254. Comparison of metabolizable energy in coarse fodders and grains. - The following table selected from the data of the same authors admits of a direct comparison of the proportions of metabolizable energy in coarse fodders and grains.

\section{TABLe XXXIV}

Coarse Foods

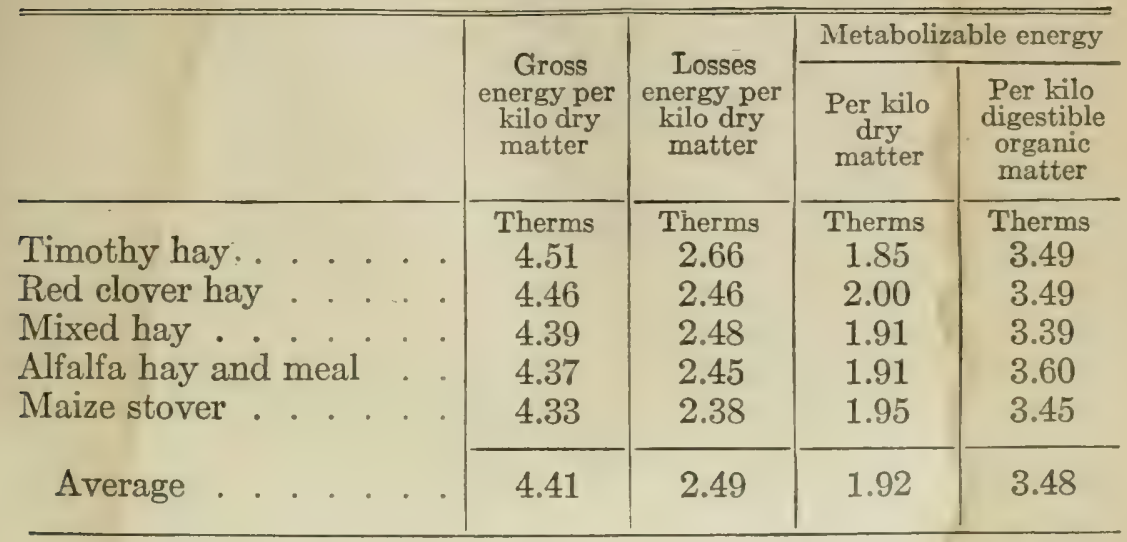

These data show that approximately 56 per cent of the gross energy of the dry matter fed in coarse fodders is lost in the feces, urine, and gases evolved.

Grains

\begin{tabular}{|c|c|c|c|c|}
\hline & \multirow[b]{2}{*}{$\begin{array}{l}\text { Gross } \\
\text { energy per } \\
\text { kilo dry } \\
\text { matter }\end{array}$} & \multirow[b]{2}{*}{$\begin{array}{l}\text { Losses } \\
\text { energy per } \\
\text { kilo dry } \\
\text { matter }\end{array}$} & \multicolumn{2}{|c|}{ Metabolizable energy } \\
\hline & & & $\begin{array}{l}\text { Per kilo } \\
\text { dry } \\
\text { matter }\end{array}$ & $\begin{array}{c}\text { Per kilo } \\
\text { digestible } \\
\text { organic } \\
\text { matter }\end{array}$ \\
\hline $\begin{array}{l}\text { Maize meal } \\
\text { Wheat bran } \\
\text { Hominy chop }\end{array}$ & $\begin{array}{c}\text { Therms } \\
4.44 \\
4.53 \\
4.71\end{array}$ & $\begin{array}{c}\text { Therms } \\
1.11 \\
2.02 \\
1.19\end{array}$ & $\begin{array}{c}\text { Therms } \\
3.33 \\
2.51 \\
3.52\end{array}$ & $\begin{array}{c}\text { Therms } \\
3.80 \\
3.95 \\
4.07\end{array}$ \\
\hline Average . & 4.56 & 1.44 & 3.12 & 3.94 \\
\hline
\end{tabular}


The loss from the grains is relatively much less than from the coarse fodders, being only an average of 31.5 per cent. This is easily accounted for by the greater digestibility of the grains.

We are to understand, then, that the metabolizable energy of a ration is represented by the fuel value of the dry matter which is digested from it, minus the dry matter of the urine and that lost in gases.

If, however, we wish to know the actual energy gain to the animal from a particular ration, we must go farther than a determination of its available energy.

255. Net energy. - Within a comparatively short time we have begun to speak of the net energy of foods, and as this is a practical consideration which is likely to be the subject of much future discussion, it is well to notice it in an explanatory way. As we have learned, food is not applied to use until it reaches the blood. Between the time when it is taken into the mouth and when it passes into the circulation, it must have work expended on it in the way of mastication, solution, moving it along the digestive tract and assimilation, and it seems probable that the amount of this work for a pound of food must vary greatly in different cases. In fact, this seemed to be proven by the result of some masterly investigations conducted by Zuntz and associates in Germany.

256. Work of mastication (Zuntz).-Zuntz determined the oxygen consumption, that is, increased energy used, during the mastication of several feeds by a horse as compared with what occurred with the animal at rest. In considering the data shown in Table XXXV it should be remembered that mastication is only one factor of the loss of energy involved in the appropriation of food, and perhaps a minor one. 
TABLE XXXV

\begin{tabular}{|c|c|c|c|c|}
\hline Feed & $\begin{array}{l}\text { Number } \\
\text { of } \\
\text { experi- } \\
\text { ments }\end{array}$ & $\begin{array}{l}\text { Additional } \\
\text { oxygen } \\
\text { con- } \\
\text { sumed }\end{array}$ & $\mid \begin{array}{c}\text { Additional } \\
\mathrm{CO}_{2} \\
\text { excreted }\end{array}$ & $\begin{array}{l}\text { Equivalent } \\
\text { energy }\end{array}$ \\
\hline $\begin{array}{l}\text { Oats and cut straw }(6: 1) \\
\text { Hay } \\
\text { Hay, oats, and cut straw } \\
\text { Maize and cut straw }(6: 1) \\
\text { Green alfalfa } \\
\text { Computed for oats alone } \\
\text { Computed for maize alone }\end{array}$ & $\begin{array}{l}8 \\
8 \\
8 \\
2 \\
7\end{array}$ & $\begin{array}{r}\text { Liters } \\
12.964 \\
33.840 \\
20.072 \\
7.133 \\
6.171\end{array}$ & $\begin{array}{r}\text { Liters } \\
10.679 \\
27.813 \\
17.677 \\
6.205 \\
4.980\end{array}$ & $\begin{array}{r}\text { Calories } \\
64.17 \\
167.44 \\
100.79 \\
35.72 \\
30.42 \\
47.00 \\
13.80\end{array}$ \\
\hline
\end{tabular}

257. Difference in total energy use with different rations.-Zuntz and Hagemann determined the oxygen use and carbon dioxid excretion during an exclusive hay diet as compared with a diet of mixed hay and grain.

\section{TABLE XXXVI}

\begin{tabular}{|c|c|c|}
\hline & Hay & $\begin{array}{c}\text { Hay } \\
\text { and grain }\end{array}$ \\
\hline Time since last fed . . . . . hours & 2.6 & 2.8 \\
\hline $\begin{array}{l}\text { Ration- } \\
\text { Hay }\end{array}$ & About 10.5 & $\begin{array}{l}4.75 \\
6 . \\
1 . \\
5,697\end{array}$ \\
\hline $\begin{array}{l}\text { Per kilogram and minute- } \\
\text { Oxygen consumed } \\
\text { Carbon dioxid given off } . \text { cub. cent. } \\
\text { Energy set free (computed) cent. } \\
\text { Energy katabolism per day and head Cals. } \\
\text { Calories }\end{array}$ & $\begin{array}{c}3.9837 \\
3.6586 \\
19.552 \\
\\
12,450\end{array}$ & $\begin{array}{c}3.6986 \\
3.6695 \\
18.339 \\
\\
11,678\end{array}$ \\
\hline
\end{tabular}

The comparison of the energy use for the consumption of the exclusive hay ration and hay-and-grain ration shows that the latter, carrying 5,697 grams of digesti- 
ble matter, used 1,213 gram-calories less energy than the exclusive hay ration, carrying 4,125 grams of digestible matter. The hay ration cost for consumption 4.7 Calories per gram of digestible dry matter and the mixed ration only 3.2 Calories. This increased use of energy can only be explained by assuming that the cost of consuming the grain was proportionately less than that of the hay, a difference presumably due to the greater cost of masticating the hay.

The differences revealed by Kuntz's figures are interesting and important. Chewing green food cost in labor only about 18 per cent of the effort required to masticate its equivalent of dry hay, the proportions of labor for hay, oats, and corn being in the ratio of 100,28 and $81 / 3$.

This author goes farther and calculates that the work of mastication and digestion combined is 48 per cent of the energy value of the digested material from hay and 19.7 per cent of that from oats. He also makes the statement that in general the coarse foods have 20 per cent less net energy value than the grains. All these deductions are based upon the excess of oxygen used by the aniraal when engaged in the work of chewing and digestion, over that used when at rest. It would follow from these results that anything in the way of growth or treatment of a fodder which tends to toughen or harden the tissue reduces the net energy value.

258. The work of digestion.-Armsby regards the work of digestion outside of mastication as a small factor. His experiments when he attempted to measure the work of mastication by the increased heat elimination, showed no distinct evidence of such increase. He concludes that there must have been an increased production of heat 
during mastication which was not given off promptly. The Zuntz method of measuring the increase of oxygen consumption would seem to be the more reliable.

The results of Kellner and of Armsby and Fries, which follow, do not appear to ratify the conclusions of Zuntz and Hagemann, although the work of mastication was not determined as a separate factor.

259. Total energy expended in feed consumption.Extensive determinations of the total energy expended in feed consumption have been made, both by Kellner and by Armsby and Fries. The use of energy in this direction is determined by comparing the heat production of two rations of unlike quantity, heat production being equivalent to the energy expenditure by the animal. The increased heat production for the larger ration should be credited, therefore, to the increase of material in the ration, whether a single feed or a mixture of feeds. Results by Armsby and Fries follow:

TABLE XXXVII

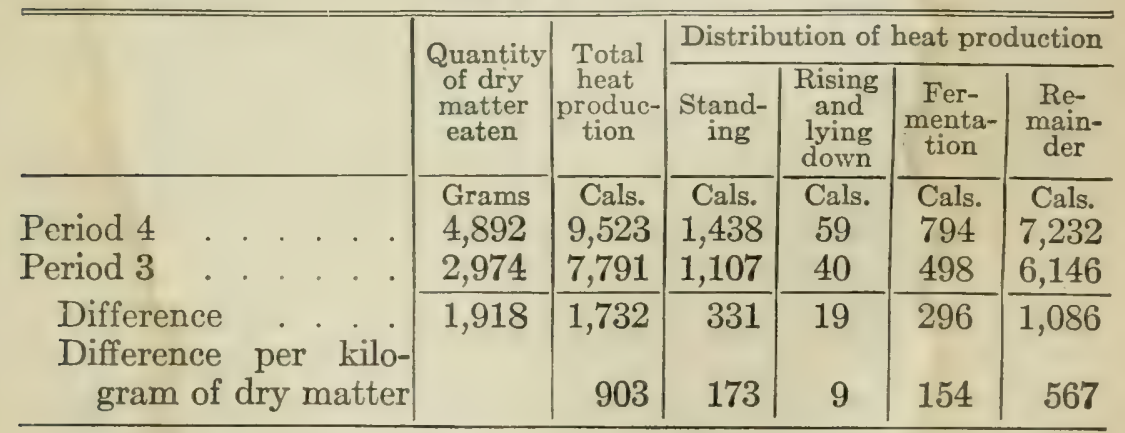

The "remainder," after deducting from the total heat production that caused by standing, rising, lying

Note. - In a recent publication by Armsby (Pennsylvania State College Bulletin No. 142) the position is emphatically taken that the consumption cost with concentrates is as great as with coarse feeds, and suggests other factors which obscure differences caused by unlike mechanical work. 
down, and fermentation, is that which should be charged to the work of consumption. As the smaller ration was less than the other by 1,918 grams and the heat production was 1,086 Calories less for the smaller ration, it appears that the work of consumption was 567 Calories to a kilo of dry matter or 258 Calories to a pound.

260. Calculation of net energy value.-The following is an example of the calculation of net energy value:

\section{TABLE XXXVIII}

$$
\text { Calories Calories Calories }
$$

Total chemical energy . . . . . . 4,408

Losses of chemical energy . . . .

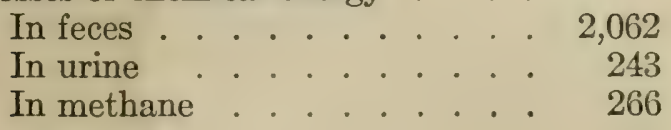

Total ........ 2 2,571

Increased heat production . . . 1, 1,202

Total losses . . . . . .

3,773

Net energy value

635

261. Net energy of various feeds.-In this way the following table was derived from the data secured by Armsby and Fries:

TABLE XXXIX

\begin{tabular}{|c|c|c|c|c|}
\hline Feeding-stuff & $\begin{array}{l}\text { Gross } \\
\text { energy }\end{array}$ & $\begin{array}{l}\text { Losses of } \\
\text { chemical } \\
\text { energy }\end{array}$ & $\begin{array}{l}\text { Enercy } \\
\text { expended } \\
\text { in feed } \\
\text { consump- } \\
\text { tion }\end{array}$ & $\begin{array}{l}\text { Net } \\
\text { energy } \\
\text { values }\end{array}$ \\
\hline & $\begin{array}{l}\text { Per kilo } \\
\text { Calories }\end{array}$ & $\begin{array}{l}\text { Per kilo } \\
\text { Calories }\end{array}$ & $\begin{array}{l}\text { Per kilo } \\
\text { Calories }\end{array}$ & Per kilo \\
\hline Timothy hay & 4,518 & 2,664 & 782 & 1,072 \\
\hline Red clover hay & 4,462 & 2,461 & 962 & 1,039 \\
\hline *Alfalfa hay . & 4,372 & 2,451 & 1,169 & 752 \\
\hline Maize stover & 4,332 & 2,380 & 1,065 & 887 \\
\hline Maize meal & 4,442 & 1,115 & 1,434 & 1,893 \\
\hline Wheat bran & 4,532 & 2,021 & 1,177 & 1,334 \\
\hline Grain mixture, No. 1 & 4,685 & 1,621 & 1,327 & 1,737 \\
\hline Hominy chop & 4,709 & 1,187 & 1,365 & 2,157 \\
\hline
\end{tabular}

*Includes alfalfa meal. 
The values arrived at by Kellner are in the next table. These differ, as would be expected, somewhat from the values reached by Armsby and Fries because of a difference in the character of the materials fed.

TABle XL

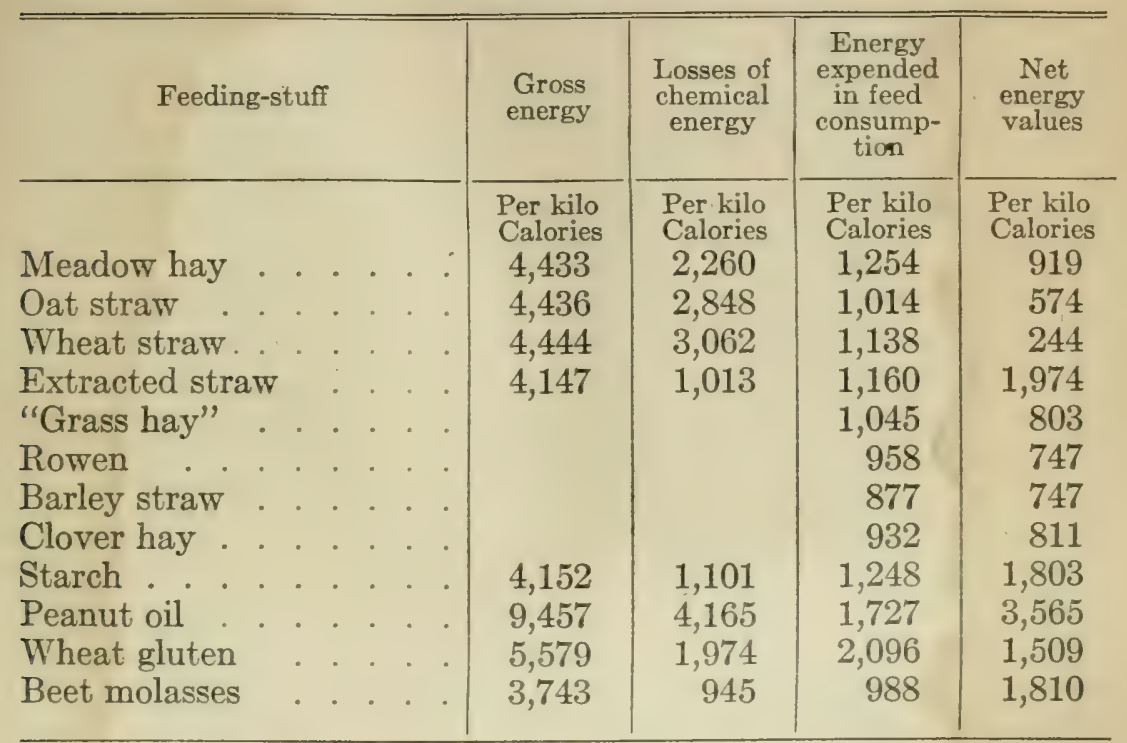

262. Computing net energy values of feeding-stuffs.It is very evident that it is not possible to make direct determinations of the net energy values of all feedingstuffs, but these may be estimated with reasonable accuracy. The following method of computing these estimates may be followed, which is based on the total digestible material, and the conclusion that each gram of digestible organic matter contains 3.5 calories of metabolizable energy. The energy used for feed consumption is reduced to the percentage of dry matter in the three feeds entering into the computation shown in Table XLI. 
TABLE XLI

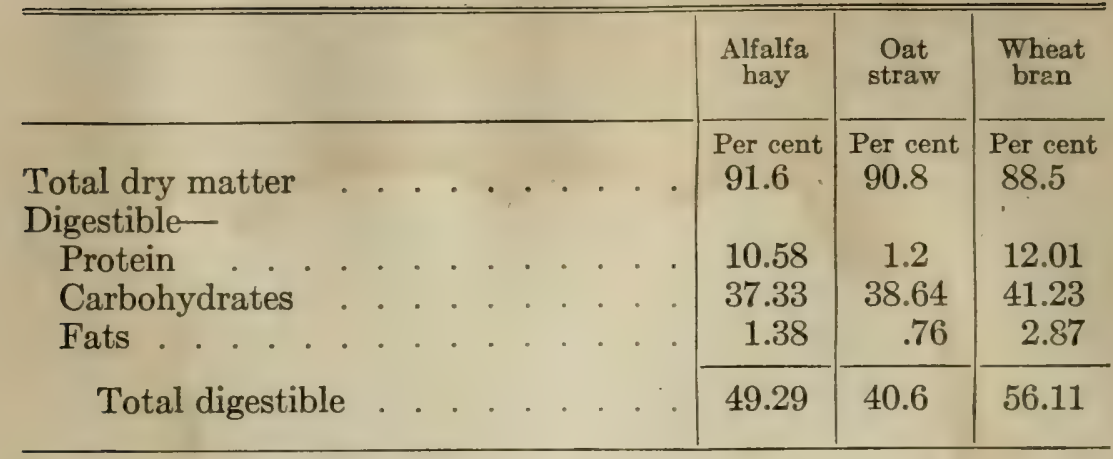

Alfalfa hay, 1,169 calories $\times 91.6$ per cent dry matter $=1,071$ calories per kilogram air-dry feed.

Oat straw, 1,014 calories $\times 90.8$ per cent dry matter $=921$ calories per kilogram air-dry feed.

Wheat bran, 1,138 calories $\times 88.5$ per cent dry matter $=1,007$ calories per kilogram air-dry feed.

Alfalfa hay (3.5 calories $\times 492.9$ grams digestible matter) $-1,071$ calories $=654$ calories per kilogram $=29.7$ therms per 100 pounds air-dry feed.

Oat straw (3.5 calories $\times 406$ grams digestible matter)-921 calories $=500$ calories per kilogram $=22.7$ therms per 100 pounds air-dry feed.

Wheat bran (3.9 calories $\times 561.1$ grams digestible matter) $-1,007$ calories $=1,181$ calories per kilogram $=53.6$ therms per 100 pounds air-dry feed.

These methods of ascertaining net values of feeds may be regarded as complex, but they are unquestionably the most accurate of any methods so far developed.

The results of Armsby and Fries and Kellner do not accord with a somewhat widespread teaching that the energy expended in the consumption of coarse feeds is greatly more for a unit of dry matter than is the case with the concentrates. It is conceded, of course, that the energy expended in the mechanical work of mastication must be greater in the coarse foods than in the grain 
feeds. It seems, from the later determinations, however, that when all factors are considered, the difference in the total energy expenditure in the two classes of feeds is not greatly unlike.

263. Estimation of production values proposed by Armsby.-Instead of using net or production values as experimentally determined for each individual feed, Armsby has computed a table based largely on the results of investigations by Kellner.

This investigator arrived at what is termed the production values of pure nutrients, such as a single protein, starch, or one of the fats. His figures are as follows:

Table Xlit. Production Values per Pound

Digestible proteins. . . . . . . . . . . . 1016

Digestible starch or crude fiber . . . . . . . 1071

Digestible cane-sugar . . . . . . . . . 812

Digestible fat-

In coarse fodders and roots . . . . . . . 2041

In grains and by-products . . . . . . . . 2273

In feeds with over 5 per cent fat . . . . . . 2585

In making up the tables of production values, these values for pure nutrients are used in connection with a given allowance for the expenditure of energy in mastication due to the presence of crude fiber. Kellner found it was possible to estimate fairly. accurately the production value of concentrated feeds by means of these factors, but in the case of the coarse fodders carrying a much higher proportion of fiber such a method of computation was not reliable. He found, however, that if he deducted from the figures obtained through the use of the production values for pure nutrients 617 calories for each pound of crude fiber in the coarse fodder the computed value 
was little different from the real value. In the use of this method only the true proteins are brought into the calculation, so that the values are based upon the digestible true proteins and the total heat value of the nutrients minus the energy expended on the crude fiber. The following table illustrates production values that have been made up after this method, with the exception that the deductions for crude fiber are less for the green fodders and roots than with the dry coarse fodders.*

\section{TABLe XLIII}

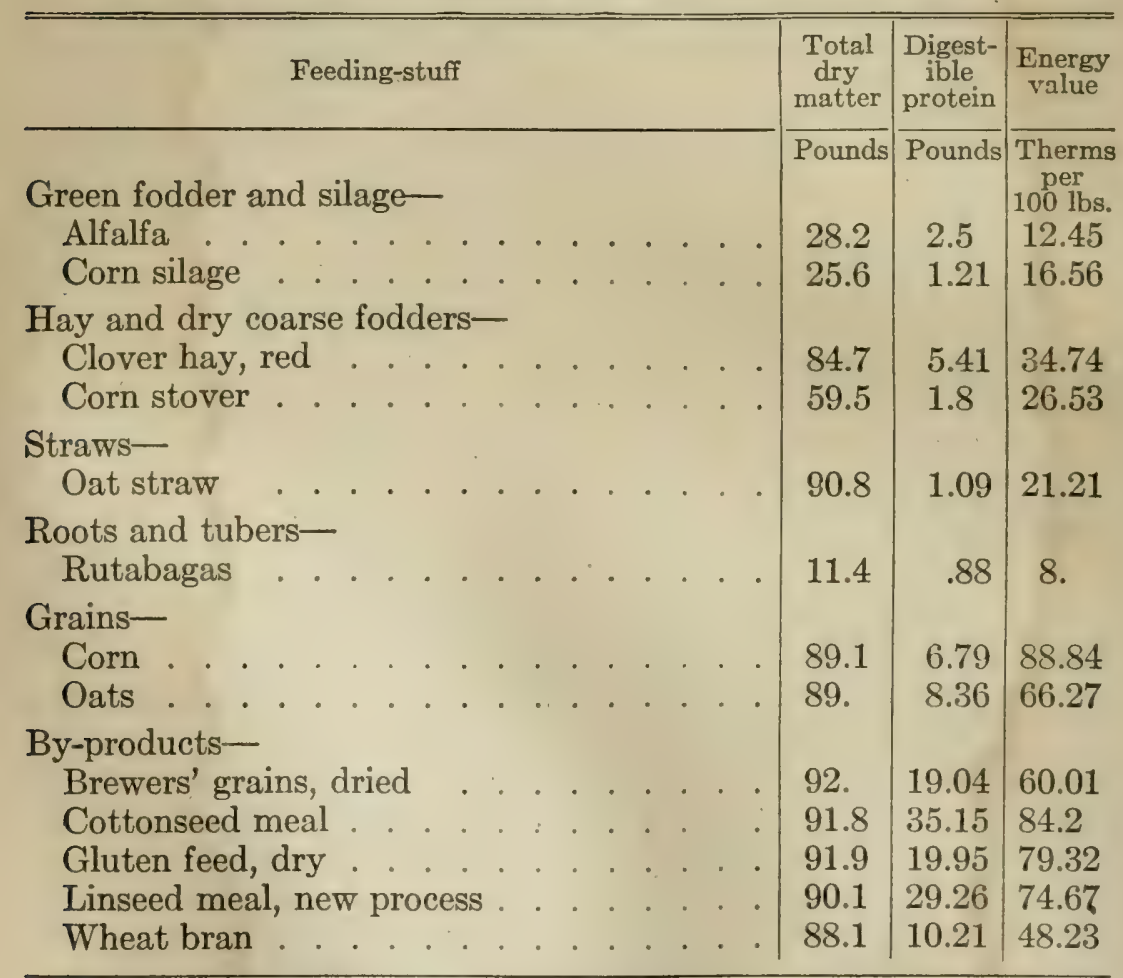

* Since writing the above, Armsby has published a newly computed and very full table of production values, based upon the composition of feeding-stuffs as found in "Feeds and Feeding," by Henry and Morrison. This table, computed by a simpler method than the above, may be found in the Appendix. 


\section{ENERGY RELATIONS.-HEAT REGULATION}

As has been pointed out, the animal body is the field of numerous mechanical activities. What is the relation of the several nutrients to these manifestations of vital energy is an interesting and in some ways an intensely practical matter.

264. Relation of protein to muscular activity.-The belief prevailed at one time that muscular contraction caused a wasting of the muscle substance which must be replaced by the protein compounds of the food; in other words, protein alone was believed to sustain the work of the animal body, both internal and external. It would follow from this that the more work is done the more protein is needed. This view is no longer held. The more exact methods of modern research have revealed the fact that an increase of muscular effort, even up to a severe point, increases but little, if any, the nitrogen compounds of the urine, these being the measure of the protein that is destroyed.

265. Energy chiefly from carbohydrates and fats.There has come to light a corresponding fact that the consumption of fuel in the body other than proteins increases proportionately with the increase of work. This means that as animals are ordinarily fed mechanical work is largely sustained through the combustion of carbohydrates and fats, although a fairly generous amount of protein seems to promote the well-being of a draft animal.

266. Heat regulation.-As no energy is ever lost, into what is the energy converted that is applied to muscular contraction? It is concluded that muscular energy used by the animal is partly transformed into 
external motion (work) and partly into heat, and this certainly is consistent with facts as observed. Violent exercise by the animal greatly increases the production of heat. We know this is so because under these conditions an increased amount of blood is thrown to the surface of the body, thereby greatly increasing the loss of heat by radiation; perspiration sets in and with it the consequent evaporation of much more moisture, thus disposing of much heat. The dog, and sometimes other animals, pants and thereby causes a large loss of heat from the expanded surface of the moist tongue. All this occurs without reducing the body temperature below the normal. In fact, nature adopts these various devices, such as increased circulation of the blood and perspiration, in order to regulate the body temperature and prevent its rising above the proper point. The explanation of this greater heat during labor is that the mechanical energy manifested by the muscles is converted to heat, which under circumstances of severe exercise is more than enough to keep the body at its usual temperature and maintain the usual radiation. When it is severely cold, on the other hand, vigorous exercise is sometimes necessary in order to keep sufficiently warm.

267. Animal heat a secondary or waste product.The view now obtains that under certain conditions body heat is wholly a secondary product, that combustion first supports muscular activity with heat as a by-product; in fact, that at usual temperatures no food is burned primarily to keep the animal warm. Under certain conditions there may be combustion of food for the specific purpose of warming the body. In any case, animal heat is sustained either directly or indirectly by the oxidation of the nutrients. 
268. The critical temperature.-Recent investigations show that under given conditions there is an air temperature, called the "critical temperature," at which metabolism (oxidation) reaches a minimum. If the air temperature falls below this point thus causing a greater radiation of heat from the body surface, increased oxidation occurs. If the temperature of the air rises above this point there is no diminution of oxidation but rather a slight increase, hence the conclusion that there is a minimum oxidation necessary to the maintenance of the vital functions which must go on however much the demands for the radiation of heat may be lessened by a rise of the air temperature. It is evident then that at the higher air temperatures there is an excess of oxidation above that which is required for warming the animal, so that some heat must be thrown off as a waste product. Whichever way the air temperature moves from the critical point there is heat regulation, this being chemical for the lower temperatures and physical for the higher.

The critical temperatures for our various farm animals have not been determined, so that we are not yet able to draw therefrom conclusions as to the influence of given temperatures upon production. The opinion is ventured, however, that with animals protected by a coat of hair, that are kept under comfortable winter conditions, the temperature of the surrounding air does not fall below the critical point.

THE NUTRITIVE INTER-RELATION OF THE FOOD COMPOUNDS AND THE NEED OF COMBINING THESE IN THE RATION

As we have seen, the conclusion reached by many extended and severe investigations is that the compounds 
of foods have certain functions in common. For instance, the proteins, carbohydrates, and fats are all oxidized wholly or in part to supply the necessary energy for muscular activity. The proteins then serve both constructive and fuel purposes. Carbohydrates and fats are alike in being sources of energy through oxidation, and in being utilized for the deposition of animal fat. In view of these facts, the question arises whether the physical welfare of the animal requires the mixture of nutrients that commonly exist in the average ration and that is enforced in the standards that are recommended by students of animal nutrition. It is certain that some species of animals may exist wholly on a flesh diet which is practically devoid of carbohydrates, but this is not true of farm animals.

269. Protein physiologically necessary.-The necessity of protein in the ration is abundantly demonstrated. Many investigations have shown that when the food contains no protein, the waste of body nitrogen continues, no matter how abundant is the supply of carbohydrates and fats. In other words, a continuous protein cleavage is demanded by the animal organism, and no other nutrients can serve as a substitute for protein in meeting this demand. If the food contains no protein, body tissue will be depleted. It cannot be said that either carbohydrates or fats are an essential part of the diet in the sense protein is, because it is possible to substitute the one for the other as energy-producers and protein for both.

270. Carbohydrates physiologically economical.-In spite of these facts, it is safe to assert that the welfare of the animal organism demands a food carrying a mixture of the three classes of nutrients. The larger part of the 
animal's food is used for the production of energy, and it is physiologically economical that this energy be largely supplied by the non-nitrogenous nutrients, particularly carbohydrates. If the proteins are broken down to supply energy, there is always a definite proportion of urea and uric acid residue that must be eliminated through the kidneys. An unnecessarily heavy protein diet burdens these organs and floods the system with these nitrogenous wastes. On the other hand, the carbohydrates, when not stored as fat, are completely oxidized to the simplest compounds, carbon dioxid and water, which are eliminated through the lungs and skin, part of the water so formed acting as a solvent of the urinary compounds. Investigation seems to prove conclusively that the animal body has a physiological preference for carbohydrates over the fats or other nutrients as a source of energy. After the free ingestion of sugar, the respiratory quotient in certain experiments has become 1.00 when just previously it was much less than 1.00. This demonstrates that while fat was being oxidized before the sugar was taken, the oxidation immediately changed wholly to the sugar. This indicates the physiological adaptability of starches and sugars for maintaining muscular activity.

271. Protein-sparers.-The carbohydrates and fats are sometimes classed as "protein-sparers." This means that, with an adequate supply of these bodies in the food, protein destruction may be reduced to the lowest possible limit. To illustrate, if a man doing moderate work were maintaining an energy balance when eating of digestible nutrients 218 grams of protein, 400 grams of carbohydrates, and 56 grams of fat, and 100 grams of digestible carbohydrates were added to the daily food, approximately 100 grams of digestible protein could 
undoubtedly be withdrawn from the daily food without causing any drain upon body protein to meet the demands of the organism. As stated, however, such a substitution cannot be carried beyond certain limits without depressing the protein-supply below the body needs for maintenance. Fats are not as efficient protein-sparers as are carbohydrates. To be more explicit, fats and carbohydrates do not replace protein in proportion to their energy equivalents, carbohydrates being the more efficient. In brief, then, experience and science both indicate that carbohydrates are the most healthful, and physiologically the most economical, source of a large proportion of the food energy. There is every justification for the relative abundance of starch foods in the rations of farm animals.

272. Nutritive value of the gums. - The question has been raised as to whether the gums (pentosans) which exist so abundantly in many coarse foods and in some grain products like wheat bran are not inferior as sources of energy to the other more soluble carbohydrates. It has been observed that the sugars which result from the action of ferments on these bodies have, in some instances, not been oxidized, but have passed off in the urine as such. It appears that under normal and usual conditions this does not occur to any extent with herbivora. Pentosans are present in all rations for farm animals, and we have no reason for believing that the pentose sugars are constant ingredients of their urine. Muccollum and Brannon studied extensively the fate of various pentosans in the digestive tract of bovines. They found that these compounds are not equally digestible from all sources. Those from the corn, oat, and wheat plants were studied and the range of digestibility was 46 
to 67 per cent. The corn-plant pentosans were digested most fully and those from the wheat plant least so.

Swartz concluded from extensive investigation that the water-soluble hemicelluloses are resistant to the action of enzyms and disappear from the digestive tract only in proportion as they are attacked by bacteria. Pentosans and mannans which are hydrolized by bacterial action were found to be almost wholly digested, while galactans were largely excreted as such. In considering their digestibility the groups of hemicelluloses evidently must be considered separately. In any case, digestibility should not be considered as a measure of nutritive value.

273. Relative importance of the nitrogen compounds of feeding-stuffs. - What is known as the crude protein of feeding-stuffs is the total nitrogen multiplied by the factor 6.25. As has been stated, protein as so estimated contains a variety of nitrogen compounds that are unlike in character and exist in various cattle foods in greatly unlike proportions. For example, a much larger part of the crude protein of coarse fodders and roots consists of amides than is the case with grains, the latter being correspondingly richer in true proteins. If, therefore, it is found that the true proteins differ from the amides in function and value, we have established one point of unlikeness between grain foods and roots or the coarse fodders. We have convincing proof that the true proteins are the main flesh-formers found in cattle foods. Are the amides such as glutamin and asparagin also fleshformers? Earlier experiments with these compounds led to the conclusion that they may exercise a protective function toward the true proteins and thus reduce the minimum of such proteins necessary to satisfy the needs 
of an animal under given conditions of production. Some of the more recent investigations indicate that the amides should be classed as to function with the true proteins, or, in other words, that they may take part in the synthesis of the proteins that are used constructively in the animal body though probably with not the same percentage of efficiency. Evidence exists, moreover, that the different amides are not of equal value. (See Par. 85.)

274. Relative nutritive efficiency of the true proteins.-Notwithstanding possible function of the amide compounds in the synthesis of animal proteins, the true proteins of our cattle foods must be regarded as the main flesh-formers. There are, however, many true proteins which are unlike in their constitution. It is desirable to know whether these single proteins differ in nutritive value for specific purposes, like growth or milk formation. Are the alcohol-soluble proteins, such as gliadin and zein of equal value with an albumin, a globulin, or casein? Reference has been made to the fact that while the cleavage products of these various proteins (amino acids), or what are called the building-stones, are to a great extent similar as to kind, these building-stones are not found in the same proportions in the several proteins, and with some proteins certain building-stones are lacking. The investigations of Mendell and Osborne, previously mentioned, indicate great unlikeness in nutritive function and value. It is found, for instance, that the gliadin of wheat and rye does not function as does the casein in milk and that zein is particularly inefficient as a means of even sustaining life, and it is significant that the gliadin is deficient in lysine, and that zein is further lacking in tryptophane, whereas the proteins of the animal body contain both of these animo acids. (See Par. 85.) 
275. A single amino acid a limiting factor.-Evidence on this question is seen in experimental work carried on by Osborne and Mendell. These authors brought rats to full size and kept them in health when the diet contained 18 per cent of casein. When the casein was reduced to 12 per cent, growth fell below the normal. When reduced to 9 per cent, growth was promptly limited by the protein factor. If, however, cystine was added to the 9 per cent of casein, the ration was rendered much more efficient for growth, showing that the presence of an insufficient quantity of this one building-stone was the limiting factor. Similar results were secured in experiments with edestin. When 15 per cent of the ration consisted of edestin, normal growth was secured, but not with 9 per cent. The addition of lysine to the 9 per cent of edestin caused an improvement. Lact-albumin was efficient because all the building-stones, including lysine and tryptophane, are relatively abundant in this protein.

McCollum has determined, through a series of experiments in which he fed single foods to pigs, the proportion of protein used by the animal for building protein tissue. His conclusions are as follows:

Oil meal proteins

Per cent deposited

Wheat proteins

Corn proteins . . 16-17

Oat proteins

Wheat germ

25

Casein

40

Skimmed milk proteins

45

63

The author also gives figures showing that the proteins of one food supplement those of another in producing more growth when the two foods are combined than when fed singly: 
Corn proteins 90 per cent, oil meal proteins 10 per cent . 31 Per cent deposited Corn proteins 75 per cent, oil meal proteins 25 per cent . 37 Corn proteins 60 per cent, oil meal proteins 40 per cent . 32

Those proteins are most efficient, evidently, whose building-stones correspond most nearly in proportion to those of animal proteins.

276. Nutritive value of the gelatinoids.-The gelatinoids which belong to the class of non-proteins cannot be regarded as taking the place of proteins. It has been found that they protect protein from cleavage and thus make a minimum protein-supply more efficient but they do not function in the synthetical processes as the true proteins do. Gelatin also is lacking in certain buildingstones, namely tyrosine, cystine, and tryptophane. This consideration of the protein compounds on the basis of their building-stones is a new and interesting point of view and leads to the conclusion that those proteins are most efficient for constructive purposes whose buildingstones correspond in kind and proportion most nearly to those of the proteins in the animal body.

277. Synthesis in the animal of phosphorus-bearing proteins.-One interesting question which has been considered is whether the nucleo-proteins and phosphoproteins which are found so abundantly in eggs and in milk must be supplied as such in the food, or whether they may be built up in the animal from the simple proteins and phosphates. If we could learn that the food must contain these peculiar proteins all ready for use, then we would have a valuable suggestion for feeding cows and poultry. It now seems that this is not the case. The sea salmon, which, during its stay up the river, is believed to take no food, undoubtedly produces large 
masses of eggs from the body substance, and it seems unlikely that so much nuclein as is needed exists in the flesh. If a cow gives thirty pounds of milk daily, nearly or quite a pound of casein must come from somewhere, and there is no evidence that any ordinary ration would contain so large a quantity of phospho-proteins of like constitution. Hens' eggs are rich in nuclein, beyond any amount which the food seems likely to supply. Experimental evidence supports these general inferences.

278. The function of certain unidentified bodies.An important addition to the science of nutrition is the recent demonstration that certain compounds are associated with animal foods which have a growth-promoting function and in the absence of which either artificial or natural foods fail to sustain growth and even life. (See Par. 118.) It has been known for some time that some such substance was associated with the shells of rice which, when given to animals afflicted with beri-beri from eating polished rice, would restore them to a normal condition. Substances of this class were named vitamines by Funk.

An enlargement of the knowledge of bodies of this class was led up to through studies by American investigators as to the relative nutritive value of single proteins. Heretofore the attention of investigators in animal nutrition has been focussed chiefly upon the constructive and energy functions of the various classes of nutrients, and it was expected that when the proteins, carbohydrates, and ash compounds, supposedly necessary to complete nutrition, were all supplied to an animal, satisfactory results would be accomplished. It was discovered that, when there was fed a combination of purified nutrients artificially prepared with great care and in accordance with the best knowledge of the needs of the 
animal, growth was not secured. When, howerer, what was termed "protein free" milk was used in connection with such a preparation, normal growth resulted. This result, observed by Mendel and Osborn, led up to a series of investigations in which Hart and McCollum have taken a prominent part. It now appears from abundant data that two classes of growth-promoting substances exist, which have been termed Fat-soluble A and Watersoluble $\mathrm{B}$, terms which are temporary until these bodies have been identified. The proof of the existence of these bodies has been illustrated as follows (McCollum): If to a mixture of purified proteins, carbohydrates, and salt mixtures containing all the salts found in the animal body there is added either a small amount of egg yolk or milk powder, growth proceeds normally; whereas the mixture of nutrients before such addition fails to produce growth. If the dried egg yolk is extracted with ether to remove the fat, the addition of the residue does not give the desired result. The addition of the fat alone also is shown to be futile. If, however, there is added to the nutritive mixture along with the extracted egg-fat a water-extract of the fat-free yolk residue, growth is normal. Similar results occur with other substances, such as milk powder. This is the basis for the classification into Fat-soluble A and Water-soluble B, both of which are essential to growth. It appears that the milk of an animal which has been fed on purified nutrients fails to sustain her young, showing that these growth-promoting substances are transferred from the food to the mother's milk and are not synthesized within the body.

It seems certain that the disease known as beri-beri, brought about by a restricted diet of polished rice, is due to the absence of one of these classes, and it is probable 
that pelagra, prevalent in the South where the diet of many individuals is considerably restricted, is due to the absence or insufficient supply of one or both of these classes.

These accessory substances appear to be abundant in egg, milk, and the forage portion of many plants, Fatsoluble A being deficient in the body fats of animals and absent from the fats or oils of many species of plants. The knowledge of the presence or absence of these growthpromoting substances in cattle foods will undoubtedly be enlarged as investigation proceeds.

It is shown in experiments by Hart and McCollum that when the rations of animals were restricted to a single plant, that the wheat germ contains a toxic body. Animals fed wholly on the corn plant or its products developed normally and produced young. Those fed on the wheat plant or its products, without the addition of other food, failed to make satisfactory growth and to produce vigorous young. Similar results were obtained with wheat products when fed to swine. Such results with the wheat plant were evidently not due to a lack of nutrients but investigation showed that the operating cause was a poisonous principle located in the fat of the wheat, this principle being removed when the wheat oil was extracted. We have here, then, an example of a toxic body contained in one of the most common of our feeding-stuffs, the effect of which has been less observed because wheat by-products have constituted only a portion of the food of the animal.

279. Relation of production values to profit from feeding animals. - The production from a given quantity of food varies greatly under unlike conditions. It can scarcely be doubted that the proportion of the available 
nutrients which are consumed, that is, burned as fuel, increases as the ration increases above what is needed for maintenance, and inversely the proportion of the nutrients stored in the body as flesh and fat undoubtedly is less the greater the quantity fed is in excess of the demands for maintenance. A large excess over maintenance is relatively less efficient than a small one in the production of flesh or milk. There comes a point where additional food produces no additional gain, but only additional consumption. The age of the growing animal and the condition of a fattening animal also modify the efficiency of the food for production purposes, as does individuality, and with a cow the stage in the period of lactation. With all these variations no averages are possible which express with any definiteness fixed production values for the different nutrients. 


\section{CHAPTER XI}

\section{LAWS OF NUTRITION}

THE preceding pages have been devoted to a discussion of the origin of cattle foods, what they are in substance, how their nutrients are made available and how used. So far no attempt has been made to bring together in a concise form what may be called the fundamental principles or laws of nutrition. It is desirable, however, before passing to the consideration of the practice of cattle-feeding, to summarize the principles on which the science of cattle-feeding is based.

280. All energy and building-material applied to the maintenance and growth of the animal body come from the food, water, and oxygen being included in this term. The animal originates neither energy nor matter.

281. Only that portion of the food which is digested, i. e., that which is rendered soluble and diffusible by the digestive fluids so that it passes into the blood, is available for any use whatever.

282. The unutilized food and the wastes pass from the body in several directions. The undigested part mainly constitutes the solid excrement or feces. The urea and other nitrogenous compounds which are the unoxidized portion of the protein, pass out wholly in the urine. All digested nitrogen not stored is found here. The carbon dioxid is eliminated through the skin and lungs, chiefly the latter, and water is disposed of through the kidneys, skin, and lungs. 
283. The digested food is used in two general directions, (a) for the production of energy and (b) for constructive purposes.

(a) The food energy is made available through combustion, i. e., the oxidation of the carbon compounds of the food to simpler substances, carbon dioxid and water, thus liberating the energy stored in the plant during its growth. Protein is never fully oxidized, but carbohydrates and fats may be. All the organic nutrients may be oxidized to produce energy, the phycological energy values of protein, carbohydrates, and fats being approximately as $1,1,2.25$. The larger part of the energy used by farm animals comes from the carbohydrate portion of the food. This liberated energy finds expression in the animal organism in various ways, as heat, mechanical energy or motion, and chemical transformations. The total energy of food is never all available to the animal because of a loss in the excreta and gases. Moreover, the productive energy is much less than the available energy, because much energy is used in the work of appropriation of the food.

(b) The food compounds are used for constructive purposes, either without changing their general character, as, for instance, the building of muscular tissue from the plant proteins, or they may be reorganized into bodies of a very different character, as in the formation of animal fats from starch and sugar. Protein is used to construct muscular tissue, in fact, all the nitrogenous parts, and is a source of fat. Carbohydrates can only be used constructively for the formation of fat, and the same is true of food fats or oils. Mineral matter is needed for the formation of bone, enters into the constitution of the soft parts, and has important metabolic functions. 
284. The matter of the digested food, including water and oxygen, is exactly equal to that stored in the body or in milk, or both, plus that in waste products-feces, water, carbonic acid, and urine solids. Such a balance may not be maintained for any particular day, but will ultimately be found to exist.

285. Under given conditions of species, sex, climate, and use, a definite amount of digested organic matter is necessary to maintain a particular animal without gain or loss of body substance. This means simply that tissue wastes must be replaced, and the fuel-supply must be kept up.

If the animal receives no food, or less than the amount needed for maintenance purposes, tissue waste and the production of energy do not cease, but go on wholly or in part at the expense of the body substance.

286. Food supplied above a needed maintenance quantity may be utilized for the production of new substances or work or may be eliminated in part increasing the waste. Within limits, both things generally occur. In the proper sense of the term, no production ever occurs without an excess of food above maintenance requirements. Milk formation may sometimes go on at the expense of the body substance, but with proper feeding, milk, flesh or muscular work are produced at the expense of food supplied in excess of that needed for maintenance.

287. Regard must be had to the supply of particular nutrients as well as of total food. Even with an animal doing no work and giving no milk a certain amount of protein will be broken up constantly into urea and similar compounds, an amount which will be withdrawn from the body tissues to the extent that it is not supplied by the food. In addition to this, a milch cow, for instance, 
must have protein for the formation of the nitrogen compounds of the milk, or a steer for the growth of flesh, in a quantity proportional to the production, and food must supply it. There is, therefore, a minimum supply of protein, which, in a particular case, is necessary for the maintenance and for constructive purposes, less than which ultimately diminishes production to the extent of the deficiency, or else requires the use of body tissue.

288. The different classes of nutrients are to some extent interchangeable in their functions. That is to say, all the organic nutrients may be burned to supply energy. Protein may be so used even to withdrawing it from the purposes to which it is necessary unless the carbohydrates or fats are sufficient to protect it from being consumed as fuel. A proper supply of the non-nitrogenous nutrients is required, therefore, to insure the application of the necessary minimum of food protein to its peculiar uses. The carbohydrates and fats are the physiologically economical source of the main part of the energy used by farm animals. 


\section{CHAPTER XII}

\section{SOURCES OF KNOWLEDGE}

THE foregoing chapters embody many statements of principles and facts which have been made positively and without modification. To quite an extent these are based upon the conclusions of scientific men, i.e., conclusions which have been reached after such study of the problems involved as is competent to secure accurate information. In some cases this study has been severe and long continued, having been carried on by the use of methods and apparatus capable of the most precise measurements. Moreover, in the investigations of science an effort has been made to proceed logically, so that the results attained shall not be fallacious. Notwithstanding the fact that a great deal of our knowledge is the result of an earnest and impartial search after truth, under conditions especially favorable to its discovery, many persons are disposed to give more credit to traditions and conclusions of practice than to the carefully prepared verdicts of science. It may not be out of place, therefore, to present in this connection some of the considerations and methods which have to do with the acquisition of knowledge concerning animal nutrition, for this may aid us to appreciate the value of well-established facts and to exercise caution in accepting the verdicts either of science or of practice before they are thoroughly justified.

There are three general ways in which we may be 
said to have acquired knowledge in regard to feeding animals:

1. The observation of ordinary practice.

2. Practical experiments, so called.

3. Scientific investigation.

289. Conclusions from feeding practice.-Until within recent years, the practice of cattle-feeding has been entirely governed by the conclusions drawn from ordinary practice. Among the many men engaged in animal husbandry, certain ones possessed of more than average powers of observation and business ability have secured good results with certain feeding-stuffs and methods of feeding, and their practice has been accepted by their neighbors with no further demonstration than that these successful farmers sold fat cattle and obtained large returns from the dairy. During the centuries that man has had domestic animals under his care, certain results have appeared to follow from certain systems of feeding or the use of certain foods, and upon these so-called practical observations the feeder has built his creed.

In these ways there have come to be accepted, sometimes locally and sometimes generally, standards of feeding as to quantity, kind of ration, and times of feeding. At the same time, it was necessary only to attend a farmers' convention fifty years ago to become convinced of a great variety of opinions as to the best methods of practice. In fact, opinion was the court of last resort. There were then no known, well-established fundamentals to which appeal could be made as a basis for discussion. While many false notions were entertained, many of the beliefs then prevailing were undoubtedly correct or contained a germ of truth. It is generally safe to assume that when an opinion is 
widely and persistently held it is not altogether without reason or foundation. It is often the expression, in more or less correct terms, of some important principle. No one should lightly turn aside from widespread traditions and convictions in regard to any line of practice. A knowledge of the precepts governing the feeder's art that are the accumulation of experience in the care of animals is to be respected and is, to a great extent, essential to successful practice. It is also true that little substantial progress can be realized in any art if its underlying truths are not understood, for when this is the case the results of experience under one set of conditions do not serve as a guide under circumstances entirely different.

290. Practical feeding experiments. - With the advent of modern science and of the efforts to utilize it in agriculture, an attempt has been made to search for important truths more systematically, an effort undertaken chiefly by experiment stations. As one means of gaining knowledge, these institutions, and to some extent private farmers, have conducted many so-called practical feeding experiments in order to verify present beliefs, test theories, and solve existing problems. The relative value of various feeding-stuffs and rations for producing growth and milk and the influence of different fodders and grain foods upon the quality of the product have been the subjects of numerous feeding tests. Much valuable information has been secured in this way, but there has not always been a full recognition, even by experiment stations, of the limitations which should be observed in drawing conclusions from this manner of experimentation.

291. Inconclusiveness of ordinary feeding experiments. - In order to view this matter more in detail, let us 
consider experiments in testing rations for growth and milk production. The usual method of procedure with such feeding trials is either to feed two lots of animals on the rations to be compared and note the comparative growth or milk yield, or to feed the same lot on one ration for a time and then change to another ration.

If these tests are made with growing or fattening animals, the increase in live weight is taken as the measure of the relative efficiency of the rations compared. It should be said of these experiments that their apparent verdict is to be accepted with great caution, and definite conclusions are not justified until repeated extended trials of two rations or of two systems of feeding, made with the use of all possible precautions against error, and under a variety of conditions, give uniform and consistent results in the same direction. There are several reasons why this is so, the main one being that the increase in the weight of an animal is an uncertain measure of actual growth. Variations in the contents of the alimentary canal due to the irregularity of fecal discharge and to a lack of uniformity in the water drank may cause temporary variations in the live weight of considerable magnitude. Moreover, the nature of the growth of body substance is revealed neither by the mere weighing of an animal nor by his general appearance. Even if the changes in weight are due to an increase of body tissue, this may be more largely water in one case than in another, so that the real contribution of the food to the dry substance of the body may not be shown. Nor is the character of the solids deposited in the animal discovered by merely weighing him. In fact, by such practical experiments we simply learn that one set of 
animals has gained more or less pounds of weight than another set, but the why and the how are not explained.

Practically the same considerations pertain to feeding tests for milk production. When the milk flow from one ration is larger than from another, we can easily satisfy ourselves as to the comparative yield of milk solids, which is the real test of such production; but we are not able to decide whether the cow either may not have contributed to the milk secretion from the substance of her own body, or may not have gained in body substance, the extent of such loss or gain being greater, perhaps, with one ration than with another.

Even if these uncertainties did not exist, we have the still greater disadvantage of not learning by this means why a particular combination of feeds has superior qualities for causing growth or sustaining milk secretion. The mere data showing that an animal ate so many pounds of food and produced so many pounds of beef or milk are important business facts, but they reveal nothing concerning the uses of the several classes of nutrients and of themselves furnish slight basis for developing a rational system of feeding. We must somehow learn the function of protein, carbohydrates, and fats in maintaining the various classes of animals and the real effect of varying the source, quantity, and relative proportions of these nutrients before we can draw safe general conclusions.

292. Chemical and physiological studies.-As preliminary to more comprehensive and convincing methods of investigating feeding problems, there has been going on during many years a necessary study of the compounds which are found in plants and animals. Much has been learned about the ultimate composition and the constitution of the proteins, carbohydrates, and fats, their 
physical and chemical properties, the compounds into which these bodies break under certain conditions, the chemical changes to which they are subject through certain agencies, and their relation to one another. Investigations along these lines have for years occupied the time of some of our ablest scientists, and, while such researches when they were conducted may have seemed to the extreme utilitarian to be of little value, we now see how directly they are contributing to human progress and welfare.

To the above information has been added through physiological investigations a knowledge of the ways in which the several food compounds are transformed in digestion and in other metabolic changes, the avenues along which these compounds travel, and the ways in which their products of decomposition are discharged from the animal organism. We have learned how to distinguish between the digested and undigested food, have demonstrated that all the nitrogen of the decomposed proteins passes off in the urine, have measured the combustion of the nutrients and have learned how to strike a balance between the income and outgo of the animalbody. It is now possible to determine with reasonable accuracy just how much substance is retained or lost from the body of the experimental animal while eating a given ration, and what is the nature of the gain or loss. Very recently means have also been devised for measuring the heat given off by a man or an animal in order to ascertain the actual physiological values of different feeding-stuffs.

- 293. More accurate methods of investigation than practical feeding tests.-In applying the principles and facts of chemistry and physiology, the first advance from 
the ultra-practical feeding experiment in the direction of an accurate history of what occurs when the animal is eating a particular ration is the measurement of the digested nutrients and the determination of the gain or loss of nitrogen. This is accomplished, as heretofore stated, by ascertaining the quantity of various compounds eaten and the amount of the same in the feces, the difference being the digested portion. The urine is also collected, and if the nitrogen in it is less or more than that in the digested protein, then the animal is either gaining or losing nitrogenous body substance, unless the measurement is with a milch cow, when the nitrogen in the milk must be taken into account. By an experiment conducted in this way, with careful and continued weighings of the experimental animal, it is possible to secure a probable relation between a unit of digested dry matter and a unit of production. Such a method has been used to determine what is a maintenance ration for animals of several classes, and in those cases where the experiments have been continued for a sufficient length of time and have shown on repetition a reasonable agreement, we are justified in accepting the results as a close approximation to fact. When a ration keeps an animal in nitrogen equilibrium for one or more months and no material gain or loss of weight occurs, we may safely regard it as approximately a maintenance ration under the conditions involved. Experiments of the same kind are equally useful in testing the productive power of various food combinations, and whenever by such continued tests one ration shows no superiority over another, it is safe to assume that no differences exist which would be especially important to the farmer's pocketbook. This may be accepted as a business fact. 
294. Studies of food sources of animal fats.-Another class of experiments somewhat more severe in their requirements are those designed to give information as to the relation between the constituents of the food and the growth of the various tissues in the animal body or the formation of milk solids. The experiments conducted by Lawes and Gilbert on the formation of fat with swine may be cited in illustration of the methods used. These were planned so as to learn the amounts of digested protein, carbohydrates, and fat consumed by the animal and also the quantities of protein and fat stored in the body during a given period. "In experiment No. 1, two pigs of the same litter, of almost exactly equal weight, and, so far as could be judged of similar character, were selected." One was killed at once and its composition determined, and the other was fed for ten weeks on a fattening ration of known composition and then slaughtered and analyzed. The quantity of protein and fat which the pig's body had gained during the ten weeks as ascertained from the composition and weight of the two pigs was then compared with the food-supply of similar compounds. It was assumed that a pound of food fat could produce a pound of body fat and that 51.4 per cent of all the protein not stored in the body as such could be used for fat formation. Even with the most liberal allowances it was found that the protein and fat of the food could not possibly have been the sole source of the new body fat, thus forcing the conclusion that the carbohydrates are fat-formers. Practically the same plan has been followed in studying the source of milk-fat. Several cows were fed on carefully weighed and analyzed rations extremely poor in fat, and the amount and composition of the feces, urine, and milk were ascertained during sixty to ninety days. The fat 
digested from the food and the theoretical fat equivalent of the decomposed protein as measured by the urine nitrogen were charged up against the milk-fat, and a large quantity of the latter could be accounted for only as having had its source in carbohydrates.

Another method of investigating fat formation has been used with dogs. It is well known that when an animal is deprived of food the expenditure of energy by the body is maintained at the expense of body substance. Both muscular tissues and fatty substance are broken down and used in this way, the latter being regarded as furnishing the most natural and available supply of fuel. It was found in the case of dogs that after a certain number of days of starvation there occurred a sudden and large increase in the waste of nitrogen compounds as shown by the urine excretion, the explanation for this being that the body fat had become exhausted and a demand was at once made upon the protein tissues for the necessary supply of energy. As soon as this rise of nitrogen waste appeared, then the dog was allowed to eat, and whatever fat was found in the body at the end of the feeding-period was regarded as having been formed from the food taken after the starvation period. If, for instance, the ration was wholly protein and fat was found to have become deposited in the body, this was regarded as proof of the formation of fat from protein. Such experiments as these have not always been conclusive, although they are regarded by some scientists as having furnished proof that protein may be a source of fat.

295. The respiration apparatus.-After all, the investigations of the kinds described fail to furnish data so accurate and so complete as are necessary for entirely 
safe conclusions. In every instance, one or more assumptions are involved where definite proof is not furnished. Nothing short of a complete record of the income and outgo of the animal organism during the experimental period is conclusive evidence as to whether there has been a gain or loss of body substance and what is the kind and extent of the growth or waste. The securing of such a record is an expensive and laborious task. It requires not only complete information in regard to the quantity and composition of the food, but also an acccurate measurement of the excreta, including the feces, the urine, the respiratory products, and the matter given off through the skin. Such measurements are taken by means of a respiration apparatus, a costly and complicated mechanism, a detailed description of which would be of little use to most readers. It is sufficient to state that this apparatus makes possible the collection and analysis of all the excretory products, whether solid or gaseous. The experimental man or animal lives in a closed chamber into which is introduced food and fresh air and from which is pumped the vitiated air, the water and carbon dioxid of which are absorbed and weighed.

All conclusions drawn from experiments with the respiration apparatus are based largely upon the income and outgo of nitrogen and carbon. As carbon is a constituent of all possible compounds of the animal body except the mineral, it is certain that when the body gains in carbon it gains in organic substance of some kind, and if it loses in carbon there is a waste of organic body substance. The general character of the gain or loss can be determined by the nitrogen balance. If more nitrogen is taken in by the experimental animal than is given off, it is clear that the nitrogen 
compounds of the body have received an accession. Knowing as we do the proportions of nitrogen and carbon in the various tissues of the animal, we can calculate how much of the gain or loss of carbon belongs in the nitrogenous substance deposited or wasted. If more carbon is gained or lost than can possibly be associated with the nitrogen gained or lost, then there has been a gain or loss of fat, because protein and fat being the main constituents of the animal carcass, any considerable retention of carbon must be in one of these forms. If there has been nitrogen equilibrium, all excess or deficit of carbon belongs to a deposit or waste of fat. By such searching methods as these, it is possible to ascertain with a good degree of accuracy how food is used and what quantity and kind of nutrients are needed in maintaining an animal under given conditions.

296. Determination of energy values.-We have reached a point in our study of animal nutrition where we realize that food values are to some extent commensurable with energy values and that it is desirable to know the energy product of different compounds and feeding-stuffs. Moreover, we cannot possess sufficiently full knowledge concerning the energy needs of the several classes of animals until we have measured energy use in terms of heat given off under the various conditions of work and of production. The mere determination of the income and outgo of the animal body does not necessarily measure energy needs or use. We may go so far as to ascertain that a certain amount of carbon from a certain source was consumed in a given time, but from this alone we do not learn the extent to which this combustion has supported the internal and external work of the body. 
297. Calculation of the energy value of a ration.Three methods may be adopted for determining the energy expenditure by an animal eating a given ration. The one of these most easily carried out is largely a matter of mathematical calculation. By the use of average digestion coefficients it is possible to ascertain approximately the amounts of digestible protein, carbohydrates, and fats contained in any ration which is apparently accomplishing a desired result. We have learned from previous determinations what are the calorific values of individual compounds such as albumin, starch, sugar, stearin, and olein and these compounds are assumed to represent the energy value of the classes of nutrients to which they belong. If, then, we multiply the calculated quantities of digestible protein, carbohydrates, and fats by their respective assumed energy factors, we get a number which has been taken as an expression of the available energy of the ration under consideration. This method must now be regarded as greatly inaccurate, because the metabolizable energy of the digestible material of feeding-stuffs is found to be much below the calorific value of the pure nutrients to which energy measurements have been applied. See Tables XXVIII and XXXIII. The older theoretical method by computation might give the relative, but not the actual, units of metabolizable energy in the several feeding-stuffs, for the results by means of combustion in a Zuntz calorimeter of pure nutrients do not measure physiological results with complex mixtures.

298. Energy value of digested nutrients.-A second method, which is probably a step in the direction of greater accuracy, is to determine by the use of a calorimeter the heat units of the ration and also of the urine and feces. 
The differences between the food heat units and those found for the excreta might seem to represent the energy value of that portion of the ration digested by the animal. This would be an accurate measurement of the available or metabolizable energy of the ration if it were not for the loss of unoxidized gases, chiefly methane, which contribute nothing to the maintenance of the animal. Accurate work requires that these gases be measured. But even then it does not appear to what extent the digested nutrients have been oxidized with a corresponding radiation of heat or whether there has been a gain or loss of body substance. If there has been a gain of body substance, then the ration is productive, but if there has been a loss of body substance, then the ration is below the required standard for the maintenance of the particular animal under investigation. In a study of energy relations, it is therefore even more necessary to resort to a respiration apparatus of some sort than in determining food balances. We must learn the actual extent of the food combustion which occurs if we would have all the data necessary for measuring energy used, and here we come to the third and most accurate method of determining energy expenditure, viz., experiments with a respiration apparatus.

299. Measurement of food combustion.-There are two general ways of ascertaining the extent to which food is burned by any living organism. One is to measure the products of combustion and the other is to measure the amount of oxygen used. It is self-evident that no combustion can occur without the use of oxygen, and so if the experimenter is able to learn just how much of this element is taken up in uniting with the carbon and hydrogen of the food, he has a direct and accurate means of 
measuring actual energy production. The older forms of respiration apparatuses simply allowed an estimation of the carbon dioxid and water given off by the animal. How much of the water was formed by the oxidation of the hydrogen of the food and how much was simply evaporated from the store taken in as water, it was impossible to know by direct determination. This could only be calculated. The carbon dioxid was, on the other hand, a direct and accurate measure of the combustion of carbon. Later devices, as, for instance, the one used by Zuntz, allow a direct determination, not only of the products of combustion, but of the oxygen absorbed by breathing. This method of work seemed to have advantages, as one measurement not only checks the other, but makes it possible to ascertain the actual oxygen consumption during any given period of the experiment, as, for instance, when the animal is at rest, when masticating food, or when performing a given amount of external work. In this way, Zuntz made his masterly demonstrations of the differences in oxygen use with different foods during the period of mastication.

300. Respiration calorimeter.-None of the older apparatuses, whether allowing the determination of oxygen consumption or not, measured the heat radiation from the animal body, or, in other words, the amount of energy actually evolved from internal combustion. Professors Atwater and Rosa first devised a respiration apparatus which was at the same time a calorimeter. The quantity of heat radiated from a man or other animal confined in this calorimeter is absorbed by a known volume of water and is thus determined. This is a great advance towards certainty, because direct measurements of the energy production of a ration are 
thus made possible and the necessity for theoretical assumptions is largely removed.

301. Study of the efficiency of individual proteins.The type of investigation in animal nutrition upon which much emphasis is now placed is a study of the function and relations of individual compounds. The proteins have been especial objects of studies of this kind, studies which have been made possible through the isolation and identification of many individual vegetable and animal proteins. The general plan of work has been to feed only one well-identified protein in connection with a sufficient supply of all the other nutrients necessary to maintenance and growth. In this way it has been demonstrated that the individual proteins are greatly unlike in their nutritive value and relations, it being found that some will not sustain growth or even maintenance, while other single proteins constitute an efficient protein-supply for any known protein use.

It is already made clear to the reader, doubtless, that the demonstration of facts and principles in the domain of animal nutrition is exceedingly difficult. It should be equally clear that when conclusions are reached in ways which have been briefly described, they are worthy of respect and should have greater weight than the necessarily imperfect observations of common practice. Science often errs in her deductions, but the efforts of her workers are constantly directed toward the elimination of false conclusions, so that unsound theories are not likely to be accepted for a great length of time. 



\section{PART II}

THE PRACTICE OF FEEDING 



\section{CHAPTER XIII}

\section{CATTLE FOODS-NATURAL PRODUCTS}

THE number of cattle foods now available for use is very large, and the list appears to be constantly increasing. Not only have several fodder plants been added to those formerly grown, but we have now a great variety of waste products from the manufacture of oils, starch, and human foods that are being placed upon the market as feeding-stuffs. At one time farmers produced all their cattle ate, and this was done without going outside a very limited list of forage plants and grains. All this is changed, especially in the older, more thickly-settled portions of the United States, so that considerable knowledge is now needed regarding the composition and specific characters of the numerous kinds of feeding-stuffs if they are to be used intelligently.

302. Classification of cattle foods.-It will aid in discussing this branch of our subject if we first note the divisions into which the materials used for feeding farm animals are grouped. There is more than one basis upon which it is possible to make these divisions-botanical relations, the portion of the plant used, whether stem or fruit, and chemical composition. As a matter of fact, all these and other distinctions are involved in the classification of the cattle foods in common use at the present time.

The feeding-stuffs of vegetable origin are generally divided into four classes: (1) Forage crops, consisting 
of the stem and leaves of herbaceous plants, either in green or air-dry condition, to which is attached in some cases the partially formed or wholly mature seed or grain; (2) roots and tubers, or the thickened underground portions of certain plants; (3) seeds or grains; (4) parts of a plant which are the by-products from the removal of other parts by some manufacturing process. These are the commercial by-product feeding-stuffs.

FORAGE FOODS

303. Classes of forage crops. - The valuable forage plants of the United States belong mostly to two families, the grasses (Gramineæ) and the legumes (Leguminosæ). June grass, red-top, timothy and the cereal grain plants are types of the former; and the clovers, alfalfa, the vetches, and peas, of the latter. Whether in the pasture or in tilled fields, few plants outside of these divisions contribute materially to the supply of highclass fodders. The most essential difference between the members of these two families of plants when considered as feeding-stuffs is the larger proportion of nitrogen compounds in the legumes. It is characteristic of all legumes that their proportion of protein is high as compared with any other forage crops, and for this reason they are greatly prized on dairy farms. The fact that they are regarded as increasing materially the nitrogen supply of the farm from sources outside the soil also adds to their value.

304. Green vs. dried fodders; conditions of drying.Nearly all of the herbaceous plants that are grown for consumption by farm animals may be fed either in a green or dry state. Oats, maize, clover, alfalfa, and other spe- 
cies which serve so useful a purpose as soiling crops for summer feeding are also dried that they may be successfully stored for winter feeding, although mazei, and, to some extent, other crops, are now preserved in a green condition through the process of ensilage. (See Pars. 37-41.)

305. Effect of drying fodders.-The advantages and disadvantages of green as compared with dry fodders have been much discussed. It is safe to assert that the compounds of a dried fodder which has suffered no fermentation are practically what they were in the green, freshly cut material, excepting that nearly all of the water contained in the green tissues has evaporated and that in drying there is a possible loss of an imperceptible amount of volatile compounds, whose presence in the plant affects its flavor more or less. It is certain that curing a plant generally diminishes its palatableness and increases its toughness, or its resistance to mastication, although with many crops, as for instance the early cut native grasses, these changes do not affect nutritive value to a material extent. There is no question but that the mere matter of being green or being dry has very little influence upon the energy value of a fodder or upon the extent to which it will sustain growth or milk formation. We must, however, take into account the desirability of the highest state of palatableness.

306. Losses through curing fodders.-Drying fodders under perfect conditions is not always possible. The long-continued and slow curing of grass in cloudy weather, especially when there is more or less rainfall, is accompanied by fermentations that result in a loss of dry substance more or less extensive, and which oxidize some of the most valuable compounds, principally the sugars. The tissues of certain plants, maize for instance, are so 
thick that rapid curing in the field is never possible, and fermentative changes are unavoidable. It is probable that maize fodder and stover are never field-dried without a material loss in food value, for it is found that even when the stalks are finely chopped, drying by artificial heat is necessary to a complete retention of the dry matter. The extent of the loss from curing fodders must be very variable. So far as we know, grass, which in "good haying weather" is well stirred during the day and packed into cocks over night so as to avoid the action of heavy dew, suffers practically no deterioration, while dull weather or rain may cause a serious loss. It is doubtful, however, whether night exposure during good weather is sufficiently injurious to justify the expense of cocking partially cured hay. On the other hand, the economy of using hay caps during unfavorable weather is without question. The over-drying of hay before raking into winrows and "bunching" so as to cause a loss of the leaves and the finer parts through brittleness may be as wasteful as under-drying and the consequent fermentation. Overdried hay does not pack well in the mow and is less palatable. The leguminous hays, such as clover and alfalfa, are expecially subject to loss from over-drying before handling. Fodder crops, if dried at all, should be dried to such a percentage of moisture that they will not "heat" to discoloration after being packed in large masses and lose value from the same general causes that operate in field-curing under bad conditions. (See Par. 45.)

307. The harvesting of forage crops.-The result to be achieved in the growing of forage crops is the production on a given area of the maximum quantity of digestible food materials in a palatable form. The age or period of growth at which a forage crop is harvested is an impor- 
tant factor in this relation and may affect the product in three ways: (1) in the quantity of material harvested, (2) in the composition of the crop, and (3) in the palatableness of the resulting fodder. In discussing this question we must recognize the fact, first of all, that in these respects no general conclusion is applicable to all crops. What would be wisest in the management of the meadow grasses might be wasteful in handling the legumes, and especially so in harvesting maize.

308. Maximum yield of forage crops at maturity.It is safe to assert that in general the maximum quantity of dry matter is secured when forage crops are allowed to mature fully and ripen. The only exception to the rule is found in the legumes such as the clovers and alfalfa, where at maturity the leaves unavoidably rattle off and are lost, either before or during the process of curing. The fact that growth of dry matter takes place up to the time of full maturity is well illustrated by the results of experiments conducted on the farms of the Pennsylvania State College, the New York Experiment Station, and the University of Maine, in cutting timothy grass, clover, and maize at different stages of growth. These results are summarized in the accompanying tables:

Table XliV. Thmothy Grass (Yield of Dry Hay to the Acre)

\begin{tabular}{|c|c|c|c|}
\hline \multirow{2}{*}{ Stage of growth } & \multicolumn{2}{|c|}{ Results in Maine } & \multirow{2}{*}{$\begin{array}{c}\text { Results in Pennsyl- } \\
\text { vania-two farms } \\
\begin{array}{c}\text { Av. } 2 \text { years } \\
1881-1882\end{array}\end{array}$} \\
\hline & $\left|\begin{array}{c}\text { Av. } 3 \text { years } \\
1878-1880\end{array}\right|$ & $\begin{array}{l}1 \text { year } \\
1889\end{array}$ & \\
\hline $\begin{array}{l}\text { Nearly in head } \\
\text { Full bloom } \\
\text { Out of bloom or nearly ripe } \\
\text { Ripe }\end{array}$ & $\begin{array}{l}\text { Pounds } \\
3,720 \\
4,072 \\
4,136 \\
3,832\end{array}$ & $\begin{array}{l}\text { Pounds } \\
4,225 \\
5,086\end{array}$ & $\begin{array}{l}\text { Pounds } \\
2,955 \\
3,501\end{array}$ \\
\hline
\end{tabular}


Maize for Silage (Yield of Dry Matter to the Acre)

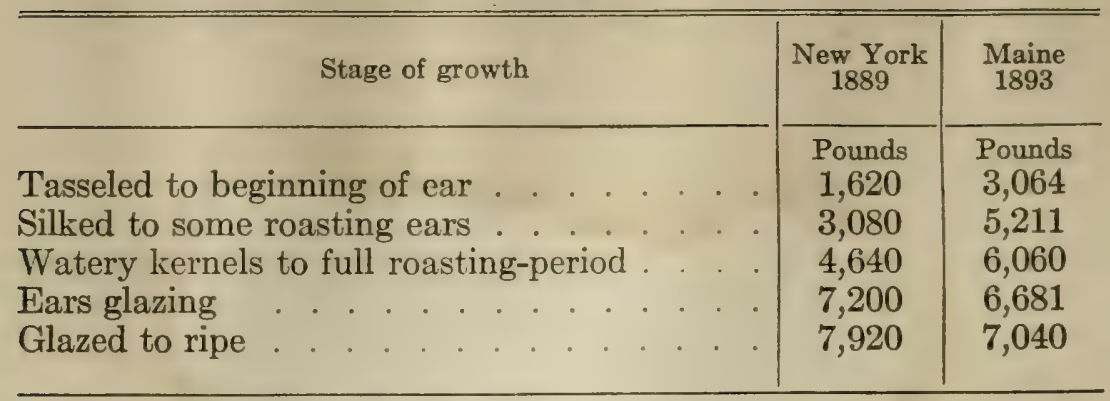

Red Clover (Yield of Dry Matter to the Acre)

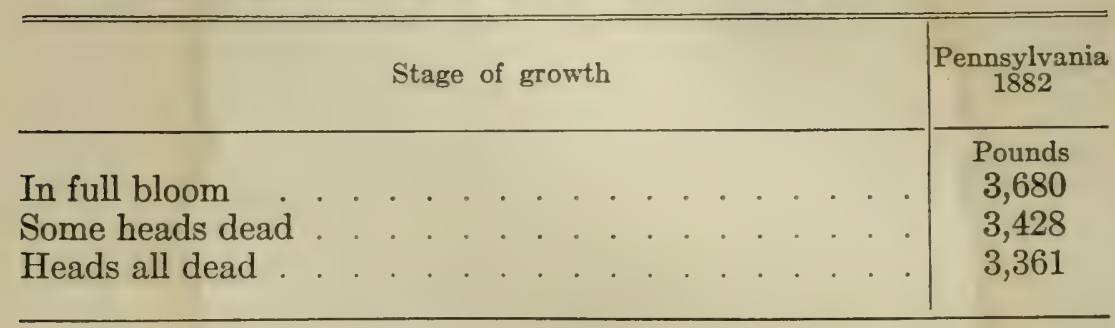

These data are convincing testimony as to the growth of dry substance in certain forage crops up to and including the period of ripening. Clover is an apparent exception, but is probably not really so because after the heads begin to die there is an actual loss of dry matter from the shedding of the leaves.

309. Value of crops not proportional to yield.-It does not follow when a plant increases in its yield of dry matter that its nutritive value has proportionately increased. The end to be sought is the largest possible quantity of available food compounds, and it is entirely possible that changes in texture and in the composition of the dry substance may partially or fully offset the greater yield. With the meadow grasses this undoubtedly happens. The dry matter of mature grass contains a larger proportion of fiber than the immature. The progressive 
increase of fiber as the plant approaches ripeness is well illustrated by analyses made at the Connecticut Experiment Station of a sample of timothy grass cut at different periods of growth:

Table Xlv. Composition of Dry Substance (Per Cent)

\begin{tabular}{|c|c|c|c|c|c|}
\hline Stage of growth of timothy & Ash & Protein & $\begin{array}{l}\text { Crude } \\
\text { fiber }\end{array}$ & $\mid \begin{array}{c}\text { Nitro- } \\
\text { gen-free } \\
\text { extract }\end{array}$ & Fats \\
\hline Well headed out & 4.7 & 9.6 & 33. & 50.8 & 1.9 \\
\hline In full blossom & 4.3 & 7.1 & 33.3 & 53.3 & 2. \\
\hline When out of blossom & 4.1 & 7.1 & 33.8 & 53.3 & 1.7 \\
\hline Nearly ripe ... . & 3.6 & 6.8 & 35.4 & 52.2 & 2. \\
\hline
\end{tabular}

These analyses show that the changes are not confined to an increase of fiber. The relative proportions of ash and protein grow less as the plant matures. An examination of the nitrogen-free extract would probably show an accompanying decrease of the soluble carbohydrates.

The combined effect of these changes is to cause the plant to harden in texture and become less palatable and more difficult of mastication.

310. Age decreases digestibility.-The digestibility is naturally affected by age. Three American digestion experiments with timothy hay cut in bloom or before show an average digestibility of the organic matter of 61.5 per cent, the average from four experiments with timothy cut when past bloorn being 55.4 per cent. Doubtless the increase in dry matter when timothy stands beyond the period of full bloom no more than compensates for the decrease in digestibility. Using the average coefficients of digestibility and the average yields, as given in this connection, the yield of digestible 
organic matter would be in full bloom, 2,306 pounds, and when out of bloom or nearly ripe, 2,350 pounds. If one considers the decrease in palatableness the advantage is with the earlier cut hay.

These facts do not pertain to timothy alone. Other meadow grasses are similar in their characteristics of growth. The clovers, and especially alfalfa, deteriorate to a marked degree from the same cause when allowed to ripen too fully before cutting.

It is probable, all factors considered, that if the grasses and clovers which are cut for hay could be harvested when in full bloom a desirable compromise would be effected between quantity and quality. Alfalfa should be cut no later than when the first bloom makes its appearance.

311. Maize unlike other grasses.-Conditions are quite different with maize. This plant in maturing gains not only in quantity but in quality. In support of this statement data are cited from an experiment conducted at the Maine Experiment Station.

The following is the composition of the dry matter of the corn when cut at several periods of growth:

Table XLVI. In 100 Parts Water-free Substance of Matze

\begin{tabular}{l|r|r|r|r|r|r|r}
\hline \multicolumn{1}{c|}{ Stage of growth } & Ash & Protein & $\begin{array}{c}\text { Crude } \\
\text { fiber }\end{array}$ & Sugar & Starch & $\begin{array}{c}\text { Total } \\
\text { nitro- } \\
\text { gen-free } \\
\text { extract }\end{array}$ & Fat \\
\hline Very immature, Aug. 15 & 9.3 & 15. & 26.5 & 11.7 & & 46.6 & 2.6 \\
A few roasting-ears, Aug. 28 & 6.5 & 11.7 & 23.3 & 20.4 & 2.1 & 55.6 & 2.9 \\
All roasting-stage, Sept. 4 & 6.2 & 11.4 & 19.7 & 20.6 & 4.9 & 59.7 & 3. \\
Some ears glazing, Sept. 12 & 5.6 & 9.6 & 19.3 & 21.1 & 5.3 & 62.5 & 3. \\
All ears glazed, Sept. 21 & $\mathbf{5 . 9}$ & $\mathbf{9 . 2}$ & $\mathbf{1 8 . 6}$ & $\mathbf{1 6 . 5}$ & 15.4 & 63.3 & 3. \\
\hline
\end{tabular}

Here we see the same decrease in the proportions of ash and protein as occurs with timothy, but, unlike 
timothy, the maturing of the maize causes a decrease in the percentage of fiber and a material increase in the relative amount of the soluble carbohydrates, sugar, and starch.

These data give us every right to expect that the dry matter of the mature corn plant is more digestible than that of the immature plant, and experimental tests show this to be the case. There follows a summary of American digestion experiments bearing on this point:

Table XlViI. Digested from 100 Parts Organic Matter

\begin{tabular}{ll|l|l|l|l|l|l|l}
\hline & & \multicolumn{2}{|c|}{ Corn fodder } & \multicolumn{2}{c}{ Corn silage } \\
\cline { 2 - 6 } & & Max. & Min. & Av. & Max. & Min. & Av. \\
\hline Cut before glazing, 13 experiments &. &. & 71.4 & 53.6 & 65.7 & 77.8 & 56.6 & 67.4 \\
Cut after glazing, 10 experiments . . . & 74.2 & 61.2 & 70.7 & 80.2 & 65.2 & 73.6 \\
\hline
\end{tabular}

The advantage is seen to be with the mature corn. It is fair to conclude from all these observations that harvesting the corn plant when immature is injudicious from every point of view.

312. Alfalfa.-Alfalfa has become in many parts of the United States one of our most important forage crops. Its points of excellence are a high degree of palatableness, large relative yield, its partial independence, at least, of a soil-supply of nitrogen, and its efficiency as a soilrenovating crop. From three to five cuttings may be made annually; and the yield, according to records in central New York, sometimes reaches the equivalent of five tons of hay. The fact that it is a leguminous plant indicates a useful place in farm cropping because of the fact that the percentage of protein it contains is considerably higher than that of the true grasses. 
In order to successfully establish this plant in many sections it is necessary to inoculate the soil with the bacterium that sustains a symbiotic relation with this legume, and coapply some form of lime when the soil has a high degree of acidity.

It should be stated that the relative feeding value of alfalfa has been overestimated as compared with other legumes, such as the clovers. It is doubtful whether alfalfa hay cut and cured under the best of conditions is superior in quality to the best quality of clover hay.

\section{SILAGE}

About forty years ago a new process for preserving crops in a green condition was introduced into the United States, viz., ensilage. This consists in storing green material in receptacles called silos, in masses sufficiently large to insure certain essential conditions. Within a brief period after maize or other green material is packed in a silo the mass becomes perceptibly warm, and in the course of two or three days it reaches its maximum temperature, which is much above the average heat outside. This rise in temperature is due to chemical changes which involve the consumption of more or less oxygen and the production of compounds not previously existing in the fresh material.

313. Nature of the changes in the silo.-These changes are very complex. They have been regarded as due to the activity of a variety of ferments, principally those which are believed to cause the formation of alcohol and acetic, lactic, and other acids. Whether the oxidations occurring in the silo are wholly induced by ferment action or in part at least are the result of oxidations 
brought about in other ways is a point over which there has been some recent interesting discussion.

Babcock and Russell carried on at the University of Wisconsin able and very suggestive investigations concerning the causes of silage formation. They conclude that the theory that silo changes under normal conditions are due wholly to bacteria "does not rest on a sound experimental basis."

Their data led them to regard respiratory processes, both direct by the plant cells and intramolecular, as the main causes of the chemical transformations which produce carbon dioxid and the evolution of heat within the ensiled mass. The direct respiration appropriates the oxygen confined in the air spaces of the silo, and the intramolecular respiration uses oxygen combined in the tissues. Both forms of respiration go on only so long as the plant cells remain alive. Concerning bacteria the authors say: "The bacteria, instead of functioning as the essential cause of the changes produced in good silage, are on the contrary only deleterious. It is only where putrefactive changes occur that their influence becomes marked."

Doubtless intramolecular respiration is continued longer in immature and succulent plant tissues than in tissues where the cells have reached maturity, and so the losses in the silo with immature plant substance are greater than with mature. Analyses of silage from frozen corn and feeding trials with this material show that it is not economy to cut immature corn for fear of frost, as the increase of dry matter much more than balances the loss from the freezing.

314. Losses in silo.-Whatever are the inducing causes, a careful record of what takes place in the silo, 
shows that the silage contains considerably less dry substance than the original fresh material. Loss occurs through the formation of volatile products. An examination of the fresh corn and of the silage shows that the latter contains much less sugar than the former, sometimes none at all. In the place of the sugar we find a variety of acids, chiefly acetic and lactic. This is a change similar to the formation of acetic acid in cider and lactic acid in milk, in all cases sugars being the basal compounds. Determinations of acidity in silage by Morse during several years showed it to vary from .8 to 1 per cent. Along with the development of these acids, carbon dioxid and water are formed from the carbon compounds of the ensiled material. In other words, combustion takes place and more or less of dry matter is actually burned up, thus generating heat and causing rise of temperature of the fermenting mass. The amount of dry matter thus lost is determined partly by the kind of crops and the care with which the silo is built and filled.

Another important chemical change induced by fermentation is a splitting up of a certain portion of the proteins of the fermenting material into amino acids, some of which compounds may have a more limited nutritive function than the proteins. Investigation conducted at the Pennsylvania State College showed that in some cases over half the nitrogen of silage existed in the amino acid or amide form, this being between two and three times as much as was found in the original fodder. Probably the same change takes place in the field-curing of fodder, but no data are available on this point. Starch seems to resist the usual silo oxidations. In certain experiments a considerable loss of nitrogen is reported. It is hard to understand, though, how this can occur to any 
large extent unless the conditions in the silo are very bad, so that putrefactive fermentations set in. An extensive loss of nitrogen compounds certainly would indicate very serious and long-continued destructive changes.

Steaming the corn seems to depress the fermentations and decrease the percentage of acids that form. Knisely found .3 to .88 per cent acidity in steamed silage and 1 to 1.6 per cent in unsteamed.

315. Corn an important silo crop.-The nature of the changes and losses in producing silage have been dwelt upon partly because corn, the principal silo crop, is one of our most important forage crops, perhaps the most so on a dairy farm, and partly in order to illustrate the necessity and value of good management in preserving this crop by the silo method. Moreover, the loss that is incident to the field-curing of maize is practically the same in kind and is fully as large as that pertaining to silage, so that the facts presented are pertinent to both methods as well as to all circumstances where similar oxidations and fermentations are likely to ensue.

316. Extent of loss in the silo.-The extent of the loss of dry substance is important. It measures in a general way the difference between the food value of the silage and of the fresh material. The silo combustion reduced the energy or heat value which the fermented fodder will have whenever it is eaten by the animal. The heat lost would supply energy to an animal were the combustion to occur within the animal instead of in the silo. It is desirable, therefore, to know the extent to which dry substance is actually broken up in the preparation of silage. This loss has been measured by several investigators, and, as was to be expected, it has been found to depend greatly upon the conditions involved, 
the figures reached varying from about 2 to nearly 40 per cent of the dry matter of the fresh crop. In a majority of cases the loss has been over 15 and less than 20 per cent. King, of the Wisconsin Experiment Station, who gave the production of silage much study, concluded upon the basis of his observations that in good practice the necessary reduction of dry matter in making corn silage need not exceed 4 to 8 per cent, and with clover silage from 10 to 18 per cent.

317. Necessary loss in silo.-The necessary loss is explained as being that which occurs in the interior of the mass where all outside air is excluded and other favorable conditions prevail. Considering the contents of the silo as a whole, it will require careful attention to all details in order to reach King's estimate with the best conditions attainable.

This investigator found that 64.7 tons of silage packed in a silo lined with galvanized iron, thus securing a perfect exclusion of air, lost an average of 6.38 per cent of dry matter. This silo was filled in eight detached layers, and the proportion of loss in these several divisions, as affected by location, is most suggestive:

TABLE XLVIII

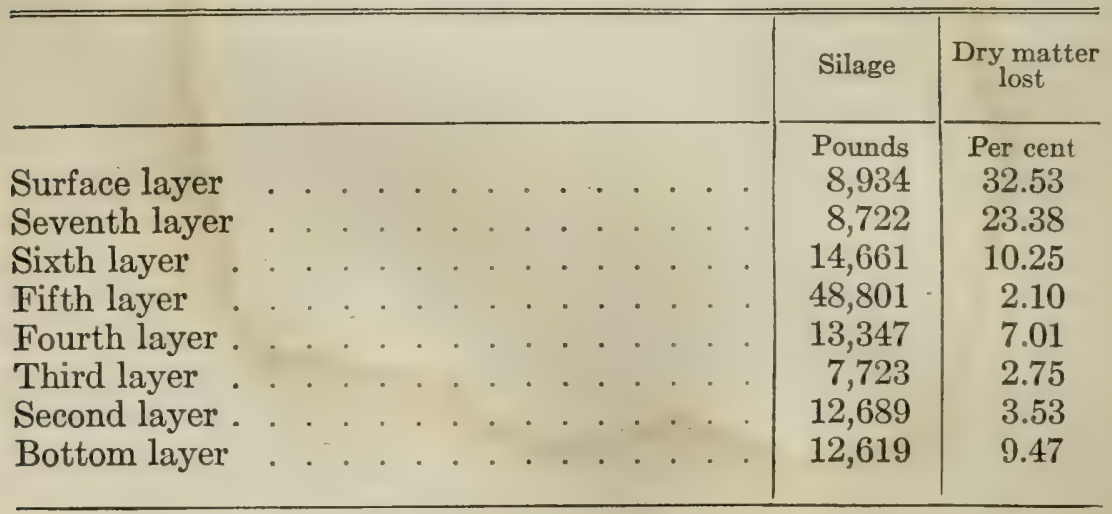




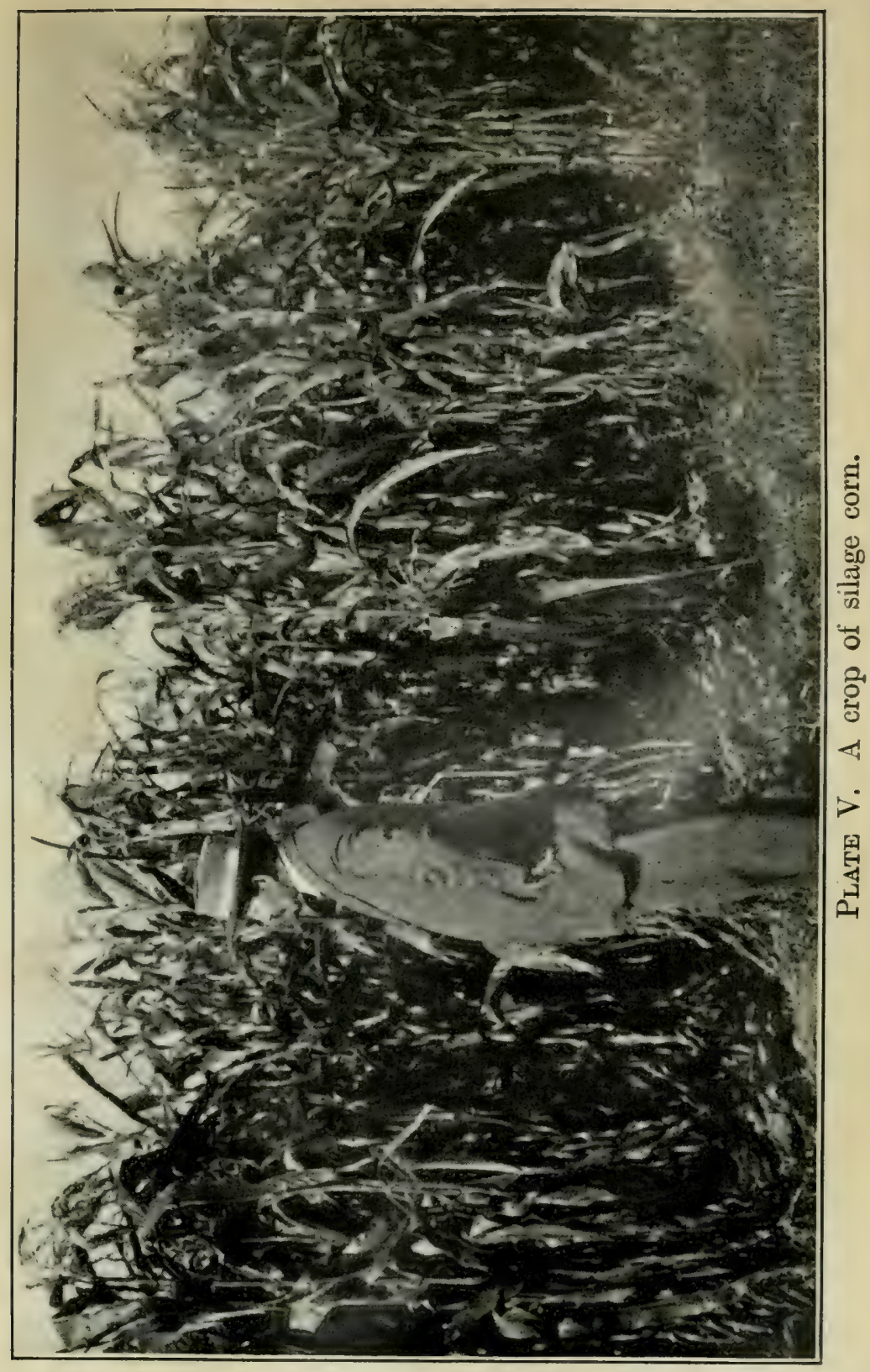



The mean loss of dry matter in the lower six layers was only 3.66 per cent. These figures show that it is profitable to make the walls of the silo air-tight, even at large expense.

318. Financial importance of silo losses.-The importance of reducing the loss in the silo to the lowest possible percentage is almost self-evident. As this point is capable of mathematical demonstration, it will be interesting and suggestive to calculate what might take place in a hundred-ton silo. In many of the trials which appear to have been conducted under not unusual conditions, a loss as high as 20 per cent of the dry matter put in the silo has been observed. In a hundred-ton silo filled with corn containing 25 per cent of dry matter, or 50,000 pounds, this would amount to the destruction of 10,000 pounds of dry food substance. As the loss falls chiefly on the sugars or other soluble bodies which are wholly digestible, the available nutrients in the fresh material are diminished by an amount of digestible dry matter equivalent to what would be required by ten milch cows during two months. If, therefore, by good planning and extra care this waste could be reduced threefourths or even one-half, the food resources for carrying a herd of cows through the winter would be materially increased, from five to seven and one-half tons of timothy hay being the measure of the saving in a hundred-ton silo.

319. Ensiling vs. field-curing.-The question is often raised whether ensilage or field-curing is the more wasteful method of preserving a forage crop. Considerable study has been given this matter, and the results secured have been taken as a justification of the statement that one method is about as economical as the other, which 
is correct if we consider only the outcome of certain comparisons. A general survey of the data accumulated shows that on the whole the waste has been the larger in field-curing. Observations made in six states reveal a loss by the old method as low as 18 per cent in only one case, and from 21 to 34 per cent in all others. Possibly under favorable conditions of weather, field-cured corn fodder may lose as little dry matter as silage, though this is doubtful, but in bad weather the waste from the exposed fodder is extensive. The greatest advantage in silo preservation is that conditions can usually be controlled with more satisfactory average results than are possible in field-curing. Other advantages pertain to the silo which are of a business nature and which need not be discussed here further than to affirm that the cost of a unit of food value is in general diminished by the use of the silo.

320. Crops for silage.-The number of crops that may be successfully ensiled is not large. Maize is the most valuable one for this purpose, and clover and alfalfa are stored in this manner with a fair degree of success although silage from these latter crops often, if not generally, carries an offensive odor. So are peas, especially when mixed with corn. The true grasses and cereal grains outside of corn are not desirable silo crops, first because the silage from them is generally poor in quality, and second because usually they may be successfully and more cheaply stored in an air-dry condition. Any crop with a hollow stalk, giving an inclosed air space-oats, for instance-is not adapted to silo conditions, and there is no justification for ensiling any fodder which is susceptible of prompt and thorough drying in the field, because in such cases there is an unnecessary waste of 
food substance by fermentation and an unnecessary handling of many tons of water contained in the green material, with no compensating advantages. But any crop used for the production of silage should be managed in the most efficient manner. A few general facts may be discussed in this connection.

321. Construction of silos. - Silos that are of proper construction and shape have air-tight perpendicular walls and a height considerably in excess of either of the horizontal dimensions. These conditions are essential to the completest possible exclusion of air and to the closest possible packing of the material, with a minimum of exposed upper surface.

Silos may be either round, square, or rectangular, provided that in the latter case one horizontal dimension is not too greatly in excess of the other. The shape of a silo which is most economical and efficient is not the same for all conditions, although the round and square forms hold most in proportion to the wall area. Many farmers desire to have the silo in the barn, and generally there the square or rectangular form is more economical of space than a round one. When built outside the barn, the round form, according to the opinion of many, may be used to advantage both as to expense and results. If a square or rectangular silo is built the corners should be cut off inside in order to prevent an access of air and the decay which occurs at those points when this is not done. Several kinds of materials have been used succesfully in building silos, wood, brick, and stone. If the walls are of masonry the inner surface must be cemented not only air-tight but so smoothly as to allow easy and uniform settling of the silage without leaving air spaces. If wood is used, which is the more common material, the 
inside construction must meet the same requirements. Lining a wooden silo with iron has been suggested as practical and economical. Cement is used successfully in the same way. Economy demands that as a preventive against decay the inner woodwork should at least be treated with some preservative, which may also serve the purpose of obviating excessive swelling and shrinking of the lining boards.

322. Filling the silo.-The condition of the crop and the manner of filling a silo determine to a great extent the character of the silage. Obviously it should be so done as to reduce the loss of food compounds to the lowest possible point. Three points are prominently discussed in this connection: (1) the condition of the crops, (2) the preparation of the material, and (3) the rate of filling.

323. Mature corn desirable for silage.-Experience has thoroughly demonstrated that the maturity of a crop influences its value for silage. This is known to be especially true of the corn crop. An immature corn fodder, which always carries a high percentage of water with less of the matured products, such as starch, is always certain to change to very acid silage. On the contrary, mature corn, when properly handled, is converted into a product with the minimum acidity and with an appearance and aroma much superior to that from the immature plant. Neither are satisfactory results secured from material that is overdry. It may be stated in general terms that the best results are obtained when the proportion of dry matter falls between 25 and 30 per cent. If corn is harvested for the silo after the kernels have begun to glaze, while the leaves are still green and before they show dryness, other conditions being favorable, it will meet every requirement for good silage. 
324. Cutting and shredding ensilage material.Whether the material with which a silo is filled shall be put in whole or after cutting or shredding depends to quite an extent upon its degree of coarseness. It is probable that clover, and even the smaller varieties of maize, are often successfully preserved without cutting, but no one professes that this can be done with the coarser varieties of maize. It is generally admitted that, with maize, cutting or shredding it increases the probability of satisfactory preservation, because the finer mechanical condition allows more uniform packing and prompter and more uniform settling. The highest grade of silage with the minimum loss is undoubtedly more surely made from cut or shredded material.

325. Rate of filling silo. - In the early days of silos it was taught that to insure the least possible waste by fermentation, the silo should be filled with the maximum rapidity and then promptly weighted. Following this view was the conclusion on the part of some that very slow filling with no packing other than that given by the weight of the mass, was the proper way to make silage of the highest quality. This method was advocated for producing sweet (?) silage. It allowed violent fermentation at first with resulting high temperatures, by which means bacteria were supposed to be killed and subsequent fermentations prevented, a conclusion so far not sustained by scientific observations. Moderately slow and continuous filling, rather than very rapid, has been advocated by leading authorities. Two advantages were claimed for this method, one being that more material can be stored in the silo and the other is that silage of a higher quality is produced with a smaller loss of dry matter. The first point must be conceded and the second 
claim may be true, although in part it lacks proof. It is hard to understand why slow filling, especially if intermittent, should not increase rather than decrease the losses of food compounds. Certainly the less compact the mass the more intense the oxidation and the higher the temperature, the latter condition indicating with certainty the extent of the combustion. This point is illustrated by results reached at the Pennsylvania State College when the chemical changes in two large tubs of sorghum silage were studied, one of which was compactly filled and weighted at once and the other loosely filled and weighted after five days. The temperature rose $17^{\circ}$ higher in the latter than in the former, with a loss of two and one-half times as much organic matter from the loosely filled tub. It follows from the theory of Babcock and Russell, previously noted, that the less the oxygen available in the air spaces and the quicker the plant tissue dies the less will be the combustion or loss of organic matter. These authors suggest as a practical application of their theory that the air be excluded from the silo as rapidly as possible and only mature corn be ensiled, because such tissue will die sooner than immature, having less vitality. Their data seem to prove conclusively, also, that the evolution of much heat when a fodder is first ensiled is not essential to the formation of first-class silage. The repeated exposure of a loose upper stratum, which occurs with slow, intermittent filling, must cause extensive loss from portions of the silo. It must be held, in view of the experimental data now at hand, that the more promptly the air is excluded and expelled by the reduction of the contents of the silo to a condition of maximum compactness, the less will be the fermentation losses. The term "sweet silage" me ins 
but little as indicating completeness of preservation, for it may even be the result of extensive fermentations, a condition expensively secured. Its significance is entirely different when the sweetness is due to proper maturity of the fodder plant.

\section{THE STRAWS}

326. When the grain plants which produce seeds valuable for cattle and human foods are threshed, or in some way manipulated to remove the seeds, the other parts of the plant constitute what we call straw in the case of the cereal grains and legumes, and stover in the case of maize. These fodders differ from the same plants, when cut in a less mature condition for hay or fodder, in being more tenacious and less palatable, with a smaller proportion of the more digestible, and therefore more valuable, compounds. The most useful of these materials for feeding purposes are corn stover, oat straw, and the legume straws. These are better relished by farm animals than wheat and barley straws, which are utilized mostly for litter.

\section{ROOTS AND TUBERS}

327. Certain species of plants, more especially beets, mangel-wurzels, turnips, rutabagas, carrots, and potatoes, are agriculturally valuable because of the store of nutrients which they deposit in subterranean branches or in roots. The original purpose of this deposit is, in the case of potatoes and artichokes, to nourish the young plants of the next generation, or, in the case of biennials like beets, to supply the materials for the seedstalk and seeds of the second year. Potatoes are not grown primarily as food for cattle, but roots have for 
many years been a standard crop for feeding purposes. This class of crops has the advantage of furnishing very palatable, succulent food, which may be kept in perfect condition during the entire winter season, an advantage which is not wholly measured by the actual quantity of nutrients supplied by these materials.

The disadvantages of these crops are that they are somewhat expensive to grow and necessitate the handling of large weights of water. A ton of turnips or mangels may furnish even less than 200 pounds of dry substance, to secure which 1,800 pounds of water must be lifted several times. The percentage of dry matter in roots and tubers varies in American products, on the average, from 9.1 per cent in mangel-wurzels and turnips to 28.9 per cent in sweet potatoes. Potatoes are more nutritive pound for pound than roots. The dry matter of this class of cattle foods is principally carbohydrate in its character, though the proportion of protein is as large and in some cases larger than in certain grain foods.

Two conditions are essential to the winter storage of roots without deterioration, viz., a low temperature, as near freezing as possible, and abundant ventilation. Large masses of roots unventilated are apt to "heat," and sometimes decay, with a resulting large loss in nutritive value.

\section{GRAINS AND SEEDS}

328. The conditions which provide for the maintenance of plant life also subserve the interests of the animal kingdom. We have seen that this is true of the store of starch and other compounds in tubers and roots, and it is a fact of much larger significance in the produc- 
tion of seeds, especially those of our cereal grains, including barley, maize, oats, rice, rye, and wheat. Other seeds, such as buckwheat, cottonseed, flaxseed, beans, and peas, also contribute an important addition to our animal feeding-stuffs. In all these species there is deposited in the seed coats and either around the chit or embryo or in the seed leaves of the embryo, a store of protein, starch, and oil, the purpose of which is to supply materials for growth during germination. This deposit of plant compounds represents the highest type of vegetable food, whether we consider concentration, palatableness, or nutritive efficiency. Besides, it is in such form that with ordinary precautions it is capable of indefinite preservation, without loss.

329. Storage of grain.-It often occurs that when newly-harvested grain is stored in bulk it heats and grows "musty." This condition is due to fermentations that are made possible by the high water-content of the fresh grain and which involve a loss of dry substance. It is very desirable that grain shall be thoroughly dried before threshing, and it is generally desirable to secure additional drying after threshing before storing it in large bins.

The agricultural value of the cereal grains is much enhanced by their adaptability to a great range of soil and climatic conditions. They are the American farmer's great reliance for the production of the highest class of cattle foods. Maize, especially, is grown from Maine to Florida and from the Atlantic to the Pacific. These crops are useful, not only for their seeds but as fodder plants. For soiling purposes, as well as a source of dried forage they are highly important. 


\section{CHAPTER XIV}

\section{CATTLE FOODS-COMMERCIAL FEEDING- STUFFS}

THE cereal grains and other seeds are the source of a great variety of by-product feeding-stuffs which have a large and widespread use, especially in the dairy sections of the United States. In the preparation of a great variety of human foods and of other materials important in industrial life, certain by-products are obtained which represent particular parts or compounds of the grain or seed. Whenever the methods of manufacture are such as not to injure the palatableness or healthfulness of these waste products, they may be utilized as cattle foods. As a matter of fact, a large proportion of our commercial feeding-stuffs is of this general kind and because these materials differ greatly in composition and nutritive value, the purchaser should clearly understand their source and character. Changes in methods and new manufacturing enterprises are constantly modifying the composition of old products and introducing new ones, consequently the facts as they exist at one time may not be applicable for a long period. There is need therefore of constantly keeping informed in regard to the various cattle foods found in the markets, if they are to be economically purchased and wisely used.

330. Classes of commercial by-product feedingstuffs.-For the purposes of description, the various 
by-product feeding-stuffs may be classified according to their origin. Their sources are mainly as follows:

1. The milling of wheat and other grains.

2. The manufacture of oatmeal and a variety of breakfast foods.

3. The manufacture of beer and other alcoholic drinks. 4. The manufacture of starch and sugars, chiefly from corn.

5. The manufacture of beet-sugar.

6. The extraction of oils, chiefly linseed oil and cottonseed oil.

7. Screenings from the milling of wheat, and other refuses.

8. Compounded feeds made up from a variety of by-products.

331. Wheat offals.-No commercial feeding-stuffs are regarded with greater favor, or are more widely and largely purchased by American feeders than the byproducts from milling wheat. Wheat bran and middlings are cattle foods of standard excellence, whether we consider composition, palatableness, or their relation to the quality of dairy products. These feeding-stuffs consist of particular parts of the wheat kernel, a knowledge of the structure of which aids greatly in understanding what they are and why they possess certain chemical and physical properties.

332. Structure of the wheat grain.-To ordinary observation the wheat grain appears to be merely a seed, but it is really a seed contained in a tightly-fitting seed pod. This pod, which is woody and tough, constitutes the outer coating of the kernel. On the seed itself are two more hard and resisting coatings, one of which is double, that serve to protect the softer parts. 
We find, then, that in every wheat kernel there are three coats entirely unlike the rest of the grain, because they consist of hard, thick-walled cells containing but little starch, if any, with a much larger proportion of cellulose or fiber than is found in the inner portion of the kernel. (Figs. 11 and 12.)

Just inside the innermost of the three outer coats is a layer of material very rich in protein compounds,

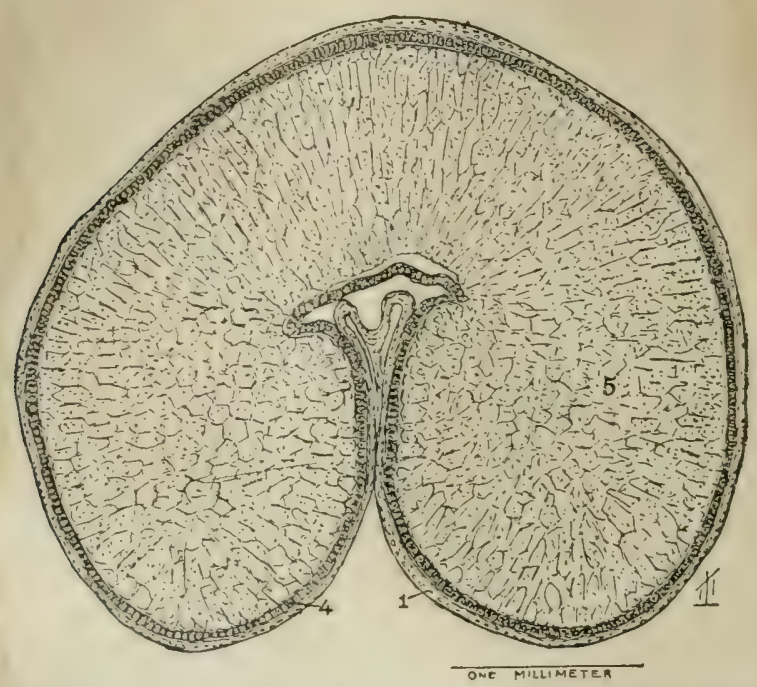

FIG. 11. Section of entire wheat kernel (enlarged 16 diameters). 1, seed pod and seed coatings; 4 , gluten layer; 5 , mass of starch cells.

which may properly be called the gluten layer. The great bulk of the wheat kernel is made up of cells closely filled with starch grains.) This is the soft white portion of the seed and is that which furnishes the flour. All of these parts serve to protect, and, in germination, to nourish the essential portion of the seed, the germ or embryo which lies "at the lower end of the rounded back of the kernel." Bessey, in an admirable description of 
the wheat kernel, tells us that the percentage proportions of its various parts are as follows:

\begin{tabular}{|c|c|c|}
\hline & $\begin{array}{l}\text { Per cent } \\
5\end{array}$ & Sta \\
\hline
\end{tabular}

333. The milling of wheat.-We are now prepared to understand the significance of the statement that in milling wheat the flour of various grades comes from the starch cells, the other portions passing into the bran, shorts, and middlings, which collectively are termed the offal. If only the coatings, gluten layer, and germ went to make up the offal it would include only about 14 or 15 per cent of the kernel, the flours taking the remainder, but, as a matter of fact, no milling methods so far

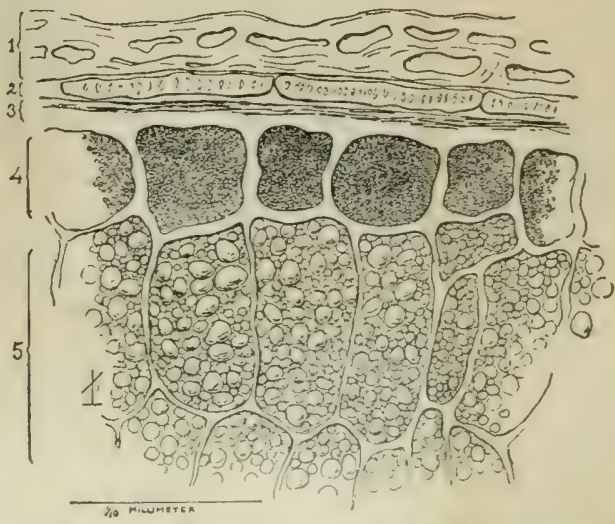

FIG. 12. Partial scetion of wheat kernel (enlarged 155 diameters). 1, seed pod; 2 , outer seed coat; 3 , inner seed coat; 4, gluten cells; 5 , starch cells.

used completely separate the starch cells from the inclosing tissue, so that the offal is perhaps never less than 25 per cent of the whole grain. In milling tests conducted by the Minnesota Experiment Station, the offal from several lots of wheat, good and bad, varied from 25 to 40 per cent. If four bushels of wheat are consumed per capita by the population of the United States, which is below the estimate, and if only one-quarter of this is converted into offals, the amount of bran and middlings annually consumed by our domestic animals is not less 
than $3,000,000$ tons, barring the quantity which may be exported.

334. Composition of milling products of wheat.-It is a fact worthy of special comment that because of a somewhat irrational standard of excellence for bread, certain parts of the wheat kernel best adapted to the nourishment of young and growing animals are separated with great care to be used by the brute life of the farm rather than by the farmer and his family. A comparison of the composition of the whole wheat kernel, white flour, and the various parts of the offal emphasizes this point. The figures given are taken from the results of an investigation by Snyder, of Minnesota, in which he compared the composition of different grades of wheat with that of the flour and products obtained from them:

Table XliX. Composition of Wheat and Its Miling Products (Per Cent)

\begin{tabular}{|c|c|c|c|c|c|c|c|c|}
\hline & \multirow{2}{*}{ Water } & \multirow{2}{*}{ Ash } & \multicolumn{2}{|c|}{ Protein } & \multirow{2}{*}{ Fiber } & \multirow{2}{*}{$\begin{array}{c}\text { Nitrogen- } \\
\text { free } \\
\text { extract }\end{array}$} & \multirow{2}{*}{$\mid \begin{array}{c}\text { Starch } \\
\text { and } \\
\text { dextrine }\end{array}$} & \multirow{2}{*}{ Fat } \\
\hline & & & Total & Gluten & & & & \\
\hline Wheat kernel & 10.2 & 1.8 & 13.7 & 13.5 & 3.2 & 69. & 64.9 & 2. \\
\hline Wheat flour & 10.6 & .4 & 11.2 & 11. & & 77.3 & 70.4 & .5 \\
\hline Wheat germ & 10.4 & 2.7 & 15.7 & 15.3 & & 67.7 & & 3.5 \\
\hline Wheat shorts & 10.1 & 3.1 & 13.1 & 12.9 & 5.4 & 65.3 & & 2.9 \\
\hline Wheat bran & 10.4 & 5.9 & 15.4 & 14.8 & 10.2 & 52.9 & & 5. \\
\hline
\end{tabular}

The greater richness of the coatings of the kernel in mineral matter, protein, fiber, and oil is made plain by this comparison. There is four times as large a percentage of mineral matter and of oil in the whole wheat as in the flour, nearly one-third more protein and considerably less starch. On the other hand, the bran is not less than ten times richer in mineral compounds and oil 
than the flour, one-third richer in protein, with correspondingly less starch. "Graham" flour, which contains more or less of those parts which pass into the offal in milling white flour, does not differ so much from the whole kernel. Middlings differ from bran in containing less of the hard, tough coatings and more of the finer parts of the kernels, and this feeding-stuff varies from the coarser kinds to the fancy middlings, according to the proportion of starchy material present. Red Dog flour is counted among the offals from milling wheat, and it represents the dividing line between the middlings and the high-grade flour.

335. Milling processes compared.-There is a belief more or less prevalent that bran from the old milling processes which contained more of the starchy part of the kernel than is now the case, was more valuable than roller process bran is. It is probable that a greater proportion of starch increases the digestibility of bran, and in this sense the old process bran was superior to the roller process product; but, on the other hand, the latter is more nitrogenous than the former and is therefore more efficient as a protein supplement to home-raised foods.

336. Screenings. - Wheat, when sold to the mills, contains besides inferior wheat grains a certain percentage of foreign materials such as other grains, weed seeds, chaff, bits of straw, and even particles of grit. Before the wheat is milled these materials are removed and in commerce are known as screenings. While the percentage of this foreign matter in wheat is small, the aggregate quantity of this offal put on the market is very large. Screenings contain ingredients of greatly varying quality, some of which are very inferior. This offal is almost 
wholly used as a part of the so-called compounded feeds, a fact to be reckoned with by purchasers of these mixtures.

Recently millers are mixing these screenings with the bran. Unquestionably the bran thus suffers deterioration proportionate to the quantity and quality of the screenings. The guarantee accompanying such mixtures generally specifies "wheat bran with the mill run

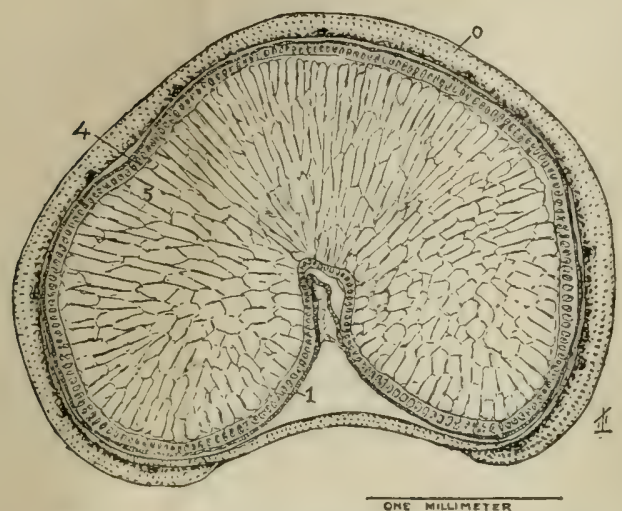

FIG. 13. Section of entire oat grain (enlarged 16 diameters). 0 , hull; 1 , seed coat; 4 , gluten layer; 5 , mass of starch cells. of screenings." This is a part of the growing practice to foist upon the consumer a great variety of by-products and refuses, some good and some bad.

337. Residues from breakfast foods.-In the manufacture of breakfast foods, the use of which has become so prevalent, certain by-products are obtained which are now found in the market as cattle foods. The preparation of oatmeal and similar materials involves the selection of the finest oat grains, i. e., those having the largest kernels, from which the hulls are removed. These hulls and the smaller oat grains, and perhaps bran, constitute by-products which, after being finely ground, are sold as oat-feed and in various mixtures. As the sale of oat hulls as such, or in a fraudulent way when mixed with other substances, is likely to occasion a financial loss to feeders, it is desirable to clearly understand the situation. We shall accomplish this by a 
study of the relation of the oat hulls to the kernel in quantity and composition. (Figs. 13 and 14.)

338. The oat grain, oat hulls.-It is common knowledge that the oat grain consists of a hull and kernel, which are easily separated. The former is fibrous and tough, and the latter soft with very little fiber. The hull forms a considerable portion of the grain. In 1894, the Ohio Experiment Station made a study of numerous varieties of oats. It was found that with sixty-nine varieties the hulls constituted from 24.6 to 35.2 per cent of the whole grain, the average being 30 per cent. It did not appear, contrary to the general opinion, that the proportion of hull was larger with light oats than with heavy, although observa-

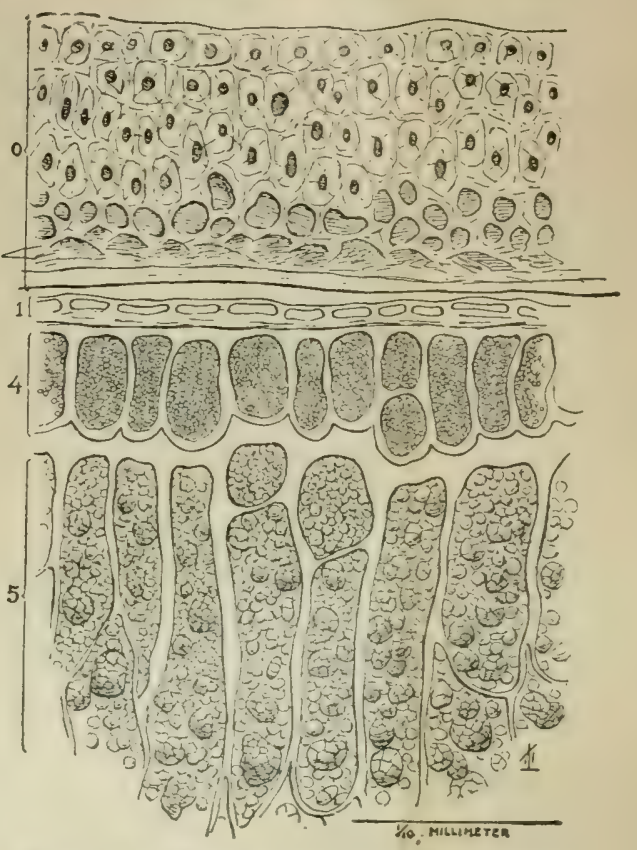

Frg. 14. Partial section of oat grain (enlarged 170 diameters). 0 , hull; 1 , seed coat; 4 , gluten cells; 5 , starch cells.

tions elsewhere have sustained the popular view. At the Mustiala Agricultural College twenty-eight samples of Finnish oats and twenty samples from five other countries gave from 28 to 32 per cent of hulls. Wiley states that the average proportion of hull to kernel is as three to seven, which varies with locality. The figures in the next table show the composition of the dry matter of whole oats, oat hulls, and the hulled kernel: 
Tabie $L$

\begin{tabular}{|c|c|c|c|c|c|}
\hline & Ash & Protein & Fiber & \begin{tabular}{|c|} 
Nitrogen- \\
iree \\
extract
\end{tabular} & Fat \\
\hline Whole oats, 30 samples & $\begin{array}{c}\text { Per cent } \\
3.4\end{array}$ & $\mid \begin{array}{c}\text { Per cent } \\
13.2\end{array}$ & $\begin{array}{c}\text { Per cent } \\
10.8\end{array}$ & $\begin{array}{c}\text { Per cent } \\
67 .\end{array}$ & $\begin{array}{c}\text { Per cent } \\
5.6\end{array}$ \\
\hline Hulls, New Jersey . & 7.2 & 3.5 & 32. & 56.3 & 1. \\
\hline Hulls, Vermont . & 6.9 & 4.4 & 29.5 & 57.2 & 2. \\
\hline Hulls, Wisconsin & 7.8 & 2.3 & 50.1 & 39. & .8 \\
\hline Hulled kernels, 179 analyses & 2.3 & 15.4 & 1.5 & 72.1 & 8.7 \\
\hline
\end{tabular}

The inferiority of the hulls as compared with the whole grain or with the hulled kernels is very apparent, because of their smaller proportion of protein and oil and their much larger percentage of fiber. If hulls are purchased at all the price should be on a par with that at which the coarsest and cheapest grades of fodders are sold.

339. Oat clippings.-Oat clippings is an offal introduced into the market at a later date than oat hulls. This waste consists of the hairs, oat dust, and light oats mostly separated from the oat kernel by the clipping process. Such material is inferior both as to composition and digestibility. It is now much used in compounded feeds. Farmers will do well to carefully inquire into the character of the so-called oat feeds and compounded feeds offered to them. These articles are often oat hulls, poor oats, and other refuse mixed with corn or with by-products of another class and are distinctly inferior to the whole grains. Such low-grade mixtures are not wisely purchased at prices nearly equal to those ruling for whole cereal grains of any kind.

340. Barley feed.-This is a by-product from the manufacture of pearled barley, and like oat feed consists of the hulls and portions of the grain and contains more 
fiber and less starch than the original grain, its value being proportionately less.

341. Hominy feed.-Hominy is made from corn and consists of the hard portions of the kernel, leaving as a residue the hull, germ, and part of the starch cells, which collectively are sold as hominy feed or chop. This differs from the whole kernel but little in composition and is practically as digestible.

342. Brewers' grains; maltsprouts.-Sugar in some form is at present essential to the production of alcoholic beverages, a cheap supply of which is obtained by converting the starch of certain cereal grains into maltose, which afterward passes into fermentable sugars. This result is accomplished by placing barley and other grains under such conditions of moisture and temperature that they germinate. We have already seen that during germination the starch of a seed is converted into maltose through the action of a diastatic ferment (see Par. 94), and the maltster arrests this germination at a point which gives the maximum quantity of sugar. The malted grains are subsequently dried and the sprouts after removal appear in our markets in an air-dry condition, constituting one of our valuable nitrogenous feedingstuffs. The malted grains are then crushed, the sugar is extracted from them, and the residue is known in commerce as brewers' grains, a by-product feeding-stuff fairly rich in protein. The high proportion of protein is due to the fact that the starch has been largely removed, leaving the other constituents behind in a more concentrated form. These grains are mostly dried and may then be shipped to distant markets in a perfectly sound and healthful condition. 
343. Residues from starch and glucose manufacture.The gluten meals, gluten feeds, corn bran, and the like are residues obtained in the manufacture of starch and glucose from the maize kernel. This kernel, like that of wheat, is not homogeneous in structure and composition, a condition which makes it possible, through mechanical or chemical operations, to secure a variety of by-products greatly unlike in texture and in their proportions of nutrients.

344. Structure of the maize kernel.-All this is made plain through a consideration of the structure of the maize kernel. This seed is in some respects similar to that of wheat. We have first an outside husk or skin made up of two distinct layers, one less than we find in

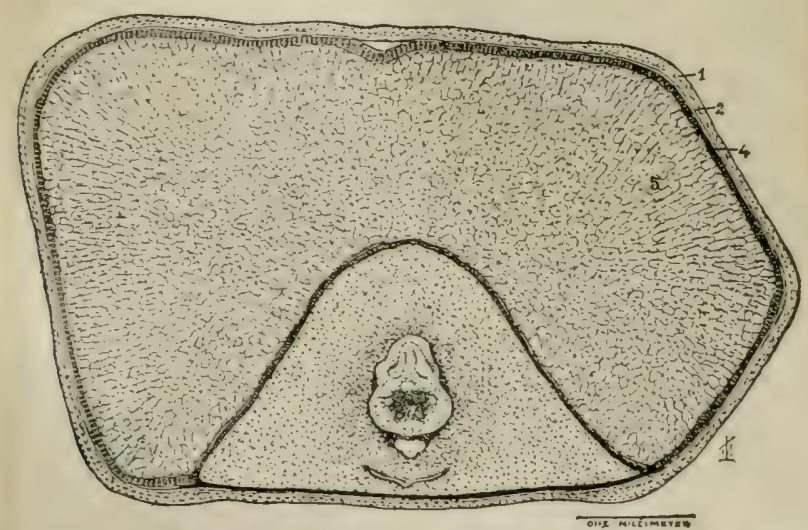

FIG. 15. Section of entire maize kernel (enlarged 10 diameters). 1. outer layer of husk or skin; 2 , inner layer of skin; \&, gluten layer; 5 , mass of starch cells.

wheat. This skin is rich in fiber, scarcely any being found in the other portions of the kernel. Next on the inside is a layer of cells rich in gluten. The body of the kernel surrounding the germ or embryo consists of closely compacted starch cells, though some of this interior tissue on 
the sides of the kernel next to the walls is flinty. We may properly speak of the maize kernel, then, as consisting of four parts-the husk, the gluten layer, the germ, and the starchy and hard part. (Figs. 15 and 16.) At the New Jersey Experiment Station one hundred grains of the maize kernels were separated as nearly as possible into the skin, germ, and main or starchy and hard portions. These parts were analyzed, and below is given their composition:

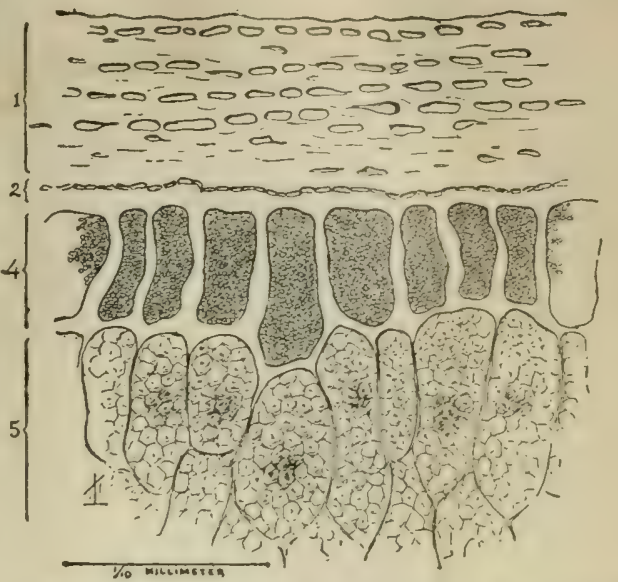

Frg. 16. Partial section of maize kernel (enlarged 170 diameters). 1 , outer layer of skin; 2 , inner layer of skin; 4, gluten cells; 5 , starch cells.

Table LI. Composition of Dry Substance of Maize Kernel (Per Cent)

\begin{tabular}{l|r|r|r|r|r|r}
\hline \hline & Ash & Protein & Fiber & $\begin{array}{r}\text { Nitrogen- } \\
\text { free } \\
\text { extract }\end{array}$ & Fat & $\begin{array}{c}\text { Propor- } \\
\text { tion } \\
\text { of parts }\end{array}$ \\
\cline { 1 - 5 } Original kernel . . & 1.7 & 12.6 & 2. & 79.4 & 4.3 & 100. \\
Skin . . . . . & 1.3 & 6.6 & 16.4 & 74.1 & 1.6 & 5.5 \\
Germ . . . . . . & 11.1 & 21.7 & 2.9 & 34.7 & 29.6 & 10.2 \\
Starch and hard part. & .7 & 12.2 & .6 & 85. & 1.5 & 84.3 \\
\hline
\end{tabular}

These figures are essentially similar to those obtained by other investigators, including Salisbury, Atwater, and Balland.

345. Manufacture of starch.-The separation of starch cells (see Par. 102) from other parts of the kernel is accomplished mechanically. Either before or after soak- 
ing in warm water, the maize kernels are crushed into a coarse powder. The various parts separate in water by gravity, the hulls floating on the surface and the germs sinking to the bottom. The starch and harder portions of the kernel remain in suspension in the water, which is conducted slowly through long troughs, where the starch settles to the bottom and the more glutinous portions float off and are recovered.

It is now easy to see how these various by-products may differ widely. When made up largely of the hulls or bran they are characterized by a relatively high proportion of fiber with comparatively low percentages of protein and fat. The presence of the germs increases the relative amount of protein somewhat and of the fat very greatly. The fine glutinous part, that is finally separated from the starch, when unmixed with other materials is distinguished by its high content of protein.

As found in the market, the principal brands are corn bran, gluten meal, that comes from the flinty portion of the kernel, and gluten feed, which is now a mixture of hulls, the gluten part, and the steep water residue. When unmixed with other parts of the kernel, the hulls are also known as corn bran and the germ portion from which the oil has been pressed is called, when ground, germ oil meal. The corn bran contains the least protein and the gluten meal the most, while the gluten feed and germ oil meal occupy a position between these.

In recent years the practice has been adopted of adding to the gluten feeds the solids found in what is known as the steep water, that is, the water in which the maize kernel and its parts have been soaked during the process of separation of one part from another. This steep water contains all that is soluble in the maize kernel or has 
become so through the treatment it receives, including soluble proteins, amino acids, and the soluble mineral salts of the corn. This steep water residue darkens the color of the feed and renders it acid in varying degrees, which at first caused an unwarranted prejudice against gluten feeds with these characteristics.

346. Residues from the manufacture of beet-sugar.An industry apparently now established in the United States, the manufacture of beet-sugar, is offering to farmers two waste products, sugar-beet pulp and sugarbeet molasses. The former is the extracted beet tissue from which all the sugars and more or less of other soluble compounds have been removed. This pulp as it leaves the factory has been found to contain an average of scarcely 10 per cent of solids. One ton of pulp supplies, then, not over 200 pounds of total dry substance, or perhaps 160 pounds of digestible dry substance. This means that it would require six tons of wet pulp to supply as much of digestible nutrients as one ton of good hay. The solids of the pulp must be regarded as inferior to those of the beets before extraction because consisting more largely of fiber and gums whose productive value is below that of sugar. Experiments at Cornell University indicated that the pulp is worth about one-half as much as corn silage, which would be approximately the relation of digestible matter in the two materials.

Sugar-beet pulp is, however, a useful, succulent food, and may be fed to advantage in quantities from seventyfive to one hundred pounds daily to full-grown animals, provided it can be purchased at a price proportional to its value.

The pulp is not adapted to transportation for long distances because of the heavy expense of freight and 
handling, but is most available for consumption near the factories. It may be preserved in pits or silos.

Dried beet pulp is now on the market. Its proteincontent is low, and the carbohydrate-content high. The rate of digestibility is fairly high. Cattle-feeders should bear in mind that the use of this material only intensifies the already high carbohydrate-content of the home-raised feeds.

The molasses is generally four-fifths or more dry substance and contains from 40 to 50 per cent of sugar, which is all digestible and which gives to this product its only value for feeding purposes.

This material has been fed successfully to bovines and swine. When given as an addition to coarse foods and home-raised grains it obviously should be combined with some nitrogenous feeding-stuff like gluten meal or the oil meals.

347. The oil meals in general.-Materials of this class may properly be regarded as among the standard feeding-stuffs. Because of their uniformity in quality and composition, their general usefulness in compounding rations and their value in maintaining soil fertility, their use has had the sanction of scientific men and of successful practice. The oil meals are so called because they are the residues left after the extraction of the oil from certain seeds and nuts, among which are cottonseed, flaxseed, hemp and poppy seed, rape seed, sesame seed, sunflower seed, coconuts, palm nuts, peanuts, and walnuts. Of the residues from these sources, those from cottonseed and flaxseed are most common in the United States; in fact, no other oil meals have become greatly important in our cattle-feeding. A description, therefore, of the production of cottonseed meal and linseed meal 
will not only cover the points of practical interest to American feeders, but will serve to illustrate the main facts that pertain to the manipulation of these oil seeds.

348. Methods of extracting oils.-It may be stated in a general way that two methods have been used for removing vegetable oils from seeds, expressing by pressure and extraction with a solvent. With the first method, it was formerly the custom to express the oil from the cold crushed seed, but now the seed is more generally submitted to heat, either by boiling or steaming, afterward applying the pressure to the warm material. More oil is obtained by the latter process. The second or extraction method involves the use of a solvent, generally a light naphtha, which leaves less oil behind than either cold or warm pressure. Before extraction the crushed seed is heated just as when pressure is used.

349. Cottonseed meal.-The cotton seed as gathered from the plant consists on the exterior of a mass of long white fibers that are attached to the outer coat or hull, inside of all of which is the kernel or meat. The seed is first delinted by running it through a gin, which removes the lint or cotton of commerce. After this operation there is still attached to the seed a soft down, which is subsequently removed and which constitutes what is known as "linters," a short lint that is used in making cotton batting. The remaining portion is that from which cottonseed oil and certain by-product feeding-stuffs are produced.

350. Cottonseed hulls.-The first process in the manufacture of the oil is to remove the hull from the inside meat. This is done by a sheller, which breaks the seed coat and forces it from the kernel. These seed coats, 
which constitute from 45 to 50 per cent of the delinted seeds, are known in commerce as cottonseed hulls, and are used to some extent as a feeding-stuff. They are characterized by a very low proportion of protein and a very high content of fiber. Twenty-two analyses show a range of protein from 1.6 to 4.4 per cent, and of fiber from 35.7 to 66.9 per cent. Such material as this belongs with the very lowest grade of coarse fodder, as both composition and experience demonstrate.

351. Extraction of oil from the cottonseed kernels.The hulless kernels make up from 50 to 55 per cent of the delinted seed, and from those the oil is obtained. These meats are first cooked twenty or thirty minutes in large, steam-jacketed kettles in order to drive off the water and render the oil more fluid, and then after being formed into cakes in wire cloths, they are submitted to a pressure of 3,000 to 4,000 pounds to the square inch. This removes at least four-fifths of the oil and leaves the cakes very solid, which after drying are cracked and ground into a fine meal, known in commerce as cottonseed meal. Formerly a ton of ginned seed yielded the following quantities of the different parts:

Linters

Pounds

Hulls . . . . . . . . . . . . . 891

Cake or meal . . . . . . . . . . . . . 800

Crude oil

289

Since the above estimate was prepared the manufacturing process has been so improved that from forty to forty-five gallons of oil are now obtained from a ton of seed, giving a correspondingly smaller amount of cake. Cottonseed meal at the present time is less rich in oil than was the case a few years ago. 
352. Composition of cottonseed oil by-products.The composition of the cottonseed oil by-products is the following:

\section{TABLE LII}

\begin{tabular}{|c|c|c|c|c|c|c|}
\hline & Water & Ash & Protein & Fiber & $\begin{array}{c}\text { Nitrogen- } \\
\text { free } \\
\text { extract }\end{array}$ & Fat \\
\hline & Percen & Percen & Per cent & Per cent & Per cent & Per cent \\
\hline Cottonseed hill & 9.9 & 4.7 & 19.4 & 22.6 & 24 & 19.4 \\
\hline Cottonseed kernels & 11.4 & 2.7 & 4.2 & 45.3 & 34.2 & 2.2 \\
\hline $\begin{array}{l}\text { Cottonseed cake } \\
\text {. }\end{array}$ & 6.9 & 6.9 & 30.3 & 4.8 & 21.4 & 29.6 \\
\hline Cottonseed cake & 8.6 & 7. & 44.1 & 4.9 & 21.2 & 14.2 \\
\hline
\end{tabular}

These figures represent the composition of the several materials when the separations are fairly complete. Cottonseed products are sometimes sold, however, in a more or less mixed condition. There has been found in the market undecorticated cottonseed meal, or the meal with all the hulls ground in without removal from the seed. The meal that is free from hulls should be light yellow in color and have a slightly nutty flavor. It should show few or no black specks, because the presence of these indicate either accidental or intentional adulteration with hulls. Cottonseed meal now contains less protein than was formerly the case, which means, undoubtedly, that a larger proportion of hulls or lint, or both, is present. Cottonseed feed is a finely-ground mixture of cottonseed hulls and cottonseed meal, and its value is less than that of the pure meal.

353. Linseed meal (oil meal).-The original source of this feeding-stuff is the flax plant. This plant serves a very useful purpose in producing a valuable fiber, and oil which now seems indispensable as a constituent of paint and a high-class stock-food. Flaxseed, of which 
the annual production in this country was about 19,500 ,000 bushels in 1909, contains a very high percentage of oil, ranging in the analyses so far made from 22 to 40 per cent. The average is variously stated by different compilers at from 33 to 37 per cent, and the mean of these two numbers is probably fairly correct. On this basis a bushel of flaxseed, weighing fifty-six pounds, contains nineteen and one-half pounds of oil and thirty-six and one-half pounds of other substances.

354. Extraction of linseed oil.-Linseed oil is obtained from the seed by both the pressure and extraction methods. The oldest method was to subject the cold crushed seeds to a heavy pressure, which expressed from 70 to 80 per cent of the oil, leaving a cake containing from 10 to 15 per cent. Later the warm pressure process was introduced, which consists of moistening the crushed seed, heating it to from $160^{\circ}$ to $180^{\circ} \mathrm{F}$., and submitting it to a pressure of 2,000 to 3,000 pounds to the square inch. This improvement increased the output of oil from a given quantity of seed, the amount expressed being about 90 per cent of the whole, leaving a cake containing from 6 to 7 per cent. The latest and most effective process is the extraction of the oil by a light naphtha. The seed is crushed and heated as in the warm pressure method, and the oil is then extracted by repeated leachings with naphtha until the residue when dry contains only about 3 per cent of oil. The naphtha is thoroughly driven from this residue with steam so that the resulting meal is entirely free from odor and is as palatable as the residue from the pressure process.

355. Old process vs. new process linseed meal The terms "old process" and "new process" are now applied to linseed meal, the former referring to that made 
by the cold and warm pressure processes, and the latter to the residue from naphtha extraction. The composition differences between the two are seen in the following average of several analyses of each kind which were made by Woll:

TABLE LIII

\begin{tabular}{|c|c|c|c|c|c|c|}
\hline & Water & Ash & Protein & Fiber & $\begin{array}{c}\text { Nitrogen- } \\
\text { free } \\
\text { extract }\end{array}$ & Fat \\
\hline & $\overline{\text { Percent }}$ & Percent & Percent & Percent & Per cent & Percen \\
\hline $\begin{array}{l}\text { Old process linseed meal } \\
\text { New process linseed } \\
\text { meal }\end{array}$ & $\begin{array}{l}9.4 \\
9.2\end{array}$ & $\begin{array}{l}5.4 \\
5.4\end{array}$ & $\begin{array}{l}35.6 \\
36.6\end{array}$ & $\begin{array}{l}7.1 \\
8.6\end{array}$ & 37 & $\begin{array}{l}7.5 \\
3.2\end{array}$ \\
\hline
\end{tabular}

These averages show 1 per cent more protein and 3 per cent less fat in the new process meal.

The old process samples analyzed by Woll were doubtless from the warm pressure methods and do not fairly represent the linseed meal which was found in the markets when it first came into general use. Four hundred and twenty-eight analyses of old process cake compiled by Dietrich and König, which were made previous to 1888 , show an average of only 28.6 per cent of protein and 10.6 per cent of fat. An average by the same authors of 179 analyses of the meal shows 30 per cent of protein and 9.9 per cent of oil, those samples taken previous to 1880 being poorer in protein and richer in fat than those analyzed after that date. The average of twelve samples of linseed cake made prior to 1883 and compiled by Jenkins, gives 29.7 per cent of protein and 11.2 per cent of fat. There is no question but that the meal now found in the markets is considerably richer in protein and poorer in fat than that with which American farmers were first acquainted. 
The relative values of the old and new process meals are much discussed. Many farmers are prejudiced in favor of the former, possibly because anything which has been treated chemically is regarded with suspicion when considered as a food. No good evidence exists, however, that new process meal is less palatable or less healthful than the old process product, nor has practice demonstrated that in a general way it is less nutritious.

A very useful inquiry by Woll into the characteristics of the two kinds of meal showed certain differences which are interesting in this connection. Two points were studied: the digestibility and the property of swelling to a mucilaginous condition when stirred up with water. Experiments with animals both in Germany and in this country have shown a quite uniformly lower coefficient of digestibility for the protein of the new process than for the old process, meal. Woll tested this matter by artificial digestion with a solution of pepsin, and his results verified those secured with animals, the protein of the old process sample proving to be 10 per cent the more soluble. This difference is believed to be caused by the additional cooking with steam which attends the driving out of the naphtha from the new process meal, for it seems to be well proven that the digestibility of vegetable protein is diminished by cooking. American experiments do not indicate a lower digestibility of total dry matter for the new process meal, which is contrary to the verdict of German digestion trials.

The property of swelling to a mucilaginous condition is one well known to pertain to flaxseed. This is due to mucilage cells found in the seed coat. When this mucilaginous matter has once been swollen, it will not repeat the process after drying. Woll's tests showed 
that the old process meal responded to the swelling test, but not the new process, a result due probably to the steam cooking of the latter. This may serve as a means of determining the method used in manufacturing a given lot of meal, but probably has no special significance as to feeding value, unless it indicates the new process meal to be less useful in making a porridge for feeding calves.

\section{CHEMICAL DISTINCTIONS IN CATTLE FOODS}

The classes of cattle foods as arranged in the previous discussion have had reference to several factors, chiefly those relating to origin and texture. Chemical facts have not been considerd in these divisions. There are, however, certain chemical differences among the various groups of feeding-stuffs, a knowledge of which is helpful in selecting materials for compounding rations.

356. Coarse foods vs. grains and grain products.-In comparing hays, straws, and other fodders with grains and grain products there are points of chemical unlikeness which bear an important relation to problems of nutrition. In the first place, the nitrogen compounds differ. In the grains we find the nitrogen combined mostly in the form of true proteins, while in the fodders and roots a proportion of it, and sometimes quite a large one, exists in amides. This is a point in favor of the grains, for the nutritive function of amides is probably more limited than that of the true proteins. Again, the non-nitrogenous material of the grains is in general superior to that of the herbaceous cattle foods. In the former, especially in the cereal grains, there is but little fiber and the nitrogen-free extract is made up largely of 
starch and other bodies, whose net value in nourishing an animal is quite surely greater than that of fiber and gums found in such abundance in the hays and other fodders. The work of masticating fibrous materials is greater than with sugar or starch, and less is digested. The terms protein and carbohydrates do not signify the same compounds or the same values when applied to different feeding-stuffs.

357. Classification of feeds according to the proportions of nutrients. - The relative proportion of nitrogenous and non-nitrogenous compounds in feeding-stuffs is greatly varied. There is no fixed proportion in the same species, even, but it varies to some extent with the season, period of cutting, and other conditions. At the same time, there are differences of composition between several groups of feeding-stuffs that are constant within not very wide limits, and which it is important to recognize.

358. Misleading terms for feeding-stuffs.-There are a few terms that are popularly used to differentiate feeding-stuffs which are misleading. For instance, corn meal is often spoken of as "carbonaceous" in contrast to cottonseed meal, which is called "nitrogenous." It may be seen by reference to preceding data that there is a higher proportion of carbon in the proteins than in starch or sugars. Cottonseed meal is more carbonaceous than corn meal, rather than less so. Such a distinction is therefore absurd.

"Heat-forming" is another term often applied to foods rich in carbohydrates, while the more highly nitrogenous materials are characterized as "muscle-forming," a distinction apparently based upon the facts that carbohydrates are usually largely burned in the animal body, and that the food proteins are the source of the body 
proteins. But, as a matter of fact, the potential heat value of the digestible part of an oil meal is certainly greater than that of digestible corn meal. Under certain conditions one feeding-stuff is no more fully used than the other for tissue-forming purposes, and both may be utilized outside of the usual wastes in the production of some form of energy, ultimately heat.

359. Classification of feeding-stuffs.-The satisfactory division of feeding-stuffs into as few as two classes, according to their composition, is not possible by the use of any terms whatever. Such a division is necessarily based upon the relation in quantity of the protein to the non-nitrogenous part, and there is an almost uniform gradation of foods in protein-content from those containing the least to those most highly nitrogenous. Any division into groups with reference to the percentage amount of protein must be entirely arbitrary and should take account of at least four classes of materials, otherwise the extremes of each division are too widely apart. Probably no more convenient and rational classification of grains and grain products can be suggested than the one proposed by Lindsey:

Class I. Thirty to 45 per cent protein, 30 to 45 per cent carbohydrates. The oil meals and gluten meals and certain distillers' dried grains.

Class II. Twenty to 30 per cent of protein, 60 to 70 per cent carbohydrates. Gluten feeds, the lower grade distillers' dried grains, dried brewers' grains, maltsprouts, buckwheat middlings, and beans and peas.

Class III. Fourteen to 20 per cent protein, 70 to 75 per cent carbohydrates. Wheat brans and middlings, rye bran, and mixed feeds. 
Class IV. Eight to 14 per cent protein, 75 to 85 per cent carbohydrates. Barley, corn, oats, rye, wheat, cerealine, hominy, oat feeds, corn and oat chop, and corn bran. The fodders and roots properly belong with Class IV.

By reference to these groups it is possible to ascertain about what place a particular feeding-stuff will take in making up a ration, for instance, to what extent it will serve as a protein amendment to a mixture of materials composed largely of carbohydrates.

\section{FOODS OF ANIMAL ORIGIN}

360. The principal materials of animal origin that are used in feeding domestic animals are milk, dairy byproducts, and offals from slaughter-houses. They are mostly characterized by their large relative proportion of protein and their high rate of digestibility. The net nutritive value of their solid matter is very high, because it is practically all utilized and a minimum amount of energy is required for its mastication and digestion. Practice has long recognized the peculiar efficiency of feeding-stuffs of this class, which is due to the directly available forms of the nutrients.

361. Milk.-Whole milk has a greatly varying food value according to its proportion of solid matter. Its composition is determined by several factors. The milks of different species of domestic animals are greatly unlike both in their proportions of total solids and in the relation in quantity of the different constituents.

The table of the average composition of the milk of several species, given herewith, is taken mostly from figures given in Richmond's "Dairy Chemistry;" 
Table LIV. Composition of the Milk of Mammals (Per Cent)

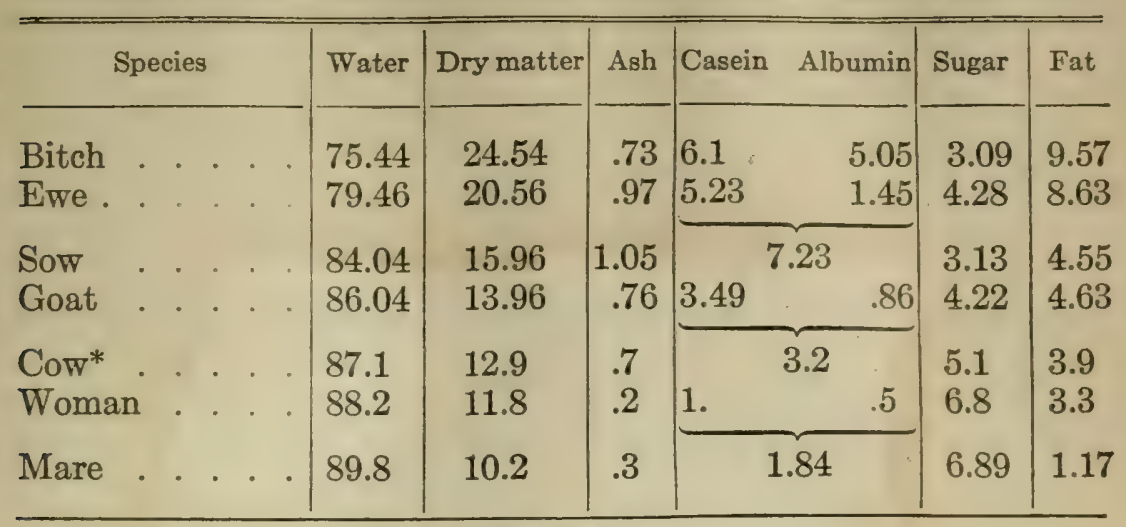

*Van Slyke.

The milks are arranged in the order of their richness, the dry matter present varying from 24.54 to 10.2 per cent. Those containing a high proportion of total solids, particularly those from the bitch and the ewe, are especially rich in proteins and fat, the percentages of sugar being less than half those in the poorer milks. It is noteworthy that the proportions of proteins and fats in the milk decrease, and the percentage of sugar increases, as the total solids diminish. Two-thirds of the solids of mare's milk is sugar, the proportion of this constituent in the dry matter of an ewe's milk being only about oneeighth.

If we assume that the milk of each species is best adapted to its own progeny, it follows that when the young of other species is fed the milk of the cow, as is so often done, this milk should be modified so far as possible to simulate that provided under natural conditions. When, for instance, cow's milk is fed to a colt, it should be diluted and have its content of milk-sugar increased; or when lambs are given cow's milk it may well be made richer, by the addition of cream, perhaps. 
362. Milk of several breeds.-The milk of the cow varies with the breed, the individual, and the period of lactation, and in its use for feeding purposes these variations should be considered.

TABLE LV

\begin{tabular}{lllll|l|l|l|l|l|l}
\hline & & & & Ash* & Solids & Casein & Albumin & Sugarst & Fat \\
\hline Holstein-Friesian & & & & & & & & & & \\
\hline
\end{tabular}

*Assumed.

†Calculated.

While we have few or no data on the subject, it is probable that the same causes operate in affecting the milk of all species.

363. Dairy by-products.-These by-products are three in number, skim-milk, both from the gravity and the separator processes, buttermilk, and whey. Their average composition, as taken from compilations by several authors, is as follows:

Table LVI. Composition of Dairy Offals (Per Cent)

\begin{tabular}{|c|c|c|c|c|c|c|}
\hline & Water & $\begin{array}{l}\text { Total } \\
\text { solids }\end{array}$ & Ash & $\begin{array}{l}\text { Casein and } \\
\text { albumin }\end{array}$ & Sugar & Fat \\
\hline Skim-milk, general average, Cooke & 90.25 & 9.75 & .8 & 3.5 & 5.15 & .3 \\
\hline Skim-milk, gravity, Fleischman . & 89.85 & 10.15 & .77 & 4.03 & 4.6 & .75 \\
\hline Separator-milk, Richmond . & 90.5 & 9.5 & .78 & 3.57 & 4.95 & .1 \\
\hline Buttermilk, Cooke . . . & 90.5 & 9.5 & .7 & 3. & $5.3^{*}$ & .5 \\
\hline Buttermilk, Vieth . & 90.39 & 9.61 & .75 & 3.6 & $4.06+$ & .5 \\
\hline Whey, Cooke . . & 92.97 & 7.03 & .6 & .93 & & .5 \\
\hline Whey, Van Slyke . . . . & 93.07 & 6.93 & $.6 \S$ & .83 & 5.16 & .34 \\
\hline
\end{tabular}

*Probably includes the lactic acid. $† .80$ per cent lactic also present. §Assumed. 
Skim-milk and buttermilk are not greatly unlike in richness in solid matter or in general composition. In case the skim-milk is sweet, buttermilk differs from it because in the latter the sugar has changed partially or wholly to lactic acid. Whey is considerably poorer in solids than the other dairy by-products and also differs from them in the proportions of the several constituents.

Skim-milk is the residue left after removing the cream. It differs in composition according to the composition of the original whole milk and the thoroughness of the creaming. The percentage of solids which it contains is proportional in a general way to the richness of the whole milk. At one time a contrary notion prevailed and the skimmed milk of the butter breeds, especially the Jersey and the Guernsey cows, was popularly supposed to be of inferior quality. Numerous analyses have been made of this by-product from several breeds, and the succeeding figures give the proportion of solids and fat in skimmed milk from the gravity process:

\section{TABLE LVII}

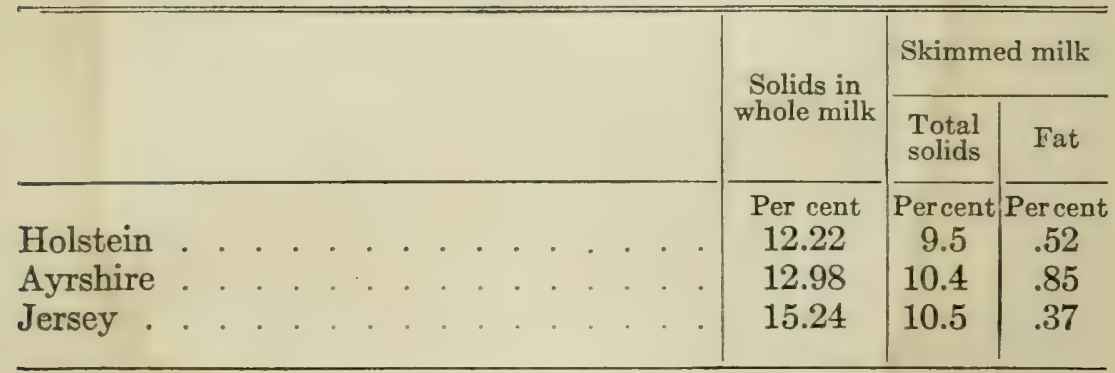

These figures show most clearly that the Jersey product is more valuable than that from Holstein cows, volume for volume.

Skim-milk is also affected by the manner or thorough- 
ness with which the cream is removed. The more perfectly the fat is taken out, the less the percentage of solids left behind, and the less their unit value as a source of energy. For these reasons gravity-process skimmed milk is often more valuable for feeding than that from the separator, though under the best conditions of skimming in both cases the difference is small.

Buttermilk, which is the residue after extracting butter from cream, varies in composition from such causes as the composition of the cream and the perfectness of the churning. The more fat that is left in it the more it is worth for feeding purposes. Its feeding value is but little less than that of skim-milk.

Whey solids are mostly sugar. In good cheese-making practice, whey retains scarcely any of the casein and fat of the milk. It therefore takes a place in the ration quite different from that of skim-milk, as it is essentially a carbohydrate food.

The dairy offals are peculiarly valuable as food for young animals and swine. It is safe to say that for calves and pigs no other materials can fully take their place in their relation to health and vigor.

364. Slaughter-house and other animal refuses. -The offals from slaughter-houses and from fish, which have a somewhat limited use in feeding domestic animals, are meat scraps, meat meal, dried blood, and dried and ground fish. The materials serve admirably as a supplement to the home-raised feeds which are largely of a carbohydrate character, especially in feeding poultry and swine. In the case of meat-scraps it is desirable to distinguish between those having a large proportion of bone and those mostly meat. The accompanying analyses display their composition, which is subject to great variations: 
Table LVIII. Composition of Slaughter-Hotse and Other Refuses (Per Cent)

\begin{tabular}{|c|c|c|c|c|}
\hline & Water & Ash & Protein & Fat \\
\hline Animal meal, N. Y. station & 2.2 & 38.7 & 37.5 & 13.2 \\
\hline Meat meal, German analysis & 10.7 & 4.1 & 71.2 & 13.7 \\
\hline Fish scrap, German analysis & 13.9 & 31.3 & 48.4 & 6.4 \\
\hline Dried blood, Henry & 8.5 & 4.7 & 84.4 & 2.5 \\
\hline
\end{tabular}

The meat and fish offals vary greatly according to proportion of bone which they contain. The percentage of protein is always large, nevertheless. Dried blood is much less rich in mineral matter and fat than other slaughter-house offals are generally, and the proportion of protein is correspondingly larger. All these materials are excellent poultry foods when used as a part of the ration. They may be fed to swine also as an amendment to cereal grains when dairy by-products are not available. 


\section{CHAPTER XV \\ THE PRODUCTION OF CATTLE FOODS}

THE farmer, in deciding what forage and grain crops he shall grow, should take into consideration several factors, of which the following are the main ones: (1) The adaptability of the various crops to the soil and climate; (2) the adaptability of the various crops to the kind of business which is to be followed, whether dairying, stock-growing, or sheep husbandry; (3) the capacity of the various crops for the production of digestible food; (4) the protein supply; (5) the maintenance of fertility.

365. Adaptability of crops to environment.-Concerning the adaptability of crops to the great variation of soil and climate in this country, it is not possible to treat extensively in this connection without going too fully into questions of agricultural botany. There are however, a few general facts worthy of mention. In the first place, few farmers have accurate information concerning the species of grasses which are growing on their farms. Only occasionally is one found who carefully observes what species are most prosperous under his conditions. This is equivalent to the statement that but little attention is given to the matter of the adaptability of forage plants to the environment under which they must be grown. While it may be said that nature carries on for the farmer more or less of a selective process, it must be remembered that the rotation of crops, involving of necessity an artificial selection of species, inter(272) 
feres with this process. The old practice of maintaining mowing fields for ten to twenty years without breaking the sod might allow the grasses most congenial to the soil and climate to establish themselves, but successful farming on this basis is now scarcely possible. It is essential, therefore, especially in dealing with meadows and pastures, to know what members of the grass family or other forage plants find the environment congenial.

366. New vs. old species of plants.-It is commonly remarked, with much reason, that more is to be gained by the proper selection and proper care of the forage crops which have maintained successful, though perhaps unrecognized, existence among us for years, than by seeking for better results from some introduced species. No cultivated plant possesses qualities that will defend the farmer against the evil effects of poor or ill-directed culture, and when intelligent, thorough methods prevail, many of the familiar species will do for us all we can reasonably expect. Occasionally an introduced species may serve a useful purpose, as is true of alfalfa, but in general a more economical production of cattle foods will be reached most surely through an improvement of methods in growing what we already have.

367. Adaptability of crops to kind of animal production. - It is obvious that the home production of feeding-stuffs must be adapted to the kind of stock kept. A herd of dairy cows can hardly be most successfully managed on the old basis of exclusive pasturing in the summer and exclusive dry food in the winter. To attain the best results the pasture must be amended by soilingcrops, at least during late summer and early autumn, and a succulent food is a decided improvement to a winter ration. On the other hand, the successful growing of 
steers, sheep, or horses requires in many localities only a good pasture and plenty of dried fodder and grain, although some succulent foods are desirable with any class of animals. Every feeder, no matter what his line of business, should have at command quite a variety of fodders.

368. Productive capacity of crops.-The productive capacity of the different crops used as cattle foods is greatly unlike. A satisfactory crop of maize or alfalfa contains greatly more dry matter an acre than one of oats, peas, or any of the usual meadow grasses, and in order that land may yield a maximum supply of feedingstuffs it is necessary to step outside grass and grain farming, where long rotations are practised and where a major part of the farm is kept in meadow grasses and only small areas are devoted to cultivated crops. Rapid rotation and the use of the more grossly feeding crops are necessary to a vigorous development of the resources of any land for the maintenance of animal husbandry.

Other things being equal, the most desirable crop is the one producing the largest amount of digestible dry matter. This will not be the same crop for all localities. In one section it may be maize, in another alfalfa, or in another roots. The selection must be determined by circumstances, and no rule of general application is possible. Of course, other things outside of quantity of production are not generally equal. The cost of production varies so that the largest yielding crop is not necessarily the most economical. This is a local matter also, concerning which no safe general statement can be made. It would be convenient if some correct, universal standards of production and cost could be formulated for the guidance of farmers, but both growth and cost are 
much modified by locality and other circumstances and data are not available, and doubtless never will be, from which useful averages may be obtained.

The most that it is possible to show is the relative productive capacity of different crops when the yield is what is regarded as highly satisfactory in favorable localities under good culture. This is done in the accompanying table. Attention is again called to the fact that judgment should be based upon the amount of digestible dry matter produced:

\section{TABLE LIX}

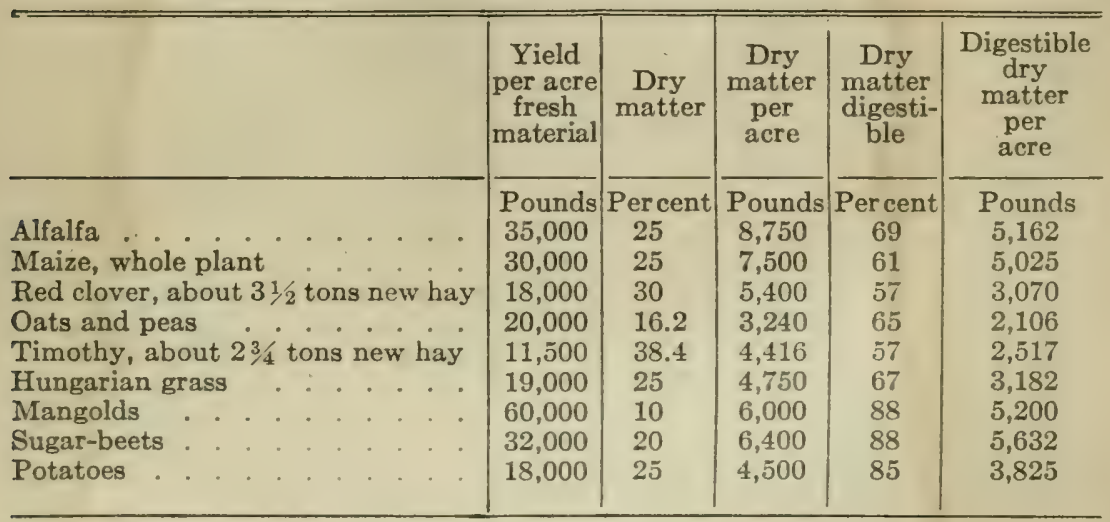

The estimates here given may not coincide with the views of all as to what constitutes a fair crop, but from the data shown, anyone can easily make a calculation on the basis of his own estimate.

369. Crops of high productivity.-The foregoing figures emphasize the relative high productivity of alfalfa, maize, and roots, as compared with certain cereal grains and the meadow grasses. The former crops fill an important place in intensive stock husbandry. Probably no species of forage plants are known that are more economical sources of high-class cattle food than alfalfa and 
maize. While the latter crop is no more productive than mangolds and sugar-beets when these are at their best, the corn crop costs much less in labor.

Crops of such large productive capacity are especially adapted to dairymen located on limited areas of high-priced land. They occupy a place in intensive culture which will become more and more important as grazing and long rotations are replaced by soiling and stable feeding during the entire year.

370. Home supply of protein.-The protein supply of the farm may be augmented by the growth of leguminous crops, such as peas, beans, alfalfa, and the clovers. In so far as climate and soil permit the economical production of this class of fodders, there will be a correspondingly less necessity for the purchase of nitrogenous feeding-stuffs.

371. Legumes and fertility.-The leguminous crops are regarded as sustaining an important relation to fertility in acting as nitrogen-gatherers, and for this reason they are believed to be a valuable adjunct of any system of farming. Just what proportion of the nitrogen in a crop of clover, for instance, comes from outside the soil is not known, however, either for particular conditions or as to the average.

\section{SOILING-CROPS}

372. Soiling-crops a necessity.-The production of green crops as an amendment to the pasture, or as a substitute for it, is a practice essential to the highest success in dairying on many farms, and is to some extent desirable in other branches of stock husbandry.

There are few pastures, perhaps none, that afford 
grazing in August and September of such a quality as to maintain a satisfactory flow of milk. In many instances, moreover, farmers owning a limited area of high-priced tillable land wish to krep the maximum number of animals an acre, and to do this they must cultivate soilingcrops for stable feeding.

It is no longer a debatable question, whether or not soiling is profitable under most conditions. Unlimited testimony can be furnished showing the great gain from every point of view of even partial soiling as an amendment to the pasture. Whether soiling should be substituted entirely for grazing is a business matter which should be decided according to the conditions involved.

373. Conditions favorable to soiling.-New England farmers owning upland rocky pastures in which grow native grasses of the highest quality for any class of animals could not widely discard them. Such land generally absorbs but little capital, and the labor of supplying food by this method is reduced to a minimum. The case is different with high-priced, easily tilled land located near good markets. These conditions call for intensive farming, and grazing animals on permanent pastures is not a part of intensive practice. Under such circumstances the wisdom of a soiling system is clearly indicated.

374. The economy of soiling-crops.-In the first place, much more food is produced on a unit of area by soiling than by pasturage. Armsby found that two soiling-crops in one season, for instance rye followed by corn, yielded five times as much digestible organic matter as pasture sod, when the whole growth on the latter was plucked without waste, the quantities being, respectively, 5,845 and 1,125 pounds. It is variously estimated from observations in practice that three to five times as many 
animals can be supported on a given area by soiling as by grazing.

Again, grazing is wasteful because of the imperfect consumption of the growth that is made. Much grass is tramped down and much is fouled with dung and urine. These facts are well understood. Other advantages besides economy of land and material pertain to soiling, such as saving of fences, comfort of the animals and an increased supply of manure, but these factors do not require discussion in this connection.

375. Selection of soiling-crops.-Outside of considerations previously noted, productiveness especially, the dairy farmer in selecting soiling-crops must have regard chiefly to the number of animals to be fed, the time when the crops will be needed, and the number of days required for their development. If soiling is adopted in order to amend the pasture during the late summer and early fall, a limited number of crops will meet the demand. Three sowings of peas and oats in late May and early June and two plantings of corn, one at the usual time and one two weeks later, would furnish a supply of green food when it is most likely to be needed. If it is a question of selecting crops for a system of complete soiling, nothing more suggestive can be offered as to species and succession than schemes prepared by Phelps for Connecticut, and by Voorhees for New Jersey: 


\section{Table LX. Connecticut Scheme}

Winter 'es of crop

Spec'es of crop Time of seeding

Winter rye ..... Sept. 1

Winter wheat . . . Sept. 5-10

Clover ...... July 20-30

Grass (from meadows)

Oats and peas

Oats and peas

Oats and peas

Hungarian

Clover, rowen

Soybeans

Cowpeas

Rowen grass (meadows)

Barley and peas
April 10

April 20

April 30

June 1

May 25

June 5-10

Aug. 5-10
Approximate

time of feeding

May 10-20

May 20-June 5

June 5-15

June 15-25

June 25-July 10

July 10-20

July 20-Aug. 1

Aug. 1-10

Aug. 10-20

Aug. 20-Sept. 5

Sept. 5-20

Sept. $20-30$

Oct. 1-30

\section{New Jersey Scheme}

Species of crop

Winter wheat

Crimson clover

Oats and peas

Oats and peas

Mixed grasses

Oats and peas

Cowpeas

Corn

Japanese Millet

Cowpeas

Corn

Soybeans

Japanese millet

Corn

Barley and peas

Barley and peas
Time of seeding

Sept.

Sept.

Sept.

April 1

April 10

Sept.

May 10

May 20

June 1

June 20

June 10

June 20

July 10

July 20

July 1

Aug. 10

Aug. 20
Approximate time of feeding

May 1-10

May $10-20$

May 20-June 1

June 1-10

June 10-20

June 20-30

July 1-10

July 10-20

July 20-Aug. 1

Aug. 1-10

Aug. 10-20

Aug. 20-Sept. 1.

Sept. 1-10

Sept. 10-20

Sept. 20-Oct. 10

Oct. 10-20

Oct. $20-30$

The schemes are not practicable for all sections of the United States. In the southern and western states more especially, they would need modification to suit local conditions.

Alfalfa is not included in either of the foregoing lists. 
For all sections where this plant can be grown successfully it takes first rank as a soiling-crop. In portions of New York, for instance, in favorable seasons it can be cut continuously from about the last of May until October, and no other crop is more thoroughly relished by horses and cattle. It is valuable for horses, even when they are doing hard work.

376. Soiling-crop area and rotations.-The area devoted to soiling-crops must be determined by the number of animals and the productiveness of the land which is to be used. Voorhees states that seven acres, devoted to the succession of crops which he recommends, will supply twenty-five cows from May 1 to November 1 . This estimate hold only when two or three crops are grown on the same land in a single season, which requires a generous use of manure or of commercial fertilizers, or of both. The following are suggestions of possible rotations:

$\begin{array}{ll}\left\{\begin{array}{l}\text { Winter rye, or crimson clover } \\ \text { Oats and peas } \\ \text { Soybeans }\end{array}\right. & \left\{\begin{array}{l}\text { Winter wheat } \\ \text { Cowpeas } \\ \text { Japanese millet }\end{array}\right. \\ \left\{\begin{array}{l}\text { Oats and peas } \\ \text { Japanese millet } \\ \text { Barley and peas }\end{array}\right. & \begin{array}{l}\text { Oats and peas } \\ \text { Cowpeas } \\ \text { Barley and peas }\end{array} \\ \left\{\begin{array}{l}\text { Winter rye, or winter wheat } \\ \text { Corn }\end{array}\right. & \left\{\begin{array}{l}\text { Crimson clover } \\ \text { Corn }\end{array}\right.\end{array}$

Some writers estimate the needed area of soilingcrops on the basis of one-quarter to one-half a square rod a day for each full-grown animal, the smaller unit applying to corn and the larger to oats and peas, and similar crops. All this must be a matter of judgment based upon the circumstances involved. 


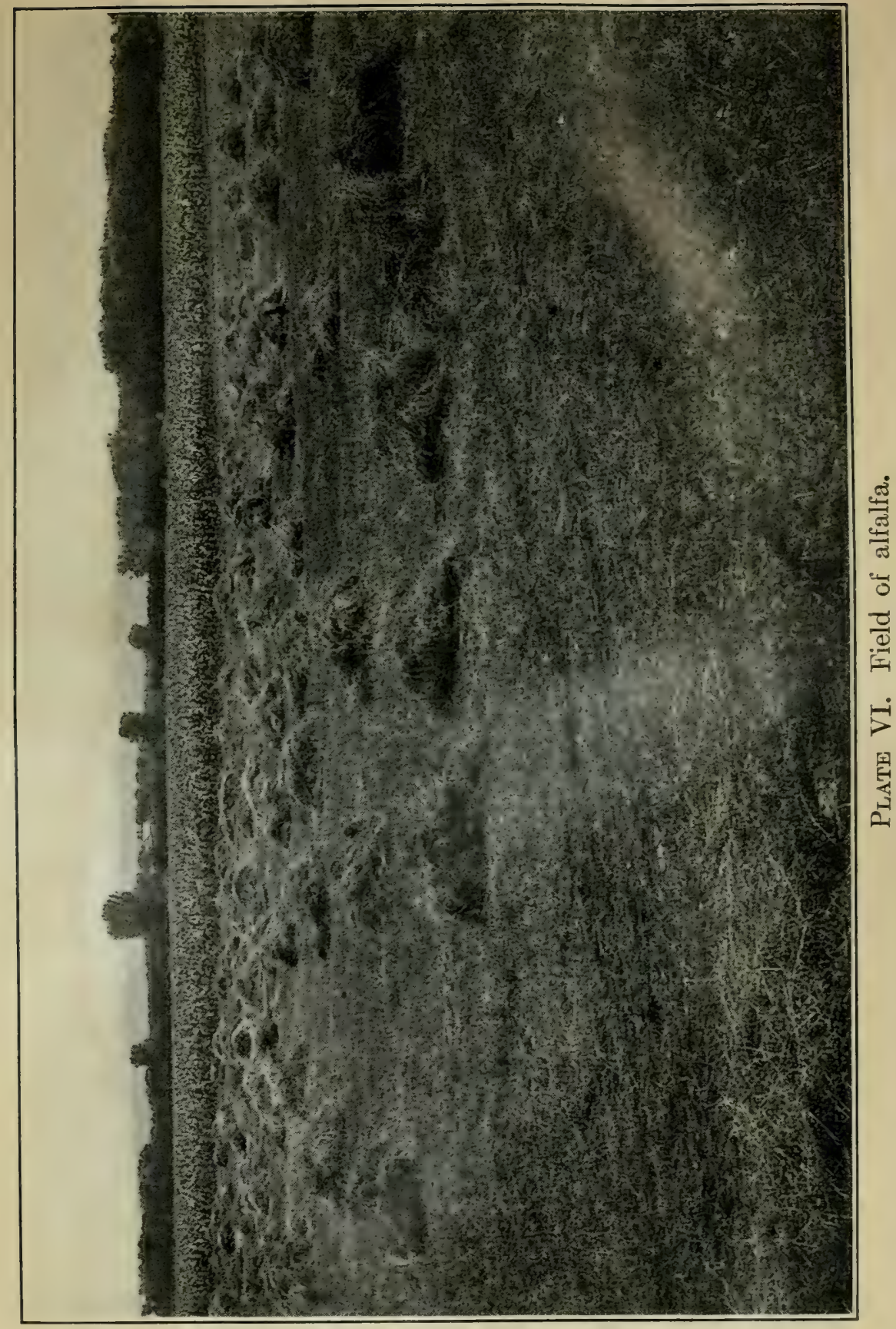





\section{CHAPTER XVI}

\section{THE VALUATION OF FEEDING-STUFFS}

IT seems to be very generally supposed that it is possible to state fixed relative money values for feeding-stuffs, and that by comparing these with market prices the relation of value to cost may be ascertained. Such a state of knowledge is certainly much to be desired, for it would be of great practical use to feeders. For various reasons, however, it is not yet attained, and there is little present prospect that it will be. The establishment of such relative values for cattle foods, as a whole and for general use, is a much more complex matter than many suppose it to be, for it touches on one side some of the most profound problems of physiological chemistry, concerning which we have only partial knowledge.

377. Basis of assigning values to feeding-stuffs.The problem of assigning values to the classes of nutrients in feeding-stuffs may be approached from two directions, viz., from the commercial side and from the physiological side. In the first case, the effort would be to calculate on the basis of the prices of standard commercial feeds what is the actual pound-cost of each of the classes of nutrients, and thus have a means of ascertaining whether a particular feed is selling for less or more than the existing market conditions warrant. In the second case, the attempt would be to determine the relative physiological importance of digestible protein, carbo- 
hydrates, and fats, and this being done, the relative agricultural values of feeding-stuffs would be established on the basis of their composition and digestibility, thus providing purchasers with a guide for selecting the materials costing the least in proportion to their value.

378. Commercial values of feeding-stuffs.-Experiment stations have for many years published relative commercial valuations of the various brands of fertilizers that are in the market. We are not able to establish values similarly with cattle foods because of existing conditions. The dry matter of cattle foods is made up of ash, protein, carbohydrates, and fats. We practically ignore the ash and base the value of a given food upon the other three classes of compounds, which are the same in number as the three useful ingredients of mixed fertilizers. Now if we could find in the market a cattle food supplying only a single ingredient, as is the case with fertilizers, we could from its composition and market price determine the cost of this ingredient. As a rule, however, these classes of nutrients must be bought in a mixed condition. All commercial cattle foods, except, perhaps, one waste product from sugar production, are mixtures in varying proportions of protein, carbohydrates, and fats. When we buy one we buy all three. Protein, starch, sugar, or oils as found in commerce have become, through the necessary processes of separation, too costly to be considered for cattle-feeding purposes, and their prices in these forms are not a proper basis of calculation. If, therefore, a farmer pays $\$ 25$ for a ton of wheat bran, the problem would be what proportion of this sum he should assign to the 320 pounds of protein, the 1,240 pounds of carbohydrates, or the 84 pounds of fats.

Commercially considered the problem is complex, 
and no simple process will solve it. If we were to determine what is the cost of one pound of dry matter through the simple division of the price of a ton of feed by the pounds of dry matter which it contains, and then declare that all forms of dry matter have equal cost, we would get as many prices for protein and starch as there are commercial feeds, with no distinction as to the money value of these nutrients. Such a method would be absurd. It would be a bare assumption to declare that all the compounds of a food should have equal market cost.

379. Valuation of feeds by method of least squares. An attempt was made in Germany, and to some extent in this country, to calculate by the "method of least squares" what should be considered the cost of protein, carbohydrates, and fats as based upon the ton prices of a variety of feeding-stuffs. Valuations so derived appeared to find favor for a time, and some of our experiment stations, following the lead of German chemists, published pound prices for the three classes of nutrients, and calculated what commerçial cattle foods should cost when valued on a common basis. It was soon found, however, that, mathematically as well as practically, most absurd results were obtained.

In the first place, it is already demonstrated that the money valuations are often greatly influenced by the choice of feeds which shall enter into the calculation. Penny, in New Jersey, using cottonseed meal, bran, middlings, cob meal, corn meal, and oats, obtained certain values for protein, carbohydrates, and fats. Hills showed that if Penny had left out the cob meal the value for fat would be only half that found, and the value of the protein and carbohydrates would be a quarter more. Woll obtained certain pound prices with a list of common 
feeds, but Hills showed again that if Woll had left out rye bran these prices would be greatly changed. It appears that varying individual judgments as to the list of feeds which shall determine values may cause absurd differences in the calculated market cost of the nutrients, and introducing into the list or withdrawing from it a comparatively unimportant feeding-stuff may lower or raise the price of one nutrient even one-half.

A still more serious difficulty arises from the fact that often when an apparently typical and proper list of feeds is used from which to calculate prices, the use of the method of least squares results in giving a negative value to one of the nutrients. In several cases of this kind the fat was shown to be worth less than nothing, a most absurd conclusion. This mathematical method is, therefore, not available for the valuation of feeding-stuffs, and so far no mathematician has offered one that is.

330. Physiological values.-We are left now to inquire whether we may not use physiological values, in other words the work which a nutrient will perform in the animal body, as a starting-point from which to calculate relative values. If, for instance, it could be demonstrated that protein has a fixed physiological value twice, and fats three times, that of carbohydrates, it would then be a very simple matter to ascertain what proportion of the cost of a ton of cottonseed meal should be applied to each class of nutrients. To illustrate, a ton of high-grade cottonseed meal contains about 590 pounds of carbohydrates, 860 pounds of protein, and 260 pounds of fat. If these ingredients are assumed to have a ratio of value of 1,2 , and 3 , then the whole would be equivalent to 3,090 units of carbohydrates, the cost of one unit 
of which would be about one cent, when we pay $\$ 30$ a ton for the cottonseed meal. On this basis it would be necessary to assign to the protein a cost of two cents per pound, and to the fats three cents. If our premise were correct we could calculate the cost of the nutrients in any one of the feeding-stuffs, and could either ascertain which was the cheapest source of each ingredient, or by averaging could establish a basis for a general valuation. Unfortunately no such a premise can be correctly formulated. We are not yet wise enough to establish fixed relative physiological values for the three classes of nutrients.

381. Energy values as a basis of valuation.-It may be stated that the energy values of a unit of each of the nutrients, protein, starch, and fat have been found with apparent accuracy. Why, then, may we not establish the relative value of the nutrients on the basis of their potential energy, which is measured by the heat they produce upon combustion? Simply because foods have another function beside furnishing motive power to the animal and keeping him warm. They act as buildingmaterial. The protein and fat of milk and of the body tissues are derived from the food compounds, and the actual relative money value of these compounds for constructive purposes is not yet known. No one has yet succeeded in actually determining the relative money value of protein, carbohydrates, and vegetable fats as fat producers, and we have no data that allow a definite conclusion concerning the comparative money worth of the muscle-forming function of protein as against the fatforming function or energy function of starch. There is no promising prospect, at present, of being able to compare foods on the basis of their physiological importance 
as a means of determining what should be the relative market cost.

382. Conditions involved in the selection of feedingstuffs.-Much useful knowledge is available to the stock-feeder as a means of guiding him to an economical selection. Some of the important facts to keep in mind are: Some feeds carry more nitrogenous matter than others; some feeds are largely carbohydrates; cereal grains contribute to the ration much the same compounds in much the same proportions; the variations of composition among the waste products that are in the market as commercial feeds; how the coarse foods differ among themselves and from the grains; some feeds are better adapted than others to a certain class of animals, even though of essentially the same composition, and what practice and science have taught concerning the mixtures necessary to secure an efficient combination of nutrients for the work to be done.

383. Digestibility as a basis for selecting feedingstuffs.-After all this is understood, there may be several feeds which are essentially alike in composition and nutritive function but which have different prices, and there still remains the problem of selecting the most economical. It is clear that the best a feeder can do is to select the feeds that supply the largest quantity of available nutrients for the least money with due reference to the class of nutrients desired. If all the feeding-stuff's were digested in equal proportions, there would be no need of considering digestibility, but this is not the case. Large differences in digestibility exist. From 86 to 88 per cent of the dry matter of the cereal grains, oats excepted, is digested, while the digestibility of wheat bran, brewers' grains, and oats is on the average only 
about 62 per cent. Oats are nearly one-fourth less digestible than corn, barley, or rye. The refuse products known as the oil meals are less digestible than the gluten feeds and meals, due, doubtless, to the hulls contained in the former. These facts are important and affect the nutritive value of commercial feeds very materially.

384. Values based on digestibility.-Farmers should base their judgment of the value of feeding-stuffs primarily upon the proportions of digestible dry matter which they contain. This method will probably allow as close an approximation to relative values as any which it is feasible for the farmers to use now in practice. Doubtless "production" values (see Par. 263) will ultimately offer a closer comparison. It is certainly more accurate than a comparison of the proportions of total dry matter. A hundred pounds of corn contains even less dry matter than the same weight of oats, but the digestible material of the former is over 20 per cent in excess of that in the latter. It is to be remembered, however, that comparisons of this kind can be instituted only between feeding-stuffs of the same class. The relative values of oil meal and corn meal cannot be ascertained in this way, neither should the relative values of coarse feeds and the grains be so compared. We should not pay for oil meal and corn meal on the basis of the quantities of digestible nutrients which they furnish, because the nutrients are not identical in the two cases. Digestible material which is 40 per cent protein cannot be measured by digestible material which is only 10 per cent protein.

385. Digestibility of various feeds.-The following table shows the digestible material in 100 pounds of various feeding-stuffs, as calculated from average composition and digestibility. In the case of hays, the water- 
content is assumed to be uniform, viz., 12.5 per cent, while the percentages given for the grains are the averages found by analysis:

TABLE LXI

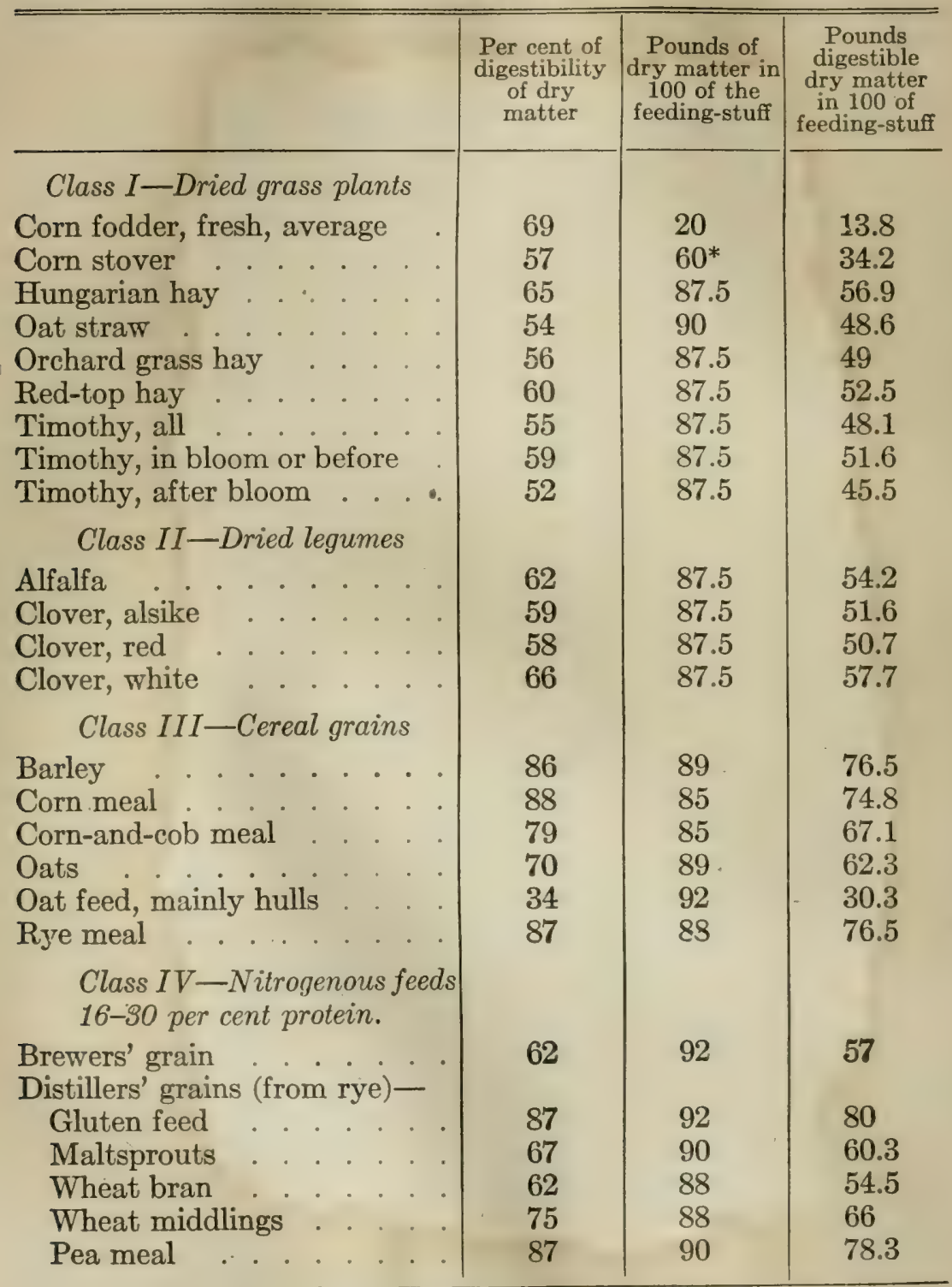


Table LXI, Continued

\begin{tabular}{c|c|c|c}
\hline \hline & $\begin{array}{c}\text { Per cent of } \\
\text { digestibility } \\
\text { of dry } \\
\text { matter }\end{array}$ & $\begin{array}{c}\text { Pounds of } \\
\text { dry matter in } \\
\text { 100 of the } \\
\text { feeding-stuff }\end{array}$ & $\begin{array}{c}\text { Pounds } \\
\text { digestible } \\
\text { dry matter } \\
\text { in 100 of } \\
\text { feeding-stuff }\end{array}$ \\
\hline Class V-Nitrogenous feeds & & & \\
30-45 per cent protein & & & \\
Distillers' grains (from corn)- & 87 & 92 & 80 \\
Gluten meal . . . . . & 89 & 91 & 71.9 \\
Linseed meal, old process & 79 & 90 & 70.2 \\
Linseed meal, new process & 78 & 92 & 82.8 \\
Cottonseed meal, high grade & 90 & 92 & 59.8 \\
Cottonseed meal, low grade & 65 & 92 & \\
\hline
\end{tabular}

It is fully recognized that these figures cannot be taken as absolute relative values. Feeding-stuffs, bearing the same name, are not always exactly similar in composition or in equally good condition. Variations in the moisture-content occur, especially with the coarse fodders. Even after allowing for all these factors, results will not follow exactly the quantities of digestible matter supplied, because there seems to be a greater adaptability of some feeds to the needs of a particular species. Nevertheless we are forced to conclude that food materials of the same class must furnish energy and buildingmaterial closely in proportion to what is digested from them.

386. Valuations based on protein-content.-Certain writers and speakers base the value of nitrogenous feeding-stuffs, from bran up, entirely on the protein-content, and they divide the price by the pounds of protein in a ton in order to determine the relative economy of purchasing this or that material, and the feeding-stuff in which the protein cost is the least when so reckoned is 
regarded as the economical one to purchase. This method seems to be absurd, for it is an assumption that the nutritive value of the carbohydrates and fat in commercial foods may be ignored. The argument is that the farm furnishes carbohydrates in abundance, and that commercial products should merely serve the purpose of reinforcing the protein-supply. If the carbohydrates of the farm have no selling value then this argument has some force, but this is ordinarily not the case. When starch and similar compounds must be purchased as a necessary accompaniment of protein, thus causing a surplus of carbohydrate food, certainly hay, oats, corn, barley, or some other home product may be sold to relieve this surplus.

387. Feed values based on feeding experiments.Many practical feeding experiments have been conducted for the purpose of comparing the different grain products as foods for the various classes of animals. Useful facts have been reached in this way, especially as to the greater adaptability of some materials than others for a particular species. But experiments of this kind cannot be relied upon to fix relative values of feeding-stuffs for milk production, beef production, or for any other purpose. This is so, first of all, because the errors of such tests are so large that we cannot regard their apparent outcome as establishing constants. Again, the problems involved are too complex and the effect of a given ration too dependent upon variable conditions, to allow logical conclusions from such experimental data. The difficulties of the situation will be made clear to anyone by a careful study of the whole mass of data resulting from feeding tests. Differences appear, some of which are consistently in one direction, especially in comparing nitrog- 
enous with carbohydrate foods, but as between materials of the same class their comparative values as indicated by different experiments are greatly variable, even contradictory. Any one who endeavors to reach fixed and universal valuations on an experimental basis of this kind will find himself involved in hopeless confusion.

388. The verdict of the cow.--Once in a while some one talks wildly about leaving food valuation to the "old cow." It is sometimes considered a telling argument against the chemist's wisdom to declare that he and the old cow do not agree. Certainly the cow knows better than the chemist what she likes to eat, and it is little use to offer her foods she does not relish. Even a chemist knows that. If, however, a dozen commercial feedingstuffs were spread around on a barn floor it would be much safer to trust an agricultural chemist, especially one experienced in stock-feeding, to select a ration than any cow ever grown-Holstein, Ayrshire, Jersey, longhorned, dishorned, or what not. The cow would probably get at the corn meal and stay with it until well on the way to a fatal case of indigestion. Her juagment is just about as good as that of a child with a highly cultivated "sweet tooth." 


\section{CHAPTER XVII}

\section{THE SELECTION AND COMPOUNDING OF RATIONS}

There are several factors that must be considered in selecting an efficient and economical ration-factors which relate to both science and practice. It is generally desirable that a food mixture shall be "balanced," but this gives no assurance that a ration can be fed under particular conditions with satisfactory results. Intelligent observation in the barn or stable really takes the first place in formulating a method of feeding, which is supplemented to a valuable extent by the scientific insight of the chemist and physiologist. A ration may be chemically right and practically wrong, but, at the same time, it is worth much to the feeder to be assured that the nutrients which he supplies to his animals will meet their physiological needs. Moreover, commercial relations such as the prices of feeds and product must be considered, and this is a business question and not a scientific matter.

389. Palatableness as a factor in feeding animals.A successful ration must be palatable. An agreeable flavor is not a source of energy or of building-material, but it tends to stimulate the digestive and assimilative functions of the animal to their highest efficiency, and is a requisite for the consumption of the necessary quantity of food. Common experience teaches that when cows or animals of any other class do not like their food, they 
"do not do well." Persons sometimes claim that they have contracted dyspepsia by eating food which is not relished, even food that is nutritious and well cooked, and which would be entirely satisfactory to other individuals. The situation is still worse when the food is undesirable both as to texture and flavor. We have reason to believe that animals are susceptible to the same influences as man, though perhaps not to the same extent. An animal is more than a machine, and is possessed of a nervous organism, the existence of which should never be ignored.

One way of stimulating an animal's appetite is to feed a variety of materials. Continuous feeding on a single coarse food and one grain is not conducive to the best results. The various available fodders and grains should be so combined as to allow the feeding of all of them throughout the season, and avoid the exclusive use of one or two kinds for any extended period of time. The skilful feeder, then, will not fail to make the ration as palatable as possible, and will always consider the idiosyncrasies of appetite of each animal.

390. Adaptation of rations.-The ration must be adapted to the species. This is obvious as relates to quantity, but is equally true of the kinds of materials. For instance, both poultry and swine generally eat cottonseed meal with reluctance and with danger to health. Wheat bran is less desirable for swine than for other species. The horse and the hog are not adapted to rough fodder as are the ruminants. It is useless, however, to mention at this point other instances of this character, or to comment on their importance, further than to emphasize the foolishness of trying to bring all species of animals to a common basis in the supply of feeding-stuffs. 
391. Physiological requirements.-The physiological requirements of the animal must be considered. A ration of maximum physiological efficiency and economy must contain the several nutrients in such quantities and proportions as will meet the needs of the particular animal fed, without waste. This statement is based upon facts given elsewhere in this volume relative to the demands of the animal body and the functions of the nutrients.

It remains now for us to consider how to compound such rations as are desired, or those that are adapted in kind and quantity to the requirements which they are to meet. Obviously, the first essential for doing this is the adoption of standards to which rations should conform, for if we do not have these there is no possibility of concluding whether one food mixture is better or worse than another for a particular purpose.

392. Feeding standards. - Such standards have been proposed, which we knew first as German feeding standards. The standards that are now accepted are the result of numerous and elaborate studies of the balance of loss or gain to the animal organism when rations of various kinds were fed to animals at rest, at work, and when producing meat, wool, or milk, in desirable quantities. They relate entirely to physiological demands without reference to the cost of the rations or to the profits which may result from their use.

The earlier standards were developed chiefly in Germany but those now most in favor are based upon American experimental data.

These standards are variable in two main factors: (1) The quantity of available nutrients, and (2) the relative proportions of the classes of nutrients. Quan- 
tity is an essential consideration, for it is obvious that enough energy and building-material must be supplied to do a given work. It is also obvious that quantity must be a variable factor according as the animal is large or small, doing hard or light work, giving much or little milk, or fattening rapidly or slowly.

Account must be made of the proportions of the nutrients, because protein, for instance, has peculiar functions which other nutrients cannot exercise, and less than a certain minimum of the proteins in any given case, would limit production by just the amount of the deficiency. In order for the protein to serve its maximum usefulness, its energy should not be encroached upon to fill a place equally well or better taken by carbohydrates; consequently, the proportion of carbohydrates must also be considered.

393. Nutritive ratio.-The relative proportion of the nutrients of a ration is known as the nutritive ratio. By this term is meant the relation in quantity of the digestible protein to all the other digestible organic matter reckoned in terms of carbohydrates. If we multiply the quantity of fat by 2.25 we get its carbohydrate equivalent, and if we add this product to the quantity of digestible carbohydrates present we have the carbohydrate value of the digestible matter other than the protein. This sum divided by the number representing the protein gives the nutritive ratio. For instance, in a ration mentioned later there are .94 pound protein, 9.65 pounds carbohydrates, and .49 pound fat. $(.49 \times 2.25+9.65) \div$ $.94=11.4$. $1: 11.4$ is therefore the nutritive ratio of the ration.

A nutritive ratio may be designated as "narrow," "wide," or "medium." These terms do not represent 
exact limits to which there is universal agreement. A narrow ratio is one where the proportion of protein is relatively large, not less perhaps than 1:5.5. A wide ratio is one where the carbohydrates are very greatly predominant, or in larger proportion perhaps than 1:8. Anything between $1: 5.5$ and $1: 8$ may properly be spoken of as a medium ratio.

Merely for the purpose of illustration, three feeding standards are given in this connection. These are selected from standards proposed by Wolff, as modified by Lehmann. They refer in all instances to animals weighing 1,000 pounds:

Table LXII. For 1,000 Pounds Live Weight Daily

\begin{tabular}{|c|c|c|c|c|c|c|}
\hline & $\begin{array}{c}\text { Dry } \\
\text { sub- } \\
\text { stance }\end{array}$ & $\begin{array}{l}\text { Diges- } \\
\text { tible } \\
\text { pro- } \\
\text { tein }\end{array}$ & \begin{tabular}{|c|} 
Diges- \\
tible \\
car- \\
bohy- \\
drates
\end{tabular} & $\begin{array}{c}\text { Diges- } \\
\text { tible } \\
\text { fat }\end{array}$ & \begin{tabular}{|c|} 
Total \\
diges- \\
tible \\
organic \\
matter
\end{tabular} & $\begin{array}{l}\text { Nutri- } \\
\text { tive } \\
\text { ratio }\end{array}$ \\
\hline $\begin{array}{l}\text { Cow, yield milk, } 22 \text { lbs. . } \\
\text { Fattening steer, 1st per. } \\
\text { Horse, medium work. . }\end{array}$ & $\left|\begin{array}{c}\text { Pounds } \\
29 \\
30 \\
24\end{array}\right|$ & \begin{tabular}{|l} 
Pounds \\
2.5 \\
2.5 \\
2
\end{tabular} & $\begin{array}{c}\text { Pounds } \\
13 \\
15 \\
11\end{array}$ & $\begin{array}{l}\text { Pounds } \\
.5 \\
.5 \\
.6\end{array}$ & $\begin{array}{c}\text { Pounds } \\
16 \\
18 \\
13.6\end{array}$ & $\begin{array}{l}1: 5.7 \\
1: 6.5 \\
1: 6.2\end{array}$ \\
\hline
\end{tabular}

These and other standards will be discussed later when we come to consider the feeding of the various farm animals. Our present purpose is simply to make clear the steps necessary to bringing the quantity and composition of the ration into conformity with the standard selected.

394. Calculating a ration.-As a means of showing the steps involved in calculating what a ration is, and how to improve it if necessary, we will assume that it is desired to learn whether a food mixture which a milch cow is eating is what it should be, and if it is not, how to 
make it so. The standard ration for a 1,000-pound cow, giving twenty-two pounds of average milk, expressed in terms of water-free nutrients, has been given in the preceding table.

The first point which requires our attention is that this standard is mainly expressed in terms of water-free digestible nutrients. This means that we must take into account the composition and digestibility of the particular feeding-stuffs which enter into a ration, if we would discover what it really is supplying of available food compounds. It is evident that usually feeders cannot have their cattle foods analyzed, and so they must resort to the tables of composition and digestibility, which are, or may be, in the hands of every farmer.

395. Calculation of digestible nutrients.-Feedingstuffs, especially fodders, differ within quite wide limits in what they contain and in what the animal will dissolve from them, according to the species, stage of growth and conditions of curing, and an average percentage of protein or an average coefficient of digestibility is likely to differ widely from the actual facts as pertaining to a particular material. All that can be done is to select as nearly as possible the figures which have been found for feeding-stuffs in the condition of those which are to be fed. If the hay is from mature grass, use the composition percentages and digestion coefficients given for such hay; if the silage is from mature corn, pursue a similar course in this case, and so on. Difficulty may be met in finding suitable figures, because tables of composition and digestibility are not fully developed and classified on the basis of the character of the materials.

The assumed ration which we wish to discuss consists of: 


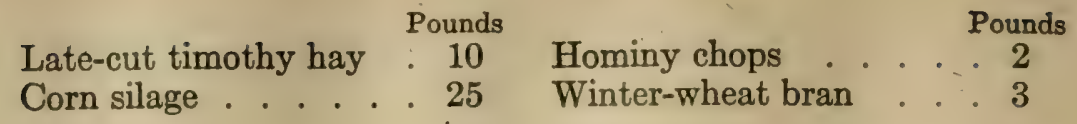

The averages for composition and digestibility, which are as likely as any to represent these and other materials, are the following:

TABLE LXIII

\begin{tabular}{|c|c|c|c|c|c|c|c|c|c|c|}
\hline & \multicolumn{6}{|c|}{ Composition } & \multicolumn{4}{|c|}{ Digestibility } \\
\hline & 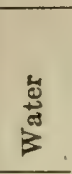 & $\frac{5}{4}$ & 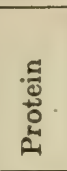 & 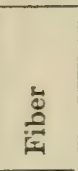 & 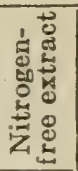 & 苟 & م & $\frac{\text { L. }}{0}$ & 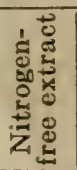 & $\underset{E}{\overrightarrow{5}}$ \\
\hline & Per & Per & Per & Per & Per & $\begin{array}{l}\text { Per } \\
\text { cent }\end{array}$ & $\begin{array}{l}\text { Per } \\
\text { cent }\end{array}$ & $\begin{array}{l}\text { Per } \\
\text { cent }\end{array}$ & $\begin{array}{l}\text { Per } \\
\text { cent }\end{array}$ & $\begin{array}{l}\text { Per } \\
\text { cent }\end{array}$ \\
\hline $\begin{array}{c}\text { Timothy hay, late } \\
\text { cut . . . . }\end{array}$ & $\begin{array}{c}\text { cent } \\
14\end{array}$ & $\begin{array}{l}\text { cent } \\
3.9\end{array}$ & $\begin{array}{r}\text { cent } \\
5.2\end{array}$ & $\begin{array}{l}\text { cent } \\
29.7\end{array}$ & $\begin{array}{l}\text { cent } \\
45.2\end{array}$ & 2. & $\begin{array}{l}\text { cent } \\
43\end{array}$ & $\begin{array}{l}\operatorname{cent} \\
46\end{array}$ & $\begin{array}{l}\operatorname{cen} \tau \\
59\end{array}$ & $\begin{array}{c}\text { cent } \\
51\end{array}$ \\
\hline Clover hay & 15 & 7.7 & 13.3 & 24.3 & 37.2 & 2.5 & 58 & 54 & 65 & 56 \\
\hline Corn silage & 80 & 1.1 & 1.7 & 5.4 & 11.1 & .7 & 51 & 65 & 71 & 82 \\
\hline Hominy feed & 11 & 2.5 & 10.4 & 4.2 & 63.9 & 8. & 65 & 67 & 89 & 92 \\
\hline Wheat bran & 10 & 6.2 & 16.1 & 10. & 53.3 & 4.4 & 77 & 39 & 71 & 63 \\
\hline $\begin{array}{c}\text { Linseed meal, new } \\
\text { process }\end{array}$ & 9 & 5.6 & 37.4 & 8.9 & 36.4 & 2.7 & 85 & 74 & 84 & 93 \\
\hline
\end{tabular}

The first step in the calculation is to find out what percentages of digestible material the components of our proposed ration contain, and we shall obtain these by multiplying the percentages of composition by the coefficients of digestibility and dividing the product by 100 ; that is, if timothy hay contains 5 per cent of protein, 45 per cent of which is digestible, then .45 of 5 will be the percentage of digestible protein in the hay. In this way the following figures were obtained. The percentage of digestible carbohydrates represents the sum of the quantities digested from both the crude fiber and the nitrogen-free extract. Tables are now published which show percentages of digestible ingredients, and which will render this calculation largely unnecessary: 
TABLE LXIV

Timothy hay

Clover hay .

Corn silage

Hominy feed

Wheat bran

Linseed meal

\begin{tabular}{|c|c|c|c|}
\hline $\begin{array}{l}\text { Digest- } \\
\text { ible } \\
\text { protein }\end{array}$ & $\begin{array}{c}\text { Digest- } \\
\text { ible } \\
\text { carbo- } \\
\text { hydrates }\end{array}$ & $\begin{array}{l}\text { Digest- } \\
\text { ible } \\
\text { fats }\end{array}$ & $\begin{array}{c}\text { Total } \\
\text { digest- } \\
\text { ible } \\
\text { organic } \\
\text { nutrients }\end{array}$ \\
\hline $\begin{array}{c}\text { Per cent } \\
2.2\end{array}$ & $\begin{array}{c}\text { Per cent } \\
40.4\end{array}$ & $\begin{array}{l}\text { Per cent } \\
1 .\end{array}$ & $\begin{array}{c}\text { Per cent } \\
43.6\end{array}$ \\
\hline 7.7 & 37.3 & 1.4 & 46.4 \\
\hline .9 & 11.4 & .6 & 12.9 \\
\hline 6.8 & 58.7 & 7.4 & 72.9 \\
\hline 12.4 & 41.7 & 2.8 & 56.9 \\
\hline 31. & 37.1 & 2.5 & 70.6 \\
\hline
\end{tabular}

396. Digestible nutrients in a given ration.-The second step is to calculate the pounds of digestible nutrients in the quantities of the several feeding-stuffs to be used. It is clear, for instance, that 10 pounds of hay will contain .10 of the amounts in 100 pounds, so we simply need to multiply the percentage of digestible protein and so on by 10 and divide by 100 in order to learn what 10 pounds of hay will furnish to the animal. If we make this computation for each constituent of each feeding-stuff, we reach the figures of the following table:

TABLE LXV

\begin{tabular}{|c|c|c|c|c|c|}
\hline & $\begin{array}{c}\text { Digestible } \\
\text { protein }\end{array}$ & $\begin{array}{c}\text { Digestible } \\
\text { carbo- } \\
\text { hydrates }\end{array}$ & $\begin{array}{c}\text { Digestible } \\
\text { fat }\end{array}$ & $\begin{array}{c}\text { Total } \\
\text { digestible } \\
\text { organic } \\
\text { matter }\end{array}$ & $\begin{array}{c}\text { Nutritive } \\
\text { ratio }\end{array}$ \\
\hline $\begin{array}{l}\text { Timothy hay, } 10 \mathrm{lbs} \text {. } \\
\text { Corn silage, } 25 \mathrm{lbs} \text {. } \\
\text { Hominy feed, } 2 \text { lbs. } \\
\text { Wheat bran, } 3 \text { lbs. }\end{array}$ & $\begin{array}{c}\text { Pounds } \\
.22 \\
.22 \\
.14 \\
.37\end{array}$ & $\begin{array}{c}\text { Pounds } \\
4.04 \\
3.85 \\
1.17 \\
1.25\end{array}$ & $\begin{array}{c}\text { Pounds } \\
.10 \\
.12 \\
.15 \\
.08\end{array}$ & $\begin{array}{c}\text { Pounds } \\
4.36 \\
4.19 \\
1.46 \\
1.70\end{array}$ & \\
\hline & .95 & 10.31 & .45 & 11.08 & $1: 12$ \\
\hline
\end{tabular}

Several authors have published tables showing the proportions of digestible nutrients in feeding-stuffs. 
397. Correcting an insufficient ration.-When we come to compare this ration with the standard ration we find it is seriously defective in two particulars: it contains far too little digestible organic matter and the nutritive ratio is too wide.

In order to correct these faults, we must add digestible organic matter which contains a much larger proportion of protein than is found in any of the materials so far selected, and we must seek such a supply, in part at least, among the highly nitrogenous feeding-stuffs like the oil meals and gluten meals. It is easy for one with experience to see, also, that all the necessary additional organic matter cannot be secured from a highly nitrogenous food without increasing the protein supply unnecessarily. In order to avoid this, the amount of silage may be raised ten pounds and still not feed an excessive quantity. If clover hay is available, it would also be well to substitute five pounds of it for five pounds of the timothy. If, then, we add to the ration three pounds of linseed meal we shall approximate more nearly to our standard.

TABLE LXVI

\begin{tabular}{|c|c|c|c|c|c|}
\hline & Protein & $\begin{array}{c}\text { Car- } \\
\text { bohy- } \\
\text { drates }\end{array}$ & Fat & \begin{tabular}{|c|} 
Total \\
digest- \\
ible \\
organic \\
matter
\end{tabular} & $\begin{array}{c}\text { Nutri- } \\
\text { tive } \\
\text { ratio }\end{array}$ \\
\hline $\begin{array}{l}\text { Timothy hay, } 5 \text { pounds } \\
\text { Clover hay, } 5 \text { pounds } \\
\text { Corn silage, } 35 \text { pounds } \\
\text { Hominy feed, } 2 \text { pounds } \\
\text { Wheat bran, } 3 \text { pounds } \\
\text { Linseed meal, } 3 \text { pounds }\end{array}$ & $\begin{array}{l}.11 \\
.37 \\
.31 \\
.13 \\
.37 \\
.93\end{array}$ & $\begin{array}{l}2.62 \\
1.86 \\
3.99 \\
1.17 \\
1.25 \\
1.11\end{array}$ & $\begin{array}{l}.05 \\
.07 \\
.21 \\
.15 \\
.08 \\
.07\end{array}$ & $\begin{array}{l}2.18 \\
2.30 \\
4.51 \\
1.45 \\
1.70 \\
2.11\end{array}$ & \\
\hline Linseed meal, 3 pounds & 2.22 & 11.40 & .63 & 14.25 & $1: 6.8$ \\
\hline
\end{tabular}


This ration is still below the standard in quantity, but as the relation of the nutrients is approximately what is called for, it is only necessary to increase the quantities of each component about one-fifteenth in order to furnish the animal sixteen pounds of digestible organic matter. It is, however, a good ration for cows of the smaller breeds weighing from 800 to 900 pounds.

398. Relation of ration to size of animal.-There are several points to be considered in this connection. First of all, the standard rations are the quantities to be fed a day and for 1,000 pounds live weight. This is ordinarily taken to mean that if a 1,000-pound cow requires 16 pounds of digestible nutrients, an 800-pound cow should be supplied with only four-fifths as much, or 12.8 pounds, or that a 1,200-pound horse needs 50 per cent more food than one weighing 800 pounds. Unfortunately this simple mathematical way of calculating rations does not meet the plain requirements of practice. The needs of a producing or working animal are not directly proportional to its size, for the work done or the quantity of production is the dominating factor. It is certain that feeding milch cows or working horses in proportion to weight alone contravenes known facts.

However, we cannot ignore the size of the animal in determining the quantity of the ration. Concerning this, Armsby says: "The function of the maintenance ration is essentially to supply heat to the body to replace the constant loss that takes place. Now, Henneberg has long ago shown that, in round numbers, over 90 per cent of this heat is removed by radiation and evaporation. Consequently, we should expect the demands of the organism for heat (i. e., for maintenance), to be proportional to its surface (including lung surface), rather 
than to its weight, and the more recent researches of Rubner have confirmed this theoretical conclusion." For the purposes of calculation, it is assumed that animals are geometrically similar figures and therefore that their surfaces are proportional to the cube root of the square of their weights. Several steers having weights from 1,000 up to 1,700 pounds would need, on this basis, amounts of digestible food for maintenance proportional to figures given in the table below:

Weight of the animal approximately

1,000 pounds

Proportion of food per 1,000

1,100 pounds pounds live weighi

1,200 pounds 100

1,300 pounds 96

1,400 pounds

93

90

1,500 pounds

1,600 pounds

86

1,700 pounds

84

82

For adjusting a maintenance ration to the weight of a steer or horse, this method seems to have a plausible basis, but it is evidently less applicable to dairy cows or rapidly growing or fattening animals, for in these cases production and not size must be chiefly considered.

399. The protein-supply. - The matter of the proteinsupply is important. If we are trying to supply the needs of a cow giving twenty-five pounds of milk, or of a steer gaining two pounds of body substance daily, there is without question a minimum quantity of food protein absolutely necessary in each case. These necessary quantities are certainly not the same for all individuals, but they are not likely to differ widely between single animals of the same class and productive capacity. It is safe to assert that the earlier protein standards are those which it is practicable to feed and which unquestionably 
generously meet the demands of the class of animals for which they are designed.

400. Earlier protein standards revised.-Through more recent investigations, revisions of the earlier protein standards have been recommended. These are in general in the direction of a lower minimum of protein, and the data secured seem to justify the change. At the same time, care should be taken in not fixing the protein minimum too low, partly because a generous protein-supply promotes the general welfare of the animal, and partly because of the variable efficiency of the single proteins which are found in the different feeding-stuffs in greatly unlike proportions. The amount of protein fed in a given case should be such as to guarantee a sufficient amount for the actual constructive work demanded. (See Par. 275.) Probably with certain feeding-stuffs the minimum might be lower than with others. It is very evident then that the protein-supply in feeding formulas for production cannot safely be resolved to the exact limitation of the nitrogen compounds needed. The standards that have been suggested will be considered in the following pages.

401. Presence of growth-promoting bodies.-The discovery of growth-promoting bodies attached to cattle foods (see Par. 278) leads to the conclusion that rations should be selected under certain conditions with reference to the presence of these essential compounds. This is especially true where animals are likely to be fed on a restricted diet, as, for instance, swine, or where byproduct feeds are used the treatment of which may have removed part or all of the food accessories. With animals eating the forage portion of plants in large quantities, such as the bovines, there is little danger that there will be a deficiency in the food of these essential compounds. 
As these compounds exist in much smaller proportion in grain, swine when confined to a restricted grain diet may suffer from a lack of such accessory bodies. The addition, therefore, to the grain food of swine of some green food, such as alfalfa, would appear to insure the animal against defective growth.

Dairy by-products are carriers of both Fat-soluble A and Water-soluble $\mathrm{B}$, and the recognized value of these by-products in pig-feeding is perhaps partly due to the presence of these substances. As time proceeds, the knowledge necessary to the compounding of rations with reference to the growth-promoting value will doubtless be greatly enlarged.

402. Influence of ration on quality of product.-The rations should be compounded with reference to the quality of the product. Our knowledge of the influence of foods upon the quality of meat products is by no means complete, but that food has an influence upon the flavor of milk and upon the chemical and physical properties of butter, seems to be fairly well established.

403. Home supply of feeding-stuffs to be considered.Rations should be compounded with reference to the home supply of feeding-stuffs and to market prices. Economy often demands that the materials in hand shall be used even if the ration is not ideal. Again, there are several protein foods which may be used, and it is often only a question of price in determining which should be purchased. Notwithstanding the claims of manufacturers, there is no one feeding-stuff essential to the health of animals or to the highest quality of the product, so that the feeder may often consider the matter of cost and select the cheapest source of protein without in any way impairing the ration. 
404. Selection of a ration largely a business matter.Those who have carefully followed the preceding statements must have become convinced that the selection of a ration which shall be the best possible from a business standpoint is not a simple matter. We must always distinguish between the combination that is most efficient physiologically or productively, and the one that is the source of largest profit. It is often the case-perhaps generally - that a food mixture which induces a high rate of production is the most profitable one to use, but this occurs only when business conditions make it possible. Many seem to think that if a ration is "balanced" it necessarily meets all the requirements for the maximum profit, but this is an erroneous view.

For instance, a farmer somewhat remote from the markets may have on hand an abundant supply of hay and home-raised grains of such a character that it is impossible to compound them so as to conform to the accepted feeding standard for milch cows. If the prices of dairy products are low, and those of purchased feeding-stuffs are high, it is entirely possible for the farmer to secure more profit from his cows with an "unbalanced" ration than with one which has a more nearly correct nutritive ratio.

The western stockman can often afford to waste corn on fattening steers rather than use it with greater physiological economy by mixing it with purchased grains. The cost of the latter would soon offset the profits otherwise possible. All this is equivalent to saying that practical considerations often justify a wide departure from the standard rations. Hills states the case well when he says:

"The study of the requirements of the individual 
animal and the adapting of food to its needs is to be preferred to placing the herd, as a whole, upon any inflexible ration. The capacity of an animal to receive, its ability to produce, the effects of the sundry feeds upon the health and condition of the animal, upon its appetite and taste, upon the quality of the product, the money values of feed, and the profits to be derived from their use, are important considerations which do not enter into the make-up of the physiological standard, but which are vital factors in the feeder's problem. Clearly the physiological standards may supplement, and in some measure guide, judgment, but cannot take its place." 


\section{CHAPTER XVIII}

\section{MAINTENANCE RATIONS}

Ir has already been shown that the demands on the food vary greatly with different individuals or classes of animals according to size and the kind and quantity of production. It is proposed to indicate how rations should be compounded in order to meet varying conditions and demands for production of various kinds, but as preliminary to this an understanding should be reached as to what is required to support the producing organism.

405. Definition of maintenance ration.-A maintenance ration is one supplying the needs of an animal without production of any kind and with no loss of body substance. To be more specific, when an ox doing no work excretes just the quantities of nitrogen and carbon that are contained in the food consumed, he is said to be eating a maintenance ration. The work done by the animal at rest is largely needed in the following directions: The chewing of food and its movement along the intestinal tract; the muscular action of the heart in causing blood circulation; and the metabolic activity of the cells in causing the chemical transformation of the nutrients. Some work is also done in moving the body and in the effort of standing. The demands upon the food for maintenance purposes are therefore largely for the support of some form of muscular activity.

406. Character of maintenance ration.-Nine-tenths or more of a maintenance ration may consist of carbo- 
hydrates which, because the income and outgo are balanced, are used solely as fuel. Only a very small amount of protein is necessarily destroyed by a resting animal, although a minimum supply is absolutely essential if the nitrogenous tissues of the body are to be kept from wasting. If an animal is not eating protein, the cleavage of body protein will go on and urea will continue to appear in the urine and in time protein starvation will cause death.

407. Uses of production ration.-Any ration, fed for production, may be looked upon as made up of two parts, that which is needed to maintain the animal and that which may be applied to growth or the formation of milk solids. It is possible, of course, for the production of milk or wool to occur when the cow or sheep is fed what is really only a maintenance ration, but the materials for production under these circumstances are furnished at the expense of the body substance. With what is regarded as liberal feeding, from one-third to one-half of a production ration is needed for maintenance purposes. It seems fitting, then, to speak of a maintenance ration as a fundamental quantity, a knowledge of which is important to both science and practice. It is clear that no rational understanding of the uses of food can be had, unless we know what amount is required simply for maintenance, and the feeder is certainly helped to a more intelligent compounding of rations if he has some means of judging how large an excess he is supplying for production purposes. Occasionally, too, it is desired to provide horses and other animals when not at work with just enough food to keep them in a uniform condition without gain or loss.

408. Maintenance ration easily provided.-No ration is more easily provided from the ordinary farm supply 
than is that for maintenance, for two reasons: (1) Because the quantity of available nutrients which must be eaten is so small that this ration may be wholly or mostly made up of bulky materials such as corn fodder and hay; (2) because investigation has demonstrated that mere maintenance demands a comparatively small amount of protein and so this ration may have a wide nutritive ratio such as pertains to the nutrients of the more common farm products.

\section{MAINTENANCE RATION FOR BOVINES}

409. Various investigations concerning maintenance needs.-Experiments, having for their object a determination of the daily quantity of nutrients necessary to simply maintain animals of this class, were conducted by Henneberg and Stohman with oxen as long ago as 1858. A number of rations were fed and the conclusions which were reached were based upon the amount of food digested, the gain or loss of nitrogenous tissue by the animals, their weights, and general appearance. The average daily quantities of digestible nutrients which appeared to be sufficient to maintain a 1,000-pound ox without growth or loss was approximately 8.2 pounds, of which .53 pound was protein, the whole having an energy or heat value of not far from 15,000 calories. Because of the high temperature of the stalls used in the above-named experiments, Wolff estimated later that for winter feeding the standard should be 8.9 pounds of digestible nutrients, of which .7 pound should be protein, the energy value being approximately 16,000 calories, and for a long time Wolff's figures were published as the standard maintenance ration. 
This standard has been revised. The earlier experiments on which it was based furnished data insufficient for accurate conclusions, for the only means of judging whether the animals were gaining or losing body substance were the changes in live weight, which cannot be regarded as conclusive evidence. Some of the earlier feeding experiments conducted in the United States, especially those of Sanborn and Caldwell, indicated that a ration based on Wolff's standard was capable of causing a material growth of steers, and the accuracy of Wolff's figures was called into question. Later observations of a more exact character have shown quite conclusively that a 1,000-pound steer may be maintained without loss of body substances on considerably less than 8.9 pounds, or even 8 pounds, of digestible nutrients a day.

Elaborate experiments by Kühn from the years 1882 to 1890 , afterwards discussed by Kellner, were regarded by the latter as justifying the conclusion that the minimum quantity of digestible organic matter which will maintain a 1,000-pound mature ox at rest is 7.3 pounds, .7 of a pound of which should be protein. Later Armsby, in presenting the results of experiments of his own in connection with a critical review of Kühn's work, concludes that "we may place the average maintenance of a steer weighing $500 \mathrm{kgs}$. (1,100 pounds) and receiving only a mainly coarse fodder at 13,000 calories of available energy." As Armsby has found one gram of digestible matter from roughage to be equal to 3.5 calories of available energy, 13,000 calories would equal 7 pounds of digestible matter from this source. This would be the same as 6.54 pounds for a 1,000-pound animal.

Still later, Kellner, basing his figures upon extensive researches by himself and associates, which were the 
most elaborate made up to that time, gave us the following as the minimum quantities which will satisfy the maintenance needs of mature animals of different weights:

\section{Approximate weight} of animal

Pounds

1,000

1,100

1,200

1,300

1,400

1,500
Energy

Calories

10,740

11,520

12,280

13,010

13,720

14,420
Digestible organic

substance from average meadow hay Pounds

6.75

7.22

7.72

8.18

8.62

9.06

The researches of Armsby and Fries with the respiration calorimeter, in a study of the fasting katabolism of a steer, furnish us data much more reliable than can be secured in any other way.

410. Fasting katabolism as a measure of maintenance needs. - The exact maintenance needs of a given animal are most accurately determined while the animal is fasting. When an animal is receiving no food there is no cessation of the vital activities. In the maintenance of these activities there is necessary a certain amount of protein cleavage and a sufficient oxidation of organic compounds to meet the energy needs of the animal. The material that is so used is taken from the body structure, and by determining the metabolic nitrogen excreted, and the gaseous products resulting from oxidation, the exact maintenance needs of the animal are ascertained. This is a determination of the fasting katabolism of the animal body.

The investigation by Armsby and Fries was conducted with a steer which first was fed daily 3.2 kilograms of timothy hay, an amount not sufficient to maintain the 
animal without loss of body substance. The metabolizable energy of this insufficient ration was found to be 5.7 therms, and during the time it was fed, the steer lost from his own tissues an amount of protein and fat equivalent to 2.4 therms a day. In another period, the steer ate 5.2 kilograms of the same hay, having a metabolizable energy of 9.26 therms, or 3.58 therms more than was contained in the smaller ration. By feeding the larger ration, the use of body protein and fat was reduced to .357 therms or 2.02 therms less than was the case with the smaller ration. It seems, then, that 3.58 therms of metabolizable energy in the ration replaced 2.02 therms of energy derived from body substance; or, in other words, the metabolizable energy in the hay was only 56.5 per cent as efficient as was the energy derived from the oxidation of body protein and fat. The other 43.5 per cent of the hay energy was used, as we have seen, in the way of mastication, digestion, and other internal functions requiring the use of energy in order to prepare the food and transmit it to the tissues.

411. Distribution of maintenance energy.-A study of fasting katabolism has made possible not only the energy used in maintenance but also the approximate determination of the distribution of the uses of energy. Zuntz, on the basis of observations made with a fasting man, computed that muscular activity, including circulation, respiration, and the voluntary muscles, used about 60 per cent of the metabolism and that the internal organs, such as the liver, intestines, kidneys, pancreas, and salivary glands, used about 40 per cent.

412. Use of nutrients in fasting metabolism.-The studies of fasting metabolism have made it possible to measure accurately the relative use of the nitrogenous 
and the non-nitrogenous tissues. Determinations with many species of animals, including man, swine, dog, rabbit, guinea pig, goose, and hen, show that the protein katabolism in per cent of total katabolism varied from 7.3 to 15.6. In all but two cases the range was from 10.8 to 15.6 per cent. This shows that the energy derived from the fat and carbohydrates, largely from the fat where this has been stored, is from six to nine times as great as from the body protein.

413. Computation of maintenance needs.-The foregoing data allow a computation of the metabolizable energy that must be supplied in the ration in order to meet the maintenance needs of the experimental animal that was under observation.

The larger ration supplied the need of the animal to within .357 therm, which was derived from body substance. This deficit would be equal to .632 therm of matabolizable energy supplied by the hay. The computation would be as follows:

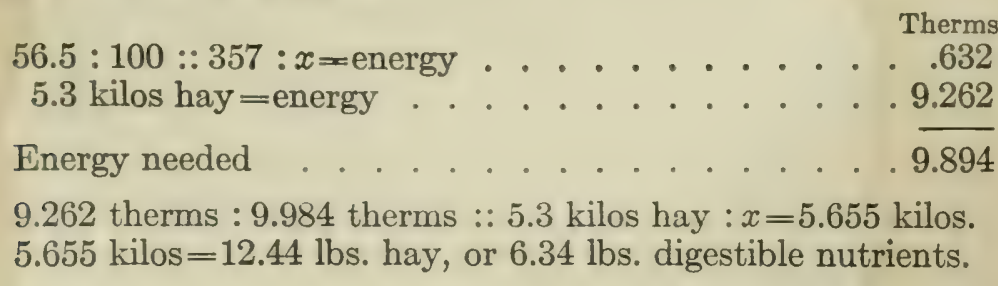

The animal weighed 822 pounds. If the animal had weighed 1,000 pounds, using the formula for body surface, the figures for digestible nutrients would be 7.21 pounds. These figures correspond closely to those derived from previous investigations.

Armsby suggests the following maintenance requirements based on production values for cattle, which include growing animals: 


$\begin{gathered}\text { Table LXVII. Matntenance } \\ \text { Live }\end{gathered}$
$\begin{gathered}\text { weight } \\ \text { Pounds }\end{gathered}$

414. Maintenance rations for bovines.-In order to express a maintenance ration for bovines in terms of hay and grain, there are given in this connection several mixtures, based upon energy values in Table XXXIX, which, on the basis of average composition and digestibility, will furnish fairly closely the necessary protein and energy:

To Maintain a 1,000-Pound Animal

$1\left\{\begin{array}{rl}12 & \mathrm{lbs} \text {. average timothy hay. } \\ 4 \mathrm{lbs} . \text { wheat bran. }\end{array}\right.$

$3\left\{\begin{array}{l}23 \text { lbs. mature corn silage. } \\ 4 \text { lbs. timothy hay. } \\ 2 \text { lbs. wheat bran. }\end{array}\right.$

$2\left\{\begin{array}{l}8 \mathrm{lbs} \text {. corn stover, much water. } \\ 6 \mathrm{lbs} \text {. clover hay. } \\ 3 \mathrm{lbs} . \text { corn-and-cob meal. }\end{array} 4\left\{\begin{array}{l}5 \mathrm{lbs} \text {. timothy hay, ripe. } \\ 5 \mathrm{lbs} \text {. clover hay. } \\ 4 \mathrm{lbs} \text {. corn-and-cob meal. }\end{array}\right.\right.$

5. $17 \mathrm{lbs}$. good mixed hay.

These combinations are merely illustrative. Many others furnishing an equivalent quantity of available nutrients may be used. Doubtless these various mixtures will not show equal efficiency. Ration No. 3 would probably be more satisfactory than No. 5 , because of greater palatableness. All such factors as the proportion of grain in the mixture; the stage of growth of the fodder, whether early or late cut, immature or mature; the amount of moisture present, as in stover; and the completeness of preservation, will have an influence upon the 
nutritive effect of a ration, and these factors must be considered according to the best judgment of the feeder. It is possible, without question, to maintain an animal on one fodder alone, such as hay, but for several obvious reasons it is better to feed some grain.

The maintenance rations heretofore stated apply to a 1,000-pound animal. For animals weighing more or less the quantity should be increased or diminished, but not in just the ratio in which the animal varies in weight.

\section{MAINTENANCE FOOD FOR HORSES}

The general facts which have been presented in relation to the function and character of a maintenance ration are as applicable to horses as to bovines. It is true, however, that rations simply sufficient for maintenance purposes have a very limited application with horses, because in nearly all cases they are at least used for occasional driving or light work, and even if merely "boarded," regular exercise is necessary to their welfare.

415. Studies of the maintenance needs of the horse.Zuntz, who so thoroughly studied the nutrition of the horse, concluded, after a critical survey of the results of other men in connection with the elaborate data from his own extended investigations, that a 1,000-pound horse can be maintained on 6.4 pounds of nutrients, provided the total ration contains not more than 3 pounds of crude fiber. This means that the nutrients should come from a mixture of hay and grain if this minimum quantity is to be sufficient. Were only hay to be fed, the necessary nutrients would probably exceed the amount named.

Grandeau in his experiments found that three horses, whose mean weight was 852 pounds, were maintained 
for fourteen months on 17.6 pounds of hay a day, from which the three animals digested an average of 6.06 pounds of organic matter. Using the method of computation already described, this is equal to 6.75 pounds of digestible nutrients for a 1,000-pound horse, a result not greatly different from that of Zuntz.

The latest conclusion of Wolff was that a 1,100pound horse should have for maintenance at rest 7.26 pounds of digestible organic matter daily, exclusive of the digested crude fiber, which would be the same as 6.78 pounds of fiber-free nutrients for a 1,000-pound horse. As Wolff regarded the fiber as useless to a horse, either for maintenance or for production of work, the last figures represent his estimate of the maintenance needs of a horse at rest.

It is proper to remark that Wolff's views as to the nutritive value of crude fiber are not generally accepted.

The following maintenance standards, based on production values, are offered by Armsby:

\begin{tabular}{|c|c|c|c|}
\hline TABLE LXVIII. & Maintenance & REQUIREMENTS OF & Horses \\
\hline $\begin{array}{c}\text { Live } \\
\text { weight }\end{array}$ & & $\begin{array}{l}\text { Digestible } \\
\text { protein }\end{array}$ & $\begin{array}{l}\text { Energy } \\
\text { value }\end{array}$ \\
\hline Pounds & & Pounds & Therms \\
\hline $\begin{array}{l}150 \\
250\end{array}$ & & · .3 & $\begin{array}{l}2 . \\
28\end{array}$ \\
\hline 500 & & .6 & 4.4 \\
\hline 750 & & .8 & 5.8 \\
\hline 1,000 & & 1. & \\
\hline 1,250 & & 1.2 & 8.15 \\
\hline 1,500 & & 1.3 & 9.2 \\
\hline
\end{tabular}

In calculating rations for horses, the coefficient of digestibility obtained in experiments with this class of animals should be used, coarse fodders, as stated previously, not being so efficiently digested by horses as by bovines or sheep. 
416. Maintenance rations for horses.-Accepting the standard given on page 316 as the daily requirement of a resting horse, the following rations would maintain a 1,000-pound animal for one day:

$1\left\{\begin{array}{l}20 \mathrm{lbs} . \text { medium quality } \\ \text { mixed hay. }\end{array}\right.$

$2\left\{\begin{array}{c}10 \text { lbs. timothy hay. } \\ 5 \text { lbs. oats. }\end{array}\right.$

$3\left\{\begin{array}{r}10 \mathrm{lbs} \text {. timothy hay. } \\ 4 \mathrm{lbs} \text {. cracked corn. }\end{array}\right.$

$4\left\{\begin{array}{l}10 \mathrm{lbs} \text {. medium mixed hay. } \\ 4 \frac{1}{2} \mathrm{lbs} \text {. wheat middlings }\end{array}\right.$ $5\left\{\begin{array}{l}10 \text { lbs. mixed hay. } \\ 4 \text { lbs. bran, or } \\ 5 \text { lbs. oats, or } \\ 4 \text { lbs. cracked corn. }\end{array}\right.$

$6\left\{\begin{array}{l}10 \mathrm{lbs} \text {. timothy hay. } \\ 10 \mathrm{lbs} \text {. carrots. } \\ 3 \mathrm{lbs} \text {. corn. }\end{array}\right.$

$7\left\{\begin{array}{c}10 \text { lbs. mixed hay. } \\ 10 \text { lbs. carrots. } \\ 4 \text { lbs. oats. }\end{array}\right.$

$8\left\{\begin{array}{l}10 \text { lbs. mixed hay. } \\ 8 \text { lbs. carrots. } \\ 4 \text { lbs. bran. }\end{array}\right.$

These rations serve as examples and also indicate how with ten or twelve pounds of hay the several grains mentioned may be combined to give a maintenance ration. It is not wise to feed a horse on hay alone, even when doing no work. Ten to twelve pounds of hay are enough coarse fodder, which may be supplemented to advantage by both roots and grain.

417. Maintenance food for sheep.-Basing his recommendation of maintenance rations for sheep upon Kellner's production values, Armsby suggests the following:

$\begin{gathered}\text { Live } \\ \text { weight } \\ \text { Pounds }\end{gathered}$
20


This means that seven sheep weighing 140 pounds each, or approximately 1,000 pounds, would require daily approximately the following quantities of food for maintenance purposes:

Alfalfa hay ................. 20

or

Clover hay ... . . . . . . . . 14

Rutabagas . . . . . . . . . . . 14

Pea meal . . . . . . . . . . . . . $41 / 2$

Soybean hay ............ . . . 14

Rutabagas . . . . . . . . . . 14

Wheat bran . . . . . . . . . 5

These rations supply protein in excess of the standard given, but this should not be condemned, as liberal allowance should be made for the growth of wool. 


\section{CHAPTER XIX}

\section{MILK PRODUCTION}

MrLk, like all other animal products, is derived from the food. Its secretion stands almost unrivaled as an example of the rapid, extensive, and continuous transformation of the food into animal compounds. In no other instance, except perhaps in the case of the earliest growth of animals, is so large a proportion of the digested nutrients utilized in building new material, or is there so intimate a relation between the extent and kind of the feeding and the extent and character of the resulting product. For these and other reasons, the successful feeding of milch cows requires, perhaps, greater expertness and a wider knowledge of facts than any other department of animal husbandry. This will appear more fully as we continue to develop this subject.

It is not proposed in this connection to enter into an elaborate discussion of the chemistry and secretion of milk, for this is presented elsewhere in the series of which this volume is a part. It is essential to present purposes, however, that we call to mind certain facts which are pertinent to a consideration of the food relations of milk formation.

418. Composition of cow's milk.-Milk is a fluid that is secreted by all mammals in a gland which with the cow is called the udder. It contains water and solids, the latter being made up of mineral compounds, proteins, fats, and sugar. The average composition of normal 
cow's milk, excluding samples of unusual character, according to a compilation by Van Slyke of 5,552 American analyses is as follows:

$\begin{array}{cccccc}\text { Total solids } & \text { Ash } & \text { Proteins } & \text { Fats } & \text { Sugar } & \text { Water } \\ \text { Per cent } & \text { Per cent } & \text { Per cent } & \text { Per cent } & \text { Per cent } & \text { Per cent } \\ 12.9 & .7 & 3.2 & 3.9 & 5.1 & 87.1\end{array}$

The variations in the composition of cow's milk are large, the proportion of water ranging, under perfectly normal conditions, from 84 to 89 per cent, with occasional analyses entirely outside these limits. The chief known causes of such variations are breed, individuality, period of lactation, and nervous disturbances. There are material daily fluctuations as well, for which no reasons can now be assigned. These changes are mostly in the proportions of water and total solids, for the composition of the solids, that is, the relative proportion of proteins, fats, and sugar, is remarkably constant with the same animal. The effect of breed in cows is illustrated by averages shown in Par. 362. These variations and those due to other causes are important in considering the relation of milk formation to nutrition, because the food expense of milk is determined, other things being equal, not by the volume but by the milk solids elaborated, for which reason the draft upon the supply of nutrients, water excepted, is greater for the secretion of 100 quarts of Jersey milk than for the same quantity of Holstein milk. In studying the economy of milk production, therefore, we should consider the relation of food to milk solids and not to milk volume.

419. Milk secretion.-There is no milk in an animal's food, that is to say, hay and grain contain no casein, butter-fat, or milk-sugar. They do contain nutrients, which, when subjected to the vital processes of the animal, 
are ultimately transformed into the constituents of milk. The mammary gland is not a sieve through which certain compounds in the blood are strained into the udder cavities, but it is a specialized tissue in which wonderful and extensive chemical changes occur. Here, for the first time, we find casein, the mixture of compounds known as butter-fat, and a sugar unlike any that is found in plants, or in any other part of the animal organism. Vegetable fats contain glycerides similar to some of those found in milk, to be sure, but not in the same number or proportions. One fact, moreover, which dairymen have been slow to recognize in all its significance, is that the udder of each individual cow is a law unto itself in the characteristics of the milk which it secretes, and is not subject in any large degree to control through feeding or other treatment that is not actual abuse.

The manner of milk secretion is something of which we know but little, and this is, perhaps, not immediately important to the dairyman. The food source of the constituents of milk is, on the other hand, a matter of great practical interest, and here we have information more or less definite.

420. Food sources of milk proteins.-The previous discussion of the functions of nutrients must have made it clear that the proteins of the milk can have only one source, viz., the proteins or closely related compounds in the food, a unanimous conclusion which rests upon experimental evidence as well as upon the universally accepted truth that the animal organism does not have the power to construct proteins from the simpler compounds used by plants for that purpose.

421. Food sources of milk-fats.-It now seems quite certain that the proteins are the only constituents of 
milk which must have their origin exclusively in the nitrogen compounds of the foods, for we have apparently sound reasons for believing that milk-sugar and the butter-fats are constructed, in part at least, from carbohydrates. In an investigation at the New York Agricultural Experiment Station as to the food sources of milk-fat, two cows, both of which gained materially in live weight during experiments continuing two months or over, produced respectively nineteen pounds and forty pounds more of butter-fat than could be accounted for from the food fat and available proteins. The amount of digestible food fat supplied was relatively insignificant and the secretion of milk-fat seemed to be related in no direct way to the protein exchange. These observations led straight to the conclusion that carbohydrates are millfat formers. The extent to which food fat assists in the production of milk-fat is not yet determined. While the ingested fats appear to pass directly into the millk to some extent, it seems quite evident that the larger part of the glycerides of milk have their origin in the animal. We are not sure, either, whether protein is ever a source of milk-fat, but that it is not a necessary source now seems to be proved.

422. The rate of formation of milk solids.-A cow yielding 6,000 pounds of average milk a year is not regarded as an unusual animal. This means, however, the annual production of not less than 780 pounds of milk solids, an amount at least double the dry matter in the body of a cow weighing 900 pounds. When we consider that this manufacture of new material is carried on not only during a single year, but through the entire adult life of the animal, we begin to realize how extensive are the demands upon the food-supply. Still more 
striking is the case of high-grade cows yielding annually over half a ton of milk solids, and when we remember the performance of Duchess Skylark Ormsby, whose 27,761 pounds of milk produced in one year certainly contained approximately 3,700 pounds of solid matter or more than twice the weight of the cow, we must regard the cow as possessing wonderful powers of transmutation. Her capacity for the rapid and economical production of human food of the highest quality is not equaled by any other animal.

No facts could more forcibly illustrate the necessity of liberal and proper rations for the milch cow.

423. Uses of nutrients in milk production.-This ration is used in various directions. It must supply the raw materials for milk formation, provide for the growth of the fœetus, sustain the effort of milk secretion, and maintain the usual and necessary functions of the animal body. The nature and extent of these uses are in part quite definitely understood. First of all, the kind and quantity of milk solids may be estimated for any given case. The daily production of 30 pounds of average milk, a performance reasonably to be expected in a good herd, involves the elaboration of 3.87 pounds of milk solids. Thirty pounds of high-grade milk would contain not less than 4.6 pounds of solids. For mere maintenance it is fair to assume that the food requirements of the cow and steer would not be greatly unlike, disregarding the demand for energy utilized in milk secretion, and for the material used in the growth of the young. On this basis the milk solids and the maintenance needs of a non-productive cow call for about 11.2 to 12 pounds of dry matter daily, a quantity utterly insufficient, as experience teaches, to maintain a cow giving 30 pounds of any kind of milk. 
We are led to the reasonable conclusion that, outside the building of milk solids, a large expenditure of food energy is required to sustain the work of additional food consumption, the increased metabolic cell activity and warming of the extra water and food, which are necessarily involved in milk secretion. This view is sustained by the results of investigation. In experiments by the writer with two cows in full flow of milk, which made only a slight gain in body weight, the energy of the digestible part of the rations and of the milk was determined. The figures reached were approximately as follows:

\section{TABLE LXIX}

Energy of digested nutrients

Energy of milk solids

Energy not used in milk

Maintenance needs of non-productive animal

Cow 10 wt. $775 \mathrm{lbs}$.

Calories

27,120

8,450

18,670

Cow 12 wt. $1,200 \mathrm{lbs}$.

Balance of energy not accounted for

$\frac{10,100}{8,570} \quad \frac{13,700}{7,400}$

This energy not accounted for, amounting with the two cows to more than one-fourth the total energy of the nutrients digested, may properly be charged to the work of milk production, including of course, food appropriation. Science and practice agree in naming 15.5 to 16.5 pounds of digestible organic matter as approximately the proper daily amount of digestible nutrients for economical milk production with a productive cow of average size, much less than which is not to be considered as generous feeding. The necessary supply of nutrients will vary according to the size and productiveness of the cow. Productivity independent of size is a controlling factor. 
In general, small cows eat proportionately more food than larger ones.

424. Protein requirements for milk production.-The question now arises, What proportion of this quantity should be protein? The actual amount of proteins in 30 pounds of average milk, for instance, is about 1 pound. If .70 pound is needed daily for mere maintenance then 1.7 pounds of protein must be used for maintenance and milk formation, a quantity which is now regarded as too small to sustain such milk production when both food economy and the efficiency of the ration are considered. With this amount of protein in 16 pounds of total digestible matter, the nutritive ratio of the ration would be about 1:9.5. A ration with as wide a ratio as this would be regarded by the great majority of careful experimenters, and most intelligent dairymen, as less efficient than one richer in protein. Few instances are on record where, in carefully conducted experiment-station work, other conditions being the same, a moderate ration with a nutritive ratio of $1: 5.5$ to $1: 6.5$ has not proved to be more efficient than one equivalent in quantity but with a ratio materially wider. The observations of Atwater and Woods among the dairy herds of Connecticut, where the owners were induced to narrow the rations they were found to be using, gave emphatic testimony as to the desirability of a larger proportion of protein than is usually supplied in the ordinary home-grown ration.

There are several possible reasons why the protein requirement of a non-productive animal plus the protein found in the milk does not constitute a proper standard for a milk ration:

1. The stimulating effect of a generous supply of protein upon metabolic activity. 
2. The use of food proteins for the synthesis of milk proteins over and above in weight the milk proteins actually formed.

The partial non-availability of certain food proteins, because of their constitution, for reconstruction into milk proteins, must now be conceded. (See Pars. 274, 275.)

According to the greater part of testimony available, a cow of average size and capacity should receive at least two pounds of protein daily during the full flow of milk, the ration to have a nutritive ratio not wider than $1: 6.5$. The nutritive ratio of young pasture grass, perhaps as efficient a milk-producing food as we have, is even narrower than this, a fact which doubtless explains in part the large flow of milk from abundant June pasturage, and which offers a suggestion for the compounding of winter rations.

425. Relative importance of protein overstated.While the importance of nitrogenous feeding-stuffs to a dairy herd is conceded, there is a tendency with certain writers to distort the relation of protein to milk production. Their utterances give the impression that in feeding milch cows, protein is about the only factor to be considered. This view is typified by the assertion that "a cow gives milk only in proportion to the protein that she receives," a remark which might be made with equal accuracy about carbohydrates. It is true that even if carbohydrates are supplied in abundance, a depression of the protein below a certain limit in a given case will diminish the milk flow. It is also true that when sufficient protein is fed, a reduction of the carbohydrates below the necessary quantity will cut down the milk yield. An adequate supply of easily digestible carbohydrates is no less 
important physiologically than keeping up the necessary proportion of protein, though the former may be accomplished more easily than the latter because of the usual character of home-raised crops.

\section{FEEDING STANDARDS FOR DAIRY COWS}

The feeding standards for dairy cows, which are regarded as embodying our most advanced knowledge, have been reached through several stages of development. The following are brief descriptions of these stages with suggestions as to their imperfections:

426. Thaer's hay values.-Albrecht Thaer, known as the father of scientific agriculture, more than a half-century ago suggested "hay values" as the basis for expressing feeding standards. He calculated the relative values of feeding-stuffs in terms of good meadow hay, the necessary quantities of rations and substitutions of feedingstuffs in them to be based on such values. It is now perfectly understood how crude are such standards for they ignore the varying digestibility of feeding-stuffs and the necessary relations in the proportion of nutrients. Thaer seems to have ignored weight and production as factors in determining what a ration should be.

427. Grouven's milk-feeding standards. - Grouven later introduced the factor of weight, and formulated eight standards for milch cows to be applied to animals weighing from 772 to 1,543 pounds. The matter of varying production was ignored. The daily ration suggested for cows weighing 1,000 pounds was not irrational, this being: Dry matter 28.7 pounds, crude protein 2.76 pounds, fat .86 pound, and carbohydrates 14.55 pounds, a ration adequate to sustain a generous flow of milk. 
428. Wolf's feeding standard.-Emil von Wolff seems to have been the first one to give a definite recognition to digestibility as a factor in calculating feeding standards. The standards he proposed were in terms of digestible constituents, the quantities fed to be directly proportional to live weight without reference to varying productivity. It was the Wolff standards that first became known, and somewhat widely advocated, in the United States. Their advocates conceded that they were only approximations to actual nutritive needs and chiefly valuable as suggestions in the compounding of rations.

429. Kuhn's feeding standard.-The fact that Wolff's standards made no allowances for varying productivity caused them to be severely criticised, and properly so. The most prominent critic was Julius Kühn, who proposed a basal maintenance ration, additions to be made to this somewhat in proportion to the demands for production. The quantities of digestible nutrients recommended by Kühn ranged between 20 and 23.5 pounds of dry matter, 1.5 and 2.4 pounds of digestible protein and 12 to 14 pounds of digestible amides, crude fiber, and nitrogen-free extract, Kühn holding to the point of view of his time that amides function nutritively as do the carbohydrates.

430. The Wolff-Lehman feeding standards. - The first standards to recognize, in an extended way, the varying nutritive needs of animals according to production, are those known as the Wolff-Lehman, which are an attempt to so modify the original Wolff standards as to meet the requirements of cows of unlike productivity. This was certainly a step.in the right direction.

These standards have been widely used in the literature of animal nutrition in the United States. 
431. American feeding standards.-Beginning with the feeding standard suggested in 1894 by F. W. Woll for dairy cows, several standards have been proposed by American authors and experimenters. These proposals have been based upon studies of the practice of successful feeders, or upon more or less extended feeding experiments. It cannot be said that with a single exception these so-called American rations are based upon close physiological studies. They are, in fact, mostly modifications and extensions of the Wolff or Wolff-Lehman standard, arrived at through a critical study of what have proved in practice to be productive rations.

It is well to submit these various commendable and useful efforts to arrive at practical feeding standards to a critical analysis, not only for the purpose of presenting the conclusions reached, but also in order to set forth the limitations that accompany experimental work of the type upon which the conclusions were based.

432. Woll's standard.--This standard is based upon the average of about 100 rations in apparently successful use by American and Canadian farmers. From the average was deduced the following daily ration for milk production: Dry matter 24.5 pounds, digestible protein 2.15 pounds, digestible carbohydrates and fat 14.5 pounds. This ration is suggested, apparently, on the assumption that what is being done by a group of successful feeders is a safe guide to the practice of others. In a sense this is true, when conditions are similar. This method of reaching a conclusion gives no assurance, however, that the practice observed is the best that could be devised, even though under given conditions it may be found profitable. Such a study of existing practice is suggested, however. 
433. Standards for milk production based on elaborate American feeding experiments.-Three investigators, Haecker, Savage, and Eckles, carried on extensive semi-practical experiments for the purpose of determining the relation between the food of a cow and her milk production. These several studies were inaugurated for practically the same purposes, viz., to determine protein demand for milk production and the necessary quantities of total digestible nutrients. Moreover, the data secured have been applied differently from those derived from previous similar experimental work. The final measurements have been based, not wholly upon the weight of the animal or upon total milk production, but also upon the protein and total nutrients necessary for the production of one pound of milk with a given percentage of fat. It is on this basis that these three pieces of experimental work may be compared.

Haecker began his records in 1892 and carried them through, during definite periods, until 1901. The experiments upon which his final conclusions are principally based were carried on in 1894-1895 for a period of 154 days, and in 1900-1901 for a period of 113 days, the number of cows involved in the first period being 12 and in the last period 20. The fodders were analyzed only in part, and the digestibility of the various feeding-stuffs was calculated on the basis of average digestion coefficients, with due reference to the condition of the coarse fodders.

Savage's work was done from 1909 to 1911. In both experiments twelve cows were used in three feeding periods of six weeks each, production records being kept for five weeks in each period. The fodders were analyzed but their digestibility was calculated from average digestion coefficients. 
The experimental feeding by Eckles was in the years 1910-1911, and his observations continued for one year. The various foods used were analyzed. Digestion experiments were conducted during two periods, one with three animals while they were on a maintenance ration, and one with five animals when near the time of maximum milk production. Eckles, therefore, secured rather more accurate data than was the case with the other two experimenters. He was able to calculate more nearly the exact digestibility of the materials involved in the experimental work.

With all three of these experiments the amount of milk produced was accurately determined and analyses made to determine the percentage of fat. By ascertaining, therefore, the estimated or the actual amounts of digestible material fed and the milk production with its fat-content, it was possible to calculate the relation to the product of the protein and total nutrients digested. The following table permits a comparison of the recommendations of the three experimenters based on the data secured. A fuller table appears later. (See Appendix.)

Table LXX. Standards for Milk Production as Developed by Haecker, Savage, and Eckles. Protein and Total Nutrients for ONe Pound of Milk.*

\begin{tabular}{|c|c|c|c|c|c|c|}
\hline \multirow{2}{*}{$\begin{array}{c}\text { Per } \\
\text { cent } \\
\text { fat in } \\
\text { mill }\end{array}$} & \multicolumn{2}{|c|}{ Haecker } & \multicolumn{2}{|c|}{ Savage } & \multicolumn{2}{|c|}{ Eckles } \\
\hline & Protein & $\begin{array}{c}\text { Total } \\
\text { nutrients }\end{array}$ & Protein & $\begin{array}{c}\text { Total } \\
\text { nutrients }\end{array}$ & Protein & $\begin{array}{c}\text { Total } \\
\text { nutrients }\end{array}$ \\
\hline 3.4 & $\begin{array}{c}\text { Pounds } \\
.0444\end{array}$ & $\begin{array}{c}\text { Pounds } \\
265\end{array}$ & Pounds & Pounds & Pounds & $\begin{array}{c}\text { Pounds } \\
285\end{array}$ \\
\hline 3.8 & .0468 & .287 & .0632 & .3369 & .051 & .283 \\
\hline 3.9 & .0474 & .292 & .064 & .3428 & .056 & .298 \\
\hline 5.3 & .0558 & .357 & .0753 & .4209 & .048 & .332 \\
\hline 5.5 & .057 & .366 & .077 & .4311 & .0587 & .396 \\
\hline 6.1 & .0606 & .392 & .0818 & .4619 & .072 & .505 \\
\hline
\end{tabular}

* In excess of maintenance needs. 
The figures here given represent the actual use of nutrients by the several animals in Eckles' experiment, and not the suggested standards. These follow:

$\begin{array}{llll}\text { Protein } & \begin{array}{c}\text { Total } \\ \text { nutrients } \\ \text { Pounds }\end{array} & \begin{array}{c}\text { Protein } \\ \text { Pounds }\end{array} & \begin{array}{c}\text { Total } \\ \text { nutrients } \\ \text { Pounds }\end{array} \\ .05 & .26 & .062 & .36 \\ .052 & .28 & .066 & .4 \\ .055 & .3 & .07 & .45 \\ .058 & .33 & .075 & .5\end{array}$

These figures are calculated on the basis of the nutrients fed minus the nutrients necessary for the maintenance of the animal without production. Students of these figures should bear in mind that in these investigations the only measures of the efficiency of the rations have been the milk production and the changes in weight of the animals. It is evident that it was not possible by the methods used to determine whether there was, with a given animal, a gain or loss of body substance other than would be indicated by a change in weight, which, as is well known, is often a deceptive standard of measurement. It should be said, however, that probably no practical feeding experiments with dairy cows so far conducted give figures more reliable as a guide to the feeding of dairy animals than those above cited. It will be noted that the increase in the protein and total nutrient requirement for each increase of one-tenth per cent fat in milk is as follows:

\begin{tabular}{|c|c|c|}
\hline & $\begin{array}{l}\text { Haecker } \\
\text { Pounds }\end{array}$ & $\begin{array}{l}\text { Savage } \\
\text { Pounds }\end{array}$ \\
\hline $\begin{array}{l}\text { Average protein increase for } 1 \text { per cent of fat } \\
\text { in milk. }\end{array}$ & .0006 & .0008 \\
\hline Average total nutrient increase for .1 per cent & & \\
\hline
\end{tabular}

434. Requirements of certain feeding standards for dairy cows.-In order to apply the various standards for 
feeding dairy cows that have been set forth, it is necessary first to determine what the standards require. These requirements for a 1,000-pound cow giving thirty pounds of 5 per cent milk would be as follows:

TABLE LXXI

\begin{tabular}{|c|c|c|c|c|c|c|}
\hline & \multicolumn{2}{|c|}{ Maintenance } & \multicolumn{2}{|c|}{ Production } & \multicolumn{2}{|c|}{ Total } \\
\hline & Protein & $\begin{array}{c}\text { Total } \\
\text { nutrients }\end{array}$ & Protein & $\begin{array}{c}\text { Total } \\
\text { nutrients }\end{array}$ & Protein & $\begin{array}{c}\text { Total } \\
\text { nutrients }\end{array}$ \\
\hline Wolff-Lehman§ & $\begin{array}{l}\text { Pounds } \\
.7\end{array}$ & $\begin{array}{c}\text { Pounds } \\
8.22\end{array}$ & $\begin{array}{l}\text { Pounds } \\
2.6\end{array}$ & $\begin{array}{c}\text { Pounds } \\
9.88\end{array}$ & $\begin{array}{l}\text { Pounds } \\
3.3\end{array}$ & $\begin{array}{c}\text { Pounds } \\
18.1\end{array}$ \\
\hline Haecker & .7 & 7.92 & 1.62 & 11.19 & 2.32 & 19.11 \\
\hline Savage & .7 & 7.92 & 2.18 & 12.14 & 2.88 & 20.06 \\
\hline
\end{tabular}

In the next table are given the energy equivalents of the nutrients required by the several standards:

TABLE LXXII

\begin{tabular}{|c|c|c|c|c|c|c|}
\hline & \multicolumn{2}{|c|}{ Maintenance } & \multicolumn{2}{|c|}{ Production } & \multicolumn{2}{|c|}{ Total } \\
\hline & Protein & Energy* & Protein & Energy* & Protein & Energy* \\
\hline $\begin{array}{l}\text { Wolff-Lehman§ } \\
\text { Haecker . . . } \\
\text { Savage . . . } \\
\text { Armsbyll . . . }\end{array}$ & $\begin{array}{l}\text { Pounds } \\
.7 \\
.7 \\
.7 \\
.5 \ddagger\end{array}$ & $\begin{array}{l}\text { Therms } \\
13.05 \\
12.573 \\
12.573 \\
6.1\end{array}$ & $\begin{array}{l}\text { Pounds } \\
2.6 \\
1.62 \\
2.18 \\
1.35 \ddagger\end{array}$ & $\begin{array}{l}\text { Therms } \\
15.685 \\
17.765 \\
19.273 \\
11.7 \dagger\end{array}$ & $\begin{array}{l}\text { Pounds } \\
3.3 \\
2.32 \\
2.88 \\
1.85 \ddagger\end{array}$ & $\begin{array}{l}\text { Therms } \\
28.735 \\
30.338 \\
31.843 \\
17.7^{\dagger}\end{array}$ \\
\hline
\end{tabular}

*Metabolizable.

†Net energy.

True protein.

$\S$ For 27.5 pounds of milk daily, per cent fat not given.

॥Older production values used.

435. Calculation of rations for dairy cows. - In order to determine what a ration should be for this particular animal, use is made of the following figures showing the digestible protein and total digestible nutrients in the various feeds entering into the combinations that are suggested: 


\section{TABle LXXIII. In 100 Pounds}

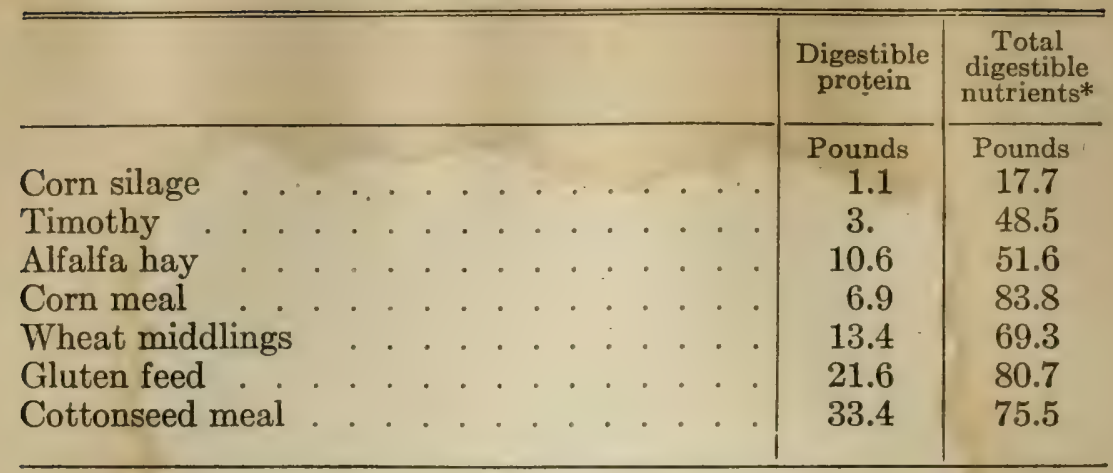

*Carbohydrates $+($ Fat $\times 2.25)+$ Digestible protein.

The next table shows the rations that would meet the demands of each of the five standards that have been suggested, three of these rations corresponding to the several standards for feeding a 1,000-pound cow giving thirty pounds of 5 per cent milk:

TABLE LXXIV

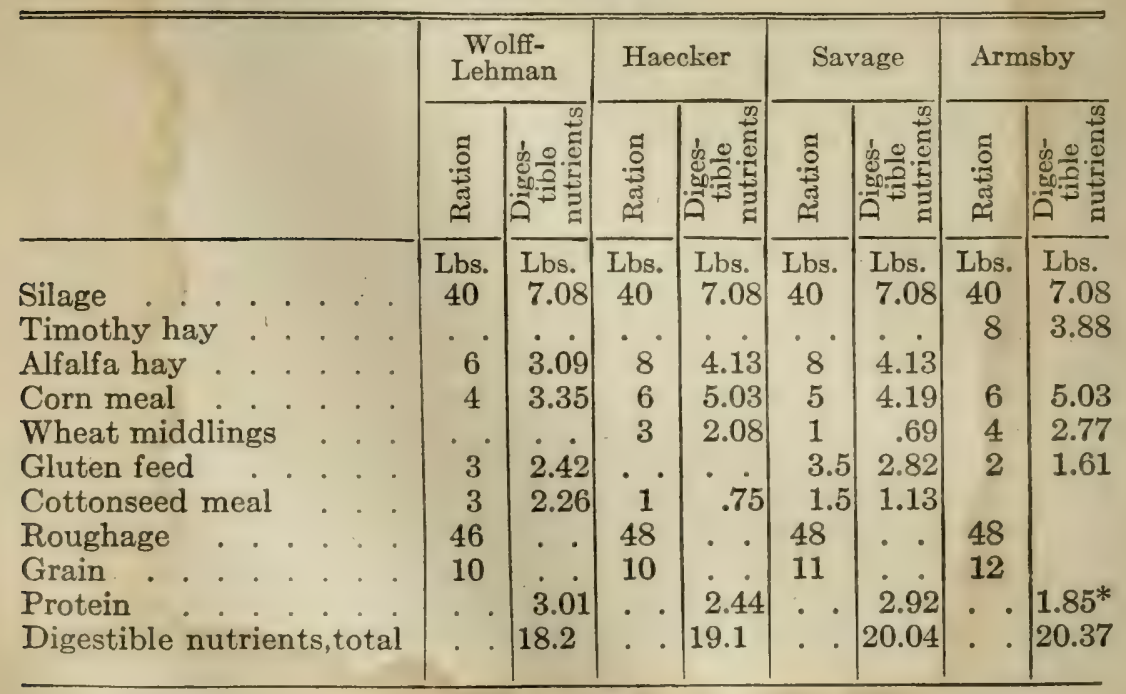

*True protein. 
It is to be noted that these several rations do not differ essentially in quantity but show some variations in the proportions of the several ingredients in order to reach an adjustment with the protein requirement. The quantities of the several feeds in the Armsby standard are based upon the production values which he has set forth. (See Par. 263.) The Wolff-Lehman ration is based upon the standard for a 1,000-pound cow giving 27.5 pounds of milk, the fat content not stated.

It should be remarked that these rations would be regarded by practical feeders as sufficiently generous. It is a question whether the amount of protein required by the Wolff-Lehman and Savage standards are not unnecessarily generous, a point to be considered when protein feeds are more costly than feeds bearing a large proportion of carbohydrates.

436. Suggested practical rations for dairy cows.The following are suggested as practical rations for cows of moderate size and fairly large productive capacity:

10 lbs. clover hay.

$35 \mathrm{lbs}$. corn silage.

$1\{2$ lbs. hominy chops.

$4 \frac{1}{2} \mathrm{lbs}$. wheat bran.

$21 / 2$ lbs. linseed meal, N.P.

$2\left\{\begin{array}{l}10 \mathrm{lbs} . \text { mixed meadow hay. } \\ 40 \mathrm{lbs} . \text { corn silage. } \\ 4 \mathrm{lbs} . \text { wheat middlings. } \\ 3 \mathrm{lbs} . \text { maltsprouts. } \\ 1 \mathrm{lb} . \text { gluten meal. }\end{array}\right.$

6 lbs. clover hay.

$10 \mathrm{lbs}$. mixed meadow hay.

25 lbs. mangels.

3 3 lbs. corn meal.

2 lbs. wheat bran.

2 lbs. brewers' grains.

2 lbs, gluten meal.
10 lbs. corn stover.
5 lbs. alfalfa hay.
425 lbs. sugar-beets.
3 lbs. corn-and-cob meal.
$3 \mathrm{lbs}$. buckwheat middlings.
$11 / 2$ lbs. cottonseed meal.

\footnotetext{
12 lbs. clover or alfalfa hay.

4 lbs. ground silage.

$3 \mathrm{lbs}$. ground peas.

2 lbs. brewers' grains.
} 
These rations may be criticized on the ground that they are too small to sustain heavy milk production. This would be a just criticism for cows of large capacity that are furnishing high-priced milk.

It is the writer's opinion that a majority of cows not over 1,000 pounds in weight, maintained under ordinary business conditions, will not render larger profit from heavier rations.

437. The sources of commercial protein for milk production: the home supply.-The dairyman has constantly to face the fact that from the usual list of home-grown feeding-stuffs it is difficult to make up a ration throughout an entire season with a nutritive ratio much narrower than 1:8, and a proportion of protein even as high as this requires a generous admixture of clover in the hay, and the use of more or less oats or peas in the grain ration. It should not be forgotten that the plants used for forage crops are generally not harvested until they are approaching maturity, and as the later growth of most plants is largely due to the formation of non-nitrogenous compounds, the hay and other fodders stored for winter feeding are comparatively poor in nitrogen compounds. On those farms where the hay crop comes largely from the true grasses, like timothy and red-top, and where the corn crop is a prominent feature, a home-raised winter milk ration having a maximum efficiency for each unit of dry matter consumed is not possible. On the other hand, where alfalfa and clovers constitute a good proportion of the hay, and where generous areas of peas and oats are grown, a ration compounded from home resources may have a high milk-producing efficiency.

438. Commercial protein.-It must be confessed, however, that most dairy farms are lacking in a proper 
home-raised supply of the more nitrogenous feedingstuffs, and as nearly all dairymen depend to come extent upon purchased grain, it is a quite prevalent custom for them to seek those by-products that will strengthen the protein side of the ration. It is unquestionably true that farmers should be more independent of the markets, and they certainly may be if an intensive system of cultivating well-selected crops is adopted; but so long as more or less grain will certainly be purchased, it is wise to consider the matter of selecting commercial protein feeds for dairy cows. Those from which it is possible to choose are the oil meals, distillers' grains, the gluten meals and feeds, brewers' grains, maltsprouts, peas, and buckwheat middlings. The offals from the milling of wheat, while somewhat more nitrogenous than the cereal grains, cannot be considered as an abundant source of protein, although they are excellent components of a milk ration.

439. No single protein food essential.-Notwithstanding the claims which trade interests may make to the contrary, no one of the above-mentioned feedingstuffs is alone essential to the economical production of the best of milk. There is no single food or any one combination of foods that is always best for dairy cows. Apart from certain considerations which will be discussed later, a selection of the source of commercial protein is a matter of availability and of relative market cost. For instance, if gluten meal were to cost $\$ 30$ a ton, few buyers could afford to pay $\$ 35$ for linseed meal to feed in any considerable quantity. If prices were reversed, oil meal should be selected. Both oil meals and gluten products may be ignored if buckwheat middlings or the brewers' residues are available at more favorable prices. 
It is simply necessary that the grain ration shall contain protein in sufficient quantity and proportion, and shall be made up of a variety of materials, better not less than three kinds, all of which should be palatable and exert no deleterious influence upon the milk or its products. There are few grain products that cannot be used successfully in grain mixtures, even though they are undesirable when fed alone.

THE RELATION OF FOOD TO THE COMPOSITION AND QUALITY OF 'MILK

The character of milk is believed by many to be intimately related to the kind and quantity of food from which it is produced, i. e., that a dairyman who is possessed of sufficient knowledge may, by variations in the rations, cause material changes in the composition of the milk of his herd. This is equivalent to believing that thin milk or rich milk, milk rich in fats and poor in casein or the reverse, may be obtained at the will of the feeder. Such a view in its extreme form is very far from the truth. While below a certain limit for each cow the quantity of milk is mostly determined by the ration, other factors, such as breed, individuality, and period of lactation, are much more potent than the food in fixing its composition.

In discussing this topic, it must be confessed, first of all, that the experiments touching its several phases have not furnished information satisfactorily definite and conclusive in all respects. The testimony arrived at is more or less confusing and contradictory. There are several directions in which it has been necessary to look for the effect of food upon milk: (1) Effect upon composi- 
tion: $(a)$ in changing the proportion of water and total solid matter; $(b)$ in changing the relative proportions of proteins, fat, and sugar, $(c)$ in changing the constituents of the fat. (2) Effect upon flavor.

440. Effect of food on the proportion of milk solids. -In discussing the effect of food upon the proportion of total solids, the question is, Can the richness of milk be modified by changes in the ration? For instance, is the milk from a very generous food-supply richer than that from a moderate or scanty ration, or will a highly nitrogenous ration cause a secretion of milk with a higher percentage of solids than a ration poor in protein? It would probably be generally conceded that if variations in milk are caused in these ways, they are small as compared to those due to breed characteristics or to individuality. Can we bring about variations sufficiently large to be important? This question has been much discussed and much investigated from the work of Kühn in 1868 down to the present day. Many experiments have been conducted for long periods and short periods in which very moderate rations have been compared with very large ones, highly nitrogenous foods with those of a low protein-content, dry with green or succulent materials, and grains of the same class with one another, and, in a great majority of cases, the verdict has been that no consistent relation appears to exist between the quantity or character of the ration and the proportion of solids in the milk, a conclusion that has run counter to a very persistent popular belief. In some cases, a temporary change has appeared in the milk immediately after a violent change in the ration, but in most instances of this kind, there was very soon a return to the animal's normal product. In a small proportion of experiments, the milk appeared to 
sustain a permanent, though not extensive, modification. The weight of testimony bears out the statement that the content of solids in milk cannot be modified at will by the farmer, but is largely determined by causes not under his control, such as breed and individuality, although feeding and treatment, especially the latter, have more or less influence upon the character of the milk secreted. It is possible, even probable, that continuous feeding, either very poorly or very highly, may bring about in time a permanent change in a cow's milk, but today no one is wise enough to point out a way of definitely controlling this product through the food.

441. Effect of food upon the constitution of milk solids.-In the discussions relative to feeding dairy cows, another point has received much attention, viz., the effect of foods upon the proportions of the constituents which make up the dry matter of milk. A popular notion has prevailed that it is possible to "feed fat into milk," having its origin in part, perhaps, in misconceptions as to the manner of milk formation. If the mammary gland served simply to capture the unchanged constituents of the food, then it might be reasonable to expect the milk to partake of the character of the digested nutrients and be "fat" or "lean" according to the proportions of proteins and fats supplied to the animal. When, however, we consider that this gland has the function of transforming the raw material of the food into a milk which is characteristic of the breed or of the individual in accordance with somewhat fixed constitutional limitations, and that from the same food the Jersey cow will make Jersey milk and the Holstein cow Holstein milk, that a cow which starts in life giving thin milk is never transformed into a producer of rich milk, we can easily 
understand the general failure to find a recipe for feeding fat into milk. Experimenters who have added large quantities of fat or oil to a ration have in all but a very few instances failed to permanently; or even temporarily, increase the percentage of fat in the milk solids; and, on the other hand, rations rich in protein do not appear to cause a larger relative amount of proteins in the milk-dry substance than rations with a wide nutritive ratio. As a matter of fact, after years of investigation and intelligent observation, we are not able to affirm that the proportion of fat to other milk solids is in any way related to the feeding of the cow, and if apparent exceptions to the general experience have been noticed, no one has discovered any general method or law whereby the exception may be made the rule.

Physiological disturbances may result from feeding a ration so selected or treated that it is greatly deficient in certain nutrients. In experiments by Jordan, Hart, and Patten, the deficiency of phosphorus compounds in the rations of milch cows appeared to cause, among other effects, a marked diminution of the proportion of fats in the milk solids. By-product feeding-stuffs similarly deficient might cause a similar result.

442. Influence of food on the milk-fats.-It should not be inferred from the previous statements that none of the compounds of the food enter the milk as such, or that the qualities of the milk are in no way influenced by the character of the ration. Such conclusions would not be consistent with the outcome of numerous investigations. While it has become quite evident that the composition of butter, and therefore its qualities, such as hardness and melting-point, are sometimes materially modified by the cow's food, it is not now possible to state 
with any definiteness just what influence all the various feeding-stuffs have upon the chemical and physical properties of butter. Experimenters are fairly unanimous, however, in concluding that the liberal feeding with cottonseed or cottonseed meal has the effect of raising the melting-point of butter and of diminishing the percentage of the volatile fatty acids. On the other hand, when gluten meal rich in oil has been introduced into the ration in generous proportion, the butter has been found to melt at a lower point, and appeared softer. Certain chemical reactions indicate that this decrease in the melting-point has been accompanied, in some cases at least, by an increase in the butter of olein, a fat which is a prominent constituent of olive oil, and is liquid at ordinary temperatures. Ore set of experiments, where gluten meal with different proportions of oil was used, appears to warrant the conclusion that the softening of the butter from feeding this material is not marked when its percentage of fat is small, as is the case with some brands of gluten meal at the present time. The conclusion which has been reached as a result of some experiments, that gluten meal causes softer butter than corn meal, the fats and other compounds in the two feeds being similar in kind, is wholly irrational unless we conclude that the larger quantity of fat fed in the former is the cause of its specific influence. In a few cases where various oils were fed in liberal quantity the butter is reported to have varied in ways corresponding to the composition of the oils, a result not at all improbable.

In looking over the record of investigations along this line it is found that food rich in sugar and other soluble carbohydrates is credited with producing soft butter, potatoes are charged with the same effect, and 
even cooked or sour foods are said to have a peculiar influence. Some writers go so far as to present lists of feeding-stuffs in the order in which they increase the volatile fatty acids, but such definite representations must at present be taken "with a grain of salt." In most instances, no relation is established between the effect observed and the market value of the butter. In fact, it is distinctly asserted by one or two experimenters that there is no clear relation between the melting-point and hardness. It seems quite probable that when the ration includes a variety of grain foods, practically the entire list of feeding-stuffs may be utilized under proper conditions without damaging the market value of the butter for local consumption.

443. Effect of food on the flavors of milk and its products.- It is not possible with our present knowledge to establish a relation between the flavors of dairy products and the presence of definite compounds. Whatever causes flavor in milk or butter is generally present in such minute quantities that even if the nature of the substance were known the determination of its amount would be beyond the skill of the chemist. Milk satisfactory to the critical taste and smell may be so simply because bad flavors are absent, or there may be present the positive influence of some constituent of the ration. It is probably safe to assert that compounds in the food pass into the milk as such, and the superiority of June butter, if such exists, may be due to the almost imponderable volatile odors which are derived from the young grasses. Nothing is more certain than that the deleterious odors of certain foods and those that pertain to the stable are often absorbed by milk, as, for instance, when cabbage, turnips, and onions are fed. 
It is generally believed that odors or flavors from the foods which affect milk in so marked a manner may enter it in two ways, by transference through the animal and by absorption from the air of the stable. Unfortunately, however, the various views which are accepted regarding this matter are not based upon satisfactory experimental evidence. Some farmers declare in most positive terms that they can feed turnips to their cows with no harm to the quality of the butter, while others assert that this cannot be done. It is claimed that the time of feeding, whether just before or just after milking, has a marked influence upon the extent to which turnips and similar materials impart a flavor to the milk. Concerning all these points, we have but little evidence other than the somewhat loose observations of practice.

The results of certain experiments are worthy of mention in this connection. King and Farrington, of the Wisconsin Experiment Station, declare that their experiments show beyond question that when silage is fed before cows are milked a sweetish flavor is imparted to the milk, and that such a flavor is not detected when the silage is fed after milking. These experimenters also placed milk within a silo exposed to the air for an hour, and silo air was forced through the contents of some cans. In seven out of twenty tests no silage odor could be detected, and it was less in any case than when silage was fed before milking.

Canadian experiments on the effect of feeding turnips seemed to warrant the conclusion that the mere presence of a strong turnip flavor in the stable did not affect the milk, and that when the turnips were fed in small quantity (one peck) daily no flavor was imparted, but that when one bushel or more was given the flavor 


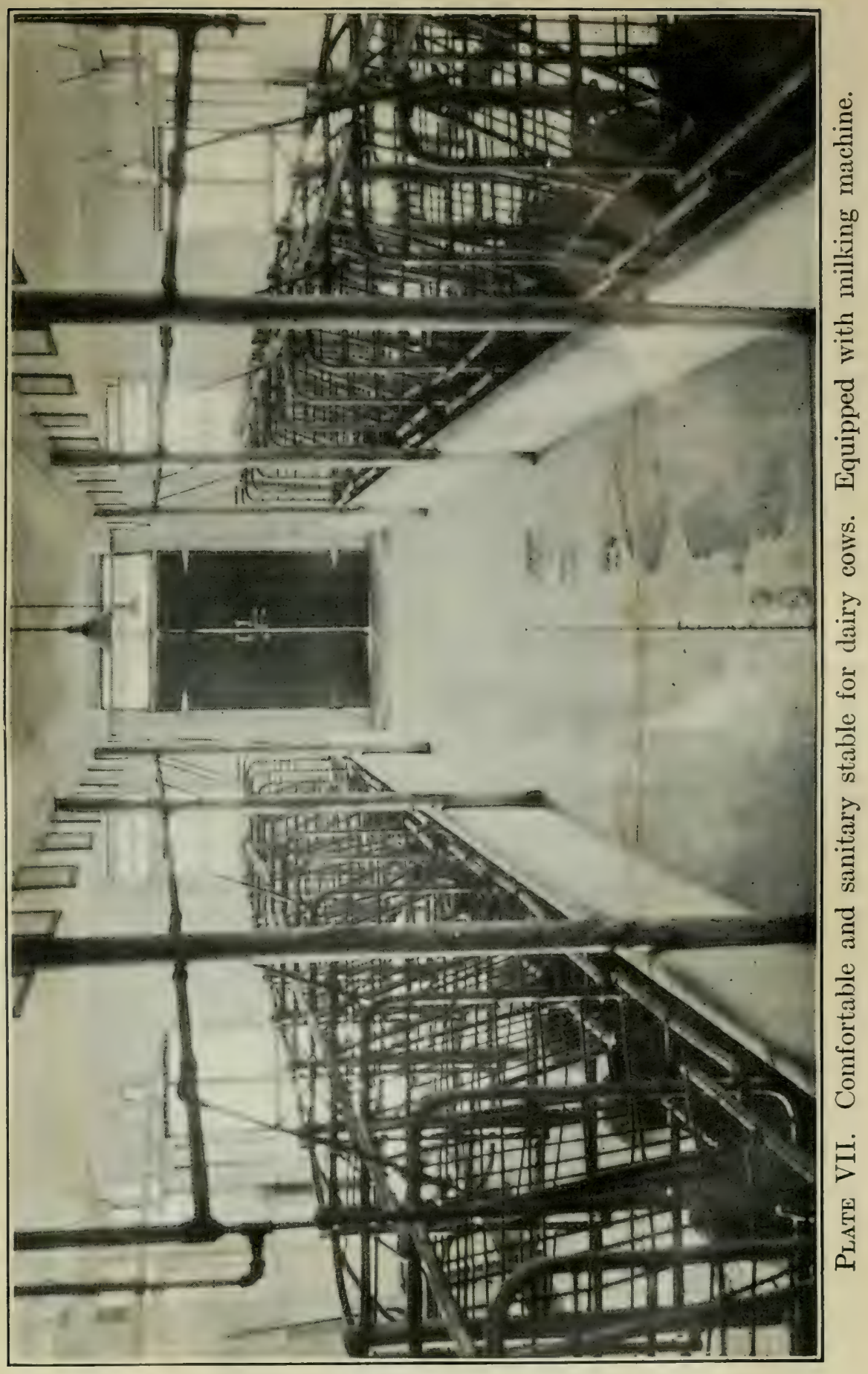



appeared whether the turnips were fed before milking or after. On the other hand, in a Norwegian experiment as high as 2.8 bushels of turnips were fed to cows daily and no turnip taste could be detected in the milk. The cows were fed in one place and milked in another, and so the experimenter concluded that when this taste is observed it is due to absorption by the milk after it is drawn. That warm milk may absorb odors is shown by Russell. These observations illustrate fairly the somewhat inconclusive state of the testimony on the points in question. 


\section{CHAPTER XX}

\section{FEEDING GROWING ANIMALS}

A DISCUssion of rations for growing animals relates in large part to the uses of food for constructive purposes. The formation of bone and soft tissue proceeds rapidly in the young organism, the nutrition of which must be adapted in kind and quantity to large demands in this direction. This is true of all young domestic animals.

444. The requirements for growth.-The actual daily increase in live weight of a well-nourished calf may be as great as that of a mature steer when liberally fed. It is not unusual for the former to gain two pounds a day in weight, and 1.5 pounds is less than would be satisfactory. It is possible to calculate approximately what this growth would require of actual dry matter. The only analysis of a calf's body which is available is that made by Lawes and Gilbert, from which it appears that the entire animal when fat has approximately the following composition:

$\begin{array}{cccc}\begin{array}{c}\text { Water } \\ \text { Per cent }\end{array} & \text { Ash } & \text { Protein } & \text { Fat } \\ 64.6 & 4.8 & \text { Per cent } & \text { Per cent } \\ 64.6 & 16.5 & 14.1\end{array}$

A gain of 1.5 to 2 pounds live weight means a storage of not less than .24 to .33 pound of dry protein in the animal's body, and the laying on, when the animal is fed for fattening, of .21 to .28 pound of actual fat. Here, then, is an actual daily increase of dry body substance of .45 to .61 pound, which may be equal to one- 
fifth or more of the total dry substance of the ration for a very young animal.

445. Food freely appropriated by growing animal.More definite information is furnished by the somewhat limited studies which have been made of the metabolism of the calf. As long ago as 1878 Soxhlet studied the income and outgo of three young calves fed on whole milk. One pound of milk solids, practically all digestible, produced one pound increase of live weight, which was equivalent to a storage of at least one-third pound of body dry substance, a food efficiency for growth practically ten times that exhibited with animals somewhat mature. Nearly 70 per cent of the protein of the food was fixed in the bodies of these calves and only a small proportion was broken down, conditions quite the reverse of those which pertain to the use of food by well-grown steers. Seventy-two per cent of the phosphoric acid and 97 per cent of the lime were retained for the purposes of growth. Later experiments with calves fed on rations in whole or in part composed of skim-milk, show a deposit of from 26 to 43 per cent of the protein. These results illustrate the vigor with which a young animal assimilates food for growth. The facts show the necessity of feeding young animals on liberal quantities of constructive materials, viz., the proteins and ash ingredients.

446. Influence of kind of food on the kind of growth.During recent years there has been much discussion and many experiments touching the influence of food upon the development of the animal body. Several experimenters, notably Sanborn and Henry, in this country, have compared the growth of swine on rations presenting extreme differences, as, for instance, middlings and blood against corn meal alone, or shorts and 
bran against potatoes, tallow, and corn meal. As would be expected, the development of the two lots of pigs was in these cases greatly unlike. Those fed on the nitrogenous rations contained more blood than the other; their organs, such as the kidneys and liver, were much larger in proportion to the weight of the body, the bones were stronger, and the proportion of muscle in the carcass was much greater. The differences were very marked. It should not be forgotten, however, that these were extreme and somewhat unusual rations. It is doubtful whether there are generally sufficient differences in the food combinations of ordinary practice to occasion such marked differences of body structure.

At the Cornell University Experiment Station lambs fed on oil meal and bran made a much more satisfactory gain than did those the grain ration of which was corn meal alone, but the photographs of the carcasses do not show a larger proportionate growth of muscular tissue from the nitrogenous foods.

An elaborate study of the influence of the ration upon the composition of the carcass was made at the Maine Experiment Station, where two lots of steers were fed from calfhood on rations widely unlike in their nutritive ratio. The hay fed was the same for both lots. The grain food of one lot was oil meal, wheat bran, and corn meal, and of the other lot corn meal, mixed with a minimum proportion of wheat bran, the nutritive ratios being respectively $1: 5.2$ and $1: 9.7$. One animal from each lot was killed at the end of seventeen months of feeding and the others at the end of twenty-seven months, the entire bodies of the four steers, exclusive of the skins, being analyzed. It was found that the composition of the animals did not differ materially. (See Table LXXV.) 
Table LXXV. Percentage Composition of Total Dressed Carcasses of the Steers

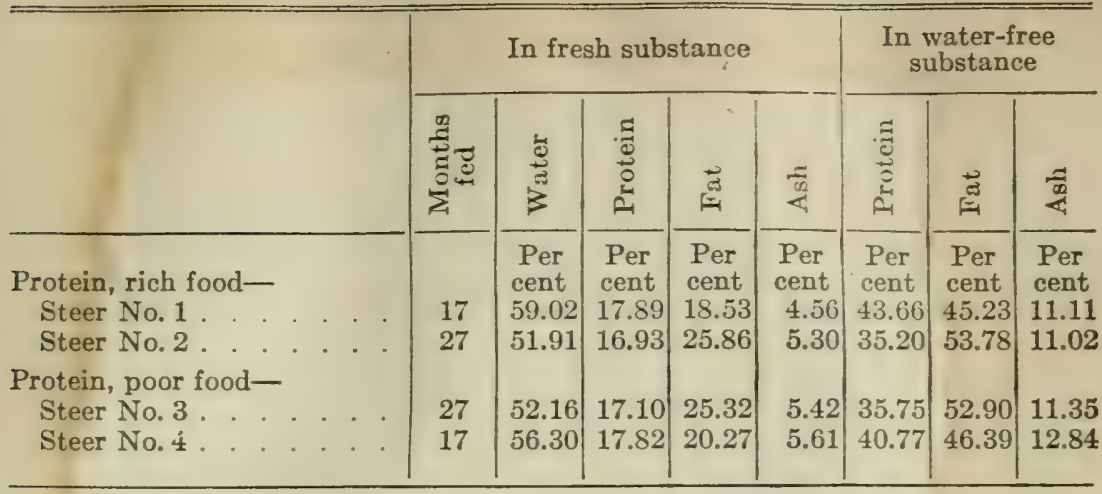

The amount of growth was at first more rapid with the more nitrogenous ration, but the kind of growth appeared to have been controlled by the somewhat fixed constitutional habits of the breed. Nevertheless, the evidence of all well-conducted experiments and of all experience is unanimous in emphasizing the necessity of supplying in the food of young animals an abundance of those nutrients which are needed for the building of bone and muscle. A satisfactory development of the organism at maturity is insured only when the early growth is liberal and uniform, and is such as to produce strong bone and a vigorous muscular system. More than this, there is induced by proper nourishment a lively temperament of energy of body, which chemical analysis cannot search out or measure, but which gives the chief value to certain classes of animals and is desirable in all. It is believed that this condition of strong vitality is promoted by a liberal supply of the proteins in the food.

447. Estimated energy requirements for one pound of gain in weight by growing cattle and sheep.-Armsby 
has made estimates of the requirements for each pound of growth of cattle and sheep at different ages, for which he does not claim any high degree of accuracy.*

\begin{tabular}{|c|c|c|}
\hline & Age & Energy value \\
\hline $\begin{array}{c}\text { Months } \\
3 \\
6 \\
12 \\
18 \\
24 \\
30\end{array}$ & & $\begin{array}{l}\text { Therms } \\
1.5 \\
1.7 \\
2 . \\
2.5 \\
2.75 \\
3 .\end{array}$ \\
\hline
\end{tabular}

This would indicate that for an animal of the age of three months a pound of growth would require an addition to the ration of two and one-fourth pounds of oats, and at the age of thirty months four and one-half pounds.

The same author gives estimated requirements a day and head for growing cattle, these to include the maintenance requirement:*

TABLE LXXVII

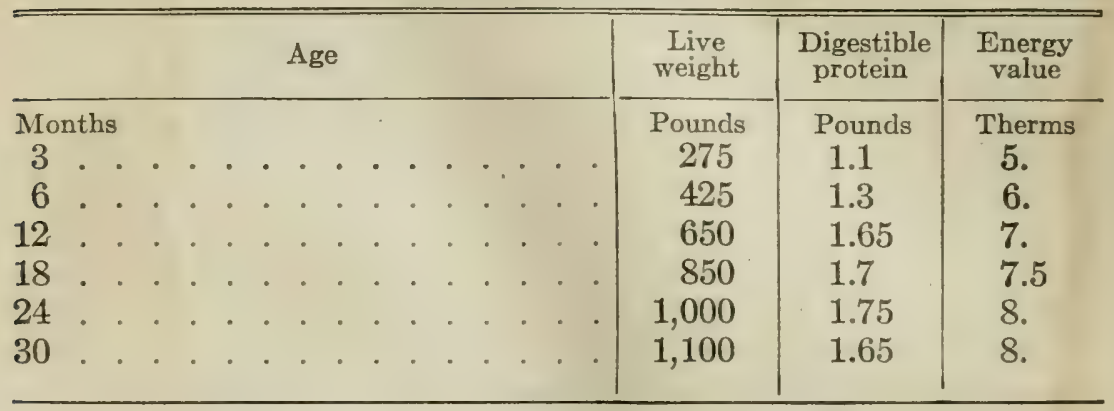

In order to give concrete expression to the standard that applies to a growing animal one year old, weighing 650 pounds, there has been calculated the necessary ration:

* Based on true protein and production values. 
Clover hay .............. . . 10

Wheat middlings . . . . . . . . . . . 3

Linseed meal . . . . . . . . . . 2

448. Milk for young animals.-In considering the feeding of very young animals, we recognize the mother's milk as in general supplying the necessary nutrients in the best forms and proportions. It is true in the case of cows that the very rich milk of the butter breeds, when generously fed, often causes a serious disturbance of the calf's digestive organs, but the fact remains that casein, milk-fat, and milk-sugar are adapted through Nature's design to the digestive processes and the nutrition of young animals. Moreover, milk is rich in the mineral compounds needed for bone formation. When, therefore, it becomes necessary or desirable to substitute other food for the mother's milk, it is essential not to act counter to physiological necessities and conditions.

One fact of importance is that the very young animal is somewhat undeveloped in its capacity to digest the starchy grains and similar substances, the secretions necessary for this purpose not yet being abundant. It follows, then, that the first substitute for whole milk should not consist largely of the insoluble carbohydrates. Again, the young animal's stomach is at first unfitted for receiving and utilizing bulky, fibrous food. Some time must elapse before the calf or colt can secure much nourishment from grass, hay, or like materials.

\section{THE FEEDING OF CALVES}

449. Skimmed milk as a substitute for whole milk in feeding calves.-The most successful way of feeding 
calves to secure rapid growth, especially to produce veal of the highest quality, is to supply them with whole milk up to the limit of their capacity when this can be done with safety. Where they are to be raised for stock purposes, satisfactory growth may be maintained with the use of substitutes for whole milk, which is fortunate, because with the exception of the western plains, where cows are cheaply kept simply for breeding purposes, or where a breeder is selling his increase at fancy prices, the feeding of whole milk is not warranted by the value of the resulting animal.

For this reason most dairymen, particularly those who sell milk as such, kill the calves at the age of a few days, excepting, perhaps, during that portion of the year when veal sells at a very high price. On the other hand, many dairymen who have a supply of skimmed milk successfully feed this to growing calves, when it is desired to raise heifers or even steers. Experience has shown that it is entirely practical to do this, and it is certainly economical, for experiments have demonstrated that, as prices average, the cost of a pound of growth so produced is at least not over one-third what it would be if whole milk were fed.

As a guide in providing a substitute for whole milk, it may be stated that a vigorous calf should very early be made to eat daily not less than three pounds of highly digestible matter with a nutritive ratio at first not wider than that of whole milk solids. The exclusive feeding of skimmed milk for any length of time is not to be recommended. Experience shows that for young calves it should be so combined with other materials that a mixture is obtained which, so far as possible, resembles whole milk in its nutritive ratio. After the fat is removed 
from the milk, the non-nitrogenous compounds are probably not present in sufficient proportion to protect the protein from waste as fuel. No feeding-stuff appears to be a more efficient amendment of skimmed milk for the earliest feeding than flaxseed meal cooked into a porridge. The explanation of this is the high percentage of oil in this meal, its low content of starch, and its high rate of digestibility. Besides, it appears to promote a healthy condition of the organs of digestion. Oil meal may be used in its stead, but it is less desirable at first. The calf should be allowed whole milk for a few days, not necessarily more than a week, when it may be gradually changed over to skimmed milk and flaxseed meal. An admirable mixture is prepared by cooking the flaxseed meal in water in the proportion of one to six by volume, and adding a small amount of this (the equivalent of three or four tablespoonfuls of the dry meal at first) to eighteen or twenty pounds of warm skimmed milk, which may serve as a day's ration. The quantity of meal should be gradually increased up to one pound a day inside of a few weeks. In six or eight weeks the calf should be allowed access to dry oatmeal, or oatmeal and wheat middlings, or the oatmeal and middlings may be boiled with the flaxseed meal and mixed with the milk. After ninety days the flaxseed meal may be dropped for the sake of economy. The calf will soon appreciate a wisp of early cut hay, some coarse food becoming a necessity before many months pass. This method of feeding has repeatedly produced rapid growth and fine animals. For heifers it is probably to be preferred to whole-milk feeding, as it is fúlly as conducive to the vigorous development of the muscular system and is less likely, perhaps, to promote a tendency to lay on body fat. 
450. Calf rations without milk products.-An examination of the results of much experimental work shows very clearly that strong, healthy calves can be raised without skimmed milk or even milk of any kind after a brief period, although the rate of gain may not be so rapid as when whole milk or skimmed milk is available for at least part of the ration. In these experiments, where careful records have been made, mixtures of oatmeal and other cereal products with linseed meal, thoroughly cooked, may be used to produce satisfactory growth, even if growth is not so rapid as with milk products. This appears to be no disadvantage in the subsequent development of the animal. Even if skimmed milk is available, cereal products and the oil-meal products make desirable amendments to the milk.

The Dairy Division of the United States Department of Agriculture, in experiments with twenty-two animals, has showed that calves make as rapid gain upon sour skimmed milk as upon sweet skimmed milk, other experiments indicating that whey may be used as a substitute for skimmed milk, provided proper foods are combined with it.

Hay tea is sometimes used as a milk substitute, but it is a poor one. Only a small proportion of the nutrients of hay is soluble, and the water-extract is a dilute and comparatively innutritious food for a growing animal, the use of which can be justified only in the absence of milk in any form, and which, when used, must be very liberally fortified by grain feeds.

\section{THE FEEDING OF LAMBS}

451. Feeding ewes with lamb.-The first growth of lambs is chiefly from the mother's milk and we have little 
occasion to consider substitutes for this food. The fact first in order and most important in this connection is that well-fed mothers are absolutely essential to rapid growth. A lamb must be fed through its dam. Nothing is more pitiable than the sight of a pair of hungry twin lambs making an effort to satisfy their insistent demands for growth with the milk furnished by a small, lean, under-fed mother. The treatment of the ewe before the birth of her young should be such as to prepare her for the strain of supplying a generous flow of milk.

Ewes that are suckling lambs, while fed from the barn, should be supplied with good clover or alfalfa hay, or hay from fine mixed grasses. Pea and bean straws are excellent coarse feeds for sheep. Timothy hay is an abomination as sheep food, especially under these conditions. The grain ration should not be less than three-fourths of a pound daily, made up in part of one or more of the highly nitrogenous feeding-stuffs. It is also desirable to feed a small proportion of some succulent food. What is needed is a milk-producing ration, and the discussion of feeding cows for milk production in a preceding chapter is in part pertinent to ewes. Corn, oats, wheat bran or middlings, beans, peas, gluten and oil meals are all useful in making up such a ration. With safe feeding, one pound daily of a mixture of oil or gluten meal one part, wheat bran two parts, and corn meal two parts, combined with two or three pounds of roots or silage and what coarse feed the appetitite will bear, is a good milk ration, and will bring the ewes through the strain of suckling lambs in good condition.

452. Grain foods accessible to lambs. - If it is desired to produce the most rapid growth of the lambs, they should also have access from nearly the first to a grain 
mixture. Experiments indicate that this mixture is most economical, especially if the lambs are to be fed later for the market, when containing a generous proportion of corn meal, to which may be added, among other materials, ground oats, wheat bran, gluten feed or meal, or oil meal, reference being had to the ruling market prices. In an experiment at the Maine Experiment Station, lambs suckled by grain-fed mothers and with access to grain themselves made 75 per cent or more gain in live weight than those did that received no grain and which were suckled by mothers that ate a limited grain ration. Five and three-fourths pounds of grain produced one pound of growth. At the Wisconsin Experiment Station, as an average of three trials, lambs fed grain before weaning gained in ten to twelve weeks seven and a half pounds more each than those not so fed. Four pounds of grain produced one pound of live weight.

Liberal feeding means more economical growth, a higher quality of product, and the earliest possible market. The foregoing discussion is applicable to the raising of early lambs. If, however, they are dropped during the grazing season where the ewes have abundant pasturage, the question of feeding is simplified, for no ration is more promotive of abundant milk secretion than young grass; besides, the low price at which late lambs are usually sold does not encourage extensive grain feeding. When lambs are grown for breeding stock their early grain rations should be lighter, and may properly consist more largely of oats and bran, with a smaller proportion of corn.

453. Standards for growing sheep.-For growing sheep beyond the age of six months, Armsby has offered the. following standards, based on Kellner's production values: 
Table LXXVIII. Estimated Requirements per Day and Head for Growing Sheep

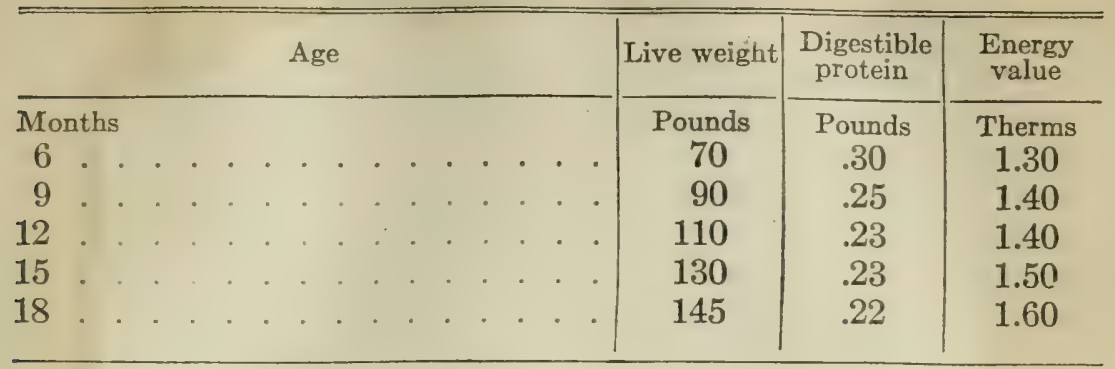

Expressed in terms of an actual ration a bunch of ten growing lambs nine months old would require on the basis of the foregoing standard the following quantities:

Ration for Ten Lambs, 900 Poends. Age Nine Months

Clover hay . . . . . . . . . . . 20

Pounds

Turnips . . . . . . . . . . . 20

Peas .. . . . . . . . . . . . . 4

Linseed meal . . . . . . . . . . 2 $23 / 4$

\section{FEEDING COLTS}

454. Food as related to quality of the horse.-The value of a horse for either draft or road purposes is greatly dependent upon those physical qualities which secure vigor and endurance. A horse is not regarded as desirable that is devoid of "nerve" and that cannot sustain, if necessary, the strain of hard, or even severe, work; and breeders seek to produce animals having these characteristics. Two main factors are involved in the proper physical development of the colt: food and exercise. The latter is a part of the general management to which the horse-breeder must give detailed attention and will not be discussed in this connection. The technics with which 
the horseman should be familiar must be learned through experience and by consulting special literature.

It is proper to state that our knowledge concerning the feeding of colts consists largely of the conclusions derived from experience of practical men. Very little experimental attention has been given to this subject by investigators. During the years that experiment stations have existed in the United States few stations have reported experiments along this line, and these were not extensive; but notwithstanding the lack of direct data from scientific sources there are well-proven and safe facts to which we can refer.

455. Feeding the colt through the dam.-The proper feeding of the young foal is accomplished first through the proper feeding of the dam. The mare with a colt at her side should be regarded as a milch animal, making demands upon the food for generous milk production similar to those made by the milch cow. This is equivalent to the statement that when suckling her foal the dam should be given foods that stimulate milk secretion. If she is allowed the run of a good pasture, both mother and colt will usually thrive satisfactorily. Young pasture grass is as efficient with the mare as with the cow. If, on the other hand, the feeding is from the stable, either wholly or to amend an insufficient or inferior food-supply from grazing, then the grain ration should be made to - include such feeding-stuffs as barley, oats, wheat, wheat bran, wheat middlings, peas, and even a small proportion of linseed meal. Whenever soiling-crops are grown these may be fed, especially alfalfa. In case the legume fodders are available, either green or dried, the necessity for protein in the grain is not so great and corn may form a larger proportion of the ration. 
A good grain mixture for ordinary conditions would be cracked corn two parts, wheat bran seven parts, and linseed meal one part; or ground oats four parts, wheat middlings five parts, and linseed meal one part.

456. Rations for the colt before weaning.-Before the colt is weaned, with good management, he will learn to eat grain which is very likely to be the same mixture as that eaten by the dam. If desired, an enclosure may be built, into which the colt and not the mother can pass, where a special grain food may be provided. This brings us to the consideration of what shall be the grain ration of the colt, both before and after weaning.

457. Oats as horse feed.-The opinion is generally held that oats are superior to all other feeding-stuffs as horse food, particularly for the development of those qualities of temperament and muscle which are regarded as so desirable, especially in a carriage horse. Oats are usually comparatively costly, but it is claimed that the superior results, whether in the kind of development of the colt or in the quality of service of the mature animal, justify their use. In this particular case, as in others, certain statements are currently accepted as facts which have no well-established basis.

Reference is frequently made to the tonic effect of oats, and there has existed a popular notion that this grain contains a peculiar compound which acts as a nerve stimulant and imparts "life" to the horse.

It was announced in 1883 that Sanson had discovered in oats a characteristic alkaloid having a stimulating effect upon the motor nerves of the horse, but subsequent elaborate investigations by Wrampelmyer failed to verify Sanson's conclusions. Notwithstanding the fact that the oat kernel has been the subject of very care- 
ful chemical studies, it is not found that it contains any compounds so characteristically unlike those of other grains as to account for an unusual influence upon the nervous system, or for a superior development of the muscles.

It may be suggested that the "life," or nervous condition, of a horse is a resultant of several factors or influences. These are the quantity of digestible food supplied, the proportion of protein in the ration, the condition of the digestive tract, care, exercise, and all the many small influences which affect health. In those instances where feeding oats has seemed to improve the performance of the horse, even if this has actually occurred, we have no assurance that in changing the ration the amount and proportions of the nutrients digested have remained the same. It seems entirely probable that if thorough comparison could be made between oats and the best grain mixtures which could be suggested in the light of present knowledge, the oats would not maintain so great a superiority over other feeds for growing colts as is now generally attributed to them. Experiments which have been made indicate that for producing rapid growth oats were inferior to either a mixture of peas and middlings, or to a mixture of middlings, gluten meal, and linseed meal; but these observations were not carried far enough to determine the relative effect upon the quality of the animal.

458. Rations for growing colts.-Doubtless all necessary conditions for producing growth and quality in colts can be met by a ration of which oats form a part. The following grain mixtures are suggested as illustrative of good ones: 


\section{Mixture 1}

Oats or middlings

Peas

Parts
4
4
2

Mixture 2

Corn

Parts

Oats

Bran

Oil meal
2

4

3

These mixtures are generally less expensive than oats alone, and in kind fully meet the demands for growth of both bone and muscle.

Henry gives as a fair allowance of grain for a colt, measured in oats, the following quantities: Up to one year of age, two to three pounds; from one to two years, four to five pounds; from two to three years, seven to eight pounds. In using the other grain feeds suggested, which mostly have a higher rate of digestibility than oats, no larger quantities would be necessary. Skim-milk may be fed to colts in limited amounts with good results, as experiments show. Feeding it in quantities sufficient to force very rapid growth is not wise.

It is generally conceded that the colt should be allowed to eat a reasonable proportion of coarse feed as a means of properly developing the digestive tract. It is entirely possible to supply concentrated grains too freely, to the exclusion of more bulky materials, and in that way fail to secure a desirable distension of the alimentary canal. This does not mean that the colt should be allowed to gorge himself with hay or other coarse material, as an unfortunate extreme in this direction is easily reached. 


\section{CHAPTER XXI}

FEEDING ANIMALS FOR THE PRODUCTION OF MEAT

The production of beef was at one time a source of income to nearly all farms. In earlier days the New England farmer annually sent to the market a few fat steers or oxen. The beef consumed in the United States and that exported now comes very largely from the wide grazing areas of the West, where the cost of feed and the necessary amount of labor are at a minimum. The reasons for this change are not hard to find. The food cost of beef-making is relatively large as compared with dairy products, and in the East the growth of home markets for milk and cream has made it possible for farmers to turn their high-cost feeding-stuff into products having a higher proportionate market price than beef. Moreover, certain eastern lands have, with enlarging markets, been occupied to good advantage with fruit and vegetables. The time has come, now that the wide areas of the West are more densely peopled, when beef production is receiving more attention in the eastern states. Some eastern farmers appear now to find it profitable. It is certain that it involves good judgment, skill, and the art of feeding to the highest degree, especially if fair returns are to be secured. The breeding or selection of animals of the most profitable type that will supply the market with a high-grade product, and stable feeding, so as to produce rapid and continuous increase, 
requires experience and an intelligent application of all the factors involved.

\section{BEEF PRODUCTION}

459. Nature of the growth with beef production.Feeding steers or oxen for the market may be carried on with young animals that are still making some growth of bone and muscle, or with those so mature that additional weight comes almost wholly from a deposition of fat in the tissues already formed. This is the difference between feeding a two-year-old and a five-year-old steer. In either case the predominating constituent of the increase is fat. This fact is established by the investigation of Lawes and Gilbert and by one experiment in this country. Gilbert, in his lectures summarizing the Rothamsted work, gave the following figures:

Table LXXIX. Composition of Increase When Steers Are Fattening

\begin{tabular}{|c|c|c|c|c|}
\hline & Water & Ash & Protein & Fat \\
\hline $\begin{array}{l}\text { Oxen fattened very young } \\
\text { Matured animals, final period } \\
\text { American results with well-fed steers, } \\
\text { growth from } 17 \text { months to } 27 \text { months }\end{array}$ & $\begin{array}{r}\text { Per cent } \\
32-37 \\
25-30\end{array}$ & $\begin{array}{l}\text { Percent } \\
21 / 4 \\
11 / 2\end{array}$ & $\begin{array}{c}\text { Per cent } \\
10 \\
7-8\end{array}$ & $\begin{array}{l}\text { Percent } \\
50-55 \\
60-65\end{array}$ \\
\hline of age & 42.4 & 6. & 14.1 & 37.5 \\
\hline
\end{tabular}

These figures may be regarded as reliable, and they show most conclusively that in beef production the constructive use of the food is largely in the direction of fat-forming.

460. Rate of increase of fattening animals.-The extent of the actual production which occurs can be 
closely estimated for any given case. It is considered satisfactory if the rate of increase during a reasonably long period of fattening is 2 pounds live weight a day. This means the actual addition to the dry substance of the body of from 1.3 to 1.5 pounds. Sometimes during short periods with excessive feeding the daily gain may be 3 pounds live weight, and generally after animals are well fattened, during the finishing period, it may be as low as 1 pound or less. The actual daily growth of new material may vary then, aside from the water, from .6 to 2.25 pounds a day. Actual fat formation may thus range from .4 to 1.8 pounds a day. The protein-content of the increase, on the other hand, probably does not exceed .3 pound daily in any instance, and with mature animals it is very insignificant.

461. The food needs of the fattening steer.-In view of the foregoing facts and of the conclusion as to the fatforming function of carbohydrates, it is clear that the non-protein part of the ration may be the source of the chief part of the body substance laid on by a fattening steer. The amount of protein necessary for constructive work seems to be very small-with mature animals it is practically nothing. It would seem, then, looking at the matter merely from the standpoint of the demands for growth, that in feeding fairly mature animals for beef production a ration may be efficient with a wide nutritive ratio, much wider than was recommended in the German standards.

It is recognized, though, that we cannot decide upon a ration merely upon the basis of the raw materials that are needed for constructive purposes. The influence of a particular feed or of a variety of feeds on the appetite and on what we speak of as general condition, as 
well as upon the quality of the product, and the necessity of avoiding so large a preponderance of carbohydrates as to cause a possible depression of digestibility, are all points which must be considered in determining the value of a ration. We should remember, also, that the stimulating effect of the food upon the vital functions is a factor in successful feeding. So, after all, we must appeal to experience, scientific and practical, for information as to what rations are efficient for fattening purposes.

The German standard rations for fattening bovines which were recommended called for 18 to 18.4 pounds of digestible organic matter daily for each 1,000 pounds of live weight, with a ratio of $1: 5.4$ to $1: 6.5$, requiring from 2.5 to 3 pounds of a digestible protein. In view of more recent scientific conclusions concerning the functions of nutrients, it is not easy to understand why a fattening steer requires more protein than a milch cow or even as much.

462. Scientific experiments with fattening animals.Feeding experiments with fattening oxen, conducted under the improved methods of research, give results not inconsistent with the facts to which attention has been called. Kellner made a large number of experiments with fattening animals by the aid of the respiration apparatus, and he concluded that the nutritive ratio of a fattening-ration may vary from $1: 4$ to $1: 10$ without affecting the increase of body substance from a unit of digestible food material, provided, however, that the nutrients supplied above maintenance needs shall come from the more easily digestible feeding-stuffs. He cites, in the support of his conclusion, the outcome of nineteen previous experiments by Wolff, in which rations varying in nutritive ratio from $1: 4$ to $1: 9.5$ showed no material 
differences in the efficiency of a unit of digestible matter. It seems to be agreed that a wide nutritive ratio is not inconsistent with most successful feeding of fattening steers, especially those that are mature. If the animals are so young as to be making material growth, there is more reason for avoiding a very wide ratio.

463. Practical feeding experiments in fattening animals.-Among the practical feeding experiments conducted in the United States, there are several instances where the wide-ratio rations have been found equal to the more nitrogenous. On the other hand, and perhaps in a majority of experiments, the rations containing the largest proportion of protein have caused the most rapid growth. In 1893 the writer made a careful study of many previous experiments and found that the addition of some highly nitrogenous feeding-stuff to corn meal, or other home-raised grain, in most instances increased the productive value of the ration. This fact stands in apparent conflict with the more scientific conclusions to which reference has been made. The probable explanation of this discrepancy is that the rations richest in protein have generally contained the greater variety of feedingstuffs, have been more palatable, more stimulating to the appetite, and, in general, have caused a more vigorous exercise of the animal's functions. The proportion of protein has probably been a minor factor. If as great a variety of as palatable and as easily digestible materials can be fed without the use of highly nitrogenous feedingstuffs as with them, the result will doubtless be just as favorable. This means that a mixture of home-raised grains may form as efficient a ration for fairly mature fattening steers as when the oil meals or gluten meals are introduced. Palatableness, variety, and ease of 
digestion are the main points to be secured, and these factors have been somewhat overshadowed by the effort to secure merely a definite nutritive ratio.

It need not be feared that when mixed cereal grains are fed as the major part of the ration, there will be a materially lower rate of digestibility than when a protein food is introduced. There is still something to be said, however, in favor of adding to a fattening-ration a small proportion of an oil meal, or of some material of similar character, for palatableness is thus promoted, and observations show, in many instances, that an appearance of greater thrift and vigor is thus induced, which is perhaps due to the stimulating effect of the greater amount of circulatory protein upon the metabolic processes of the animal. With young steers making some growth of bone and muscle, a small quantity of a protein food is of unquestioned advantage.

464. German fattening for bovines' ration excessive.The German standard for fattening cattle is open to criticism as to the quantity of nutrients recommended for 1,000 pounds of live weight. In order to supply 18.4 pounds of digestible organic matter it would be necessary to feed, for instance, 8 pounds of hay and 21.5 pounds of an ordinary mixture of corn meal, bran, and oil meal. While it may be possible to induce young steers weighing from 600 to 800 pounds to eat at this rate for a short time, so large a ration is seldom, if ever, so profitable as a smaller one, even if it could be fed with safety. If an attempt were made, however, to apply this formula to mature steers weighing from 1,300 to 1,500 pounds the situation would become absurd, because the ration would then be from 10.5 to 12 pounds of hay and from 25 to 32 pounds of mixed grains for a single animal. An appeal 
to concrete examples of steer-feeding will clearly show the excessive requirements of the German standard for fattening cattle. In 1891 to 1893 the Kansas Agricultural Experiment Station conducted feeding experiments with three-year-old steers, and as these are good examples of practical management, the data from them will serve to illustrate the point under discussion. These data are stated in a tabular form:

\section{TABLE LXXX}

Number of animals

Days fed

Weight per animal, average for period .

Hay eaten per day

Grain eaten per day

Daily gain per animal

Digestible organic matter daily per animal

Digestible organic matter per 1,000 pounds live weight

$\begin{array}{cc}\begin{array}{c}\text { First } \\ \text { experiment }\end{array} & \begin{array}{c}\text { Second } \\ \text { experiment }\end{array} \\ 5 & 3 \\ 182 & 129 \\ \text { Pounds } & \text { Pounds } \\ 1,412 & 1,237 \\ 7.8 & 6.7 \\ 23.9 & 23 . \\ 2.39 & 2.4 \\ 19.5 & 19 . \\ 13.8 & 15.3\end{array}$

In 1895-1896 the Iowa Agricultural College fed steer calves for fourteen months, during ten of which a record was kept of all the food consumed. During the second period the steers were fattened for market. This particular experiment is cited because the animals were young and all the conditions were favorable to the maximum consumption of food in proportion to live weight:

\section{TABLE LXXXI}

Number of animals

Days fed

$\begin{array}{cc}\begin{array}{c}\text { First } \\ \text { period }\end{array} & \begin{array}{c}\text { Second } \\ \text { period }\end{array} \\ 5 & 5 \\ 120 & 181 \\ 9 \text { to } 10 \text { mos. } & 16 \text { to } 17 \text { mos. } \\ \text { Pounds } & \text { Pounds } \\ 766 & 1,197 \\ 11 & 12.8 \\ 9 & 19.5 \\ 2.04 & 2.11 \\ 2.66 & 1.76 \\ 10 . & 14.1 \\ 13 . & 11.8\end{array}$

Weight per animal, average for period

Coarse food eaten daily (partly roots and green fodder)

Grain eaten daily (partly snapped corn)

Daily gain per animal

Digestible organic matter daily per animal

Digestible organic matter daily per 1,000 pounds live weight

13.

11.8 
The largest amount of digestible nutrients fed daily to each animal at any time during this experiment was about 17.5 pounds, after the animals had reached an average weight of 1,200 pounds or over. This would be approximately 14.5 pounds digestible organic matter for each 1,000 pounds live weight.

These two experiments are instances of successful feeding where the increase was rapid and very satisfactory and where the quantity of digestible nutrients supplied daily was greatly below 18 pounds for each 1,000 pounds live weight.

It is concluded, from observation and a study of the results of experiments, that under proper conditions 8 to 10 pounds of dry coarse food and 15 to 18 pounds of grain is all that can generally be fed with greatest profit to a steer actually weighing 1,000 pounds, and may be even more than is utilized by the animal to the best advantage. Such a ration would supply about 16 pounds of digestible organic matter. If considerably smaller steers are fed, the ratio of food to weight may be increased, but if the animals are several hundred pounds heavier the ratio may be materially diminished. It is safe to accept as a general principle the rule that the larger the animal the less the proportion of food to weight. The fixing of the quantity of a fattening-ration directly in proportion to the size of the animal is a simple and quite convenient rule, but is utterly impracticable and is so recognized at present in the standards for growing animals, and should be in all estimates and proportions.

465. The selection of a fattening-ration.-Two conditions already mentioned that are of the highest importance should not be forgotten, viz., that the ration should be palatable and be composed of a variety of easily diges- 
tible materials. Rough fodder in any quantity is not adapted to fattening bovines. With this exception, the whole list of high-class cattle foods may be regarded as available, and the selection will properly depend largely upon prices and the local supply. In the northern states, hays from the fine grasses and the legumes, silage, roots, cereal grain mixtures, and such by-product feeding-stuffs as offer digestible nutrients at the least cost will all appeal to the experienced feeder. In the South, cottonseed by-products may, with economy, enter largely into the ration. In the West, the fodders peculiar to that region will be utilized, corn being the chief, and sometimes the only, grain that can be fed with economy.

466. Suggested rations for fattening steers.-The following may be regarded as good types of mixtures for the full feeding of fattening steers weighing approximately 1,000 pounds each at the beginning of the feeding period. They will supply about 16 pounds of digestible organic matter if their components are of average quality and composition:

$1\left\{\begin{array}{r}5 \text { lbs. clover hay. } \\ 16 \text { lbs. corn silage. } \\ 13 \text { lbs. corn meal. } \\ 3 \text { lbs. wheat bran. }\end{array}\right.$

$2\left\{\begin{array}{l}10 \text { lbs. corn stover. } \\ 20 \text { lbs. mangels. } \\ 14.5 \text { lbs. corn meal. } \\ 2 \text { lbs. cottonseed meal. }\end{array}\right.$

$\left\{\begin{array}{c}8 \text { lbs. mixed hay. } \\ 12.5 \mathrm{lbs} \text {. corn meal. }\end{array}\right.$

$3\{3$ lbs. wheat bran:

2 lbs. oil meal or gluten feed.

$4\left\{\begin{array}{c}8 \text { lbs. alfalfa hay. } \\ 12 \text { lbs. corn meal. } \\ 5 \text { lbs. ground oats. }\end{array}\right.$ $5\left\{\begin{array}{l}5 \text { lbs. clover hay. } \\ 50 \text { lbs. beet pulp. } \\ 11 \text { lbs. corn meal. } \\ 2 \text { lbs. cottonseed meal. }\end{array}\right.$

8 lbs. corn stover.

$6\{12.5$ lbs. corn meal.

20 lbs. brewers' grains, wet.

( 2 lbs. oat straw.

$75 \mathrm{lbs}$. beet pulp.

10 lbs. beet molasses.

4 lbs. gluten meal.

$8\left\{\begin{array}{c}5 \text { lbs. alfalfa hay. } \\ 3 \text { lbs. corn stover. } \\ 11 \text { lbs. corn meal. } \\ 6 \text { lbs. ground barley. }\end{array}\right.$ 
The above rations are well up to the quantity limit for the profitable feeding of animals weighing approximately 1,000 pounds. They are simply illustrative, however, both in kind and in quantity. Many mixtures equally efficient may be used, and the quantity of the ration must vary not only with the age and size of the animal but with individuals, according to appetite and capacity. Any feeder of experience will understand, of course, that such rations will be eaten with safety to the animal only after a period of preliminary feeding, during which there has been a gradual increase in the quantity of food offered.

\section{MUTTON PRODUCTION}

Attention has been called to the fact that beef production in the United States has gravitated to the extreme West. This is also true of the production of mutton though not to the same extent. Flocks of sheep are still kept on many farms of the eastern and middle West states, and the growth of early lambs and the fattening of maturer animals to supply the demands of the local markets is found to be most profitable by those farmers who possess the knowledge and skill requisite for this branch of stock husbandry.

467. Place of sheep on the farm.-Sheep occupy a peculiar place on the farm in that they will accommodate themselves to pasturage that is not adapted to cows and horses, and will utilize some kinds of rough fodder not readily eaten by other farm animals without submitting it to somewhat expensive methods of preparation. If it were not for the discouragement which sheep husbandry has received from the depredations of dogs, sometimes 
real and sometimes greatly overestimated or even imagined, the production of wool and mutton would greatly increase on the hill farms of this country, with undoubted profit to eastern agriculture, especially where soil fertility needs strengthening in every possible way.

468. The nature and extent of the growth in fattening sheep.-The character of the animal that is fatteried for mutton varies within wider extremes than in steerfeeding. This is due chiefly to the greater range in maturity of the former, from the two months' lamb to the mature wether. There, are corresponding differences in the nature of the increase while fattening, according as the animal is young and making growth of all parts of the body, or is simply storing fat in the mature organism. The character of the body substance stored, probably, is also influenced by the stage in the fattening period, whether at the beginning when the animal is thin or near the end when a fat sheep is becoming fatter. The only definite data which can be presented relative to the composition of the increase of fattening sheep are based upon the analyses by Lawes and Gilbert of animals in various states of fatness. These investigators analyzed a "store" sheep, a "fat" sheep, and a "very fat" sheep, and from the figures thus obtained is calculated the increase in two stages of fattening:

Table LXXXil. Composition of Increase of Fattening Sheep

\begin{tabular}{|c|c|c|c|c|}
\hline & $\begin{array}{c}\text { Dry } \\
\text { substance } \\
\text { Per cent }\end{array}$ & $\begin{array}{r}\text { Ash } \\
\text { Perce }\end{array}$ & $\begin{array}{l}\text { Protein } \\
\text { Per cent }\end{array}$ & $\begin{array}{l}\text { Fat } \\
\text { Per cent }\end{array}$ \\
\hline $\begin{array}{l}\text { rease from "store" to "fat" } \\
\text { ondition }\end{array}$ & 78. & 2.12 & 7.16 & 68.8 \\
\hline from & 81.8 & 3.12 & 7.75 & 70.9 \\
\hline
\end{tabular}


A comparison with the increase of fattening oxen shows that the sheep stores the larger proportion of fat in the dry substance laid on.

Sheep liberally fed give a larger increase to the 1,000 pounds live weight than steers. With animals weighing from 75 to 150 pounds each, the daily gain with good management may range from .2 to .5 pound a head, or from 2 to 5 pounds to the 1,000 pounds, live weight, the increase varying according to age, conditions, and liberality of feeding. Lambs will sometimes greatly exceed the above maximum. If we base our estimates upon what will occur with the maturer animals, a number of lambs or sheep weighing 1,000 pounds, perhaps seven, perhaps twice as many, will store daily .15 to .40 pound of protein and from 1.4 to 3.5 pounds of fat.

469. Food needs of fattening sheep.-After long-continued and careful experiments in feeding a fatteningration to mature sheep, whose composition was investigated at various stages of fatness, Henneberg concludes that the very small amount of protein tissue laid on by such animals may be ignored. Pfeiffer reached the same conclusion from experiments with the same class of animals. This view would not hold with lambs during their increase from weaning time to one hundred pounds in weight, for in this period there must be a material and continuous storage of nitrogenous tissue.

As is the case with steers, the demand for protein storage is seen to be small with mature fattening sheep, the constructive use of the ration being largely directed to fat formation. The more recent views of the function of the nutrients allow us to believe that, as with bovines, carbohydrates and perhaps fats play a leading part in supplying raw materials for the carcass increase. 
There is one point of difference between steers and sheep, however, viz., the growth of wool with the latter, that requires the use of more or less food protein.

The German standard for fattening sheep is 18.5 to 18.6 pounds of total digestible organic matter for each 1,000 pounds live weight, 3 to 3.5 pounds of which shall be protein, thus giving a nutritive ratio ranging from $1: 4.5$ to $1: 5.4$. There is little doubt that this standard calls for an unnecessarily large proportion of protein. Neither scientific facts nor the observations of practice justify the conclusion that sheep will fatten faster when protein is so liberally supplied than when properly compounded rations with a wider nutritive ratio are fed. Doubtless more regard should be paid to the proteinsupply with sheep than with steers, but it is difficult to adduce a single argument for insisting upon so narrow a nutritive ratio with any species of fattening animal, unless it becomes incidental to an economical purchase of feeding-stuffs. We may safely conclude that the resources of the farm are sufficient to supply enough protein for a ration of an efficient character for the class of animals under consideration, though we should give due recognition to the fact that, with fattening lambs especially, the protein feeding-stuffs may be most effciently utilized.

470. Quantity of nutrients for fattening sheep.-The quantity of nutrients prescribed by the published standard for fattening is practically the same for each unit of weight as that given for fattening bovines. This runs contrary to common observation and the results of experiments. The standard for steers has been characterized as excessive, but this fault cannot be charged to the one for sheep, for, if anything, it is below the demands 
of practice. Even mature sheep about average size will consume 18.5 pounds of digestible nutrients for 1,000 pounds live weight, but this ratio does not meet the requirements for the prevalent intensive feeding of lambs and yearlings weighing from 75 to 125 pounds each. It is easily demonstrable not only that sheep will utilize a proportionately larger quantity of food than bovines, but that they will make a relatively greater increase. The results of two experiments in fattening wether lambs, reported from the Iowa Agricultural College in 1896 and 1897, when compared with the outcome of steer-feeding trials, serve admirably to illustrate the correctness of this statement. The lambs were divided among seven mutton breeds. Sixty-nine were fed 90 days and 64 others were fed 107 days.

The main facts derived from these feeding trials are as follows:

\section{TABLE LXXXIII}

Number of animals 133.

Average days fed

Total average weight of animals 16,400

Average weight single animal

Dry matter consumed

Digestible organic matter consumed 34,500

Dry matter eaten daily per 1,000 pounds live weight

Digestible organic matter eaten daily per 1,000 pounds live weight .

Daily gain per 1,000 pounds live weight

Daily gain per animal

The food consumption in this instance of the successful fattening of lambs is considerably in excess of the German standard, and the amount of food consumed is not unusual, though it is stated that in the latter stages of the experiments the animals were crowded to their full capacity. 
If a comparison is made of this experiment with the steer-feeding experiments previously cited it becomes clearly evident that the published feeding standards are not consistent in calling for practically the same quantity of nutrients for the same live weight of the two species. Sheep will consume at least one-quarter more food than steers and lay on flesh proportionately faster. Moreover, sheep appear to make a larger gain in live weight than steers for each unit of nutrients consumed. It may be that the testimony of the experiments cited relative to the points under discussion is not a correct expression of average conditions, but the differences shown are too marked to be accounted for by any unusual conditions pertaining to these feeding trials, and therefore indicate what may generally be expected in practice.

471. The selection of a ration for sheep.-The range of feeding-stuffs from which a sheep ration may be selected is wide and includes practically all home-raised fodders and grains and the whole list of by-products. It cannot be said, though, that all materials are equally desirable as sheep food. Of the fodders, those from the legumes are especially to be sought, even pea and bean straws, and among the grains corn stands preëminent as the basis of a fattening-ration. Probably no feedingstuffs are more favored for mixing with corn than oats, bran, and linseed meal, probably because none are more successfully used. Barley, peas, beans, gluten feed, gluten meal, and cottonseed meal have also been successfully fed to sheep. A mixed grain ration is unquestionably to be preferred to any single grain or by-product, because with the mixture greater palatableness is insured, it is possible to maintain the consumption of a larger ration, and the danger to health of heavy feeding is less. 
The selection of the components of the grain mixture should be governed somewhat by market prices. A supply of silage or roots is much to be desired as a part of a sheepfattening ration, especially when heavy grain rations are to be fed during a long period, although successful feeding during a limited time is entirely possible without these. A succulent food promotes appetite and health, however, and is usually economical and sometimes necessary.

Rations made up in definite quantities will not be presented in this connection. The quantity of nutrients which it is desirable to supply is so variable according to the age and maturity of the animals to be fattened that a feeding standard is applicable to only one set of conditions not long maintained and therefore it must be freely and frequently modified according to the judgment of the feeder. It is, nevertheless, possible to offer practical suggestion as to the proportions of grains in the mixtures that will be found acceptable, and as to the kinds and quantities of coarse foods ordinarily utilized.

In the Iowa experiments cited in this connection the grains used were corn, oats, bran, and linseed meal. In the last of these trials the grain ration for fifteen days at first was made up of corn, oats, and bran in the proportions 2, 2, and 1 . When the feeding was well established the grains were oats, corn, bran, and oil meal, the relation in quantity being $8,8,2$, and 1 respectively. Each animal ate about one pound of roots daily and about two-thirds as much hay as grain. The lambs were fed up to the full ration very gradually, several weeks being occupied in doing this. For such preparatory feeding bran and oats are especially useful. When these tests began, each animal ate from one and a half to two pounds of grain daily, which quantity was increased later to 
three pounds with the largest eaters, some individuals not taking over two. The conduct of these feeding trials typifies good practice, both as to materials and management, and may serve as a guide in handling other similar feeding-stuffs.

It is undoubtedly possible to feed sheep with equal success without the use of purchased grains, especially on farms where clover or alfalfa, roots, corn, oats, or oats and peas, are produced. We are not justified by experimental results in concluding that bran and oil meal or any other by-product feeds are essential to the highest success in fattening sheep, although these feedingstuffs are very useful for this purpose. A mixed grain ration is always better than any single grain fed alone.

Instances are on record of a successful combination of green forage crops with grain in fattening sheep. The legume fodders and rape may be fed profitably in the green state with the usual grain mixtures, care being taken to avoid indigestion from excessive eating of the green material. Grain in connection with ordinary pasturage is a successful method of fattening sheep or lambs for the fall market.

\section{PORK PRODUCTION}

The feeding of swine is a matter of almost universal interest to farmers. Even in the older portions of the East a few animals of this class are kept on nearly every farm. Swine are well adapted to the disposal of certain wastes, particularly those from the table and the dairy. They are especially useful as a means of profitably converting dairy by-products into a marketable form, and, moreover, during the past twenty-five years pork produc- 
tion has offered more encouraging inducements to the home consumption of grain than has beef production.

472. Changes in pork production.-Within recent years there has been a great change in the methods of pig-feeding and in the character of the animal when placed upon the market. This is emphatically true of the eastern and middle states, where pork is grown wholly for local consumption. Formerly good feeders were not supposed to slaughter a pig under 300 pounds carcass weight, and many animals dressed 400 pounds when taken to the market, this size being secured only after a feeding period of twelve to eighteen months. Pork of this character was regarded as well adapted to packing. At the present time the demand of the local markets is for small carcasses weighing not over 150 pounds, and supplying the maximum proportion of lean cuts. This change is in the direction of greater profits for the farmer because the food expenditure required for the production of small carcasses is much less a unit of weight than under the old system, when the feeding was continued during a longer period. Pigs properly fed are now wisely turned off at the age of a few months, excepting, perhaps, in those localities where a slow early growth is cheaply secured on pasturage.

473. Character of the growth in pork production.-The modern hog is emphatically a fat-producing organism, having a capacity in this particular greatly surpassing any other species of domestic animal. The dry matter of the carcasses of individual animals has been found to consist of over 80 per cent of fat, even after the leaf lard was removed, and the average proportion in the dry substance of eight dressed pigs, representing six breeds, was found by Wiley to be 78 per cent. 
The statement of the composition of a Berkshire pig and of a Duroc-Jersey will be found interesting in this connection:

Table LXXXIV. Composition of the Entire Dressed Antmal, Head, Leaf-Lard, and Kidneys Removed. (Wiley.)

\begin{tabular}{|c|c|c|c|c|c|c|}
\hline & $\left|\begin{array}{l}\text { Weight } \\
\text { carcass }\end{array}\right|$ & Water & $\begin{array}{c}\text { Dry } \\
\text { sub- } \\
\text { stance }\end{array}$ & Ash & Protein & Fat \\
\hline \multirow{4}{*}{$\begin{array}{l}\text { Berkshire . . } \\
\text { Duroc-Jersey } \\
\text { Fat pig, entire animal } \\
\text { (Lawes \& Gilbert) }\end{array}$} & $\begin{array}{c}\text { Pounds } \\
129\end{array}$ & $\begin{array}{c}\text { Percen } \\
43.1\end{array}$ & \begin{tabular}{|l} 
Perent \\
56.9
\end{tabular} & $\begin{array}{c}\text { Percen } \\
2.6\end{array}$ & $\begin{array}{l}\text { Percent } \\
13 .\end{array}$ & Percent \\
\hline & 149 & 30.6 & 69.4 & 1.8 & 9. & 57.7 \\
\hline & & & 561 & 10 & 110 & 423 \\
\hline & 200 & 43.9 & 50.1 & 1.9 & & \\
\hline
\end{tabular}

It appears that there were stored in the part of the animal analyzed by Wiley only 13 pounds of protein with the Duroc-Jersey and about 17 pounds with the Berkshire, the quantities of fat being 52 pounds and 86 pounds, respectively. The figures for the entire animal, as analyzed by Lawes and Gilbert, are at the rate of 23.8 pounds protein and 84.6 pounds fat, in a pig weighing 200 pounds.

These proportions bring out sharply the character of the growth with swine. It is to be noted that in no other species, very fat sheep possibly excepted, does the body consist so largely of dry matter, which means that the increase of a unit of live weight involves the storage of more food substance than with other domestic animals. The data at our command warrant the statement, in a general way, that when a pig gains 1.5 pounds daily in live weight he stores not less than .84 pound of dry substance, of which .18 pound is protein and .63 pound is fat, these figures representing the average growth during the life of the animal. Lawes and Gilbert estimate that 
the increase of pigs while fattening has the following composition:

$\begin{array}{ccccc}\begin{array}{c}\text { Water } \\ \text { Per cent }\end{array} & \begin{array}{c}\text { Dry substance } \\ \text { Per cent }\end{array} & \begin{array}{c}\text { Ash } \\ \text { Per cent }\end{array} & \begin{array}{c}\text { Prótein } \\ \text { Per cent }\end{array} & \begin{array}{c}\text { Fat } \\ \text { Per cent }\end{array} \\ 22 & 78 & .10 & 6.4 . & 71.5\end{array}$

According to these figures the protein storage, with 1.5 pounds daily gain, would be only .10 pound and the fat 1.07 pounds.

474. Food requirements for pork production.-Under a system of intensive production pigs go to market so young that we may properly discuss their feeding from birth. We deal first with the mother as a milch animal. According to observations by Henry, in an inquiry as to the yield and composition of sow's milk, it seems probable that in proportion to their weight small sows yield as large a quantity of milk solids daily as a good cow. The average daily production of milk solids of one animal appeared to be about one pound. This would be four pounds for four sows, which is the equivalent of the solids in over thirty pounds of cow's milk of average quality. It follows, therefore, that the demands upon the food for milk formation are proportionally as heavy with swine as with cows, and consequently the ration should be one that will stimulate and sustain abundant milk secretion. Such feeding is not only necessary, but economical, for independent experiments indicate that the food cost of the growth of pigs before weaning is no greater than it is after weaning.

Skimmed milk or buttermilk combined with a mixture of wheat middlings and any of the ground cereal grains, barley, oats, or corn, cannot be improved upon as food for milch sows. The supply of protein should be liberal. The feeding should be quite up to the limits of capacity, 
and even then the dam suckling a large litter of young will grow thin.

475. Pigs unwisely fed.-If we merely consider the nature of the body substance of swine in its relation to the constructive functions of the nutrients, it would not be unreasonable to believe that rations with a wide nutritive ratio are adapted to the needs of this class of animals for growth. In a certain sense, practice ratifies this view. Thousands of fat hogs have been the product of almost exclusive corn-feeding, especially during the later stages of growth. There is no doubt but that large size and an excessively fat condition may be secured through a liberal supply of carbohydrate material, but such one-sided nutrition is not now regarded as being adapted to the physiological requirements of the pig or as producing pork which meets the existing demands of the market.

It is doubtful whether any other species of domestic animal has been the subject of so much abuse through improper feeding, combined with an unhealthful environment, as has the pig. We now regard the abnormal masses of porcine fat which have heretofore appeared in our markets as not only an exhibition of physical monstrosities, but as not serving the health interests of the human family.

476. Point of view in feeding pigs.-The primary object in feeding pigs should be, as with all domestic animals, the securing of a normal and vigorous physiological development, i. e., an organism with a strong bony structure and with such a growth of muscular tissue as shall insure full exercise of all the vital functions. The view seems to have prevailed, in a practical way at least, that pigs can be fed on anything, live and sleep anywhere, 
and still not suffer ill effects, as would be the case with the other farm animals. This has been unfortunate, because probably no domestic species is more susceptible to abnormal development through improper feeding than are swine. It is true, at least, that no other species has shown so marked a response to changes in the character of the rations, through modifications of the bony structure and through variations in the proportions of muscle and fat tissue.

477. Influence of ration on the development of swine. - Notable proof of the plasticity of the pig's organism was supplied by the experiments of Sanborn and Henry in comparing rations extremely nitrogenous with those extremely carbohydrate in character. Pigs fed liberally on blood, milk, and shorts combined with more or less corn meal, made growth more rapidly, had stronger bones, larger organs, and more muscular tissue than those fed on corn meal or a mixture of corn meal with other highly non-nitrogenous materials, such as potatoes and tallow. The latter combination was deficient both in protein and in bone-forming compounds. Such marked differences are not usually seen, because rations are not generally so extremely one-sided. These experiments teach the lesson, though, that as much care should be exercised in choosing the pig's ration as the cow's.

Experimental observations demonstrate that the pig's ration should be selected with reference to supplying an abundance of bone-making material and a reasonably large proportion of protein. Evidence is not wanting that the feeding of wood-ashes and ground bone to growing pigs promotes both a normal development of the bony framework and a more liberal consumption of food. Animals that are grazing may not need to have the ration 
so supplemented but it is wise and even necessary with those confined in pens.

478. Dairy wastes as food for pigs.-In selecting foods for the production of small pork where the development of all forms of tissue is taking place, first rank must be given to the dairy wastes. As a means of promoting rapid growth and a condition of health and vigor, and also as a supplement to cereal-grain products, skim-milk and buttermilk are not excelled, and perhaps not equaled, by any other feeding-stuffs. Dairy wastes are more profitably used in pork production than perhaps in any other way. (See Pars. 360-363.) In order to secure the maximum result from a given quantity of dairy wastes, they should be fed in combination with grain products. When this is done, and the proportions of skim-milk or buttermilk and grain are what they should be, it appears to require less digestible food substance for a pound of growth than when grain is fed alone or when the liquid food is largely eaten. In other words, dairy wastes are not only efficient in themselves in producing growth, but in proper combination they cause a. saving of the grain products necessary to secure a given ratio of gain. Henry states, on the basis of eight feeding trials involving the use of ninety pigs, that 462 pounds of skimmed milk effected a saving of 100 pounds of corn meal. This means that 46.2 pounds of digestible milk solids, when combined with corn meal, saved, approximately, 76 pounds of digestible corn meal substance.

Henry's experiments were arranged so as to gain information as to the most desirable proportion of milk and meal, and from his data the writer has calculated the quantity of digestible nutrients required in each combination for one pound of growth: 
Mixed grains alone

Combination

Digestible matter required
for 1 pound of gain
Pounds

$1 \mathrm{lb}$. corn meal to 1-3 lbs. skim-milk . . . . 3.

$1 \mathrm{lb}$. corn meal to $3-5 \mathrm{lbs}$. skim-milk . . . 3.1

$1 \mathrm{lb}$. corn meal to $5-7 \mathrm{lbs}$. skim-milk . . . 3.3

$1 \mathrm{lb}$. corn meal to 7-9 lbs. skim-milk . . . 3.2

These results show the greatest food efficiency with the minimum proportion of skim-milk. Other experiments, notably those by Linfield and Robertson, give similar testimony. With the former, in seven experiments, a milk and grain ration produced 1 pound of gain for each 2.58 pounds of digestible matter, the requirement with milk alone being 2.85 pounds and with grain alone 3.19 pounds. When 2 pounds of skim-milk was fed with 1 pound of grain, 100 pounds of the milk replaced 31 pounds of grain, but when the milk and grain were as 4 to 1,100 pounds of milk replaced only 24 pounds of grain.

Doubtless with pigs in the earliest stages of growth after weaning, the proportion of milk to grain may well be larger than in the more mature periods, and in any case the ratio will naturally depend somewhat on the relative supply of the milk and grains.

479. Protein foods other than milk products for swine.-In the absence of dairy wastes, meat meal, dried blood, and fish scraps may be used to supplement the grain products or a mixture of the more nitrogenous feeding-stuffs with corn and barley will be found greatly superior to the corn or barley alone. Milk is more efficient with young pigs than the grain feeds rich in protein, but in the maturer periods the digestible matter of certain of the latter seems to have a value not greatly, if any, below that of skim-milk solids. 
The protein feeds adapted to pigs are gluten meal, gluten feed, buckwheat middlings, brewers' wastes, peas, and middlings. The oil meals, except in small quantities, affect the health of swine unfavorably and wheat bran is inferior to middlings.

Of the carbohydrate foods, oats, barley, wheat, rice products, and especially corn, are all useful. Although the excessive corn-feeding of swine is to be deplored, this grain is second in value to no other in the pig's ration, and only needs to be reinforced with more nitrogenous feeds in order to find a safe and profitable use. In the later stages of growth or fattening it may well form the major part of the ration. Probably no combination has been found more satisfactory for all around use than skim-milk, wheat middlings, and corn meal, the latter constituting the larger proportion of the grain food.

480. Forage crops for swine.-At the present time much attention is given to forage crops for swine. Clover, alfalfa, rape, sorghum, rye, and ordinary pasturage have all been found to be adapted to hogs. When fed with grain, economical and satisfactory production is secured. When fed alone, the growth is so slow as to be unsatisfactory. In two experiments at the Wisconsin Experiment Station, one acre of rape when combined with grain proved to be equal to 2,767 pounds of corn and shorts. Other observations show beyond question that such feeding is practicable and under some conditions profitable. Better results seem to follow when the pigs are allowed to graze than when the fodder crop is cut and fed to animals confined in pens. 


\section{CHAPTER XXII \\ FEEDING WORKING ANIMALS}

Working animals are rapidly being displaced by power vehicles. Those now in use in the United States are chiefly horses and mules. Oxen were once employed extensively for farm labor and in lumbering, but these are rarely seen under the yoke at the present time except in remote rural districts. It will be proper, therefore, to treat in this connection chiefly of horses that are used for draft and road purposes.

481. The horse a machine.-In feeding a working animal, the essential product of the food is energy to be used in drawing, walking, or trotting. The latent food energy is made available, as heretofore stated, by the oxidation of the several nutrients into the ordinary products of combustion, and the units of heat or work or other forms of kinetic energy evolved are directly proportional to the quantity of digested food which suffers combustion, just as the possible work of a steam engine under given conditions is proportional to the fuel consumption in the boiler. The establishment of fundamental relations between food and work requires on the one hand an understanding of the energy values of food, and on the other hand at least a general conception of the amount of work performed. The energy values of food have been considered and it now remains for us to ascertain what is known concerning energy consumption by a laboring animal. 
482. The work performed by a horse.-The labor performed by a draft or road animal, exclusive of the energy required for maintenance, may be regarded as consisting of two components, viz., the effort of moving the load and that of moving the animal's body. If a horse weighing 1,000 pounds draws 1 mile a wagon which, with its load, weighs 1,500 pounds, 2,500 pounds of matter have been moved through the distance traveled. In other words, a horse moves himself and his load whether the load is drawn on a wagon or is loaded on his back.

The exact expenditure of energy involved in both of these components cannot be measured directly. The work of drawing a load may be determined by the use of a dynamometer, but it can only be estimated so far as the body of the horse is concerned. If the latter factor could be calculated on the basis of simply projecting a mass of matter through the space traveled, it would be a comparatively simple problem. There is a vertical motion of the horse's body to be accounted for, as well as a horizontal, and the reduction of both to units of work is a difficult matter. If this could be done, our present knowledge of the food energy necessary for the performance of a unit of mechanical labor would allow quite definite calculations of the daily food needs of horses of different classes. As a matter of fact, the actual work accomplished by laboring animals has been and still is to quite an extent, a matter of estimation.

Chardin, a French army veterinarian, estimates that the average daily work performed is about 2,580 foottons. Lavalard calculates that the total ordinary work of any army horse equals 8,500 foot-tons. As stated by Armsby, the ordinary day's work of a horse is estimated at 1,500,000 kilogram meters, or 5,425 foot-tons, this 
evidently meaning the mechanical labor outside the motion of the body. With the knowledge we now possess it is possible to estimate approximately the actual work performed in a given case.

It would be a good day's labor if a 1,000-pound horse travels 20 miles over a smooth, level, dirt road hauling a wagon with a load of 2,000 pounds. The draft of the loaded wagon would be not far from 100 pounds. A simple calculation shows that the mere moving of such a load the distance of 1 mile would be equivalent to 264 foottons. The energy expenditure in walking a given distance has been measured by Zuntz, who ascertained the difference in oxygen consumption of a horse when at rest and when traveling at a walk over a level road. According to these measurements, it appears that a 1,000-pound horse in walking 1 mile at the rate of 2 to 3 miles an hour would expend a total energy of 473 foot-tons, 44.4 per cent or 201 foot-tons of which belong to the effort of walking, over and above the energy needed for mere maintenance. In the case assumed, a horse would perform a total labor, in walking and drawing 20 miles, equivalent to lifting 9,300 tons through a space of 1 foot. This estimate is presented merely as an approximation of the work done under given conditions.

483. Influence of conditions on the food expenditure for a unit of work.- These figures are, perhaps, less important to the owner of work or driving horses than is a knowledge of the influence of speed upon the labor expended in a unit of time. "According to Marcey, the work accomplished in a given time is proportionate to the square of the velocity. His coefficients were 3.42 for walking or pacing, 16 for trotting, 28.62 for cantering, and 68.39 for a full gallop." This general fact would be 
applicable to horses under all conditions of labor. Moreover, it is clearly demonstrated by two investigators that the food energy required for a unit of work increases with the speed. In other words, a horse that trots 20 miles a day must have more food than when he walks the 20 miles. In the same way draft animals require food somewhat in proportion to the pace with which they travel over a given distance. Grandeau has shown that a horse was kept in condition with 19.4 pounds of hay when he walked $121 / 2$ miles, but 24 pounds was insufficient when he trotted the same distance. Zuntz measured the oxygen used for each kilogram meter when a loaded horse traveled at different velocities. When the pace was 3 miles an hour, with a load of 275 pounds, the energy required was equal to 4,600 calories for each kilogram meter of horse, which increased to 7,753 calories when the speed reached $61 / 3$ to $71 / 2$ miles an hour. The food needed for a unit of work increased nearly 70 per cent in increasing the speed from 3 to 7 miles. Zuntz shows that if a horse exerts himself to the utmost the use of oxygen rises at a rapid rate, and that the food consumed for a unit of work is nearly one-half more than with ordinary draft. It appears to be a rule that as the intensity of exertion of the horse increases the food cost of a given amount of labor performed increases. Men of experience recognize this fact in a general way when they insist on favoring their animals to the slowest pace that is consistent with the conditions involved.

484. The food requirements of a working horse.There are two general ways of ascertaining the food needs of a working horse: by practical experiments in which the rations are varied until a conclusion is reached as to what will support an animal under given conditions, and by 
determining through scientific investigations the amount of work performed in various ways and the relation of a unit of food to a unit of work. It would not be far from the truth to state, however, that the feeding standards which are offered to us through investigations made by Boussingault, Wolff, LeClerc, Grandeau, Hoffmeister, Lavalard, Zuntz, Kellner, and others, are the outgrowth of both practical observations and scientific research, a most desirable combination. In a large number of instances the kind and quantities of digestible food consumed daily by working horses have been determined, and in many cases the accompanying wastes and gain and loss of the animal body have been measured.

The standard rations now found in German tables are the result of such observations. According to these standards a 1,000-pound horse requires 11.4 pounds of digestible food daily when doing moderate work, 13.6 pounds for average work, and 16.6 pounds for heavy work. With a basal ration of 10 pounds of hay, the grain needed to furnish these quantities of digestible nutrients, when consisting of a mixture in equal parts of corn and oats, would be approximately 11.5 pounds, 15 pounds, and 20 pounds for the three conditions of labor. Lavalard, who made observations covering a period of a number of years for 32,000 omnibus, army, and draft horses, has reached the conclusion that "a horse performing ordinary work requires 115 grams of digestible protein and 1,100 grams of digestible carbohydrates per 100 kilograms live weight." This is at the rate of 1.215 pounds of digestible nutrients for 100 pounds of live weight. This observer bases the ration upon the weight of the animal, but practically concedes that "somewhat larger amounts of protein and carbohydrates are considered necessary 
with small horses," a conclusion which is entirely consistent with observation and related facts. Lavalard's formula would furnish a 1,000-pound horse, doing ordinary work, with 12.1 pounds of digestible nutrients daily, a quantity not inconsistent with the German standard.

Kellner has recommended the following average standards for working horses to include maintenance:

REQUTREMENTS OF THE. Working Horse*

For light work . . . . . . .

For medium work

For heavy work

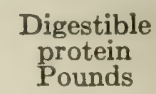

1.

1.4

2.

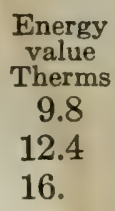

16.

Rations corresponding to these standards would be as follows:

For light work

10 lbs. mixed haj.

5 lbs. cracked corn.

2 lbs. wheat middlings.

$1 \mathrm{lb}$. wheat bran.
For medium work

$10 \mathrm{lbs}$. mixed hay.

7 lbs. cracked corn.

$3 \mathrm{lbs}$. wheat middlings.

$1 \mathrm{lb}$. brewers' grains, dried.

For heavy work

$10 \mathrm{lbs}$. mixed hay.

10 lbs. cracked corn.

$4 \mathrm{lbs}$. wheat middlings.

$1 \mathrm{lb}$. brewers' grains.

485. Estimate of work ration for the horse based on energy relations. - The results of the masterly and extensive metabolism investigations which Zuntz had carried on with a horse under various conditions may properly be used for computing a ration. This investigator determined the oxygen consumption, which is equivalent to ascertaining the food use, by a horse at rest, when

* Based on true protein and productive values. 


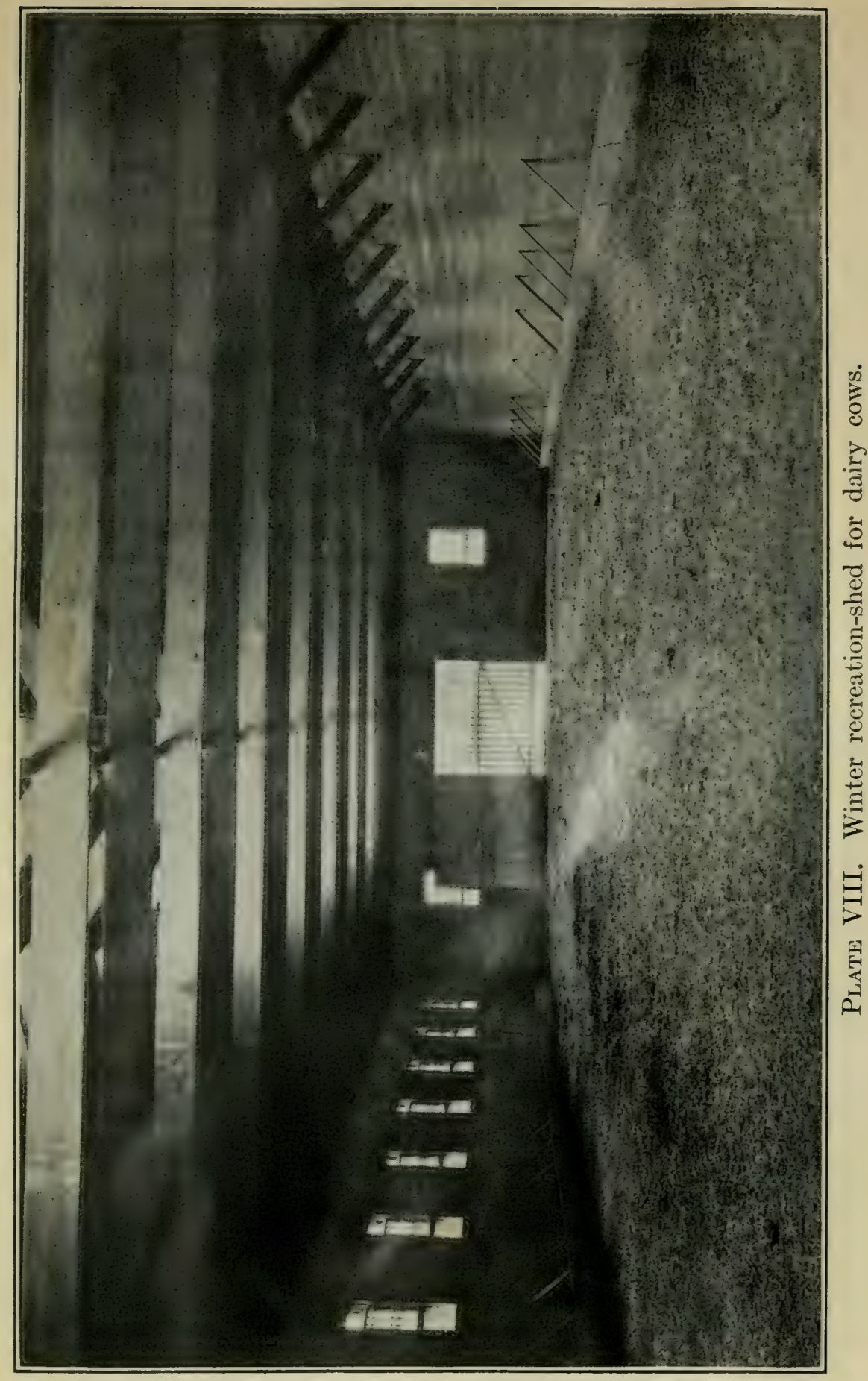


walking on a smooth level without load, and when performing both light and heavy work. First of all, it appears from his observations that 31.6 per cent, or about onethird, of the total food energy can be converted into useful work. This is much less than the coefficient of useful work found by Wolff, whose conclusions Zuntz regards as erroneous. But even if Zuntz's figures are none too low, it is evident that the animal machine uses fuel with much greater economy than a steam engine where the coefficient of usefulness might not be over 10 per cent. The figures he reached show further that the total expenditure of energy by a horse weighing 1,000 pounds in walking 1 mile equaled 453 foot-tons, which would be furnished by .164 pound of digestible food. As 44.4 per cent of this, or 201 foot-tons, was due to the effort of walking over and above the needs for maintenance, the extra digestible food needed per mile of walking was .07216 pound.

Zuntz also found that when a horse increases the external mechanical labor performed, such increase costs .001155 pound digestible dry matter for each foot-ton of work. On this basis the 264 foot-tons of energy which is needed for pulling 1 mile a load with a draft of 100 pounds would be furnished by .3049 pound of food matter. The total food expenditure, therefore, for walking and a draft of 100 pounds over a smooth, level road for 1 mile, would be .377 pound digestible nutrients, and for 20 miles 7.54 pounds. If we add to this the 6.4 pounds needed for mere maintenance, we have 13.94 pounds digestible matter as the proper ration for a horse doing the work stated for a distance of 20 miles. These figures are certainly not inconsistent with the standard reached by other methods for a horse doing average work. Such a calculation is at least useful in showing the direct rela- 
tion of food expenditure to work performed, and the necessity of feeding a laboring animal somewhat proportionately to what he does. It should be borne in mind constantly that when the intensity of effort of the horse increases, even if only the same work is performed in a shorter time, the food needs for each unit of work are greater. If a driver in making the regular number of trips to the railroad station needlessly hurries his horse, or if a drayman whips his team into a fast walk and then lets it stand idle, more food must be consumed than if the slowest possible gait was allowed.

486. Source of the ration for working horses.-In treating of this matter we must, in the first place, consider the digestive apparatus or storage capacity of the horse. It is certainly not adapted to the consumption of large quantities of coarse food, as is the case with ruminants. If a horse at severe labor needs 17.7 pounds of digestible dry matter each day, he could get it from hay only by eating over 40 pounds - a most absurd requirement. It is especially necessary, therefore, with hardworking animals, that the larger part of their nutriment comes from the concentrated feeding-stuffs. Ten to 12 pounds of hay is all a draft horse should consume in one day. Working horses on the farm generally eat too much coarse fodder.

The net values of feeding-stuffs are also important in this connection. It has been shown that the net energy value of a unit of dry matter from hay is less than with that from the grains, and consequently when it is necessary to supply an animal with a large amount of energy for external mechanical uses, requiring high feeding, we must resort to the grains in order to construct a ration of maximum efficiency. 
487. Nutritive ratio for working horses.-Concerning the nutritive ratio or proportion of protein in a ration designed for working horses, there is a variety of recommendations. The German standards call for ratios from $1: 7$ to $1: 6$, according to the severity of labor, the daily weight of protein for a 1,000-pound horse to be from 1.5 to 2.5 pounds. This is greatly more protein than is recommended by Lavalard, who, on the basis of extensive experience, declares that 1.15 pounds of protein daily is sufficient for ordinary work, this to be increased to 1.35 pounds when the labor becomes more severe. There is one fundamental fact that is pertinent to a discussion of this point, which is that the non-nitrogenous constituents of the ration are largely the source of muscular energy. As stated before, it was formerly thought that muscular effort was sustained at the expense of muscular tissue, but when it was found that no more urea was excreted by men climbing a mountain than when they were much less active, this view was abandoned. Later researches have clearly shown that when work increases the excretion of carbon dioxid increases in like proportion without any important rise in the protein exchange. In other words, the carbohydrates and fats are largely the fuel that supplies energy for mechanical purposes. Common experience ratifies this conclusion of science. Many horses and oxen have successfully endured severe labor on meadow hay, oats, and corn, sometimes the grain being largely the latter.

A ration properly compounded from ordinary farm products, such as silage, roots, meadow hay, legume hays, and the cereal grains, will generally contain protein in sufficient proportion, and will seldom need reinforcing with the nitrogenous feeding-stuffs. It is probably true, 
however, that when working animals are called upon to endure a severe strain material advantage is gained from introducing into the ration a small quantity of some nitrogenous feeding-stuff, such as beans or oil meal.

488. Oats for working horses.-One of the opinions regarding the feeding of horses, which has widely prevailed and which is still held by many, is that oats in liberal proportions are essential to the successful maintenance of road and work horses, especially the former. It has been believed, as has been stated, that this grain imparts to the horse greater nervous activity or life than any other feeding-stuff, and when it was announced that "avenine," an alkaloid, had been extracted from oats, this was quickly accepted as an explanation of their peculiar effect. We have given up the avenine and seem likely to modify our views in other ways, for it is becoming increasingly evident that other grains may be substituted for oats with no detriment to the horse and with a material saving to his owner. Barley, brewers' grains, maize, maize cake, wheat, wheat bran, wheat middlings, have been extensively and safely fed in the place of oats, wholly or in part, by experiment stations and in practice by omnibus and horse-car companies. In this way the cost of maintaining horse labor is materially decreased, for usually oats are comparatively much more expensive than other grains and the by-products in proportion to their feeding value. It is often the case that a farmer can afford to sell a part of the oats he raises and buy other grains, and he can do this with confidence that he will be able to maintain his road and working horses in proper flesh, good health, and spirit on the cheaper materials. A great variety of grain mixtures may be used successfully in feeding horses. 
489. Suggested rations for working horses.-As a suggestion to feeders concerning the ways in which several feeding-stuffs may be combined so as to furnish practically the same quantity of digestible organic matter, the following rations are presented as meeting the needs of a horse weighing 1,000 pounds and doing moderate work:

$\{10$ lbs. timothy or mixed hay.

$\left\{11 \frac{1}{2}\right.$ lbs. oats.

$10 \mathrm{lbs}$. hay. $\left\{\begin{array}{c}101 / 2 \mathrm{lbs} \text {. oats and corn, equal } \\ \text { parts by weight. }\end{array}\right.$

$10 \mathrm{lbs}$. hay.

$\left\{10 \frac{1}{2} \mathrm{lbs}\right.$. oats and barley, equal parts by weight.

$\{10$ lbs. hay.

$\{8$ lbs. oats.

4 lbs. brewers' grains.

(10 lbs. hay.

$\{8$ lbs. oats.

( 4 lbs. wheat bran.
(10 lbs. hay.

$\{5$ lbs. corn.

4 $\frac{1}{2}$ lbs. barley.

$\{10$ lbs. hay.

$\{\mathrm{lbs}$. corn.

( $61 / 2$ lbs. wheat bran.

(10 lbs. hay.

$\{5 \mathrm{lbs}$. corn.

( 6 lbs. brewers' grains.

(10 lbs. hay.

$\left\{\frac{1}{2}\right.$ lbs. barley.

4 lbs. wheat bran.

( 3 lbs. brewers' grains.

(10 lbs. hay.

$3 \frac{1}{2}$ lbs. corn.

4 lbs. wheat bran.

( 4 lbs. brewers' grains.

Silage, roots, and other green materials may often be substituted for a minor part of the hay with advantage to the animal's appetite and health.

No definite rations are suggested for more severe labor. The amount of food must simply be increased with the amount of work performed. Any increase should apply to the grain and not to the hay, the proportions of the several feeding-stuffs in the grain ration to remain the same in the larger quantity. It is well understood, of course, that a ration should increase proportionately 
faster than the amount of work done, and that an old animal generally demands higher feeding than does a young one. The condition of the road, the intensity of the effort, and other circumstances also modify the needs of the working horse, so that the feeder is always called upon to exercise the trained judgment which comes from experience. No working animal can be fed successfully by mechanical rules. 


\section{CHAPTER XXIII \\ THE FEEDING OF POULTRY}

By William P. Wheeler

UNDER moderate climatic conditions some profit is possible with poultry, oftener than with large animals now, without very critical attention to the food-supply. This is because much of the food natural to birds, and often some of the best and cheapest, cannot be utilized except as selected and found by the fowls themselves. It is even necessary for the best results with certain species to provide some approximation to the feeding habits of the once wild parents. Nevertheless, artificial conditions must be met for part of the year, and continued success cannot be assured without full consideration of the essential food requirements so far as they may be known.

490. Food needs of birds intensive.-One pronounced characteristic of birds is an intense vitality. Their life is never sluggish. The growth of the young and the transformation of food into eggs are exceedingly rapid. The temperature is high, running with certain species from a little above $100^{\circ} \mathrm{F}$. to $112^{\circ}$ or more. The energy expended in this direction is proportionately great and material for its supply is in urgent demand; for a vigorous animal is the seat of rapid metabolic change. The large appetite is an indication of the extensive needs. The very active digestive apparatus must be in good order and supplied with efficient food.

The domestic fowls may be classed with the large (399) 
number of birds as omnivorous. While seed-eaters like the common fowl are able to subsist for long periods on grain alone, as can also the goose by grazing, the natural food of most young birds is largely animal. Many wild birds which feed almost entirely on seeds supply their rapidly-growing young with an abundance of animal food.

491. Kinds of foods for poultry.-It is a common experience that better success follows the use of several foods combined rather than a few and it seems to be a fact that some variety is essential. While in practice a combination must be employed for best results which are partly due to the usually greater palatability and other indirect effects on the general health, it is not because of a greater nutritive value of the constituents from different sources that the different foods are needed. The important consideration seems to be the proportion of constituents. In experiments made at the New York Agricultural Experiment Station, the better results from rations containing animal food were found to be largely due to the greater amount of mineral matter, chiefly phosphate of lime, in the animal food used. When rations of grains naturally lacking in ash-content were supplemented by bone ash, their efficiency was increased without addition of other food. For chicks, during the periods of most rapid growth, the rations of vegetable origin supplemented by material rich in phosphate of lime were equal or even superior to rations supplying large quantities of animal protein and fat. For laying hens the time during which such rations were equally efficient was limited to a few months. Rations containing animal food were much superior for ducklings, although the addition of bone ash to rations of grain and other vegetable food notably increased their efficiency. 
Although it is possible, for some purposes, to compound effective rations from grain alone when the deficiency of ash is made good, it is better in practice to use some animal food. A variety of grain food supplying enough nitrogenous matter is not always to be found, and animal foods when rich in protein, as most of them are, prove of great service; for with them can be freely fed some of the cheaper, starchy foods, typical among which is the palatable and remarkably efficient Indian corn. For fattening mature fowls, animal food is not so important except when its use improves the palatability of the ration. This last is a matter always to be considered.

Succulent vegetable foods are eagerly eaten by domestic fowls. Aside from the beneficial effect on the health of the birds, it is important to use such foods as far as possible, for the nutriment they supply is cheaply obtained. With most rations the more nitrogenous fodders, such as clover, alfalfa, and very immature grasses, are best. These foods also contain more of the needed lime than do grains. It must be remembered, however, that fowls are not fitted to depend largely on such bulky materials while production is rapid. The goose is better adapted than most birds to live by grazing, but the liberal use of the more concentrated grain and animal foods has been found necessary except during the idle season.

At the time of greatest egg production the choice of bulky foods should preferably be confined to those of the most tender and succulent nature. Certain experiments also indicate that a ration which contains any considerable proportion of dry or woody coarse fodder, although finely ground, is not suited to young chicks, and that only the more succulent kinds of bulky foods, like the 
first shoots of grasses and clovers, should be fed in the fresh condition. After the birds approach maturity and growth is slower, so that a much larger proportion of the food is used for maintenance, and during colder weather when the heat from the extra energy required for digestion is useful, more of the coarse foods can be fed without apparent disadvantage.

492. Incidental effects of the food with laying hens.Another reason, sometimes a very important one, for using such foods as young clover, fresh or dried, is the effect on the color of the egg yolk. Eggs from hens which are fed only certain grain and animal substances generally have yolks of a pale yellow color. This is often objected to by those who have a preference for eggs with darker orange-colored yolks. The liberal feeding of fresh or dried young clover, alfalfa, or grass will generally insure the deeper coloration. The cause for this frequent lack of what may be considered the normal yellow color of the egg yolk is not well known, but the occurrence of the pale color can be generally prevented by attention to the food.

At the New York Experiment Station, pens of hens which were fed alike except that no hay or green food was given to one, while three others had different amounts apportioned by geometrical ratio, of clover hay alternated with green alfalfa, produced eggs showing marked differences in color. The orange-yellow shade of the yolk corresponded directly in intensity with the proportion of hay or green fodder in the ration. The greenish color of the white also varied but not so regularly. Eggs from each lot were very uniform in appearance.

The differences in flavor and other qualities which are probably caused by the food cannot be satisfactorily 
explained at present. They are, however, slight with normal rations. In general the color of the shell is determined by the breeding or by the individual characteristics of the fowl.

493. Digestive apparatus of birds (Fig. 17).-The process of digestion with birds is essentially similar to that with mammals although there are important differences in the apparatus by which it is accomplished. It is necessary to know something of the general arrangement and working of the digestive canal when attempting to establish proper methods of feeding, and for a better selection and combination of suitable foods.

Although some extinct species of birds were well supplied with teeth, existing forms have the mouth armed only with a horny beak. The common fowls must swallow grains whole but are able to tear some food into small fragments, which they particularly do when feeding the young. Ducks, and geese more especially, have the mouth supplied with laminæ which serve to cut soft herbage.

In birds the salivary glands are small and the limited amount of saliva probably has little effect on the food.

The esophagus is of great caliber and very expansible. It is dilated in the cervical portion in ducks and geese. In gallinaceous birds, instead of this dilatation there is attached to, and forming practically a part of, the esophagus, the reservoir called the crop. The food is temporarily retained in the crop, but is changed very little other than being softened by the water swallowed with it, the small amount of mucus, and the inconsequential amount of saliva. The high temperature doubtless assists this softening effect, and fermentation also 
progresses rapidly when food is retained long in the crop from injury or by overloading with coarse material.

The divided crop of pigeons secretes, with both sexes for several days after the young are hatched, a thick milky fluid which serves to feed the young birds. With other domestic birds the crop serves for little more than a temporary retaining reservoir.

The stomach, which is a single organ in some birds, is represented by two reservoirs in domestic fowls. The first, through which the food passes after leaving the crop, is the glandular stomach, the succentric ventricle or proventriculus, and the second, closely connected, is the gizzard or muscular stomach. The first, from its structure, has been considered the true stomach, but it is now believed that gastric juice is secreted in the gizzard. The food does not accumulate in the first stomach but in passing through carries along such juices as are there secreted.

The gizzard is a powerful grinding apparatus. There is a strong lining which is capable of resisting great pressure and the action of the sharp sand and pebbles. In this organ the grains and seeds, with other materials, are more finely ground than by the mastication of many other animals.

The intestines are long in domestic fowls. While serving the same purpose as in mammals and having a general resemblance to the mammalian form, they do not clearly show the same divisions. The diameter is about the same throughout. The cæca, each of which is closed at one end and opens into the intestines at the other, seem to be important and essential modifications of that canal. Each cæcum is from 6 to 7 inches long in mature fowls. Not far from the openings of the cæca 
the intestine ends in a dilatation, the cloaca, into which the genito-urinary passages also open. It is because of the mixing here of the undigested residues of the food with the secretions from the kidneys and with some other

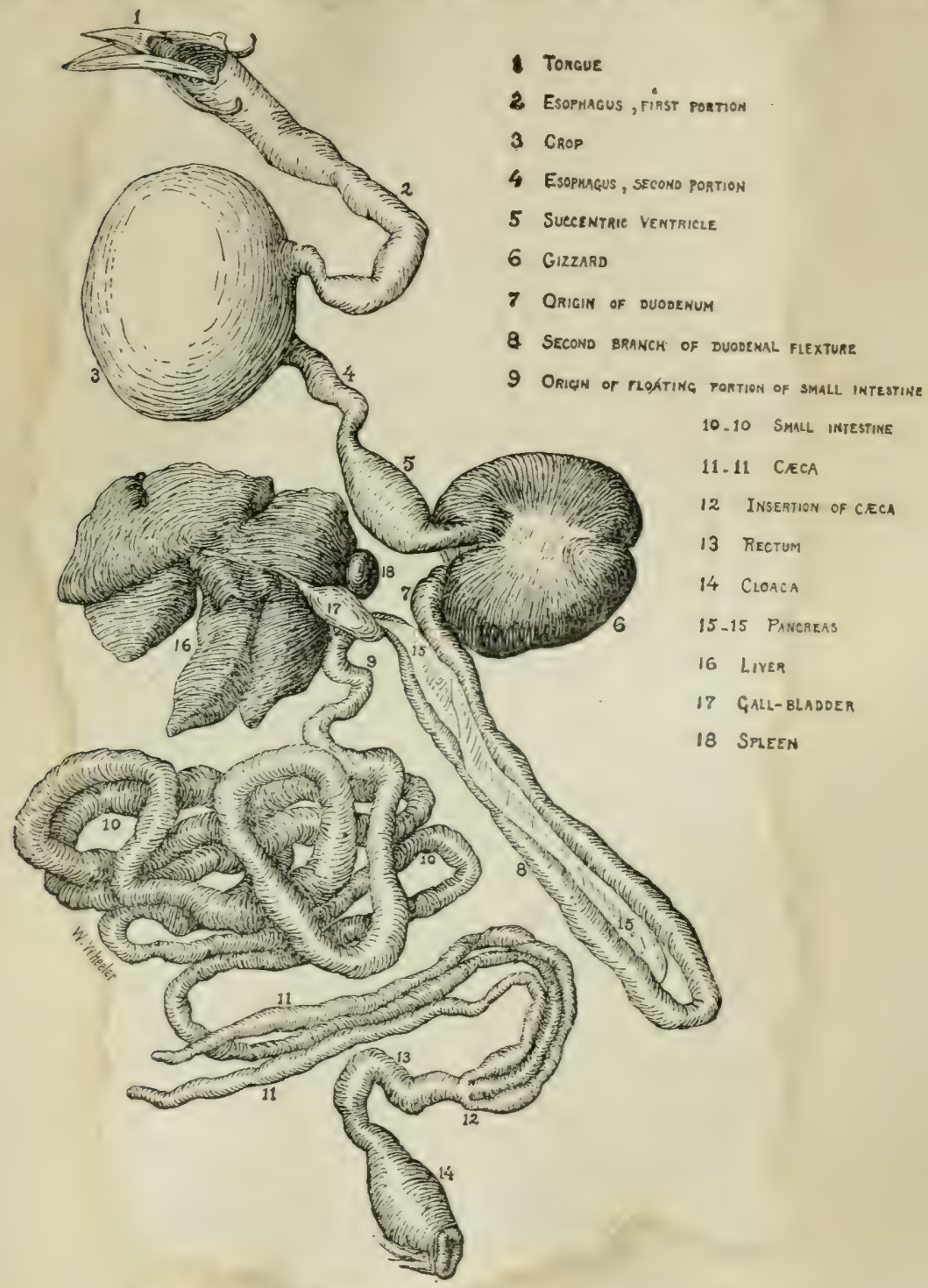

FIG. 17. Digestive apparatus of the common fowl. 
products of metabolism, that an accurate estimation of the digestibility of food by birds is so difficult. No satisfactorily accurate methods for separating some of the nitrogenous residues from different organs seem yet to be perfected.

Into the intestine shortly after it leaves the gizzard two ducts from the liver and two from the pancreas enter, discharging the bile and pancreatic juices. The liver, as usual, is a large organ. The pancreas also is very largely developed, and extends for several inches along the duodenal loop of the intestines, reaching in the common fowl a length of over 5 inches.

Altogether the structure of the digestive apparatus of birds indicates extreme efficiency and the capacity for rapid work. A study of it suggests, also, as does that of any complicated and delicately adjusted apparatus, that it should not be overloaded nor violently disturbed when running at high pressure. It may be said to run at high pressure while the extremely rapid growth of young birds occurs and during the extended laying season, for the resulting products call for an uninterrupted supply of food and the transformation of all material that is available. Chickens of two pounds weight at ten weeks of age show a gain over the weight of the first week of nearly 1,700 per cent. Ducklings five pounds in weight at nine weeks show a gain during about eight weeks of 3,900 per cent. Such rates of growth are not very unusual for young fowls under favorable conditions.

494. Constituents of the body of the hen.-Whether the production of meat or of eggs is the prime object, the young fowl must first be grown. It is desirable, then, to consider what constituents make up the body of the animal, for all must be derived from the food. Many 
slight variations in composition exist, of course, but there is always a certain approximation to the normal fullgrown animal.

In the whole body of the common fowl, unless especially fattened, not far from one-half of the dry matter is protein and about 8 per cent ash. This of itself would suggest that a slow growth must follow the use of foods containing small amounts of nitrogenous and mineral matter.

Analyses made, mostly by Jenter at the New York Experiment Station, give as the average composition of the body of a Leghorn hen, typical of the laying breeds, 55.8 per cent of water, 21.6 per cent of protein, 3.8 per cent of ash, and 17 per cent of fat. This is not the composition of the edible portion alone nor of the carcass as found in the market, but that of the whole body, bones, blood, feathers, and all the viscera. The different parts of the body were all separately analyzed. Separate analyses of four individual hens each gave a close approximation to the average. The composition of the body of a Leghorn pullet in full laying was little different from the average for the hens, being 55.4 per cent of water, 21.2 per cent of protein, 3.4 per cent of ash, and 18 per cent of fat.

The body of a mature capon (Plymouth Rock) contained 41.6 per cent of water, 19.4 per cent of protein, 3.7 per cent of ash, and 33.9 per cent of fat. If the extra amount of fat were removed, the composition would be very similar to that of the other fowls. In younger and immature birds the percentage of fat is very much less than in older birds.

495. Composition of eggs.-The egg, which aside from the shell is potentially a chick, shows in the general 
proportions of the constituents a striking resemblance to the body of the grown bird. Of the dry matter of eggs analyzed, aside from the shell, 49.8 per cent on the average was protein, 3.5 per cent ash, and 38.6 per cent fat. Of the dry matter of the bodies of hens 48.9 per cent was protein, 8.6 per cent ash, and 38.5 per cent fat.

Of the total dry matter in the entire egg, 35.6 per cent is ash, 25.9 per cent fat, and about 33.3 per cent protein, or 38.5 per cent if estimated by difference. The fresh egg with a good firm shell consists of about 11.4 per cent shell, 65.7 per cent of water, 8.9 per cent of fat, 11.4 per cent of protein by factor, or 13.2 per cent by difference, and .8 per cent of ash constituents aside from the shell. Of this ash 53.7 per cent is phosphoric acid. Over .2 per cent of the edible portion of the egg is phosphorus. This composition is the average from twenty-four analyses by Thompson, and eighteen by Wheeler, representing over 400 eggs from hens of several breeds under different rations. None of the analyses differed much from the average.

496. Necessity for considering the water-supply.In the products, which have been mentioned, as in most animal products sought by feeding, there is always a large amount of water. In every dozen eggs there is a pint of water. Aside from that necessary for constructive use there is required for the activities of the living animal a free supply. Particular mention is made of the necessity for water, because its great importance is sometimes overlooked, for an especially provided supply is not necessary under some circumstances. Instances occur when the lack of water is the cause of ill success.

497. Efficiency of protein from animal sources for fowl.-Mention of the characteristics and composition 
of the different nutrients of the food and a discussion of their functions will be found elsewhere in this volume. The facts apply to the feeding of poultry as well as to that of other animals.

It appears from present knowledge that protein derived from animal sources is more efficient for certain uses, particularly the feeding of ducklings, than that derived from vegetable foods. Previous mention has been made of experiments at the New York Experiment Station, the results of which accord with this assumption. The rations which contained animal food proved much more efficient than those of vegetable origin, the latter having, according to the ordinary methods of estimation, the same nutritive value as the former.

498. Ash constituents important for egg production.It seems probable that the ash constituents have sometimes not been sufficiently considered in feeding. While the importance of the mineral nutrients can be largely overlooked without serious practical disadvantage when feeding some animals for certain purposes, it must be given consideration when feeding domestic fowls. While in milk, for instance, about 5 per cent of the dry matter is ash, in eggs over 35 per cent of the dry matter is represented by the mineral constituents.

The shell of the egg, which represents about 11 per cent of the fresh egg, consists almost entirely of carbonate of lime. Most grain foods, which naturally constitute the bulk of ordinary rations, contain little mineral matter and the amuunt of lime is notably low. For simply supplying the deficiency of material for the egg shell, carbonate of lime in the form of oyster shell can be used. This was shown in experiments at the New York Experiment Station made with laying hens after they were 
closely confined on a clean floor for over three weeks. It was then found that about nine-tenths of the lime in the egg shell was unaccounted for in the food aside from the oyster shells which were fed.

While less than 10 per cent of the body of a fowl is mineral matter, it consists largely of phosphate of lime and exceeds in proportion that of many foods. The bony framework is also rapidly formed in the growing bird so that mineral matter is in imperative demand. The results of many trials made at the New York Experiment Station are clearly in accord with this assumed need. As has been previously mentioned, the addition of phosphate of lime from several sources to rations for young fowls has noticeably increased their efficiency.

499. Common salt a necessity for fowls.-Common salt in considerable quantity is a necessity to the living animal. Some foods contain a probably sufficient amount but in others the proportion is very small. In order to make sure of an excess, and to avoid any possible deficiency, it is well to add salt regularly to the food, especially when it also increases the palatability of the ration. About five ounces in every 100 pounds of food has been found a safe proportion. Fowls regularly accustomed to salt are not likely to eat an injurious quantity of very salty material when it is accidentally within their reach. Pigeons are very fond of salt and a liberal allowance is generally considered necessary to insure health in the loft.

500. Supply of grit for fowls.-Fowls at liberty are generally able to find grit enough in the form of sharp pebbles and sand to facilitate the grinding which occurs in the gizzard. When they are confined or do not have extended range, sharp and hard grit of some kind should 
always be freely supplied. Clean, sharp sand is useful for the very young birds and is quite generally considered an essential part of all mixtures fed to ducklings. Good results accompany its free use.

501. Feeding standards for fowls.-In studying and comparing different rations, it is not possible to consider all the combinations that can be made of the many foods. It is only practicable to consider foods with reference to their varying proportions of constituents. The only portion of these constituents of nutritive value is that which can be digested. Therefore, in compounding rations, we are guided primarily by the amount of the digestible nutrients supplied by the food; and feeding standards are for convenience limited to a statement of the assumed requirements in terms of digestible protein, ash, carbohydrates, and fat. The bulk of the ration supplying these nutrients must also, of course, fall within certain limits. In the absence of enough specific data, calculations must be based on the coefficients of digestibility observed for other animals. These afford safe enough approximations for present use, for the feeding standards must be largely provisional.

Growth and egg production can only be sustained by the food in excess of that required to support life, although egg production can temporarily occur at the partial expense of the body. The amount of food, then, required for simple maintenance puts a limit on one side to an efficient and profitable ration. In the other direction, it is only limited by the capabilities of the individual animal. So the highest possibilities depend altogether on the intelligent judgment, and careful, daily attention of the experienced feeder. In a general way only averages can be considered. 
502. Maintenance rations for fowls. - A number of feedings trials made at the New York Experiment Station supply information relative to the amount of food required for simple maintenance. The amount varies, as might be expected, with the size of the animal. The larger fowls required more food but much less for each pound of live weight. These feeding trials did not cover any molting-period and egg production was, for the time, suspended. From the data secured maintenance rations have been deduced which correspond very closely to those actually fed for quite extended periods during which practically no change in live weight occurred. The data were from an aggregate of 52 capons, averaging by different lots from 9 to 12 pounds in weight, for 158 days' feeding, and from 60 hens ranging from 3 to 7 pounds in weight for 150 days' feeding.

The rations are stated in the following tabulated form:

Table LXXXV. Maintenance Rations. Digestible Nutrients a: Day for Each 100 Pounds Live Weight

\begin{tabular}{|c|c|c|c|c|c|c|c|}
\hline & $\begin{array}{c}\text { Total dry } \\
\text { matter }\end{array}$ & Ash & Protein & $\begin{array}{c}\text { Carbohy- } \\
\text { drates }\end{array}$ & Fat & $\begin{array}{l}\text { Fuel } \\
\text { value }\end{array}$ & $\begin{array}{l}\text { Nutritive } \\
\text { ratio }\end{array}$ \\
\hline $\begin{array}{l}\text { Capons of } 9 \text { to } 12 \text { lbs.wt } \\
\text { Hens of } 5 \text { to } 7 \text { lbs. wt. } \\
\text { Hens of } 3 \text { to } 5 \text { lbs. wt. }\end{array}$ & $\begin{array}{l}\text { Lbs. } \\
2.3 \\
2.7 \\
3.9\end{array}$ & $\begin{array}{l}\text { Lbs. } \\
.06 \\
.1 \\
.15\end{array}$ & $\begin{array}{c}\text { Lbs. } \\
.3 \\
.4 \\
.5\end{array}$ & $\begin{array}{l}\text { Lbs. } \\
1.74 \\
2 . \\
2.95\end{array}$ & $\begin{array}{l}\text { Lbs. } \\
.2 \\
.2 \\
.3\end{array}$ & $\begin{array}{l}\text { Cal. } \\
4,600 \\
5,300 \\
7,680\end{array}$ & $\begin{array}{l}1: 7.5 \\
1: 6.2 \\
1: 7.4\end{array}$ \\
\hline
\end{tabular}

503. Rations for laying hens.-Hens in full laying seem to require rations which have a larger relative content of protein and ash, and which show an increase in fuel value of from 15 to 40 per cent, according to size, over those required for maintenance. The following standards approximate the requirements for two general groups not sharply separated. 
Table lXXXVi. Rations for Hens in Full Laying. Digestible Nutrients a Day for Each 100 Pounds Live WEIGHT.

\begin{tabular}{l|c|c|c|c|c|c|c}
\hline \hline & $\begin{array}{c}\text { Total dry } \\
\text { matter }\end{array}$ & Ash & Protein & $\begin{array}{c}\text { Carbohy- } \\
\text { drates }\end{array}$ & Fat & $\begin{array}{c}\text { Fuel } \\
\text { value }\end{array}$ & $\begin{array}{c}\text { Nutritive } \\
\text { ratio }\end{array}$ \\
\cline { 2 - 3 } & Lbs. & Lbs. & Lbs. & Lbs. & Lbs. & Cal. & \\
\hline Hens of 5 to 8 lbs. wt. & 3.3 & .2 & .65 & 2.25 & .2 & 6,240 & $1: 4.2$ \\
Hens of 3 to 5 lbs. wt. & 5.5 & .3 & 1. & 3.75 & .35 & 10,300 & $1: 4.6$ \\
\hline
\end{tabular}

These standards are not absolute and inflexible rules, for such would not be justified by a thousand times the number of available data. They supply a definite starting point and are not supposed to obviate the use of judgment. Because it is found convenient, on account of different requirements and capabilities, to divide hens into two groups, it should not be presumed that a hen just under five pounds in weight must always have one ration or a hen just over five pounds must always have the other.

A ration which corresponds to the standard given for maintenance for hens of the larger size could be composed of one pound of cracked corn, one pound of corn meal, one-half pound each of ground oats, wheat middlings, and clover hay, one-fourth pound of fresh bone and two ounces of meat scraps.

The following stated ration is given as an illustration of one which would supply the nutrients called for in the standard for laying hens of the larger size: One pound of cracked corn, three-fourths pound of wheat, threefourths pound of corn meal, one-half pound each of wheat middlings, buckwheat middlings, and animal meal, twothirds pound of fresh bone, and three-fourths pound of young green alfalfa.

504. Rations for young birds.-The requirements of the rapidly-growing young fowl are so constantly chang- 
ing that a satisfactory average ration for any extended period cannot be easily formulated. In the following statement of rations for chicks, they are averaged for periods of two weeks at different ages during the time of most rapid growth. The ration for the last period will suffice for several weeks longer, although the amount required to the 100 pounds live weight will gradually diminish up to maturity. For fattening nearly mature fowls, a ration with a wider nutritive ratio of about $1: 8$ can be liberally fed for limited periods.

The duck grows faster than the common fowl and more food is required during an equal time. Rations for ducklings differing somewhat from those for chicks are given separately.

Table LXXXVII. Rations for Chicks. Digestible Nutrients a Day for Each 100 Pounds Live Weight

\begin{tabular}{l|c|c|c|c|c|c|c}
\hline \hline & $\begin{array}{c}\text { Total } \\
\text { dry } \\
\text { matter }\end{array}$ & Ash & Protein & $\begin{array}{c}\text { Carbohy- } \\
\text { drates }\end{array}$ & Fat & $\begin{array}{c}\text { Fuel } \\
\text { value }\end{array}$ & $\begin{array}{c}\text { Nutri- } \\
\text { tive } \\
\text { ratio }\end{array}$ \\
\hline For the first 2 weeks . & Lbs. & Lbs. & Lbs. & Lbs. & Lbs. & Cal. & \\
From 2 to 4 weeks of age & 9.6 & .5 & 2. & 7.2 & .4 & 18,800 & $1: 4.1$ \\
From 4 to 6 weeks of age & 8.6 & .6 & 2.2 & 6.2 & .5 & 17,730 & $1: 3.4$ \\
From 6 to 8 weeks of age & 7.4 & .5 & 1.6 & 4.6 & .4 & 15,640 & $1: 3.3$ \\
From 8 to 10 weeks of age & 6.4 & .5 & 1.2 & 4.4 & .3 & 11,680 & $1: 3.7$ \\
From 10 to 12 weeks of age & 5.4 & .4 & 1. & 3.7 & .3 & 10,000 & $1: 4.4$ \\
\hline
\end{tabular}

Rations for Ducklings. Digestible Nutrients a Day for Each 100 Pounds Live Weight

\begin{tabular}{l|c|c|c|c|c|c|c}
\hline \hline & $\begin{array}{c}\text { Total } \\
\text { dry } \\
\text { matter }\end{array}$ & Ash & Protein & $\begin{array}{c}\text { Carbohy- } \\
\text { drates }\end{array}$ & Fat & $\begin{array}{c}\text { Fuel } \\
\text { value }\end{array}$ & $\begin{array}{c}\text { Nutri- } \\
\text { tive } \\
\text { ratio }\end{array}$ \\
\hline For the first 2 weeks & Lbs. & Lbs. & Lbs. & Lbs. & Lbs. & Cal. & \\
From 2 to 4 weeks of age & 17.2 & 1.6 & 4. & 11.2 & 1.4 & 34,180 & $1: 3.7$ \\
From 4 to 6 weeks of age & 11.2 & 1.5 & 4.1 & 10.1 & 1.3 & 31,900 & $1: 3.2$ \\
From 6 to 8 weeks of age & 8. & .6 & 2.7 & 7.7 & .7 & 21,000 & $1: 3.3$ \\
From 8 to 10 weeks of age & 7. & .5 & 1.4 & 4.7 & .5 & 14,940 & $1: 3.8$ \\
From 10 to 15 weeks of age & 4.6 & .3 & .9 & 3.2 & .2 & 8,470 & $1: 4.1$ \\
\hline
\end{tabular}


As an example of a day's ration which would correspond to the requirements of the standard given for young chicks during the second week the following is stated: Four pounds of cracked wheat, two pounds of granulated oatmeal, three pounds of corn meal, one-half pound each of wheat middlings, buckwheat middlings, ground oats, and old process linseed meal, two and onefourth pounds of animal meal, and two and three-fourths pounds of young green alfalfa. This would feed from 800 to 1,000 chicks of this age.

Another ration in accord with the standard given for ducklings about three weeks old might be constituted as follows: Eight pounds corn meal, three pounds wheat middlings, two pounds ground barley, two pounds of old process linseed meal, six pounds of animal meal, two pounds of fresh bone, and three pounds of young green alfalfa. This and other specimen rations are given under the assumption that free supplies of sharp grit, as well as water, are also provided.

505. Adaptability of various foods for fowls.-A consideration of the adaptability of the different foods, aside from their composition, and of the apparent requirements of the young at different periods suggests a ration somewhat wider in nutritive ratio for the first few days than for some weeks afterward.

In providing a ration, it may be possible to devise one in accord with the formal standard which will be decidedly inefficient at times if the chemical composition and coefficients of digestibility are alone considered. The adaptability of foods that are palatable must be considered. The difference in the energy required to digest various foods which can supply equal proportions of digestible matter may be important sometimes. 
A large number of the ordinary grains seem practically interchangeable and many grain by-products can be freely substituted for different whole grains or for each other and all combined as desired. But some foods, such as cottonseed meal, do not seem suited to common fowls, even in very small quantities. Linseed meal can be fed more freely, but the unground flaxseed is less satisfactory. It is probable that oats, whole or ground, which appear so valuable sometimes, should not be freely used at other times. About 30 per cent of the entire grain is hull. To obtain the available material from this requires an expenditure of energy that can be better applied during periods of rapid transformation, especially during the first few weeks of the young bird's growth. The products of the oat kernel, however, from which the hull has been separated are in the unquestioned class of foods. The same observation applies to buckwheat, some kinds of pea meal, and to certain other foods less commonly used, containing a large proportion of crude fiber. Reference to this point has been made before under the topic of coarse and bulky foods.

Primary consideration has naturally been given to those domestic fowls upon which we depend for the great bulk of eggs and meat. Other kinds are of considerable importance in certain localities, or often to the fancier, but concerning them not enough is recorded to establish separate feeding standards. It is probable that their requirements will be found to correspond fairly well with those of either the duck or of the common fowl. The general food of the turkey is similar to that of the common fowl but it should be less artificial, and conditions of general feeding, more nearly resembling those which exist in a wild state, are required. 
506. Knowledge of the nutrition of fowls limited.Unsatisfactory as is our present knowledge of the fundamental laws which underlie the science of nutrition applied to man and other animals, there are nevertheless volumes of carefully collected data that make it possible to ascribe fairly narrow limits to their operations. Compared with mammals, however, the class of birds has received very little consideration. There have been a few careful studies made, but for lack of enough information our feeding must be guided by the rules applying in common to all animals. Undoubtedly, the accepted laws of nutrition observed for other animals are applicable in a general way to domestic fowls, and it is safe to apply in the light of the specific data we have any general principles of feeding that have already been established. This has been done in formulating the feeding standards which are here presented, and all available data of a reliable character have been considered. There have not been enough, however, to justify narrow limitations, and the suggested standards should not be considered final and unchangeable. They simply represent the averages of rations which, under careful management and like conditions, have given better results than various other rations with which they have been contrasted. Slight modifications were made in accord somewhat with the habits of the different fowls and with a consideration of the character of the products desired. It is important that the feeder, while following such standards in a general way, should give enough consideration to the subject to make modifications suited to the species and breed and to his particular conditions of market and farm. 


\section{CHAPTER XXIV}

\section{THE RELATION OF FOOD TO PRODUCTION}

ONE of the questions much discussed by farmers, and which has an important bearing upon the economics of animal husbandry, is the food cost of the various animal products. To illustrate, a herd of cows consumes a certain quantity of food and produces a certain weight of milk, milk solids, cheese, or butter, according to the terms in which we state the production. If the same food is fed to a lot of steers a certain increase in their live weight is secured. There is in each case a relation of quantity between the food and the product. The food cost, that is, the food consumption, involved in growing a pound of beef, is quite unlike the food requirements for producing a pound of pork, a pound of veal, or a pound of eggs. If we consider merely food expenditure, that branch of animal husbandry is most economical of raw materials in which the largest proportion of the food dry substance is converted into some new, useful product, or, differently stated, where the food units bear the lowest ratio to a unit of product.

507. Food unit defined.-In presenting the matter it is necessary to first define our units. Certainly it cannot be a pound of food as eaten. One farmer feeds his cows silage or roots, and grain, with but little hay, while another fattens steers on dry food alone. A comparison of production in the two instances on the basis of the gross weight of food consumed would be absurd, because with the cows the 
dry matter is largely diluted with water. It would be equally absurd to accept the dry matter in the ration as a standard. In instituting a comparison between bovines and swine, we must remember that the former consume materials much less digestible than do the latter, and so a unit weight of food does not represent the same weight of available nutrients with the two classes of animals.

We should, so far as possible, reduce rations to their units of nutritive value, and so the digestible dry matter is now the nearest approach we can make to a basis for comparing rations with each other or with the production which they sustain. It follows, then, that if we wish to show the comparative economy of production in dairy farming and in beef farming, food alone considered, we should express this relation on one side in terms of digestible dry food substance.*

508. The unit of production.-What shall we consider as a unit of production? We may answer this question from two standpoints. We may measure production by the quantity of the commercial article which the farmer places on the market, or by the actual contribution which any given production makes to the food resources of the human family. More specifically stated, we may determine the relation of a unit of digestible food substance to the live animal, beef, pork, milk, cheese, butter, or eggs resulting from its use, and calculate the ratio of any one of these to the actual nutrients consumed, or we may ascertain the ratio of food consumption to the edible dry substance in the various animal

* Since the above was written, we are able to reduce the food unit for production to what is termed production value. This is more fundamental than the digestible matter as a basis for comparison. The comparisons hereafter made are, however, with the digestible matter consumed as related to the unit of production. 
products. The latter is the important ratio to consider if we are seeking to learn how we can most efficiently apply farm crops to the sustenance of the human family.

509. Factors involved in food economics. - This study of food economics requires a knowledge of several factors. In the first place, we must have the information coming from feeding experiments, where a careful record has been kept of the kind and amount of food consumed and the weight of the resulting growth, milk, eggs, or what not. This information must be supplemented by a knowledge of the digestibility of feeding-stuffs, of the ratio between the live animal or other gross product and the commercial products, and of the composition and proportion of edible material supplied by the commercial article. For instance, we find it takes, on the average, 7.4 pounds of digestible organic substance in the ration to produce 1 pound of growth in a steer, and we have learned by slaughter tests that the average per cent of carcass for 97 animals was 61.4 , and by the butchers' and chemists' analyses, that the carcass contains an average of 33.2 per cent of edible dry matter. From these data it is easy to calculate that 12 pounds of digestible food are needed for the growth of 1 pound of carcass or 36.3 pounds for the growth of 1 pound of edible beef solids.

510. Relation of food to production with various species.- The following tables give the data upon which is based the productive power of food when utilized by the various classes of animals. Data of this kind are practically our only means of studying the economics of producing those human foods which are most costly in proportion to their nutritive value, a study which is very important wherever it becomes necessary to economize energy. It shows the coefficients of efficiency of 
various species of animals in maintaining human life. The sources of all these figures are not given, for they are so numerous as to make this difficult.

It is true, in general, that prices are proportional to the cost of production. If, therefore, natural resources are to be utilized for human sustenance in the most efficient way and the cost of living brought to the lowest possible point, the raw materials of the farm should be applied to the production of those animal foods that are most cheaply grown.

The time will probably come when the relation of population to land areas will be such as to make necessary an application of food economics along this line.

Table LXXXVIII. Production by Farm Antmals. Proportions of Carcass and Edible Substance

\begin{tabular}{|c|c|c|c|c|}
\hline & $\begin{array}{l}\text { Number } \\
\text { of } \\
\text { animals }\end{array}$ & $\begin{array}{c}\text { Carcass } \\
\text { in per cent } \\
\text { of live } \\
\text { weight } \\
\end{array}$ & $\begin{array}{c}\text { Per cent* } \\
\text { of edible } \\
\text { dry matter } \\
\text { in carcass } \\
\end{array}$ & \begin{tabular}{|l|} 
Per cent of \\
edible dry \\
matter in \\
live animal
\end{tabular} \\
\hline Steers, general average & 97 & 61.4 & 33.2 & 20.4 \\
\hline Steers, Iowa & 5 & 64. & 33.2 & 21.2 \\
\hline Steers, Kansas & 5 & 61.4 & 33.2 & 20.4 \\
\hline Steers, Maine† & 8 & 57.7 & 32.3 & 18.6 \\
\hline Sheep. . . . & 4 & 50.7 & 37.4 & 19. \\
\hline Lambs & 44 & 50.7 & 33.7 & 17.1 \\
\hline Lambs, Iowa & 133 & 54. & 33.7 & 18.2 \\
\hline Swine, general average & 97 & 81.2 & 62.7 & 50.9 \\
\hline Pigs, Iowa & 56 & 77.9 & 62.7 & 48.8 \\
\hline Calves & 23 & 57.2 & 22.2 & 12.7 \\
\hline Fowl, large & 12 & 80.8 & 27. & 21.8 \\
\hline Fowl, small & 7 & & 27. & 21.1 \\
\hline Chickens, broilers & 107 & $82.1 \ddagger$ & 14.7 & 12.1 \\
\hline Eggs & $34 \S$ & $88.8 \|$ & 26.3 & $23.3^{* *}$ \\
\hline
\end{tabular}

* From Bull. No. 28, Office of Experiment Stations. Revised edition.

+ Grown from calfhood, entire bodies analyzed.

\pm Not drawn.

$\S$ Number of samples.

Per cent after removing shells.

**In eggs with shells. 
Table LXXXiX. Relation of Food to Proddct

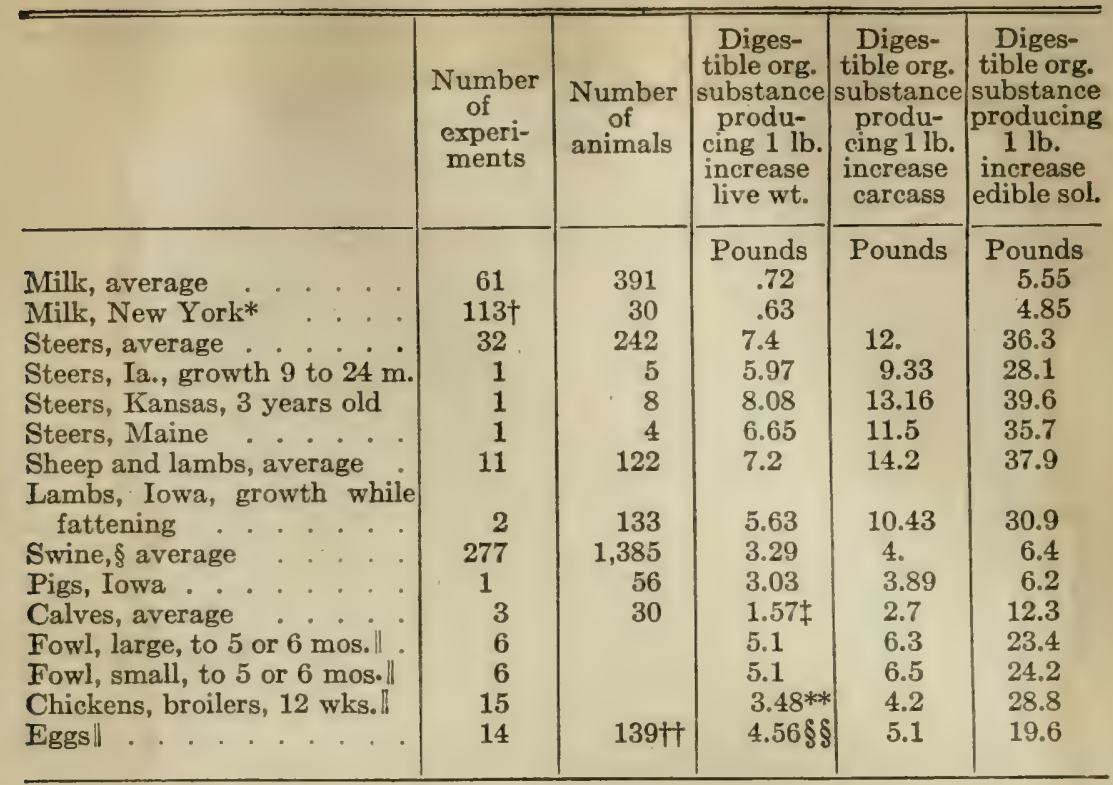

*Extending over seven years.

tShort periods.

§Deduced from compilation by Dr. Armsby for U. S. Dept. of Agriculture.

†Dry matter, mostly from milk, practically all digestible.

Unpublished data from experiments at the New York Agric. Exp. Station.

**4.35 lbs. dry matter, assumed to be 80 per cent digestible.

+Egg product, 100 eggs per year.

$\S 85.7$ lbs. dry matter, assumed to be 80 per cent digestible.

The figures of the foregoing tables can be regarded as being trustworthy for average conditions. They are obtained from the recorded data of experiment stations, and involve a large number of observations with dairy cows and with growing and fattening animals.

In most cases the amount of digestible matter in the ration is calculated from the average coefficients of digestibility.

The facts brought out by this study of the relation of food to product are emphatic and suggestive. In order to display them as clearly as possible there are shown in the next table the quantities of the various 
commercial animal products, and of human food in animal forms, which can be produced by the use of a quantity of cattle food containing 100 pounds of digestible organic matter:

Table XC. Relation of Food to Product

\begin{tabular}{|c|c|c|c|c|c|c|c|}
\hline & & & & & & $\begin{array}{l}\text { Produced by } \\
\text { digestible } \\
\text { matter in }\end{array}$ & $\begin{array}{l}\text { y } 100 \mathrm{lbs} . \\
\text { organic } \\
\text { ration }\end{array}$ \\
\hline & & & & & & $\begin{array}{c}\text { Marketable } \\
\text { product }\end{array}$ & $\begin{array}{l}\text { Edible } \\
\text { solids }\end{array}$ \\
\hline & & & & & & Pounds & Pounds \\
\hline $\begin{array}{l}\text { Milk, general average } \cdot{ }^{\cdot} \cdot{ }^{\prime} \\
\text { Milk. New York experiments }\end{array}$ & $\cdot$ & $\cdot \cdot$ & . & & - & 139. & 18. \\
\hline $\begin{array}{l}\text { Muk, New York experiments } \\
\text { Cheese, green . . . . . . . }\end{array}$ & . & $\cdot \cdot$ & & 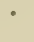 & - & 158.6 & 20.6 \\
\hline Butter . . . . . . . . & & $\cdot \cdot$ & & • & - & $\begin{array}{r}14.8 \\
6.4\end{array}$ & $\begin{array}{l}9.4 \\
5.44\end{array}$ \\
\hline Steers, general average, live wei & igh & it. & & & . & 13.5 & $0.4 \pm$ \\
\hline Steers, Iowa, live weight . . & . & . . & ${ }^{\circ}$ & . & . & 16.8 & \\
\hline Steers, Kansas, live weight . & . & . & & & . & 12.4 & \\
\hline Steers, Maine, live weight . . & . & .. & 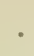 & - & . & 15. & \\
\hline Steers, general average, carcass & & .. & e & 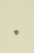 & - & 8.3 & 2.75 \\
\hline Steers, Iowa, carcass . . . . & & . . & & . & . & 10.7 & 3.56 \\
\hline Steers, Kansas, carcass . . . & & & & . & . & 7.6 & 2.52 \\
\hline Steers, Maine, carcass . . . & & & • & . & & 8.7 & 2.84 \\
\hline Sheep and lambs, general avera & ge, & live & & ei & ght & 13.9 & \\
\hline Lambs, Iowa, live weight . . & & & & . & . & 17.8 & \\
\hline Sheep and lambs, general avera & & car & & & & 7. & 2.60 \\
\hline Lambs, Iowa, carcass & & . & & . & . & 9.6 & 3.23 \\
\hline Swine, general average, live wei & igh & $\mathrm{t}$ & & 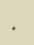 & & 30.4 & \\
\hline Swine, Iowa, live weight . . & & . . & & . & . & 33. & \\
\hline Swine, general average, carcass & & . & & . & . & 25. & 15.6 \\
\hline Pigs, Iowa, carcass . . . . . & . & . & & . & . & 25.7 & 16.1 \\
\hline Calves, live weight . . . . & & & & . & 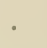 & 63.7 & \\
\hline Calves, carcass . . . . & . & 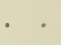 & & . & . & 36.5 & 8.1 \\
\hline Fowl, large, live weight . . & . & & & . & & 19.6 & \\
\hline Fowl, small, live weight & . & & & - & & 19.6 & \\
\hline Fowl, dressed carcass, average & . & & & . & & 15.6 & 4.2 \\
\hline Broilers, live weight . . . . & & . & & & & 28.7 & \\
\hline Broilers, dressed carcass . . & & 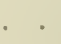 & & - & 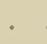 & 23.8 & 3.5 \\
\hline Eggs . . . . . . . . . & & & & . & & 19.6 & 5.1 \\
\hline
\end{tabular}


It may properly be said of the foregoing figures that they are only averages and that the relation of food to production varies with different animals of the same class and with the conditions involved. While this is true, the relations shown in the preceding calculations represent differences too wide to be explained on any other ground than that the various animal products have greatly unlike food cost.

The most noticeable fact brought out by this comparison is the low relative food cost of milk and other dairy products. The growth of a pound of edible beef solids requires a food expenditure nearly seren times as great as is necessary for the elaboration of a pound of milk solids. On the other hand, swine are fed with nearly as great economy as are milch cows. In fact, when proper allowance is made for the period of growth of the cow and for the annual periods when she is giving no milk, she seems to have no advantage over the pig except in kind of product. Next, in the order of economical use of food, comes the calf when fed largely on milk. Poultry products stand next in line. Sheep and lambs do not differ materially from steers, meat products of these two classes requiring the largest proportional food consumption of any form of growth here considered. The order of food efficiency as related to the several animal products is therefore as follows: milk, pork, veal, poultry and eggs, mutton, and beef.

It is suggestive, at least, to notice that the food factor is inversely as the labor factor in these various lines of production. For instance, labor is a large factor of the cost of a pound of any dairy product and a small factor in the cost of beef or mutton, while the reverse is emphatically true of the food cost. 


\section{CHAPTER XXV}

\section{GENERAL MANAGEMENT}

There are many considerations pertaining to the feeding and management of live-stock that have a more or less common application to all classes of animals and which may be discussed conveniently under one head. They are partly of a business character and to quite an extent lie outside the chemical and physiological principles of nutrition. Some of those questions are matters of much importance, but many of them which relate, for instance, to times and methods of feeding are given a prominence in current discussions out of proportion to their real influence in determining success. It should be understood, too, that many of the details of practice are not limitable by fixed rules but must be variable according to the conditions involved. Tact and judgment are demanded of the farmer who wisely adjusts his practice to business principles.

511. Factors in general management of animals.General management properly includes, among other considerations, the following topics:

(1) The selection of animals; (2) manipulation of the ration and manner of feeding; (3) the intensity of feeding; (4) environment and treatment of the animal.

The object to be sought in feeding animals is the conversion of a unit of food into the largest possible quantity of the product best adapted to the producer's commercial opportunities, and here the limitations of the 
animal are often the limitation of the farmer's profits. Within each species varietal and individual differences determine the rate of production and also whether the food shall be transformed into poor milk or rich milk, inferior beef and mutton or superior meat products, fine wool or coarse, trotters or draft horses, and small eggs or large ones.

The selection of animals should have reference to three general factors, which largely fix the rate and character of production, viz., breed, individuality, and age.

512. The selection of cows.-The breed and individuality of the cow largely determine the quality of her product and the quantity of production from a unit of food. Neither heavy feeding nor skill in compounding rations can be made the means of causing her to overstep her constitutional limitations.

The selection of cows simply with reference to breed is a question of adaptability. If the production of milk at the minimum food cost for a unit of volume is the result most desired, the dairy breeds, characterized by milk with a low proportion of solids should be chosen; but if the object is merely to secure butter-fat with the lowest possible food expenditure, the so-called butter breeds are in general to be preferred.

When the chief consideration is the manufacture of milk solids most economically, we must deal not so much with breeds as with individuals. In fact, with all breeds and with animals of no breed, individual capacity is the consideration fundamental to profitable feeding. Some Holsteins will return both more milk and more butter for a unit of food cost than will some Jerseys, and the reverse is equally true. There is no magic in heredity 
which overcomes lack of capacity either for the breeder or for the dairyman.

513. The general-purpose cow.-The "general-purpose" cow has been much discussed in recent years. While her specifications have never been fully and clearly set forth, it is supposed that she is an animal reasonably profitable along both beef and milk lines. It is doubtful whether such a cow, even if she exists, is one adapted to general utility. There are few localities where milk is not more profitable than beef or beef more profitable than milk, and whichever is the more profitable should be produced by an animal of specialized capacity. Any extra value which the calf's or the cow's carcass may have when flesh-forming tendencies are prominent, will generally come far short of compensating for a merely mediocre milk yield in those localities where there is a market for milk and its products; and the stockman who is endeavoring to put on the market beef animals of the highest quality cannot afford to compromise with dairy qualities. Milk formation and flesh formation are antagonistic, and not correlated, functions, both of which do not operate intensely in the same individual. At present we have no breed or fixed type of animals that can be regarded as presenting and perpetuating "general-purpose" qualities. Such a type, if found at all, must be sought among individuals.

514. The selection of animals for meat production.It is generally conceded that the selection of breeds of the beef and mutton types is essential to the highest success in the production of meat. This is true with steers, not because those from the dairy breeds will make very much slower growth than Shorthorns or Herefords, for this does not seem to be the fact, but because the quality 
of the product is higher with the latter, that is, the proportion of valuable parts is greater and the distribution of fat and lean tissue is more desirable, in the distinctly beef animal.

A choice from the beef and mutton types and from the various breeds of swine may safely be left to personal preference. Many experiments have been conducted with a view of determining the relative capacity of growth of the prominent breeds of bovines, sheep, and swine, and the testimony so far adduced is of a negative character and does not point to any one breed of any species as clearly superior to all others. It is well understood, however, that within every breed individual variations are important and that from a "bunch" of steers it is possible to select some animals superior to the others in their capacity to make profitable use of food.

515. Relation of age to meat production.-A most important factor in this connection is the relation of age to the profits of meat production. Nothing has been more fully established by experimental evidence than that the younger the animals the larger the ratio of increase to body weight and the greater the increase for each unit of food consumed.

Some of the more striking evidence on these points is presented in the following figures:

\section{TABLE XCI}

Results with steers from five breeds slaughtered at the Smithfield (England) Fat-Stock Show (from Henry's compilation)

\section{Age}

One year old

Two years old

Three years old
Number animals

77

89

54
Daily gain

2. lbs.

1.76 "

1.58 “ 


\section{TABLE XCI, CONTINUED}

Steers at American Fat-Stock Show (Stewart's compilation)

$\begin{array}{rcc}\text { Age } & \text { Number animals } & \text { Daily gain } \\ 297 \text { days } & 30 & 2.6 \mathrm{lbs} . \\ 612 \text { " } & 152 & 2.2 \text { " } \\ 943 \text { " } & 145 & 1.7 \text { " } \\ 1,283 \text { " } & 133 & 1.5 \text { " }\end{array}$

American experiments with pigs (Henry's compilation)

Weight of pigs

$38 \mathrm{lbs}$.

78

128 “

174 “

227 “

271 “

320 "
Number feeding trials

41

100

119

107

72

46

19
Food for $100 \mathrm{lbs}$. gain

293 lbs.

400 “

437 "

482 “

498 “

511 “

535 “

Results of Danish experiments with pigs.

Weight of pigs

35 to $75 \mathrm{lbs}$.

75 to 115

115 to 135

155 to 195

195 to 235

235 to 275

275 to 315
Number experiments

3

10

13

15

14

11

3
Food for 100 lbs. gain

$376 \mathrm{lbs}$.

435 “

466 "

513 “

540 "

614 "

639 “

Testimony of this character is abundant, and the lesson for practice is that animals should be fed for market at the earliest age that is consistent with other conditions.

516. Manipulation of the ration.-A great deal of experiment and discussion has been devoted to the economy of various methods of treating cattle foods, such as cutting, grinding, wetting, and cooking. The economy of these operations requires no extended comment. It is a simple and safe rule that any fodder or grain, that in its natural condition is palatable, is wholly eaten, and is thoroughly masticated, should be fed with- 
out the unnecessary expense which these manipulations would cause. Grinding any material that is not otherwise thoroughly masticated doubtless increases the efficiency of the food, but when the grinding costs as much as 10 per cent of the market price of the grain it is doubtful if any advantage accrues. Cutting, unless for the purpose of mixing, has the sole advantage of saving the animal a little work.

Wetting and cooking render certain foods more tender and more palatable, and when this secures the consumption of materials otherwise wasted these operations may become economical. On the contrary, similar treatment of grain foods already much liked by the animal is, according to the majority of testimony, an occasion of loss rather than of gain.

Practice differs as to the number of portions into which the daily ration shall be divided. Some herds are fed three times a day and some twice. While it would be possible to feed too many times or too much at any one time, it seems more than probable that if animals are fed regularly the ration may be as efficient when divided into two portions as when there are three feeding periods. The adaptation of any system to the requirements of farm work is a matter of more importance, probably, than any influences proceeding from the number of feeding-periods. The warming of the water consumed has been introduced to some extent with dairy herds. Certainly it is bad practice to force cows to drink ice-cold water, but it is also bad practice to warm the water above the point of palatableness. The likes and dislikes of animals must be considered, and to ignore them, even to save the small food expense necessary for warming the ingested water, is not advisable. 
517. Quantity of the ration.-Great stress is usually laid upon the fact that it is only the food that is supplied above maintenance needs which is productive. This truth, indiscriminately accepted, has led to feeding so excessively as to injure the health of the animals and diminish profits. The largest production is not always the most profitable. Abundant testimony can be cited in support of the statement that very heavy rations yield smaller returns for each unit of food consumed than more moderate ones. It is possible, also, to adopt an unprofitable extreme in the direction of light feeding. Heavy rations are sometimes warranted by the low cost of feeds and the high price of the resulting product, a condition which has not existed for the past ten years. In the writer's judgment, milk is more economically produced by cows not unusual in character or size when the grain ration, wisely compounded, ranges between eight and ten pounds daily, according to the weight and capacity of the animal, than when more is fed, provided the coarse foods are supplied in the ordinary proportion. It is especially important with breeding animals, where the physical condition of the dam should be kept at its best, that the indigestion and high physical tension induced by extreme rations should be avoided. The welfare of future generations demands this.

518. Environment and treatment of animals.-The quarters in which animals live should be comfortable, that is, they should be neither too warm nor too cold and should be well ventilated. These conditions are essential to health and the most profitable production. The stable temperature in winter should be held above $45^{\circ} \mathrm{F}$. as a minimum, and may well be kept below $60^{\circ}$. A constant exchange of air should be secured without creating 
cold drafts, and the "King" system of ventilation seems to be worthy of commendation.

All domestic animals, whether the milch cow or the fattening steer, should have a reasonable amount of exercise under comfortable conditions. Little sympathy should be shown toward the modern fad of tying cows by their heads in one spot for five or six months, under the plea that exercise is work and work costs food. The statement had better be in accordance with the experience of all time, that exercise is health and vigor and that food is well used in maintaining these. The cow is more than a machine; she is a sentient being, susceptible to many of the influences which are essential to the physical welfare of the human species. Let no one take this opinion as an excuse for the cruel and wasteful exposure of farm animals to inclement weather, which is so often observed, for this is simply a violation of the laws of kindness and economy in the other direction.

A sympathetic relation should be established between the animal and the herdsman. Close observers declare that such a relation promotes greater thrift and larger production, especially with dairy cows. These animals, possessed of the instincts and affections of motherhood, respond to fondling through its influence upon their nervous organization.

Moreover, the economic relation is not the only one man sustains to the animal world. Farm animals are man's companions and friends for which he may entertain even sentiments of affection. The daily life of the farm-house is full of pleasant experiences that belong to the care of, and association with, the grateful creatures whose wants must be supplied-the motherly cow, the faithful horse, or the noisy, cackling fowl. No farmer 
has reached his best estate who does not find in the animal life about him an enjoyable companionship of which he need not be ashamed, and without a sense of which he is not prepared to fulfil his obligations to the creatures dependent upon him.

519. Cruelty to animals. - While it is the purpose of this volume to deal with the facts and principles of science and practice, it is not improper briefly to urge the need of the cultivation of right sentiment concerning kindness in the care of animals, for we really do not fully: appreciate the unkindness shown by man toward the inferior species under his control. In no way has he more clearly demonstrated that he partakes of the brute nature than in his treatment of the brute. As a master he has been guilty of cruelty which it is humiliating to contemplate, a cruelty not so swift in its operation as that of the beast of prey, but which is greatly more shocking and is wholly at variance with the exalted characteristics that we attribute to humanity. The halfsheltered animals that have endured our cold northern winters - the spavined, wind-broken wrecks of our livery stables, whose infirmities secure for them no relief from hard service - the daily exhibitions on our city streets of the patient draft horse with raw flesh under the collar and smarting under blows from unfeeling, cursing drivers -and especially the deliberately brutal practices of the race-track, where amid the plaudits of a throng of men and women who would claim to have kind hearts, noble animals, by unjustifiable "scoring" and in the subsequent race, are often forced to the last limits of endurance -these are all evidences of an utterly selfish indifference to the suffering of living creatures that can neither utter a complaint nor avenge their wrongs. A certain 
proportion of humanity appears to regard the animal as a mere unfeeling machine out of which pleasure and gain are to be forced even to the pound of flesh, and not as sentient beings capable of the keenest physical pain and with rights that should be respected. The constant occurrence of the ill-treatment of animals is perhaps the cause of the complaisance with which it is regarded, but it is no excuse for such thoughtless indifference. Society notes and punishes flagrant cases of abuse, but the average human conscience is not yet sufficiently tender toward man's treatment of his faithful servants. 


\section{APPENDIX}

\section{COMPOSITION, DIGESTION, AND FEEDING STANDARDS BY TABLES}

1. Average composition of American feeding-stuffs, page 435.

2. Average coefficients of digestion, page 441.

3. Energy-production values of feeding-stuffs, page 448.

4. Food standards for milk production as developed by Haecker, Savage, and Eckles, page 455.

5. Feeding standards, page 457.

6. Fertilizing constituents of American feeding-stuffs, page 460 .

1. AVERAGE COMPUSITION OF AMERICAN FEEDINGSTUFFS

The figures in the following table have been taken from Bulletin No. 11, Office of Experiment Stations; Farmers' Bulletin No. 22, United States Department of Agriculture; Bulletin No. 81, Vermont Agricultural Experiment Station, and Bulletin No. 166, New York Agricultural Experiment Station (Geneva).

The percentages given represent averages from which there are material variations. These variations are mostly due to differences in the water-content, the influence of locality and of the stage of growth and the changes brought about by the methods and conditions of curing. They are not so large and important with the grains as with the fodders.

A more complete table of the composition of feedingstuffs is to be found in Henry \& Morrison's "Feeds and Feedings," the edition of 1915 . The figures given in the 
following tables, however, are sufficiently full and accurate to illustrate the composition of the various classes of feeds.

\section{Composition of Feeding-StuFfs}

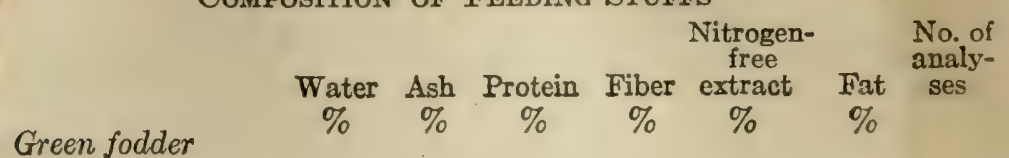

Corn fodder-*

Flint varieties......

Flint varieties cut after kernels had glazed...........

Dent varieties.......

Dent varieties cut after kernels had glazed...........

Sweet varieties......

All varieties.........

Leaves and husks, cut green.........

Stripped stalks, cut green............

Sorghum fodder......

Rye fodder...........

Barley fodder. . . . . . . .

Oat fodder...........

Pasture grass.........

Red-top, $\uparrow$ in bloom... . .

Tall oat grass, $\ddagger$ in bloom ...........

Orchard grass, in bloom............

Meadow fescue, in bloom...........

Italian rye grass, com-

ing into bloom.....

Timothy, $\S$ at different stages...........

Kentucky blue-grass,**

$\begin{array}{lllllll}79.8 & 1.1 & 2 . & 4.3 & 12.1 & .7 & 40\end{array}$

$\begin{array}{lllllll}77.1 & 1.1 & 2.1 & 4.3 & 14.6 & .8 & 10\end{array}$

$\begin{array}{lllllll}79 . & 1.2 & 1.7 & 5.6 & 12 . & .5 & 63\end{array}$

$\begin{array}{rlllllr}73.4 & 1.5 & 2 . & 6.7 & 15.5 & .9 & 7 \\ 79.1 & 1.3 & 1.9 & 4.4 & 12.8 & .5 & 21 \\ 79.3 & 1.2 & 1.8 & 5 . & 12.2 & .5 & 126\end{array}$

$\begin{array}{llllllll}66.2 & 2.9 & 2.1 & 8.7 & 19 . & 1.1 & 4\end{array}$

$\begin{array}{rrrrrrr}76.1 & .7 & .5 & 7.3 & 14.9 & .5 & 4\end{array}$

$\begin{array}{lllllll}79.4 & 1.1 & 1.3 & 6.1 & 11.6 & .5 & 11\end{array}$

$\begin{array}{lllllll}76.6 & 1.8 & 2.6 & 11.6 & 6.8 & .6 & 7\end{array}$

$\begin{array}{lllllll}79 . & 1.8 & 2.7 & 7.9 & 8 . & .6 & 1\end{array}$

$\begin{array}{lllllll}62.2 & 2.5 & 3.4 & 11.2 & 19.3 & 1.4 & 6\end{array}$

$\begin{array}{llrrrrr}80 . & 2 . & 3.5 & 4 . & 9.7 & .8 & \ldots\end{array}$

$\begin{array}{lllllll}65.3 & 2.3 & 2.8 & 11 . & 17.7 & .9 & 5\end{array}$

$\begin{array}{lllllll}69.5 & 2 . & 2.4 & 9.4 & 15.8 & .9 & 3\end{array}$

$\begin{array}{lllllll}73 . & 2 . & 2.6 & 8.2 & 13.3 & .9 & 4\end{array}$

$\begin{array}{lllllll}69.9 & 1.8 & 2.4 & 10.8 & 14.3 & .8 & 4\end{array}$

$\begin{array}{lllllll}73.2 & 2.5 & 3.1 & 6.8 & 13.3 & 1.3 & 24\end{array}$

$\begin{array}{lllllll}61.6 & 2.1 & 3.1 & 11.8 & 20.2 & 1.2 & 56\end{array}$

$\begin{array}{ccccccrr}\text { at different stages.... } & 65.1 & 2.8 & 4.1 & 9.1 & 17.6 & 1.3 & 18 \\ \text { Hungarian grass....... } & 71.1 & 1.7 & 3.1 & 9.2 & 14.2 & .7 & 14 \\ \text { Japanese millet....... } & 75 . & 1.5 & 2.1 & 7.8 & 13.1 & .5 & 12\end{array}$
*Corn fodder is the entire plant, usually a thickly planted crop. Corn stover
is what is left after the ears are harvested.

†Herd's grass of Pennsylvania.

\$Herd's grass of New England and New York. **June Grass. 
Green Fodder-continued

\begin{tabular}{ccccccc} 
& & \multicolumn{3}{c}{$\begin{array}{c}\text { Nitrogen- } \\
\text { free }\end{array}$} & $\begin{array}{c}\text { No. of } \\
\text { analy- }\end{array}$ \\
Water & Ash & Protein & Fiber extract & Fat & ses \\
$\%$ & $\%$ & $\%$ & $\%$ & $\%$ & $\%$ &
\end{tabular}

Red clover, at different stages. at different

Alsike clover, $*$ in bloom.

Crimson clover........

Alfalfa, $\dagger$ at different stages............

Serradella, at different stages...........

Cowpea.............

Soja bean............

Horse bean..........

Flat pea (Lathymus sylvestris)..........

Rape.............

$\begin{array}{lllrrrr}70.8 & 2.1 & 4.4 & 8.1 & 13.5 & 1.1 & 43 \\ 74.8 & 2 . & 3.9 & 7.4 & 11 . & .9 & 4 \\ 80.9 & 1.7 & 3.1 & 5.2 & 8.4 & .7 & 3 \\ 71.8 & 2.7 & 4.8 & 7.4 & 12.3 & 1 . & 23 \\ 79.5 & 3.2 & 2.7 & 5.4 & 8.6 & .7 & 9 \\ 83.6 & 1.7 & 2.4 & 4.8 & 7.1 & .4 & 10 \\ 75.1 & 2.6 & 4 . & 6.7 & 10.6 & 1 . & 27 \\ 84.2 & 1.2 & 2.8 & 4.9 & 6.5 & .4 & 2 \\ & & & & & & \\ 66.7 & 2.9 & 8.7 & 7.9 & 12.2 & 1.6 & 2 \\ 84.5 & 2 . & 2.3 & 2.6 & 8.4 & .5 & 2 \\ & & & & & & \\ 79.1 & 1.4 & 1.7 & 6 . & 11 . & .8 & 99 \\ 76.1 & 1.1 & .8 & 6.4 & 15.3 & .3 & 6 \\ 72 . & 2.6 & 4.2 & 8.4 & 11.6 & 1.2 & 5 \\ 74.2 & 2.8 & 4.1 & 9.7 & 6.9 & 2.2 & 1 \\ 79.3 & 2.9 & 2.7 & 6 . & 7.6 & 1.5 & 2 \\ 50.1 & 3.5 & 5.9 & 13 . & 26 . & 1.6 & 1\end{array}$

\section{Silage}

Corn silage............

Sorghum silage........

Red-clover silage......

Soja-bean silage......

Cowpea-vine silage... .

Field-pea-vine silage.. . .

Silage of mixture of cowpea vines and soja-bean vines....

Millet and soja bean...

Corn and soja bean... .

Rye...............

Apple pomace........

$\begin{array}{lrrrrrr}69.8 & 4.5 & 3.8 & 9.5 & 11.1 & 1.3 & 1 \\ 79 . & 2.8 & 2.8 & 7.2 & 7.2 & 1 . & 9 \\ 76 . & 2.4 & 2.5 & 7.2 & 11.1 & .8 & 4 \\ 80.8 & 1.6 & 2.4 & 5.8 & 9.2 & .3 & 1 \\ 85 . & .6 & 1.2 & 3.3 & 8.8 & 1.1 & 1\end{array}$

Hay and Dry Coarse Fodder

Corn fodder, $\neq$ field-cured.

42.2

Corn leaves, field-cured.

Corn husks, field-cured.

Corn stalks, field-cured.

Corn stover $\S$ field-cured

Barley hay, cut in milk.

Oat hay, cut in milk. . .

Hay from-

Red-top, ${ }^{* *}$ cut at different stages......

Red-top, cut in bloom

Orchard grass.......

*Swedish clover.

†Lucerne.

¿ntire plant.

$\begin{array}{llllrr}2.7 & 4.5 & 14.3 & 34.7 & 1.6 & 35 \\ 5.5 & 6 . & 21.4 & 35.7 & 1.4 & 17 \\ 1.8 & 2.5 & 15.8 & 28.3 & .7 & 16 \\ 1.2 & 1.9 & 11 . & 17 . & .5 & 15 \\ 3.4 & 3.8 & 19.7 & 31.5 & 1.1 & 60 \\ 4.2 & 8.8 & 24.7 & 44.9 & 2.4 & 1 \\ 5.2 & 9.3 & 29.2 & 39 . & 2.3 & 1\end{array}$

$\begin{array}{rlllllr}8.9 & 5.2 & 7.9 & 28.6 & 47.5 & 1.9 & 9 \\ 8.7 & 4.9 & 8 . & 29.9 & 46.4 & 2.1 & 3 \\ 9.9 & 6 . & 8.1 & 32.4 & 41 . & 2.6 & 10\end{array}$
\$W hat is left after the ears are harvested. **Herd's grass of Pennsylvania. 


\begin{tabular}{|c|c|c|c|c|c|c|c|}
\hline $\begin{array}{l}\text { Hay and Dry Coarse Fodder } \\
\text { - continued }\end{array}$ & $\begin{array}{c}\text { Water } \\
\%\end{array}$ & $\begin{array}{c}\text { Ash } \\
\%\end{array}$ & $\begin{array}{c}\text { Protein } \\
\%\end{array}$ & $\begin{array}{c}\text { Fiber } \\
\%\end{array}$ & $\begin{array}{c}\text { Nitrogen- } \\
\text { free } \\
\text { extract } \\
\%\end{array}$ & $\begin{array}{l}\text { Fat } \\
\%\end{array}$ & $\begin{array}{l}\text { No, of } \\
\text { analy- } \\
\text { ses }\end{array}$ \\
\hline \multicolumn{8}{|l|}{ Hay from- } \\
\hline $\begin{array}{l}\text { Timothy,* all analy's. } \\
\text { Timothy, cut in full }\end{array}$ & 13.2 & 4.4 & 5.9 & 29. & 45. & 2.5 & 68 \\
\hline bloom.............. & 15. & 4.5 & 6. & 29.6 & 41.9 & 3. & 12 \\
\hline $\begin{array}{l}\text { Timothy, eut soon af- } \\
\text { ter bloom........ }\end{array}$ & 14.2 & 4.4 & 5.7 & 28.1 & 44.6 & 3. & 11 \\
\hline $\begin{array}{c}\text { Timothy, cut when } \\
\text { nearly ripe........ }\end{array}$ & 14.1 & 3.9 & 5. & 31.1 & 43.7 & 2.2 & 12 \\
\hline $\begin{array}{l}\text { Kentucky blue-grass.. } \\
\text { Cut when seed was }\end{array}$ & 21.2 & 6.3 & 7.8 & 23. & 37.8 & 3.9 & 10 \\
\hline in milk......... & 24.4 & 7. & 6.3 & 24.5 & 34.2 & 3.6 & 4 \\
\hline ripe.......... & 27.8 & 6.4 & 5.8 & 23.8 & 33.2 & 3. & 4 \\
\hline Hungarian grass..... & 7.7 & 6. & 7.5 & 27.7 & 49. & 2.1 & 13 \\
\hline Meadow fescue...... & 20. & 6.8 & 7. & 25.9 & 38.4 & 2.7 & 9 \\
\hline Italian rye grass. ... . & 8.5 & 6.9 & 7.5 & 30.5 & 45. & 1.7 & 4 \\
\hline Perennial rye grass... & 14: & 7.9 & 10.1 & 25.4 & 40.5 & 1.7 & 4 \\
\hline Mixed grasses....... & 15.3 & 5.5 & 7.4 & 27.2 & 42.1 & 2.5 & 126 \\
\hline Rowen (mixed) †.... & 16.6 & 6.8 & 11.6 & 22.5 & 39.4 & 3.1 & 23 \\
\hline Mixed grasses and & & & & & & & \\
\hline clovers.......... & 12.9 & 5.5 & 10.1 & 27.6 & 41.3 & 2.6 & 17 \\
\hline Swamp hay........ & 11.6 & 6.7 & 7.2 & 26.6 & 45.9 & 2. & 8 \\
\hline Salt marsh........ & 10.4 & 7.7 & 5.5 & 30. & 44.1 & 2.4 & 10 \\
\hline Red clover.......... & 15.3 & 6.2 & 12.3 & 24.8 & 38.1 & 3.3 & 38 \\
\hline Red clover in bloom.. & 20.8 & 6.6 & 12.4 & 21.9 & 33.8 & 4.5 & 6 \\
\hline Alsike clover........ & 9.7 & 8.3 & 12.8 & 25.6 & 40.7 & 2.9 & 9 \\
\hline White clover........ & 9.7 & 8.3 & 15.7 & 24.1 & 39.3 & 2.9 & 7 \\
\hline Crimson clover...... & 9.6 & 8.6 & 15.2 & 27.2 & 36.6 & 2.8 & 7 \\
\hline Japan clover........ & 11. & 8.5 & 13.8 & 24. & 39. & 3.7 & 2 \\
\hline Vetch............ & 11.3 & 7.9 & 17. & 25.4 & 36.1 & 2.3 & 5 \\
\hline Serradella.......... & 9.2 & 7.2 & 15.2 & 21.6 & 44.2 & 2.6 & 3 \\
\hline Alfalfał............ & 8.4 & 7.4 & 14.3 & 25. & 42.7 & 2.2 & 21 \\
\hline Cowpea........... & 10.7 & 7.5 & 16.6 & 20.1 & -42.2 & 2.2 & 8 \\
\hline Soja bean.......... & 11.3 & 7.2 & 15.4 & 22.3 & 38.6 & 5.2 & 6 \\
\hline Flat pea (Lathyrus & & & & & & & \\
\hline sylvestris)......... & 8.4 & 7.9 & 22.9 & 26.2 & 31.4 & 3.2 & 5 \\
\hline $\begin{array}{l}\text { Peanut vines (with- } \\
\text { out nuts)......... }\end{array}$ & 7.6 & 10.8 & 10.7 & 23.6 & 42.7 & 4.6 & 6 \\
\hline Pea vines.......... & 15. & 6.7 & 13.7 & 24.7 & 37.6 & 2.3 & 1 \\
\hline Soja-bean straw..... & 10.1 & 5.8 & 4.6 & 40.4 & 37.4 & 1.7 & 4 \\
\hline Horse-bean straw... & 9.2 & 8.7 & 8.8 & 37.6 & 34.3 & 1.4 & 1 \\
\hline Wheat straw..... & 9.6 & 4.2 & 3.4 & 38.1 & 43.4 & 1.3 & 7 \\
\hline straw.......... & 7.1 & 3.2 & 3. & 38.9 & 46.6 & 1.2 & 7 \\
\hline straw............ & 9.2 & 5.1 & 4. & 37. & 42.4 & 2.3 & 12 \\
\hline Buckwheat straw..... & 9.9 & 5.5 & 5.2 & 43. & 35.1 & 1.3 & 3 \\
\hline
\end{tabular}

*Herd's grass of New England and New York. †Second cut. †Lucerne. 


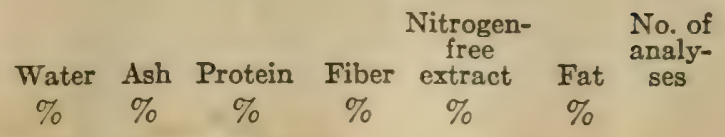

Roots and Tubers

\begin{tabular}{|c|c|c|c|c|c|c|}
\hline Potatoes....... & 78.9 & 1. & 2.1 & .6 & 17.3 & .1 \\
\hline Sweet potatoes. & 71.1 & 1. & 1.5 & 1.3 & 24.7 & .4 \\
\hline Red beets...... & 88.5 & 1. & 1.5 & .9 & 8. & .1 \\
\hline Sugar-beets. . & 86.5 & .9 & 1.8 & .9 & 9.8 & .1 \\
\hline Mangel-wurzels. . & 90.9 & 1.1 & 1.4 & .9 & 5.5 & .2 \\
\hline Turnips......... & 90.5 & .8 & 1.1 & 1.2 & 6.2 & .2 \\
\hline Rutabagas..... & 88.6 & 1.2 & 1.2 & 1.3 & 7.5 & .2 \\
\hline Carrots. & 88.6 & 1. & 1.1 & 1.3 & 7.6 & .4 \\
\hline Artichokes. . & 79.5 & 1. & 2.6 & .8 & 15.9 & .2 \\
\hline
\end{tabular}

Grains and Other Seeds

Corn kernel-

Dent, all analyses.... $\quad 10.6$

$\begin{array}{ll}1.5 & 10.3\end{array}$

$2.2 \quad 70.4$

5.

86

Flint, all analyses.... 11.3

$1.4 \quad 10.5$

1.7

70.1

5.

68

Sweet, all analyses... $\quad 8.8$

$1.9 \quad 11.6$

2.8

66.8

8.126

Pop varieties....... 10.7

1.511 .2

Soft varieties.......

9.3

$1.8 \quad 69.6$

5.2

2. $70.2 \quad 5.5$

12

All varieties and analyses.........

Sorghum seed. . . . . . . .

Barley

10.9

$1.5 \quad 10.5$

$2.1 \quad 69.6$

5.4208

$\begin{array}{lll}12.8 & 2.1 & 9.1\end{array}$

2.6

10.9

$2.4 \quad 12.4$

Oats....

11.

Rye.

11.6

3. 11.8

2.7

69.8

$3.6 \quad 10$

$2.7-69.8$

$1.8 \quad 10$

1.910 .6

$\begin{array}{ll}1.7 & 72.5\end{array}$

5. 30

Wheat-

Spring varieties......

Winter varieties, all analyses.........

All varieties........

Rice.

$\begin{array}{lll}10.4 & 1.9 & 12.5\end{array}$

$\begin{array}{lll}1.8 & 71.2 & 2.2\end{array}$

13

$\begin{array}{lll}10.5 & 1.8 & 11.8\end{array}$

1.872.

$2.1 \quad 262$

10.5

12.4

$1.8 \quad 11.9$

1.8

71.9

2.1310

Buckwheat.

12.6

.47 .4

Sunflower seed (whole).

Flaxseed

Cottonseed (whole,with

hulls)...........

8.6

2. 10 .

.279 .2

$.4 \quad 10$

9.2

$2.6 \quad 16.3$

8.7

64.5

2.2

$\begin{array}{lll}29.9 & 21.4 & 21.2\end{array}$

$\begin{array}{lll}7.1 & 23.2 \quad 33.7\end{array}$

8

$4.3 \quad 22.6$

50

$\begin{array}{lllllll}10.3 & 3.5 & 18.4 & 23.2 & 24.7 & 19.9 & 5\end{array}$ (without hulls)....

6.2

$4.7 \quad 31.2$

$\begin{array}{lll}3.7 & 17.6 & 36.6\end{array}$

2

Cottonseed whole, roasted...........

Peanut kernels (with-

$\begin{array}{lll}6.1 & 5.5 & 16.8\end{array}$

$20.4 \quad 23.5 \quad 27.7$

2

$\begin{array}{lllllll}7.5 & 2.4 & 27.9 & 7 . & 15.6 & 39.6 & 7\end{array}$

$\begin{array}{lllllll}11.3 & 3.8 & 26.6 & 7.2 & 50.1 & 1 . & 1\end{array}$

Soja bean............

$10.8 \quad 4.7 \quad 34$.

$\begin{array}{lll}4.8 & 28.8 & 16.9\end{array}$

8

Cowpea.............

$\begin{array}{lll}14.8 & 3.2 & 20.8\end{array}$

$\begin{array}{lll}4.1 & 55.7 & 1.4\end{array}$

5 


\section{Mill Products}

Corn meal. ......... 15

Corn-and-cob meal.... 15.1

Oatmeal........... 7.9

Barley meal. . . . . . . . 11.9

Rye flour........... 13.1

Wheat flour, all analyses

Buckwheat flour...... .

Ground linseed........

Pea meal. . . . . . . . . . .

Soja-bean meal........ equal parts........

\section{Waste Products}

Corn cobs............

Hominy chops..... . . .

Corn bran.

12.4

14.6

8.1

10.5

10.8

13. 2.210 .5
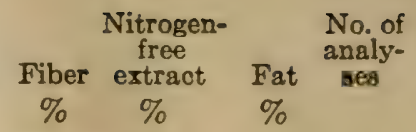

Corn germ.

Corn-germ meal......

Gluten meal-

Cream .............

$$
\text { King }
$$

Gluten feed

\section{Buffalo*}

Peoria*.

Diamond, or Rockford.

Chicago maize feed.

Glucose feed and glucose refuse........

Dried starch feed and sugar feed.

Starch feed, wet.

Oat hulls.

Oat feed.

Barley screenings

Maltsprouts

\begin{tabular}{rll}
10.7 & 1.4 & 2.4 \\
11.1 & 2.5 & 9.8 \\
9.1 & 1.3 & 9. \\
10.7 & \multicolumn{1}{l}{4.} & 9.8 \\
8.1 & 1.3 & 11.1 \\
& & \\
10.1 & .8 & 33.7 \\
12.3 & 1.3 & 36.5 \\
7.4 & .5 & 33.7 \\
7.8 & 1.1 & 24. \\
9.6 & 2.3 & 27.1 \\
7.5 & .8 & 19.8
\end{tabular}

$\begin{array}{ll}1.9 & 68.7\end{array}$

3.8

$\begin{array}{ll}1.4 & 9.2 \\ 1.5 & 8.5\end{array}$

2. 14.7

$2.6 \quad 10.5$

$\begin{array}{ll}.7 & 6.7\end{array}$

$\begin{array}{ll}.5 & 10.8\end{array}$

$\begin{array}{lr}.5 & 10.8 \\ 1 . & 6.9\end{array}$

$4.7 \quad 21.6$

$\begin{array}{ll}2.6 & 20.2\end{array}$

$\begin{array}{ll}2.6 & 20.2 \\ 4.5 & 36.7\end{array}$

6.6

.9

64.8

3.5

6.5

67.4

7.1

.4

66.3

78.3

2.2

.2

75.

.8

.3

75.8

1.1

7.3

$\begin{array}{ll}5.8 & 1.4\end{array}$

14.4

$27.9 \quad 30.4$

4.5

$51.1 \quad 1.2$

$27.3 \quad 16.2$

$\begin{array}{lll}5.7 & 64.2 \quad 4.4\end{array}$

77

7

6

3

4

20

4

2

2

1

Brewers' grains, wet

Brewers' grains, dried.

Grano gluten

$\begin{array}{lll}8.9 & .8 & 23.6 \\ 9.1 & .9 & 22.8\end{array}$

30.1

54.9

3.8

12.7

4.1

9.9

64.5

62.2

64.

62.5

$\begin{array}{rr}.5 & 18 \\ 8.3 & 12 \\ 5.8 & 5 \\ 7.4 & 3 \\ 7.1 & 6\end{array}$

\section{$1.7 \quad 51.1$}

$1.4 \quad 45.8$

2.6

1.2

52.6

2.7

5.3

6.7

51.2

4.6

8.2

51.10 .6

$51.1 \quad 3.2$

$51.1 \quad 12.6$

11

1

\section{$\begin{array}{lll}6.5 & 1.1 & 20.7\end{array}$}

6.6

$56 . \grave{6}$

3.5

7.6

52.7

6.9

3

\section{(0.9.}

$\begin{array}{lll}10.9 & .9 & 19.7\end{array}$

$\begin{array}{llll}4.5 & 56.8 & 10.4 & 2\end{array}$

$\begin{array}{lll}65.4 & .3 & 6.1\end{array}$

$\begin{array}{lll}4.7 & 54.8 & 9 .\end{array}$

$\begin{array}{lll}7.3 & 6.7 & 3.3\end{array}$

3.122.

9. 4

7.7

3.716 .

29.7

$\begin{array}{lll}12.2 & 3.6 & 12.3\end{array}$

6.1

52.1

3.1

12

$\begin{array}{lll}\text { 5. } & 6.4 & 27.6\end{array}$

7.3

59.4

1.

$\begin{array}{lll}75.7 & 1 . & 5.4\end{array}$

10.9

61.8

7.1

․

8.2

$\begin{array}{ll}3.6 & 19.9\end{array}$

3.8

47.1

2.8

3.

$\begin{array}{llll}5.8 & 2.8 & 31.1 & 12 .\end{array}$

Rye bran.

$\begin{array}{lll}11.6 & 3.6 & 14.7\end{array}$

11.

12.5

1.615

Rye shorts.

9.3

5.918.

3.5

51.7

5.6

$\begin{array}{ll}33.4 & 14.9\end{array}$

3

$63.8-2.8$

Wheat bran from spring wheat...........

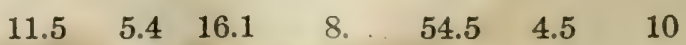


Waste Products-continued \begin{tabular}{ccccccc} 
& & & \multicolumn{3}{c}{$\begin{array}{c}\text { Nitrogen- } \\
\text { free }\end{array}$} & $\begin{array}{c}\text { No. of } \\
\text { analy- } \\
\text { Water }\end{array}$ \\
$\%$ & $\%$ & $\%$ & $\%$ & $\%$ & $\%$ &
\end{tabular}

Wheat bran from winter wheat...........

Wheat bran, all analyses

Wheat middlings.......

Wheat shorts.........

Wheat screenings......

Rice bran ...........

Rice hulls... . . . . . . . .

Rice polish..........

Buckwheat hulls......

Buckwheat bran......

Buckwheat middlings...

Cottonseed meal.......

Cottonseed hulls.......

Lins'd meal, old proc's.

Lins'd meal, new proc's

Peanut meal..........

Peanut hulls.........

\begin{tabular}{rrrrllr}
12.3 & 5.9 & \multicolumn{1}{c}{16.} & \multicolumn{1}{c}{8.1} & 53.7 & \multicolumn{1}{l}{4.} & 7 \\
11.9 & 5.8 & 15.4 & \multicolumn{1}{c}{9.} & 53.9 & \multicolumn{1}{l}{4.} & 88 \\
10. & 3.8 & 17.4 & 5.2 & 58. & 5.6 & $\cdots$ \\
11.8 & 4.6 & 14.9 & 7.4 & 56.8 & 4.5 & 12 \\
11.6 & 2.9 & 12.5 & 4.9 & 65.1 & 3. & 10 \\
9.7 & 10. & 12.1 & 9.5 & 49.9 & 8.8 & 5 \\
8.2 & 13.2 & 3.6 & 35.7 & 38.6 & .7 & 3 \\
10. & 6.7 & 11.7 & 6.3 & 58. & 7.3 & 4 \\
13.2 & 2.2 & 4.6 & 43.5 & 35.3 & 1.1 & 2 \\
10.5 & 3. & 12.4 & 31.9 & 38.8 & 3.3 & 2 \\
13.2 & 4.8 & 28.9 & 4.1 & 41.9 & 7.1 & 3 \\
6.8 & 6.2 & 45.6 & 5.4 & 25.2 & 10.8 &. \\
11.1 & 2.8 & 4.2 & 46.3 & 33.4 & 2.2 & 20 \\
8.3 & 5.3 & 35.7 & 7.5 & 36. & 7.2 & $\cdots$ \\
10. & 5.2 & 36.1 & 8.4 & 36.7 & 3.6 &. \\
10.7 & 4.9 & 47.6 & 5.1 & 23.7 & 8. & 2,480 \\
9. & 3.4 & 6.6 & 64.3 & 15.1 & 1.6 & 5
\end{tabular}

\section{Miscellaneous}

Acorns

Apples.

Beet pulp.

Beet molasses.

Cabbage.

Prickly comfrey.

Pumpkin (field).

Sugar-beet leaves.

$\ldots \ldots$
$\ldots \ldots$
$\ldots \ldots$
$\ldots \ldots$
$\ldots \ldots$
$\ldots \ldots$
$\ldots \ldots$
$\ldots \ldots$

55.3
80.8
76.7
89.8
20.8
90.5
88.4
90.9
88.

$\begin{array}{rrr}1 . & 2.5 & 4.4 \\ .4 & .7 & 1.2 \\ .5 & 1.4 & 3.9 \\ .6 & .9 & 2.4 \\ 10.6 & 9.1 & . \\ 1.4 & 2.4 & 1.5 \\ 2.2 & 2.4 & 1.6 \\ .5 & 1.3 & 1.7 \\ 2.4 & 2.6 & 2.2\end{array}$

$\begin{array}{rrr}34.8 & 1.9 & \ldots \\ 16.6 & .4 & \ldots \\ 16.2 & 1.3 & 7 \\ 6.3 & \ldots & 16 \\ 59.5 & \ldots & 35 \\ 3.9 & .4 & 2 \\ 5.1 & .3 & 41 \\ 5.2 & .4 & \ldots \\ 4.4 & .4 & \ldots\end{array}$

\section{AVERAGE COEFFICIENTS OF DIGESTION}

The coefficients of digestion which follow are mostly taken from the compilation by Jordan and Hall as published in Bulletin No. 77, Office of Experiment Stations. Others, marked G, are from the compilation of Dietrich and König ("Composition and Digestibility of Cattle Foods," Vol. II). Later figures are found in Report of Hatch Experiment Station, Massachusetts, 1905, and in Henry \& Morrison's "Feeds and Feeding," 1915. 


\section{DIgestion BY RUMiNaNTS}

No. ex- Kind and condiperim'ts tion of food

Green Fodders

\section{Meadow Grasses}

3. Hungarian

4. Barnyard millet

1. Timothy ............

1. Timothy rowen......

1. Pasture grass........ .

1. Mixed-grass rowen.....
2. Barley

8. Dent corn, immature. .

6. Dent corn, mature....

14 . Dent corn, all samples..

6. Sweet corn..........

3. Oats.............

1. Rye.............

2 . Sorghum...........

$\begin{array}{lllllll}65.9 & 67.5 & 54.4 & 71.8 & 60.8 & 71.2 & 59.9 \\ 68.8 & 70.7 & 45.4 & 65.2 & 66.6 & 73 . & 72 . \\ 66.6 & 68.5 & 19.4 & 52.3 & 51.6 & 74.7 & 77 . \\ 67.8 & 69.8 & 35.6 & 59.7 & 60.2 & 73.7 & 74.1 \\ 71.1 & 72.2 & 55.3 & 64 . & 62.9 & 76.6 & 75.6 \\ 59.5 & 60.9 & 53.4 & 71.8 & 52.8 & 62.6 & 69.2 \\ 73.4 & 75.3 & 55.8 & 79.4 & 79.2 & 70.1 & 74.5 \\ 67.3 & 69 . & 42.4 & 46.8 & 59 . & 74.6 & 74.2\end{array}$

Clovers and Legumes

6. Alfalfa $(G) \ldots \ldots \ldots$

1. Crimson clover........

1. Red clover...........

1. Red clover, before bloom $(\mathrm{G})$.........

2. Red clover, beginning bloom $(G)$.........

2. Red clover, bloom to end $(G) \ldots \ldots \ldots$.

1. Red-clover rowen......

1. Canada peas.........

2. Cowpea.............

4. Soybean.............

1. Common vetch.......

3 . Hairy vetch........

Mixed

1. Barley and peas.......

4. Oats and peas.........

1 . Vetch and oats....... $\begin{array}{llllll}\text {. } 64 . \quad \ldots & 81 . & 41 . & 72 . & 45 .\end{array}$

$\begin{array}{lllllll}67.9 & 69.1 & 56.1 & 77.1 & 56.1 & 74.5 & 66.5\end{array}$

$\begin{array}{lllllll}66.1 & 68.1 & 55 . & 67 . & 52.6 & 77.6 & 64.5\end{array}$

$\begin{array}{llllll}\text {. 74. } & \text {. } & 74 . & 60 . & 83 . & 65 .\end{array}$

$\begin{array}{llllll}\ldots & 71 . & \text {. } & 74 . & 57 . & 79 .\end{array}$

$\begin{array}{lllllll}\text {. 61. } & 64 . & 64 . & 71 . & 53 .\end{array}$

$\begin{array}{lllllll}59.3 & 60.8 & 43.4 & 61.9 & 52.5 & 65.3 & 60.8\end{array}$

$\begin{array}{lllllll}68.4 & 71.3 & 42.3 & 82 . & 62.4 & 71 . & 52.4\end{array}$

$\begin{array}{lllllll}68.3 & 74.1 & 22.8 & 75.6 & 59.6 & 80.6 & 59.4\end{array}$

$\begin{array}{lllllll}59.8 & 64.5 & 18.9 & 75.1 & 47 . & 73.2 & 54.1\end{array}$

$\begin{array}{lllllll}61.8 & 65.7 & 17.3 & 71.4 & 44.2 & 76.1 & 58.6\end{array}$

$\begin{array}{lllllll}70.3 & 73.1 & 45.1 & 82.8 & 61.1 & 76.3 & 71.6\end{array}$ $\begin{array}{lllllll}53.4 & 60.2 & 46.2 & 77.2 & 43.5 & 61.4 & 59.7\end{array}$ $\begin{array}{lllllll}65.4 & 67.2 & 45.4 & 76.1 & 59.7 & 67.7 & 67.7\end{array}$ $\begin{array}{lllllll}67 . & 68.4 & 52.7 & 74.8 & 68.3 & 67.9 & 47.2\end{array}$
Digestion coefficients

Dry Organic

Pro-

matter Ash tein Fiber tract Fat

$\begin{array}{lllllll}67.2 & 68.6 & 52.2 & 64.3 & 71.2 & 67.9 & 65.7\end{array}$

$\begin{array}{lllllll}66.6 & 67 . & 59.5 & 61.5 & 66.5 & 68.3 & 64.3\end{array}$

$\begin{array}{lllllll}63.5 & 65.6 & 32.2 & 48.1 & 55.6 & 65.7 & 53.1\end{array}$

$\begin{array}{lllllll}64.8 & 66.4 & 45.2 & 71.7 & 63.8 & 67.8 & 52.9\end{array}$

$\begin{array}{lllllll}68.7 & 70 . & 49.7 & 65.5 & 74.3 & 72.5 & 54.7\end{array}$

$\begin{array}{lllllll}65.6 & 67.4 & 46.2 & 67.4 & 62.6 & 71.6 & 55.2\end{array}$ 
No ex-
perim'ts $\quad \begin{gathered}\text { Kind and condi- } \\ \text { tion of food }\end{gathered}$

Siluage

Maize
9. Dent corn...........

6. Flint corn...........

13. Dent corn, immature. .

10. Dent and flint corn, mature...........

1. Sweet corn.

\section{Miscellaneous}

1. Cowpea............

1. Soybean (steers).......

1. Soybean (goats).......

1. Corn and soybean.....

1. Millet and soybean....

1. Corn, horse beans, and sunflower heads.....

1. Corn, horse beans, and sunflower plants....

\section{Dried Fodders \\ Meadow Grasses}

1. Black grass (Juncus bulbosus)..........

1. Black grass (Juncus Gerardii).

2. Blue joint.

1. Branch grass (Spartina stricta glabra)...

1. Branch grass (Distichlis spicata)..........

1. Chess or cheat.

2. Crab grass..........

1. Fox grass (Spartina patens)............

1. Fox grass (Spartina juncea, etc.).......

1. Flat sage.

1. Hungarian grass .....

2. Johnson grass.........

1. Barnyard millet......

1. Cat-tail millet........

2. Orchard grass:

2. Red-top.............

1. Red-top and sedge.

17. Timothy.........
Digestion coefficients-

Dry Organic Pro- Nitrogen-

matter matter. Ash tein Fiber tract Fat $\begin{array}{lllllll}\% & \% & \% & \% & \% & \% & \%\end{array}$

$\begin{array}{lllllll}65.1 & 67.1 & 32.2 & 49.3 & 66.7 & 68.6 & 80 .\end{array}$

$\begin{array}{llllllll}73.1 & 76.1 & 32.9 & 62.8 & 75.1 & 76.9 & 81.8\end{array}$

$\begin{array}{lllllll}65.6 & 67.4 & 34.3 & 51.3 & 70.6 & 67.4 & 80.2\end{array}$

$\begin{array}{llllllll}70.8 & 73.6 & 30.3 & 56 . & 70 . & 76.1 & 82.4\end{array}$

$\begin{array}{llllllll}68.1 & 70.1 & 31.9 & 54 . & 71.1 & 71.8 & 83.5\end{array}$

$\begin{array}{llllllll}59.6 & 63.4 & 30.3 & 57.5 & 52 . & 72.5 & 62.6\end{array}$

$\begin{array}{lllllll}49.8 & 53.8 & 28 . & 55.3 & 42.9 & 61.2 & 48.9\end{array}$

$\begin{array}{lllllll}59 . & 59.3 & 56.7 & 75.7 & 54.8 & 52 . & 71.9\end{array}$

$\begin{array}{lllllll}69 . & 71 . & \ldots & 65 . & 64.8 & 74.9 & 82.1\end{array}$

$\begin{array}{lllllll}58.8 & 59.9 & \ldots & 58.4 & 69.4 & 59.2 & 72.2\end{array}$

$\begin{array}{lllllll}65.6 & 67.8 & 41.1 & 62.7 & 60.1 & 72.4 & 76.7\end{array}$

$\begin{array}{lllllll}65.5 & 69.3 & 25.6 & 58 . & 65.3 & 73.7 & 74.1\end{array}$

$\begin{array}{lllllll}59.5 & \ldots & \ldots & 63 . & 60.5 & 57 . & 41.5\end{array}$

$\begin{array}{lllllll}53.4 & 52.1 & 69 . & 54.3 & 57.4 & 49 . & 45.7\end{array}$

$\begin{array}{lllllll}54.3 & 55.8 & 29.4 & 63.4 & 54.5 & 55.9 & 44.7\end{array}$

56. $\ldots \quad \ldots \quad 62.5 \quad 52 . \quad 54 . \quad 32$.

$\begin{array}{lllllll}49.7 & 48.9 & 58.1 & 51.7 & 56.4 & 45.7 & 36.6\end{array}$

$45.47 .3 \quad 23.42 .46 .49 .32$.

$\begin{array}{llllllll}53.6 & 55 . & 37.6 & \ldots & 59.1 & 54.5 & 46.8\end{array}$

$\begin{array}{lllllll}54.8 & 54.5 & 58.2 & 59.3 & 57.4 & 53.1 & 36.4\end{array}$

53. $\ldots . \quad \ldots \quad 57 . \quad 51 . \quad 52.24$.

$\begin{array}{lllllll}56.1 & 57.3 & 62 . & 51.8 & 60.4 & 55.1 & 36.1\end{array}$

$\begin{array}{lllllll}65 . & 66.3 & 47.4 & 60 . & 67.6 & 67.1 & 63.9\end{array}$

$\begin{array}{lllllll}56.5 & 58.3 & 30.5 & 41.4 & 65.7 & 56.9 & 38.4\end{array}$

$\begin{array}{lllllll}57.4 & 56.8 & 63.1 & 63.7 & 61.6 & 51.6 & 46.3\end{array}$

$\begin{array}{lllllll}62.3 & 61.6 & 68.4 & 62.6 & 66.5 & 59.1 & 46.1\end{array}$

$\begin{array}{llllllll}56.6 & 57.8 & \ldots & 59.5 & 60.4 & 55.4 & 53.8\end{array}$

$\begin{array}{lllllll}59.7 & 61.2 & 29 . & 61.3 & 61.3 & 61.9 & 50.5\end{array}$

46. $\quad \begin{array}{lllllll}48.5 & 10 & 1 & 37.2 & 55.7 & 45.6 & 49 .\end{array}$

$\begin{array}{lllllll}56.5 & 57.9 & 32.8 & 46.9 & 52.5 & 62.3 & 52.2\end{array}$ 
No. ex- Kind and condiperim'ts tion of food

Digestion coefficients

\begin{tabular}{ccccccc}
\hline \multicolumn{4}{c}{} & & Digestion coefficients & \multicolumn{2}{c}{$\begin{array}{c}\text { Nitrogen- } \\
\text { Dry Organic }\end{array}$} & \multicolumn{1}{c}{ Pro- } & \multicolumn{3}{c}{ free ex- } \\
matter matter & Ash & tein & Fiber & tract & Fat \\
$\%$ & $\%$ & $\%$ & $\%$ & $\%$ & $\%$ & $\%$
\end{tabular}

3. Timothy, before or in bloom.............

4. Timothy, past bloom. .

1. Timothy rowen.......

2. Wild-oat grass........

2. Witch grass...........

1. Black grass and redtop (cove mixture)...

5 . Mixed grasses........

Meadow hayBest (G).......... Medium (G)....... Poor $(G) . . . . . . .$.

2. Pasture grass.......

1. Swale hay..........

1. High-grown salt hay...

1. Salt-hay mixture.....

2. Rowen hay..........

$\begin{array}{lllllll}60.7 & 61.5 & 44.2 & 56.8 & 58.8 & 64.3 & 58.4 \\ 53.4 & 54.5 & 30.3 & 45.1 & 47.1 & 60.4 & 51.9 \\ 62.2 & 64.4 & 56.4 & 68 . & 66.5 & 63.4 & 49.5 \\ 64 . & 65.2 & 34.7 & 58.3 & 67.9 & 65.5 & 50.5 \\ 61.2 & 62.3 & 40.9 & 58.6 & 62.8 & 65.6 & 57.2 \\ & & & & & & \\ 54.6 & 54.3 & 57.5 & 47.9 & 59.7 & 53.2 & 40.3 \\ 57.1 & 58.8 & \ldots & 58.5 & 59.7 & 58.7 & 48.5 \\ & & & & & & \\ . & 67 . & \ldots & 65 . & 63 . & 68 . & 57 . \\ \ldots & 61 . & \ldots & 57 . & 60 . & 64 . & 53 . \\ \cdots & 56 . & \cdots & 50 . & 56 . & 59 . & 49 . \\ 72.6 & 73.2 & 51.8 & 73.4 & 76.1 & 74.2 & 67.3 \\ 39 . & \ldots & \ldots & 34 . & 33 . & 46 . & 44 . \\ 53 . & \cdots & \cdots & 63 . & 50 . & 53 . & 47 . \\ 56.4 & 54.9 & 69.8 & 42.6 & 60.7 & 54.7 & 29.7 \\ 64.4 & 65.8 & 46.6 & 69.1 & 66.6 & 66.2 & 47.4\end{array}$

\section{Cereal Plants}

1. Barley hay..........

17 . Dent corn fodder.....

7 . Flint corn fodder.....

13. Dent and flint corn fodders (immature). .

10. Dent and flint corn fodders (mature)....

3 . Sweet corn fodder.....

5 . Corn stover..........

3. New corn product.....

2. Topped corn fodder....

1. Corn blades and husks.

2 . Corn leaves (pulled fodder)............

1. Corn husks..........

1. Corn butts..........

1. Oat hay............

1. Oat straw..........

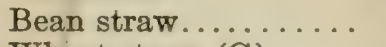
Wheat straw $(\mathrm{G}) \ldots .$. Rye straw (G)....... Barley straw $(\mathrm{G}) \ldots . .$. Rice straw $(\mathrm{G})$........

1. Sorghum fodder (pulled)

1. Sorghum bagasse.... . .

$\begin{array}{lllllll}61.2 & 62.3 & 44.8 & 65.2 & 61.7 & 63.3 & 40 . \\ 64.3 & 66.1 & 30.7 & 50.4 & 62.2 & 68 . & 73.6 \\ 68.6 & 71.7 & 42.6 & 60 . & 74.9 & 70.3 & 71.4\end{array}$

$\begin{array}{lllllll}63.9 & 65.7 & 37.2 & 51.7 & 66 . & 66.2 & 72.2\end{array}$

$\begin{array}{lllllll}68.2 & 70.7 & 30.6 & 56.1 & 65.8 & 72.2 & 73.9\end{array}$

$\begin{array}{lllllll}67.2 & 69.8 & 35.6 & 64.1 & 73.8 & 68.2 & 73.6\end{array}$

$\begin{array}{lllllll}57.2 & 59.1 & 32.6 & 35.9 & 64.2 & 57.9 & 70.4\end{array}$

$\begin{array}{llllllll}58.1 & 59.2 & 38.7 & 46.7 & 57 . & 60.5 & 78.2\end{array}$

$\begin{array}{lllllll}57.4 & 62.3 & 3.8 & 38.7 & 71 . & 57.9 & 67.4\end{array}$

$\begin{array}{lllllll}63.8 & 67.1 & 22.6 & 47.7 & 72.9 & 66.4 & 58.1\end{array}$

$\begin{array}{lllllll}59.8 & 63.6 & 26.8 & 48.4 & 67.5 & 63 . & 59.9\end{array}$

$\begin{array}{lllllll}72 . & 74.2 & 16 . & 29.5 & 79.5 & 75 . & 32.5\end{array}$

$\begin{array}{lllllll}66.5 & 69.4 & 11.5 & 21 . & 73.5 & 69 . & 79.5\end{array}$

$\begin{array}{llllllll}49.3 & 50.1 & 34.6 & 54.2 & 43.5 & 52 . & 61.9\end{array}$

$\begin{array}{lllllll}50.3 & 52 . & \ldots & \ldots & 57.6 & 53.2 & 38.3\end{array}$

. $55 . \quad \ldots \quad 49.43 .67 .57$.

. $46 . \quad$ 23. 55.39 .36 . 36.

. 48. ․ 25. 63. 39. 29.

. 53. ․ 25. 55. 54. 42 .

. 47. ․ 45. 57.32 .47$.

$\begin{array}{lllllll}63.1 & 64.8 & 29.5 & 60.8 & 70.4 & 64.5 & 46.7\end{array}$

$\begin{array}{lllllll}60.6 & 62.2 & 13.4 & 13.7 & 63.8 & 64.8 & 46.4\end{array}$ 
No, ex-
perim'ts Clovers
Digestion coefficients

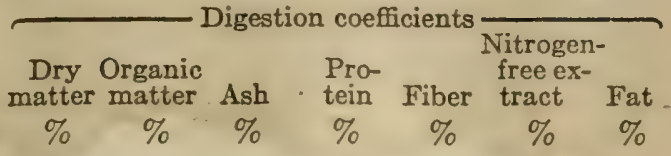

$\begin{array}{lllllll}62.3 & 63.2 & 52.2 & 66.1 & 53.5 & 70.7 & 50.2 \\ 58.1 & 59.1 & 51.9 & 68.7 & 46.7 & 64.6 & 43.4 \\ 57.4 & 59.7 & 29.1 & 58 . & 54.2 & 64.4 & \mathbf{5 5 . 2} \\ 58 . & 59.1 & 45.8 & 64.8 & 47.4 & 62.8 & 59.8 \\ 66 . & 66.6 & 58.5 & 73.2 & 60.6 & 69.5 & 50.6\end{array}$

\section{Legumes Other Than Clovers}

3. Alfalfa.............

1. Cowpea vine.........

1. Peanut vine.........

1. Soybean............

1. Hairy vetch......... Bean straw $(G) \ldots \ldots$ Pea straw, good $(\mathrm{G})$...

Miscellaneous and Mixed

1. Buttercup hay.......

1. Whiteweed hay.......

1 . Vetch and oats........

Grains and Seeds

Barley $(\mathrm{G}) \ldots \ldots \ldots$. . . Oats $(\mathrm{G}) \ldots \ldots \ldots \ldots$

5. Corn meal.

2. Corn-and-cob meal...

1. Rye meal. .

1. Pea meal.....

Field beans.

1. Soybean meal .

1. Cottonseed, raw.

1. Cottonseed, roasted.

Linseed.

Acorns.

\section{By-Products}

\section{Cereals}

1. Atlas meal...........

1. Cerealine feed.........

2 . Corn cobs.

79.6

90.4

51.4

1 . Dried brewers' grains..

5. Gluten feed ...........

4. Gluten meal.

1. H. O. dairy feed.
58.9

59.2

59.9

62.4

69.4

..

56.1

57.8

54.6

58.1

$\begin{array}{lcllll}60.7 & 39.5 & 72 . & 46 . & 69.2 & 51 . \\ 60 . & 49.5 & 64.8 & 42 . & 70.6 & 51.8 \\ 63.1 & 20.4 & 63.3 & 51.9 & 69.5 & 65.9 \\ 63.9 & \ldots & 71.1 & 60.8 & 68.8 & 29.2 \\ 71.8 & 42.2 & 82.3 & 61.1 & 72.9 & 70.3 \\ 55 . & \ldots & 49 . & 43 . & 67 . & 57 . \\ 59 . & \ldots & 60 . & 52 . & 64 . & 46 .\end{array}$

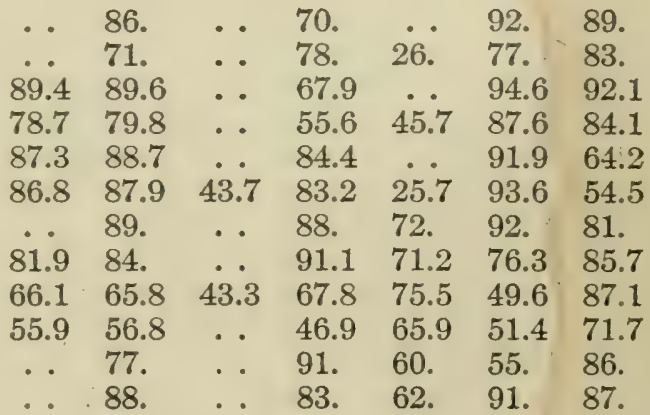

$\begin{array}{lllllll}61.6 & 65.4 & \ldots & 79.3 & 52.6 & 57.8 & 91.1\end{array}$

$\begin{array}{lllllll}86.3 & 87.3 & \ldots & 85.6 & 78 . & 89.2 & 84.4\end{array}$

$\begin{array}{llllllll}89.7 & 90.4 & \ldots & 88.2 & \ldots & 89.8 & 94.4\end{array}$

$\begin{array}{lllllll}65.3 & 68 . & \ldots & 77.8 & 40.8 & 69.9 & 85.5\end{array}$ 


\section{No. ex- Find and condi- perim'ts tion of food}

\section{Cereals-continued}

1. H. O. horse feed.......

1. Maize feed..........

1. Quaker oat feed......

1. Victor corn-and-oat feed.......................

7. Wheat bran.

1. Wheat bran and shorts.

3 . Wheat middlings.....
1. Maltsprouts..........

Digestion coefficients

\begin{tabular}{|c|c|c|c|c|c|c|}
\hline$\underset{\text { matter }}{\text { Dry }}$ & $\begin{array}{l}\text { Organic } \\
\text { matter }\end{array}$ & Ash & $\begin{array}{c}\text { Pro- } \\
\text { tein }\end{array}$ & Fiber & $\begin{array}{l}\text { Nitrogen } \\
\text { free ex- } \\
\text { tract }\end{array}$ & Fat \\
\hline$\%$ & $\%$ & $\%$ & $\%$ & $\%$ & $\%$ & $\%$ \\
\hline
\end{tabular}

$\begin{array}{lllllll}70.1 & 72.6 & \ldots & 74.4 & 35.2 & 78.7 & 84 .\end{array}$

$\begin{array}{llllllll}87.1 & 87.1 & \ldots & 85.5 & 82.5 & 87.9 & 91.5\end{array}$

$\begin{array}{lllllll}67.1 & 67.2 & \ldots & 80.2 & 32.9 & 68.1 & 104.6\end{array}$

$\begin{array}{lllllll}62 . & 65.3 & \ldots & 81.1 & 42.6 & 67.4 & 89 .\end{array}$

$\begin{array}{lllllll}74.7 & 77.4 & \ldots & 70.8 & 48.3 & 83 . & 86.8\end{array}$

$\begin{array}{llllllll}62.3 & 65.7 & \ldots & 77.8 & 28.6 & 69.4 & 68 .\end{array}$

$\begin{array}{lllllll}60.2 & 60.7 & 7.5 & 75.8 & 18.3 & 64.3 & 45 .\end{array}$

$\begin{array}{lllllll}75 . & 78.5 & \ldots & 79.8 & 33.1 & 81.3 & 86.3\end{array}$

\section{Oil-bearing Seeds}

3 . Cottonseed hulls......

5. Cottonseed meal......

1. Linseed meal, old process..............

2 . Linseed meal, new process..............

$\begin{array}{lll}39.8 & 40.5 \quad 23.2\end{array}$

$\begin{array}{llll}\cdots & 40 . & 41.1 & 85.7\end{array}$

$\begin{array}{lllllll}73.7 & 76.1 & 23.7 & 88.4 & 55.5 & 60.6 & 93.3\end{array}$

$\begin{array}{lllllll}78.7 & 81.2 & \cdots & 88.8 & 57 . & 77.6 & 88.6\end{array}$

$\begin{array}{lllllll}79.2 & 81.8 & \ldots & 85.2 & 80.4 & 86.1 & 96.6\end{array}$

\section{Miscellaneous}

1. Peanut feed

32.1

$\begin{array}{llllll}32.8 & \ldots & 70.6 & 11.7 & 49.1 & 89.7\end{array}$

$\begin{array}{lllllll}73.8 & 81.6 & \ldots & 61.9 & \ldots & 92.3 & 91.1\end{array}$

Roots

1. Mangolds. .

1. Potatoes, raw ........

1. Potatoes, boiled......

1. Rutabagas...........

1. Sugar-beets.........

1. Turnips........... $\begin{array}{llllll}78.5 & 84.8 & 16.4 & 74.7 & 42.8 & 91.3\end{array}$

$\begin{array}{lllllll}75.7 & 77 . & \ldots & 44.7 & \ldots & 90.4 & 13 .\end{array}$

$\begin{array}{lllllll}80.1 & 81.2 & \ldots & 43.4 & \ldots & 92.1\end{array}$

$\begin{array}{lllllll}87.2 & 91.1 & 31.2 & 80.3 & 74.2 & 94.7 & 84.2\end{array}$

$\begin{array}{lllllll}94.5 & 98.7 & 31.9 & 91.3 & 100.7 & 99.9 & 49.9\end{array}$

$\begin{array}{lllllll}92.8 & 96.1 & 58.6 & 89.7 & 103 . & 96.5 & 87.5\end{array}$

\section{Animal Products}

Cow's milk (G)...... . . 98.

Meat meal (G)...... . . 93.

Dried blood $(G) \ldots \ldots . \quad \ldots 63$.

94. $\quad \ldots \quad 98.100$.

Dried fish, ground $(G)$.

\section{Digestion BY Horses}

Dried Fodders

2. Timothy hay in full

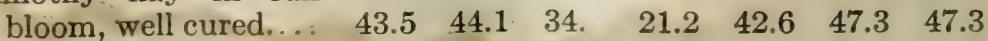

$\begin{array}{lllllllll}2 . & \text { New corn product.... } & 49.9 & 51.7 & 21.7 & 67.5 & 54.6 & 46.9 & 59.8\end{array}$ 
Na. ex- Find and condiperim'ts tion of food

Dried Fodders-continued

Meadow hay-

Best (G) .....

Medium (G)

Poor (G)

Red-clover hay (G)...

Alfalfa hay (G).

Wheat straw (G).....
Digestion coefficients

\begin{tabular}{|c|c|c|c|c|}
\hline $\begin{array}{l}\text { Dry Org } \\
\text { matter ma }\end{array}$ & As & $\begin{array}{l}\text { Pro- } \\
\text { tein }\end{array}$ & Fi & $\begin{array}{l}\text { free ex } \\
\text { tract }\end{array}$ \\
\hline$\%$ & $\%$ & $\%$ & $\%$ & $\%$ \\
\hline
\end{tabular}

..

58

63. 48.

65. 22.

. $50 . \quad \ldots 57$.

$46 . \quad \ldots 55$.

39 .

38.

58.

18.

-.

$51 . \quad \ldots 56$.

58. . . 73.

37.

52.

24.

21. . 28. 18.28 .

66.

\section{Roots}

Potatoes (G) ....... . . 93. . . $88 . \quad$. 99.

Carrots $(\mathrm{G}) \ldots \ldots \ldots \ldots$.. $87 . \quad \ldots 99 . \quad$. 94.

\section{Grains}

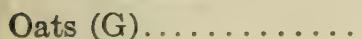

Barley $(\mathrm{G}) \ldots \ldots \ldots \ldots$

Corn $(G) \ldots \ldots \ldots \ldots$. .

Field beans $(\mathrm{G})$

Peas (G).

2. Dent corn, unground

2 . Corn meal, same material, ground......

2 . White oats, first quality, unground.......

2. Oats, same material, ground..........

$\begin{array}{ccccccc}\cdots & 69 . & \ldots & 79 . & 29 . & 75 . & 71 . \\ \cdots & 87 . & \ldots & 80 . & \ldots & 87 . & 42 . \\ \cdots & 89 . & \ldots & 76 . & 40 . & 92 . & 61 . \\ \cdots & 87 . & \ldots & 86 . & 65 . & 94 . & 13 . \\ 74.4 & 75.3 & 26.3 & 57.8 & (?) & 88.2 & 47.7 \\ 88.4 & \ldots & \ldots & 75.6 & (?) & 95.7 & 73.1 \\ 72.4 & 74.1 & 33.1 & 86.1 & 31.1 & 79.4 & 82.4 \\ 75.7 & 77.7 & 29.2 & 82.4 & 14.4 & 86.1 & 79.9\end{array}$

\section{Grains and Seeds}

Digestion BY SwINE

1. Barley, whole kernel. .

1. Flint corn, unground .

1. Corn meal, same material, finely ground..

1. Corn-and-cob meal, whole ear ground ..

?. Wheat, unground....

?. Wheat, cracked......

1. Peas, ground........

\section{By-products}

1. Wheat bran......... Rye bran (G) ........

2. Wheat shorts........

2. Linseed meal.

$\begin{array}{lllllll}80.1 & 80.3 & 5.4 & 81.4 & 48.7 & 86.6 & 57 . \\ 89.7 & 91.3 & \ldots & 89.9 & 48.7 & 93.9 & 77.6 \\ 89.5 & 91.2 & \ldots & 86.1 & 29.4 & 94.2 & 81.7 \\ & & & & & & \\ 75.6 & 76.7 & \ldots & 75.7 & 28.5 & 83.6 & 82 . \\ 72 . & . . & 44 . & 70 . & 30 . & 74 . & 60 . \\ 82 . & . . & 50 . & 80 . & 60 . & 83 . & 70 . \\ 89.8 & 91.5 & 40.3 & 88.6 & 77.9 & 95.1 & 50 .\end{array}$

$\begin{array}{lllllll}89.8 & 91.5 & 40.3 & 88.6 & 77.9 & 95.1 & 50 .\end{array}$

\begin{tabular}{ccccccl}
65.8 & & & 75.1 & 33. & 65.5 & 71.8 \\
\hdashline & 67. & $\cdots$ & 66. & 9. & 74. & 58. \\
76.5 & $\cdots$ & 5.4 & 73.5 & 36.5 & 86.8 & \\
77.5 & $\cdots$ & 10. & 86. & 12. & 85. & 80.
\end{tabular}




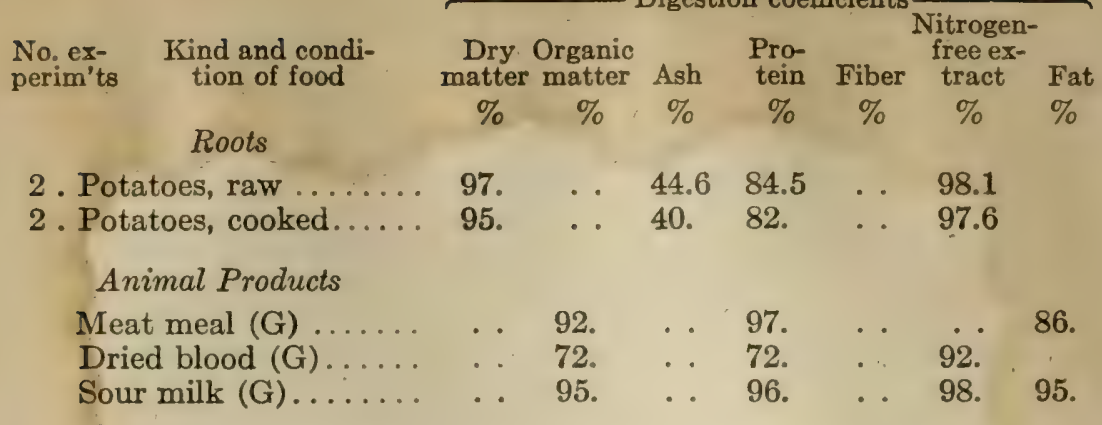

\section{COMPUTATION OF ENERGY-PRODUCTION VALUES (TO THE 100 POUNDS)}

The following remarks and tables are by Armsby and Putney (Pennsylvania Experiment Station, Bulletin No. 142), who write: "It is obviously impracticable to apply the laborious methods of respiration and calorimeter experiments to all the great variety of feeding-stuffs now in use. It does appear possible, however, to select a few typical representatives of the different classes and to apply the results obtained upon them to other similar materials, much as is even yet done to a considerable extent with the results of digestion experiments. The somewhat complicated method used by Kellner for this purpose has already been described in Bulletin No. 71 of this Station as well as in Kellner's smaller textbook, of which an English translation entitled 'The Scientific Feeding of Farm Animals' has lately been published. (Kellner expresses the results in terms of so-called 'starch values,' which are really energy values and can equally well be expressed in Therms.) A simpler method, however, can be used. Extensive tables are available which show with more or less accuracy for a large number of feeding-stuffs the digestible nutrients, the sum of which, of course, makes up the total digestible organic matter." 
As an illustration of the method of computation we may take average timothy hay, containing the following amounts of digestible matter:

In 100 Podnds of Timothy Hay

Dry matter ..................... 88.4

Digestible

Protein .......................... 3.

Carbohydrates. . . . . . . . . . . . . . . . . . 42.8

Fat .................. 1.2

Total digestible organic matter ......... 47 .

According to previous figures, each pound of digestible organic matter in roughage contains approximately 1.588 Therms of metabolizable energy, while Table 1 shows that each pound of dry matter of timothy hay causes a heat expenditure of 0.3547 Therms. The net energy value, therefore, of the 88.4 pounds of dry matter contained in 100 pounds of the hay would be:

Metabolizable energy . . 1.588 Therms $\times 47.0=74.64$ Therms

Heat expenditure...0.3547 Therms $\times 88.4=31.36$ Therms

Net energy value .............. 43.28 Therms

Continuing, Armsby and Putney discuss the net energy values of American feeding-stuffs as follows:

"Henry and Morrison ('Feeds and Feeding,' 15th edition, pages 633-66) have recently published a very valuable compilation of American analyses of feedingstuffs and of the results of American digestion experiments, and on this basis have calculated the content of digestible nutrients (for ruminants) in a great variety of feeding-stuffs.

"With the permission of these authors, we have undertaken to compute from their tables the net energy values of the more important feeding-stuffs in the manner illus- 
trated in the last paragraph of the foregoing paper and with the results contained in the following table, which includes also the digestible (true) protein and the nonprotein. In regard to this table it is to be remarked:

"First, both the digestion coefficients used by Henry and Morrison and the data for the expenditure of energy due to feed consumption are derived exclusively from experiments on ruminants (in the latter case, on cattle). Consequently, the net energy values here computed are applicable to ruminants only and not to horses nor to swine.

"Second, the table shows primarily the net energy values for maintenance or fattening. There seems good reasons for believing, however, that they may be taken without serious error to represent also the net energy values for growth and at least the relative values for milk production.

"Third, in comparing the figures for the various feeding-stuff's, account should be taken of the differences in moisture-content. Many of Henry and Morrison's averages for dry feeds show a remarkably low moisturecontent, tending to raise the suspicion that some of the analyses averaged were made on partially dried samples, although the authors state that every precaution was taken to exclude such cases from the compilation. It is evident at least that more study of the actual percentage of moisture in feeding-stuffs as they are used in practice is much to be desired.

"Fourth, Henry and Morrison's tables include only the crude protein $(\mathrm{N} \times 6.25)$. The amount of non-protein has been estimated from the crude protein by the writers on the basis of Kellner's averages."

In accordance with the method and data mentioned the following table was calculated: 
Average Dry Matter, Digestible Crude Protein, Digestible Trde Protein, and Net Energy Valdes to the 100 Pounds FOR RUMINANTS:

\section{Dried Rodghage}

Hay and Fodder from Cereals

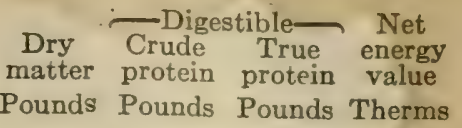

Brome grass, smooth.............

Corn fodder (ears included, medium dry)

Corn stover (ears removed, medium dry)

Millet, Hungarian................

Mixed timothy and clover.

Oat Hay....................... .

Orchard grass................

Red top...................

Timothy, all analyses.............

Timothy, before bloom.............

Timothy, early to full bloom.........

Timothy, late bloom to early seed......

Timothy, nearly ripe..............

Hay and Fodder from Legumes

Alfalfa, all analyses...............

Alfalfa, before bloom..............

Alfalfa, in bloom................

Alfalfa, in seed................

Clover, alsike....................... .

Clover, crimson. .

91.5

81.7

81.

85.7

87.8

88.

88.4

90.2

88.4

92.8

87.2

85.1

87.5

5. 3.540 .83

$\begin{array}{lll}3 . & 2.3 & 43.94\end{array}$

$\begin{array}{lll}2.1 & 1.6 & 31.62\end{array}$

$\begin{array}{lll}5 . & 3.9 & 46.96\end{array}$

$\begin{array}{lll}5.3 & 3.2 & 41.07\end{array}$

$\begin{array}{lll}4.5 & 3.9 & 32.25\end{array}$

$\begin{array}{lll}4.7 & 3.3 & 44.93\end{array}$

$\begin{array}{lll}4.6 & 3.9 & 51.22\end{array}$

$3 . \quad 2.2 \quad 43.02$

$\begin{array}{lll}4.7 & 2.9 & 43.52\end{array}$

$\begin{array}{lll}3.6 & 2.5 & 47.4\end{array}$

$\begin{array}{lll}2.4 & 1.8 & 37.54\end{array}$

$\begin{array}{lll}2.2 & 1.8 & 38.59\end{array}$

91.4

93.8

92.5

89.6

87.7

89.4

87.1

89.6

86.1

77.9

91.4

90.3

92.2

89.4

91.4

10.6

7.1

15.4

10.5

8.5

7.9

9.7

7.6

11.6

8.1

6.8

10.9

13.1

17.8

12.6

11.7

10.3

6.7

6.2

5.3

6.9

4.9

5.4

5.3

4.5

6.7

9.2

12.8

9.5

8.8

34.23

36.23

32.33

32.23

34.42

36.21

38.68

42.17

39.12

34.51

38.98

37.59

33.54

39.11

Soybeans....................

\section{Straws}

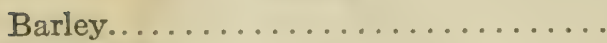

Búckwheat.

85.8

90.1

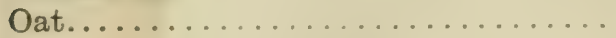

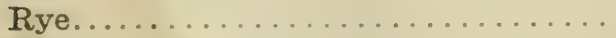

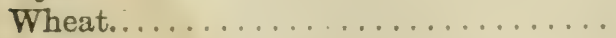

88.5

92.9

91.6
36.61

4.55

34.81

17.59

7.22 
Fresh Green Rotghage

Green Cereals, Etc.

Barley fodder.

Blue-grass, Kentucky, before heading...

Blue-grass, Kentucky, headed out.....

Blue-grass, Kentucky, after bloom.....

Buckwheat, Japanese...... . . . . . . . . .

Cabbage..

Cabbage, waste outer leaves..........

Corn fodder, dent, all analyses........

Corn fodder, dent, in tassel.........

Corn fodder, dent, in milk...........

Corn fodder, dent, dough to glazing...

Corn fodder, dent, kernels glazed.

Corn fodder, dent, kernels ripe .

Corn fodder, flint, all analyses. .

Corn fodder, flint, in tassel..... . . . . .

Corn fodder, flint, in milk...........

Corn fodder, flint, kernels glazed...... .

Corn fodder, flint, kernels ripe.........

Corn fodder, sweet, before milk stage...

Corn fodder, sweet, roasting-ears or later

Corn fodder, sweet, ears removed..... .

Millet, Hungarian... . . . . . . . . . . .

Oat fodder.....................

Orchard grass.................

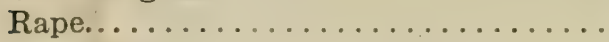

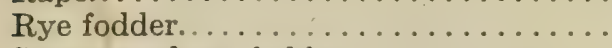

Sweet sorghum fodder............

Timothy, before bloom..............24.2

Timothy, in bloom................. 32.1

Timothy, in seed................. 46.4

Wheat fodder................. 27.4

\section{Green Legumes}

Alfalfa, before bloom.............. 19.9

Alfalfa, in bloom............... . 25.9

Alfalfa, after bloom.............. 29.8

Clover, alsike.................. . 24.3

Clover, crimson.................. 17.4

Clover, red, all analyses........... 26.2

Clover, red, in bloom............... 27.5

Clover, red, rowen................. 34.4

Cowpeas...................... 16.3

Peas, Canada field............. 16.6

Soybeans, all analyses.............. 23.6

Soybeans, in bloom
23.6
20.8
CDigestible- Net Crude True energy protein protein value

Pounds Pounds Therms
23.2

2.3

3.7

2.8

1.9

2.2

1.9

1.7

1.

1.1

1.

1.3

1.1

1.5

1.

.9

.9

1.

1.2

.8

1.2

1.

1.9

2.3

1.7

2.6

2.1

.7

1.8

1.3

1.5

2.8

2. 14.08

$\begin{array}{ll}2.8 & 14.82\end{array}$

$\begin{array}{ll}2.2 & 17.77\end{array}$

$\begin{array}{ll}1.6 & 21.01\end{array}$

$\begin{array}{ll}1.5 & 17.78\end{array}$

$1.3 \quad 8.87$

1.17 .05

$.8 \quad 14.6$

$\begin{array}{ll}.8 & 9.52\end{array}$

$.8 \quad 13.64$

1. $\quad 17.35$

$.8 \quad 16.74$

$\begin{array}{ll}1.1 & 22.48\end{array}$

$.8 \quad 13.53$

$\begin{array}{ll}.7 & 6.89\end{array}$

$\begin{array}{rr}.7 & 10.39\end{array}$

$.8 \quad 13.49$

$.9 \quad 17.84$

.6 7.82

.913 .38

$.8 \quad 14.26$

$1.1 \quad 17.24$

2. 14.06

$\begin{array}{ll}1.1 & 15.81\end{array}$

$\begin{array}{ll}1.7 & 13.07\end{array}$

$1.4 \quad 15.99$

$.4 \quad 15.37$

$1.1 \quad 18.36$

$.8 \quad 18.89$

1. 26.36

$1.9 \quad 18.75$

$\begin{array}{lll}3.5 & 1.9 & 9.2\end{array}$

$\begin{array}{lll}3.3 & 1.8 & 11.5\end{array}$

$\begin{array}{lll}2.1 & 1.3 & 11.1\end{array}$

$\begin{array}{lll}2.7 & 1.5 & 14.56\end{array}$

$\begin{array}{lll}2.3 & 1.6 & 10.83\end{array}$

$\begin{array}{lll}2.7 & 1.7 & 15.87\end{array}$

$\begin{array}{lll}2.7 & 1.8 & 16.74\end{array}$

$\begin{array}{lll}3.3 & 2.2 & 17.3\end{array}$

$\begin{array}{lll}2.3 & 1.7 & 10.42\end{array}$

$\begin{array}{lll}2.9 & 2.1 & 9.78\end{array}$

$\begin{array}{lll}3.2 & 2.4 & 12.53\end{array}$

$\begin{array}{lll}3 . & 2.3 & 10.44\end{array}$ 


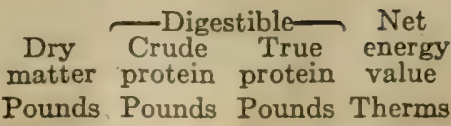

$\begin{array}{llll}24.2 & 3.1 & 2.5 & 12.7 \\ 18.1 & 3.5 & 2.4 & 11.95\end{array}$

SILAGE

Corn, well-matured, recent analyses....

Corn, immature................

Corn, from frosted ears............

Corn, from field-cured stover.........

Clover.......................

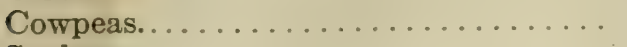

Soybeans. . . . . . . . . . . . . . . .

Sugar-beet pulp................. 10

\begin{tabular}{lrrr}
26.3 & 1.1 & .6 & \multicolumn{1}{c}{15.9} \\
21. & \multicolumn{1}{l}{1.} & .4 & 11.96 \\
25.3 & 1.2 & .6 & 14.27 \\
19.6 & .5 & .3 & 8.98 \\
27.8 & 1.3 & .8 & 7.26 \\
22. & 1.8 & .1 .1 & 11.05 \\
27.1 & 2.6 & 1.5 & 11.59 \\
10. & .8 & .5 & 9.32
\end{tabular}

Roots, Tubers and Fruits

Apple.

Beet, common.

Beet, sugar-

Carrot. .

Mangels.

Potatoes

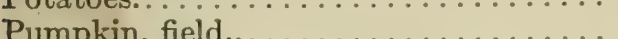

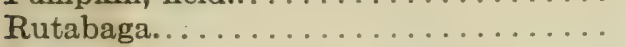

Turnip

Grains

Cereal Grains

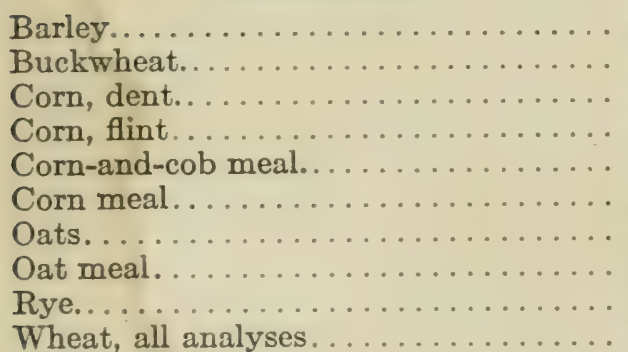

Wheat, winter.

Wheat, spring.

90.7

87.9

89.5

87.8

89.6

88.7

90.8

92.1

90.6

89.8

89.1

89.9

$\begin{array}{rcl}9 . & 8.3 & 89.94 \\ 8.1 & 7.2 & 59.73 \\ 7.5 & 7 . & 89.16 \\ 7.7 & 7.2 & 87.5 \\ 6.1 & 5.7 & 75.8 \\ 6.9 & 6.4 & 88.75 \\ 9.7 & 8.7 & 67.56 \\ 12.8 & 11.5 & 86.2 \\ 9.9 & 9 . & 93.71 \\ 9.2 & 8.1 & 91.82 \\ 8.7 & 7.7 & 91.66 \\ 9.2 & 8.1 & 91.41\end{array}$

\section{Leguminous Seeds}

Bean, navy................... 86.6

Cowpea...................... 88.4

Pea, field.

90.8

89.1

93.5

Peanut with hull.

Peanut kernel

94.

$\begin{array}{lrr}18.8 & 16.4 & 73.29 \\ 19.4 & 16.9 & 79.46 \\ 19 . & 16.6 & 78.72 \\ 19.8 & 17.2 & 77.62 \\ 19.4 & 16.9 & 83.15 \\ 24.1 & 22.2 & 109.04 \\ 30.7 & 27.3 & 81.29\end{array}$

Soybean.

90.1

$\begin{array}{rrr}.4 & .1 & 15.92 \\ .9 & .1 & 7.84 \\ 1.2 & .4 & 11.2 \\ .8 & .5 & 9.21 \\ .8 & .1 & 5.68 \\ 1.1 & .1 & 18.27 \\ 1.1 & .6 & 6.05 \\ 1 . & .3 & 8.46 \\ 1 . & .4 & 6.16\end{array}$


Oil Seeds

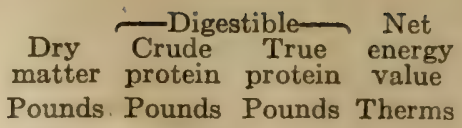

Cotton seed..................... 90.6

Flax seed...................... 90.8

Sunflower seed................. 95.5

$\begin{array}{lll}13.3 & 11.9 & 78.33 \\ 20.6 & 19.2 & 83.17 \\ 23.3 & 20.2 & 95.77 \\ 13.5 & 11.7 & 92.49\end{array}$

\section{Datry Products}

Buttermilk....................

Cow's milk.........................

Skim-milk-centrifugal.............

Skim-milk-gravity...............

Skim-milk-dried.. . . . . . . . . . . . . .

Whey..................... 6.6

$\begin{array}{rrrr}9.4 & 3.4 & 3.4 & 13.32 \\ 13.6 & 3.3 & 3.3 & 29.01 \\ 9.9 & 3.6 & 3.6 & 14.31 \\ 9.6 & 3.1 & 3.1 & 15.43 \\ 91.7 & 34.4 & 34.4 & 103.91 \\ 6.6 & .8 & .8 & 10.39\end{array}$

By-Products

Fermentation Industries

Brewers' grains, dried.............

Brewers' grains, dried, below 25 per cent protein..................

Brewers' grains, wet..............

Distillers' grains, dried, from corn......

Distillers' grains, dried, from rye.......

Distillers' grains, wet..............

Malt.....................

Maltsprouts .................

$\begin{array}{llll}92.5 & 21.5 & 20.2 & 53.38\end{array}$

$\begin{array}{llll}91.8 & 18.7 & 17.5 & 50.93\end{array}$

$\begin{array}{llll}24.1 & 4.6 & 4.4 & 14.53\end{array}$

$\begin{array}{llll}93.4 & 22.4 & 18.3 & 85.08\end{array}$

$\begin{array}{llll}92.8 & 13.6 & 11.1 & 56.01\end{array}$

$\begin{array}{llll}22.6 & 3.3 & 2.8 & 22.05\end{array}$

$\begin{array}{llll}94.2 & 15.8 & 11.8 & 87.82\end{array}$

$\begin{array}{llll}92.4 & 20.3 & 12.5 & 72.72\end{array}$

\section{Milling}

Buckwheat bran.............. 88.8

Buckwheat hulls....... . . . . . . . . 89.7

Buckwheat middlings... . . . . . . . 88.

Hominy feed................. 89.9

Rye bran.................... 88.6

Wheat bran ................... 89.9

Wheat middlings, flour........... 89.3

Wheat middlings, standard........ 89.6

$\begin{array}{lll}10.5 & 9.1 & 30.59\end{array}$

$\begin{array}{lll}.4 & ? & -7.69\end{array}$

$\begin{array}{lll}24.6 & 20.8 & 72.19\end{array}$

$\begin{array}{lll}7 . & 6.5 & 81.31\end{array}$

$\begin{array}{lll}12.2 & 10.5 & 79.35\end{array}$

$12.5 \quad 10.853$.

$15.7 \quad 14 . \quad 75.02$

$13.4 \quad 12.59 .1$

\section{Oil Extraction}

Coconut meal, low in fat........... 90.4

Coconut meal, high in fat.......... 92.3

Cottonseed hulls................ 90.3

Cottonseed meal, choice........... 92.5

Cottonseed meal, prime............. 92.2

Germ oil meal, corn................. 91.1

Linseed meal, new process. . . . . . . . 90.4

Linseed meal, old process........... 90.9

Palmnut cake............... 89.6

$\begin{array}{rlr}18.8 & 18.3 & 83.49 \\ 18.4 & 18 . & 100.31 \\ .3 & ? & 9.92 \\ 37 . & 35.4 & 93.46 \\ 33.4 & 32 . & 90 . \\ 16.5 & 14.3 & 83.88 \\ 31.7 & 30.9 & 85.12 \\ 30.2 & 28.5 & 88.91 \\ 12.4 & 12 . & 94.18\end{array}$




\begin{tabular}{|c|c|c|c|c|}
\hline & \multirow[b]{2}{*}{$\begin{array}{c}\text { Dry } \\
\text { matter }\end{array}$} & \multicolumn{2}{|c|}{-Digestible- } & \multirow{2}{*}{$\begin{array}{l}\text { Net } \\
\text { energy } \\
\text { value }\end{array}$} \\
\hline & & $\begin{array}{l}\text { Crude } \\
\text { protein }\end{array}$ & $\begin{array}{c}\text { True } \\
\text { protein }\end{array}$ & \\
\hline & Pounds & Pounds & Pounds & Therms \\
\hline ake from hulled nuts. & 89.3 & 42.8 & 41.4 & 93.55 \\
\hline ke, hulls included... & 94.4 & 20.2 & 19.5 & 42.57 \\
\hline aeal, fat extracted. & 88.2 & 38.1 & 37.3 & 99.65 \\
\hline seed cake. & 90. & 32. & 29.1 & 88.87 \\
\hline
\end{tabular}

\section{Starch Manufacture}

Gluten feed..................

Gluten meal.....................

Starch feed, dry................

Starch feed, wet.................

$\begin{array}{rrrr}91.3 & 21.6 & 20.1 & 80.72 \\ 90.9 & 30.2 & 28.1 & 84.15 \\ 90.7 & 11.2 & 9.2 & 77.46 \\ 33.4 & 4.1 & 3.7 & 30.45\end{array}$

\section{Sugar Manufacture}

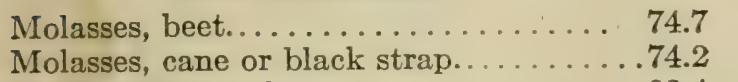

Molasses beet pulp............... 92.4

Sugar-beet pulp, dried............. 91.8

Sugar-beet pulp, ensiled........... 10.

Sugar-beet pulp, wet........... 9.3

\section{Packing-House}

Dried blood

Tankage

Over 60 per cent protein ........ 92.6

55-60 per cent protein........... .92.5

45-55 per cent protein.......... 92.5

Below 45 per cent protein........ 93.5

\begin{tabular}{rrr}
1.1 & \multicolumn{1}{c}{57.1} \\
1. & \multicolumn{1}{c}{5} & 55.38 \\
5.9 & 3.5 & 76.28 \\
4.6 & .7 & 75.87 \\
.8 & .5 & 9.32 \\
.5 & .5 & 8.99 \\
& & \\
69.1 & 68.6 & 68.12 \\
& & \\
58.7 & 55.6 & 93.04 \\
54. & 51.1 & 83.58 \\
48.1 & 45.5 & 72.96 \\
37.6 & 35.6 & 54.16
\end{tabular}

4. STANDARDS FOR MILK PRODUCTION AS DEVELOPED BY HAECKER, SAVAGE, AND ECKLES

Protein and Total Nutrients for One Pound of Milk

\begin{tabular}{|c|c|c|c|c|c|c|}
\hline \multirow{4}{*}{$\begin{array}{l}\text { Per cent } \\
\text { fat in } \\
\text { milk* }\end{array}$} & \multicolumn{2}{|c|}{ Haecker } & \multicolumn{2}{|c|}{ - Sayag } & \\
\hline & $-\mathrm{Ha}$ & Total & & Total & & \\
\hline & Protein & nutrients & Protein & nutrients & Protein & nutrients \\
\hline & $\begin{array}{l}\text { Pounds } \\
\quad 07\end{array}$ & $\begin{array}{l}\text { Pounds } \\
78\end{array}$ & $\begin{array}{l}\text { Pounds } \\
.07\end{array}$ & $\begin{array}{l}\text { Pounds } \\
.7925\end{array}$ & Pounds & Pounds \\
\hline 2.5 & .039 & .219 & .0527 & .2574 & & \\
\hline 2.6 & .0396 & .224 & .0535 & .2629 & & \\
\hline 2.7 & .0402 & .229 & .0543 & .2685 & & \\
\hline 2.8 & .0408 & .233 & .0551 & .2743 & & \\
\hline 2.9 & .0414 & .239 & .0559 & .2812 & & \\
\hline 3. & .042 & .244 & .0567 & .287 & & \\
\hline 3.1 & .0426 & .249 & .0575 & 2928 & & \\
\hline & & *For mai & ance, pe & 00 pounds & & \\
\hline
\end{tabular}




\begin{tabular}{|c|c|c|c|c|c|c|}
\hline \multirow{4}{*}{$\begin{array}{l}\text { Per cent } \\
\text { fat in } \\
\text { milk* }\end{array}$} & \multicolumn{2}{|c|}{-Haecker $\longrightarrow$} & \multicolumn{2}{|c|}{ Savage -} & \multicolumn{2}{|c|}{$\longrightarrow$ Eckles $\longrightarrow$} \\
\hline & & Total & & Total & & Total \\
\hline & Protein & nutrients & Protein & nutrients & Protein & nutrients \\
\hline & Pounds & Pounds & Pounds & Pounds & & Pounds \\
\hline 3.2 & .0432 & .254 & .0583 & .2987 & & \\
\hline 3.3 & .0438 & .26 & .0591 & .3055 & & \\
\hline 3.4 & .0444 & .265 & .0599 & .3115 & .0469 & .285 \\
\hline 3.5 & .045 & .271 & .0608 & .3185 & & \\
\hline 3.6 & 0456 & .276 & .0616 & .3243 & & \\
\hline 3.7 & .0462 & .282 & .0624 & .3312 & & \\
\hline 3.8 & .0468 & .287 & .0632 & .3369 & .051 & .283 \\
\hline 3.9 & .0474 & .292 & .064 & .3428 & .056 & .298 \\
\hline 4. & .048 & .297 & .0648 & .3497 & & \\
\hline 4.1 & .0486 & .302 & .0656 & .3555 & & \\
\hline 4.2 & .0492 & 307 & .0664 & .3612 & & \\
\hline 4.3 & .0498 & .312 & .0672 & .3671 & & \\
\hline 4.4 & .0504 & .317 & .068 & .3729 & & \\
\hline 4.5 & .051 & .322 & .0689 & .3787 & & \\
\hline 4.6 & .0516 & .327 & .0697 & .3842 & & \\
\hline 4.7 & .0522 & .331 & .0705 & .389 & & \\
\hline 4.8 & .0528 & .335 & .0713 & .3945 & & \\
\hline 4.9 & .0534 & .339 & .0721 & .3992 & & \\
\hline 5. & .054 & .344 & .0729 & .4048 & & \\
\hline 5.1 & .0546 & .349 & .0737 & .4105 & & \\
\hline 5.2 & .0552 & .353 & .0745 & .415 & & \\
\hline 5.3 & .0558 & .357 & .0753 & .4209 & .048 & .332 \\
\hline 5.4 & .0564 & .361 & .0761 & .4253 & & \\
\hline 5.5 & .057 & .366 & .077 & .4311 & .0587 & .396 \\
\hline 5.6 & .0576 & .37 & .0778 & .4355 & & \\
\hline 5.7 & .0582 & .375 & .0786 & .4413 & & \\
\hline 5.8 & .0588 & .38 & .0794 & .4469 & & \\
\hline 5.9 & .0594 & .384 & .0802 & .4517 & & \\
\hline 6. & .06 & .388 & .081 & .4572 & & \\
\hline 6.1 & .0606 & .392 & .0818 & .4619 & .072 & .505 \\
\hline 6.2 & .0612 & .397 & .0826 & .4676 & & \\
\hline 6.3 & .0618 & .401 & .0834 & .4721 & & \\
\hline 6.4 & .0624 & .407 & .0842 & .4791 & & \\
\hline 6.5 & .063 & .41 & .0851 & .4835 & & \\
\hline 6.6 & .0636 & .415 & .0859 & .4882 & & \\
\hline 6.7 & .0642 & .419 & .0867 & .4926 & & \\
\hline 6.8 & .0648 & .423 & .0875 & .4984 & & \\
\hline 6.9 & .0654 & .428 & .0883 & .504 & & \\
\hline 7. & .066 & .431 & .0891 & .5075 & & \\
\hline
\end{tabular}




\section{FEEDING STANDARDS}

The feeding standards for the various classes of farm animals are taken from Mentzel \& Lengerke's Landw. Kalender for 1899. They are intended to apply to animals of average size fed under normal conditions. They are not to be regarded as feeding recipes, but are to be varied according to circumstances. Small animals should receive proportionately more food than large ones; milch cows in proportion to the quantity and richness of the milk; growing and fattening animals according to the rapidity of increase desired; work animals according to the severity of labor, and individual animals according to their peculiar needs.

The quantity of "dry substance" will vary according to the digestibility of the ration, with no harm. It is important to maintain the necessary quantity of digestible dry substance. This should be somewhat more if the ration has a larger proportion of coarse materials than when it is mostly grain. The nutritive ratio may widely vary according to the availability and price of feeding-stuffs. The method of calculating a standard ration is explained in Chapter XIX.

Per 1,000 Las. Live Weight, Daily Dry -Digestible organic substances- Nutri-

Kind of animal sub- Pro- Carbo-
stance tein hydrates Fat Total ratio 1:
Lbs. Lbs. Lbs. Lbs. Lbs.

1. Oxen-

At rest .......... 18

Light work........ 22

Moderate work...... 25

Severe work........ 28

\begin{tabular}{llllr}
.7 & \multicolumn{1}{c}{8.} & .1 & 8.8 & 11.8 \\
1.4 & 10. & .3 & 11.7 & 7.7 \\
2. & 11.5 & .5 & 14. & 6.5 \\
2.8 & 13. & .8 & 16.6 & 5.3
\end{tabular}

2. Fattening bovines-

First period ........ 30

Second period ....... 30

Third period ........ 26

$2.5 \quad 15 . \quad .5 \quad 18$.

$\begin{array}{lllll}3 . & 14.5 & .7 & 18.2 & 5.4\end{array}$

$\begin{array}{lllll}2.7 & 15 . & 7 & 18.4 & 6.2\end{array}$ 


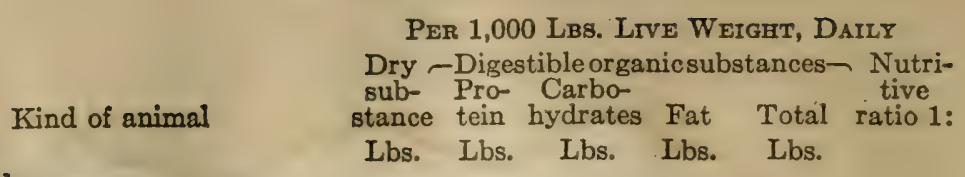

3. Milch cows-

Daily milk yield 11 pounds ............ pounds.............

Daily milk yield 22 pounds........... $271 / 2$ pounds........... $\begin{array}{llllll}25 & 1.6 & 10 . & .3 & 11.9 & 6.7\end{array}$

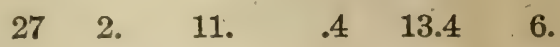
$\begin{array}{lllllll}29 & 2.5 & 13 . & .5 & 16 . & 5.7\end{array}$ $\begin{array}{llllll}32 & 3.3 & 13 . & .8 & 17.1 & 4.5\end{array}$

4. Sheep-

Coarse wool ......... 20

Fine wool .......... 23

$\begin{array}{lllll}1.2 & 10.5 & .2 & 11.9 & 9.1\end{array}$

$\begin{array}{lllll}1.5 & 12 . & .3 & 13.8 & 8.5\end{array}$

5. Ewes, sucking lambs .... 25

$\begin{array}{lllll}2.9 & 15 . & .5 & 18.4 & 5.6\end{array}$

6. Fattening sheep-

First period ........ 30

Second period ....... 28

$\begin{array}{lllll}3 . & 15 . & .5 & 18.5 & 5.4\end{array}$

7. Horses-

Light work........ 20

Moderate work........ 24

Severe work........ 26

8. Brood sows .......... 22

$\begin{array}{lllll}3.5 & 14.5 & .6 & 18.6 & 4.5\end{array}$

9. Fattening swine-

First period ..........36

Second period ....... 32

Third period ........ 25

$\begin{array}{lllll}1.5 & 9.5 & .4 & 11.4 & 7 . \\ 2 . & 11 . & .6 & 13.6 & 6.2 \\ 2.5 & 13.3 & .8 & 16.6 & 6 . \\ 2.5 & 15.5 & .4 & 18.4 & 6.6 \\ & & & & \\ 4.5 & 25 . & .7 & 30.2 & 5.9 \\ 4 . & 24 . & .5 & 28.5 & 6.3 \\ 2.7 & 18 . & .4 & 21.1 & 7 .\end{array}$

10 Growing Cattle

Dairy Breeds

\begin{tabular}{|c|c|c|c|c|c|c|}
\hline & & & & & & \\
\hline Age in & $\begin{array}{l}\text { Live weight } \\
\text { per head }\end{array}$ & & & & & \\
\hline months & Lbs. & & & & & \\
\hline & $.150 \ldots 23$ & 4. & 13. & 2. & & 4.5 \\
\hline $3-6$. & $.300 \ldots .24$ & 3. & 12.8 & 1. & 16.8 & 5.1 \\
\hline 6-12. & $.500 \ldots .27$ & 2. & 12.5 & .5 & 15. & 6.8 \\
\hline $12-18$ & $.700 \ldots 26$ & 1.8 & 12.5 & .4 & 14.7 & 7.5 \\
\hline $18-24$ & $.900 \ldots 26$ & 1.5 & 12. & .3 & 13.8 & 8.5 \\
\hline
\end{tabular}

Beef. Breeds

\begin{tabular}{|c|c|c|c|c|}
\hline $2-3 \ldots \ldots \ldots \ldots \ldots 165 \ldots 23$ & 4.2 & 13. & 2. & 19.2 \\
\hline$\ldots 330 \ldots 24$ & 3.5 & 12.8 & 1.5 & 17.8 \\
\hline $.550 \ldots .25$ & 2.5 & 13.2 & .7 & -16.4 \\
\hline$\therefore 750 \ldots 24$ & 2. & 12.5 &. .5 & 15. \\
\hline $18-24 \ldots \ldots \ldots \ldots \ldots .935 \ldots . .24$ & 1.8 & 12. & .4 & 14.2 \\
\hline
\end{tabular}


Per 1,000 Lis. Live Weight, Dailt

Kind of animal

\section{Growing Sheep}

\section{Wool Breeds}

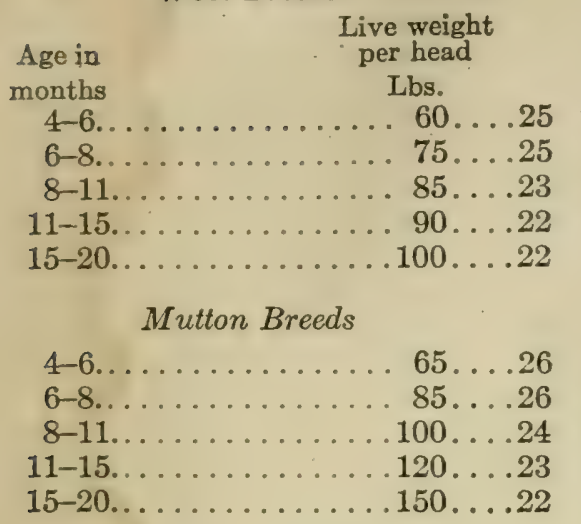

GRowING SwINE

Breeding Stock

2-3............ 45 . . 444 $3-5 \ldots \ldots \ldots \ldots \ldots . . \ldots 35$

$5-6 \ldots \ldots \ldots \ldots . \ldots . \ldots 120 \ldots . . .32$

$6-8 \ldots \ldots \ldots \ldots \ldots . . .28$

$8-12 \ldots \ldots \ldots \ldots \ldots 260 \ldots 25$

Growing Fattening Animals

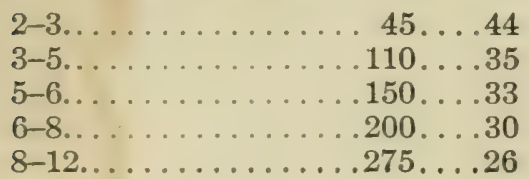

$\begin{array}{llll}3.4 & 15.4 & .7 & 19.5\end{array}$

$\begin{array}{llll}2.8 & 13.8 & .6 & 17.2\end{array}$

$\begin{array}{llll}2.1 & 11.5 & .5 & 14.1\end{array}$

$\begin{array}{llll}1.8 & 11.2 & .4 & 13.4\end{array}$

$\begin{array}{llll}1.5 & 10.8 & .3 & 12.6\end{array}$

5.

5.4

6.

7.

7.7

$\begin{array}{lllll}4.4 & 15.5 & .9 & 20.8 & 4 . \\ 3.5 & 15 . & .7 & 19.2 & 4.8 \\ 3 . & 14.3 & .5 & 17.8 & 5.2 \\ 2.2 & 12.6 & .5 & 15.3 & 6.3 \\ 2 . & 12 . & .4 & 12.4 & 6.5\end{array}$

$\begin{array}{lllll}7.6 & 28 . & 1 . & 35.7 & 4 .\end{array}$

5. $\quad 23.1 \quad 8 \quad 28.9 \quad 5$.

$\begin{array}{lllll}3.7 & 21.3 & .4 & 25.4 & 6 .\end{array}$

$\begin{array}{lllll}2.8 & 18.7 & .3 & 21.8 & 7 .\end{array}$

$\begin{array}{lllll}2.1 & 15.3 & .2 & 17.6 & 7.5\end{array}$

$\begin{array}{llll}7.6 & 28 . & 1 . & 35.7\end{array}$

4.

$\begin{array}{lllll}5 . & 23.1 & 8 & 28.9 & 5 .\end{array}$

$\begin{array}{lllll}4.3 & 22.3 & .6 & 27.2 & 5.5\end{array}$

$\begin{array}{llllll}3.6 & 20.5 & .4 & 24.5 & 6 .\end{array}$

$\begin{array}{lllll}3 . & 18.3 & .3 & 21.6 & 6.4\end{array}$ 


\section{FERTILIZING CONSTITUENTS OF AMERICAN FEEDING-STUFFS}

This table is the one prepared by the Office of Experiment Stations, United States Department of Agriculture, and published in the Handbook of Experiment Station Work, Bulletin No. 15.

$\begin{array}{ccccc}\text { Moisture } & \text { Ash } & \text { Nitrogen } & \text { phoric } & \text { acium } \\ \text { oxide } & \text { oxide } \\ \% & \% & \% & \% & \%\end{array}$

\section{Corn fodder..............}

$\begin{array}{lcccc}78.61 & 4.84 & .41 & .15 & .33 \\ 82.19 & . & .23 & .09 & .23 \\ 62.11 & . & .33 & .15 & .73 \\ 83.36 & 1.31 & .49 & .13 & .38 \\ 62.58 & . & .61 & .19 & .41 \\ 71.05 & . & .53 & .2 & .34 \\ 74.31 & . & .39 & .16 & .55 \\ & & & & \\ 73.14 & 2.09 & .43 & .16 & .76 \\ 66.9 & 2.15 & .48 & .26 & .76 \\ & & & & \\ 75.2 & 2.6 & .47 & .28 & 1.1 \\ 74.85 & 2.84 & .54 & .29 & 1.14 \\ 63.12 & 3.27 & .91 & .23 & .75 \\ 80 . & . . & .53 & .13 & .46 \\ 81 . & . . & .56 & .2 & .24 \\ & & & \\ 81.8 & 1.47 & .44 & .11 & .2 \\ & & & & \\ 82.5 & . . & .43 & .13 & .49 \\ 75.3 & 2.25 & .72 & .13 & .56 \\ 78.81 & 1.47 & .27 & .1 & .31 \\ 82.59 & 1.82 & .41 & .14 & .42 \\ 73.2 & . . & .29 & .15 & .53 \\ 74.71 & . & .68 & .33 & 1.37 \\ 85.35 & . & .44 & .35 & 1.73 \\ 83.15 & .96 & .51 & .11 & .15 \\ 71.6 & 1.93 & 1.13 & .18 & .58 \\ 84.5 & 1.94 & .59 & 1.19 & .7 \\ & & & & .75 \\ 84.36 & 2.45 & .42 & .11 & .75 \\ 77.95 & . & .28 & .11 & .37 \\ 71.03 & . .5 & .79 & .42 & .44 \\ 75 . & 1.05 & .32 & .15 & .4 \\ \text { nng und Verdaulichkeit der } & \text { Futtermittei. } \\ & & & & \end{array}$

Sorghum fodder..................

Rye fodder................

Oat fodder.................

Common millet..............

Japanese millet..............

Hungarian grass (German millet)

Orchard grass (Dactylis glomer$a t a)^{*} \ldots \ldots \ldots \ldots \ldots \ldots$.

Timothy grass (Phleum pratense)*

Perennial rye grass (Lolium perenne) $)^{*} . \ldots \ldots \ldots \ldots$.........

Italian rye grass (Lolium italicum $)^{*}$..................

Mixed pasture grasses..........

Red clover (Trifolium pratense)..

White clover (Trifolium repens)..

Alsike clover (Trifolium hybridum)..................

Scarlet clover (Trifolium incarnatum)................

Alfalfa (Medicago sativa)........

Cowpea..................

Serradella (Ornithopis sativus)....

Soja bean (Glycine soja).........

Horse bean (Vicia faba) .........

White lupine (Lupinus albus)....

Yellow lupine (Lupinus luteus)*..

Flat pea (Lathyrus sylvestris)*...

Common vetch (Vicia sativa)* ..

Prickly comfrey (Symphytum asperrimum)...............

Corn silage...............

Corn and soja-bean silage.......

Apple pomace silage*........ 75

*Dietrich and König: Zusamensetzung und Verdaulichkeit der Futtermittei. 


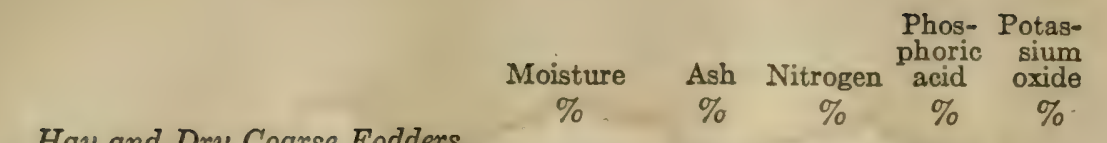
Hay and Dry Coarse Fodders

Corn fodder (with ears)........ 7.85

Corn stover (without ears)......

Teosinte (Euchlæna luxurians)...

Common millet. .............

Japanese millet. . . . . . . . . . . .

Hungarian grass... . . . . . . . . .

Hay of mixed grasses..........

Rowen of mixed grasses........

Red-top (Agrostis vulgaris)......

Timothy.................

Orchard grass...............

Kentucky blue.grass (Poa pratensis) .................

Meadow fescue (Festuca pratensis)

Tall meadow oat grass (Arrhenathrum avenaceum)..........

Meadow foxtail 'Alopecurus pratensis).................

Perennial rye grass. . . . . . . . . .

Italian rye grass............

Salt marsh hay..............

Japanese buckwheat. ... . . . . .

Red clover...............

Mammoth red clover (Trifolium medium $). . . . . . . . . .$.

White clover...............

Scarlet clover* ${ }^{*} \ldots \ldots \ldots \ldots \ldots$

Alsike clover................ .

Blue melilot (Melilotus cæruleus).

Bokhara clover (Melilotus alba)..

Sainfoin (Onobrychis sativa)...

Sulla (Hedysarum coronarium).

Lotus villosus.

9.12

$4.91 \quad 1.76$

.54

6.06

9.75

10.45

7.69

11.99

18.52

7.71

7.52

8.84

$3.74 \quad 1.04$

$6.53 \quad 1.46$

.29

.55

. 1.28

$5.8 \quad 1.11$

$6.18 \quad 1.2$

6.34

9.57

1.41

4.59

1.61

4.93

1.15

6.42

1.26

10.35

8.89

\subsection{6}

1.31

.49

.4

.35

.27

.43

.36

.53

.89

15.35

8.08

1.19

.99

1.4

3.7

1.69

1.22

1.3

1.55

1.49

1.02

.41

.9

1.88

15.35

9.13

8.71

5.36

5.72

11.33

$4.92 \quad 1.16$

.4

1.57

2.1

11.41

$5.24 \quad 1.54$

$\begin{array}{ll}6.79 & 1.23\end{array}$

. 1.19

$\therefore \quad 1.18$

.. 1.63

$6.93 \quad 2.07$

.4

1.72

18.3

8.72

2.23

.32

1.99

.44

1.55

.56

1.27

.25

.85

.72

3.32

2.2

9.94

6.55

8.22

7.43

12.17

9.39

11.52

6.3

77

2.75

.55

1.22

Soja bean (whole plant).

Soja bean (straw)...

13.

Cowpea (whole plant)..

Serradella.

10.95

7.39

11.11

2.05

.52

1.81

Scotch tares.

15.8

2.34

.67

1.31

$\begin{array}{lll}2.19 & .51 & 1.68\end{array}$

$\begin{array}{lll}13.65 & 1.92 & .54\end{array}$

2.8

$\begin{array}{llll}7.7 & 1.98 & .56 & 1.83\end{array}$

$\begin{array}{lllll}7.55 & 2.63 & .76 & 2.02\end{array}$

$\begin{array}{llll}\text {. } & 2.46 & .45 & 2.09\end{array}$

$8.23 \quad 2.1$

$6.47 \quad 2.32$
.

.59

1.81

.67

1.08

$.4 \quad 1.32$

.. 1.75

8.4

1.95

1.47

$10.6 \quad 2.7$

.52

.65

Ox-eye daisy (Chrysanthemum leucanthemum)...............

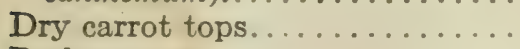

Barley straw.

9.65
9.76
11.44
13.08

.. 2.96

.82

3.

Barley chaff.

6.37
12.52
5.3

.28

.44

1.25

$.61 \quad 4.88$

$.3 \quad 2.03$

.27

.99

*Dietrich and König. 
Hay and Dry Coarse Fodders-

Moisture $\%$

As

Phos- Potas. continued

Wheat straw.
Wheat chaff.

12.56

8.05

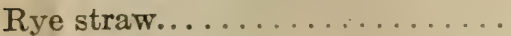

7.61

9.09

Oat straw......

11.9

Roots, Bulbs, Tubers, etc.

Potatoes.................. 79.75

Red beets................ 87.73

Yellow fodder beets. . . . . . . . . . 90.6

Sugar-beets ................ 86.95

Mangel-wurzels............. 87.29

$\begin{array}{ll}\text { Turnips ................... . } & 89.49 \\ \text { Rutabagas... . . . . . . . . . } & 89.13\end{array}$

89.79

Carrots.

.99

\subsection{1}

7.18

3.25

4.76

1.04

1.22

1.01

1.06

9.22
.21

.24

.19

.22

.19

.18

.19

.15

.07

.09

.09

.1

.09

.1

.12

.09
.51

.42

.79

.21 .24

$.07 \quad .52$

Grains and Other Seeds

Corn kernels ............... 10.88

Sorghum seed .............. 14.

Barley*.

14.3

Oats

18.17

Wheat (spring)

14.35

Wheat (winter).

14.75

Rye.................... . 14.9

Common millet. . . . . . . . . . . 12.68

Japanese millet. . . . . . . . . . . . 13.68

Rice .................... 12.6

Buckwheat................ 14.1

Soja beans

18.33

$1.53 \quad 1.82$

. 1.48

2.48

2.98

1.57

1.51

2.06

2.36

.. 2.36

1.76

. 2.04

.. 1.73

$.82 \quad 1.08$

.. 1.44

$4.99 \quad 5.3$

.29

.44

.46

.48

.38

.39

.49

.51

\section{Mill Products}

Corn meal

12.95

Corn-and-cob meal

8.96

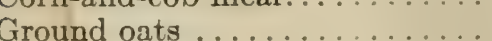

11.17

Ground barley.

13.43

Rye flour ... . . . . . . . . . . . 14.2

Wheat flour.

9.83

Pea meal..

8.85

1.41

1.58

1.41

$3.37 \quad 1.86$

2.06

1.55

1.68

1.22

2.21

2.68

3.08
.7

.81

.79

.82

.7

.89

.82

.85

.69

.18

.44

.4

.42

.48

.62

.39

.61

.54

.36

.38

.09

.21

$1.87 \quad 1.99$
.63

.57

.4

.47

$.77 \quad .59$

$.66 \quad .34$

$.85 \quad .65$

$.57 \quad .54$

$.82 \quad .99$

By-products and Waste Materials

Corn cobs................. 12.09

8.93

.82

2.21

Gluten meal.

8.59

.73

.5

1.63

Starch feed (glucose refuse)

8.1

5.03

.06

.6

2.62

.49

$.33 \quad .05$

$.29 \quad .15$

*Dietrich and König. 


\begin{tabular}{|c|c|c|c|c|c|}
\hline $\begin{array}{l}\text { By-products and Waste Materials- } \\
\text { continued }\end{array}$ & $\begin{array}{c}\text { Moisture } \\
\%\end{array}$ & $\begin{array}{c}\text { Ash } \\
\%\end{array}$ & $\begin{array}{c}\text { Nitrogen } \\
\%\end{array}$ & $\begin{array}{c}\text { Phos- } \\
\text { phoric } \\
\text { acid } \\
\%\end{array}$ & $\begin{array}{c}\text { Potas- } \\
\text { sium } \\
\text { oxide } \\
\%\end{array}$ \\
\hline Maltsprouts. & 10.38 & 12.48 & 3.55 & 1.43 & 1.63 \\
\hline Brewers' grains (dry).......... & 6.98 & 6.15 & 3.05 & 1.26 & 1.55 \\
\hline Brewers' grains (wet)........... & 75.01 & & .89 & .31 & .05 \\
\hline Rye bran ..... & 12.5 & 4.6 & 2.32 & 2.28 & 1.4 \\
\hline Rye middlings* & 12.54 & 3.52 & 1.84 & 1.26 & .81 \\
\hline Wheat bran... & 11.74 & 6.25 & 2.67 & 2.89 & 1.61 \\
\hline Wheat middlings & 9.18 & 2.3 & 2.63 & .95 & .63 \\
\hline Rice bran. & 10.2 & 12.94 & .71 & .29 & .24 \\
\hline Rice polish. & 10.3 & 9. & 1.97 & 2.67 & .71 \\
\hline Buckwheat middlings* & 14.7 & 1.4 & 1.38 & .68 & .34 \\
\hline Cottonseed meal............. & 9.9 & 6.82 & 6.64 & 2.68 & 1.79 \\
\hline Cottonseed hulls....... & 10.63 & 2.61 & .75 & .18 & 1.08 \\
\hline Linseed meal (old process) & 8.88 & 6.08 & 5.43 & 1.66 & 1.37 \\
\hline Linseed meal (new process) .... . & 7.77 & 5.37 & 5.78 & 1.83 & 1.39 \\
\hline Apple pomace. . & 80.5 & .27 & .23 & .02 & .13 \\
\hline
\end{tabular}





\section{INDEX}

Abomasum, the, 103.

Absorption of food, 116.

Accessories, food, 193.

Acids, the, 80.

fatty, 84 .

amino, 66.

limiting factor, 191.

Age, influence of, 133.

relation to meat production, 428 .

Air, carbon in, 13.

Albuminoids, 57.

Alimentary canal, parts of, 94 .

Alfalfa, 227.

Amides, 66.

Amylopsin, 109.

Animal, ash elements, 23.

bodies, mineral compounds of, 44.

fats, food sources, 208.

foods, origin of, 9, 266.

growth, chemical elements in, 12.

heat, a waste product, 184 .

regulation of, 183.

source of, 10.

organism, work performed by, 162.

production, adaptability of crops to, 273.

refuses, 270.

size of in relation to ration, 301 . substance, source of, 10.

Animals, cruelty to, 433.

elements in, 21.

environment and treatment, 431.

factors in management of, 425. fattening, experiments with, 365.

feeding experiments in, 366 .

food needs of, 364 .

DD
Animals, fattening, rate of increase, 363.

selection for meat production, 427.

young, milk for, 351 .

Anti-bodies, 85.

Argon, 17.

Ash compounds, distribution in the animal body, 45 .

distribution in parts of plants, 42.

in plants, 39 .

constituents, influence of manufacturing processes, 43 .

for egg production, 409 .

elements in, 21.

after ignition, 39.

in blood, 46 .

elements in soft tissues, 46 .

of plants, mineral compounds in, 38 .

variation in plants, 40 .

variations due to species, 40 .

Assimilation, 87.

Bacteria, 89.

intestinal, 110.

in digestive tract, 92.

Barley feed, 250.

Beef, growth in production of, 363 .

Beet, sugar-, molasses, 256.

residues from, 255.

Beri-beri, 193.

Bile, the, 106.

function of, 107.

Birds, digestive apparatus of, 403 . food needs of, 399 . young, rations for, 413 .

Blood, the, 138.

ash elements in, 46 . circulation of, 142. 
Blood corpuscles, 139. the plasma, 140 . vessels, in absorption, 115 .

Bovines, maintenance rations for, 314.

Breakfast foods, residues from, 248.

Breed, influence of, 133.

Brewers' grains, 251.

Buttermilk, 268.

Calcium, 19.

Calorie, definition of, 165 .

Calorimeter, respiration, 214.

Carbohydrates, the, 69 . as a source of fats, 161 . classification of, 70 . digestibility of, 120 . functions of, 160 . physiologically economical, 186. regulation of use, 149. source of energy, 160.

Carbon, 13. dioxide, elimination of, 147 .

Cattle foods, classification of, 219. distinctions in, 263. energy values of, 166 .

Cellulose, 78. and gums, digestibility of, 121 .

Chlorine, 18.

Coarse foods vs. grains, 263.

Collagen, 57.

Colts, feeding, 358. rations for, 359 .

Cooking foods, 128.

Combination of nutrients, influence of, 131.

Compounds, classes of, 26. classification of, 27.

Combustible and incombustible matter, 24.

Combustion, 24.

Corn, as silo crop, 231.

Cottonseed by-products, composition of, 259.

hulls, 257.

kernels, 258. meal, 257.

Cow, the general purpose, 427 .
Cows, dairy, calculation of rations. 333.

feeding standards for, 327 . practical rations for, 335 . requirements of, 331 . selection of, 426 .

Crops, adaptability to environment, 272.

to kind of production, 273.

drying of, 220 .

ensiling vs. field curing, 233.

forage, classes of, 220 .

harvesting of, 222.

influence of maturity, 223.

for swine, 386 .

high productivity, 275 .

methods of preserving, 233.

productive capacity of, 274 .

soiling, 276.

value not proportional to yield, 224.

Curing fodders, losses through, 221.

Dairy by-products, 268.

wastes, as food for pigs, 384 .

Dextrin, 78.

Dextrose, 71.

Digestible nutrients, in the ration, 299.

Digestibility, as basis of values, 286.

determination of, 135 .

influence of age, 225 .

meaning of, 122 .

Digestion, 87.

artificial, 103.

as a whole, 112.

changes in food, 88.

changes in stomach, 104.

coefficients, inaccuracies of, 136.

factors influencing, 122.

in intestines, 113.

stimuli to, 111.

stomach, 112.

summary of changes, 114 .

work of, 176.

Digestive fluids, 113.

Di-saccharides, 72. 
Drying crops, conditions of, 220. Drying fodders, effect of, $125,221$.

Eggs, composition of, 407 .

Egg production, ash constituents for, 409 .

Elements, distribution of, 27.

Energy, chief source of, 183.

determination of 165 . metabolizable, 168.

distribution of losses of, 169 . expended in feed consumption, 177.

how originated, 163.

in cattle foods, 166.

loss from food, 167.

loss in gases, 168.

maintenance, distribution of, 312.

measurement of, 165.

metabolizable, 167.

estimates of, 171 .

in feeding-stuffs, 172.

in fodders and grains, 173.

nature of, 163.

net, 174 .

calculation of, 178.

necessary to work, 163.

uses of, 151.

requirements by growing animals, 349 .

stored by plants, 10 .

transformation of, 164.

values, as basis of valuation, 285 .

calculation of, 212 .

net, computation of, 179 .

determination of, 211.

with different rations, 175 .

Enzyms, 85.

action of, 92.

in pancreatic juice, 108.

Ether-extracts, 84.

Esophageal groove, 99.

Ewes, feeding of, 354 .

Extractives, 67.

Fat, milk-, 83.

Fats and oils, 80 .

functions of, 161.
Fats, digestibility of, 121.

from carbohydrates, 161 .

in grains and seeds, 81 .

milk-, food sources of, 321 .

nature and kinds of, 82 .

Fat soluble A, 194.

Fattening animals, rate of increase, 363.

Fatty acids, 84.

Feces, constituents of, 118.

Feeding and watering, influence of frequency, 130.

experiments as basis of feed value, 290.

conclusions from, 203.

with fattening animals, 366 .

practical, 203.

practice, conclusions from, 202.

standards, 294.

American, 329.

Grouven's, 327 .

Kuhn's, 328.

the Wolff-Lehmann, 328.

Wolff's, 328.

Woll's, 329 .

stuffs, classification of, 265.

commercial by-product, 242 .

commercial values of, 282 .

home supply of, 304 .

misleading terms for, 264 .

physiological values of, 284 .

selection of, 286 .

valuation of, 281 .

valuation by method of least squares, 283.

Feeds, classification of, 264.

digestibility of various, 287.

Fermentation, intestinal, 110.

results of, 91 .

Ferments, 88.

action of, 91.

conditions of growth, 80 .

definition of, 89 .

organized, 89

structure and distribution of, 89

unorganized, 92.

Fertility and legumes, 276.

Fibrinogen, 55.

Fibroin, 57. 
Fodders, effect of drying, 221. losses through curing, 221. preserving of, 126.

Food, absorption of, 114, 116. appropriation by growing animals, 347 .

as a source of energy, 162 .

combustion, measurement of, 213.

compounds; inter-relation of, 185.

relation to the digestive processes, 119 .

economics, factors involved in, 420.

effect on constitution of milk solids, 340 .

effect on the flavors of milk, 343.

effect on the proportion of milk solids, 339.

general uses of, 151.

influence on kind of growth, 347.

maximum absorption of, 117 .

needs of fattening sheep, 373.

relation to quality of the horse, 357.

relation to production, $\mathbf{4 2 0}$.

requirements for pork production, 381.

unit, the, 418 .

use of, 145 .

wetting, 128.

Foods, animal, origin of, 266. cooking, 128.

influence of grinding, 129.

influence on milk-fats, 341 .

kinds for poultry, 400 .

Forage crops, classes of, 220.

harvesting of, 222.

yield at maturity, 223.

Fowls, adaptability of various foods to, 415 .

feeding standards for, 411. maintenance ration for, 412 . salt a necessity for, 410 . supply of grit, 410 .
Galactose, 71.

Gastric juice, the, 103.

Gelatin, 57.

Gelatinoids, nutritive value of, 192.

Gliadin, 56

Globulins, 53.

animal, 55.

plant, 54 .

serum, 56 .

Glucose, 93.

Glutenins, 56 .

Gluten products, 252.

Glycogen, 77.

Glyco-proteins, 59.

Grain, storage of, 241.

Grains and seeds, 240. coarse food, 263.

Green versus dried fodders, 220.

Grinding foods, influence of, 129.

Grit, supply for fowls, 410 .

Growing animals, energy requirements of, 349 .

Growth, effect on water-content, 32.

in beef production, 363 .

in fattening sheep, 372 .

influence of food upon, 347 .

requirements for, 346 .

Growth-promoting bodies, 303.

Gums, the, nutritive value of, 188 .

Hay values, Thaer's, 327.

Heart, the, 140.

Hæmatin, 60.

Hemi-celluloses, 77 .

Hæmoglobin, 60.

Hen, constituents of the body, 406 .

Hens, laying, effects of food upon, 402.

rations for, 412 .

Histones, 58.

Hominy feed, 251.

Hordein, 56.

Hormones, 85.

Horse, the, a machine, 164, 387.

estimate of work ration, 392 .

food requirements, 390 .

maintenance needs of, 315 . 
Horse, relation of food to quality, 357.

the stomach of, 104. work performed by, 388 .

Horses, digestibility of coarse foods by, 134 .

maintenance food for, 315 . rations for, 317 .

oats as food, 396.

working, nutritive ratio for, 395 . rations for, 397. source of the ration, 394 .

Hydrochloric acid in stomach digestion, 104.

Hydrogen, 15.

Hydrolysis, 72, 93.

Individuality, influence of, 133. influence on energy losses, 171.

Intestinal juices, 109. action of, 113.

tract, changes in the walls of, 116.

Intestines, the, 105.

form and length of, 105.

Invertase, 93.

Iodine, 19.

Iron, 19.

Katabolism, fasting, 311 .

Keratins, 57.

Knowledge, sources of, 201

Lactase, 93.

Lactose, 73.

Lacteals, function of, 115 .

Lambs, feeding of, 354 . grain food for, 355 .

Lecithins, 85.

Lecitho-proteins, 60.

Legumes and fertility, 276.

Levulose, 71.

Linseed meal, 259. oil, extraction of, 260.

Liver, the, 149.

Lungs, the, 143.

Lymphatic system, 115.
Maintenance food for horses, 315. for sheep, 317.

measured by fasting katabolism, 311.

needs, computation of, 313 .

investigations concerning, 309 . of the horse, 315 .

rations for bovines, 314 . for fowls, 412 .

Maize, 226.

kernel, the, structure of, 252.

Maltsprouts, 251.

Maltase, 93.

Maltose, 73.

Manufacturing processes, influence on ash, 43.

Man's relation to animal life, 3.

Mastication, 94.

work of, 174.

Matter, classes of, 23.

Meat production, relation of age to, 428.

selection of animals for, 427 .

Metabolism, fasting, use of nutrients in, 312 .

Meta-proteins, 61.

Methane, losses through, 171.

Milk, 266.

cows', composition of, 319.

effect of food upon flavors, 343.

fats, food sources of, 321 .

fats in, 83.

influence of food upon, 341.

for young animals, 351 .

of several breeds, 268 .

production, protein requirements for, 325 .

production, use of nutrients in, 323.

proteins, food sources of, 321 .

relation to food, 338 .

secretion of, 320 .

solids, effect of food upon constitution of, 340 .

effect of food upon proportions, 339 .

rate of formation of, 322 .

substitutes for calves, 354 .

substitutes for swine, 385 . 
Milling processes, 247.

Mineral compounds, in animal bodies, 44 .

in ash of plants, 38 .

elements, distribution of in animal body, 154 .

equilibrium of in animal body, 154.

functions of, 152.

relation to animal structure, 153.

relation to tissue development, 155.

relation to elimination of waste products, 154 .

relation to muscular control, 155.

relation to osmosis, 155 .

relation to vital processes, 152.

supply of, 156.

Mono-saccharides, 70 .

Motive power, source of, 11.

Mouth, the, 94 .

Muscular activity, relation to protein, 183.

control, relation to mineral elements, 155.

Mutton production, 371.

Myosin, 55.

Myosinogen, 55.

New process linseed meal, 260.

Nitrogen, 16.

compounds, relative importance of, 189 .

supply of, 16 .

uses of, 17.

Non-nitrogenous compounds, classification of, 69. composition of, 68 .

Non-proteins, 66.

Nucleo-proteins, 58.

Nutrients, digestible, calculation of, 297.

energy value of, 212.

energy values, 166.

functions of, 151.

how oxidized, 145.
Nutrients, quantity for fattening sheep, 374. rate of oxidation, 146. use in fasting metabolism, 312 . uses in milk production, 323.

Nutrition, laws of, 197.

Nutritive ratio, 295.

Oat clippings, 250.

grain, the, 249.

hulls, 248.

Oats, as horse feed, 359. for working horses, 396.

Oil meal, 259. meals, the, 256.

Oils, methods of extracting, 257 .

Old process linseed meal, 260 .

Omasum, the, 102.

Organic and inorganic matter, 25.

Osmosis, relation to mineral elements, 155 .

Oxidases, 146.

Oxygen, 14.

uses of, 15.

Oxy-hæmoglobin, 60.

Palatableness, 292.

Pancreatic juice, the, 123, 108. enzyms of, 108.

Pectin bodies, the, 78 .

Pellagra, 195.

Pentosans, the, 77.

Pentoses, the, 72.

Peptones, the, 62.

Pepsin, 104. in gastric juice, 104.

Phospho-proteins, 59.

Phosphorus, 18.

compounds, relative efficiency of, 157.

Physiological requirements, 294.

Pig, stomach of, 104.

Pigs, dairy wastes for, 384 . unwise feeding, 382 .

Plant ash, elements in, 21.

Plans, elements in, 20. new versus old species, 273 .

Plasma, of blood, 140.

Poly-saccharides, 74 . 
Pork production, 378.

food requirements for, 381 .

Potassium, 19.

Poultry, kinds of food for, 400 .

Preparation of food, influence of methods, 127.

Preserving fodders, influence of conditions and methods, 126.

Problems in feeding animals, 5.

Production, relation to food, 420 . the unit of, 419.

values, estimation of, 181 . relation to profit, 195.

Proteans, 61.

Protein as a source of energy, 159. of fats, 159 .

coagulated, 61 .

commercial, 336.

content as basis of valuation, 289.

derivatives, 60 .

efficiency from animal sources, 408.

foods, no single one essential, 337.

functions of, 158.

home supply of, 276,336 .

how determined, 48 .

importance of, 47 .

physiologically necessary, 186.

relation to muscular activity, 183.

relative importance overstated, 326.

requirements for milk-production, 325.

sparers, 187.

standards, revision of, 303.

supply of, 302.

Proteins, alcohol soluble, 56.

as tissue formers, 158.

classification of, 49.

cleavage products of, 63 .

digestibility of, 119 .

efficiency of, 215.

familiar examples of, 52 .

greatly unlike, 49 .

glyco-, 59 .
Proteins, lecitho-, 60.

milk, food sources of, 321 .

not wholly oxidized, 146 .

nucleo-, 58.

phospho-, 59.

phosphorus-bearing synthesis of, 192.

properties of, 62 .

simple, 52.

the true, 50. relative efficiency of, 190. ultimate composition of, 51 . unlike constitution of, 63 .

Proteoses, 62.

Psychic factor, the, 111.

Ptyalin, 98.

Ration, calculating of, 296.

influence on development of swine, 383.

and quantity of, 124.

of size of, 171.

on quality of product, 304 .

insufficient, correcting of, 300 .

maintenance, 307.

character of, 307.

for bovines, 309 .

for horses, 317.

how provided, 308.

proportion used as fuel, 160 .

the manipulation of, 429 .

the quantity of, 431 .

relation to size of animal, 301.

selection of, 305 .

uses of production, 308 .

Rations, adaptation of, 293. calculations for dairy cows, 333.

fattening, selection of, 369 .

for laying hens, 412 .

for young birds, 413 .

practical, for dairy cows, 335 .

selection of, for sheep, 376 .

Rennin, in stomach, 104.

Respiration, 143.

apparatus, 209.

calorimeter, 214.

object of, 144 .

Reticulum, the, 101.

Rigor mortis, 55 . 
Roots and tubers, 239.

Rumen, the, 100.

Rumination, 102.

Saccharose, 72.

Saliva, the, 97. origin of, 97.

properties and office of, 97 . quantity excreted, 98.

Salt, effect of, 129.

a necessity for fowls, 410 .

Sap, 31.

Season and storage, influence of, 131.

Screenings, 247.

Secretins, 85, 111.

Sheep, fattening, food needs of, 373.

quantity of nutrients for, 374.

nature of growth, 372 .

growing, standards for, 356 .

maintenance food for, 317 .

place on the farm, 371 .

selection of rations for, 376 .

Silage, acidity of, 230.

cutting and shredding, 237.

crops for, 234.

growth of corn for, 236.

Silo, changes in, 228.

cleavage of proteins in, 230 .

extent of loss in, 231.

filling the, 236.

importance of losses in, 233.

losses in, 229.

necessary loss in, 232.

rate of filling, 237.

Silos, construction of, 235 .

Skimmed milk, 268. for calves, 351 .

Sodium, 19.

Soft tissues, ash elements in, 46.

Soiling, conditions favorable to, 277.

crops a necessity, 276.

area and rotation, 280.

selection of, 278.

the economy of, 277.

Soil moisture, influence of, 33 .
Species, influence of, 133.

Spongin, 57.

Stage of growth; influence of: 127.

Standards, German, for fattening animals, 367.

for milk production, 330 .

Starch, manufacture of, 253.

Starches, the, 75 .

rate of digestibility, 120 .

Steapsin, 108.

Steers, fattening, rations for, 370.

Stomach, the, 99.

Straws, the, 239.

Sugar-beet pulp, 255.

Sugars, the, 74 . simple, 70 .

Swine, changes in production, 379.

character of the growth, 379 .

feeding of, 378.

forage crops for, 386 .

influence of ration on development, 383.

Teeth, the, 95 .

Temperature, the critical. 185.

regulation of, 183.

Therm, definition of, 165 .

Urea, elimination of, 147.

Vitamines, 85, 193.

Vitellin, 56.

Wastes, elimination of, 146.

Water, 28.

content, conditions affecting, 34 . measurement of, 29.

variation in animal bodies, 37.

elimination of, 147 .

functions of, 152 .

hygroscopic, 29.

in feeding-stuffs, 34 .

in living plants, 30 .

in the animal, 36.

physiological, 30 . 
Water, proportion in plants, 31. relation to preservation of foods, 35.

Water soluble B, 194.

Water-supply, for fowls, necessity of, 408 . to plants, 33 .

Wheat, composition of milling products, 246.
Wheat, grain, structure of, 243. offals, 243.

the milling of, 245.

Whey, 268.

Work, food expenditure for, 389. influence of, 133. of animal organism, 162 .

Zein, 56. 

The following pages contain advertisements of a few of the Macmillan books on kindred subjects 



\section{The Breeds of Live Stock}

By Live Stock Breeders. Revised and arranged by CARL W. GAY, Professor of Animal Husbandry in the University of Pennsylvania.

\section{RURAL TEXT-BOOK SERIES}

Illustrated, 8vo, $\$ 1.75$

A more urgent demand, from a constantly increasing number of consumers, for animal products must stimulate a greater exploitation of pure-bred live stock as the source of the seed from which market animals and their products are derived. The breeders who will get the most out of the respective breeds with which they work will be those best informed as to the inherent possibilities of their stock. Study of the origin, history and development of the breeds is, therefore, important. The most successful breeders are essentially specialists, and the most authoritative presentation of the historic facts, points of merit and fconomic importance of the different breeds should be expected from those who have devoted themselves most exclusively to these breeds.

Men who have been more or less eminently identified with the respective breeds were chosen to prepare the breed material for the Cyclopedia of American Agriculture. This matter has been revised, brought up to date and amplified to include types in their relation to breeds, and the whole material has been edited, arranged and revised by Dr. Carl W. Gay, Professor of An'mal Husbandry in the School of Veterinary Medicine of the University of Pennsylvania. The original illustrations are reproduced in half-tones, and the book is offered as the most complete and recent work on the types and breeds of livestock.

\section{THE MACMILLAN COMPANY}




\section{The Principles and Practice of Live-Stock Judging}

\section{BY CARL WARREN GAY}

Professor of Animal Industry in the University of Pennsylvania

Rural Textbook Series. Cloth, I2mo, illuistrated, $\$ r .50$

This book has been prepared to meet the demand incident to the progress made in livestock husbandry for a more comprehensive, thorough, and systematic study of the judging of animals. The effort has been made in its preparation to take the student and stockman a step further than they have gone heretofore. Part I introduces the principles upon which the practice of judging is founded ; Part II applies to the practice of judging, definition and procedure - the features of animal form to be considered, the means of making observations and practice judging by the score card, demonstrations, comparative and competitive judging. The balance of the work is devoted to special judging, one part being given to each of the following : horses, cattle, sheep, swine, the judging of breeding animals, and livestock shows. The volume is profusely illustrated, typical representatives of the types and breeds being shown in untouched photographs of animals to which championship honors have been awarded.

THE MACMILLAN COMPANY Publishers 


\section{THE SCIENTIFIC FEEDING OF ANIMALS}

By Professor O. KELLNER

Authorized Translation by WILLIAM GOODWIN, B.Sc., Pн.D., Lecturer on Agricultural Chemistry, and Head of the Chemical Department, South-Eastern Agricultural College (University of London), Wye, Kent.

New Edition. Cloth, 12mo, $\$ 1.75$

An authorized English translation of the valuable work of Dr. O. Kellner. It explains in simple language the general laws which underlie the feeding of animals and the scientific foundations upon which the principles of animal nutrition rest.

"I wish to say that it is one of the most valuable books in the English language on Feeding Farm Animals. The author is extremely lucid in expression and concise in statement. He covers his field in a manner that is well planned and such as will give the reader a most excellent knowledge of the general principles of Feeding." Professor Charles S. Plumb, Ohio State University.

"Dr. Kellner's standing as a student and investigator in this subject is too high for any words of commendation to be needed, and I feel sure that the translator and publisher have done a service in rendering this work available to English and American students." Professor Henry P. Armsby, Pennsylvania State College.

\section{THE MACMILLAN COMPANY}

PUBLISHERS

64-66 Fifth Avenue

NEW YORK 


\section{Animal Husbandry for Schools}

By MERRITT W. HARPER

Cloth, 12mo, illustrated, 409 pp., $\$ 1.40$

\section{RURAL TEXT-BOOK SERIES}

With the increasing study of agricultural subjects in the schools has come a demand for a book on Animal Husbandry suitable for use by students of high school age. It is to meet such a need that this book has been written, and in content, style, and arrangement it is admirably adapted to the purpose. It belongs to the Rural Textbook Series prepared under the editorial supervision of Professor L. H. Bailey, of Cornell University.

In the five parts into which the book is divided the author treats horses, cattle, sheep, swine, and poultry, and each is discussed with reference to breeds, judging the animal, feeding, and care and management. There is also a chapter on the general principles of feeding. Practical questions and numerous laboratory exercises supplement the text and compel the student to think through each subject as he proceeds. The book is extensively illustrated. Designed for use as a textbook, it is also well suited for use as a reference book in schools in which time limitations make it impossible to use it as a text.

\section{Manual of Farm Animals}

A Practical Guide to the Choosing, Breeding, and Keep of Horses, Cattle, Sheep, and Swine

By MERRITT W. HARPER, Assistant Professor of Animal Husbandry in the New York State College of Agriculture at Cornell University

Illustrated, decorated cloth, 12 mo, 545 pages, index, $\$ 2.00$

RURAL MANUAL SERIES

"The work is invaluable as a practical guide in raising farm animals."-Morning Telegram.

"A book deserving of close study as well as being handy for reference and should be in the possession of every farmer interested in stock."-Rural World.

\section{THE MACMILLAN COMPANY}

PUBLISHERS

64-66 Fifth Avenue

NEW YORK 




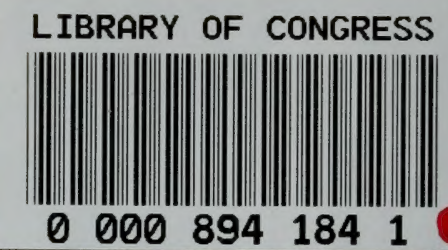

